Gerhard Rösl

\title{
Seigniorage in der EWU
}

Eine Analyse der Notenbankgewinnentstehung und -verwendung des Eurosystems 


\section{Gerhard Rösl}

\section{Seigniorage in der EWU}

Die Satzung des Europäischen Systems der Zentralbanken sieht eine Umverteilung von Geldschöpfungsgewinnen (Seigniorage) zwischen den Notenbanken des Eurosystems vor. Die Diskussion um die "Gewinner" und "Verlierer" aus dieser Regelung wird sehr kontrovers geführt. Die Arbeit versucht, diese Umverteilungsproblematik systematisch $\mathrm{zu}$ analysieren. Insbesondere die theoretischen Grundlagen des Seigniorage, die mannigfaltigen Tätigkeiten der EWU-Zentralbanken und deren Auswirkungen auf die Entstehung der Notenbankgewinne sowie die Verwendung der Geldschöpfungsgewinne werden detailliert untersucht.

Gerhard Rösl wurde 1970 in Altdorf bei Nürnberg geboren. Er studierte Volkswirtschaftslehre an der Universität Erlangen-Nürnberg.Von 1997 bis 2002 war er wissenschaftlicher Mitarbeiter am Institut für Theoretische Volkswirtschaftslehre an der Universität der Bundeswehr Hamburg. Promotion 2002. Seit Mitte 2002 ist er bei der Deutschen Bundesbank, Hauptabteilung Volkswirtschaft beschäftigt. 
Seigniorage in der EWU

Gerhard Rösl - 978-3-631-75006-3

Downloaded from PubFactory at 01/11/2019 09:21:25AM

via free access 


\section{SCHRIFTEN ZUR \\ WIRTSCHAFTSTHEORIE UND WIRTSCHAFTSPOLITIK \\ Herausgegeben von \\ Rolf Hasse, Jörn Kruse, Wolf Schäfer, Thomas Straubhaar und Klaus W. Zimmermann}

Band 25

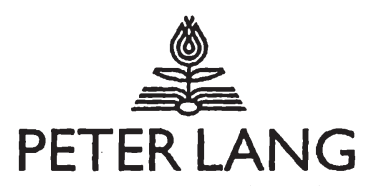

Frankfurt am Main - Berlin - Bern - Bruxelles - New York - Oxford - Wien 


\title{
Gerhard Rösl
}

\section{Seigniorage in der EWU}

\author{
Eine Analyse \\ der Notenbankgewinnentstehung \\ und -verwendung des Eurosystems
}

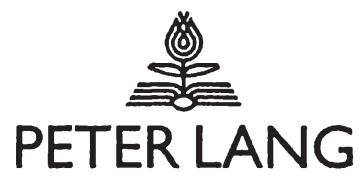

Europäischer Verlag der Wissenschaften 
Bibliografische Information Der Deutschen Bibliothek Die Deutsche Bibliothek verzeichnet diese Publikation in der Deutschen Nationalbibliografie; detaillierte bibliografische Daten sind im Internet uber <http://dnb.ddb.de> abrufbar.

Open Access: The online version of this publication is published on www.peterlang.com and www.econstor.eu under the international Creative Commons License CC-BY 4.0. Learn more on how you can use and share this work: http://creativecommons. org/licenses/by/4.0.

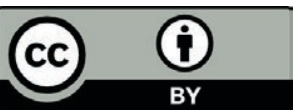

This book is available Open Access thanks to the kind support of ZBW - Leibniz-Informationszentrum Wirtschaft.

Gedruckt mit Unterstützung der Universität der Bundeswehr Hamburg.

Gedruckt auf alterungsbeständigem, säurefreiem Papier.

\author{
D 18 \\ ISSN 1433-1519 \\ ISBN3-631-39750-X \\ ISBN 978-3-631-75006-3 (eBook) \\ (C) Peter Lang GmbH \\ Europäischer Verlag der Wissenschaften \\ Frankfurt am Main 2002 \\ Alle Rechte vorbehalten.
}

Das Werk einschließlich aller seiner Teile ist urheberrechtlich geschützt. Jede Verwertung außerhalb der engen Grenzen des Urheberrechtsgesetzes ist ohne Zustimmung des Verlages unzulässig und strafbar. Das gilt insbesondere für Vervielfältigungen, Übersetzungen, Mikroverfilmungen und die Einspeicherung und Verarbeitung in elektronischen Systemen.

Printed in Germany 123457

www.peterlang.de 


\section{Meinem Bruder Ulli Rösl}


Gerhard Rösl - 978-3-631-75006-3

Downloaded from PubFactory at 01/11/2019 09:21:25AM

via free access 


\section{Vorwort}

Mein ganz besonderer Dank gilt meinem Doktorvater Prof. Dr. Wolf Schäfer. Ihm habe ich sowohl den Anstoß zu dieser Dissertation als auch vielfältige inhaltliche Anregungen zu verdanken. Seine entgegenkommende Art sowie seine überragende fachliche Kompetenz waren ein unbedingter Gewinn für mich.

Herrn Prof. Dr. Rolf Hasse möchte ich für die Übernahme des Korreferats danken. Seine Einschätzung, daß die Schwierigkeit des Themas in dessen institutionellen Komplexität begründet liege, bewahrheitete sich in vollem Umfang.

Meinen Kolleginnen und Kollegen Babette Hagemann, Dr. Andreas Henning, Christoph Kimmel, Annette Olbrisch und Dr. Sarah Schniewindt, die ein ausgezeichnetes Lehrstuhlklima schufen und mir gerade in der Endphase den „Rücken freihielten“, sei ein herzliches Dankeschön gesagt. Auch bei den anderen Mitgliedern des Fachbereichs Wirtschafts- und Organisationswissenschaften an der Universität der Bundeswehr Hamburg möchte ich mich für die schöne Zeit in der Hansestadt bedanken.

Die Hauptlast meiner Promotion hatte ohne Frage meine Frau Silke zu tragen. Ihr liebes Wesen und ihre verständnisvolle Art gaben mir die Stabilität, die Sache erfolgreich zu Ende zu bringen. Ebenso habe ich meinen Eltern, meinem Bruder Ulli sowie meinem Freund Christian Riedl für ihre unentwegte Unterstützung zu danken.

Frankfurt, im August 2002

Gerhard Rösl 
Gerhard Rösl - 978-3-631-75006-3

Downloaded from PubFactory at 01/11/2019 09:21:25AM

via free access 


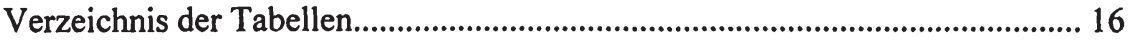

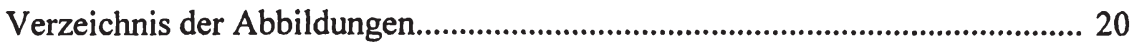

Verzeichnis der Abkürzungen...................................................................... 21

Verzeichnis der verwendeten Zentralbankgesetze, -satzungen und -statuten.... 24

I. PROBLEMSTELLUNG UND AUFBAU DER ARBEIT........................ 25

II. THEORETISCHE ÜBERLEGUNGEN ZUM SEIGNIORAGE........... 29

1. Zur Begriffsdefinition............................................................................... 29

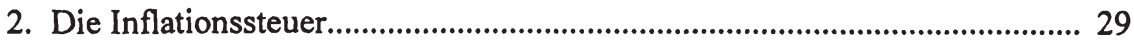

2.1.Definition der Inflationssteuer............................................................... 29

2.2. Grenzen der Einnahmeerzielung des Geldproduzenten durch die

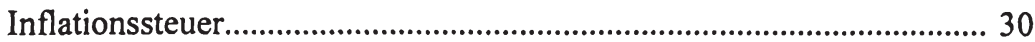

2.3.Kritische Würdigung des Konzepts der Inflationssteuer........................ 30

3. Der Monetäre Seigniorage................................................................................. 31

3.1.Entstehung und Verwendung des Monetären Seigniorages.................... 31

3.2. Grenzen der Einnahmeerzielung des Geldproduzenten durch den Monetären Seigniorage................................................................... 32

3.3.Monetärer Seigniorage und Inflationssteuer............................................ 33

3.4.Kritische Würdigung des Monetären Seigniorage-Konzepts................ 35

4. Der Totale Seigniorage (Erweiterter Monetärer Seigniorage)..................... 37

4.1.Entstehung des Totalen Seigniorages................................................ 37

4.1.1. Der Totale Münzgewinn............................................................ 37

4.1.2. Der Totale Banknotengewinn............................................... 39

4.1.3. Der Totale Seigniorage............................................................... 41

4.2. Verwendung des Totalen Seigniorages................................................. 42

4.2.1. Der Fiskalische Seigniorage.................................................... 43

4.2.1.1.Die Kreditgewährung der Notenbank an die Regierung........................................................ 44

4.2.1.2.Die Partizipation der Regierung am realen Notenbankgewinn....................................................... 45

4.2.1.3.Der Netto-Münzgewinn................................................ 45

4.2.2. Der Zentralbankseigniorage..................................................... 46

4.3.Grenzen der Einnahmeerzielung des Geldproduzenten durch den

Totalen Seigniorage................................................................................. 47

4.3.1. Grenzen der Einnahmeerzielung des Geldproduzenten durch den Zinsseigniorage................................................................. 48

5. Der Opportunitätskostenseigniorage....................................................... 49

5.1.Entstehung des Opportunitätskostenseigniorages................................ 49

5.2. Verwendung des Opportunitätskostenseigniorages................................. 50 


\section{DAS EUROPÄISCHE SYSTEM DER ZENTRALBANKEN UND} DAS EUROSYSTEM.

1. Die Zusammensetzung des Europäischen Systems der Zentralbanken (ESZB) und des Eurosystems...................................................................5 55

2. Die Beschlußorgane des ESZB und des Eurosystems............................. 57

\section{DIE GEWINNENTSTEHUNG UND - VERWENDUNG DER} EUROPÄISCHEN ZENTRALBANK.

IV.1. Die Entstehung des EZB-Gewinns.

1. Die Nettoerträge der EZB aus der (Anfangs-) Ausstattung mit Kapital und Währungsreserven. 61

1.1.Die Zeichnung und Finanzierung des EZB-Kapitals............................. 61

1.2.Die Erträge der EZB aus der Investition ihres Kapitals.......................... 65

1.3.Die Übertragung von Währungsreserven auf die EZB............................ 65

1.4.Die Nettoerträge der EZB aus übertragenen Währungsreserven............ 68

2. Die Nettoerträge der EZB aus der operativen Geld- und Devisenpolitik.... 72

2.1.Die Nettoerträge der EZB aus der operativen Geldpolitik..................... 72

2.2.Die Nettoerträge der EZB aus der Devisenpolitik................................. 74

3. Die Nettoerträge der EZB aus anderen Tätigkeiten...................................... 78

3.1.Die Beteiligung der EZB am grenzüberschreitenden

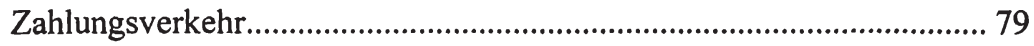

3.2.Die Aufsichtsfunktion der EZB..................................................... 80

3.3.Die Erhebung statistischer Daten durch die EZB................................... 81

3.4.Die internationale Zusammenarbeit der EZB........................................ 81

3.5.Sonstige Tätigkeiten der EZB.......................................................... 83

4. Die Nettoerträge der EZB aus realisierten Buchgewinnen,

Abschreibungen und Operationen mit Reserven.............................................85

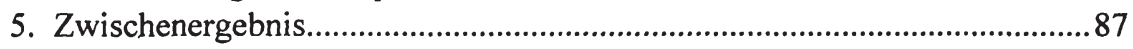

\section{IV.2. Die Verwendung der EZB-Gewinns und die Finanzierung des}

EZB-Verlusts.................................................................................................8 88

1. Die vertraglichen Regelungen..................................................................... 88

1.1.Die Verwendung des EZB-Gewinns..................................................88

1.2.Die Finanzierung des EZB-Verlusts......................................................... 88

2. Die Gewinnverwendung bzw. Verlustfinanzierung der EZB in den Jahren 1998 bis 2001 
IV.3. Umverteilungseffekte im Zuge der EZB-Gewinnentstehung und -verwendung bzw. EZB-Verlustfinanzierung.

1. Umverteilungseffekte im Zuge der Gewinnentstehung und -verwendung der EZB

1.1.Umverteilungseffekte im Zuge der satzungsgemäßen Übertragungen

von Kapital und Währungsreserven durch die NZBen

1.2. Umverteilungseffekte im Zuge der Finanzierung von

Zinsverpflichtungen der NZBen aus NZB-TARGET-

Verbindlichkeiten gegenüber der EZB.

2. Umverteilungseffekte im Zuge der Verlustfinanzierung der EZB. .95

2.1.Umverteilungseffekte durch Rückgriff auf die Monetären

Einkünfte der NZBen

2.2.Umverteilungseffekte durch Wertberichtigungen von NZB-

Forderungen 96

2.3.Umverteilungseffekte durch die direkte Belastung der Einkünfte der

NZBen aus ihrem nationalen Banknotenumlauf.......................................96

2.4.Umverteilungseffekte durch andere direkte Transfers der NZBen..........96

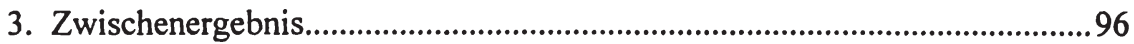

V. DIE GEWINNENTSTEHUNG UND -VERWENDUNG DER NATIONALEN ZENTRALBANKEN.

V.1. Die Disaggregation der Eurosystembilanz und die Harmonisierung der Gewinn- und Verlustrechnungen der EWU-Zentralbanken....... 97

V.2. Die Entstehung der NZB-Gewinne.

V.2.1. Die Analyse der Eurosystem-spezifischen Tätigkeiten der NZBen.

1. Die satzungsgemäße Übertragung von Aktiva auf die EZB

2. Die Beteiligung der NZBen an der Festlegung und Durchführung der gemeinsamen Geldpolitik

2.1.Die Beteiligung der NZBen an der Festlegung der gemeinsamen Geldpolitik 
2.2.Die Beteiligung der NZBen an der Durchführung der gemeinsamen Geldpolitik.

2.2.1. Das geldpolitische Instrumentarium des Eurosystems

2.2.2. Die Beteiligung der NZBen an der Durchführung der Offenmarktgeschäfte des Eurosystems.

2.2.3. Die Beteiligung der NZBen an der Bereitstellung der Ständigen Fazilitäten des Eurosystems

2.2.4. Die Beteiligung der NZBen am Mindestreservesystem des Eurosystems.

2.3. Die Beteiligung der NZBen an der Durchführung der geldpolitischen Geschäfte des Eurosystems im ersten Jahr der EWU.

2.3.1. Die geldpolitischen Geschäfte des Eurosystems im Überblick

2.3.2. Die Verschiebung der Refinanzierungsstruktur innerhalb des Eurosystems.

2.3.3. Die Partizipation der NZBen an der Netto-

Zentralbankgeldbereitstellung des Eurosystems und deren Auswirkung auf die NZB-Gewinne.

3. Die Beteiligung der NZBen an der Banknotenemission.

3.1.Die Beteiligung der NZBen an der Herstellung der Banknoten............ 133

3.2.Die Beteiligung der NZBen an der Ausgabe der Banknoten.................. 135

4. Die Beteiligung der NZBen an der Erstellung von Statistiken des Eurosystems.

5. Die Beteiligung der NZBen an Verrechnungs- und Zahlungssystemen...... 139

6. Die internationale Vertretung des Eurosystems durch die NZBen.

V.2.2. Die Analyse der Eurosystem-unabhängigen Tätigkeiten

V.2.2.1. Eurosystem-unabhängige Tätigkeiten, die im einzelnen in der ESZB-Satzung geregelt sind.

1. Die Beteiligung der NZBen an internationalen Organisationen und bilaterale Geschäftsbeziehungen der NZBen mit Drittländern.

1.1.Die Beteiligung der NZBen an internationalen Organisationen

1.1.1. Die Beteiligung der NZBen am Internationalen

Währungsfonds (IWF)

1.1.1.1.Die Beteiligung der NZBen an der Finanzierung der „originären" Ressourcen des IWF.

1.1.1.2.Die Beteiligung der NZBen an der Finanzierung des IWF-Sondervermögens.

1.1.1.3.Die Bedeutung der Zinseinkünfte der NZBen aus der IWF-Beteiligung für die NZB-Gewinne. 
1.1.2. Die Beteiligung der NZBen an der Bank für Internationalen Zahlungsausgleich (BIZ)

1.1.3. Die Beteiligung der NZBen an weiteren internationalen

Organisationen.

1.2.Bilaterale Geschäftsbeziehungen der NZBen mit Finanzinstituten und Zentralbanken in Drittländern.

1.2.1. Bilaterale Kredite der NZBen an Zentralbanken und Finanzinstitute in Drittländern

1.2.2. Die Beteiligung der NZBen an besonderen bilateralen Wechselkursabkommen. 160

1.2.3. Andere Geschäftsbeziehungen der NZBen mit Zentralbanken und Finanzinstituten in Drittländern.

2. Verfügung über die den NZBen nach der Übertragung auf die EZB verbliebenen Währungsreserven.

3. Kontenverwaltung für öffentliche Stellen und andere Marktteilnehmer.

4. Eurosystem-unabhängige Offenmarkt- und Kreditgeschäfte der NZBen... 171

4.1.Eurosystem-unabhängige Wertpapiergeschäfte.

4.2.Eurosystem-unabhängige Kreditgewährung der NZBen an

Ansässige des Euro-Währungsgebiets.

4.3.Eurosystem-unabhängige Emission und Einzug von

NZB-Schuldverschreibungen.

5. Fiscal Agent für öffentliche Stellen. 180

6. Die Geschäfte der NZBen für ihren eigenen Betrieb und für ihr Personal.

\section{V.2.2.2. Eurosystem-unabhängige Tätigkeiten der NZBen, die nicht} im einzelnen in der ESZB-Satzung geregelt sind.

1. Die Beteiligung der NZBen an Unternehmen (keine EZB-, IWF- und BIZ-Beteiligungen)

2. Unterhalten von Immobilien, die nicht direkt dem Geschäftsbetrieb dienen.

3. Die Verwaltung der NZB-Eigenmittel und Sonderausschüttungen der NZBen.

4. Die Beteiligung der NZBen an der staatlichen Münzemission.

5. Die Beteiligung der NZBen an der Aufsicht über Finanzinstitute.

6. Sonstige Eurosystem-unabhängige Tätigkeiten der NZBen 
V.3.1. Die (Um-)Verteilung der Monetären Einkünfte................................... 204

V.3.1.1. Die Indirekte Methode in der Übergangsphase (1999 bis 2001)... 205

1. Die vertraglichen Regelungen................................................................ 205

2. Die Indirekte Methode nach dem Beschluß des EZB-Rats vom 3. November 1998 205

3. Umverteilungseffekte bei Anwendung der Indirekten Methode................. 206

4. Kritische Würdigung der Indirekten Methode............................................ 209

V.3.1.2. Das Earmarking-Verfahren ............................................................... 210

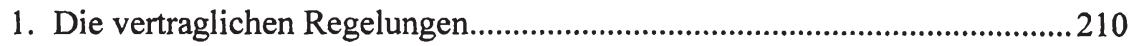

2. Das Earmarking-Verfahren nach dem Beschluß des EZB-Rats vom

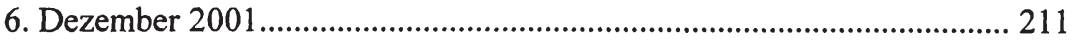

2.1.Der Berichtsrahmen für das Earmarking-Verfahren.............................. 211

2.2.Bestimmung der Bemessungsgrundlage zur Ermittlung der

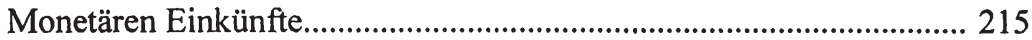

2.3.Bestimmung der ,gesondert erfaßbaren Vermögenswerte“.................. 216

2.4.Die Berechnung der Ausgleichsbeträge........................................... 217

2.5.Die Ermittlung der Monetären Einkünfte durch das Earmarking-

Verfahren.

220

2.5.1. Ermittlung der Monetären Einkünfte für das Jahr 2002............ 220

2.5.2. Ermittlung der Monetären Einkünfte ab dem Jahr 2003 bis einschließlich 2007.................................................................. 221

2.5.3. Ermittlung der Monetären Einkünfte ab dem Jahr 2008............ 222

2.6.Analyse der Konstruktionselemente des Earmarking-Verfahrens........ 223

2.6.1. Eingrenzung der Earmarking-fähigen NZB-Aktiva.................. 223

2.6.2. Analyse der Earmarking-Bemessungsgrundlage......................... 224

2.6.3. Spezifische Probleme anderer denkbarer Earmarking-

Varianten und deren Vermeidung durch die Earmarking-

Methode des EZB-Rats............................................................ 230

2.6.3.1.Einzelposten-Earmarking......................................... 232

2.6.3.2.Sukzessives Earmarking............................................... 232

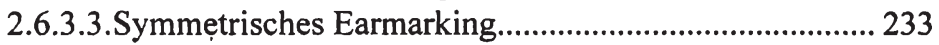

2.6.3.4.Freies Earmarking.......................................................... 234

2.6.3.5.Quantifizierung heterogenitätsinduzierter

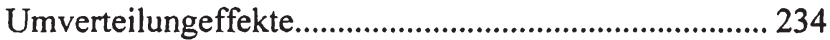

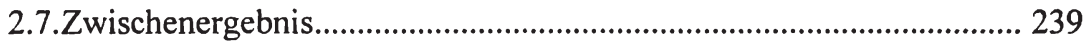

3. Umverteilungseffekte des Earmarking-Verfahrens................................... 240

3.1.Rechtfertigung der Umverteilung von Geldschöpfungsgewinnen im Eurosystem. 
3.2.Unerwünschte Umverteilungseffekte des Earmarking-

Verfahrens.............................................................................................. 241

3.2.1. Die empirischen Seigniorage-Studien im Überblick.................. 244

3.2.2. Kritische Würdigung der Seigniorage-Studien........................... 249

3.2.2.1.Seigniorage-Studien, die die Umverteilungseffekte auf Jahresbasis berechnen..............................................2 249

3.2.2.2. Seigniorage-Studien, die die Umverteilungseffekte mit der Barwertmethode berechnen.............................. 252

3.2.3. Lösungsansätze zur Vermeidung der unerwünschten

Umverteilungseffekte............................................................ 265

3.2.3.1.Anrechnung der Monetären Pre-EWU-Basen auf das Geldschöpfungsvermögen der NZBen.......................... 265

3.2.3.2.Anrechnung der Ausgleichsbeträge im Zeitraum von 2002 bis einschließlich 2007.

3.3.Die Auswirkungen der EWU-Erweiterung auf die Umverteilung der Geldschöpfungsgewinne durch das Earmarking-Verfahren

4. Analyse des Earmarking-Verfahrens unter konzeptionellen Gesichtspunkten.......................................................................................... 273

4.1.Konzeptionelle Begründung des Earmarking-Verfahrens.

4.2. Konzeptionelle Kritik an der Umsetzung des EarmarkingVerfahrens.

V.3.2. Die Gewinnverwendung der NZBen nach dem Pooling der Monetären Einkünfte.

VI. ZUSAMMENFASSUNG.

Anhang 283

Literaturverzeichnis 
Verzeichnis der Tabellen

\section{Tabellen im Text}

Tabelle 1: Die Gewinn- und Verlustrechnung der EZB für die Jahre

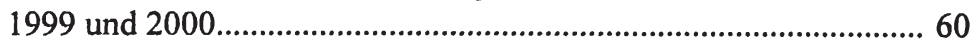

Tabelle 2: Die Ausstattung der EZB mit Kapital.......................................... 63

Tabelle 3: Zins- und Dividendeneinkünfte der Europäischen Zentralbank aus der Investition ihres Kapitals....................................................... 64

Tabelle 4: Die Ausstattung der EZB mit Währungsreserven durch die NZBen

Tabelle 5: Die Zinseinkünfte und Zinsaufwendungen der Europäischen

Zentralbank aus übertragenen Währungsreserven im Jahr 1999 und 2000

Tabelle 6: Personalentwicklung, Personalkosten und Sachaufwendungen der EZB in den Jahren 1998, 1999 und 2000.

Tabelle 7: Erträge und Aufwendungen der EZB aus realisierten Buchgewinnen, Abschreibungen und sonstigen Bilanztransaktionen in den Jahren 1999 und 2000.

Tabelle 8: Die Gewinnverwendung und Verlustfinanzierung der Europäischen Zentralbank in den Jahren 1998, 1999 und

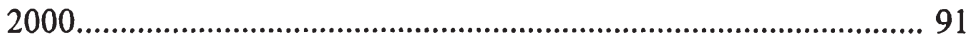

Tabelle 9: Die Eröffnungsbilanz des Eurosystems unterteilt nach EZB und NZBen zum 1.1.1999 in Mio. Euro.

Tabelle 10: Die Gewinn- und Verlustrechnungen der EZB und der NZBen für das Jahr 1998 in Mio. EUR.

Tabelle 11: Die Bilanz des Eurosystems unterteilt nach EZB und NZBen zum 31.12.1999 in Mio. Euro 105

Tabelle 12: Die Gewinn- und Verlustrechnungen der EZB und der NZBen für das Jahr 1999 in Mio. EUR

Tabelle 13: Die Offenmarktgeschäfte des Eurosystems.

Tabelle 14: Die geldpolitischen Geschäfte des Eurosystems im ersten Jahr der EWU.

Tabelle 15: Die Beteiligung der NZBen an der Refinanzierung des Finanzsektors zum 1.1.1999 und 31.12.1999 in Mio. EUR 124

Tabelle 16: Die Verteilung des in 1999 geschöpften (Netto-) Zentralbankgelds auf die einzelnen NZBen und der grenzüberschreitende Überweisungsverkehr mit Basisgeld im ersten Jahr der EWU in Mio. Euro. 
Tabelle 17: Geschätzte Zinserträge der NZBen aus der NettoZentralbankgelderhöhung des Eurosystems im ersten Jahr der EWU in Mio. Euro.

Tabelle 18: Die Beteiligung der NZBen an der Herstellung der Erstausstattungsmenge an Euro-Banknoten.

Tabelle 19: Schlüssel zur Verteilung der Euro-Banknoten innerhalb des Eurosystems.

Tabelle 20: Die Beteiligung der NZBen an der Finanzierung der „originären" Ressourcen des IWF zum 31.12.1999 in Mio. Euro.

Tabelle 21: Die Beteiligung der NZBen an der Finanzierung des IWFSondervermögens zum 31.12.1999 in Mio. Euro. 150

Tabelle 22: Geschätzte Zinseinkünfte der NZBen aus der IWF-Beteiligung zum 31.12.1999 in Mio. Euro.

Tabelle 23: Die Beteiligung der NZBen an der Bank für Internationalen Zahlungsausgleich zum 31.12.1999.

Tabelle 24: Die Beteiligung der NZBen an den BIZ-Krediten zugunsten der Banco Central do Brasil.

Tabelle 25: Die Fremdwährungsaktiva der NZBen zum 31.12.1999.

Tabelle 26: Eurosystem-unabhängige Kontenverwaltung der NZBen im Auftrag von inländischen Geschäftspartnern (keine Kreditinstitute mit Mindestreserveverpflichtung) (Angaben zum

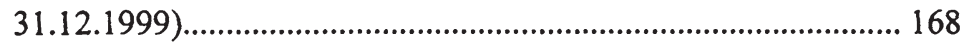

Tabelle 27: Eurosystem-unabhängige Transaktionen der NZBen mit Euro-Wertpapieren in 1999 in Mio. Euro.

Tabelle 28: Personalentwicklung, Personalkosten und administrative Aufwendungen der NZBen in 1999.

Tabelle 29: Unternehmensbeteiligungen der NZBen zum 31.12.1999 (keine EZB-, IWF, und BIZ-Beteiligungen).

Tabelle 30: Organisationsform, Eigenkapital und Sonderausschüttungen der NZBen.

Tabelle 31: Sicherheitsbestände an Münzen im Besitz der NZBen und

Nationaler Münzumlauf der Jahre 1998 und 1999 sowie genehmigte Münz-Neuemissionen für 2000.

Tabelle 32: Die Beteiligung der NZBen an der Aufsicht über Finanzinstitute.

Tabelle 33: Andere Eurosystem-unabhängige Tätigkeiten der NZBen 201

Tabelle 34: Die Umverteilung der Monetären Einkünfte im Jahr 1999 in Mio. Euro. 
Tabelle 35: Gegenüberstellung der harmonisierten „alten“ und „neuen“" Bilanzstruktur des Eurosystems.

Tabelle 36: Ausgleichsbeträge für die Berechnung der Monetären Einkünfte im Zeitraum von 2002 bis 2007 in Mio. Euro

Tabelle 37: Die „Deckungsstruktur“ der Monetären NZB-Basen zum 31.12.1999.

Tabelle 38: Die Auswirkungen unterschiedlicher Earmarking-Verfahren auf die Umverteilung der Monetären Einkünfte aus den Pre-EWU-Aktiva der NZBen (Angaben in Mio. Euro) 236

Tabelle 39: EZB-Kapitalanteile der EWU-11-NZBen und die Verteilung der Monetären NZB-Basen zum 1.1.1999.

Tabelle 40: Seigniorage-Studien im Überblick.

Tabelle 41: Die Auswirkungen der Verzinsung der Mindestreserve sowie des Earmarkings unverzinslicher Goldbestände auf die Umverteilung der Monetären Einkünfte.

Tabelle 42: Die Gewinner und Verlierer der Umverteilung des Pre-EWUGeldschöpfungsvermögens nach der Barwertmethode von Sinn und Feist. 254

Tabelle 43: Geschätzte Zinsersparnisse bzw. entgangene Gewinne der NZBen aus dem Pre-EWU-Seignioragepooling im Zeitraum von 1999 bis 2007. 262

Tabelle 44: Effektive Nettopositionen der NZBen aus dem Pooling von Pre-EWU-Geldschöpfungsgewinnen 264

Tabelle 45: Umverteilung von Seignioragevermögen und EWU-Erweiterung. 272

Tabelle 46: Die Verwendung der NZB-Bilanzgewinne des Jahres 1999. 276

Tabellen im Anhang

Tabelle A1: Die Bilanz der Europäischen Zentralbank zum 31.12.1999 und 31.12.2000 in Mio. Euro. 284

Tabelle A2: Die Berechnung der Ausgleichsbeträge für die Ermittlung der Monetären Einkünfte der Jahre 2002 bis 2007 in Mrd. Euro 286

Tabelle A3: ,Freies Earmarking“ zum 1.1.1999 288

Tabelle A4: Die Ermittlung der Monetären Einkünfte durch die Indirekte Methode (inkl. Banknotenumlauf) und durch „sukzessives“ Earmarking. 
Tabelle A5: Berechnung des Earmarking-fähigen Goldbestandes der NZBen zum 1.1.1999.

Tabelle A6: Berechnungen der Netto-Poolingpositionen der EWU-12-

NZBen mit unterschiedlichen Zinshöhen 293

Tabelle A7: Die Verteilung der gewogenen Stimmen der NZBen im EWU-12-EZB-Rat. 294 
Verzeichnis der Abbildungen

Abbildung 1: Stilisierte Münz- und Zentralbankbilanz mit zugehörigen Gewinn- und Verlustrechnungen................................................. 38

Abbildung 2: Das Europäische System der Zentralbanken und das Eurosystem (aktuelle Zusammensetzung seit dem 1.1.2001).....56

Abbildung 3: Die bilanztechnische Erfassung der Interventionen des Eurosystems (Stützungskäufe zugunsten des Euro gegen Verkauf von Devisen).

Abbildung 4: Die Tätigkeiten der NZBen in legalistischer und funktionaler Hinsicht

Abbildung 5: Die Forderungen der NZBen an den heimischen Finanzsektor zum 1.1.1999 und 31.12.1999 in Mio. EUR

Abbildung 6: Die bilanzielle Erfassung der grenzüberschreitenden

Zentralbankgeld-Überweisungen in den NZB-Bilanzen.

Abbildung 7: Die Euro-Banknotenemission in Europa und in außereuropäischen Territorien.

Abbildung 8: Die Auswirkungen des grenzüberschreitenden Überweisungsverkehrs auf die Umverteilungseffekte des Earmarking-Verfahrens. 226

Abbildung 9: Umverteilung von Pre-EWU-Geldschöpfungsvermögen und die Anrechnung der Ausgleichsbeträge 268 
Verzeichnis der Abkürzungen

\begin{tabular}{|c|c|c|}
\hline Abs. & $=$ & Absatz \\
\hline AKV & $=$ & Allgemeine Kreditvereinbarungen \\
\hline Art. & $=$ & Artikel \\
\hline ATS & $=$ & Österreichischer Schilling \\
\hline BBk & $=$ & Deutsche Bundesbank \\
\hline $\mathrm{BCL}$ & $=$ & Banque Centrale du Luxembourg \\
\hline Bd. & $=$ & Band \\
\hline BdE & $=$ & Banco de España \\
\hline $\mathrm{BdF}$ & $=$ & Banque de France \\
\hline BdI & $=$ & Banca d'Italia \\
\hline $\mathrm{BdP}$ & $=$ & Banco de Portugal \\
\hline $\mathrm{BEF}$ & $=$ & Belgischer Franc \\
\hline BIP & $=$ & Bruttoinlandsprodukt \\
\hline $\mathrm{BIZ}$ & $=$ & Bank für Internationalen Zahlungsausgleich \\
\hline $\mathrm{BoE}$ & $=$ & Bank of England \\
\hline $\mathrm{BoF}$ & $=$ & Bank of Finland \\
\hline bzw. & $=$ & beziehungsweise \\
\hline $\mathrm{CBI}$ & $=$ & Central Bank of Ireland \\
\hline CCBM & $=$ & Correspondent Central Banking Model \\
\hline CFA & $=$ & $\begin{array}{l}\text { Franc de la Coopération Financière en Afrique Central (XAF) } \\
\text { bzw. Franc de la Communauté Financière Africaine (XOF) }\end{array}$ \\
\hline CFP & $=$ & Colonies Françaises du Pacifique \\
\hline DEM & $=$ & Deutsche Mark \\
\hline DKK & $=$ & Dänische Krone \\
\hline $\mathrm{DNB}$ & $=$ & De Nederlandsche Bank \\
\hline DaNB & $=$ & Danmarks Nationalbank \\
\hline EG & $=$ & Europäische Gemeinschaft \\
\hline EGV & $=$ & Vertrag zur Gründung der Europäischen Gemeinschaft \\
\hline ELA & $=$ & Emergency Liquidity Assistance \\
\hline ERP & $=$ & European Recovery Program \\
\hline ESP & $=$ & Spanische Peseta \\
\hline ESZB & $=$ & Europäisches System der Zentralbanken \\
\hline EU & $=$ & Europäische Union \\
\hline EURS & $=$ & Eurosystem \\
\hline EWI & $=$ & Europäisches Währungsinstitut \\
\hline EWU & $=$ & Europäische Währungsunion \\
\hline EZB & $=$ & Europäische Zentralbank \\
\hline FIM & $=$ & Finnmark \\
\hline
\end{tabular}




\begin{tabular}{|c|c|c|}
\hline Fn. & $=$ & Fußnote \\
\hline FRF & $=$ & Französischer Franc \\
\hline FSF & $=$ & Forum für Finanzstabilität \\
\hline G10 & $=$ & Gruppe der 10 \\
\hline G20 & $=$ & Gruppe der 20 \\
\hline G7 & $=$ & Gruppe der 7 \\
\hline GBP & $=$ & Pfund Sterling \\
\hline GFr & $=$ & Goldfranken \\
\hline gg. & $=$ & gegenüber \\
\hline GRD & $=$ & Griechische Drachme \\
\hline $\mathrm{GuV}$ & $=$ & Gewinn- und Verlustrechnung \\
\hline H. & $=$ & Heft \\
\hline HIPC & $=$ & Heavily Indebted Poor Countries \\
\hline Hrsg. & $=$ & Herausgeber \\
\hline i.d.F. & $=$ & in der Fassung \\
\hline i.d.R. & $=$ & in der Regel \\
\hline i.V.m. & $=$ & in Verbindung mit \\
\hline IEP & $=$ & Irisches Pfund \\
\hline IMF & $=$ & International Monetary Fund \\
\hline inkl. & $=$ & inklusive \\
\hline ITL & $=$ & Italienische Lira \\
\hline IWF & $=$ & Internationaler Währungsfonds \\
\hline Jg. & $=$ & Jahrgang \\
\hline JPY & $=$ & Japanischer Yen \\
\hline k. A. & $=$ & keine Angaben \\
\hline KMF & $=$ & Komoren-Franc \\
\hline LiKo & $=$ & Liquiditäts-Konsortialbank \\
\hline lit. & $=$ & litera \\
\hline Mio. & $=$ & Millionen \\
\hline Mrd. & $=$ & Milliarden \\
\hline NBB & $=$ & Belgische Nationalbank \\
\hline NKV & $=$ & Neue Kreditvereinbarungen \\
\hline NLG & $=$ & Holländischer Gulden \\
\hline o.ä. & $=$ & oder ähnliches \\
\hline o.V. & $=$ & ohne Verfasser \\
\hline OECD & $=$ & $\begin{array}{l}\text { Organisation für wirtschaftliche Entwicklung und } \\
\text { Zusammenarbeit }\end{array}$ \\
\hline OeNB & $=$ & Österreichische Nationalbank \\
\hline PRGF & $=$ & Poverty Reduction and Growth Facility \\
\hline PTE & $=$ & Portugiesischer Escudo \\
\hline
\end{tabular}




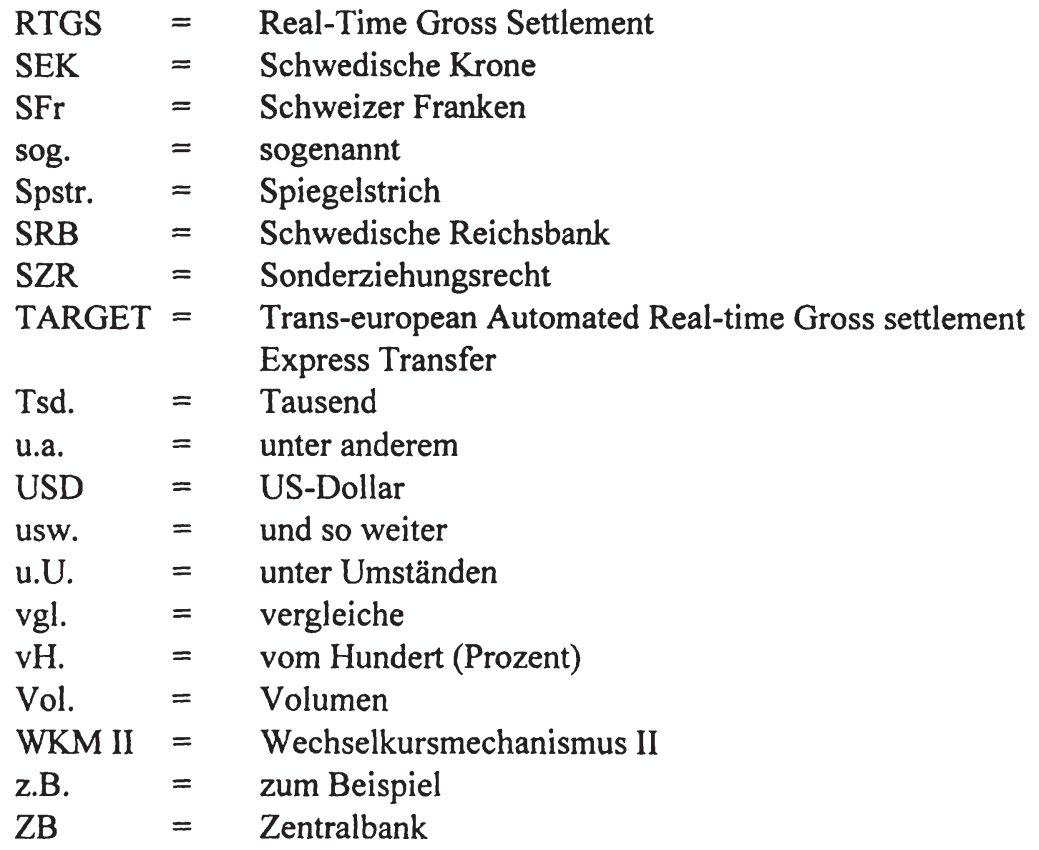


Verzeichnis der verwendeten Zentralbankgesetze, -satzungen und -statuten

BBankG: Gesetz über die Deutsche Bundesbank in der Fassung der Bekanntmachung vom 22. Oktober 1992 (BGBl. I S. 1782), zuletzt geändert durch das Sechste Gesetz zur Änderung des Gesetzes über die Deutsche Bundesbank vom 22. Dezember 1997 (BGBl. I S. 3274)

BCL-Gesetz: Law of 23 December 1998 concerning the monetary status and the Central Bank of Luxemburg (and repealing the legal tender status of the notes issued by the Banque Internationale à Luxembourg)

BdE-Gesetz: Law 12/1998, of April 28, amendment of law 13/1994 on the autonomy of the Banco de España

BdF-Statut: Statute of the Banque de France

BdI-Statut: Statute of the Bank of Italy

BdP-Gesetz: Organic Law, approved by Law No. 5/98 of January 31

BIZ-Statut: Statuten der Bank für Internationalen Zahlungsausgleich vom 20. Januar 1930 i.d.F. vom 8. November 1999

BoF-Gesetz: Act on the Bank of Finland (Nr. 214/1998)

CBI-Gesetz: Central Bank Act 1989

DNB-Satzung: Articles of Association of De Nederlandsche Bank N.V., May 1998

ESZB-Satzung: Protokoll über die Satzung des Europäischen Systems der Zentralbanken und der Europäischen Zentralbank

IWF-Statut: Articles of Agreement of the International Monetary Fund

NBB-Statut: Statutes of the National Bank of Belgium amended by the Extraordinary General Meeting of 22 February 1999 and approved by Royal Decree of 9 March 1999

OeNB-Gesetz: Bundesgesetz über die Österreichische Nationalbank (Nationalbankgesetz 1984 - NBG), BGBl. Nr. 50 i. d. F. BGBl. I Nr. $60 / 1998$ 


\section{PROBLEMSTELLUNG UND AUFBAU DER ARBEIT}

Die Umverteilung der Geldschöpfungsgewinne in der Europäischen Währungsunion (EWU) wird kontrovers diskutiert. So reichen die einschlägigen Schätzungen der „Gewinner-“ und „Verliererpositionen“ der einzelnen EWULänder von kaum nennenswerten Beträgen bis hin zu Summen substantieller Größenordnung. Dabei wird jedoch oft übersehen, daß diese Untersuchungen meist unterschiedliche Fragestellungen beantworten und/oder unterschiedliche Meßkonzepte verwenden. Eine umfassende Abgrenzung der verschiedenen Seigniorage-Studien würde hier zwar die erforderliche Klarheit schaffen, eine solche synoptische Gegenüberstellung steht aber bislang noch aus. Des weiteren greifen die erwähnten Untersuchungen in vielfacher Hinsicht zu kurz. So bleibt eine ganze Reihe institutioneller Aspekte unberücksichtigt, die unter Umständen erhebliche Auswirkungen auf die umzuverteilenden Geldschöpfungsgewinne haben können. Ohne eine genaue Kenntnis derselben lassen sich aber die Notenbankgewinne und damit auch die Verteilung derselben kaum adäquat abschätzen. Zudem ist den bisherigen Studien gemeinsam, daß sie sich auf recht heterogenes Datenmaterial beziehen, da zum Zeitpunkt der Erstellung dieser Untersuchungen noch keine harmonisierte Datenbasis verfügbar war. Ein solcher Datensatz kann jetzt aber mit Hilfe der einzelnen Veröffentlichungen der EWU-Zentralbanken erstellt werden, so daß nun nicht nur eine genauere Quantifizierung der kritisierten Umverteilungseffekte möglich ist, sondern auch weitere Probleme der konkreten Abwicklung des Notenbankgewinnpoolings identifiziert werden können. Die folgende Analyse versucht, den angesprochenen Kritikpunkten Rechnung zu tragen und eine umfassende Untersuchung der Notenbankgewinnentstehung und -verwendung im EuroWährungsraum vorzustellen.

Hierzu wird wie folgt vorgegangen. Im Anschluß an die einleitenden Ausführungen in Kapitel I setzt sich Kapitel II mit dem Geldschöpfungsgewinn (Seigniorage) unter theoretischen Aspekten auseinander. Im Mittelpunkt der Betrachtung steht hierbei die kritische Würdigung der unterschiedlichen Seigniorage-Meßkonzepte sowie die Frage nach den Grenzen der staatlichen Einnahmeerzielung aus der Geldproduktion.

Das folgende dritte Kapitel dient der institutionellen Abgrenzung zwischen dem Europäischen System der Zentralbanken (ESZB) und dem Eurosystem.

Das Kapitel IV widmet sich der Gewinnentstehung und -verwendung der Europäischen Zentralbank (EZB). Dabei werden die einzelnen Entstehungskomponenten des EZB-Gewinns ausführlich untersucht und das gegenwärtige Gewinnerzielungspotential der EZB abgeschätzt. Die anschließenden 
Ausführungen zur Gewinnverwendung bzw. Verlustfinanzierung der EZB beschreiben die Schnittstelle zu den Nettoerträgen der nationalen Zentralbanken (NZBen) des Eurosystems. Auf der Basis dieser Analysen läßt sich die Frage beantworten, ob es im Rahmen der EZB-Gewinnentstehung und -verwendung bzw. EZB-Verlustfinanzierung zu Umverteilungseffekten zwischen den Anteilseignern der EZB kommen kann.

Das fünfte Kapitel beschäftigt sich mit der Gewinnentstehung und -verwendung der NZBen des Eurosystems. Hierzu werden in einem ersten Schritt die von der EZB ausgewiesene konsolidierte Eurosystembilanz disaggregiert und die entsprechenden Gewinn- und Verlustrechnungen der einzelnen EWUZentralbanken harmonisiert. Die so erstellte Datenbasis bildet die Grundlage für die weitere Analyse. Hierbei erfolgt die Untersuchung der NZB-Gewinnentstehung in zwei Abschnitten. Der erste Abschnitt beschäftigt sich mit den als „Eurosystem-spezifisch“ definierten Tätigkeiten der NZBen. Diese Aktivitäten, die die NZBen auf Weisung der EZB ausführen, umfassen vor allem die Durchführung der gemeinsamen Geldpolitk, aber auch die Ausführung einer Reihe weiterer Aufgaben, die überwiegend der Sicherung der Funktionsfähigkeit der gemeinsamen Geldpolitik dienen. Der zweite Abschnitt untersucht die „Eurosystem-unabhängigen" Tätigkeiten der NZBen. Solche Aktivitäten führen die NZBen auf Basis ihrer nationalen Statuten und Gesetze durch, ohne daß die EZB ein Dispositionsrecht besitzt, solange die Ziele und Aufgaben des Eurosystems nicht beeinträchtigt werden. Dabei ist unter Notenbankgesichtspunkten vor allem die Beteiligung an internationalen Finanzinstitutionen wie dem Internationalen Währungsfonds (IWF) interessant. Aber auch eine ganze Reihe weiterer Eurosystem-unabhängiger Tätigkeiten werden untersucht. Die dann folgenden Ausführungen analysieren die Gewinnverwendung der NZBen, wobei vor allem der Umverteilung der „Monetären Einkünfte“ große Aufmerksamkeit geschenkt wird. So beschäftigt sich die Untersuchung zunächst mit der von 1999 bis Ende 2001 vom EZB-Rat angewandten Indirekten Methode, deren Umverteilungseffekte quantifiziert und kritisch hinterfragt werden. Der anschließende Abschnitt widmet sich dem seit Anfang 2002 durchgeführten Earmarking-Verfahren. Diese facettenreiche Methode zur Ermittlung der NZB-Geldschöpfungsgewinne wird detailliert beschrieben und deren Konstruktionselemente eingehend analysiert. Die weiteren Ausführungen untersuchen die Umverteilungseffekte der Earmarking-Methode. Hierbei lassen sich „erwünschte“ und „unerwünschte" Umverteilungseffekte unterscheiden. Gerade bei der Untersuchung der zu kritisierenden Umverteilungswirkungen können nun auch die bereits vorhandenen Seigniorage-Studien systematisiert und in die Analyse mit aufgenommen werden. Nach der Diskussion eines möglichen Lösungsansatzes zur Vermeidung der „unerwünschten“ 
Umverteilungseffekte sowie des hierfür vom EZB-Rat vorgesehenen Mechanismus wird dann noch kurz auf die Erweiterung der EWU und deren mögliche Auswirkungen auf die Seigniorageumverteilung eingegangen. Die anschließende Analyse, die das Earmarking-Verfahren unter konzeptionellen Gesichtspunkten beleuchtet, rundet die Untersuchung ab. Nach diesen Ausführungen kann die ,nationale“ NZB-Gewinnverwendung analysiert und quantifiziert werden.

Das anschließende Kapitel VI faßt die gefundenen Ergebnisse zusammen. 
Gerhard Rösl - 978-3-631-75006-3

Downloaded from PubFactory at 01/11/2019 09:21:25AM

via free access 


\section{THEORETISCHE ÜBERLEGUNGEN ZUM SEIGNIORAGE}

\section{Zur Begriffsdefinition}

Unter dem Begriff Seigniorage versteht man allgemein den realen Gewinn aus der Produktion von Geld. Dabei ist die in der Literatur verwendete Begrifflichkeit keineswegs immer einheitlich. Zudem werden oftmals die verschiedenen Varianten zur Messung des staatlichen Geldschöpfungsgewinns bzw. deren impliziten Annahmen nicht differenziert genug unterschieden. Im Folgenden sollen deshalb die wichtigsten Seignioragekonzepte gemäß ihrer Intention vorgestellt und kritisch gewürdigt werden.

\section{Die Inflationssteuer}

\subsection{Definition der Inflationssteuer}

In der Regel gibt der Staat Banknoten und Münzen als alleiniges gesetzliches Zahlungsmittel aus. Weiterhin verpflichtet er oftmals die ansässigen Kreditinstitute, Mindestreserveeinlagen bei der Zentralbank zu unterhalten. Auch freiwillig bei der Währungsbehörde gehaltene Einlagen inländischer privater (Nicht-) Banken sind (meist in geringem Umfang) zu beobachten. Die Summe dieser vorstehend genannten Komponenten aus Bargeldumlauf und Einlagen der privaten (Nicht-) Banken bei der Zentralbank wird als „Monetäre Basis“ oder „Basisgeldmenge“ $B$ einer Volkswirtschaft bezeichnet. Diese dient der Finanzierung von Tauschtransaktionen und bildet die Grundlage für die Giralgeldschöpfung der Geschäftsbanken. Eine positive Inflationsrate $g_{p}$ entwertet die nominale Basisgeldmenge der Volkswirtschaft. Wollen nun die privaten Geldverwender ihre Realkasse konstant halten, um bei gegebenen Zahlungsgewohnheiten auch weiterhin ihre realen Transaktionen vollständig finanzieren zu können, so müssen sie zusätzliches Basisgeld bei den staatlichen Geldproduzenten gegen Hergabe realer Ressourcen in Höhe von $g_{P} \cdot B / P$ (mit $P$ als Preisniveau) nachfragen. Der Umfang dieses inflationsinduzierten Ressourcentransfers wird als Inflationssteuer bezeichnet':

$$
I T=g_{p} \cdot \frac{B}{P} .
$$

Vgl. Friedman (1953), S. 255 und Bailey (1956), S. 102. 
Der Begriff der Inflationssteuer ergibt sich aus der Analogie zu „normalen“ Steuereinnahmen des Staatssektors. Die Höhe der Inflationssteuer IT (Steueraufkommen) wird durch das Produkt aus der Inflationsrate $g_{P}$ (Steuersatz) und der realen Basisgeldmenge $B / P$ (Steuerbemessungsgrundlage) bestimmt.

\subsection{Grenzen der Einnahmeerzielung des Geldproduzenten durch die Inflätionssteuer}

Wie bei allen Steuern ist auch bei der Inflationssteuer der Umfang der Ressourcen begrenzt, die der Staatssektor durch immer höhere Steuersätze sprich Inflationsraten - zusätzlich an sich ziehen kann ${ }^{2}$. Denn steigende Inflationsraten führen zu zunehmenden Nominalzinsen, so daß die Basisgeldnachfrage aufgrund der gestiegenen Opportunitätskosten der Basisgeldhaltung zurückgeht. Anhand der rechten Seite von Gleichung (1) läßt sich dies einfach zeigen. Nur dann, wenn der Steueraufkommen erhöhende Effekt einer gestiegenen Inflationsrate $g_{p}$, nicht durch einen Steueraufkommen senkenden Effekt der gleichgewichtigen realen Basisgeldnachfrage $B / P$ überkompensiert wird, läßt sich durch eine höhere Inflationsrate ein größerer realer Ressourcentransfer zum staatlichen Geldproduzenten generieren.

\subsection{Kritische Würdigung des Konzepts der Inflationssteuer}

Das Konzept der Inflationssteuer erfaßt den inflationsinduzierten Ressourcentransfer der privaten Geldverwender zu den staatlichen Geldproduzenten, der sich darauf gründet, daß die Wirtschaftssubjekte die inflationsbedingte Entwertung ihrer Kassenhaltung durch zusätzliche Basisgeldnachfrage kompensieren wollen. Für die Analyse des gesamten staatlichen Geldschöpfungsgewinns ist dieser Ansatz aber nur bedingt geeignet, da er das Transaktionsmotiv der Basisgeldnachfrage nicht voll erfaßt. So weist das Konzept der Inflationssteuer in einer Volkswirtschaft mit inflationsfreiem Wachstum keinen staatlichen Geldschöpfungsgewinn aus, obwohl die Privaten reale Ressourcen auf den Staatssektor übertragen, um zusätzliches Basisgeld zur Finanzierung des gestiegenen Transaktionsvolumens zu erhalten. Dies bedeutet aber auch, daß das Konzept der Inflationssteuer den Ressourcentransfer der privaten Geldverwender in einer wachsenden Wirtschaft systematisch unterschätzt und deshalb zur Quantifizierung des Geldschöpfungsgewinns in der

2 Vgl. Friedman (1953), S. 256 f.. 
Regel ungeeignet ist. Diese Kritik berücksichtigt jedoch das Konzept des Monetären Seigniorages, welches im Folgenden vorgestellt wird.

\section{Der Monetäre Seigniorage}

\subsection{Entstehung und Verwendung des Monetären Seigniorages}

Der Begriff „Seigniorage" stammt aus der Zeit des Goldstandards und leitet sich unmittelbar vom Inhaber des Münzrechts, dem „Seigneur“ oder Fürsten $a b^{3}$. Damals wie heute fragen die privaten Wirtschaftssubjekte Münzen nach, weil ihnen Geld in der Funktion als Zahlungs- und Wertaufbewahrungsmittel Nutzen stiftet. Da aber der Staat als Geldproduzent die Münzen nicht unentgeltlich verteilt, müssen die Privaten Aktiva in Höhe des Nennwertes der Münzen auf den Staat übertragen, um das gewünschte Geld zu erhalten. Dem Staat fließen folglich reale Ressourcen in Höhe des mit dem allgemeinen Preisniveau $P$ deflationierten Nominalwertes der neu emittierten Münzen $\Delta C$ zu. Der so definierte Brutto-Münzgewinn läßt sich folglich formulieren als

$$
S_{(m n}=\frac{\Delta C}{P} \text {. }
$$

Diese Überlegungen können auf die Produktion von Zentralbankgeld übertragen werden. Auch hier geben die privaten Geldnachfrager reale Ressourcen meist in Form von verzinslichen Forderungen, Wertpapieren oder Devisen gegen Zentralbankgeld an die staatliche Notenbank ab. Dieser Ressourcentransfer kann analog zum Münzgewinn als Brutto-Banknotengewinn bezeichnet werden und läßt sich als den mit dem allgemeinen Preisniveau $P$ deflationierten Nennwert des neu geschaffenen Zentralbankgeldes in Händen der inländischen Privaten $\Delta M_{1}$ darstellen:

$$
S_{\text {Note }}=\frac{\Delta M_{D}}{P}
$$

3 Vgl. Black (1992), S. 438 und Bofinger/Reischle/Schächter (1996), S. 47f.. 
Die reale Erhöhung der nominalen Monetären Basis, definiert als Summe aus Münzgewinn und Banknotengewinn, bestimmt nun die Höhe des Monetären Brutto-Seigniorages ${ }^{4} S_{M}$ :

$$
S_{M}=\frac{\Delta C+\Delta M_{D}}{P}=\frac{\Delta B}{P} .
$$

Subtrahiert man von $S_{M}$ die realen, operativen Kosten der Münz- und Banknotenproduktion $\left(O C_{C}+O C_{C: B}\right) / P$, läßt sich der Umfang der realen Ressourcen $S_{\Lambda t}^{n t}$ bestimmen, die dem Staat netto zufließen. Die Verwendung des Monetären Brutto-Seigniorages läßt sich folglich formulieren als:

$$
S_{M}=S_{M}^{n e t}+\frac{\left(O C_{C}+O C_{C B}\right)}{P} \text {. }
$$

Wie Gleichung (5) zeigt, wird der im Zuge der Geldschöpfung entstehende Ressourcentransfer zum staatlichen Geldproduzenten einerseits zur Finanzierung der operativen Kosten der Geldproduktion und andererseits zur Erhöhung des staatlichen Nettovermögens herangezogen.

\subsection{Grenzen der Einnahmeerzielung des Geldproduzenten durch den Monetären Seigniorage}

In Analogie zu den Überlegungen zur Inflationssteuer ist auch das Einnahmeerzielungspotential des Geldproduzenten durch den Monetären Seigniorage begrenzt. Dies wird deutlich, wenn man den in Gleichung (4) definierten Monetären Seigniorage umformuliert zu:

$$
(6)=(4) \quad S_{M}=\frac{\Delta B}{P}=\frac{d B}{d t} \cdot \frac{1}{P}=\frac{d B / d t}{B} \cdot \frac{B}{P}=g_{B} \cdot \frac{B}{P} \text {. }
$$

In dieser alternativen Form wird der Monetäre Seigniorage als Produkt aus der Wachstumsrate der nominalen Basisgeldmenge $g_{B}$. und der realen Basisgeldmenge $B / P$ dargestellt.

In Analogie zur Theorie der Besteuerung kann der Monetäre Seigniorage als Produkt aus Steuersatz $g_{B}$ und Steuerbemessungsgrundlage $B / P$ gesehen werden ${ }^{5}$. Wie bei „normalen“ Steuereinnahmen, kann man davon ausgehen, daß

\footnotetext{
4 Der Begriff Monetärer Seigniorage wurde wohl von Klein in die Literatur eingeführt. Vgl. Klein (1989), S. 3.

5 Vgl. auch Issing (1995), S. 235.
} 
(mäßig) steigende Steuersätze (bei entsprechend niedrigem Ausgangsniveau) zunächst die einsetzenden Ausweicheffekte überkompensieren, was insgesamt zu einem höheren Steueraufkommen führt. Der Monetäre Seigniorage steigt somit an. Ab einer bestimmten Wachstumsrate der nominalen Basisgeldmenge, nimmt der Monetäre Seigniorage aber nicht mehr zu, sondern geht wegen der sinkenden realen Geldnachfrage insgesamt sogar zurück. Diesen allgemein auch als „Laffer-Kurvenzusammenhang“ bezeichneten trade-off muß der staatliche Geldproduzent beachten, will er den Monetären Seigniorage maximieren ${ }^{6}$.

\subsection{Monetärer Seigniorage und Inflationssteuer}

Die Ausführungen zur Inflationssteuer und zum Monetären Seigniorage legen die Vermutung nahe, daß die Inflationssteuer als eine Art Teilkonzept des Monetären Seigniorages interpretiert werden kann ${ }^{7}$.

Logarithmiert man die nominale Geldmenge $B=B / P \cdot P$ und leitet sie nach der Zeit ab, dann läßt sich die Wachstumsrate der nominalen Basisgeldmenge $g_{B}$ als die Summe aus der Inflationsrate $g_{r}$ und der mit der Realeinkommenselastizität der realen Geldnachfrage $\varepsilon_{(B / P),(Y / P)}$ multiplizierten Wachstumsrate des realen Sozialprodukts $g_{r / l}$, schreiben:

$$
g_{B}=g_{P}+\varepsilon_{(B / P),(Y / P)} \cdot g_{Y / P} \cdot
$$

Setzt man nun (7) in (6) ein, so gilt:

$$
S_{M}=g_{P} \cdot \frac{B}{P}+\varepsilon_{(R / P) /(Y / P)} \cdot g_{Y / P} \cdot \frac{B}{P} .
$$

Gemäß Gleichung (8) kann der Monetäre Seigniorage also in zwei Komponenten unterteilt werden. Er setzt sich zusammen aus der bereits beschriebenen Inflationssteuer:

6 Vgl. Easterly/Mauro/Schmidt-Hebbel (1995), S. 583. Empirische Schätzungen dieses Zusammenhangs finden sich für die USA in Neumann (1992), S. 38 und für die Bundesrepublik Deutschland in Lange (1995), S. 108. Zur Diskussion der Seigniorage maximierenden Inflationsrate vgl. Friedman (1971), S. 846 ff., Auernheimer (1974), S. 598 ff., Calvo (1978), S. 503 ff., Fry (1981), S. 261 ff. und Easterly/Mauro/SchmidtHebbel (1995), S. $583 \mathrm{ff}$..

7 Vgl. im Folgenden Friedman (1971), S. 846 ff., Fischer (1982), S. 304, Neldner (1984), S. 412 und Issing (1995), S. 235 f.. 
$(9)=(1)$

$$
I T=g_{l} \cdot \frac{B}{P}
$$

und der sog. Wachstumskomponente ${ }^{8}$ des Monetären Seigniorages:

$$
G S=\varepsilon_{(B / P),(Y / P)} \cdot g_{Y / P} \cdot \frac{B}{P} .
$$

Die Wachstumskomponente des Monetären Seigniorages beschreibt den Umfang der von den Privaten auf den Staatssektor übertragenen realen Ressourcen, der sich darauf gründet, daß die privaten Wirtschaftssubjekte in einer real wachsenden Wirtschaft $\left(g_{Y / p}>0\right)$ zusätzliches Basisgeld als Zahlungsmittel benötigen, um das steigende Transaktionsvolumen finanzieren zu können. Oft wird zusätzlich unterstellt, daß die Realeinkommenselastizität der realen Geldnachfrage $\varepsilon_{(B / P),(Y / P)}$ den Wert eins annimmt ${ }^{9}$. Diese Annahme trifft u.U. für Länder mit hoher wirtschaftlicher Entwicklung und ausgeprägtem Finanzsektor auch zu. Allerdings ist in Staaten mit starkem Wirtschaftswachstum der Wert der Realeinkommenselastizität oft größer als eins, was eine entsprechend höhere Wachstumskomponente des Monetären Seigniorage nach sich zieht ${ }^{10}$.

Obige Ausführungen zeigen, daß das Konzept des Monetären Seigniorage neben dem inflationsinduzierten Ressourcentransfer, den die Inflationssteuer beschreibt, auch den Umfang derjenigen Ressourcen umfaßt, den die Geldnachfrager auf die Geldproduzenten übertragen, um ein real steigendes Wirtschaftswachstum zu finanzieren. Inflationssteuer und Monetärer Seigniorage entsprechen sich nur dann, wenn die Wachstumsrate des realen Sozialprodukts gleich null ist. Die in zahlreichen Publikationen zu lesende Gleichsetzung zwischen (Monetärem) „Seigniorage“ und Inflationssteuer ist deshalb oftmals nicht differenziert genug. Zudem erfaßt keines dieser Seigniorage-Konzepte den vollen Umfang des Ressourcen, die die privaten Geldverwender im Zuge der staatlichen Geldbereitstellung auf die öffentlichen Geldanbieter übertragen. Dies zeigt die folgende kritische Würdigung des Monetären Seigniorage-Konzepts.

8 Dieser Begriff geht wohl auf Neldner zurück. Vgl. Neldner (1984), S. 412. Neumann bezeichnet die Wachstumskomponente auch als Monetären Null-Inflationsseigniorage. Vgl. Neumann (1995), S. 41.

9 So z.B. Issing (1995), S. 236.

10 Vgl. Friedman (1971), S. 852. 


\subsection{Kritische Würdigung des Monetären Seigniorage-Konzepts}

Das Konzept des Monetären Seigniorages findet in der Literatur weite Verbreitung ". Dies ist einerseits auf die einfache Struktur des Konzepts und andererseits auf die leichte Verfügbarkeit der Daten zurückzuführen. Allerdings birgt dieser Ansatz auch eine Vielzahl impliziter Annahmen und Vereinfachungen in sich, die im Folgenden aufgezeigt werden sollen.

In der Literatur wird of das Vorliegen eines Monopols der geldschaffenden Instanz bei der Analyse des Seigniorages unterstellt. Als Voraussetzung zur Entstehung des Monetären Seigniorages darf ein Monopol jedoch nicht angesehen werden, denn auch bei Währungswettbewerb wäre ein Privater dazu bereit, zusätzliche Ressourcen netto an konkurrierende (staatliche) Geldproduzenten abzugeben und zwar in Höhe des Grenznutzens des Geldes. Dies zeigte schon die umfangreiche Verwendung der D-Mark, die als Zahlungsmittel in vielen osteuropäischen Staaten in unmittelbarer Konkurrenz zum dortigen nationalen Geld stand ${ }^{12}$.

Eine zentrale Annahme des Monetären Seignioragekonzepts ist die Nichtrückzahlbarkeit der Monetären Basis, denn nur so lassen sich die angekauften Ressourcen als Gewinn interpretieren ${ }^{13}$. Da die privaten Geldverwender in modernen Geldverfassungen nicht das Recht haben, Banknoten und Münzen gegen Aktiva bei der Zentralbank oder der Regierung zurückzutauschen, sieht sich der private Sektor einem Ressourcenverlust in Höhe der umlaufenden Geldmenge gegenüber. Doch selbst wenn die jederzeitige Umtauschbarkeit der Monetären Basis rechtlich gesichert wäre, erlaubt die tendenziell steigende Geldmenge in wachsenden Volkswirtschaften dennoch eine derartige Interpretation des Geldschöpfungsgewinnes. Daran ändert auch nichts, daß sich der Vorgang der Zentralbankgeldschöpfung buchungstechnisch in einer Verlängerung der Notenbankbilanz widerspiegelt, die eine Erhöhung der Zentralbankverbindlichkeiten impliziert. Faktisch bezahlt der Staat die ihm zugeflossenen Aktiva mit einer „unechten“ Forderung gegen sich selbst.

$"$ Vgl. z.B. Marty (1968), Fischer (1982), Mankiw (1987), Klein/Neumann (1990), Cornelius (1990a), Chamley (1991), Lange (1995) und Lange/Nolte (1998).

12 So zirkulierten Ende 1994 ca. 30 - 40 Prozent des DEM-Notenumlaufs im Ausland. Vgl. Deutsche Bundesbank (1995), S. 67 und Seitz (1995), S. 54.

13 Vgl. Euba (1978), S. 49 f. und Lange (1995), S. 32 f.. 
Als weitere wichtige Annahme unterstellt das Konzept des Monetären Seigniorages die generelle Unverzinslichkeit der angekauften Aktiva. Solange jedoch die sich im Staatsbesitz befindlichen Assets, die gegen frühere und/oder gegenwärtige Geldschöpfung erworben wurden, nicht ausschließlich aus unverzinslichen privaten Aktiva oder verzinslichen Staatspapieren bestehen, bedeutet die Nichtberücksichtigung dieser staatlichen Zinseinnahmen eine systematische Unterschätzung der von den Privaten auf den Staat im Rahmen der Geldproduktion übertragenen Ressourcen.

Des weiteren werden Zinsverbindlichkeiten, die sich in modernen Geldverfassungen aus der emittierten Basisgeldmenge ergeben können, vernachlässigt. Dies ist jedoch im Hinblick auf eine etwaige Verzinsung von Mindestreserven, Termineinlagen und ständigen liquiditätsabsorbierenden Fazilitäten nicht differenziert genug. Zudem bleiben realisierte Bewertungsgewinne und -verluste, die aus der Differenz zwischen An- und Verkaufskurs von Assets resultieren, unberücksichtigt.

Weiterhin wird das Konzept des Monetären Seigniorages, welches den Ressoucenentzug der privaten Geldverwender im Zuge der Basisgeldexpansion (monetärer Aspekt des Seigniorages) beschreibt, oft fälschlicherweise als Partizipation der Regierung am Geldschöpfungsgewinn (fiskalischer Aspekt des Seigniorages) gleichgesetzt. Gerade aber in Ländern mit unabhängiger Zentralbank ist jedoch die notwendige institutionelle, operationale und rechtliche Trennung zwischen Regierung und der Notenbank zu berücksichtigen, die auch eine andere Verwendung des Monetären Seigniorages zuläßt ${ }^{14}$.

Zuletzt kann noch angemerkt werden, daß auch die Verwendung von inländischem Geld im Ausland einen entsprechenden Ressourcentransfer zum inländischen staatlichen Geldproduzenten impliziert. Deshalb sollte unter Seignioragegesichtspunkten der Begriff der Monetären Basis um die Auslandsverwendung des heimischen Geldes erweitert werden.

14 Vgl. Klcin/Neumann (1990), S. 206 und Hochreiter/Rovelli/Winkler (1996), S. 631. 


\section{Der Totale Seigniorage (Erweiterter Monetärer Seigniorage)}

Das von Neumann entwickelte Konzept des „Totalen“ bzw. „Erweiterten Monetären Seigniorages" berücksichtigt nun die oben beschriebene Kritik am traditionellen Konzept des Monetären Seigniorages ${ }^{15}$. Dieser Ansatz wird im Folgenden ausführlich vorgestellt und um bestimmte Aspekte wie etwa der Verzinsung von Zentralbankpassiva erweitert ${ }^{16}$. Zudem soll sich wie in der Europäischen Währungsunion üblich, das Recht zur Geldemission zwischen der Regierung, der das Münzregal zusteht, und der Notenbank, die Zentralbankgeld emittiert, aufteilen. Diese Zweiteilung bestimmt auch den Aufbau der Analyse.

\subsection{Entstehung des Totalen Seigniorages}

\subsubsection{Der Totale Münzgewinn}

Die Regierung als Münzproduzent erzielt einen Monetären Brutto-Münzgewinn in Höhe des realen Nennwertes der in einer Periode neu emittierten Münzen $\triangle C / P$. Konkret geraten die Münzen in Umlauf, indem die Regierung von den Münzverwendern außerhalb des Staatssektors inländische private Aktiva $Y_{D}$, ausländische Titel $Y_{r}$, und heimische Regierungspapiere $Y_{G}$ ankauft ${ }^{17}$. In der Münzbilanz der Regierung äußert sich dieser Vorgang in einer Bilanzverlängerung:

$$
\Delta Y_{D}+\Delta Y_{l}+\Delta Y_{(i}=\Delta C
$$

is In einem 1992 erschienenen Artikel bezeichnet Neumann sein Konzept noch als „Extended Monetary Seigniorage“, nennt dieses aber in einer neueren Publikation „Total Seigniorage“. Vgl. Neumann (1992) und Neumann (1995). In dieser Arbeit soll auf die aktuelle Bezeichnung zurückgegriffen werden.

Vgl. im Folgenden Neumann (1992), S. 29 ff. und Neumann (1995), S. 1 ff.. Eine Analyse der Buchgewinne und -verluste soll im Folgenden außen vor bleiben, da sich diese - sofern sie über ein Neubewertungskonto verrechnet werden - nicht prinzipiell von der üblichen Kapitalbildung bzw. -auflösung unterscheiden. Werden diese hingegen erfolgswirksam erfaßt, so sind sie Zinseinkünften bzw. -aufwendungen sehr ähnlich.

Vgl. auch Abbildung 1. Tatsächlich kauft in der EWU die heimische nationale Zentralbank die Umlaufsmünzen von der Regierung gegen Gutschrift an und verkauft die Münzen dann an die Geschäftsbanken gegen Einzug von Zentralbankgeld. Dieses Verfahren ist inhaltlich mit einer direkten Veräußerung der Münzen durch die Regierungen identisch. Vgl. dazu auch die Ausführungen zur Münzemission in Kapitel V.2.2.2. Abschnitt 4.. 
Abbildung 1: Stilisierte Münz- und Zentralbankbilanz mit zugehörigen Gewinn- und Verlustrechnungen
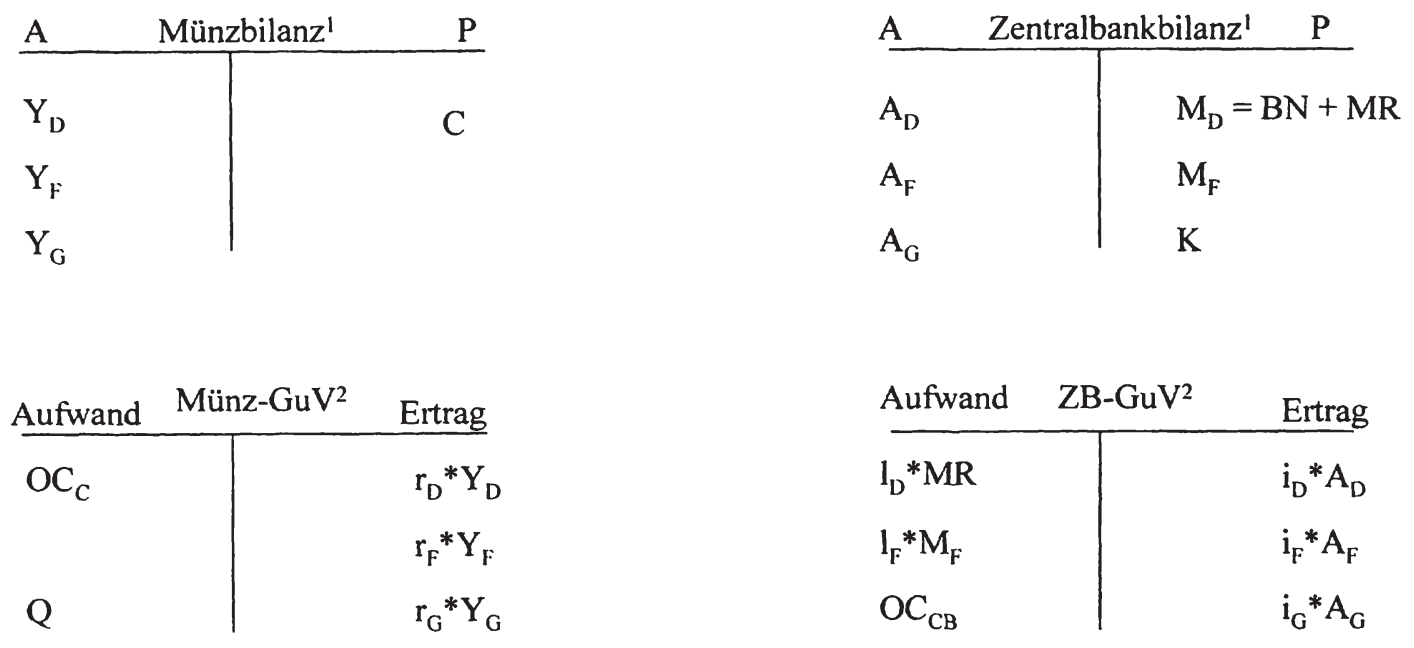

\begin{tabular}{|c|c|c|}
\hline Aufwand & $\mathrm{ZB}-\mathrm{GuV}^{2}$ & Ertrag \\
\hline $\mathrm{l}_{\mathrm{D}}{ }^{*} \mathrm{MR}$ & & $\mathrm{i}_{\mathrm{D}} * \mathrm{~A}_{\mathrm{D}}$ \\
\hline $\mathrm{l}_{\mathrm{F}} * \mathrm{M}_{\mathrm{F}}$ & & $\mathrm{i}_{\mathrm{F}}^{*} \mathrm{~A}_{\mathrm{F}}$ \\
\hline $\mathrm{OC}_{\mathrm{CB}}$ & & $\mathrm{i}_{\mathrm{G}}{ }^{*} \mathrm{~A}_{\mathrm{G}}$ \\
\hline
\end{tabular}

' Zu Beginn der Periode.

${ }^{2}$ Am Ende der Periode.

Quelle: Eigene Darstellung. 
Weiterhin fließen der Regierung Zinseinkünfte zu, die sich aus der Verzinsung der Münzbilanzaktiva ergeben. Unterstellt man, daß der gesamte Münzumlauf durch Ankauf von inländischen privaten Aktiva $Y_{D}$, von ausländischen Assets $Y$, und von heimischen Regierungspapieren $Y_{G}$ in Umlauf gebracht worden ist, hat die entsprechende Gewinn- und Verlustrechnung, die auch die Kosten der Münzproduktion erfaßt, folgende Gestalt ${ }^{18}$ :

$$
r_{D} \cdot Y_{D}+r_{F} \cdot Y_{F}+r_{G} \cdot Y_{G}=O C_{C}+Q
$$

Ein Münzbilanzgewinn $Q$ ergibt sich aus der positiven Differenz der Zinseinnahmen der Regierung in Höhe von $r_{D} \cdot Y_{D}+r_{F} \cdot Y_{F}+r_{G} \cdot Y_{G}$ und den Kosten der Münzproduktion $O C_{C}$. Dabei sollen aus Vereinfachungsgründen $r_{b}, r_{r}$. und $r_{c}$, die in heimischer Währung denominierten durchschnittlichen Nominalzinssätze der entsprechenden Aktiva darstellen.

Der Totale Münzgewinn beschreibt nun die gesamten von den Münzverwendern außerhalb des Staatssektors finanzierten realen Ressourcen, die der Regierung im Zuge der Münzproduktion brutto zufließen. Er setzt sich aus dem (traditionellen) Brutto-Münzgewinn $\Delta C / P$ und den von den Geldverwendern außerhalb des Staatssektors finanzierten Realzinszahlungen, die sich aus der Verzinsung der Münzbilanzaktiva ergeben, zusammen:

$$
S_{7,(\text { om }}=\left(\Delta C+r_{D} \cdot Y_{D}+r_{F} \cdot Y_{F}\right) / P \text {. }
$$

Die Realzinszahlungen der Regierung $r_{i} \cdot Y_{i}$, die die Regierung an sich selbst zahlt, bleiben in diesem Konzept unberücksichtigt, da diese Zinseinnahmen keinen Ressourcentransfer von außerhalb des Staatssektors begründen ${ }^{19}$.

\subsubsection{Der Totale Banknotengewinn}

Die Überlegungen zum Totalen Münzgewinn werden nun auf die Produktion von Zentralbankgeld übertragen. Grundlage hierfür sei folgende vereinfachte Notenbankbilanz ${ }^{20}$ :

18 Von einer Thesaurierung von Nettozinseinkünften wird abstrahiert.

19 Unter Opportunitätskostengesichtspunkten können diese Zinszahlungen der Regierung an sich selbst dennoch als Ressourcentransfer interpretiert werden, da der Regierung eine entsprechende reale Zinsersparnis zufällt. Vgl. dazu die Überlegungen zum Opportunitätskostenseigniorage.

20 Vgl. Abbildung 1. 


$$
A_{D}+A_{t}+A_{G}=M_{D}+M_{r}+K \text {. }
$$

Die Aktiva der Notenbankbilanz sollen in drei Gruppen zusammengefaßt werden:

- Kreditforderungen an inländische Private und/oder Outrightgeschäfte mit inländischen Privaten in einer Gesamthöhe von $A_{D}$,

- Kreditforderungen an das Ausland und/oder Outrightgeschäfte mit dem Ausland in einer Gesamthöhe von $A_{r}$ und

- direkte Kreditgewährung an die inländische Regierung ${ }^{21}$ und Ankauf von Regierungspapieren in einer Gesamthöhe von $A_{G}$.

Die Passiva der Zentralbankbilanz setzen sich aus Verbindlichkeiten der Zentralbank gegenüber den inländischen Privaten $M_{D}$, dem Ausland $M_{r}$, und aus dem Kapital der Notenbank $K$ zusammen. Dabei soll das von der Notenbank an die inländischen Privaten veräußerte Zentralbankgeld ${ }^{22} M_{D}$ die umlaufenden Banknoten $B N$ sowie die Mindestreserveeinlagen $M R$ der inländischen Geschäftsbanken bei der Notenbank umfassen ${ }^{23}$ :

$$
M_{D}=B N+M R \text {. }
$$

Die Einlagen der Regierung bei der Notenbank bleiben unberücksichtigt. Diese (rein bilanztechnische) Vernachlässigung impliziert die Unterstellung, daß die Regierung Einlagen, die ihr die Notenbank gewährt, sofort an die inländischen Privaten $M_{l}$ und/oder das Ausland $M_{t}$, verausgabt.

Die Zunahme der Verbindlichkeiten der Notenbank gegenüber den inländischen Privaten und dem Ausland äußert sich in der Notenbankbilanz wie folgt:

21 Es wird die sofortige Verausgabung des Zentralbankgeldes, welches die Regierung auf direktem Kreditwege von der Notenbank erhält, unterstellt. Dies zeigt auch die rechte Seite von Gleichung (14).

22 Nicht zu verwechseln mit dem Zentralbankgeld in Händen der inländischen Privaten. Da die emittierten Banknoten nicht notwendigerweise im Inland zirkulieren, würde bei einer derartigen Interpretation fälschlicherweise der Eindruck erweckt, der gesamte Banknotenseigniorage werde von den inländischen Privaten finanziert. Tatsächlich finanziert aber immer derjenige den Banknotenseigniorage, der die Banknoten gerade besitzt. Und dies kann eben auch ein im Ausland ansässiges Wirtschaftssubjekt sein.

23 Von Überschußreserven und anderen Einlagen der Kreditinstitute soll hier abgesehen werden. 


$$
\begin{gathered}
\Delta A_{D}+\Delta A_{F}+\Delta A_{G}=\Delta M, \text { mit } \\
\Delta M=\Delta M_{D}+\Delta M_{F} .
\end{gathered}
$$

Deflationiert man nun Gleichung (16) mit dem allgemeinen Preisniveau $P$, erhält man den Monetären Banknotengewinn, der der Zentralbank in Höhe des Realwertes des neu emittierten Zentralbankgeldes $\Delta M / P$ bilanztechnisch zufällt.

Darüber hinaus wird unterstellt, daß die Notenbank Realzinseinkünfte aus ihrem Aktivabestand in Höhe von $\left(i_{D} \cdot A_{D}+i_{r} \cdot A_{F}+i_{(i} \cdot A_{G}\right) / P$ erzielt, wobei aus Vereinfachungsgründen $i_{l}, i_{F}$ und $i_{G i}$ die in heimischer Währung denominierten durchschnittlichen Nominalzinssätze der entsprechenden Aktivagruppen darstellen sollen. Aus der Gesamtheit dieser Notenbank-Zinseinnahmen dürfen jedoch nur die Zinszahlungen der inländischen Privaten und des Auslands $\left(i_{D} \cdot A_{D}+i_{1} \cdot A_{F}\right) / P$ als Zufluß realer Ressourcen zum Staatssektor gewertet werden, da Zinszahlungen der inländischen Regierung an die Notenbank nur eine Umverteilung von Ressourcen innerhalb des Staatssektors darstellen ${ }^{24}$.

Der Totale Banknotenseigniorage erfaßt nun den gesamten realen von den nichtstaatlichen Geldverwendern finanzierten Brutto-Ressourcentransfer, der dem Staatssektor im Zuge der Geldpolitik der Zentralbank zufließt. Er kann folglich als Summe aus Monetärem Banknotengewinn und den Realzinszahlungen der inländischen privaten und ausländischen Geldverwender definiert werden:

$$
S_{T, \text { Noter }}=\left(\Delta M+i_{l} \cdot A_{D}+i_{l} \cdot A_{F}\right) / P .
$$

\subsubsection{Der Totale Seigniorage}

Faßt man nun den Totalen Münzgewinn und den Totalen Banknotengewinn zusammen, erhält man den Totalen Seigniorage:

$$
S_{T}=S_{T, \text { (nIm }}+S_{T, \text { Note }}=\left(\Delta C+r_{1)} \cdot Y_{D}+r_{F} \cdot Y_{r}+\Delta M+i_{D} \cdot A_{D}+i_{F} \cdot A_{l,}\right) / P .
$$

Gruppiert man die rechte Seite der Gleichung (18) um, kann der Totale Seigniorage auch als Summe aus dem Monetären Seigniorage $S_{M}$ und den aggregierten von den Geldverwendern außerhalb des Staatssektor finanzierten

24 Vgl. auch Wesche/Weidmann (1995), S. 9. Von realisierten Bewertungsgewinnen, die der Notenbank durch eine Differenz aus An- und Verkaufskurs von Aktiva von außerhalb des staatlichen Sektors zufließen, wird im Folgenden abstrahiert, da sich diese nicht substantiell von den Zinseinkünften der Zentralbank unterscheiden. 
Realzinseinkünften der Geldproduzenten, dem sogenannten Zinsseigniorage ${ }^{25}$ $S_{l}$, dargestellt werden:

$$
\begin{aligned}
& S_{T}=S_{A}+S_{I}, \text { mit } \\
& S_{M}=(\Delta C+\Delta M) / P=\Delta B / P \text { und } \\
& \left.S_{I}=\left(i_{I}\right) \cdot A_{D}+i_{F} \cdot A_{I}+r_{D} \cdot Y_{D}+r_{F} \cdot Y_{F}\right) / P .
\end{aligned}
$$

\subsection{Verwendung des Totalen Seigniorages}

Um nun Aussagen hinsichtlich der Verwendung des Totalen Seigniorage treffen zu können, müssen einerseits die Ausgaben und Aufwendungen der Notenbank und andererseits die Partizipation der inländischen Regierung an den Bilanzgewinnen der Zentralbank in die Analyse mit aufgenommen werden. Der Bilanzgewinn $I$ der Notenbank betrage ${ }^{26}$ :

$$
I=i_{D} \cdot A_{D}+i_{F} \cdot A_{I}+i_{(i} \cdot A_{(i}-l_{D} \cdot M R-l_{F:} \cdot M_{I:}-O C_{(B} .
$$

Die Einnahmen der Notenbank setzen sich aus den nominalen Zinseinnahmen zusammen, die sie von den inländischen Privaten, dem Ausland und der inländischen Regierung in Höhe von $i_{D} \cdot A_{D}, i_{F} \cdot A_{k}$ bzw. $i_{G} \cdot A_{G}$ erhält. Die Zinszahlungen der Zentralbank an die mindestreservepflichtigen inländischen Privaten $l_{b} \cdot M R$ und der ausländischen Einleger $l_{l} \cdot M_{r}$. werden als Aufwendungen in der Gewinn- und Verlustrechnung erfaßt, wobei in Analogie zu den Zinseinkünften aus Vereinfachungsgründen $l_{b}$ bzw. $l_{r}$ die entsprechenden, in heimischer Währung denominierten durchschnittlichen nominalen Sollzinssätze darstellen. Schließlich sind bei der Berechnung des Bilanzgewinns noch die operativen Kosten der Notenbank $O C_{C_{B}}$ anzusetzen.

Die Verwendung der Bilanzgewinns I soll sich wie folgt gestalten.

$$
I=\Delta K+R_{f i} \text {, wobei } \Delta K=\mu \cdot I \text { mit } 0 \leq \mu \leq 1 .
$$

Zunächst wird ein vom Zentralbankrat festzulegender Betrag $\Delta K$ den Rücklagen zugeführt. Der verbleibende Teil des Notenbankbilanzgewinns $R_{i j}$ wird an die heimische Regierung ausgeschüttet.

Durch Kombination der Gleichungen (11) bis (22) kann nun die Verwendung des Totalen Seigniorages dargestellt werden:

25 Der Begriff Zinsseigniorage geht zurück auf Wesche und Weidmann. Vgl. Wesche/Weidmann (1995), S. 27.

Vgl. Abbildung 1. 
(23)

$$
\begin{aligned}
& S_{T}=S_{l}+S_{\left(\mathcal{C}^{+}\right.}+S_{G}+S_{C B} \text { mit } \\
& S_{l}=\left(l_{D} \cdot M R+l_{F} \cdot M_{l}\right) / P, \\
& S_{C \cdot}=\left(O C_{C \cdot B}+O C_{C}\right) / P, \\
& S_{G}=\left[\Delta A_{G i}+\left(R_{G}-(1-\mu) \cdot i_{G} \cdot A_{G}\right)+\left(\Delta Y_{G}+\Delta Y_{D}+\Delta Y_{F}+Q-r_{G} \cdot Y_{G}\right)\right] / P, \\
& S_{C B}=\left[\Delta A_{D}+\Delta A_{1}+\left(\Delta K-\mu \cdot i_{G} \cdot A_{G}\right)\right] / P .
\end{aligned}
$$

Wie die Gleichung (23) zeigt, wird der Totale Seigniorage $S_{7}$ zur Finanzierung der realen Bruttozinszahlungen $S_{l}$, die die Notenbank an die inländischen Privaten und an das Ausland zahlt, verwendet. Des weiteren zieht der Staatssektor einen Teil des Totalen Seigniorage $S_{c x}$, zur Deckung der realen operativen Kosten der Zentralbank $O C_{C B}$ und zur Finanzierung der realen Kosten der Münzproduktion $O C_{C}$. heran. Der dem Staatssektor verbleibende Totale (Netto-) Seigniorage wird aufgeteilt zwischen der inländischen Regierung $S_{G}$, und der Zentralbank $S_{C B}$. Die zuletzt genannten Verwendungskomponenten sollen im Folgenden näher analysiert werden.

\subsubsection{Der Fiskalische Seigniorage}

Der Fiskalische Seigniorage ${ }^{27}$ gibt an, in welchem Umfang die Regierung am Totalen Seigniorage partizipiert:

$$
S_{G i}=\left[\Delta A_{G i}+\left(R_{G i}-(1-\mu) \cdot i_{G} \cdot A_{G j}\right)+\left(\Delta Y_{G j}+\Delta Y_{b}+\Delta Y_{F}+Q-r_{G i} \cdot Y_{G i}\right)\right] / P .
$$

Gemäß der Definitionsgleichung (24) fließen der Regierung Ressourcen auf drei Wegen zu:

- über die Kreditgewährung der Notenbank $\Delta A_{G} / P$,

- über die Ausschüttung des von den Geldverwendern außerhalb des staatlichen Sektors finanzierten Teils des Notenbankgewinnes $\left(R_{6},-(1-\mu) \cdot i_{i} \cdot A_{6}\right) / P$ und

- über die Münzproduktion $\left(\Delta Y_{G}+\Delta Y_{D}+\Delta Y_{F}+Q-r_{G} \cdot Y_{G}\right) / P$.

27 Der Begriff Fiskalischer Seigniorage geht wohl zurück auf Klein (1989), S. 5. Ein ähnliches Konzept wurde auch von Drazen entwickelt. Vgl. dazu Drazen (1985). Zu einer Kritik an den Überlegungen Drazens vgl. Baltensperger/Jordan (1997), S. 138 ff.. 


\subsubsection{Die Kreditgewährung der Notenbank an die Regierung}

Gemäß Gleichung (24) erhält die Regierung reale Ressourcen durch Kreditgewährung der Notenbank $\left(\Delta A_{G} / P\right)$. Dies kann auf direktem aber auch auf indirektem Wege geschehen, wenn die Notenbank von Geschäftspartnern außerhalb des staatlichen Sektors inländische Staatspapiere ankauft. Hinsichtlich des Zeitpunkts der Seigniorageentstehung muß zwischen den beiden Varianten grundsätzlich unterschieden werden. So fließen der Regierung im Falle der indirekten Kreditgewährung die realen Ressourcen in dem Augenblick zu, in dem die Notenbank Regierungspapiere von den Geldverwendern außerhalb des Staatssektors ankauft. Dagegen ist der direkte Notenbankkredit an die Regierung zum Zeitpunkt der Einlagengewährung für sich genommen noch kein Seigniorage, da durch dieses buchungstechnische Vorgehen den Geldverwendern außerhalb des staatlichen Sektors noch keine Ressourcen entzogen werden. Allerdings wurde die sofortige Verausgabung des auf direktem Kreditwege erhaltenen Zentralbankgeldes oben implizit unterstellt ${ }^{28}$, so daß auch die direkte Kreditgewährung der Zentralbank an die Regierung als Fiskalischer Seigniorage gesehen werden kann. Im Vergleich zur üblichen Zentralbankgeldschöpfung ändert sich lediglich der Emissionskanal des zusätzlichen Zentralbankgeldes.

Weiterhin wird deutlich, wie stark sich institutionelle Arrangements zwischen der Regierung und der Notenbank auf die Höhe des Fiskalischen Seigniorages auswirken. Hat die Regierung freien Zugang zu direkten Zentralbankkrediten, wie dies beispielsweise in den 20er Jahren in Deutschland der Fall war, oder kann die Regierung die Notenbank über eine Verpflichtung zur Zinsstabilisierung öffentlicher Anleihen zu quasi unbegrenzten indirekten (nominalen) Krediten zwingen, ist der Anreiz für die Regierung zur übermäßigen Zentralbankgeldproduktion hoch. Zwar ist die Fähigkeit des Staatssektors durch immer intensivere Basisgeldschöpfung immer mehr reale Ressourcen an sich zu ziehen begrenzt, doch kann gerade das fiskalische Seignioragemotiv der Geldproduktion als eigentliche Ursache aller Hyperinflationen gesehen werden. Diese mitlerweile weit verbreitete Einsicht dürfte denn auch dazu beigetragen haben, daß in der jüngeren Vergangenheit mehr und mehr Regierungen ihr Geldemissionsmonopol aufgegeben und dieses einer unabhängigen Währungsbehörde übertragen haben.

28 Vgl. Gleichung (14). 


\subsubsection{Die Partizipation der Regierung am realen Notenbankgewinn}

Die zweite Komponente des in Gleichung (24) definierten Fiskalischen Seigniorages $\left(R_{i}-(1-\mu) \cdot i_{i} \cdot A_{G i}\right) / P$ gibt an, in welchem Ausmaß der Regierung durch die Ausschüttung des Notenbankgewinns reale Ressourcen zufließen, die von den Geldverwendern außerhalb des Staatssektors finanziert wurden. Es darf also nicht der gesamte reale Ausschüttungsbetrag $R_{G} / P$ als Fiskalischer Seigniorage interpretiert werden, da die Regierung einen Teil dieses Betrages in Höhe von $(1-\mu) \cdot i_{i j} \cdot A_{i j} / P$ selbst finanziert hat. Nur der von den Geldverwendern außerhalb des staatlichen Sektors finanzierte Teil des ausgeschütteten Notenbankgewinnes ist als Seigniorage zu verstehen. Dies wird noch deutlicher, wenn man die zweite Komponente des Fiskalischen Seigniorages umformuliert zu:

$$
\left(R_{G}-(1-\mu) \cdot i_{G} \cdot A_{G}\right) / P=(1-\mu) \cdot\left[\left(i_{l)} \cdot A_{l)}-l_{l} \cdot M R\right)+\left(i_{l} \cdot A_{l}-l_{l} \cdot M_{l,}\right)-O C_{(B}\right] / P .
$$

Die rechte Seite von Gleichung (25) zeigt, daß die Regierung diejenigen, von den Geldverwendern außerhalb des Staatssektors finanzierten NettoRealzinseinkünfte der Notenbank erhält, die der Zentralbank nach Deckung der realen operativen Kosten verbleiben und zugleich nicht thesauriert wurden.

Auch an dieser Stelle soll auf die Bedeutung der institutionellen Regeln für die zweite Komponente des Fiskalischen Seigniorage hingewiesen werden. So wird die Höhe der realen Ressourcen, die der Regierung im Zuge der Gewinnausschüttung netto zufließen, einerseits durch die Gestaltungsmöglichkeit der Notenbank hinsichtlich der Zusammensetzung ihres Aktivabestandes (Assetmanagements) und andererseits durch die einschlägigen Gewinnverwendungsregeln bestimmt.

\subsubsection{Der Netto-Münzgewinn}

$$
S_{T_{(O C I I}}^{n e !}=\left(\Delta C+r_{D} \cdot Y_{D}+r_{F} \cdot Y_{F}-O C_{C}\right) / P=\left(\Delta Y_{G i}+\Delta Y_{D}+\Delta Y_{I}+Q-r_{G} \cdot Y_{G i}\right) / P
$$

Wie Gleichung (26) zeigt, fließen der Regierung im Wege der Münzemission Ressourcen in Höhe des Realwerts der neu emittierten Münzen $\Delta C / P$ zu. Weiterhin erhält die Regierung von den Geldverwendern außerhalb des Staatssektors reale Zinseinnahmen, die der Regierung aus der Verzinsung der Münzbilanzaktiva $\left(r_{l} \cdot Y_{D}+r_{l} \cdot Y_{l}\right) / P$ zufallen. Zieht man hiervon die realen 
Kosten der Münzproduktion ${ }^{29} O C_{C} / P$ ab, erhält man den Totalen NettoMünzgewinn, der der Regierung im Wege neu emittierter Münzen zufließt ${ }^{30}$. Verwendet wird der Totale Netto-Münzgewinn zur Erhöhung des Vermögens der Regierung, die sich zum einen in einer Zunahme der inländischen privaten und ausländischen Aktiva in Händen der Regierung $\left(\Delta Y_{D}+\Delta Y_{l}\right)$ und zum anderen in einer Abnahme der tatsächlichen Verschuldung der Regierung gegenüber den Geldverwendern außerhalb des Staatssektors $\Delta Y_{G}$ äußert. Der Ankauf von verzinslichen Regierungspapieren gegen neu emittierte Münzen in Höhe von $\Delta Y_{G}$ verringert insofern die tatsächlichen Schulden der Regierung, weil die Regierung eine „echte“ Forderung der inländischen Privaten (und gegebenenfalls des Auslands) in Form der emittierten Regierungspapiere gegen eine „unechte“ Forderung in Form der neu ausgegebenen Münzen eintauscht. Des weiteren steht der Regierung der von den Geldverwendern außerhalb des Staatssektors finanzierte Münzbilanzgewinn in Höhe von $\left(Q-r_{G j} \cdot Y_{G_{j}}\right)$ zur freien Verfügung.

Auch im Hinblick auf den Netto-Münzgewinn spielt die Kompetenzverteilung zwischen Regierung und Notenbank eine wichtige Rolle. Werden die Münzen ebenfalls über die Notenbank emittiert, so reduziert sich der Fiskalische Seigniorage auf die ersten beiden Komponenten von Gleichung $(24)^{31}$. Solange jedoch die Notenbank nicht ausschließlich Regierungspapiere gegen die Emission neuer Münzen ankauft und von einer Thesaurierung der von der Regierung finanzierten, dann vergleichsweise höheren, Notenbankeinnahmen absieht, ist der Fiskalische Seigniorage in dem Fall, in dem die Notenbank das alleinige Recht zur Münzemission besitzt, immer niedriger, als wenn der Regierung das Münzregal zusteht.

\subsubsection{Der Zentralbankseigniorage}

Der Zentralbankseigniorage beschreibt den Umfang der realen Ressourcen, die von den Geldverwendern außerhalb des Staatssektors finanziert wurden und der Zentralbank im Zuge der Geldpolitik netto zufließen ${ }^{32}$ :

29 Die Kosten der Münzproduktion umfassen hierbei nicht nur die Material und Herstellungskosten der neu emittierten Münzen, sondern auch die Kosten zur Aufrechterhaltung des Münzumlaufs, wie z.B. den Austausch abgenutzter Münzen. Vgl. dazu auch die Bruttoversion des Totalen Münzgewinns in Gleichung (13). Vgl. auch Gleichung (27).

32 Der Begriff Zentralbankseigniorage geht auf Wesche und Weidmann zurück. Die Autoren definieren den Zentralbankseigniorage jedoch in der Bruttoversion. Vgl. Wesche/Weidmann (1995), S.9. 


$$
S_{(B B}=\left(\Delta A_{D}+\Delta A_{l}+\left(\Delta K-\mu \cdot i_{G} \cdot A_{G}\right)\right) / P .
$$

Gemäß Gleichung (27) lassen sich drei Komponenten des Zentralbankseigniorages unterscheiden.

Zum einen fließen der Zentralbank netto Ressourcen durch den Ankauf inländischer privater Aktiva $\Delta A_{D}$ und zum anderen durch Kauf ausländischer Titel $\Delta A_{r}$ gegen neu emittiertes Zentralbankgeld zu. Weiterhin kommt die Zentralbank in den Genuß realer Ressourcen, wenn sie einen Teil der von den Geldverwendern außerhalb des Staatssektors finanzierten Realzinseinkünfte der Regierung vorenthält und diese statt dessen für die Reservenbildung $\left(\Delta K-\mu \cdot i_{i} \cdot A_{G}\right) / P$ verwendet. Hierbei wird klar, daß nicht der gesamte Umfang der Erhöhung der realen Rücklagen $\Delta K / P$ als Verwendung des Totalen Seigniorages interpretiert werden darf, da die Zentralbank auch Realzinseinkünfte thesauriert, die sie von der Regierung erhält. Zwischen den thesaurierten Realzinszahlungen der Regierung $\left(\mu \cdot i_{G} \cdot A_{G}\right) / P$ und der Entstehung des Totalen Seigniorages besteht aber kein ursächlicher Zusammenhang. Der Totale Seigniorage und damit auch der Fiskalische Seigniorage und der Zentralbankseigniorage entsteht jedoch ausschließlich durch einen realen Ressourcentransfer, den die Geldverwender außerhalb des staatlichen Sektors finanzieren. Die Thesaurierung der Real-Zinseinnahmen der Zentralbank, die sie von der Regierung erhalten hat, ist nichts anderes als eine NettoRessourcenumverteilung innerhalb des staatlichen Sektors und ist einzig auf die Gewinnverwendungsvorschriften zurückzuführen.

\subsection{Grenzen der Einnahmeerzielung des Geldproduzenten durch den Totalen Seigniorage}

Gemäß der bereits vorgestellten Gleichung (19) ist der Totale Seigniorage als Summe aus dem Monetären Seigniorage und dem Zinsseigniorage definiert:

$$
S_{l}=S_{M}+S_{l} .
$$

Da die Grenzen der Einnahmeerzielung durch den Monetären Seigniorage bereits erläutert wurden, soll im Folgenden nur kurz der Frage nachgegangen werden, ob die staatlichen Geldproduzenten auch durch den Zinsseigniorage nur in begrenzter Höhe reale Ressourcen an sich ziehen können. Bestätigt sich diese Vermutung, dann ist freilich auch die Einnahmeerzielung qua Totalem Seigniorage limitiert. 


\subsubsection{Grenzen der Einnahmeerzielung des Geldproduzenten durch den Zinsseigniorage}

Der Zinsseigniorage ist als Summe der von den Geldverwendern außerhalb des Staatssektors finanzierten realen Zinseinkünfte der staatlichen Geldproduzenten definiert:

$$
S_{I}=\left(i_{D} \cdot A_{D}+i_{F} \cdot A_{F}+r_{D} \cdot Y_{D}+r_{F} \cdot Y_{F}\right) / P .
$$

Hierbei wurden aus Vereinfachungsgründen jeweils die in heimischer Währung denominierten Durchschnittszinsen der verschiedenen Zentralbank- und Münzbilanzaktiva angesetzt. In diesem Zusammenhang darf jedoch nicht unerwähnt bleiben, daß die staatlichen Geldproduzenten nicht die gesamten von den Geldverwendern außerhalb des Staatssektors finanzierten Zinssätze direkt beeinflussen können. So hat beispielsweise die Notenbank die Höhe der Verzinsung ihrer Devisenreserven nicht in der Hand. Als direkte Variable, die den Zinsseigniorage maximieren kann, steht der Notenbank also nur ein „kontrollierbarer" Zinssatz zur Verfügung, wie etwa die von ihr erhobenen Refinanzierungszinsen. Um die folgende Analyse jedoch möglichst einfach zu halten, soll für den weiteren Verlauf unterstellt werden, daß die Zinseinnahmen der staatlichen Geldproduzenten ausschließlich aus der Verzinsung revolvierender Kreditforderungen an inländische Private resultieren. Zudem soll an dieser Stelle auch die Differenzierung zwischen Banknoten- und Münzproduktion aufgehoben werden. Der Zinsseigniorage kann dann umgeschrieben werden zu:

$$
S_{l}=i_{l} \cdot \frac{B}{P}
$$

In Analogie zu den Ausführungen zum Monetären Seigniorage und der Inflationssteuer ist nun davon auszugehen, daß eine (mäßige) Erhöhung der Refinanzierungszinsen (auf niedrigem Niveau) zunächst einen steigenden Zinsseigniorage hervorrufen wird, da der die Einnahmen erhöhende Effekt des Zinsanstiegs den Einnahmen senkenden Effekt der rückläufigen Basisgeldnachfrage überkompensiert. Ab einer gewissen Höhe des Refinanzierungszinssatzes werden jedoch die Geldverwender wegen der gestiegenen Kosten des Gelderwerbs ihre Basisgeldnachfrage immer weiter einschränken, so daß der Netto-Effekt der Zinserhöhung sogar negativ wird. Folglich ist auch das 
Einnahmeerzielungspotential des Zinsseigniorages und damit auch des Totalen Seigniorages begrenzt.

Will nun der Geldproduzent die Einkünfte aus dem Totalen Seigniorage maximieren, so muß er neben der Geldmengenwachstumsrate auch die Höhe der Refinanzierungszinsen in sein Optimierungskalkül einbeziehen. Dieser Diskussion soll hier jedoch nicht weiter nachgegangen werden, da es nach modernem Verständnis nicht die Aufgabe der Geldproduzenten ist, möglichst viele Einnahmen aus der Geldschöpfung zu erzielen. Vielmehr muß der Totale Seigniorage ausschließlich als Nebenprodukt einer stabilitätsorientierten Geldpolitik gesehen werden. Nur so lassen sich die Vorteile einer funktionsfähigen Geldwirtschaft realisieren. Auch wenn dieser Erkenntnis folgend in der jüngeren Vergangenheit mehr und mehr Regierungen das staatliche Geldmonopol unabhängigen Zentralbanken übertragen haben, erheben manche Autoren dennoch hartnäckig die Forderung nach dem Einsatz der Notenpresse zur Finanzierung von öffentlichen Infrastrukturinvestitionen und ähnlichem ${ }^{33}$.

\section{Der Opportunitätskostenseigniorage}

\subsection{Entstehung des Opportunitätskostenseigniorages}

Die bisher behandelten Seignioragekonzepte verstehen die umlaufende reale Basisgeldmenge $B / P$ als Gewinn des Staatssektors, weil die inländischen privaten Wirtschaftssubjekte (und gegebenenfalls auch das Ausland) reale Ressourcen in dieser Höhe auf die staatlichen Geldproduzenten übertragen haben und der Staat diese Ressourcen mit selbst geschaffenem Geld, also mit einer faktisch und/oder rechtlich nicht rückzahlbaren Forderung gegen sich selbst bezahlt hat. Von dieser Interpretation des Realbestands an Basisgeld weicht das Konzept des Opportunitätskostenseigniorages ab. Vielmehr versteht es die umlaufende reale Basisgeldmenge als zinslosen Kredit der Privaten an den Staatssektor. Hätte sich der Staatssektor den Umfang der ihm in Höhe des Realkassenbestands zugeflossenen Ressourcen durch Verschuldung bei den Privaten finanzieren müssen, müßte er pro Periode, also z.B. jährlich, „Marktzinsen“ in Höhe von $\rho \cdot(B / P)$ an die privaten Geldverwender zahlen ${ }^{34}$.

33 Vgl. z.B. Filc (1986), S. 47 ff. und Dornbusch (1988), S. 23 ff..

34 Vgl. Phelps (1973), S. 75, Gros (1989), S. 2, Gros/Vandille (1995), S. 177 und Lange (1995), S. 40. 
Die den inländischen privaten und ausländischen Geldverwendern entgangenen Zinsen beschreiben den Opportunitätskostenseigniorage:

$$
S_{O}=\rho \cdot \frac{B}{P} .
$$

Nutznießer dieses Ressourcentransfers sind die staatlichen Geldproduzenten. Aus Sicht des Staatssektors entspricht der Opportunitätskostenseigniorage dem potentiellen realen Zinsertrag, der durch die Anlage der gesamten Basisgeldmenge zum herrschenden Marktzinssatz pro Periode erzielbar wäre ${ }^{35}$. Für die Höhe des Opportunitätskostenseigniorage spielt es dabei keine Rolle, ob die Geldproduzenten die Monetäre Basis tatsächlich zum herrschenden Marktzins anlegen oder nicht. Haben die staatlichen Geldproduzenten beispielsweise die gesamte Monetäre Basis gegen Ankauf von Gold $G$ in Umlauf gebracht $(B=G)$, zahlen die privaten Wirtschaftssubjekte an den Staatssektor keine Zinsen. Dies bedeutet jedoch nicht, daß die Opportunitätskosten der Basisgeldhaltung null wären. Denn hätte sich der Staatssektor bei den Privaten verschulden müssen, um den Goldbestand zu finanzieren, müßte er einen „Marktzins“ in Höhe von $\rho \cdot(G / P)=\rho \cdot(B / P)$ an die Privaten zahlen. Die privaten Geldverwender haben die Opportunitätskosten der Basisgeldhaltung folglich unabhängig von den tatsächlichen Zinseinkünften des staatlichen Geldproduzenten zu tragen ${ }^{36}$. Dies zeigt auch die formale Herleitung der Verwendung des Opportunitätskostenseigniorages.

\subsection{Verwendung des Opportunitätskostenseigniorages}

Grundlage der folgenden Ausführungen ist das im Rahmen der Analyse des Totalen Seigniorage vorgestellte Buchungssystem der Gleichungen (11) - (22) ${ }^{37}$. Hierbei sollen jedoch zwei erweiternde Ergänzungen vorgenommen werden. So wird der aktivische Zentralbankbilanzposten $A_{D}$,Kreditgewährung an inländische Private und/oder Outrightgeschäfte mit inländischen Privaten“

35 Vgl. auch Drazen (1985), S. 328 und Baltensperger/Jordan (1998), S. 83.

36 Vgl. Barro (1982), S. 329 und Honohan (1996), S.294 f..

37 Vgl. im Folgenden auch Klein/Neumann (1990), S. 209 ff.. Der hier vorgestellte Ansatz weicht von der Version von Klein und Neumann insofern ab, da sich das Geldemissionsrecht zwischen der Zentralbank und der Regierung aufteilt, Zinszahlungen der Zentralbank und die Bildung von Zentralbankrücklagen in die Analyse mit aufgenommen werden. Da die umlaufende Basisgeldmenge als Kredit interpretiert wird, werden im Gegensatz zu Klein/Neumann die von den Geldproduzenten angekauften Aktiva nicht als Gewinn aufgefaßt. 
exemplarisch unterteilt in unverzinsliches Gold $G$ und in „Kreditgewährung der Notenbank an inländische Private und verzinsliche private Wertpapiere“ $W_{D}$ :

$$
A_{l}=G+W_{D}
$$

Entsprechend verändert sich dann auch die Gewinn- und Verlustrechnung der Zentralbank zu:

$$
I=i_{D} \cdot W_{D}+i_{F} \cdot A_{F}+i_{G i} \cdot A_{C i}-l_{D} \cdot M R-l_{F} \cdot M_{F}-O C_{C B} \text { mit }
$$

$i_{D}$ als durchschnittlichem nominalen Zinssatz, den die Notenbank aus der Verzinsung ihrer privaten Assets erhält.

Unter Verwendung der Gleichungen (11) - (22) und $(32,33)$ läßt sich die Verteilung des Opportunitätskostenseigniorage darstellen als:

$$
\begin{aligned}
& S_{0}=S_{0}^{D}+S_{0}^{i}+S_{0}^{O C}+S_{0}^{(B)}+S_{0}^{(j)} \text { mit } \\
& S_{O}^{(D)}=l_{D} \cdot \frac{M R}{P}+\left(\rho-i_{l}\right) \cdot \frac{W_{D}}{P}+\left(\rho-r_{D}\right) \cdot \frac{Y_{D}}{P}, \\
& S_{O}^{\prime}=l_{l} \cdot \frac{M_{l}}{P}+\left(\rho-i_{l}\right) \cdot \frac{A_{l}}{P}+\left(\rho-r_{l}\right) \cdot \frac{Y_{l}}{P}, \\
& S_{O}^{(\mathcal{C}}=\frac{O C_{(B)}}{P}+\frac{O C_{C}}{P}, \\
& S_{O}^{(B)}=\rho \cdot \frac{G}{P}+\frac{\Delta K-\mu \cdot i_{G} \cdot A_{G}}{P} \text { und } \\
& S_{o}^{\prime \prime}=\rho \cdot \frac{A_{G j}}{P}+\rho \cdot \frac{Y_{(j}}{P}+\frac{R_{c}-(1-\mu) \cdot i_{c} \cdot A_{G j}}{P}+\frac{Q-r_{G i} \cdot Y_{G j}}{P} .
\end{aligned}
$$

Gemäß Gleichung (34) fließt ein Teil des (Brutto-) Opportunitätskostenseigniorage zurück $\mathrm{zu}$ den inländischen Privaten $S_{0}^{\prime)}$ bzw. zu den ausländischen Geldverwendern $S_{\sigma}^{l}$ in Form von geleisteten Realzinszahlungen $\left(l_{D} \cdot M R / P\right.$ bzw. $\left.l_{F} \cdot M_{1} / P\right)$ und impliziten Zinssubventionen der Notenbank $\left[\left(\rho-i_{D}\right) \cdot W_{D} / P\right.$ bzw. $\left.\left(\rho-i_{l}\right) \cdot A_{F} / P\right]$. Letzteres ist immer dann der Fall, wenn die Zentralbank an die inländischen Privaten bzw. an das Ausland Kredite gewährt, deren Verzinsung unterhalb des Marktzinses liegt. Diese Überlegungen gelten in analoger Weise auch für die Münzemission der Regierung. Da jedoch das hier vorgestellte System eine zwar theoretisch denkbare Verzinsung von Münzbilanzpassiva wegen jeglicher empirischer Relevanz vernachlässigt, erfaßt obige Darstellung nur die Zinssubventionen der Regierung an die inländischen 
Privaten $\left(\rho-r_{D}\right) \cdot Y_{D} / P$ bzw. an das Ausland $\left(\rho-r_{F}\right) \cdot Y_{F} / P$. Als dritte Verwendungskomponente des Opportunitätskostenseigniorages weist Gleichung (34) die Finanzierung der realen Kosten der staatlichen Geldproduzenten $S_{0}^{O C}$ aus. Dies bedeutet, daß die Notenbank und die Regierung ihre realen Kosten der Geldproduktion durch Rückgriff auf die ihnen „GuV-technisch“ zugeflossenen Zinseinnahmen bezahlt. Nach Abzug der geschilderten Verwendungskomponenten des Opportunitätskostenseigniorage verbleibt dem staatlichen Sektor ein Netto-Opportunitätskostenseigniorage, der sich zwischen der Notenbank $S_{0}^{(B)}$ und der Regierung $S_{0}^{i}$ aufteilt. So erzielt die Notenbank einen entsprechenden Netto-Opportunitätskostenseigniorage über die Zinsersparnis in Höhe von $\rho \cdot(G / P)$, da sie über den in ihrem Besitz befindlichen realen Goldbestand $G / P$ verfügen kann, ohne entsprechende Zinsen an die Geldverwender zu zahlen. Des weiteren erhält die Notenbank von den Geldverwendern außerhalb des Staatssektors finanzierte "GuV-technisch“ zugeflossene Netto-Zinszahlungen (abzüglich der Kosten der Geldproduktion), die sie zur Erhöhung ihres Realkapitals $\left(\Delta K-\mu \cdot i_{G} \cdot A_{G}\right) / P$ verwendet. Auch der Fiskalische Opportunitätskostenseigniorage $S_{O}^{G}$ setzt sich qualitativ aus zwei Komponenten zusammen. Zum einen spart sich die Regierung reale Zinszahlungen in Höhe der "Marktverzinsung" der Regierungspapiere $\rho \cdot\left(A_{c}+Y_{G}\right) / P$, die einerseits die Notenbank gegen Zentralbankgeld $A_{G}$ und andererseits die Regierung selbst gegen Münzen $Y_{(j}$ angekauft hat. Zum anderen partizipiert die Regierung an dem von den inländischen privaten und ausländischen Geldverwendern finanzierten Teil des ausgeschütteten realen Notenbankgewinns ${ }^{38}\left(R_{i}-(1-\mu) \cdot i_{i} \cdot A_{c_{i}}\right) / P$ und an den von den Geldverwendern außerhalb des Staatssektors finanzierten Einnahmen aus der Verzinsung der Münzbilanzaktiva $\left(Q-r_{i} \cdot Y_{i}\right) / P$.

Das Konzept des Opportunitätskostenseigniorages ist vor allem theoretisch interessant, da es an der Wertschätzung der privaten Wirtschaftssubjekte für die Basisgeldhaltung ansetzt. Allerdings ist dieser Ansatz für die empirische Analyse eher ungeeignet ${ }^{39}$. Dies liegt vor allem an der Wahl des „richtigen“ Zinssatzes. So ist zu erwarten, daß je nach Verwendung beispielsweise des Zinssatzes für langfristige Staatsanleihen oder für kurzfristige Schatzanweisungen die Ergebnisse erheblich differieren.

Die theoretischen Überlegungen zum staatlichen Geldschöpfungsgewinn zeigen, daß den institutionellen Arrangements sowohl bei der Entstehung als auch bei

38 Vgl. hierzu auch die Ausführungen zur zweiten Komponente des Totalen Fiskalischen Seigniorages.

39 Vgl. Neumann (1992), S. 30 und Wesche/Weidmann (1995), S. 7. 
der Verteilung des Seigniorages eine entscheidende Bedeutung zukommt. Dies gilt freilich auch für die Europäische Währungsunion. Im Folgenden soll deshalb die institutionelle Verflechtung der EU-Zentralbanken kurz aufgezeigt und daran anschließend die Konsequenzen der entnationalisierten Geldpolitik für die jeweilige Gewinnentstehung und -verwendung der im Eurosystem zusammengeschlossenen Notenbanken eingehend untersucht werden. 
Gerhard Rösl - 978-3-631-75006-3

Downloaded from PubFactory at 01/11/2019 09:21:25AM

via free access 


\section{DAS EUROPÄISCHE SYSTEM DER ZENTRALBANKEN UND DAS EUROSYSTEM}

\section{Die Zusammensetzung des Europäischen Systems der Zentralbanken (ESZB) und des Eurosystems}

Nach Artikel 1 der Satzung des Europäischen Systems der Zentralbanken und der Europäischen Zentralbank (ESZB-Satzung) und Artikel 107 des Vertrags zur Gründung der Europäischen Gemeinschaft (EGV) ${ }^{40}$ besteht das Europäische System der Zentralbanken (ESZB) aus der Europäischen Zentralbank (EZB) und den nationalen Zentralbanken der EU-Mitgliedstaaten (EU-NZBen). Das ESZB wurde am 1.6.1999 errichtet und umfaßt seit seiner Gründung 16 Zentralbanken, die im einzelnen in der Abbildung 2 aufgelistet sind.

Allerdings verfügen die nationalen Zentralbanken der (noch) nicht an der dritten Stufe der Europäischen Währungsunion (EWU) teilnehmenden EUMitgliedstaaten (Pre-In-NZBen) im ESZB über einen Sonderstatus ${ }^{41}$. So führen die Pre-In-NZBen ihre nationale Geldpolitik eigenständig weiter, sind dafür aber auch nicht an der Festlegung und Durchfürung der gemeinsamen Geldpolitik der EWU-Länder beteiligt ${ }^{42}$. Dies trifft zur Zeit auf die Zentralbanken Dänemarks, Schwedens und des Vereinigten Königreiches zu. Die NZBen hingegen, deren Mitgliedstaaten den Euro als gemeinsame Währung eingeführt haben (EWU-NZBen), haben ihre geldpolitische Kompetenz - neben der Aufgabe weiterer Verantwortlichkeiten - an die EZB verloren. Im einzelnen sind dies gegenwärtig die Notenbanken Italiens, Spaniens, Portugals, Finnlands, Griechenlands, Luxemburgs, Frankreichs, Belgiens, Irlands, Deutschlands, Österreichs und der Niederlande.

Um nun die Trennung zwischen den ESZB-Zentralbanken, die ihre eigenständige Geldpolitik weiterhin fortführen, und den Zentralbanken des ESZB, die nach Maßgabe der EZB eine gemeinsame Geldpolitik ausüben, auch begrifflich transparenter zu fassen, verständigte man sich im EZB-Rat darauf, die EWU-NZBen zusammen mit der EZB als „Eurosystem“ zu bezeichnen.

40 Konsolidierte Fassung mit den Änderungen durch den Vertrag von Amsterdam vom 2.10.1997.

41 Vgl. auch Europäische Zentralbank (1999a), S. 126.

42 Vgl. Art. 43 ESZB-Satzung, Art. 122 EGV und die dem Maastricht-Vertrag beigefügten Protokolle „11. Protokoll über einige Bestimmungen betreffend das Vereinigte Königreich Großbritannien und Nordirland“ und „12. Protokoll uber einige Bestimmungen betreffend Dänemark". 
Abbildung 2: Das Europäische System der Zentralbanken und das Eurosystem

(aktuelle Zusammensetzung seit dem 1.1.2001)'

Europäische Zentralbank (EZB)

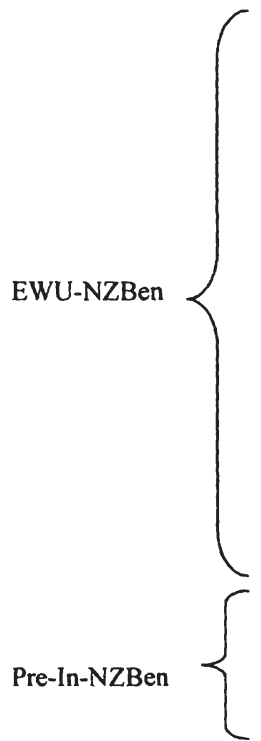

Banca d'Italia (BdI)

Banco de España (BdE)

Banco de Portugal (BdP)

Bank of Finland (BoF)

Bank of Greece (BoG)

Banque centrale du Luxembourg (BCL)

Banque de France (BdF)

Belgische Nationalbank (NBB)

Central Bank of Ireland (CBI)

De Nederlandsche Bank (DNB)

Deutsche Bundesbank (BBk)

Österreichische Nationalbank (OeNB)

Bank of England (BoE)

Danmarks Nationalbank (DaNB)

Schwedische Reichsbank (SRB)

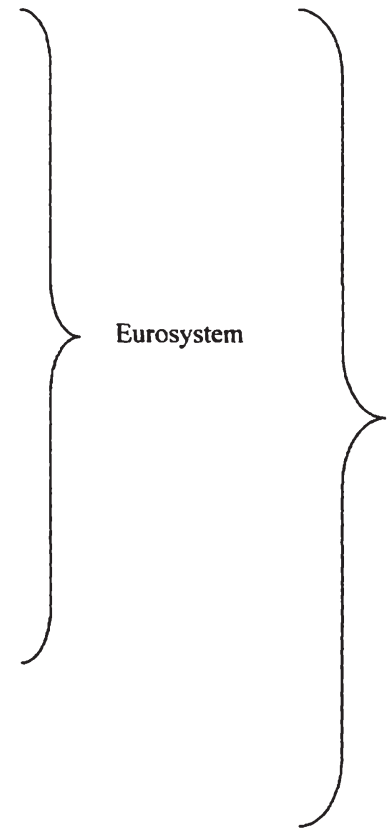

Europäisches System der

Zentralbanken

1 Die Bank of Greece ist erst seit dem Beitritt Griechenlands zum Euro-Währungsraum am 1.1.2001 Mitglied des Eurosystems, aber Teil des ESZB seit dessen Errichtung am 1.6.1998.

Quelle: Eigene Darstellung. 
Ein Beitritt der Pre-In-NZBen zum Eurosystem ist jedoch jederzeit möglich, sofern die hierfür notwendigen Voraussetzungen erfüllt $\operatorname{sind}^{43}$. Das hierfür bisher einzige Beispiel ist die griechische Zentralbank, die als Gründungsmitglied des ESZB seit dem 1.1.2001 auch dem Eurosystem angehört.

\section{Die Beschlußorgane des ESZB und des Eurosystems}

Das ESZB, bzw. der sprachlichen Differenzierung des EZB-Rats folgend, das Eurosystem wird von den Beschlußorganen der EZB, nämlich dem EZB-Rat und dem EZB-Direktorium, geleitet (Art. 107 Abs.3 EGV).

Der EZB-Rat besteht aus den Mitgliedern des EZB-Direktoriums und den Präsidenten der EWU-NZBen (Art. 112 Abs. 1 EGV). Er ist das oberste Beschlußorgan der EZB und erläßt die Leitlinien und Entscheidungen, die notwendig sind, um die Erfüllung der dem Eurosystem übertragenen Aufgaben zu gewährleisten (Art. 12.1. ESZB-Satzung).

Das Direktorium der EZB setzt sich aus dem Präsidenten, dem Vizepräsidenten und vier weiteren Mitgliedern zusammen (Art. 112 Abs.2 EGV). Es führt die Geldpolitik des Eurosystems gemäß den Leitlinien und Beschlüssen des EZBRats aus, erteilt hierzu den EWU-NZBen die erforderlichen Weisungen und ist mit der Ausführung der laufenden Geschäfte der EZB betraut (Art. 12.1. ESZBSatzung).

Der Erweiterte EZB-Rat, der als drittes Beschlußorgan der EZB eingesetzt wird, besteht aus dem Präsidenten und Vizepräsidenten der EZB sowie den Präsidenten der EU-NZBen (Art. 45 ESZB-Satzung). Er übernimmt neben den noch durchzuführenden Aufgaben des mittlerweile liquidierten Europäischen Währungsinstituts (EWI) ${ }^{44}$ auch eine Reihe anderer Funktionen, wie z.B. Beratungsaufgaben oder die Erhebung von Statistiken ${ }^{45}$. Diese dienen vor allem der Anbindung der Pre-In-NZBen an das Eurosystem. Bleibt man bei der sprachlichen Differenzierung zwischen dem Eurosystem und dem ESZB, könnte man folglich den Erweiterten EZB-Rat vereinfachend als Beschlußorgan des ESZB bezeichnen, während der EZB-Rat und das Direktorium der EZB dem Eurosystem zuzurechnen sind.

Die folgende Analyse beschäftigt sich nun mit der Entstehung und Verwendung der Notenbankgewinne des Eurosystems.

43 Vgl. Art. $121 \mathrm{EGV}$ und Art. $123 \mathrm{EGV}$.

44 Vgl. Art. 47.1. Spstr.1 i.V.m. Art. 44 ESZB-Satzung. Das EWI wurde bei der Errichtung der EZB am 1.6.1998 liquidiert. Vgl. Europäische Zentralbank (1999a), S. 147.

45 Vgl. Art. 47 ESZB-Satzung und Europäische Zentralbank (1999d), S. 65. 
Gerhard Rösl - 978-3-631-75006-3

Downloaded from PubFactory at 01/11/2019 09:21:25AM

via free access 


\section{DIE GEWINNENTSTEHUNG UND -VERWENDUNG DER EUROPÄISCHEN ZENTRALBANK}

\section{IV.1. Die Entstehung des EZB-Gewinns}

Erster Ansatzpunkt für die Analyse der EZB-Gewinnentstehung ist naturgemäß die Gewinn- und Verlustrechnung (GuV) der Europäischen Zentralbank. Diese ist in Tabelle 1 für die Jahre 1999 und 2000 dargestellt und zeigt die Größenordnungen der erzielten Einkünfte und Aufwendungen nach der von der EZB gewählten Kategorisierung ${ }^{46}$. Allerdings ist hierbei die Informationsdichte nicht sehr hoch. So unterscheidet die EZB zum Beispiel bei ihren Zinserträgen und -aufwendungen nur zwischen „Zinseinkünften aus Währungsreserven und "sonstigen Zinseinkünften". Eine konkrete Bezugnahme zu bestimmten Aktivund Passivposten nimmt sie dabei nicht vor. Zudem weist sie auch ihre anderen Einkunftsarten nicht sehr detailliert aus. Hinzu kommt, daß die einschlägigen Kommentare zur EZB-GuV kaum einen tiefergehenden Einblick in die einzelnen Entstehungskomponenten des EZB-Gewinns gewähren ${ }^{47}$. Diesbezüglich läßt allerdings die Analyse des Handlungsrahmens der EZB, also insbesondere die Aufgabenverteilung innerhalb des Eurosystems, und die relativ detaillierten Angaben zur EZB-Bilanz gewisse Schlußfolgerungen zu.

Es erscheint sinnvoll, die Komponenten der EZB-Gewinnentstehung in vier Gruppen zu unterteilen:

1. Nettoerträge aus der (Anfangs-) Ausstattung mit Kapital und Währungsreserven,

2. Nettoeinkünfte aus der operativen Geld- und Devisenpolitik,

3. Nettoerträge aus anderen Tätigkeiten,

4. Nettoeinkünfte aus realisierten Buchgewinnen, Abschreibungen und Operationen mit Reserven.

46 Die zugehörige EZB-Bilanz findet sich als Tabelle A1 im Anhang. Die Tabelle 1 umfaßt nicht die GuV für das Jahr 1998, da die EZB dort eine andere Zuordnung von realisierten Zinsertrăgen vornahm. Vgl. Europäische Zentralbank (2001d), S. 202. Diese GuVAufstellung ist in der disaggregierten Eurosystem-GuV (Tabellen 10 und 12) erfaßt.

Vgl. Europăische Zentralbank (2001d), S. 202 f. 
Tabelle 1: Die Gewinn- und Verlustrechnung der EZB für die Jahre 1999 und 2000

Zinseinkünfte aus Währungsreserven Sonstige Zinserträge

1.1 Zinseinkünfte

Zinsaufwendungen für die NZB-

Forderungen aus der Übertragung

von Währungsreserven

Sonstige Zinsaufwendungen

1.2 Zinsaufwendungen

\section{Nettozinseinkünfte}

2.1 Realisierte Gewinne (Verluste) aus Finanzgeschäften

2.2 Abschreibungen auf Finanzanlagen und -positionen

2.3 Zuführung zu (Auflösung von) Rückstellungen für Wechselkursund Preisrisiken'

2 Nettoergebnis aus Finanzgeschäften, Abschreibungen und Risikovorsorgen

3 Nettoergebnis aus Gebühren und Provisionen

4 Sonstige Erträge

Nettoeinkünfte insgesamt

5 Personalaufwendungen

6 Sachaufivendungen

7 Abschreibungen auf Sachanlagen und immaterielle Vermögenswerte

Jahresüberschuß (Jahresfehlbetrag)
1733987854

3122690418

4856678272

2507164892

4657469867

7164634759
(913067 289)

(2988 344639$)$

(3 901411928 )

955266344

(466 056435$)$

(604 920383$)$

0

(1 070976818$)$

232200

436898

(115 041 376)

(61 022091$)$

(60 748 855)

(10 468901$)$

(248 281 223)
(1 375110826$)$

(4 375476075$)$

(5 750586901$)$

1414047858

3352768266

(1 084563$)$

(2 600000000$)$

751683703

673498

904158

2167309217

(80 275 827)

(82 808 524)

(14 103 116)

1990121750

Quelle: Europäische Zentralbank (2001d), S. 192.

\footnotetext{
1 Die Verbuchung der im Jahr 2000 erfolgten Zufuhrung zu den Ruckstellungen fur Wechselkurs- und Preisrisiken (Posten 2.3) in Höhe von 2600 Mio. EUR ist nicht sehr transparent. So deutet die Erfassung dieser Transaktion als Aufwand zwar richtiger Weise auf eine Dotierung der Reserve hin. Die Klammersetzung erweckt jedoch in Kombination mit der zugehörigen Überschrift „Auflosung von Ruckstellungen für Wechselkurs- und Preisrisiken" den Eindruck einer Entnahme von Ruckstellungen, was zweifelsfrei nicht der Fall war. Vgl. Europăische Zentralbank (2001d), S. 199 und Europäische Zentralbank (2001e), S. 2. Transparenter wäre es, den Posten 2.3 umzubenennen in „2.3 Auflosung von (Zufuhrung zu) Ruckstellungen fur Wechselkurs- und Preisrisiken".
} 


\section{Die Nettoerträge der EZB aus der (Anfangs-) Ausstattung mit Kapital und Währungsreserven}

\subsection{Die Zeichnung und Finanzierung des EZB-Kapitals}

Das gezeichnete Kapital der EZB beträgt seit der Aufnahme ihrer Tätigkeit 5 Mrd. EUR ${ }^{48}$ und wird allein von den nationalen Zentralbanken der Europäischen Union gehalten (Art. 28 ESZB-Satzung). Hierbei richtet sich der Schlüssel für die zu zeichnenden Kapitalanteile nach einem Gewichtsanteil, der der Summe folgender Prozentsätze entspricht (Art. 28.2. i.V.m. Art. 29.1. ESZB-Satzung ${ }^{49}$ ):

- $50 \%$ des Anteils des jeweiligen Mitgliedstaats an der Bevölkerung der Gemeinschaft im vorletzten Jahr vor der Errichtung des ESZB;

- $50 \%$ des Anteils des jeweiligen Mitgliedstaats am Bruttoinlandsprodukt der Gemeinschaft zu Marktpreisen in den fünf Jahren vor dem letzten Jahr vor der Errichtung des ESZB.

Allerdings zahlen ausschließlich die NZBen des Eurosystems ihre gezeichneten Kapitalanteile vollständig ein, während die EU-Zentralbanken, die nicht an der dritten Stufe der EWU teilnehmen, nur verpflichtet sind, fünf Prozent ihres gezeichneten Kapitals als Beitrag zu den Betriebskosten der EZB einzubringen ${ }^{50}$. Die konkrete Einzahlung des Kapitals erfolgte dabei nach den vom Erweiterten EZB-Rat beschlossenen Bestimmungen ${ }^{51}$. So leisteten die EUNZBen am 1.6.1998 zunächst eine Anzahlung auf ihre provisorisch berechneten EZB-Kapitalanteile. Dies geschah indem sie ihre Einlagen, die sie aus der zum 1.6.1998 erfolgten Liquidation des Europäischen Währungsinstituts erhalten haben, auf die EZB übertrugen, soweit dies möglich und zur Deckung der Zahlungsverpflichtungen notwendig war $^{52}$. Die restlichen EZB-Kapital-

48 Artikel 2 Abs. 1 der Verordnung (EG) Nr. 1103/97 des Rates stellt sicher, daß die ECU 1:1 durch den Euro ersetzt wird. Vgl. Europäische Gemeinschaft (1997b).

49 Der Zusatz „Die Prozentsätze werden zum nächsten Vielfachen von 0,05 Prozentpunkten aufgerundet" (Art. 29.1. Satz 3 ESZB-Satzung) wurde bei der Anteilsbestimmung nicht angewendet, da die Kumulierung der Anteile mehr als 100 Prozent ergeben würde. Vgl. Europäische Gemeinschaft (1998a), Europäische Gemeinschaft (1998d) und Europäische Gemeinschaft (1998e).

$50 \mathrm{Vgl}$. Art. 48 ESZB-Satzung, Europäische Gemeinschaft (1998b) und Europäische Gemeinschaft (1998c).

51 Vgl. Europäische Gemeinschaft (1998b), Europäische Gemeinschaft (1998c) und Europäische Zentralbank (1999a), S. 135.

52 So konnten die Pre-In-NZBen ihre fünf-prozentige EZB-Kapitalzahlung jeweils vollständig aus ihren aufgelösten EWI-Kapitalbeständen bezahlen. Vgl. Tabelle 2. 
zahlungen wurden dann am 1.7.1998 von den NZBen in Fremdwährung abgewickelt. Der endgültige Zahlungsausgleich erfolgte schließlich am 4. Januar 1999 in Euro.

Die folgende Tabelle 2 zeigt, in welchem Umfang die EU-Zentralbanken an der Zeichnung und Finanzierung der Erstausstattung des EZB-Eigenkapitals beteiligt waren. So hält die Deutsche Bundesbank als größte Anteilseignerin mit 24,5 Prozent rund ein Viertel des gezeichneten EZB-Kapitals, während die Banque de France (16,8 Prozent), die Banca d'Italia (14,9 Prozent) und die Bank of England (14,7 Prozent) jeweils grob 15 Prozent des EZB-Kapitals gezeichnet haben. Die verbleibenden 29,1 Prozent teilen sich auf die anderen elf EUZentralbanken auf. Noch dominanter wird die Stellung der Bundesbank, wenn man die eingezahlten Kapitalbeträge betrachtet. So finanziert die Deutsche Zentralbank mit 1,2 Mrd. EUR rund 31 Prozent der Erstausstattung des EZBKapitals (4 Mrd. EUR). Eine zentrale Stellung bei der geldpolitischen Beschlußfassung besitzt die Bundesbank jedoch bekanntermaßen nicht ${ }^{53}$. Allerdings geht bei Fragen, die die Kapitaleinzahlung bzw. -erhöhung betreffen, kaum ein Weg an der Bundesbank vorbei, da in diesem Fall ausnahmsweise die Stimmen im EZB-Rat nach EZB-Kapitalanteilen gewichtet werden (Art. 10.3. ESZB-Satzung). An dieser Einschätzung ändert freilich auch der am 1.1.2001 erfolgte Beitritt Griechenlands zur Europäischen Währungsunion nichts, wenngleich der gezahlte Kapitalanteil der Deutschen Bundesbank mit jedem Beitritt eines neuen EWU-Mitglieds sinkt. So hat sich das gesamte gezahlte EZB-Kapital nach dem EWU-Beitritt Griechenlands von 3999,6 Mio. EUR auf 4097,2 Mio. EUR erhöht. Dabei entspricht die von der Bank von Griechenland Anfang 2001 erbrachte Kapital-Nachzahlung (97,7 Mio. EUR) den ausstehenden 95 Prozent ihres gezeichneten EZB-Kapitalanteils. Des weiteren leistete die Bank von Griechenland auch einen adäquaten Beitrag zu den Reserven der $\mathrm{EZB}^{54}$.

Die Europäische Zentralbank strebte sehr frühzeitig eine Erhöhung ihres gezeichneten Kapitals an. Deshalb hat sie bereits am 3. November 1998 dem Ministerrat eine Empfehlung nach Art. 28.1. ESZB-Satzung unterbreitet, die eine Kapitalverdopplung vorsieht ${ }^{55}$. Der Ministerrat hat diesem Wunsch aber erst am 8. Mai 2000 entsprochen, wohl wegen des im Geschäftsjahr 1999 recht deutlich zu Buche schlagenden Bilanzverlusts der EZB (247 Mio. EUR). Ob die EZB jedoch ihr Kapitalerhöhungspotential um 5 Mrd. EUR völlig ausschöpfen wird, muß hier offenbleiben.

53 Vgl. Art. 10.2. ESZB-Satzung. So verfügt der Präsident der Deutschen Bundesbank nur über eine von gegenwärtig 18 Stimmen im EZB-Rat.

54 Vgl. Art. 49.2. ESZB-Satzung und Europäische Zentralbank (2001d), S. 90.

55 Vgl. Europäische Gemeinschaft (1998j). 
Tabelle 2: Die Ausstattung der EZB mit Kapital

\begin{tabular}{|c|c|c|c|c|}
\hline \multicolumn{5}{|c|}{ Erstausstattung der EZB mit Kapital zum 1.6.1998 } \\
\hline & & \multicolumn{3}{|c|}{ EZB-Kapitalfinanzierung in EUR } \\
\hline & \multirow[b]{2}{*}{$\begin{array}{r}\text { Gezeichnete } \\
\text { Kapitalanteile }\end{array}$} & & \multicolumn{2}{|c|}{ Anzahlungen ${ }^{1}$} \\
\hline EU-NZBen & & $\begin{array}{r}\text { Eingezahlte } \\
\text { Kapitalbeiträge }\end{array}$ & $\begin{array}{r}\text { aus EWI- } \\
\text { Liquidation }^{2}\end{array}$ & $\begin{array}{l}\text { Überweisungs- } \\
\text { gutschriften }\end{array}$ \\
\hline Deutsche Bundesbank & $24,4935 \%$ & 1224675000 & 138808404 & 1081671596 \\
\hline Banque de France & $16,8337 \%$ & 841685000 & 104644800 & 738870200 \\
\hline Banca d'Italia & $14,8950 \%$ & 744750000 & 97565912 & 650514088 \\
\hline Banco de España & $8,8935 \%$ & 444675000 & 54476907 & 387023093 \\
\hline De Nederlandsche Bank & $4,2780 \%$ & 213900000 & 26161252 & 187818748 \\
\hline Belgische Nationalbank & $2,8658 \%$ & 143290000 & 17235643 & 127189357 \\
\hline Österreichische Nationalbank & $2,3594 \%$ & 117970000 & 14162957 & 104152043 \\
\hline Banco de Portugal & $1,9232 \%$ & 96160000 & 11387902 & 84862098 \\
\hline Bank of Finland & $1,3970 \%$ & 69850000 & 10160382 & 59794618 \\
\hline Central Bank of Ireland & $0,8496 \%$ & 42480000 & 4924381 & 36995619 \\
\hline Banque Centrale du & $0,1492 \%$ & 7460000 & 923360 & 6421640 \\
\hline Luxembourg & & & & \\
\hline Summe EWU-11-NZBen & $78,9379 \%$ & 3946895000 & 480451900 & 3465313100 \\
\hline Bank of England & $14,6811 \%$ & 36702750 & 36702750 & --- \\
\hline Schwedische Reichsbank & $2,6537 \%$ & 6634250 & 6634250 & -- \\
\hline Bank von Griechenland & $2,0564 \%$ & 5141000 & 5141000 & --- \\
\hline Danmarks Nationalbank & $1,6709 \%$ & 4177250 & 4177250 & -.. \\
\hline Summe Pre-In-NZBen & $21,0621 \%$ & 52655250 & 52655250 & -- \\
\hline $\begin{array}{l}\text { EZB-Kapital nach } \\
\text { Erstaustattung }\end{array}$ & $100,0000 \%$ & 3999550250 & 533107150 & 3465313100 \\
\hline
\end{tabular}

EZB-Kapital nach dem Beitritt Griechenlands (seit 1.1.2001)

EZB-Kapitalfinanzierung in EUR

\begin{tabular}{r|r|r|r|} 
& \multicolumn{2}{|c|}{ EZB-Kapitalfinanzierung in EUR } \\
\hline Gezeichnete & $\begin{array}{r}\text { Eingezahlte } \\
\text { Kapitalbeträge }\end{array}$ & $\begin{array}{r}\text { Bestände } \\
\text { zum }\end{array}$ & $\begin{array}{r}\text { Geleistete } \\
\text { Nachzahlungen } \\
\text { Kapitalanteile }\end{array}$ \\
$\begin{array}{r}\text { zum 1.1.2001 } \\
78,9379 \%\end{array}$ & 3946895000 & 3946895000 &.-- \\
$2,0564 \%$ & 102820000 & 5141000 & 97679000 \\
$80,9943 \%$ & 4049715000 & 3952036000 & 97679000 \\
$19,0057 \%$ & 47514250 & 47514250 & -- \\
$100,0000 \%$ & 4097229250 & 533107150 & - \\
\hline
\end{tabular}

Beitritt Griechenlands

Quelle: Darstellung in Anlehnung an Europäische Gemeinschaft (1998b), Europäische Zentralbank (1999a), S. 140 und Europäische Zentralbank (2001d), S. 200. Eigene Berechnungen.

\footnotetext{
' Die Summe der geleisteten Anzahlungen unterscheidet sich geringfugig von den am 4.1.1999 endgultig in Euro abgewickelten Kapitalzahlungen, da die Anzahlungen auf Basis eines provisorischen Kapitalschlussels erfolgte, der nach Bekanntgabe der offiziellen Berechnungszahlen in geringem Umfang revidiert werden mußte. Vgl. Europäische Gemeinschaft (1998d).

${ }^{2}$ Die Übertragung der NZB-Anteile aus der Liquidation des Europasischen Wahrungsinstituts (EWI) fand am 1.6.1998 statt. Zu den EWI-Liquidationsanteilen vgl. Europasische Zentralbank (1999a), S. 150.

${ }^{3}$ Die Überweisungsgutschriften erfolgten am 1.7.1998 in Fremdwathrupgo - 978-3-631-75006-3
} 
Tabelle 3: Zins- und Dividendeneinkünfte der Europäischen Zentralbank aus der Investition ihres Kapitals

\begin{tabular}{|c|c|c|c|}
\hline \multicolumn{4}{|c|}{1999} \\
\hline EZB-Eigenkapital & $\begin{array}{c}\text { Bilanzwerte zum } \\
\text { 31.12.1999 in } \\
\text { Mio. EUR } \\
\end{array}$ & $\begin{array}{c}\text { Verzinsung }{ }^{1} / \\
\text { Dividende }\end{array}$ & $\begin{array}{l}\text { Geschätzte Zinseinkünfte }{ }^{2} / \\
\text { Dividenden aus Kapital- } \\
\text { investitionen in Mio. EUR } \\
\text { (in vH. der gesamten } \\
\text { Nettozinseinkünfte der EZB) }\end{array}$ \\
\hline $\begin{array}{l}\text { Staatsanleihen von EU- } \\
\text { Mitgliedstaaten }\end{array}$ & 3537 & $4,66 \%$ p.a. & $\begin{array}{c}165 \\
(17 \%) \\
\end{array}$ \\
\hline Geldmarktanlagen ${ }^{4}$ & 424 & 2,96\% p.a. & $\begin{array}{c}14 \\
(1 \%)\end{array}$ \\
\hline BIZ-Beteilgung & 39 & -- & $\cdots$ \\
\hline EZB-Kapital gesamt & 4000 & - & $\begin{array}{c}179 \\
(19 \%)\end{array}$ \\
\hline
\end{tabular}

\begin{tabular}{|l|c|c|c|}
\hline & $\begin{array}{c}\text { Bilanzwerte zum } \\
\mathbf{3 1 . 1 2 . 2 0 0 0} \text { in } \\
\text { Mio. EUR }\end{array}$ & $\begin{array}{c}\text { Verzinsung / } \\
\text { Dividende }\end{array}$ & $\begin{array}{c}\text { Geschätzte Zinseinkünfte }{ }^{2} / \\
\text { Dividenden aus Kapital- } \\
\text { investitionen in Mio. EUR } \\
\text { (in vH. der gesamten } \\
\text { Nettozinseinkünfte der EZB) }\end{array}$ \\
\hline $\begin{array}{l}\text { Staatsanleihen von EU- } \\
\text { Mitgliedstaaten }\end{array}$ & 3668 & $5,44 \%$ p.a. & $\begin{array}{c}200 \\
(14 \%)\end{array}$ \\
\hline Geldmarktanlagen & 293 & $4,40 \%$ p.a. & $\begin{array}{c}13 \\
(1 \%)\end{array}$ \\
\hline BIZ-Beteilgung & 39 & 17,8 GFr/Aktie & $\begin{array}{c}0 \\
(0 \%)\end{array}$ \\
\hline $\begin{array}{l}\text { EZB-Kapital } \\
\text { gesamt }\end{array}$ & 4000 & - & $\begin{array}{c}\mathbf{2 1 3} \\
(\mathbf{1 5} \%)\end{array}$ \\
\hline
\end{tabular}

Quelle: Eigene Berechnungen. Die der Darstellung zugrunde liegenden Angaben sind entnommen aus Bank für Internationalen Zahlungsausgleich (2000a), S. 200 ff., Europäische Zentralbank (2001c), S. 26* f. und Europäische Zentralbank (2001d). Differenzen in den Summen durch Runden der Zahlen.

\footnotetext{
${ }^{1}$ Renditen von Staatsanleihen des Euro-Wăhrungsgebiets (Laufzeit 10 Jahre) im Durchschnitt des Jahres 1999 bzw. 2000 und Geldmarktsätze für Dreimonatsgeld im Durchschnitt des Jahres 1999 bzw. 2000. Vgl. Europäische Zentralbank (200Ic), S. $26^{*}$ f..

2 Die Schătzung der Zinseinkünte erfolgt durch Multiplikation der Eigenkapitalpositionen (in 1999 Geldmarktanlagen inklusive BIZ-Beteiligung, da BIZ-Beitritt erst Ende 1999) mit den zugehörigen jahresdurchschnittlichen Zinssätzen. Es handelt sich folglich nur um eine sehr grobe Schätzung, um prinzipielle Größenordnungen aufzuzeigen. Dieses Vorgehen erscheint jedoch vertretbar, da die EZB - mit Ausnahme der unter Ertragsgesichtspunkten irrelevanten BIZ-Beteiligung - bereits seit Beginn der EWU uber die entsprechenden Kapitalinvestitionen verfugte und kein sehr ausgeprägtes Portfoliomanagement betreibt.

${ }^{3} \mathrm{Vgl}$. Europåische Zentralbank (2000c) und Europäische Zentralbank (2001d), S. 190.

4 Ermittelt als Differenz zwischen dem EZB-Kapital und den ausgewiesenen Bilanzwerten der EuroStaatsanleihen bzw. der BIZ-Beteiligung der EZB.

${ }^{5}$ Die BIZ zahlte im Kalenderjahr 2000 eine anteilige Dividende auf die Ende 1999 neu ausgegebenen 12000 BIZ-Aktien für den Zeitraum zwischen der Kapitalzeichnung und dem am 31. März 2000 endenden BIZGeschäftsjahres in Höhe von 214058 Goldfranken (GFr). Vgl. Bank fur Internationalen Zahlungsausgleich (2000a), S. 200. Dies entspricht einem USD-Äquivalent von 103897,87 USD (Seit 1979 fix definierter Umrechnungskurs: $1 \mathrm{GFr}=1,94149$ USD) bzw. einem mit dem EUR-USD-Wechselkurs zum 31.12.2000 (1 EUR $=0,9305$ USD) in EUR umgerechneten Betrag von 446632 EUR. Auf die 3000 BIZ-Aktien der EZB entfallen somit Dividendeneinküfte in Höhe von 111658 EUR. Die Ausschüttung selbst erfolgte in Schweizer Franken. 


\subsection{Die Erträge der EZB aus der Investition ihres Kapitals}

Nach eigenen Angaben investierte die EZB sowohl in 1999 als auch in $2000 \mathrm{ihr}$ Kapital (fast) gänzlich in Euro-denominierte Aktiva ${ }^{56}$. Dabei handelt es sich, wie vorstehende Tabelle 3 erkennen läßt, vor allem um Staatsanleihen der EUMitgliedstaaten $^{57}$, die sowohl Ende 1999 als auch Ende 2000 mit 3537 Mio. EUR bzw. 3668 Mio. EUR um die 90 Prozent der gesamten Kapitalinvestitionen auf sich vereinigen. Investitionen am Geldmarkt hingegen spielen demnach nur eine geringe Rolle. Dies gilt auch für die Beteiligung der EZB an der Bank für Internationalen Zahlungsausgleich (BIZ). Insgesamt gesehen scheint die EZB also keine allzu risikofreudige Strategie bei der Anlage ihrer Eigenmittel zu verfolgen $^{58}$. Dies bedeutet jedoch nicht, daß die Kapitalerträge der EZB keine bedeutende Rolle für die EZB-Ertragslage spielen. So lassen sich die Einkünfte aus EZB-Eigenmittel für 1999 bzw. 2000 näherungsweise auf 165 Mio. EUR bzw. 200 Mio. EUR veranschlagen, was immerhin rund 19 bzw. 15 Prozent der gesamten Nettozinseinkünfte der EZB entspricht ${ }^{59}$. Erwartungsgemäß sind hierfür vor allem die Erträge aus den Euro-Staatsanleihen verantwortlich. Die Einkünfte der EZB aus Geldmarktanlagen und die erhaltene Dividendenzahlung von der BIZ besitzen nur einen vergleichsweise geringen Umfang.

\subsection{Die Übertragung von Währungsreserven auf die EZB}

Neben der Ausstattung der EZB mit Kapital sind die NZBen auch verpflichtet, Währungsreserven auf die EZB zu übertragen. Dabei ist nach Artikel 30.1 ESZB-Satzung der Umfang der zu transferierenden Währungsreserven zunächst auf einen Gegenwert von 50 Mrd. EUR begrenzt, wobei sich der jeweilige NZBBetrag nach dem entsprechenden Anteil am gezeichneten Kapital der EZB richtet $^{60}$. Allerdings brauchen die nicht an der Europäischen Währungsunion teilnehmenden EU-Zentralbanken ihren Anteil nicht einzubringen (Art. 43.6. i.V.m. Art. 30.2. ESZB-Satzung), so daß sich Anfang Januar 1999 der tatsächliche Maximalwert der zu übertragenen Währungsreserven auf nur 39,5 Mrd. EUR belief. Wie Tabelle 4 zeigt, ist dieser Spielraum vom EZB-Rat auch ausgeschöpft worden.

56 Vgl. Europäische Zentralbank (2000h), S. 58 und Europäische Zentralbank (2001d), S. 79.

57 Vgl. Europäische Zentralbank (2000c).

58 Vgl. Europäische Zentralbank (2001d), S. 79.

59 Vgl. die Schätzung der Zins- bzw. Dividendeneinkünfte der EZB aus ihren Kapitalinvestitionen in Tabelle 3.

$60 \mathrm{Vgl}$. Artikel 30.1. und 30.2. ESZB-Satzung sowie Europäische Gemeinschaft (1997b). 
Tabelle 4: Die Ausstattung der EZB mit Währungsreserven durch die NZBen

\begin{tabular}{|c|c|c|c|c|c|}
\hline \multicolumn{6}{|c|}{$\begin{array}{l}\text { Die Erstausstattung der EZB mit Wăhrungsreserven durch die NZBen } \\
\text { in der ersten Januarwoche } 1999\end{array}$} \\
\hline \multirow[b]{2}{*}{$\begin{array}{l}\text { EWU-11-NZBen } \\
\text { Deutsche Bundesbank }\end{array}$} & \multirow{2}{*}{$\begin{array}{l}\text { Kapital- } \\
\text { schlussel } \\
24,4935 \%\end{array}$} & \multicolumn{4}{|c|}{ Übertragene Wăhrungsreserven in EUR } \\
\hline & & Gesamt & Gold & $\begin{array}{l}\text { US-Dollar } \\
9368763750\end{array}$ & $\begin{array}{c}\text { Yen } \\
1040973\end{array}$ \\
\hline Banque de France & $16,8337 \%$ & 8416850000 & 1262527500 & 6438890250 & 715432250 \\
\hline Banca d'Italia & $14,8950 \%$ & 7447500000 & 1117125000 & 5697337500 & 633037500 \\
\hline Banco de España & $8,8935 \%$ & 4446750000 & 667012500 & 3401763750 & 377973750 \\
\hline De Nederlandsche Bank & $4,2780 \%$ & 2139000000 & 320850000 & 1636335000 & 181815000 \\
\hline Belgische Nationalbank & $2,8658 \%$ & 1432900000 & 214935000 & 1096168500 & 121796500 \\
\hline $\begin{array}{l}\text { Österreichische } \\
\text { Nationalbank }\end{array}$ & $2,3594 \%$ & 1179700000 & 176955000 & 902470500 & 100274500 \\
\hline Banco de Portugal & $1,9232 \%$ & 961600000 & 144240000 & 735624000 & 81736000 \\
\hline Bank of Finland & $1,3970 \%$ & 698500000 & 104775000 & 534352500 & 59372500 \\
\hline Central Bank of Ireland & $0,8496 \%$ & 424800000 & 63720000 & 324972000 & 36108000 \\
\hline $\begin{array}{l}\text { Banque Centrale du } \\
\text { Luxembourg }\end{array}$ & $0,1492 \%$ & 74600000 & 11190000 & 57069000 & 6341000 \\
\hline $\begin{array}{l}\text { Summe EWU-11- } \\
\text { NZBen }\end{array}$ & $78,9379 \%$ & 39468950000 & 5920342500 & 30193746750 & 3354860750 \\
\hline
\end{tabular}

Die Verbindlichkeiten der EZB aus übertragenen Wăhrungsreserven gegenüber den NZBen nach dem Beitritt Griechenlands zum 1.1.2001

EWU-11-NZBen

Summe EWU-11-NZBen

Bank von Griechenland

Summe EWU-12-

NZBen

\begin{tabular}{|c|c|c|c|c|}
\hline \multirow{3}{*}{$\begin{array}{l}\text { Kapital- } \\
\text { schlüssel } \\
78,9379 \%\end{array}$} & \multicolumn{4}{|c|}{ Übertragene Währungsreserven in EUR } \\
\hline & Gesamt & Gold & US-Dollar & Yen \\
\hline & 39468950000 & 5920342500 & 30193746750 & 3354860750 \\
\hline $2,0564 \%$ & 1028200000 & 154230000 & 786573000 & 87397000 \\
\hline $80,9943 \%$ & 40497150000 & 6074572500 & 30980319750 & 3442257750 \\
\hline
\end{tabular}

Quelle: Eigene Berechnungen. Die der Darstellung zugrunde liegenden Daten sind entnommen aus Europaische Gemeinschaft (2000f), S. 122 f., Europăische Zentralbank (2000h), S. 157, Europalische Zentralbank (2001d), S. 199 ff. und Banco de Portugal (2000a), S. 305. 
Konkret erfolgten die Zahlungen in Form von Gold (5,9 Mrd. EUR), US-Dollar(30,2 Mrd. EUR) und Yen-Reserven (3,4 Mrd. EUR) und wurden zwischen dem 4. und 7. Januar 1999 abgewickelt ${ }^{61}$. Größter Beitragszahler ist wiederum die Deutsche Bundesbank (12,2 Mrd. EUR), gefolgt von der Banque de France (8,4 Mrd. EUR), der Banca d'Italia (7,4 Mrd. EUR) und den anderen acht NZBen (zusammen 11,4 Mrd. EUR). Die Analogie zur EZB-Kapitalfinanzierung ist klar erkennbar, wenngleich die einzuzahlenden Beträge die EZB-Eigenmittel um das 10 -fache übersteigen.

Tritt nun eine ESZB-NZB dem Eurosystem bei, so hat auch diese Zentralbank einen Beitrag zu den EZB-Währungsreserven zu leisten. Dabei bestimmt sich die Höhe der Übertragung durch Multiplikation des in Euro zum jeweiligen (aktuellen) Wechselkurs ausgedrückten Werts der Währungsreserven, die der EZB von den bereits teilnehmenden NZBen übertragen wurden, mit dem Faktor, der das Verhältnis zwischen der Anzahl der von der beitrittswilligen NZB gezeichneten Anteile und der Anzahl der von den anderen NZBen bereits eingezahlten Anteile ausdrückt (Art. 49.1. ESZB-Satzung). Im Falle der am 1. Januar 2001 dem Eurosystem beigetretenen Bank von Griechenland betrug dieser Wert 1.278.260.161 EUR und war damit um 250.060.161 EUR höher als die zugehörige Forderungsgutschrift (1.028.200.000 EUR) durch die EZB ${ }^{62}$. Der angesprochene Differenzbetrag wurde als Beitrag der griechischen Zentralbank zu den EZB-Reserven und -Rückstellungen einbehalten. Durch dieses Vorgehen gelingt es, die effektive Finanzierungsleistung der Bank von Griechenland so zu bemessen, als ob sie seit Beginn der EWU Mitglied des Eurosystems gewesen wäre.

Nach Artikel 30.4 ESZB-Satzung kann die EZB auch über die oben erwähnten 50 Mrd. EUR ${ }^{63}$ hinaus innerhalb der Grenzen und unter den Bedingungen, die der Ministerrat nach dem Verfahren des Artikels 42 ESZB-Satzung festlegt, die Einzahlung weiterer Währungsreserven von den NZBen fordern. Am 8. Mai 2000 schloß sich der Ministerrat einer vorausgegangenen EZB-Empfehlung an, und machte den Weg für eine Einforderung von weiteren NZB-Währungsreserven in Höhe von zusätzlichen $50 \mathrm{Mrd}$. EUR frei ${ }^{64}$. Dies bedeutet nun, daß

\footnotetext{
61 Dabei erfolgte die Zahlung der einzelnen Aktiva streng symmetrisch, d.h. jede NZB hat bezogen auf ihre Finanzierungsverpflichtung jeweils 15 Prozent in Gold, 76,5 Prozent in US-Dollar und 8,5 Prozent in Yen eingebracht.

62 Vgl. Europäische Gemeinschaft (2000f), S. 122 f. und Europäische Zentralbank (2001d), S. 200. Die Forderungsgutschrift der Bank von Griechenland bestimmt sich ihrerseits durch den von ihr gezeichneten EZB-Kapitalanteil und der Summe an Währungsreserven, die sich ergibt, wenn alle EU-NZBen Mitglied des Eurosystems wären (50 Mrd. EUR). Vgl. Art. 30 ESZB-Satzung.

63 Dieser Betrag ergäbe sich, wenn alle EU-NZBen Mitglied des Eurosystems wären.

64 Europäische Gemeinschaft (2000c).
} 
bei Beitritt aller EU-NZBen zum Eurosystem die EZB über ein einzuforderndes NZB finanziertes Währungsreservenpotential von insgesamt $100 \mathrm{Mrd}$. EUR verfügen würde ${ }^{65}$. Da allerdings auch die Pre-In-NZBen Schwedens, Großbritanniens und Dänemarks weiterhin von einer Einzahlungspflicht befreit sind, beläuft sich das gegenwärtige Einforderungspotential der EZB nur auf 81,0 Mrd. EUR. Allerdings will die EZB diesen Spielraum „nur zur Auffüllung ihrer Bestände an Währungsreserven bis zum Höchstbetrag der ursprünglichen Übertragungen ${ }^{\text {"66 }}$ ausschöpfen. Angesprochen sind hier wohl die in Artikel 30 ESZB-Satzung erwähnten $50 \mathrm{Mrd}$. EUR, was einem Nachschuß von 9,5 Mrd. EUR entsprechen würde.

\subsection{Die Nettoerträge der EZB aus übertragenen Währungsreserven}

Die Erträge, die die EZB aus den übertragenen Währungsreserven erwirtschaftet, hängen naturgemäß stark von der Anlagepolitik ab. Diesbezüglich verfolgt die EZB eine vor allem auf Liquidität und Sicherheit bedachte Strategie $^{67}$. Erst unter Beachtung dieser Vorgaben werden die Währungsreserven so ertragreich wie möglich angelegt. Verwaltet werden die EZB-Währungsreserven jedoch nicht von der EZB selbst, sondern dezentral von den NZBen des Eurosystems. Hierzu legt der EZB-Rat den anlagepolitischen Aktionsrahmen sowie die strategische Ausrichtung fest, während das EZB-Direktorium die taktischen Benchmarks vorgibt und die Einhaltung über ein speziell für das Eurosystem konzipiertes IT-Netz online überwacht ${ }^{68}$. Diese Vorgaben beinhalten unter anderem die währungsmäßige Zusammensetzung, Liquiditätsanforderungen, Bonitätsparameter sowie definierte Richtwerte zur Abschätzung von Rendite- und Zinsänderungsrisiken. Dennoch verbleibt den NZBen ein gewisser Ermessensspielraum bei der Anlage der EZB-Währungsreserven. Dieser dient vor allem dazu, um ein Höchstmaß an Wirtschaftlichkeit bei der Verwaltung der EZB-Währungsreserven zu gewährleisten. Dabei ist jedoch für die Geschäftspartner der EZB jederzeit erkennbar, ob die NZBen in offener Stellvertretung für die EZB auftreten oder ob die NZBen auf eigene Rechnung tätig werden.

Will man nun das Währungsreservenportfolio der EZB im einzelnen näher untersuchen, so erhält man - wie auch bei vielen anderen Zentralbanken - keine

65 Durch entsprechende Devisenmarktinterventionen der EZB könnte das Volumen natürlich noch erheblich steigen.

66 Europäische Zentralbank (2001d), S. 171.

67 Vgl. im Folgenden Europäische Zentralbank (2000a), S. 57 ff., Europäische Zentralbank (2000h), S. 57 f. und Europäische Zentralbank (2001d), S. 78 ff..

68 Zur genauen Vorgehensweise vgl. Europäische Zentralbank (2000a), S. 57 ff.. 
detaillierten Angaben hinsichtlich der veranlagten Finanztitel. Dennoch läßt die Summe vieler Einzelinformationen ein relativ klares Bild erkennen. So beläuft sich der Goldbestand der EZB sowohl Ende 1999 als auch Ende 2000 unverändert auf 24 Mio. Unzen Feingold, was den naheliegenden Schluß zuläßt, daß die EZB in den ersten beiden Jahren der EWU keine Goldtransaktionen durchgeführt hat ${ }^{69}$. Des weiteren kann man davon ausgehen, daß die EZB bisher auch keine Zinseinkünfte aus Goldleihgeschäften oder aus dem Einsatz von Goldfutures und -optionen erwirtschaftet hat ${ }^{70}$. Zudem ist die EZB, was die Änderung der währungsmäßigen Zusammensetzung der ihr übertragenen Währungsreserven betrifft, nach eigenen Angaben eher zurückhaltend, um die einheitliche Geldpolitik des Eurosystems nicht zu beeinträchtigen ${ }^{71}$. Wie eng sich die EZB bei der Anlage ihrer Devisenreserven am ursprünglichen Fremdwährungsportefeuille orientiert, zeigt auch der Verkauf von Zinserträgen aus den Währungsreserven im September 2000 im Wert von über 2,5 Mrd. EUR, „um die Bilanzstruktur und das Risikoprofil der EZB auf dem Stand von Anfang $1999 \mathrm{zu}$ halten “72. Es läßt sich folglich festhalten, daß zumindest bis zu den im Herbst 2000 durchgeführten Devisenmarktinterventionen, bei denen die EZB substantielle Fremdwährungsbestände gegen Euro verkauft hat $^{73}$, die Devisenreserven der EZB zu (mindestens ${ }^{74}$ ) 90 Prozent aus US-Dollar und die restlichen Anteile auf den japanischen Yen entfielen. Dabei dürften die genannten Dollar- und Yenreserven jeweils größtenteils in US-amerikanischen und japanischen Staatsanleihen angelegt sein. Gerade für die Investition der Dollarreserven trifft diese Einschätzung wohl mit hoher Wahrscheinlichkeit zu, da die EZB explizit angibt, Ende 1999 ,große Bestände“75 an US-Staatsanleihen zu halten. Des weiteren stützt folgende Beispielrechnung die obige These. Angenommen, sowohl die gesamten von den NZBen Anfang 1999 übertragenen EZB-Bestände an US-Dollarreserven (30,2 Mrd. EUR) und Yen-Reserven (3,4

69 Vgl. Europäische Zentralbank (2000h), S. 156 und Europäische Zentralbank (2001d), S. 197.

70 So trägt die EZB auch eine Vereinbarung von 15 Zentralbanken mit, die vorsieht, Goldtransaktionen nur noch in sehr begrenztem Umfang bis 2004 vorzunehmen. Vgl. Europäische Zentralbank (2000a), S. 59. Dieses Abkommen diente der Stabilisierung des Goldpreises.

71 Vgl. Europäische Zentralbank (2000h), S. 57.

72 Europäische Zentralbank (2001d), S. 78.

73 Das Interventionsvolumen dürfte eine Größenordnung um die $10 \mathrm{Mrd}$. EUR annehmen. Vgl. Europäische Zentralbank (2001d), S. 197 und die Ausfuhrungen zu den Devisenmarktinterventionen der EZB in Kapitel IV.1 Abschnitt 2.2..

74 „Mindestens“ deshalb, da die Zinsen der US-Staatsanleihen und Geldmarktpapiere in 1999/2000 jeweils um ein vielfaches höher waren, als die Erträge vergleichbarer japanischer Finanztitel. Vgl. Europäische Zentralbank (2001c), S. 26* f..

Europäische Zentralbank (2000c). 
Mrd. EUR) wären jeweils vollständig in US- bzw. japanischen Staatsanleihen mit einer Laufzeit von 10 Jahren investiert worden, dann hätte die EZB bei einer jahresdurchschnittlichen Verzinsung von 5,64 Prozent bei den US-Obligationen bzw. von 1,75 Prozent bei den japanischen Titeln $^{76}$ einen Zinsertrag (ohne Berücksichtigung von Bewertungsgewinnen dieser Zinseinkünfte) von 1762 Mio. EUR erwirtschaftet, was den tatsächlich erzielten Zinseinkünften aus übertragenen Währungsreserven in Höhe von 1734 Mio. EUR recht nahe kommt $^{77}$.

Neben den Zinseinkünften, die die EZB aus der Anlage der Währungsreserven erwirtschaftet, hat die EZB auch zugehörige Zinsaufwendungen zu finanzieren. So leistet die EZB auf die (nicht zurückzuzahlenden) Euro-Einlagen, die die NZBen im Gegenzug für die übertragenen Währungsreserven bei der EZB erhalten haben, eine Verzinsung, die sich im wesentlichen an den kurzfristigen Refinanzierungszinsen des Eurosystems orientiert. Konkret bestimmt sich dabei die Höhe der Vergütung aus dem Produkt der jeweiligen NZB-Forderung und dem Vergütungssatz, der seinerseits 85 Prozent des geltenden Zinssatzes für Hauptrefinanzierungsgeschäfte des Eurosystems entspricht. Mit diesem Abschlag von 15 Prozent trägt die EZB dem Umstand Rechnung, daß die auf die EZB übertragenen Goldreserven, die ihrerseits 15 Prozent der gesamten übertragenen Währungsreserven ausmachen, für die EZB keine Zinseinkünfte abwerfen. Dabei erfolgt die Vergütung auf täglicher Basis ${ }^{78}$. Die Tabelle 5 zeigt nun, in welchem Umfang solche Zahlungen an die NZBen im Jahr 1999 und 2000 erfolgt sind.

Hierbei gibt es keine Überraschungen. Diejenigen NZBen, die die meisten Währungsreserven auf die EZB übertragen haben, erhalten in Abhängigkeit ihres Finanzierungsanteils auch die meisten Zinseinkünfte. Deutlich sichtbar wird auch der im Jahr 2000 erfolgte Anstieg der Hauptrefinanzierungszinsen gegenüber dem Vorjahr, was zu entsprechend höheren Aufwendungen der EZB führt. $\mathrm{Da}$ hierbei ebenfalls auch die Fremdwährungseinkünfte der EZB im Vergleich zu 1999 gestiegen sind, ist jedoch eher zufällig. So könnte es in Zukunft durchaus passieren, daß die EZB Erträge aus den Devisenreserven nicht ausreichen, um ihre Zinsverpflichtung $\mathrm{zu}$ kompensieren. In einen Finanzierungsnotstand gerät die EZB dabei jedoch nie, da sie die Verzinsung freilich immer mit Hilfe selbst geschöpfter Euros begleichen kann ${ }^{79}$.

76 Vgl. Europäische Zentralbank (2001c), S. 26*.

77 Vgl. Tabelle 5.

78 Vgl. Österreichische Nationalbank (2000), S. 131 und Europäische Zentralbank (2000c).

79 Solche Probleme gäbe es nur, wenn die Verzinsung der NZB-Gutschriften in Auslandswährung erfolgen würde. 
Tabelle 5: Die Zinseinkünfte und Zinsaufwendungen der Europäischen Zentralbank aus übertragenen Währungsreserven im Jahr 1999 und 2000'

Jahr

Zinseinkünfte aus übertragenen

Währungsreserven

Deutsche Bundesbank

Banque de France

Banca d'Italia

Banco de España

De Nederlandsche Bank

Belgische Nationalbank

Österreichische Nationalbank

Banco de Portugal

Bank of Finland

Central Bank of Ireland

Banque Centrale du Luxembourg

Zinsaufwendungen aus übertragenen

Währungsreserven gesamt ${ }^{3}$

Nettoxinseinkünfte aus

Währungsreserven

(in vH. der Gesamten

Nettozinseinkünfte)
1999

1733987854

283313823

194713426

172289406

102870726

49482769

33147995

27290668

22245058

16158552

9828256

1726610

913067289

820920565

$(85,9 \%)$
NZB-

Anteil ${ }^{2}$

$426680388 \quad 31,0288 \%$

$293245134 \quad 21,3252 \%$

$259473787 \quad 18,8693 \%$

$154926861 \quad 11,2665 \%$

$74522756 \quad 5,4194 \%$

$49922023 \quad 3,6304 \%$

$41100687 \quad 2,9889 \%$

$33501825 \quad 2,4363 \%$

24335336

14801693

2600335

1375110826

$1,7697 \%$

$1,0764 \%$

- $0,1891 \%$

$100,0000 \%$

Quelle: Eigene Berechnungen. Die der Darstellung zugrunde liegenden Daten sind entnommen aus Europäische Zentralbank (2001d), S. 192 ff..

\footnotetext{
${ }^{1}$ Angaben in EUR.

${ }^{2}$ Da sich die errechneten jeweils auf 4 Nachkommastellen gerundeten Prozentangaben nur auf 99,9998 Prozent summieren, wurden in Analogie zur EZB-Kapitalberechnung die beiden kleinsten Anteile, also die Anteile der BCL und der CBI, um jeweils 0,0001 Prozentpunkte erhöht, bis sich genau 100 Prozent ergibt. Zur EZB-Kapitalberechnung vgl. Europäische Gemeinschaft (1998d).

${ }_{3}^{3}$ Die Berechnung der EZB-Zinszahlungen an die einzelnen NZBen erfolgt durch Multiplikation der von der EZB ausgewiesenen gesamten Zinsaufwendungen aus übertragenen Währungsreserven mit dem Anteil des von der jeweiligen EWU-NZB eingezahlten Betrags zur Finanzierung der EZBWährungsreserven an der Gesamtsumme der von den EWU-NZBen eingezahlten Währungsreserven. Differenzen in den Summen durch Runden der Zahlen.
} 
Dennoch würde die EZB wohl aus Gründen der „Bilanzkosmetik“ versuchen, derartig bedingte EZB-Verluste etwa durch einen Beschluß einer niedrigeren Verzinsung der NZB-Einlagen zu verhindern. Hierfür spricht auch die im EZBRat getroffene Regelung, daß die NZBen auf einen Teil (maximal 20 Prozent) ihrer Forderungen aus den an die EZB übertragenen Währungsreserven gegebenenfalls verzichten werden, wenn die wechselkursbedingten Buchverluste der EZB aus der Anlage ihrer Währungsreserven nicht durch Nettoerträge und Rücklagen gedeckt sein sollten ${ }^{80}$. Auch dieses Abkommen regelt nur die Art der EZB-Verlustfinanzierung und nicht die relative Finanzierungsleistung der NZBen.

Anhand der Tabelle 5 wird ebenfalls deutlich, wie wichtig die Nettozinseinkünfte der EZB aus den ihr übertragenen Währungsreserven für die Ertragslage ist. So machten die Fremdwährungserträge der EZB im Jahr 199986 Prozent und im Jahr 2000 immerhin noch 80 Prozent der gesamten Nettozinseinkünfte der EZB aus. Berücksichtigt man weiterhin noch die (grob geschätzten) Erträge der EZB aus der Veranlagung ihres Kapitals wird schnell deutlich, daß die EZB - wie sie im übrigen selbst bestätigt ${ }^{81}$ - ihre Erträge in erster Linie durch die Anlage ihrer Währungsreserven und ihrem eingezahlten Eigenkapital erzielt ${ }^{82}$. Andere Einkünfte, die die EZB aus ihrer operativen Tätigkeit erzielt, spielen somit eine nur untergeordnete Rolle. Dennoch soll dieser Umfang im Folgenden näher untersucht werden, da eine Ausdehnung dieser EZB-Tätigkeiten das bisherige Bild schnell ändern könnte.

\section{Die Nettoerträge der EZB aus der operativen Geld- und Devisenpolitik}

\subsection{Die Nettoerträge der EZB aus der operativen Geldpolitik}

Gemäß der ESZB-Satzung verfügt die Europäische Zentralbank über alle erforderlichen geldpolitischen Instrumente, inklusive dem Recht zur Emission

\footnotetext{
80 Vgl. Europäische Zentralbank (2000c) und Europäische Zentralbank (2001d), S. 199.

81 Vgl. Europäische Zentralbank (2000c).

82 Die Kumulierung der geschätzten Kapitaleinkünfte (in 1999: 179 Mio. EUR bzw. 19 \% der gesamten Nettozinseinkünfte der EZB) und der von der EZB explizit angegebenen Nettoeinkünfte aus den ihr übertragenen Währungsreserven (in 1999: 821 Mio. EUR = 86 $\%$ der gesamten Nettozinseinkünfte der EZB) ergibt für 1999 einen Wert von $105 \%$, was nichts anderes bedeutet, als daß die EZB aus ihren anderen Tätigkeiten einen entsprechenden Nettozinsaufwand zu tragen hat. Wie die spätere Analyse noch zeigen wird, handelt es sich hierbei vor allem um die Nettozinsaufwendungen der EZB aus der Verzinsung ihrer Netto-TARGET-Verbindlichkeiten gegenüber den NZBen.
} 
von Banknoten ${ }^{83}$. Allerdings verzichtet die EZB - dem dezentralen Ansatz des Eurosystems folgend - weitgehend auf eine eigene operative Durchführung der Geldpolitik. Diese Aufgabe überläßt sie den NZBen des Eurosystems, die die geldpolitischen Operationen gemäß den Leitlinien und Weisungen der EZB auszuführen haben ${ }^{84}$. So sieht die Aufgabenverteilung im Eurosystem gegenwärtig vor, daß sich die EZB in operativer Hinsicht rein auf die Durchführung von sogenannten „Feinsteuerungsoperationen" konzentrieren und diese auch nur in Ausnahmefällen direkt über die EZB erfolgen sollen. So ist etwa die am 5. Januar 2000 als bisher einzig durchgeführte Feinsteuerungsmaßnahme in Form einer Hereinnahme von Termineinlagen bilanztechnisch über die NZBen abgewickelt worden, wobei die NZBen die entsprechenden Zinsaufwendungen zu finanzieren hatten ${ }^{85}$. Bis Ende des Jahres 2000 sind der EZB somit keine Aufwendungen und Erträge aus der Abwicklung der gemeinsamen Geldpolitik entstanden ${ }^{86}$.

Die EZB überläßt den NZBen auch das Inumlaufbringen und den Einzug der ihr zugeteilten Euro-Noten. Die EZB stellt jedoch seit der Einführung des EuroBargelds acht Prozent des Gesamtwerts der umlaufenden Euro-Banknoten in ihre Bilanz ein. Im Gegenzug erhält sie hierfür entsprechende „IntraEurosystem-Forderungen aus Banknoten" an die NZBen, die sich im einzelnen nach dem gezahlten EZB-Kapitalanteil richten ${ }^{87}$. Da diese Forderungen in Höhe des Satzes für die Hauptrefinanzierungsgeschäfte verzinst werden, sind substantielle Auswirkungen auf die EZB-Ertragslage zu erwarten ${ }^{88}$. So hätte die EZB Ende 1999 bei einem Banknotenanteil von 29996 Mio. EUR und einer jahresdurchschnittlichen Verzinsung von 2,71 Prozent Einkünfte von bis zu 813 Mio. EUR erzielt, was die Nettozinseinkünfte der EZB des Jahres 1999 um rund 85 Prozent erhöht hätte ${ }^{89}$.

83 Vgl. Art. 16-20 ESZB-Satzung.

84 Vgl. hierzu auch die Ausführungen zum Kapitel V.2.1. Abschnitt 2..

85 Diese Maßnahme war erforderlich, um die wegen des Jahrhundertwechsels relativ hohe Bankenliquidität bereits in der ersten Januarwoche auf ein angemessenes Niveau zurückzuführen. Hierbei wurden dem Finanzsektor rund $14 \mathrm{Mrd}$. EUR entzogen. Abgewickelt wurde diese Maßnahme über einen Schnelltender mit variablem Zinssatz. Vgl. Europäische Zentralbank (2001d), S. 70.

86 Die „Forderungen bzw. Verbindlichkeiten der EZB in Euro an Kreditinstitute im EuroWährungsgebiet", die sie in der Bilanz zum 31.12.2000 (nach geänderter Bilanzstruktur gegenüber dem Jahresausweis für 1999) ausweist, stehen nicht im Zusammenhang mit den geldpolitischen Operationen des Eurosystems, sondern dienen der Veranlagung der EZB-Eigenmittel. Vgl. Europäische Zentralbank (2001d), S. 197 f..

$87 \mathrm{Vgl}$. Europäische Zentralbank (2001f), S. 4 ff. und Europäische Zentralbank (2001h).

88 Dies gilt zumindest dann, wenn die EZB von Interimsausschüttungen ihrer so erwirtschafteten Banknoteneinkünfte absieht.

Vgl. die Tabellen 1 und 11 . 


\subsection{Die Nettoerträge der EZB aus der Devisenpolitik}

Neben der Festlegung und Ausführung der gemeinsamen Geldpolitik bestehen die grundlegenden Aufgaben des Eurosystems auch darin, Devisengeschäfte durchzuführen. Allerdings haben diese im Einklang mit etwaigen Vereinbarungen zu erfolgen, die der für die Wechselkurspolitik zuständige Ministerrat (ECOFIN) zu treffen hat (Art. 3.1. Spstr.2 ESZB-Satzung). So kann der Rat der Wirtschafts- und Finanzminister nach Art. 111 EGV für den Euro entweder förmliche Vereinbarungen über ein Wechselkurssystem oder allgemeine Orientierungen für die Wechselkurspolitik gegenüber Drittlandswährungen $^{90}$ beschließen. Allerdings dürfen die mit diesen Regelungen einhergehenden Interventionsverpflichtungen des Eurosystems ihrerseits das vorrangige Ziel der Preisstabilität nicht beeinträchtigen ${ }^{9 !}$. Bisher hat der ECOFIN-Rat jedoch weder förmliche Vereinbarungen noch allgemeine Wechselkursorientierungen für den Außenwert des Euro gegenüber Drittlandswährungen festgelegt ${ }^{92}$.

Dennoch hat das Eurosystem in den ersten beiden Jahren der EWU insgesamt vier mal an den Devisenmärkten interveniert. Dabei sieht die Aufgabenverteilung im Eurosystem vor, daß Interventionen auf Rechnung der EZB zu erfolgen haben. Ein Rückgriff auf die Währungsreserven der NZBen findet hierbei nicht statt ${ }^{93}$. Die NZBen des Eurosystems sind aber in technischer Hinsicht an den Devisenmarktinterventionen beteiligt, indem sie in offener Stellvertretung für die EZB tätig werden. Konkret kauften die NZBen am 22. September sowie am 3., 6. und 9. November 2000 auf Rechnung der EZB Euros von den heimischen Geschäftsbanken gegen Hergabe von Devisen $\mathrm{an}^{94}$. Abgewickelt wurden diese Stützungskäufe über das TARGET-Zahlungsverkehrssystem, wobei sich der Gesamtwert der verkauften Währungsreserven

90 Unter Drittlandswährungen sind hierbei die Währungen von Ländern zu verstehen, die nicht der EU angehören, wie z.B. der US-Dollar.

91 Vgl. Europäische Zentralbank (2000a), S. 56. Die vertraglichen Regelungen bezüglich der Installierung eines Wechselkurssystems gegenüber Nicht-EU-Währungen sprechen allerdings nur von einem „Bemühen, zu einem mit dem Ziel der Preisstabilität im Einklang stehenden Konsens zu gelangen" (Art. 111 Abs. 1 EGV).

92 Dies ist wohl auch in näherer Zukunft nicht zu erwarten, da der Europäische Rat am 13. Dezember 1997 eine entsprechende Entschließung verabschiedet hat. Vgl. Europäische Zentralbank (2000a), S. 56.

93 Vgl. Europäische Zentralbank (2000a), S. 60 und Europäische Zentralbank (2000h), S. 57.

94 Vgl. Europäische Zentralbank (2001d), S. 78. Die Intervention am 22. September 2000 erfolgte zusammen mit den Währungsbehörden der USA, Japans, Kanadas und Großbritanniens. 
grob auf 10 Mrd. EUR beziffern lassen dürfte ${ }^{95}$. Bilanztechnisch äußert sich dieser Vorgang wie folgt:

\section{Abbildung 3: Die bilanztechnische Erfassung der Interventionen des Eurosystems (Stützungskäufe zugunsten des Euro gegen Verkauf von Devisen)}
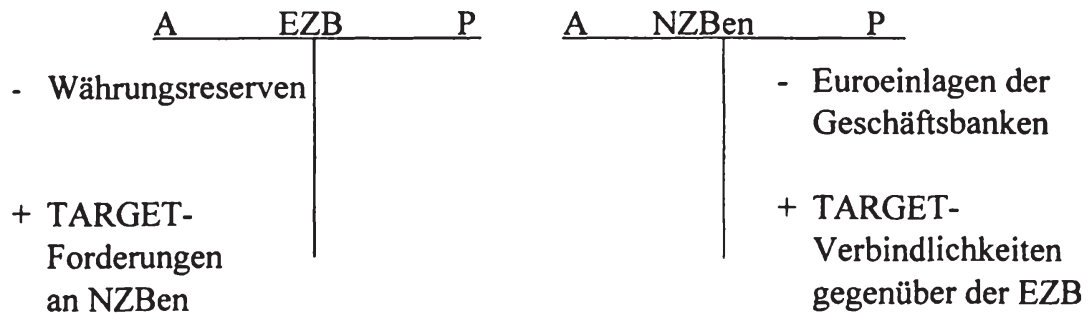

„Normalerweise" würden die Ankäufe von Euros gegen Auslandswährung in der EZB-Bilanz zu einer Bilanzverkürzung führen. Da aber die EZB, abgesehen von den Sicherungseinlagen der Euro Banking Association (EBA) und ihren Euroverbindlichkeiten aus der Anlage ihrer Eigenmittel, über keine Depositen von im Euro-Währungsraum ansässigen Kreditinstituten verfügt ${ }^{96}$, muß die notwendige Reduktion der Euro-Einlagen über die Guthaben der Geschäftsbanken bei den NZBen erfolgen. Dies führt nun dazu, daß es sowohl in der EZB-Bilanz als auch in den NZB-Ausweisen wegen der bilateralen Verrechnung der TARGET-Interventionssalden zu einem Aktiv- bzw. Passivtausch kommt ${ }^{97}$. D.h. die NZBen weisen eine TARGET-Verbindlichkeit gegenüber der EZB in Höhe der eingezogenen Euroeinlagen aus und die EZB stellt den veräußerten

95 Vgl. Europäische Zentralbank (2001d), S. 197 und European Central Bank (2001d).

96 Vgl. Europäische Zentralbank (2001d), S. 191, die Tabellen 9, 11 und A1. Mit den EBAEinlagen werden die über TARGET abgewickelte Zahlungen des Europäischen Bankenverbandes (EBA) besichert. Vgl. Europäische Zentralbank (2001d), S. 198.

97 Das TARGET-System (Trans-European Automated Real-time Gross settlement Express Transfer-System) ist ein EU-weites grenzüberschreitendes Zahlungsverkehrssystem, das die nationalen Zahlungssysteme der EU-Länder (sog. RTGS-Systeme: Real-Time-GrossSettlement Systeme) und das Zahlungsverkehrssystem der EZB über ein InterlinkingSystem miteinander verknüpft und von den Zentralbanken des ESZB bereitgestellt wird. Zur Funktionsweise des TARGET-Systems vgl. z.B. European Central Bank (1998b), Europäische Gemeinschaft (2001b) und European Central Bank (2001a). 
Währungsreserven eine größengleiche TARGET-Forderung an die NZBen in ihre Konten ein. Erst eine Konsolidierung der Zentralbankausweise zeigt dann wegen der sich gegenseitig aufhebenden TARGET-Forderungen bzw. -Verbindlichkeiten eine Verkürzung der konsolidierten Eurosystembilanz.

Diese Verbuchungsmethode hat nun eine für die EZB-Gewinnentstehung wichtige Wirkung. Würde nämlich die Intervention bilanztechnisch direkt von der EZB, also bilanzverkürzend durch Rückgriff auf (bei ihr existierende) Geschäftsbankeneinlagen erfolgen, hätte die EZB ceteris paribus in Höhe der entgangenen Fremdwährungserträge einen Rückgang ihrer Brutto-Ertragssituation hinzunehmen. Tatsächlich wird die EZB aber für die unter Opportunitätsgesichtspunkten erlittenen, interventionsinduzierten Brutto-Zinsverluste von den NZBen in bestimmten Umfang ertragstechnisch kompensiert. Der Grund hierfür liegt in der Verzinsung der bei der Intervention entstehenden bilateralen TARGET-Salden mit dem aktuellen Satz für Hauptrefinanzierungsgeschäfte ${ }^{98}$. So leisten die NZBen dann ,vollständigen“ Ersatz für die verlorenen Brutto-Fremdwährungserträge der EZB, wenn sich die Zinsdifferenzen des Hauptrefinanzierungssatzes und der Auslandserträge (korrigiert um Bewertungsänderungen) entsprechen.

Obige Ausführungen gelten analog, wenn die EZB an den Devisenmärkten Auslandswährungen gegen Euro ankaufen würde. Diese Transaktionen werden nach der gegenwärtigen Praxis ebenfalls über das TARGET-System abgewickelt, wobei in diesem Falle die EZB entsprechende TARGET-Zinsverpflichtungen gegenüber den NZBen zu begleichen hätte ${ }^{99}$. Zur Finanzierung dieser Aufwendungen könnte - ceteris paribus - die EZB ihrerseits auf zusätzliche Fremdwährungserträge zurückgreifen, die sie aus den angekauften Währungsreserven erhält. Ob die EZB aus dieser Art der Devisenmarktintervention eine positive Auswirkung auf ihre Ertragslage zu erwarten hat, hängt wiederum von der internationalen Zinsdifferenz ab.

Welche Bedeutung nun die Erträge aus der Verzinsung der TARGETInterventionssalden für die EZB-Gewinnentstehung besitzen, kann wegen der mangelnden Verfügbarkeit dieser Daten nicht exakt angegeben werden. Es läßt sich jedoch diesbezüglich eine Größenordnung von grob 69 Mio. EUR ansetzen. Dieser Betrag ergibt sich, wenn man von den gesamten ausgewiesenen Nettozinseinkünften der EZB im Jahr 2000 (1414 Mio. EUR) die geschätzten Erträge aus der Veranlagung des EZB-Kapitals (213 Mio. EUR) und die

98 Dabei erfolgt die Verzinsung auf täglicher Basis. Vgl. Österreichische Nationalbank (2000), S. 45 und S. 128.

99 In diesem Fall käme es jedoch jeweils zu einer Verlängerung der EZB- und NZBBilanzen. 
ausgewiesenen Netto-Fremdwährungserträge der EZB (1132 Mio. EUR) abzieht ${ }^{100}$. Allerdings unterstellt diese Rechnung, daß die EZB-Position im TARGET-System ohne ihre Devisenmarktinterventionen im Jahr 2000 jeweils immer ausgeglichen war, was freilich nicht realistisch ist. Da man jedoch davon ausgehen kann, daß im Jahr 2000 die nicht-interventionsinduzierten TARGETOperationen der EZB wie im Vorjahr ebenfalls „keine wesentliche Auswirkung auf das Betriebsergebnis “101 haben dürften, erscheint der Wert von 69 Mio. EUR als Maß für die EZB-Einkünfte aus der Verzinsung der TARGET-Interventionssalden durchaus brauchbar. Dieser Betrag entspricht immerhin 4,9 Prozent der gesamten Nettozinseinkünfte der EZB des Jahres 2000. Ob allerdings die von den NZBen gezahlten Zinsen aus den TARGET-Interventionssalden ausreichend sind um den Zinsverlust der EZB aus den veräußerten Währungsreserven zu kompensieren, soll hier offenbleiben.

Bisher unerwähnt blieben die Devisenmarktinterventionen des Eurosystems im Rahmen des sogenannten Wechselkursmechanismus II (WKM II). Der WKM II ist seit Beginn des Jahres 1999 in Kraft und regelt die Währungsbeziehungen zwischen dem Euro und den nicht an der dritten Stufe der EWU teilnehmenden EU-Mitgliedstaaten ${ }^{102}$. Hierbei ist vorgesehen, daß für die Währungen der am WKM II beteiligten Mitgliedstaaten ein Leitkurs gegenüber dem Euro mit einer Standardschwankungsbreite von \pm 15 Prozent festgelegt wird, die aber gegebenenfalls auch verengt werden kann. An den Interventionspunkten besitzen dann sowohl die EZB als auch die teilnehmenden Pre-In-NZBen eine zunächst unbegrenzte Interventionsverpflichtung ${ }^{103}$, der jedoch nicht nachgekommen werden muß, falls Gefahr für die inländische Preisstabilität besteht. Zur Finanzierung der Interventionsvolumina können die Zentralbanken auf die sogenannte „sehr kurzfristige Finanzierungsfazilität" zurückgreifen, nachdem sie ihre Devisenreserven zuvor in angemessenem Umfang eingesetzt haben ${ }^{104}$.

100 Vgl. die Tabellen 1, 3 und 5 sowie Europäische Zentralbank (2001d), S. 192.

101 Europäische Zentralbank (2000c).

102 Vgl. im Folgenden Europäische Gemeinschaft (1997a) und Europäische Gemeinschaft (1998f).

103 Die Interventionspflicht jeder teilnehmenden Pre-In-NZB ist aber nur auf die eigene Währung begrenzt. Es existiert also keine Pflicht auch die Währungen der anderen WKM II-Staaten zu stützen.

104 Dies gilt in bestimmten Umfang auch für die Nutzung der sehr kurzfristigen Finanzierungsfazilität bei intramarginalen Interventionen. In diesem Fall dürfen jedoch die folgenden Höchstgrenzen für die Kreditaufnahme der jeweiligen Pre-In-NZBen nicht überschritten werden: Danmarks Nationalbank (520 Mio. EUR), Schwedische Reichsbank (990 Mio. EUR), Bank of England (3480 Mio. EUR) und bis zum 1.1.2001 Bank von Griechenland (300 Mio. EUR). Vgl. Europäische Gemeinschaft (1998f). Für 
Die abgerufenen Beträge werden mit dem für die Währung des Kreditgebers geltenden repräsentativen inländischen Geldmarktsatz für Dreimonatsgelder verzinst und die Zinszahlungen haben in der Währung des Gläubigerlandes zu erfolgen ${ }^{105}$. Die Beteiligung am WKM II ist freiwillig. So nahmen zu Beginn der EWU auch nur die Zentralbank Griechenlands mit einem Leitkurs von 353,109 GRD pro Euro und einer Schwankungsbreite von \pm 15 Prozent sowie die dänische Nationalbank mit einem Leitkurs von 7,46038 DKK pro Euro und einer Bandbreite von $\pm 2,25$ Prozent am WKM II teil ${ }^{106}$. Auf obligatorische Interventionen konnte bei beiden Währungen bisher verzichtet werden. Im Falle Griechenlands war dies auch deshalb möglich, da die am 17. Januar 2001 erfolgte Anhebung des EUR-GRD-Leitkurses um 3,5 Prozent die Anpassung an den unwiderruflich fixierten Wechselkurs von 340,750 GRD pro Euro erleichtert hat ${ }^{107}$. Dennoch kann nicht ausgeschlossen werden, daß intramarginale Interventionen in geringem Umfang stattgefunden haben. $\mathrm{Ob}$ und gegebenenfalls in welchem Ausmaß die EZB an solchen Transaktionen beteiligt war, läßt sich nicht sagen. Da aber der unwiderruflich fixierte Wechselkurs zwischen dem Euro und der griechischen Drachme bereits weit im Vorfeld des griechischen EWU-Beitritts glaubwürdig den Marktteilnehmern mitgeteilt wurde ${ }^{108}$, sind solche Aktionen, wenn überhaupt vorhanden, eher als gering anzusehen. Nennenswerte Auswirkungen auf die EZB-Gewinnentstehung der Jahre 1999 und 2000 sind nicht zu erkennen.

\section{Die Nettoerträge der EZB aus anderen Tätigkeiten}

Neben den Netto-Einkünften aus der Verwaltung ihrer Eigenmittel und Währungsreserven, sowie aus ihrem Beitrag zur Abwicklung der operativen Geld- und Devisenpolitik des Eurosystems, hat die EZB noch eine Reihe weiterer Aufgaben zu erfüllen, die entsprechende Erträge abwerfen bzw. zu

die Zentralbanken Großbritanniens und Schwedens werden die angegebenen Werte allerdings erst dann relevant, wenn sie dem WKM II beitreten sollten.

Weiterhin sind verschiedene Regelungen zur Kreditprolongation und zur vorzeitigen Tilgung der bilateralen Interventionssalden vorgesehen, die an dieser Stelle jedoch nicht näher untersucht werden sollen. Vgl. dazu Art. 10 - 12 des WKM II-Abkommens in Europäische Gemeinschaft (1998f).

106 Vgl. European Central Bank (1998d).

107 Vgl. European Central Bank (2000a) und Europäische Zentralbank (2001d), S. 84.

108 Der ECOFIN-Rat legte bereits am 19. Juni 2000 den entsprechenden Wechselkurs fest und veröffentlichte ihn am 7. Juli 2000. Vgl. Europäische Gemeinschaft (2000d). Zur Wechselkursentwicklung der griechischen Drachme gegenüber dem Euro in den ersten beiden Jahren der EWU vgl. Europäische Zentralbank (2001a), S. 61*. 
bestimmten Aufwendungen führen. $\mathrm{Zu}$ nennen wären hierbei folgende Tätigkeiten:

1. die Beteiligung der EZB am grenzüberschreitenden Zahlungsverkehr,

2. die Aufsichtsfunktion der EZB,

3. die Erhebung statistischer Daten durch die EZB,

4. die internationale Zusammenarbeit der EZB und

5. sonstige (operative) EZB-Tätigkeiten.

\subsection{Die Beteiligung der EZB am grenzüberschreitenden Zahlungsverkehr}

Nach Artikel 22 ESZB-Satzung können sowohl die EZB als auch die NZBen Einrichtungen zur Verfügung stellen, um effiziente und zuverlässige Verrechnungs- und Zahlungssysteme innerhalb der Gemeinschaft und im Verkehr mit dritten Ländern zu gewährleisten. Eine solche Einrichtung ist das bereits oben erwähnte TARGET-System, welches die nationalen, von den NZBen bereitgestellten Zahlungssysteme (sog. Real-time Gross SettlementSysteme) und das Zahlungssystem der EZB über ein Interlinking-System miteinander verknüpft. Über dieses System wickelt die EZB nicht nur ihre Devisenmarktinterventionen und gegebenenfalls ihre geldpolitischen Operationen $a b$, sondern führt hierüber auch Zahlungen für internationale und europäische Organisationen, Nicht-EU-Zentralbanken und Clearing Institutionen durch $^{109}$. Besonders erwähnenswert erscheint hierbei die Durchführung des Saldenausgleichs für das Euro Clearing System (Euro I) der Clearinggesellschaft des Euro-Bankenverbands (Euro Banking Association, EBA) ${ }^{110}$. Eine Finanzierungsleistung übernimmt die EZB hierbei jedoch nicht. So haben die Mitglieder des EBA bei der EZB einen Liquiditätspool zu unterhalten, der sicherstellt, daß auch bei Forderungsausfall ein fristgerechter Saldenausgleich vorgenommen werden kann. Ende 1999 und 2000 beliefen sich die Sicherungseinlagen auf jeweils 1080 Mio. EUR ${ }^{\prime \prime \prime}$. Dabei kann man wohl davon ausgehen, daß die EZB diese Einlagen in Analogie zur Vergütung der Mindestreserveeinlagen der Kreditinstitute bei den NZBen in Höhe des Satzes für Hauptrefinanzierungsgeschäfte verzinst.

Für die EZB-Ertragslage prinzipiell wichtiger erscheint hingegen die Nettoposition der EZB im TARGET-System. So beschränkt sich die bereits

109 Vgl. European Central Bank (1998b), S. 15 f..

$110 \mathrm{Vgl}$. Europäische Zentralbank (2000h), S. 96.

III Vgl. Europäische Zentralbank (2001d), S. 191 und die Tabelle Al im Anhang. 
angesprochene Verzinsung der TARGET-Salden freilich nicht allein auf TARGET-Positionen, die auf Devisenmarktinterventionen zurückzuführen sind, sondern gelten für alle am Ende des Geschäftstags offenen TARGETForderungen bzw. -Verbindlichkeiten der EZB gegenüber den NZBen des ESZB. Dabei können die Bruttoerträge und -aufwendungen auch ohne Devisenmarktinterventionen durchaus beträchtliche Größenordnungen annehmen. Allerdings hatten im ersten Jahr der EWU, in dem die EZB von Devisenmarktinterventionen vollständig absah, die Nettoerträge aus der Verzinsung der TARGET-Salden keine wesentlichen Auswirkungen auf das EZB-Betriebsergebnis ${ }^{112}$. So läßt sich für 1999 grob ein Nettozinsaufwand von 44 Mio. EUR errechnen, wenn man von den ausgewiesenen „sonstigen“ Nettozinserträgen des Jahres 1999 (135 Mio. EUR) die geschätzten Erträge aus der Veranlagung des EZB-Kapitals (179 Mio. EUR) abzieht ${ }^{113}$.

\subsection{Die Aufsichtsfunktion der EZB}

Während sich die Kompetenzen der EZB im Hinblick auf die Bankenaufsicht gegenwärtig auf die Beratungs-, Konsultations- und Koordinationsaufgaben beschränken ${ }^{114}$, besitzt sie bei der Zahlungsverkehrsüberwachung weitergehende Zuständigkeiten $^{115}$. So bestimmt die EZB bei der Überwachung der Zahlungsverkehrssysteme nicht nur den gemeinsamen aufsichtspolitischen Kurs, indem sie die von den Zahlungssystemen zu erfüllenden Ziele und Standards festlegt, sondern ist auch direkt mit der Beaufsichtigung des bereits oben erwähnten EBA-Clearing Systems „Euro I“ betraut ${ }^{116}$. Ob sie hierbei die entstehenden Aufwendungen - wie dies bei den nationalen Behörden, die für die Bankenaufsicht zuständig sind, oft der Fall ist - von Euro I ersetzt bekommt,

$112 \mathrm{Vgl}$. Europäische Zentralbank (2000c).

113 Vgl. Europäische Zentralbank (2001d), S. 192 sowie die Tabellen 1 und 3. Dafür, daß die EZB im ersten Jahr der EWU einen Nettoaufwand aus der Verzinsung der TARGETSalden erzielt hat, spricht auch die Tatsache, daß die EZB Ende 1999 im TARGETSystem Nettoschuldner in Höhe von 1721 Mio. EUR war. Vgl. Europäische Zentralbank (2001d), S. $191 \mathrm{ff}$. und die Tabelle A1 im Anhang.

114 Vgl. Art. 3.3. und Art. 25.1. ESZB-Satzung. Nach Art. 25.2. ESZB-Satzung kann der Ministerrat der EZB jedoch besondere Aufgaben im Zusammenhang mit der Aufsicht über Kreditinstitute und sonstige Finanzinstitute (mit Ausnahme von Versicherungsunternehmen) übertragen. Zum gegenwärtigen institutionellen Rahmen der Bankenaufsicht im Euro-Währungsgebiet. Vgl. Europäische Zentralbank (2000b), S. 62 ff. und die Ausführungen zu Kapitel V.2.2.2. Abschnitt 5..

$115 \mathrm{Zu}$ den rechtlichen Grundlagen vgl. Art. 105 Abs. 2 EGV und Art. 3 bzw. Art. 22 ESZBSatzung.

116 Vgl. Europäische Zentralbank (2001d), S. 122 und die Ausführungen zu Kapitel V.2.1. Abschnitt 5.. 
soll hier offenbleiben. Ohnehin dürften diese Kosten keine allzu großen Dimensionen annehmen.

Weiterhin erzielt die EZB auch Einkünfte, die sie aus der Überwachung der Einhaltung der geldpolitischen Verpflichtungen der Kreditinstitute erhält. So haben die Kreditinstitute bei Unterschreitung ihres Mindestreservesolls Strafzinsen an die EZB zu zahlen, die bis zu fünf Prozentpunkte über dem Satz für die Spitzenrefinanzierungsfazilität oder bis zum Zweifachen des Spitzenrefinanzierungssatzes (jeweils bezogen auf den Betrag der Mindestreserveunterschreitung) betragen können ${ }^{117}$. Da allerdings in den ersten beiden Jahren der EWU kaum derartige Beanstandungen zu verzeichnen waren, fielen die erhobenen Strafzinsen mit rund 594 Tsd. EUR im Jahr 1999 und mit ca. 1,3 Mio. EUR im Jahr 2000 jeweils gering aus ${ }^{118}$.

\subsection{Die Erhebung statistischer Daten durch die EZB}

Nach Art. 5.1. ESZB-Satzung besitzt die EZB das Recht, die für die Erfüllung ihrer Aufgaben erforderlichen statistischen Daten entweder von den zuständigen nationalen Behörden oder unmittelbar von den Wirtschaftssubjekten einzuholen. Dabei hat sie jedoch soweit wie möglich auf die Unterstützung der NZBen zurückzugreifen (5.2. ESZB-Satzung). So ist es nicht verwunderlich, daß sich die EZB derzeit weitgehend auf die Aggregierung der von den NZBen bereitgestellten nationalen Statistiken beschränkt ${ }^{119}$. Deshalb sind auch die gegenwärtigen Statistikaufwendungen der EZB als eher gering einzuschätzen.

\subsection{Die internationale Zusammenarbeit der EZB}

Neben der gemeinsamen Geldpolitik ist auch die Währungspolitik nach Außen Sache der Gemeinschaft ${ }^{120}$. So befindet der ECOFIN-Rat auf Vorschlag der Kommission und nach Anhörung der EZB über die Vertretung der Gemeinschaft auf internationaler Ebene (Art. 111 Abs. 4 EGV). Legt hierbei der Rat der Wirtschafts- und Finanzminister fest, daß die Gemeinschaft durch das

117 Vgl. Europäische Zentralbank (2000g), S. 60 und Europäische Zentralbank (2000h), S. 160.

$118 \mathrm{Vgl}$. Europäische Zentralbank (2001d), S. 202.

$119 \mathrm{Vgl}$. Europäische Zentralbank (2001d), S. $152 \mathrm{ff.}$.

$120 \mathrm{Vgl}$. im Folgenden Goetze (1999), S. 156 f. und Smits (1999a), S. 563 ff.. Dennoch verbleibt den Mitgliedstaaten das Recht, unbeschadet der Gemeinschaftszuständigkeit und der Gemeinschaftsvereinbarungen das Recht in internationalen Gremien Verhandlungen zu führen und internationale Vereinbarungen zu treffen (Art. $111 \mathrm{Abs} .5 \mathrm{EGV}$ ). Vgl. dazu auch die Ausführungen zu Kapitel V.2.2.1. Abschnitt 1.. 
Eurosystem vertreten werden soll, entscheidet die EZB über die Vertretung des Eurosystems (Art. 6.1. ESZB-Satzung). So kann die EZB die Außenvertretungskompetenz entweder selbst wahrnehmen, indem sie sich z.B. an internationalen Währungseinrichtungen beteiligt ${ }^{121}$ (Art. 6.2. ESZB-Satzung) oder diese auf die NZBen übertragen. Gegenwärtig nimmt die EZB folgende internationale Aufgaben wahr ${ }^{122}$.

Beim Internationalen Währungsfonds (IWF) besitzt die EZB nur einen Beobachterstatus. Dies leuchtet ein, da das IWF-Abkommen auf dem Prinzip der Ländermitgliedschaft beruht. So verfügt die EZB weder über ein Stimmrecht in den Entscheidungsgremien des IWF noch hat sie eine Finanzierungsverpflichtung (Quote) zu übernehmen. Dennoch besitzt sie seit dem 15. November 2000 den Status eines zugelassenen Inhabers von Sonderziehungsrechten (SZR), der es ihr ermöglicht, in freiwilligen Transaktionen mit IWF-Mitgliedstaaten und anderen zugelassenen Inhabern SZR gegen konvertible Währungen (USDollar, Euro, usw.) zu tauschen ${ }^{123}$. Größere Auswirkungen auf die EZBErtragslage sind hierbei nicht zu erwarten.

Dies gilt ebenfalls für die bereits erwähnten Erträge der EZB aus ihrer Beteiligung an der Bank für Internationalen Zahlungsausgleich (BIZ) ${ }^{124}$. So dürften auch in Zukunft die ausgeschütteten BIZ-Dividenden kaum in nennenswerter Höhe anfallen, wenngleich dies nicht unbedingt auch für etwaige Provisionen gelten muß, die die EZB gegebenenfalls für übernommene Kreditrisiken von der BIZ erhält.

Des weiteren nimmt die EZB bei Fragen, die ihren Zuständigkeitsbereich betreffen, an anderen formellen wie informellen internationalen Gremien, wie die G7-, G 10-, G 20-Gruppen, dem Forum für Finanzstabilität (FSF) oder der Organisation für Wirtschaftliche Zusammenarbeit und Entwicklung (OECD), teil $^{125}$. Unter Notenbankgesichtspunkten sind diese Zusammenkünfte jedoch von nicht allzu großer Bedeutung, da hier in aller Regel Beratungs- und Koordinierungsfragen im Vordergrund stehen ${ }^{126}$.

121 Art. 23 ESZB-Satzung schließt die Finanzierungsleistungen zugunsten solcher Einrichtungen mit ein.

122 Vgl. im Folgenden Europäische Zentralbank (2000h), S. 85 ff.

123 Vgl. Europäische Zentralbank (2001d), S. 108 f..

124 Vgl. dazu die Ausführungen zur Investition des EZB-Kapitals und die Tabelle 3.

125 Vgl. im einzelnen Europäische Zentralbank (2000h), S. 96 f..

126 Bisher sind etwaige im Rahmen der G7-Gruppe koordinierte multinationale Kredite an bedürftige Drittstaaten über die NZBen im Auftrag der heimischen Regierung im Wege von IWF- oder BIZ-Krediten finanziert worden. Ob in Zukunft die EZB solche Aufgaben übernimmt, ist eher zweifelhaft. 
Für die EZB-Gewinne eher interessant könnten bilaterale Abkommen der EZB mit Finanzierungscharakter sein. Ein solches Abkommen hat die EZB z.B. mit der norwegischen Zentralbank am 1.1.1999 in Form einer Swapvereinbarung über rund 1,5 Mrd. EUR beschlossen ${ }^{127}$. Ob nun hieraus bedeutende Auswirkungen auf die Ertragslage der EZB erwachsen, ist aber auch hier eher unwahrscheinlich. Dies gilt auch für das bereits erwähnte WKM II-Abkommen der EZB mit den nicht an der EWU teilnehmenden Zentralbanken Dänemarks, Schwedens und Großbritanniens. Als empirisch relevanter hingegen könnten sich Swapabkommen der EZB mit der US-amerikanischen Notenbank erweisen. Eine solche Vereinbarung schloß die EZB im Herbst 2001 mit der US-Fed, die es den Vertragspartnern ermöglichte, gegenseitig Fremdwähungskredite bis zu einem Gegenwert von $50 \mathrm{Mrd}$. US-Dollar aufzunehmen ${ }^{128}$. Allerdings war diese Kreditlinie auf nur 30 Tage begrenzt.

Insgesamt gesehen, erscheint das gegenwärtige Gewinnerzielungspotential der EZB aus der internationalen Vertretung des Eurosystems recht bescheiden.

\subsection{Sonstige Tätigkeiten der EZB}

Die EZB ist noch mit einer Reihe weiterer Aufgaben betraut. Zu nennen wären hierbei ${ }^{129}$ :

- Überwachung der EU-Zentralbanken bezüglich der Einhaltung des Verbots der monetären Finanzierung und des bevorrechtigten Zugangs,

- Verwaltung von Gemeinschaftsdarlehen,

- Externe Kommunikation und Erstellung des Rechenschaftsberichts,

- Beratungs- und Anhörungsrechte der EZB,

- Normative Befugnisse der EZB.

Auf diese Tätigkeiten soll jedoch an dieser Stelle nicht im einzelnen näher eingegangen werden, da sie einerseits unter Ertragsgesichtspunkten unbedeutend sind und andererseits eine konkrete Zuordnung der jeweiligen Verwaltungskosten zu diesen Tätigkeiten ohnehin nicht möglich ist. Vielmehr bietet es sich an, die EZB-Betriebskosten en bloc zu untersuchen.

127 Vgl. Europäische Zentralbank (2000h), S. 97.

$128 \mathrm{Vgl}$. European Central Bank (2001f).

129 Vgl. Europäische Zentralbank (2001d), S. $122 \mathrm{ff.}$. 
Tabelle 6: Personalentwicklung, Personalkosten und Sachaufwendungen der EZB in den Jahren 1998, 1999 und 2000

\begin{tabular}{|c|c|c|c|}
\hline & $\begin{array}{c}1998 \\
(7 \text { Monate) } \\
\end{array}$ & 1999 & 2000 \\
\hline Personal & 534 & 732 & 941 \\
\hline $\begin{array}{l}\text { Personalkosten gesamt } \\
\text { in Mio. EUR } \\
\text { [Pro Kopf in EUR] }\end{array}$ & $\begin{array}{r}29,7 \\
{[55701]}\end{array}$ & $\begin{array}{c}61,0 \\
{[83364]}\end{array}$ & $\begin{array}{c}80,3 \\
{[85309]}\end{array}$ \\
\hline $\begin{array}{l}\text { Gehälter und Zulagen }{ }^{2} \\
\text { [Pro Kopf in EUR] }\end{array}$ & $\begin{array}{c}23,2 \\
{[\mathrm{ca} .43446]}\end{array}$ & $\begin{array}{c}54,1 \\
\text { [ca. 73907] }\end{array}$ & $\begin{array}{c}68,8 \\
\text { [ca. } 73114]\end{array}$ \\
\hline $\begin{array}{l}\text { Sozialabgaben und } \\
\text { sonstige Zahlungen }{ }^{3} \\
\text { [Pro Kopf in EUR] }\end{array}$ & $\begin{array}{c}6,5 \\
\text { [ca. 12172] }\end{array}$ & $\begin{array}{c}6,9 \\
\text { [ca. 9426] }\end{array}$ & $\begin{array}{c}11,5 \\
\text { [ca. 12221] }\end{array}$ \\
\hline Pensionszahlungen & --- & --- & $-\ldots$ \\
\hline $\begin{array}{l}\text { Sachaufwendungen } \\
\text { in Mio. EUR }\end{array}$ & 30,2 & 60,7 & 82,8 \\
\hline $\begin{array}{l}\text { Betriebskosten }{ }^{4} \text { gesamt } \\
\text { in Mio. EUR }\end{array}$ & 60,0 & 121,8 & 163,1 \\
\hline $\begin{array}{l}\text { Gesamte } \\
\text { Nettoeinkünfte in Mio. } \\
\text { EUR }^{5}\end{array}$ & 95,6 & $-115,0$ & 2167,3 \\
\hline $\begin{array}{l}\text { Betriebskosten gesamt } \\
\text { in vH. der Gesamten } \\
\text { Nettoeinkünfte }\end{array}$ & $62,7 \%$ & $-105,8 \%$ & $7,5 \%$ \\
\hline
\end{tabular}

Quelle: Eigene Berechnungen. Die der Übersicht zugrunde liegenden Daten sind entnommen aus Europäische Zentralbank (1999a), S. 134 ff., Europäische Zentralbank (2000h), S. 152 ff. und Europäische Zentralbank (2001d), S. 192 ff. Differenzen in den Summen durch Runden der Zahlen.

\footnotetext{
'Vom 1. Juni 1998 bis 31 . Dezember 1998.

${ }^{2}$ Inkl. Bezüge der Direktoriumsmitglieder. Angaben sind nur auf Mio. EUR gerundet erhăltlich, weshalb auch die Angaben bezliglich der Gehălter/Zulagen pro Kopf keine exakten Werte darstellen können.

3 Angaben sind nur auf Mio. EUR gerundet erhältlich, weshalb auch die Angaben bezuglich der Sozialabgaben/sonstige Zahlungen pro Kopf keine exakten Werte darstellen können.

${ }^{4}$ Betriebskosten als Summe der Personalkosten und Sachaufwendungen der EZB.

${ }^{5} \mathrm{Vgl}$. auch die Tabellen 1 und 10.
} 
Die Betriebskosten der EZB verteilen sich, wie Tabelle 6 zeigt, seit der Gründung der EZB im Jahr 1998 jeweils zu gleichen Teilen auf Personal- und Sachaufwendungen. Die Personalkosten, die ihrerseits überwiegend aus Gehaltszahlungen bestehen, orientieren sich hierbei im wesentlichen am Gehaltsschema der Europäischen Gemeinschaften und haben im Zeitablauf entsprechend des gestiegenen Personalstands zugenommen ${ }^{130}$. So beschäftigte die EZB Ende des Jahres 2000: 941 Mitarbeiter, was fast einer Verdopplung ihrer Beschäftigtenzahl im Vergleich zum 31.12.1998 gleichkommt. Auch die Sachaufwendungen der EZB sind im Beobachtungszeitraum gestiegen. Zwar waren diese im Jahr 1999 noch annähernd proportional zu den Sachaufwendungen des zweiten Halbjahres 1998, doch stiegen diese im Jahr 2000 vor allem aufgrund zunehmender operativer Kosten mit dem EZB-Hauptgebäude (dem Eurotower) und höheren Beraterhonoraren wegen der Euro-2002-Informationskampagne $a^{131}$. Setzt man nun die Betriebskosten der EZB in Relation zu ihren gesamten Nettoeinkünften, zeigt sich, daß die EZB-Erträge nicht immer ausreichend waren, um die laufenden Personalkosten und Sachaufwendungen der EZB zu decken. Vor diesem Hintergrund scheint die bereits erwähnte angestrebte Kapitalerhöhung der EZB verständlich.

\section{Die Nettoerträge der EZB aus realisierten Buchgewinnen, Abschreibungen und Operationen mit Reserven}

Bisher unerwähnt blieben die Erträge und Aufwendungen, die die EZB aus Buchgewinnen, Abschreibungen und sonstigen Bilanztransaktionen, wie der Auflösung von bzw. die Zuführung zu ihren Rückstellungen und Rücklagen, erzielt bzw. zu finanzieren hat. Hierzu sind die einschlägigen GuV-Posten der EZB für die Jahre 1999 und 2000 in der folgenden Tabelle 7 aufgezeigt ${ }^{132}$. Zunächst kann festgestellt werden, daß sowohl die Erträge der EZB aus der erfolgswirksamen Auflösung nicht in Anspruch genommener Rückstellungen auf Sachaufwendungen als auch die vorgenommenen Abschreibungen auf Sachanlagen und immaterielle Vermögenswerte in den ersten beiden Jahren der EWU jeweils keine bedeutenden Größenordnungen erreichten. Dies gilt jedoch nicht für das Nettoergebnis der EZB aus den von ihr abgewickelten Finanzgeschäften, Abschreibungen auf Finanztitel und Risikovorsorgen.

130 Vgl. Europäische Zentralbank (2001d), S. 203. Zum Vergleich der durchschnittlichen Gehaltszahlungen der NZBen vgl. Tabelle 28.

$131 \mathrm{Vgl}$. Europäische Zentralbank (2001d), S. 203.

132 Das zweite Halbjahr von 1998 wird hierbei nicht berücksichtigt, da die EZB wegen der Restrukturierung ihrer Gewinn- und Verlustrechnung keine vergleichbaren Daten zur Verfügung stellt. 
Tabelle 7: Erträge und Aufwendungen der EZB aus realisierten Buchgewinnen, Abschreibungen und sonstigen Bilanztransaktionen in den Jahren 1999 und $2000^{1}$

\begin{tabular}{|c|c|c|}
\hline & 1999 & 2000 \\
\hline $\begin{array}{l}\text { Realisierte Gewinne }(+) \text { bzw. } \\
\text { Verluste }(-) \text { aus Finanzgeschäften }\end{array}$ & $-466,1$ & 3352,8 \\
\hline $\begin{array}{l}\text { Abschreibungen (-) auf } \\
\text { Finanzanlagen und -positionen }\end{array}$ & $-604,9$ & $-1,1$ \\
\hline $\begin{array}{l}\text { Zuführung zu (-) bzw. Auflösung } \\
\text { von (+) Rückstellungen für } \\
\text { Wechselkurs- und Preisrisiken }\end{array}$ & --- & $-2600,0$ \\
\hline $\begin{array}{l}\text { I. Nettoergebnis aus } \\
\text { Finanzgeschäften, } \\
\text { Abschreibungen und } \\
\text { Risikovorsorgen } \\
\end{array}$ & $-1071,0$ & 751,7 \\
\hline II. Sonstige Erträge ${ }^{2}$ & 0,9 & 0,4 \\
\hline $\begin{array}{l}\text { III. Abschreibungen (-) auf } \\
\text { Sachanlagen und immaterielle } \\
\text { Vermögenswerte }\end{array}$ & $-14,1$ & $-10,5$ \\
\hline Gesamte Erträge (I. + II. + III.) & $-1081,0$ & 738,5 \\
\hline $\begin{array}{l}\text { Jahresüberschuß (+) bzw. } \\
\text { Jahresfehlbetrag (-) }\end{array}$ & $-247,3$ & 1990,1 \\
\hline
\end{tabular}

Quelle: Eigene Berechnungen. Die der Übersicht zugrunde liegenden Daten sind entnommen aus Europäische Zentralbank (2000h), S. 152 ff. und Europäische Zentralbank (2001d), S. 192 ff.. Differenzen in den Summen durch Runden der Zahlen.

\footnotetext{
'Angaben in Mio. EUR.

2 Vor allem Erträge aus der erfolgswirksamen Auflösung nicht in Anspruch genommener Rückstellungen für Sachaufwendungen.
} 
So hatte die EZB in 1999 einen diesbezüglichen Nettoaufwand von 1071 Mio. EUR hinzunehmen, während sie in 2000 einen Nettoertrag von 752 Mio. EUR verbuchen konnte. Dabei hängt sowohl der jeweilige Umfang der realisierten Bewertungsgewinne und -verluste als auch die Höhe der erfolgswirksam zu erfassenden, unrealisierten Abschreibungen auf Finanztitel von der in- und ausländischen Zinsentwicklung sowie vom Außenwert des Euro ab. Diese Größen sind jedoch nur bedingt von der EZB beeinflußbar. Um so verständlicher ist es, daß die EZB darauf bedacht ist, rechtzeitig geeignete Rückstellungen für Wechselkurs- und Preisrisiken vorzunehmen (Ende 2000: 2,6 Mrd. EUR) ${ }^{133}$.

Wie wichtig die verschiedenen Finanzoperationen für die Ertragslage der EZB ist, zeigt sich, wenn man die Gesamtsumme der in diesem Abschnitt beschriebenen Nettoerträge dem jeweiligen Jahresüberschuß bzw. Jahresfehlbetrag der EZB gegenüberstellt. So wird sehr deutlich, daß das Nettoergebnis der EZB aus realisierten Bewertungsgewinnen (korrigiert um unrealisierte Bewertungsverluste und Bestandsveränderungen von Rückstellungen) sowohl im Jahr 1999 als auch in 2000 das EZB-Betriebsergebnis entscheidend beeinflußt hat.

\section{Zwischenergebnis}

Die obenstehende Analyse zeigt, daß das gegenwärtige Gewinnerzielungspotential der EZB sehr begrenzt ist. So ist das Nettozinsergebnis der EZB seit Aufnahme ihrer Tätigkeit fast ausschließlich durch die Veranlagung ihres Kapitals und ihrer Währungsreserven bestimmt. Einkünfte aus der operativen Durchführung der Geld- und Devisenmarktpolitik spielen ebenfalls keine bzw. nur eine untergeordnete Rolle, wenngleich die zukünftigen Erträge aus der EuroBanknotenemission dies ändern werden. Die Erträge aus den anderen untersuchten Tätigkeiten der EZB sind in jedem Fall wenig relevant für das EZB-Betriebsergebnis. Dies gilt jedoch nicht für realisierte Bewertungsgewinne und -verluste, sowie für (als realisiert angesehene) unrealisierte Bewertungsverluste auf Finanzanlagen und -positionen. Diese ergebniswirksamen Bewertungsänderungen können, wie im Jahr 1999 auch tatsächlich geschehen, die erwirtschafteten Nettozinserträge sogar überkompensieren. Die Kosten der EZB für Personal und Sachaufwendungen hingegen bewegen sich in einem normalen prognostizierbaren Rahmen.

$133 \mathrm{Vgl}$. Europäische Zentralbank (2001e), S. 2 und Fn. 1 der Tabelle 1. Unrealisierte Bewertungsgewinne werden in der Gewinn- und Verlustrechnung der EZB nicht erfolgswirksam berücksichtigt, sondern direkt in der Bilanz unter dem Ausgleichsposten aus Neubewertung verbucht. Vgl. Europäische Zentralbank (2001d), S. 194. 


\section{IV.2. Die Verwendung des EZB-Gewinns und die Finanzierung des EZB Verlusts}

\section{Die vertraglichen Regelungen}

\subsection{Die Verwendung des EZB-Gewinns}

Die Verwendung des EZB-Gewinns ist in Artikel 33.1. ESZB-Satzung geregelt. So ist zunächst ein vom EZB-Rat zu bestimmender Betrag, der 20 Prozent des Nettogewinns nicht übersteigen darf, dem Allgemeinen Reservefonds bis zu einer Obergrenze von 100 Prozent des EZB-Kapitals zuzuführen ${ }^{134}$. Der verbleibende Nettogewinn wird dann an die Anteilseigner der EZB entsprechend ihren eingezahlten Anteilen ausgeschüttet. Konkret bestimmt sich dabei der individuelle Betrag einer NZB durch den Anteil des von ihr eingezahlten EZBKapitalbetrags an der Gesamtsumme der von den EWU-NZBen eingezahlten Kapitalbeträge. Die Kapitalzahlungen der Pre-In-NZBen bleiben bei dieser Berechnung außen vor, da die nicht an der dritten Stufe der EWU teilnehmenden Zentralbanken auch nicht an den ausgeschütteten EZB-Gewinnen partizipieren (Art. 43.1. ESZB-Satzung). Bleibt noch zu erwähnen, daß der EZB-Gewinn nicht der Besteuerung unterliegt ${ }^{135}$.

\subsection{Die Finanzierung des EZB-Verlusts}

Im Falle eines EZB-Verlusts erfolgt die Finanzierung durch die Zentralbanken des Eurosystems. Die nicht an der dritten Stufe der EWU teilnehmenden NZBen leisten hierbei keinen Beitrag (Art. 43.1. ESZB-Satzung). Im einzelnen ist das Verfahren zur EZB-Verlustfinanzierung wie folgt geregelt.

a) Nach Art. 33.2. ESZB-Satzung kann ein EZB-Verlust zunächst aus dem Allgemeinen Reservefonds der EZB gedeckt werden.

b) Ist die Allgemeine Reserve nicht ausreichend, hat der EZB-Rat nach einem entsprechenden Beschluß die Möglichkeit, die NZBen an der Finanzierung des verbleibenden Fehlbetrags zu beteiligen, indem sie auf ihren Anspruch

134 Die Höchstgrenze entspräche derzeit (ohne die von der EZB gewünschte Kapitalerhöhung) einem Betrag von 4,1 Mrd. EUR. Die gegenwärtige nach den vertraglichen Regelungen maximal mögliche Obergrenze des allgemeinen Reservefonds würde bei Beitritt aller 15 EU-Staaten zur EWU und der Durchführung der angestrebten Kapitalerhöhung $10 \mathrm{Mrd}$. EUR betragen.

135 Vgl. Art. 40 ESZB-Satzung. 
auf den Pool der sogenannten „Monetären Einkünfte“136 des betreffenden Geschäftsjahres verzichten und zwar im Verhältnis und bis in Höhe der rückverteilten Beträge (Art. 32.2. ESZB-Satzung) ${ }^{137}$.

c) Existiert weiterhin ein Fehlbetrag, soll nach einem Beschluß des EZB-Rats bis Ende des Jahres 2001 wie folgt vorgegangen werden ${ }^{138}$ :

i) Zunächst kann die EZB Wertberichtigungen bei einem Teil ihrer Verbindlichkeiten aus der Übertragung von NZB-Währungsreserven vornehmen, wobei sie allerdings an folgende Grenzen gebunden ist:

- Streichungen sind nur bis zur Höhe der unrealisierten Verluste bei den Fremdwährungs- und Goldpositionen zulässig;

- die besagten Verbindlichkeiten gegenüber den NZBen dürfen nur auf maximal 80 Prozent ihres Ursprungswerts vermindert werden.

ii) Mit verbleibenden Verlusten können - im Verhältnis zum Kapitalschlüssel der EZB - direkt die Einkünfte belastet werden, die die EWU-NZBen aus dem nationalen Banknotenumlauf erzielen. Hierbei gilt jedoch die Einschränkung, daß diese direkte Belastung nicht höher sein darf als die Einkünfte einer jeden NZB aus dem nationalen Banknotenumlauf.

Weitere Regelungen, wie verfahren wird, falls nach Anrechnung der Banknoteneinkünfte immer noch ein offener EZB-Fehlbetrag besteht, sind falls sie überhaupt existieren - der Öffentlichkeit nicht zugänglich. Eine Verteilung solcher Finanzierungslasten dürfte jedoch ebenfalls nach Maßgabe der EZB-Kapitalanteile erfolgen.

Dies bedeutet aber auch, daß man sich die verschiedenen Schritte der stufenweisen Beteiligung der NZBen an der EZB-Verlustfinanzierung sparen könnte. Eine Regelung, die die NZB-Finanzierungsleistungen in einfacher Abhängigkeit vom gezahlten EZB-Kapitalanteil beschreiben würde, wäre transparenter und käme inhaltlich dem gegenwärtig gültigen Verfahren gleich.

Der folgende Abschnitt beschäftigt sich nun mit der tatsächlichen Gewinnverwendung bzw. Verlustfinanzierung der EZB in den Jahren 1998 bis 2001.

136 Zur Ermittlung der Monetären Einkünfte vgl. Kapitel V.3.1..

137 Bei einem solchen Beschluß werden nach Art. 10.3. ESZB-Satzung die Stimmen im EZBRat nach Kapitalanteilen gewogen. Die Stimmen des EZB-Direktoriums werden mit null gewogen.

138 Vgl. Europäische Zentralbank (2000c), Europäische Gemeinschaft (2000e), S. 119 ff. und Europäische Zentralbank (2001d), S. 163. 


\section{Die Gewinnverwendung der EZB bzw. Verlustfinanzierung in den Jahren 1998 bis 2001}

Der Bilanzgewinn, den die EZB nach Aufnahme ihrer Tätigkeit am 1. Juni 1998 noch im zweiten Halbjahr 1998 aufgrund der ihr provisorisch übertragenen Aktiva erzielte, betrug 27,5 Mio. EUR ${ }^{139}$.

Dabei stellte sie diese Summe vollständig in ihre Reserven ein. Aus vertragsrechtlichen Gründen erfolgte dieser Vorgang jedoch bilanztechnisch zweigeteilt. So zahlte sie zunächst einen Betrag von 5,5 Mio. EUR in den Allgemeinen Reservefonds ein, was knapp der zulässigen Höchstgrenze entsprach ${ }^{140}$. Den restlichen Nettogewinn in Höhe von 22,0 Mio. EUR übernahm sie als Gewinnvortrag in das nächste Jahr. Dabei kann man wohl davon ausgehen, daß die Entscheidung im EZB-Rat bezüglich des Gewinnvortrags einstimmig ausfiel. Anders ist die Abweichung von der in Art. 33.1. lit. b) ESZB-Satzung vorgesehenen Pflicht zur Ausschüttung der verbleibenden Nettogewinne wohl nur schwer zu erklären ${ }^{141}$.

Im Jahr 1999 hatte die EZB vor allem wegen starker Kursverluste ihrer Wertpapiere einen Jahresfehlbetrag in Höhe von 247,3 Mio. EUR hinzunehmen ${ }^{142}$. Die Finanzierung dieses EZB-Verlusts fand hierbei in drei Schritten statt. So wurden zunächst die vorhandenen EZB-Reserven im Wert von 27,5 Mio. EUR vollständig aufgelöst. Danach erfolgte der Rückgriff auf den Pool der Monetären Einkünfte, dessen 35,2 Mio. EUR ebenfalls in vollem Umfang benötigt wurde. Die verbleibenden 184,6 Mio. EUR wurden dann nach Maßgabe der EZB-Kapitalanteile - durch direkte Belastungen der NZBen finanziert, da der EZB-Rat eine Streichung der EZB-Verbindlichkeiten aus übertragenen NZB-Währungsreserven nicht für erforderlich hielt. Dabei konnten die NZBen ihre direkten Verlustbeiträge jeweils aus ihren „Banknoteneinkünften" begleichen. Die einzelnen Finanzierungsleistungen der NZBen sind in Tabelle 8 aufgelistet.

139 Vgl. im Folgenden Europäische Zentralbank (1999a), S. 134 ff. und Tabelle 8.

140 Nach Artikel 33.1. lit a) ESZB-Satzung darf die Zuführung zum Allgemeinen Reservefonds 20 Prozent des EZB-Nettogewinns nicht übersteigen.

141 So könnte man diese Praxis als eine erfolgte Ausschüttung mit sofortiger Rückübereignung der ausgeschütteten EZB-Gewinne interpretieren.

142 Vgl. im Folgenden Europäische Zentralbank (2000c) und Europäische Zentralbank (2000h), S. 152. 
Tabelle 8: Die Gewinnverwendung und Verlustfinanzierung der Europäischen Zentralbank in den Jahren 1998, 1999 und 2000

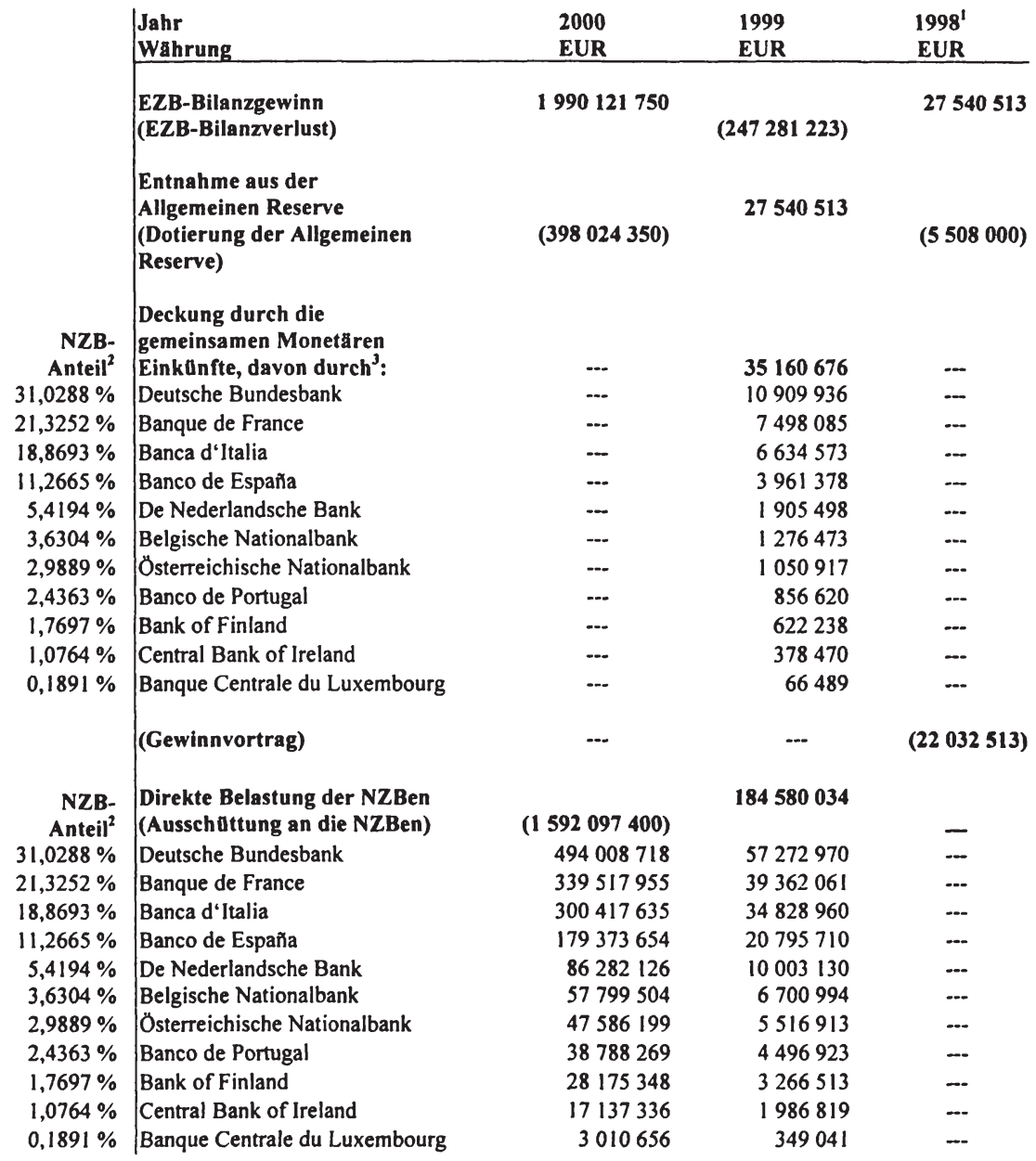

Quelle: Darstellung in Anlehnung an Europarische Zentralbank (2001d), S. 205. Eigene Berechnungen. Differenzen in den Summen durch Runden der Zahlen.

\footnotetext{
'Vom 1.6. bis 31.12.1998.

${ }^{2}$ Anteil des von der jeweiligen EWU-NZB eingezahlten Betrags zur Finanzierung des EZB-Kapitals an der Gesamtsumme der von den EWU-NZBen eingezahlten Kapitalbeträge. Da sich die jeweils auf 4 Nachkommastellen gerundeten Prozentangaben nur auf 99,9998 Prozent summieren, wurden in Analogie zur EZB-Kapitalberechnung die beiden kleinsten Anteile, also die Anteile der BCL und der CBI. um jeweils 0.0001 Prozentpunkte erhöht, bis sich genau 100 Prozent ergibt.

${ }^{3}$ An die EZB abgetretene NZB-Forderungen an den Pool der Monetären Einkunfte. Die errechneten Werte weichen im Falle der $\mathrm{Bdl}$ und $\mathrm{BdE}$ geringfugig von den ausgewiesenen NZB-Betrăgen ab. Vgl. Banca d'Italia (2000a), S. 284 und Banco de España (2000), S. 131. Aus Konsistenzgrunden bleiben diese Abweichungen hier unberucksichtigt.
} 
Nachdem die EZB ihren Bilanzgewinn in 1998 vollständig thesauriert hatte und im Jahre 1999 einen Jahresfehlbetrag erwirtschaftete, hat sie im Jahr 2001 zum ersten Mal eine Gewinnausschüttung vorgenommen ${ }^{143}$. Diese basierte auf dem im Jahre 2000 erzielten Überschuß in Höhe von 1990,1 Mio. EUR und erfolgte nach Abführung der direkten Maximalzuweisung von 20 Prozent zur Allgemeinen Reserve (398,0 Mio. EUR) in einem Volumen von 1592,1 Mio. EUR. Die NZBen partizipierten hierbei, den vertraglichen Regelungen folgend, jeweils in Abhängigkeit ihres gezahlten EZB-Kapitalanteils. Auch hier sind die einzelnen an die NZBen ausgeschütteten Beträge der Tabelle $8 \mathrm{zu}$ entnehmen.

\section{IV.3. Umverteilungseffekte im Zuge der EZB-Gewinnentstehung und -verwendung bzw. EZB-Verlustfinanzierung}

An dieser Stelle soll nun der Frage nachgegangen werden, ob es im Zuge der EZB-Gewinnentstehung und -verwendung bzw. bei der EZB-Verlustfinanzierung zu Umverteilungseffekten zwischen den an der Währungsunion teilnehmenden NZBen kommt.

\section{Umverteilungseffekte im Zuge der Gewinnentstehung und -verwendung der EZB}

Umverteilungswirkungen bei der EZB-Gewinnentstehung und -verwendung sind immer dann zu erwarten, wenn sich die relative Finanzierungsleistung einer EWU-NZB, die sie (un-) mittelbar zur Entstehung des EZB-Gewinns leistet, von ihrem Anteil an der EZB-Gewinnausschüttung bzw. von ihrem Anteil an thesaurierten EZB-Gewinnen unterscheidet. Dabei soll unter dem Begriff der relativen Finanzierungsleistung einer EWU-NZB der Anteil der von ihr finanzierten EZB-Ressourcen an der Gesamtheit aller von den EWU-NZBen finanzierten EZB-Ressourcen verstanden werden. Die von den EWU-NZBen finanzierten EZB-Ressourcen lassen sich wiederum in zwei Kategorien trennen:

- Satzungsgemäße Übertragungen in Form von Kapitalzahlungen und Währungsreserven durch die NZBen,

- NZB-Verbindlichkeiten gegenüber der EZB aus dem TARGET-Zahlungsverkehr.

143 Vgl. im Folgenden Europäische Zentralbank (2001d), S. 192 ff.. 


\subsection{Umverteilungseffekte im Zuge der satzungsgemäßen Übertragungen von Kapital und Währungsreserven durch die NZBen}

Im Hinblick auf die relative Finanzierungsleistung der einzelnen EWU-NZBen bei den satzungsgemäßen Übertragungen von Ressourcen auf die EZB sind keine Umverteilungswirkungen erkennbar. So erfolgen sowohl die von den EWU-NZBen geleisteten Kapitalzahlungen als auch die Übertragung von Währungsreserven auf die EZB in exakt dem gleichen Schlüssel wie die Gewinnausschüttung der EZB ${ }^{144}$. Es erhält also jede einzelne EWU-NZB von der EZB anteilig genau die Erträge, die sie selbst durch Zinsverzicht finanziert hat. Daran ändern auch etwaige Gewinnthesaurierungen durch die EZB nichts. Diese sind als Ressourcenverwendung zu interpretieren und haben keinen Einfluß auf das relative Finanzierungsverhältnis der EWU-NZBen. Dies gilt ebenso für alle anderen Aufwendungen der EZB, die durch Rückgriff auf ihre Kapitalanlage- bzw. Fremdwährungserträge erfolgen.

\subsection{Umverteilungseffekte im Zuge der Finanzierung von Zinsverpflicht- ungen der NZBen aus NZB-TARGET-Verbindlichkeiten gegenüber der EZB}

Neben den satzungsgemäßen Übertragungen von Währungsreserven und Kapitalzahlungen, stellen auch entstehende TARGET-Verbindlichkeiten der NZBen gegenüber der EZB einen Transfer von Ressourcen zur Europäischen Zentralbank dar. Diese Ressourcenübertragungen bemessen sich jedoch nicht nach Maßgabe der eingezahlten EZB-Kapitalanteile, sondern werden durch das Verhalten der EZB und ihren Geschäftspartnern bestimmt. Die NZBen hingegen haben diesbezüglich keinen Einfluß.

Besonders relevant erscheinen hierbei die EZB-Devisenmarktinterventionen in Form von Stützungskäufen zugunsten des Euro. Diese werden - wie oben erläutert - über die Konten der Kreditinstitute bei den (heimischen) NZBen abgewickelt und führen in Abhängigkeit der nationalen Devisennachfrage zu entsprechenden verzinslichen TARGET-Verbindlichkeiten der NZBen gegenüber der EZB. Dies wiederum hat zur Folge, daß die EZB für die BruttoErtragsverluste aus den veräußerten Fremdwährungsbeständen von den NZBen in Form der geleisteten TARGET-Zinszahlungen ertragstechnisch in bestimmtem Umfang kompensiert wird. Dabei könnte sich im Extremfall die „Entschädigungsleistung“ auf nur eine einzige NZB konzentrieren, wenn das

144 Der Finanzierungs- bzw. Verteilungsschlüssel wird bestimmt durch den Anteil einer EWU-NZB am eingezahlten EZB-Kapital, wobei die gezahlten Anteile der Pre-In-NZBen unberücksichtigt bleiben. 
gesamte EZB-Interventionsvolumen wegen einer besonders hohen nationalen Devisennachfrage über nur eine NZB abgewickelt werden sollte. Dies impliziert dann eine entsprechende Brutto-Ressourcenumverteilung von der "Interventions-NZB" auf die anderen EWU-NZBen, die sich entweder in der EZBGewinnausschüttung oder in Ansprüchen der NZBen auf die thesaurierten EZBGewinne widerspiegelt. Eine Umverteilung von Netto-Ressourcen findet hierbei jedoch nicht statt. Dies liegt daran, daß die von der "Interventions-NZB“" an die EZB abzuführenden TARGET-Zinszahlungen von allen EWU-NZBen in Abhängigkeit ihres gezahlten EZB-Kapitalanteils durch Zinsverzicht auf die Brutto-Zinserträge der EZB finanziert wurden.

Folgende Ausführungen sollen diesen Zusammenhang näher erläutern. Zunächst kann festgehalten werden, daß diejenige NZB, über die die EZBDevisenmarktintervention abgewickelt wurde, einen Zinsvorteil aus ihrer gestiegenen Nettoposition gegenüber dem heimischen Finanzsektor erzielt ${ }^{145}$. Finanziert wird dieser Zinsvorteil aber von allen EWU-NZBen, da erst der Rückgriff auf die (von den NZBen finanzierten) EZB-Währungsreserven den Zuwachs der Netto-Forderungen bzw. den Rückgang der Netto-Verbindlichkeiten der „Interventions-NZB“ gegenüber dem Finanzsektor ermöglicht. Dies bedeutet aber wiederum, daß bereits die Abwicklung der EZBDevisenmarktintervention einen Brutto-Ressourcentransfer auf die „Interventions-NZB“" impliziert. Die Verzinsung der TARGET-Verbindlichkeit der betreffenden NZB gegenüber der EZB schleust hingegen den Zinsvorteil zur EZB und damit zu allen EWU-NZBen zurück. Dies trifft zumindest dann zu, wenn die TARGET-Salden marktmäßig verzinst werden, was auch tatsächlich der Fall ist ${ }^{146}$.

Diese Überlegungen gelten analog, wenn die EZB Euro-denominierte Aktiva, die über die Kapitalzahlungen der NZBen finanziert wurden, für ihre geldpolitischen Operationen verwenden sollte. Zu denken wären hierbei z.B. an Feinsteuerungsoperationen in Form von geldpolitisch restriktiv wirkenden Outrightgeschäften, deren Abwicklung ebenfalls über das TARGET-System und die Konten der Kreditinstitute bei den NZBen möglich wäre. Auch hier führt eine Verzinsung der TARGET-Verbindlichkeiten der NZBen gegenüber der EZB in Analogie zu den geschilderten Devisenmarktinterventionen zu keinen Netto-Umverteilungseffekten zwischen den NZBen.

145 Dabei ist es völlig unerheblich, ob ihr dieser Zinsgewinn in Form von ergebniswirksamen Zinseinkünften oder in Form von Zinsersparnissen zufließt.

146 So orientieren sich die Geldmarktssätze (z.B. EONIA) am Satz für Hauptrefinanzierungsgeschäfte des Eurosystems. 
Die obigen Ausführungen lassen sich freilich auch umkehren und somit auf die TARGET-Zinszahlungen abstellen, die die EZB aufgrund von TARGETVerbindlichkeiten gegenüber den NZBen zu finanzieren hat. Auch diese Zinszahlungen stellen nur einen Brutto-Ressourcentransfer von der EZB zu der oder den NZB(en) dar. Eine Netto-Umverteilung von Ressourcen zwischen den NZBen findet hier ebenfalls nicht statt.

\section{Umverteilungseffekte im Zuge der Verlustfinanzierung der EZB}

$\mathrm{Zu}$ Umverteilungseffekten zwischen den NZBen käme es im Zuge der EZBVerlustfinanzierung dann, wenn die relative Finanzierungsleistung einer EWUNZB, die sie zur Deckung des EZB-Verlusts zu erbringen hat, von ihrem EZBKapitalanteil abweichen würde. Nach den gemeinschaftsrechtlichen Regelungen können die NZBen in drei bzw. vier verschiedenen Formen zur Finanzierung des EZB-Verlusts herangezogen werden:

a) Verzicht auf ihren Anteil am Pool der Monetären Einkünfte,

b) Forderungsverzicht gegenüber der EZB aus übertragenen Währungsreserven,

c) direkte Belastung der Einkünfte der NZBen aus ihrem nationalen Banknotenumlauf und

d) andere direkte Transfers der NZBen.

\subsection{Umverteilungseffekte durch Rückgriff auf die Monetären Einkünfte der NZBen}

Die Partizipation der NZBen am Pool der Monetären Einkünfte richtet sich gemäß Art. 32.5. ESZB-Satzung nach den eingezahlten Anteilen der NZBen am Kapital der EZB ${ }^{147}$. Dabei kommt die Abtretung der NZB-Poolansprüche an die EZB inhaltlich einer direkten Belastung der NZBen gleich, die sie auch aufgrund ihrer Eigenschaft als Anteilseigner der EZB zu tragen hätten. Die Verwendung der NZB-Poolansprüche zur Finanzierung des EZB-Verlusts führt folglich zu keinen Umverteilungseffekten zwischen den NZBen.

An dieser Stelle sei jedoch angemerkt, daß das Pooling der Monetären Einkünfte für sich genommen Umverteilungseffekte impliziert ${ }^{148}$. Diese Umverteilung findet aber direkt zwischen den NZBen statt und ist unabhängig davon, ob die Poolansprüche zur Finanzierung des EZB-Verlusts herangezogen werden oder

147 Auch hier bleiben die Kapitalzahlungen der Pre-In-NZBen unberücksichtigt. Vgl. Art. 43.1. und Art. 43.4. ESZB-Satzung.

$148 \mathrm{Vgl}$. hierzu die Ausführungen in Kapitel V.3.1. 
nicht. Aus diesem Grund können diese Umverteilungswirkungen auch nicht kausal der Verwendung des Pools zur EZB-Verlustfinanzierung zugerechnet werden.

\subsection{Umverteilungseffekte durch Wertberichtigungen von NZB- Forderungen}

Auch bei der Deckung des EZB-Verlusts durch Wertberichtigungen eines Teils ihrer Verbindlichkeiten aus übertragenen NZB-Währungsreserven sind keine Umverteilungseffekte erkennbar, da die EZB die vorgesehenen Kürzungen ihrer Verbindlichkeiten gegenüber jeder einzelnen NZB nach einem einheitlichen Prozentsatz durchführt ${ }^{149}$.

\subsection{Umverteilungseffekte durch die direkte Belastung der Einkünfte der NZBen aus ihrem nationalen Banknotenumlauf}

Sieht sich die EZB gezwungen auf die Erträge zurückzugreifen, die die NZBen aus der Bereitstellung des nationalen Banknotenumlaufs erzielen, erfolgen diese Zahlungen ebenfalls in Abhängigkeit vom Kapitalschlüssel der EZB ${ }^{150}$. Auch hier sind folglich keine Umverteilungseffekte zwischen den NZBen zu erkennen.

\subsection{Umverteilungseffekte durch andere direkte Transfers der EWU- NZBen}

Da man davon ausgehen kann, daß auch andere direkte Transfers der NZBen zur Deckung eines verbleibenden Fehlbetrags nach Maßgabe des EZB-Kapitalanteils erfolgen, sind auch hier keine Umverteilungseffekte zu erwarten.

\section{Zwischenergebnis}

Die Analyse der EZB-Gewinnverwendung und der Finanzierung der EZBVerluste zeigt, daß es bei keinem der untersuchten Verfahren zu Umverteilungen zwischen den NZBen kommt.

149 Vgl. Banco de Portugal (2000a), S. 305.

150 Vgl. die Ausführungen zur EZB-Verlustfinanzierung in Kapitel IV.2., Europäische Zentralbank (2000c) und Europäische Zentralbank (2001d), S. 163. 


\section{DIE GEWINNENTSTEHUNG UND -VERWENDUNG DER NATIONALEN ZENTRALBANKEN}

\section{V.1. Die Disaggregation der Eurosystembilanz und die Harmonisierung der Gewinn- und Verlustrechnungen der EWU-Zentralbanken}

Will man die Gewinnentstehung und -verwendung der EWU-NZBen systematisch untersuchen, gelingt dies nur, wenn man auf einen konsistenten Datensatz zurückgreifen kann. So veröffentlicht das Eurosystem zwar einen Konsolidierten Wochenausweis, der jeweils die kumulierten Bilanzwerte der NZBen und der EZB enthält. Dieser gibt jedoch nicht an, wie sich die entsprechenden Posten des Konsolidierten Wochenausweises auf die einzelnen NZBen und die EZB verteilen. Zudem gehen durch die Konsolidierung Informationen bezüglich der bilateralen Forderungen und Verbindlichkeiten der NZBen und der EZB innerhalb des Eurosystems verloren. Eine vergleichende Darstellung, die diese Informationen enthält, ist aber anhand der in den Jahresberichten der EWU-Zentralbanken veröffentlichten Bilanzen zum 1.1.1999 und zum 31.12.1999 möglich. Dies gelingt deshalb, da sich die NZBen - obwohl sie hierzu nicht verpflichtet sind ${ }^{151}$ - bei ihren in Eigenregie erstellten Jahresausweisen im allgemeinen sowohl an die von der EZB empfohlene Bilanzstruktur als auch an die Bilanzierungsgrundsätze halten. Ein Vergleich der aggregierten NZB- und EZB-Bilanzposten mit den jeweiligen Werten des Konsolidierten Wochenausweises zeigt, daß die Disaggregation sowohl für die Eröffnungsbilanz als auch für die Bilanz des Eurosystems zum 31.12.1999 aussagekräftig ist ${ }^{152}$.

Schwieriger hingegen erweist sich die Vergleichbarkeit der zugehörigen Gewinn- und Verlustrechnungen der NZBen ${ }^{153}$. Auch hier sind die NZBen beim Ausweis ihrer in Eigenregie erstellten Gewinn- und Verlustrechnungen nicht an die von der EZB vorgeschlagene GuV-Struktur gebunden ${ }^{154}$. In der Tat weicht ein Teil der NZBen von diesem Aufbau ab. Dennoch soll hier der Versuch

151 Vgl. European Central Bank (1998c), S. 16 und 19.

$152 \mathrm{Vgl}$. Tabellen 9 und 11 sowie die Erläuterungen zur Erstellung dieser Tabellen und deren Abweichungen zum Konsolidierten Wochenausweis im Anhang.

$153 \mathrm{Vgl}$. Tabellen 10 und 12 sowie die Erläuterungen zur Erstellung dieser Tabellen im Anhang. Die GuV der EZB ist aus Gründen der Vollständigkeit in dieser Zusammenstellung enthalten. Hierbei sei erwähnt, daß die EZB im Jahr 2000 ihre GuV teilweise inhaltlich umstrukturiert hat. Vgl. Europäische Zentralbank (2001d), S. 202 ff.. Deshalb weichen die hier ausgewiesenen EZB-GuV-Posten teilweise von der in Tabelle 1 vorgestellten EZB-GuV ab.

154 Vgl. European Central Bank (1998c), S. 19. 
unternommen werden, durch entsprechende Umgruppierungen die GuVen auf eine einheitliche Struktur zu bringen. Dabei orientiert sich diese sehr eng an der entsprechenden EZB-Empfehlung, umfaßt aber zusätzlich eine Reihe weiterer Detailinformationen $^{155}$.

Die folgenden Tabellen 9, 10, 11 und 12 zeigen nun die ermittelte disaggregierte Eurosystembilanz zum 1.1.1999 und zum 31.12.1999 mit den zugehörigen Gewinn- und Verlustrechnungen der NZBen und der EZB ${ }^{156}$.

Hierbei werden die großen Unterschiede zwischen den einzelnen NZBen deutlich. So verfügt Ende 1999 die Deutsche Bundesbank erwartungsgemäß über die mit Abstand höchste Bilanzsumme (242,1 Mrd. EUR), gefolgt von der Banca d'Italia (182,9 Mrd. EUR), der Banque de France (141,0 Mrd. EUR) und der Banco de España (116,9 Mrd. EUR). Danach kommen die „mittelgroßen“ NZBen der Niederlande, Belgiens, Österreichs und Portugals mit einer Aktivasumme zum 31.12.1999 zwischen 42,3 bis 26,4 Mrd. EUR. Die „kleineren“ Währungsbehörden aus Irland, Finnland und Luxemburg besitzen Ende 1999 gerade einmal einen Aktivastock von 14,8, 14,5 bzw. 11,2 Mrd. EUR. Entsprechend groß sind auch die Unterschiede in den Bruttoeinkünften und -aufwendungen der NZBen (nicht nur) im ersten Jahr der EWU.

155 Diese Erweiterungen betreffen in 1999 den separaten Ausweis der Monetären Einkünfte (ohne EZB-Verlustanrechungen) und den detaillierten NZB-Beitrag zur Finanzierung des EZB-Verlusts. Für die GuV des Jahres 1998 und 1999 werden „vorbilanzielle“ Gewinnverwendungen wie Körperschaftssteuern, Interimsdividenden und andere steuerähnliche Zugriffe auf den Brutto-Jahresüberschuß explizit ausgewiesen.

$156 \mathrm{Um}$ eine möglichst große Genauigkeit zu erhalten, wurden die Angaben in den entsprechenden Tabellen auf eine Nachkommastelle genau in Mio. EUR ausgewiesen. Für die Zentralbanken Deutschlands, der Niederlande, Finnlands und teilweise Irlands sind jedoch nur auf Mio. EUR gerundete Angaben erhältlich. 
Tabelle 9: Die Eroffnungsbilanz des Eurosystems unterteilt nach EZB und NZBen zum 1.1.1999 in Mio. Euro

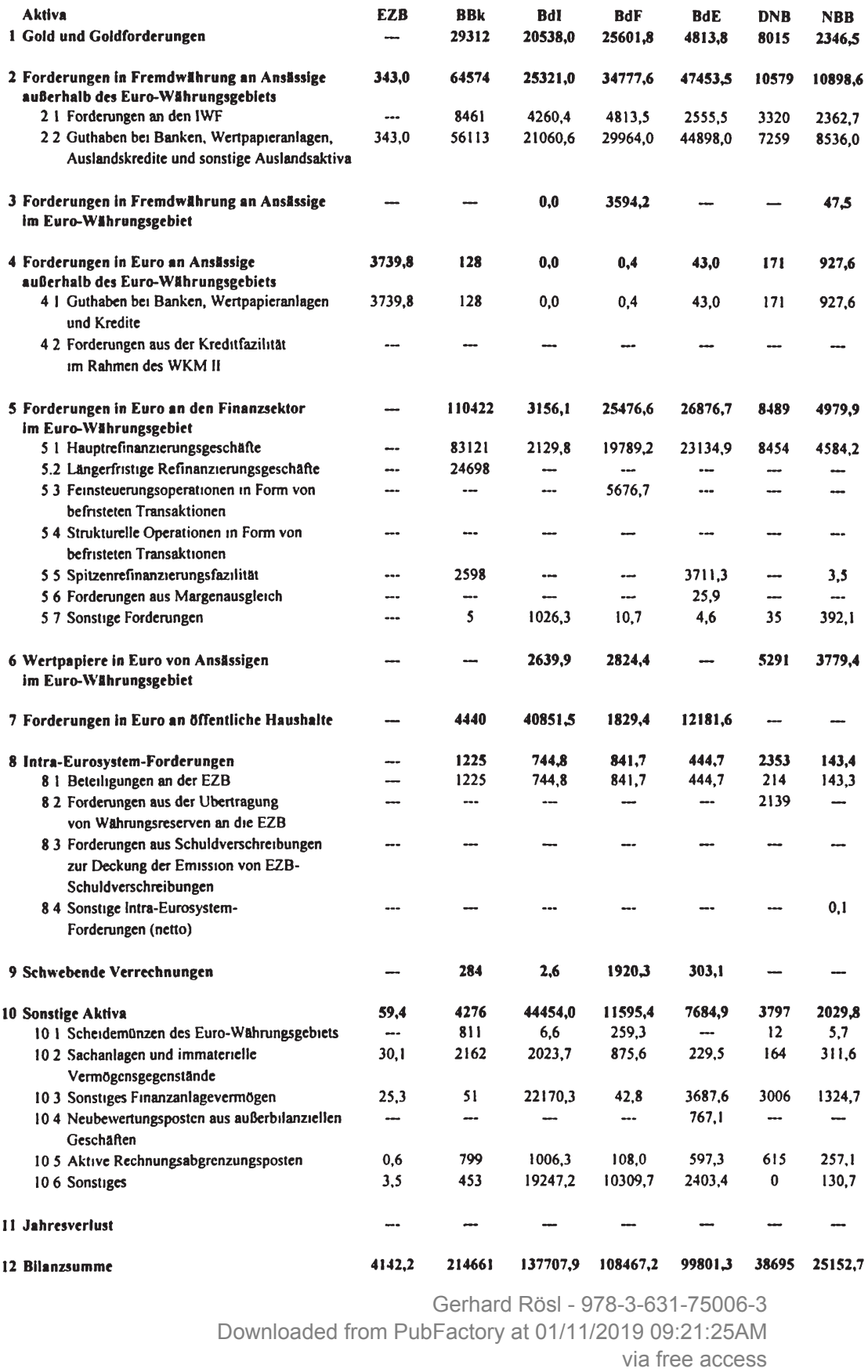


Noch Tabelle 9: Die Erbrfnungsbilanz des Eurosystems unterteilt nach EZB und NZBen zum 1.1.1999 in Mio. Euro

\begin{tabular}{|c|c|c|c|c|c|c|c|}
\hline $\begin{array}{l}\text { Aktiva } \\
\text { I Gold und Goldforderungen }\end{array}$ & $\begin{array}{l}\text { OeNB } \\
3404,7\end{array}$ & $\begin{array}{c}\text { BdP } \\
4949,2\end{array}$ & $\begin{array}{l}\text { CBI } \\
111\end{array}$ & $\begin{array}{l}\text { BoF } \\
493\end{array}$ & $\begin{array}{l}\text { BCL } \\
31,5\end{array}$ & $\begin{array}{c}\text { EURS } \\
99616,4\end{array}$ & $\begin{array}{c}\text { Kons. WA } \\
99598\end{array}$ \\
\hline $\begin{array}{l}2 \text { Forderungen in Fremdwăhrung an Ansăssige } \\
\text { außerhalb des Euro-Wăhrungsgebiets }\end{array}$ & 14790,6 & 6806,6 & 6294 & 7881 & 148,6 & 229867,4 & 230342 \\
\hline 21 Forderungen an den IWF & 1355,1 & 660,5 & 663 & 1003 & 81,9 & 29536,9 & 29500 \\
\hline $\begin{array}{l}22 \text { Guthaben beı Banken, Wertpapieranlagen, } \\
\text { Auslandskredite und sonstıge Auslandsakiıva }\end{array}$ & 13435,5 & 6146,1 & 5631 & 6878 & 66,7 & 200330,5 & 200841 \\
\hline $\begin{array}{l}3 \text { Forderungen in Fremdw } t \text { hhrung an Ansăssige } \\
\text { im Euro-Wuhrungsgebiet }\end{array}$ & 1185,7 & 718,5 & 88 & 648 & 0,0 & 6282,3 & 6704 \\
\hline 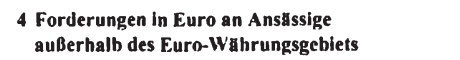 & 1618,2 & 2299,9 & 13 & $\mathbf{0}$ & - & 8940,7 & 8939 \\
\hline $\begin{array}{l}41 \text { Guthaben bei Banken, Wertpapicranlagen } \\
\text { und Kredite }\end{array}$ & 1618.2 & 2299,9 & 13 & 0 & -- & 8940.7 & 8939 \\
\hline $\begin{array}{l}42 \text { Forderungen aus der Kreditfazilitat } \\
\text { Im Rahmen des WKM II }\end{array}$ & -- & $\cdots$ & --. & - & - & & $\ldots$ \\
\hline $\begin{array}{l}5 \text { Forderungen in Euro an den Finanzsektor } \\
\text { im Euro-Wahrungsgebiet }\end{array}$ & 1519,0 & 1231,1 & 2241 & 3 & 233,2 & 184627,8 & 185120 \\
\hline 51 Hauptrefinanzicrungsgeschafte & 702,0 & $\cdots$ & 2169 & - & - & 144084,5 & 144924 \\
\hline 52 Lăngerfistıge Refinanzierungsgeschafie & -.- & -- & - & -- & -- & 24698,0 & 24698 \\
\hline $\begin{array}{l}53 \text { Feınsteucrungsoperationen in Form von } \\
\text { bcfristeten Transaktionen }\end{array}$ & 614,8 & - & - & $\ldots$ & --. & 6291,6 & 6680 \\
\hline $\begin{array}{l}54 \text { Strukturclle Operationen in Form von } \\
\text { befristeten Transaktionen }\end{array}$ & -- & - & - & $\cdots$ & & $\cdots$ & -- \\
\hline 55 Spitzenrefinanzierungsfazilitat & -.. & $\ldots$ & 59 & $\ldots$ & $\ldots$ & 6371,9 & 6372 \\
\hline 56 Forderungen aus Margenausgleich & $\ldots$ & $\cdots$ & -- & $\cdots$ & $\cdots$ & 25,9 & 26 \\
\hline 57 Sonstıge Forderungen & 202,2 & 1231,1 & 13 & 3 & 233,2 & 3156,0 & 2420 \\
\hline $\begin{array}{l}6 \text { Wertpapiere in Euro von Ansässigen } \\
\text { im Euro-Wahrungsgebiet }\end{array}$ & 1767,9 & 3753,2 & 1613 & - & 16,5 & 21685,3 & 21650 \\
\hline 7 Forderungen in Euro an ofrentliche Haushalte & 194,5 & 177,4 & 167 & - & 23,9 & 59865,4 & 60125 \\
\hline $\begin{array}{c}8 \text { Intra-Eurosystem-Forderungen } \\
81 \text { Betelligungen an der E..B }\end{array}$ & $\begin{array}{l}118,0 \\
118,0\end{array}$ & $\begin{array}{l}96,3 \\
96,3\end{array}$ & $\begin{array}{l}42 \\
42\end{array}$ & $\begin{array}{l}70 \\
70\end{array}$ & $\begin{array}{l}7,3 \\
7,3\end{array}$ & $\begin{array}{l}6086,1 \\
3947,0\end{array}$ & - \\
\hline $\begin{array}{l}82 \text { Forderungen aus der Úbertragung } \\
\text { von Wahrungsreserven an die EZB }\end{array}$ & $\ldots$ & $\ldots$ & $\ldots$ & $\ldots$ & $\ldots$ & 2139,0 & $\cdots$ \\
\hline $\begin{array}{l}83 \text { Forderungen aus Schuldverschreibungen } \\
\text { zur Deckung der Emıssion von EZB- } \\
\text { Schuldverschreıbungen }\end{array}$ & & - & $\cdots$ & & -- & $\cdots$ & $\ldots$ \\
\hline $\begin{array}{l}84 \text { Sonstıge Intra-Eurosystem- } \\
\text { Forderungen (netto) }\end{array}$ & - & $\ldots$ & - & $\ldots$ & --. & 0,1 & $\ldots$ \\
\hline 9 Schwebende Verrechnungen & - & 0,0 & 29 & - & 0,0 & 2539,0 & k.A. \\
\hline $\begin{array}{l}10 \text { Sonstige Aktiva } \\
101 \text { Scheidemunzen des Euro-Wahrungsgebiets }\end{array}$ & $\begin{array}{c}3574,3 \\
111,8\end{array}$ & $\begin{array}{c}481,1 \\
20,4\end{array}$ & 127 & $\begin{array}{c}612 \\
21\end{array}$ & 34.6 & $\begin{array}{c}78725.5 \\
1268.7\end{array}$ & $\begin{array}{l}84683 \\
k A\end{array}$ \\
\hline $\begin{array}{l}102 \text { Sachanlagen und immaterielle } \\
\text { Vermogensgegenstande }\end{array}$ & 41,8 & 108,7 & 44 & k. A & 32,4 & $k A$ & $\mathrm{kA}$ \\
\hline 103 Sonstiges Finanzanlagevermogen & 2222,8 & 93,6 & 8 & $>314.6$ & 0,0 & $\mathrm{kA}$ & k A. \\
\hline $\begin{array}{l}104 \text { Neubewertungsposten aus außerbilanziellen } \\
\text { Geschafien }\end{array}$ & $\cdots$ & 0,3 & $\cdots$ & k A & -.. & k A & k A \\
\hline 105 Aktive Rechnungsabgrenzungsposten & 0,5 & 141,1 & 55 & $\mathrm{kA}$ & 1,6 & k A & k A \\
\hline 106 Sonstiges & 1197,4 & 117,0 & 19 & k A & 0,7 & k A & k A \\
\hline 11 .Jahresverlust & - & - & 一 & - & 3,8 & 3,8 & k. A. \\
\hline 12 Bilanzsumme & 28172,9 & 20513,5 & 10725 & 9708 & 499,5 & 698246,2 & 697160 \\
\hline Jown & ded & n Puk & ctory & $\begin{array}{l}\text { Rösl } \\
01 /\end{array}$ & $\begin{array}{l}978- \\
1 / 201\end{array}$ & $\begin{array}{l}631-75 \\
09: 21: \\
\text { free a }\end{array}$ & $\begin{array}{l}06-3 \\
5 \text { AM } \\
\text { cess }\end{array}$ \\
\hline
\end{tabular}


Noch Tabelie 9: Die Eroffnungsbilanz des Eurosystems unterteilt nach EZB und NZBen zum 1.1.1999 in Mlo. Euro

Passiva

I Banknotenumlauf

2 Verbindlichkeiten in Euro gegenaber dem

Finanzsektor im Euro-IVahrungsgebiet

21 Einlagen auf Girokonten

22 Einlagefazilitat

23 Termineinlagen

24 Feınsteuerungsoperatıonen in Form von befristeten Transaktionen

25 Verbindlichkeiten aus Margenausgleıch

3 Verbindlichkeiten aus der Begebung von Sehuldverschreibungen

4 Verbindlichkeiten in Euro gegenuber sonstigen Ansassigen im Euro-Wyhrungsgebiet

41 Einlagen von offentlichen Haushalten

42 Sonstıge Verbindlichkeiten

5 Verbindlichkeiten in Euro gegenuber Ansalssigen auBerhalb des Euro-Whangungebiets

6 Verbindlichkeiten In Fremdwăhrung gegen $₫$ ber Ansussigen im Euro-W Whrungsgeblet

7 Verbindlichkeiten in Fremdwh Ansasssigen außerhalb des Euro-W Whrungsgebiets

7 I Einlagen, Guthaben und sonstige Verbındlichkeıten

72 Verbindlichkeiten aus der Kreditfazilitat im Rahmen des WKM II

8 Ausgleichsposten for vom NVF zugeteilte Sonderziehungsrechte

9 Intra-Eurosystem-Verbindlichkeiten

91 Verbındlichketten gegenuber NZBen aus ubertragenen Wahrungsreserven

92 Verbindlıchkeıten aus Schuldverschreibungen zur Deckung der Emission von EZB-Schuldverschresbungen

93 Sonstıge Intra-EurosystemVerbindlichkeiten (nctto)

10 Schwebende Verrechnungen

11 Sonstige Passiva

II I Neubewertungsposten aus außerbilanziellen Geschaften

II 2 Passive Rechnungsabgrenzungsposten

113 Sonstıges

12 Ruckstellungen

13 Ausgleichsposten aus Neubewertung

\section{Kapital und Rucklagen \\ 14 I Kapital}

142 Rucklagen

15 JahresubersehuB

16 Bilanzsumme

\begin{tabular}{|c|c|c|c|c|c|c|}
\hline $\begin{array}{c}\text { EZB } \\
---\end{array}$ & $\begin{array}{c}\text { BBk } \\
130551\end{array}$ & $\begin{array}{c}\text { BdI } \\
63220,2\end{array}$ & $\begin{array}{c}\text { BdF } \\
42263,6\end{array}$ & $\begin{array}{c}\text { BdE } \\
52731,2\end{array}$ & $\begin{array}{c}\text { DNB } \\
17287\end{array}$ & $\begin{array}{c}\text { NBB } \\
11971\end{array}$ \\
\hline$\cdots$ & 29325 & 6997,8 & 18534,2 & 7410,7 & 7777 & 6916,4 \\
\hline$\cdots$ & 29325 & 6997,8 & 16648,2 & 6431,3 & 7777 & 6910,4 \\
\hline$\cdots$ & - & - & $\cdots$ & 967,5 & - & 6,0 \\
\hline- & - & - & 1886,0 & - & - & - \\
\hline$\cdots$ & $\cdots$ & - & - & $\cdots$ & $\cdots$ & - \\
\hline - & - & - & $\cdots$ & 11,9 & - & - \\
\hline - & - & - & $\cdots$ & $63+5,8$ & - & - \\
\hline - & 856 & 22072,2 & 15817,1 & 13874,8 & 2366 & 168,7 \\
\hline- & 149 & 21797,4 & 13583,3 & 12846,1 & 2295 & 88,7 \\
\hline$\cdots$ & 707 & 274,9 & 2233,8 & 1028,7 & 71 & 80,0 \\
\hline - & 8094 & 35,5 & 898,7 & 49,0 & 618 & 166,8 \\
\hline$\cdots$ & 10 & - & - & 1,2 & 1 & - \\
\hline - & 0 & 10,9 & - & 0,5 & 4 & 108,7 \\
\hline- & 0 & 10,9 & $\cdots$ & 0,5 & 4 & 108,7 \\
\hline- & - & - & $\cdots$ & - & $\cdots$ & $\cdots$ \\
\hline- & 1458 & 846,0 & 1311,3 & 359,9 & 639 & 584,5 \\
\hline- & 5 & 0,6 & - & 0,1 & - & 1.7 \\
\hline$\cdots$ & $\cdots$ & $\cdots$ & - & $\cdots$ & $\cdots$ & - \\
\hline$\cdots$ & $\cdots$ & - & - & - & - & - \\
\hline- & 5 & 0,6 & - & 0,1 & - & 1,7 \\
\hline$\cdots$ & 36 & 12,0 & 2,0 & 509,1 & - & - \\
\hline 83,4 & 156 & 1001,5 & 4744,8 & 3524,5 & 800 & 899,2 \\
\hline 0,7 & 38 & $\cdots$ & - & 0,0 & - & 22,8 \\
\hline 4,2 & 32 & 1,2 & 276,0 & 2408,0 & 800 & 8.7 \\
\hline 78,6 & 86 & 1000,3 & 4468,8 & 1116,4 & - & 867,7 \\
\hline 31,0 & 5441 & 9496,2 & 22120,5 & 3790,1 & - & 676,7 \\
\hline 0,7 & 25322 & 13716,2 & - & 6988,2 & 6279 & 2298,2 \\
\hline 3999,6 & 5112 & 17937,9 & 2258,8 & 4,5 & 2886 & 1324,6 \\
\hline 3999,6 & 2556 & 0,2 & 457,3 & 1,4 & 500 & 9,9 \\
\hline$\cdots$ & 2556 & 17937,7 & 1801,4 & 3,2 & 2386 & 1314,7 \\
\hline 27,5 & 8295 & 2361,0 & 516,3 & 4211,7 & 38 & 36,0 \\
\hline 4142,2 & $21 \$ 661$ & 137707,9 & 108467,2 & 99801,3 & 38695 & 25153 \\
\hline
\end{tabular}


Noch Tabelle 9: Die Erøffnungsbilanz des Eurosystems unterteilt nach EZB und NZBen zum 1.1.1999 in Mio. Euro

\section{Passiva}

1 Banknotenumlauf

2 Verbindlichkeiten in Euro gegenüber dem

Finanzsektor im Euro-Waghrungsgebiet

21 Eınlagen auf Girokonten

22 Einlagefazilıtat

23 Termineınlagen

24 Feinsteuerungsoperationen in Form von befristeten Transaktionen

2.5 Verbindlichkeiten aus Margenausgleıch

3 Verbindlichkeiten aus der Begebung

von Schuldverschreibungen

4 Verbindlichkeiten in Euro gegen uber sonstigen

Ansăssigen im Euro-Whhrungsgebiet

4 I Einlagen von offentlıchen Haushalten

42 Sonstige Verbındlichkeıten

5 Verbindlichkeiten in Euro gegenuber Ansussigen auBcrhalb des Euro-Wÿhrungsgebicts

6 Verbindlichkeiten in Fremdwhhrung gegenuber Ansăssigen im Euro-IVăhrungsgebiet

7 Verbindlichkeiten in Fremdwathrung gegenuber Ans目ssigen außerhalb des Euro-Wăhrungsgebiets

71 Einlagen, Guthaben und sonstige Verbindlichkeiten

72 Verbindlıchkeiten aus der Kreditfazilitat um Rahmen des WKM II

8 Ausgleichsposten fur vom IWF zugeteilte Sonderziehungsrechtc

9 Intra-Eurosystem-Verbindlichkeiten

91 Verbindlichkeiten gegenuber NZBen aus ubertragenen Wahrungsreserven

92 Verbındlıchkeıten aus Schuldverschreıbungen zur Deckung der Limıssion von EZB-Schuldverschresbungen

93 Sonstıge intra-EurosystemVerbındlichkeiten (netto)

10 Schwebende Verrechnungen

11 Sonstige Passiva

111 Neubewertungsposten aus auBerbilanziellen Geschaften

112 Passive Rechnungsabgrenzungsposten

113 Sonstiges

12 Ruckstellungen

13 Ausgleichsposten aus Neubewertung

14 Kapital und Rücklagen

141 Kapital

142 Rucklagen

15 Jahresuberschuß

16 Bilanzsumme

\begin{tabular}{|c|c|c|c|c|c|c|}
\hline $\begin{array}{c}\text { OeNB } \\
12268,9\end{array}$ & $\begin{array}{c}\text { BdP } \\
5081,6\end{array}$ & $\begin{array}{l}\text { CBI } \\
3576\end{array}$ & $\begin{array}{c}\text { BoF } \\
2647\end{array}$ & $\begin{array}{l}\text { BCL } \\
110,8\end{array}$ & $\begin{array}{c}\text { EURS } \\
341708,7\end{array}$ & $\begin{array}{c}\text { Kons. WA } \\
341708\end{array}$ \\
\hline 3974,3 & 1331,2 & 2669 & 2176 & - & 87111,8 & 87308 \\
\hline 3974,3 & 1331,2 & 2669 & 2176 & $\cdots$ & 84240,5 & 84437 \\
\hline$\cdots$ & - & - & $\cdots$ & $\cdots$ & 973,5 & 973 \\
\hline - & $\cdots$ & -- & $\ldots$ & - & 1886,0 & 1886 \\
\hline \multirow[t]{2}{*}{-} & $\cdots$ & - & - & $\cdots$ & $\cdots$ & $\cdots$ \\
\hline & -- & - & - & -- & 11,9 & 12 \\
\hline- & 6657,0 & - & 832 & -- & 13834,8 & 13835 \\
\hline 17,4 & 2322,3 & 2054 & 95 & 162,2 & 59805,7 & 61477 \\
\hline 3,1 & 2319,7 & 2053 & - & 162,2 & 55297,7 & 58612 \\
\hline 14,3 & 2,6 & 1 & 95 & $\cdots$ & 4508,0 & 2865 \\
\hline 13,2 & 4,9 & 145 & 3 & 0,0 & 10028,0 & 9969 \\
\hline 293,0 & 202,6 & - & - & 87,0 & 594,8 & 595 \\
\hline 770.8 & 2207,9 & -- & 210 & - & 3312,9 & 3314 \\
\hline 770,8 & 2207,9 & - & 210 & - & 3312,9 & 3314 \\
\hline$\cdots$ & $\cdots$ & -- & & - & -- & -- \\
\hline 215,7 & 64,2 & 105 & 170 & 20,4 & 5774,0 & 5765 \\
\hline 1,4 & - & 1 & --- & - & 9,7 & - \\
\hline$\cdots$ & -- & $\cdots$ & -- & - & - & -- \\
\hline- & - & -- & --- & $\cdots$ & & $\cdots$ \\
\hline \multirow[t]{2}{*}{1,4} & & 1 & -- & -- & 9,7 & - \\
\hline & - & - & --. & & 559,1 & k.A. \\
\hline 958,9 & 271,7 & 227 & 4 & 1,6 & 12672,4 & 60690 \\
\hline--- & $\cdots$ & - & $\mathrm{kA}$ & $\cdots$ & $\mathrm{kA}$ & k A \\
\hline$\cdots$ & 74,0 & 23 & k A & 1,5 & k A & k A \\
\hline 958,9 & 197,7 & 204 & k A & 0,1 & k A & k A \\
\hline 92,3 & 2220,0 & - & 2147 & 44,5 & 46059,2 & k.A. \\
\hline 3742,8 & & 502 & 453 & 2,1 & 59304,7 & 59931 \\
\hline 5741,4 & 95,8 & 1293 & 969 & 71,0 & 41693,3 & 52567 \\
\hline 12,0 & 1,0 & 0 & 841 & 24,8 & 8403,1 & k.A \\
\hline 5729,4 & 94,8 & 1293 & 129 & 46,2 & 33290,7 & k A \\
\hline 82,8 & 54,1 & 153 & 0 & $\cdots$ & 15774,9 & k.A. \\
\hline 28172,9 & 20513,5 & 10725 & 9708 & 499,5 & 698246,2 & 697160 \\
\hline
\end{tabular}

Quelle Eıgene Berechnungen Zur \%usammenstellung der Daten vgl dic. Erläuterungen zu den Tabellen 9 und II im Anhang 
Tabelle 10: Die Gewinn- und Verlustrechnungen der EZB und der NZBen for das Jahr 1998 in Mio. Euro

1 Zinseinkunfle (brutto)

2 Zinsaufwendungen (brutto)

3 Nettozinsertrag $(1+2)$

4 Realısierte Gewinne (+)/

Verluste $(-)$ aus Finanzoperationen

5 Abschreibungen auf Finanzanlagen

und -positionen

6 Zufohrung ( - ) zu / Auflosung ( + ) von Rackstellungen fur Wahrungs- und Preisrisiken

7 Nettoergebnis aus Finanzoperationen, Abschreibungen und Risiokovorsorgen $(4+5+6)$

8 Ertrage aus Gebahren und Provisionen

9 Aufwendungen aus Gebuhren und Provisionen

10 Nettoergebnis aus Gebahren und Provisionen (8+9)

II Ertrüge aus Beteiligungen

12 Nettoergebnis aus Monetaren Einkunften (vor EZB-Verlustanrechnung)

13 Sonstige Ertrugge

14 Gesamte Nettoerträge $(3+7+10+11+12+13)$

15 Finanzierungsbeitrag EZB-Verlust

16 Personalaufwand

17 Andere administrative Aufwendungen

18 Abschreibungen aur Sachanlagen und immaterielle Vermögensgegenstănde

19 Aufwendungen fur Banknotenproduktion

20 Sonstige Aufwendungen

21 "Vorbilanzielle" Gewinnausschuttungen an den Staat, davon:

21 I Korperschaftssteuer u.a

212 Gewinnantell vor Bılanzgewinn

213 Interimsdividende vor dem 31121998

22 JahresuberschuB / - fehlbetrag

\begin{tabular}{|c|c|c|c|c|c|c|}
\hline EZB & BBk & BdI & BdF & BdE & DNB & NBB \\
\hline 97,9 & 7074 & 4865,6 & 2575,2 & 4471,8 & 1062 & 957,1 \\
\hline$-2,7$ & -298 & $-2787,1$ & $-441,2$ & $.936,8$ & -139 & $-228,9$ \\
\hline 95,2 & 6776 & 2078,4 & 2134,0 & 3535,0 & 923 & 728,2 \\
\hline 22,2 & 927 & 3909,1 & k A & 745,5 & 143 & 526,5 \\
\hline$-22,2$ & -69 & $\cdots$ & $\mathrm{kA}$ & $-13,5$ & -511 & - \\
\hline- & 117 & $-816,0$ & k A & - & - & $-345,8$ \\
\hline$-0,1$ & 975 & 3093,1 & 44,2 & 732,0 & -368 & 180,7 \\
\hline- & 61 & 27,8 & 52,5 & 24,2 & 11 & 3,5 \\
\hline- & -6 & $-0,4$ & $-33,7$ & $-1,6$ & -3 & $-1,0$ \\
\hline- & 55 & 27,4 & 18,8 & 22,6 & 8 & 2,5 \\
\hline- & 10 & 476,9 & 426,2 & 1,5 & 2 & k. A. \\
\hline- & - & - & - & - & - & - \\
\hline 0,5 & 1958 & 768,0 & 375,2 & 2527,1 & 4 & 53,5 \\
\hline 95,6 & 9774 & 6443,9 & 2998,4 & 6818,2 & 569 & 964,9 \\
\hline- & - & - & - & - & - & - \\
\hline$-29,7$ & -868 & $-2156,0$ & $-1281,1$ & $-164,2$ & -82 & $-172,5$ \\
\hline$-30,2$ & -238 & $-294,5$ & $-346,2$ & $-45,7$ & -65 & - \\
\hline$-8,1$ & -214 & -127.1 & $-152,8$ & $-15,5$ & -20 & $-22,9$ \\
\hline- & -127 & - & - & $-44,0$ & -15 & k.A. \\
\hline- & -32 & $-706,4$ & $-120,3$ & $-80,4$ & -53 & $-95,9$ \\
\hline- & - & $-799,0$ & $\mathbf{- 5 8 1 , 7}$ & $-2256,8$ & -296 & $-637,6$ \\
\hline$\cdots$ & - & $-799,0$ & $-581,7$ & $\cdots$ & - & $-299,3$ \\
\hline- & - & $\cdots$ & - & - & 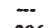 & $-338,3$ \\
\hline$\cdots$ & $\cdots$ & $\cdots$ & - & $-2256,8$ & -296 & - \\
\hline 27,5 & 8295 & 2361,0 & 516,3 & 4211,7 & 38 & 36,0 \\
\hline
\end{tabular}


Noch Tabelle 10: Dic Gewinn- und Verlustrechnungen der EZB und der NZBen fur das Jahr 1998 in Mio. Euro

\begin{tabular}{|c|c|c|c|c|c|c|}
\hline & OeNB & BdP & CBI & BoF & BCL & EURS \\
\hline 1 Zinseinkunfte (brutto) & k A & 703,7 & 414,3 & 459 & 9,5 & k A \\
\hline 2 Zinsaufwendungen (brutto) & k A & $-444,1$ & $-183,6$ & -82 & $-3,5$ & k A \\
\hline 3 Nettozinsertrag $(1+2)$ & 962,3 & 257,6 & 230,7 & 377 & 6,1 & 18103,5 \\
\hline $\begin{array}{l}4 \text { Realısierte Gewinne (+)/ } \\
\text { Verluste }(-) \text { aus Finanzoperationen }\end{array}$ & k A & -54.6 & 26,8 & -222 & 0,1 & k A \\
\hline $\begin{array}{l}5 \text { Abschreibungen auf Finanzanlagen } \\
\text { und -positionen }\end{array}$ & k A & - & -- & - & $-0,2$ & k A \\
\hline $\begin{array}{l}6 \text { Zufuhrung ( (-) zu / Auflosung (+) von Ruck- } \\
\text { stellungen fur Wahrungs- und Preisrisiken }\end{array}$ & $\mathrm{k} A$ & 53,4 & - & ... & - & k A \\
\hline $\begin{array}{l}7 \text { Nettocrgebnis aus Finanzoperationen, } \\
\text { Abschreibungen und Risiokovorsorgen } \\
(4+5+6)\end{array}$ & 392,1 & $-1,2$ & 26,8 & -222 & $-0,1$ & 4852,6 \\
\hline 8 Erträge aus Gebahren und Provisionen & k A & 3,3 & k A & k A & -.. & k A \\
\hline 9 Aufwendungen aus Gebuthren und Provisionen & $k \wedge$ & $-14,1$ & k A & k A & $-0,0$ & k A \\
\hline $\begin{array}{l}10 \text { Nettoergebnis aus Gebahren } \\
\text { und Provisionen }(8+9)\end{array}$ & $-0,0$ & $-10,8$ & 1,1 & k. A. & $-0,0$ & k. A. \\
\hline 11 Ertrüge aus Beteiligungen & 44,8 & 1,5 & 1,3 & k. A. & - & k. A. \\
\hline $\begin{array}{l}12 \text { Nettoergebnis aus Monetăren } \\
\text { Einklunften (vor EZB-Veriustanrechnung) }\end{array}$ & - & - & - & - & - & - \\
\hline 13 Sonstige Ertrllge & 296,2 & 15,2 & 0,3 & 47 & 10,0 & 6055,0 \\
\hline $\begin{array}{l}14 \text { Gesamte Nettoertrăge } \\
(3+7+10+11+12+13)\end{array}$ & 1695,4 & 262,3 & 260,2 & 202 & 16,0 & 30099,9 \\
\hline 15 Finanzierungsbeitrag EZB-Verlust & - & - & - & - & - & - \\
\hline 16 Personalaufwand & $-166,3$ & $-82,4$ & $-22,3$ & -49 & $-8,6$ & $-5082,0$ \\
\hline 17 Andere administrative Aufwendungen & $-58,9$ & $-27,9$ & $-8,1$ & -14 & $-7,5$ & $-1136,0$ \\
\hline $\begin{array}{l}18 \text { Abschreibungen auf Sachanlagen und } \\
\text { immaterielle Vermøgensgegenstånde }\end{array}$ & $-57,6$ & $-13,3$ & $-2,9$ & -18 & $-2,9$ & $-655,0$ \\
\hline 19 Aufwendungen fur Banknotenproduktion & $-10,3$ & $-2,8$ & $-2,2$ & -7 & $-0,9$ & k. A. \\
\hline 20 Sonstige Aufwendungen & $-99,8$ & $-81,7$ & $-31,3$ & -114 & $\mathbf{0 , 0}$ & -1415 \\
\hline $\begin{array}{l}21 \text { "Vorbilanziclle" Gewinnaus- } \\
\text { schuttungen an den Staat, davon: }\end{array}$ & $-1219,6$ & $-0,1$ & $-40,6$ & $\ldots$ & - & $-5831,8$ \\
\hline 21 1 Korperschaftssteuer u a & $-474,1$ & $-0,1$ & $\cdots$ & - & - & $-2154,2$ \\
\hline 212 Gewınnanteil vor Bılanzgewinn & $-745,5$ & $\cdots$ & --. & - & -.- & $-1083,8$ \\
\hline 213 Interımsdividende vor dem 31121998 & $\cdots$ & - & $-40,6$ & $\cdots$ & $\cdots$ & $-2593,7$ \\
\hline Jahresuberschuß / - fehlbetrag & 82,8 & 54,1 & 152,8 & 0 & $-3,8$ & 15771,1 \\
\hline
\end{tabular}

Quelie Eıgene Berechnungen Zur Zusammenstellung der Daten vgl die Erlauterungen zu den Tabellen 10 und 12 im Anhang Daten fur EZB und BCL nur fur 7 Monate 
Tabelle 11: Die Bilanz des Eurosystems unterteilt nach EZB und NZBen zum 31.12.1999 in Mio. Euro

\begin{tabular}{|c|c|c|c|c|c|c|c|}
\hline $\begin{array}{l}\text { Aktiva } \\
1 \text { Gold und Goldforderungen }\end{array}$ & $\begin{array}{c}\text { EZB } \\
6957,0\end{array}$ & $\begin{array}{c}\text { BBk } \\
32287\end{array}$ & $\begin{array}{c}\text { BdI } \\
22822,4\end{array}$ & $\begin{array}{c}\text { BdF } \\
28154,1\end{array}$ & $\begin{array}{c}\text { BdE } \\
4872,6\end{array}$ & $\begin{array}{l}\text { DNB } \\
9140\end{array}$ & $\begin{array}{c}\mathrm{NBB} \\
2402,5\end{array}$ \\
\hline $\begin{array}{l}2 \text { Forderungen in Fremdwhihrung an Ansässige } \\
\text { auBerhalb des Euro-Wyhrungsgebiets }\end{array}$ & 41923,0 & 60754 & 22317,5 & 40025,7 & 32655,8 & 10156 & 10885,1 \\
\hline 21 Forderungen an den JWF & - & 8332 & 4253,0 & 5805,0 & 1933,5 & 3579 & 2807,2 \\
\hline $\begin{array}{l}22 \text { Guthaben bei Banken, Wertpapieranlagen, } \\
\text { Auslandskredite und sonstige Auslandsaktıva }\end{array}$ & 41923,0 & 52422 & 18064,5 & 34220,8 & 30722,3 & 6577 & 8077,9 \\
\hline $\begin{array}{l}3 \text { Forderungen in Fremdwalhrung an Anshlssige } \\
\text { im Euro-WWhrungsgebiet }\end{array}$ & 2595,1 & - & 3603,0 & 3317,8 & 0,0 & 981 & 138,2 \\
\hline $\begin{array}{l}4 \text { Forderungen in Euro an Ansusssige } \\
\text { auBerhalb des Euro-Wharungsgebiets }\end{array}$ & 3002,6 & 9149 & 1214,2 & 494,9 & 4119,0 & 825 & 255,9 \\
\hline $\begin{array}{l}41 \text { Guthaben bei Banken, Wertpapieranlagen } \\
\text { und Kredite }\end{array}$ & 3002,6 & 9149 & 1214,2 & 494,9 & 4119,0 & 825 & 255,9 \\
\hline $\begin{array}{l}42 \text { Forderungen aus der Kreditfazilıtat } \\
\text { Im Rahmen des WKM II }\end{array}$ & - & - & - & - & - & - & - \\
\hline $\begin{array}{l}5 \text { Forderungen in Euro an den Finanzsektor } \\
\text { im Euro-W' }{ }^{\prime} \text { hrungsgeblet }\end{array}$ & - & 90571 & 35852,4 & 44933,5 & 24184,3 & 9443 & 20458.2 \\
\hline S I Hauptrefinanzierungsgeschafte & - & 48396 & 33162,5 & 37589,3 & 20347,7 & 6861 & 5437,0 \\
\hline 52 Langerfristige Refinanzierungsgeschafte & -.. & 32745 & 1892,3 & 6869,4 & 3379,3 & 2581 & 15015,0 \\
\hline $\begin{array}{l}53 \text { Feinsteuerungsoperationen in Form von } \\
\text { befristeten Transaktionen }\end{array}$ & - & - & - & 31,5 & - & - & - \\
\hline $\begin{array}{l}54 \text { Strukturelle Operationen in Form von } \\
\text { befristeten Transaktionen }\end{array}$ & - & - & - & $\ldots$ & - & - & - \\
\hline s s Spitzenrefinanzierungsfazilitat & - & 9417 & 793,9 & 398,8 & 453,0 & 1 & 5,0 \\
\hline S 6 Forderungen aus Margenausglesch & - & - & 3,3 & $\ldots$ & 1,6 & - & $\ldots$ \\
\hline 57 Sonstige Forderungen & - & 13 & 0,4 & 44,5 & 2,8 & - & 1,3 \\
\hline $\begin{array}{l}6 \text { Wertpapiere in Euro von Anslissigen } \\
\text { Im Euro-Whhrungsgebiet }\end{array}$ & 3537,1 & - & 1483.1 & 2364,1 & - & 5452 & 3683,1 \\
\hline 7 Forderungen in Euro an orfentliche Haushalte & - & 4440 & 40851.5 & 1463.5 & 11632.7 & - & - \\
\hline 8 Intra-Eurosystem-Forderungen & - & 39746 & 8192,3 & 9453,7 & 32821,8 & 2353 & 1576,2 \\
\hline 81 Beteiligungen an der EZB & $\ldots$ & $\$ 225$ & 744,8 & 847,1 & 444,7 & 214 & 143,3 \\
\hline $\begin{array}{l}82 \text { Forderungen aus der Ubertragung } \\
\text { von Wahrungsreserven an die EZB }\end{array}$ & -- & 12247 & 7447.5 & 8611,6 & 4446,8 & 2139 & 1432,9 \\
\hline $\begin{array}{l}83 \text { Forderungen aus Schuldverschreibungen } \\
\text { zur Deckung der Emission von EZB. } \\
\text { Schuldverschreibungen }\end{array}$ & - & - & - & $\cdots$ & $\ldots$ & $\cdots$ & $\cdots$ \\
\hline $\begin{array}{l}84 \text { Sonstige Intra-Eurosystem- } \\
\text { Forderungen (netto) }\end{array}$ & & 26274 & - & & 27930.4 & - & - \\
\hline 9 Schwebende Verrechnungen & - & 17 & 0.7 & 1944,8 & 4,8 & - & - \\
\hline Sonstige Aktiva & 1468,2 & 5166 & 46515,5 & 8810,1 & 6563,9 & 3948 & 2159,4 \\
\hline 101 Scheidemunzen des Euro-Wahrungsgebiets & - & 823 & 3,8 & 259,3 & - & 3 & 10,0 \\
\hline $\begin{array}{l}102 \text { Sachanlagen und immaterielle } \\
\text { Vermogensgegenstande }\end{array}$ & 42,6 & 2179 & 2008,1 & 878,8 & 223,5 & 160 & 320,2 \\
\hline 103 Sonstiges Finanzanlagevermogen & 641,8 & 51 & 25282,8 & 54,7 & 3534,8 & 3336 & 1325,7 \\
\hline $\begin{array}{l}104 \text { Neubeivertungsposten aus auBerbilanziellen } \\
\text { Geschaflen }\end{array}$ & $\ldots$ & - & - & $\cdots$ & - & - & - \\
\hline 10S Aktive Rechnungsabgrenzungsposten & 777,0 & 1361 & 1018,8 & 35,3 & 739,0 & 399 & 308,9 \\
\hline 106 Sonstiges & 6,8 & 752 & 18202,0 & 7582,1 & 2066,6 & 50 & 194,6 \\
\hline I Jahresverlust & 247,3 & - & - & - & - & - & - \\
\hline 2 Bilanzst & 59730,3 & 242130 & 182852,5 & 140962,1 & 116855,0 & 42298 & 41558,5 \\
\hline
\end{tabular}




\begin{tabular}{|c|c|c|c|c|c|c|c|}
\hline $\begin{array}{l}\text { Aktiva } \\
1 \text { Gold und Goldforderungen }\end{array}$ & $\begin{array}{l}\text { OeNB } \\
3793,0\end{array}$ & $\begin{array}{c}\text { BdP } \\
5647,1\end{array}$ & $\begin{array}{c}\text { CBI } \\
55\end{array}$ & $\begin{array}{l}\text { BoF } \\
457\end{array}$ & $\begin{array}{l}\mathrm{BCl} \\
22,1\end{array}$ & $\begin{array}{c}\text { EURS } \\
116609,8\end{array}$ & $\begin{array}{c}\text { Kons. WA } \\
116483\end{array}$ \\
\hline $\begin{array}{l}2 \text { Forderungen in Fremdwahrung an Ansüssige } \\
\text { auBerhalb des Euro-Wăhrungsgebiets }\end{array}$ & 14970,5 & 8202,4 & 5321 & 8071 & $\mathbf{7 7 , 0}$ & 255359,1 & 254880 \\
\hline 21 Forderungen an den IWF & 1269,4 & 437,0 & 453 & 930 & 76,7 & 29876,0 & 29842 \\
\hline $\begin{array}{l}22 \text { Guthaben bei Banken, Wertpapieranlagen, } \\
\text { Auslandskredite und sonstige Auslandsaktiva }\end{array}$ & 13701,1 & 7765,4 & 4868 & 7141 & 0,3 & 225483,1 & 225038 \\
\hline $\begin{array}{l}3 \text { Forderungen in Fremdwăhrung an Ansăssige } \\
\text { im Euro-Wăhrungsgebiet }\end{array}$ & 2120,9 & 865,5 & 94 & 672 & - & 14387,2 & 14383 \\
\hline $\begin{array}{l}4 \text { Forderungen in Euro an Ansüssige } \\
\text { auBerhalb des Euro-Wahrungsgebiets }\end{array}$ & 3351,5 & 2767,6 & 23 & 2389 & 720,6 & 28312,7 & 4822 \\
\hline $\begin{array}{l}\text { 4.1 Guthaben bei Banken, Wertpapieranlagen } \\
\text { und Kredite }\end{array}$ & 3351,5 & 2767,6 & 23 & 2389 & 720,6 & 28312,7 & 4822 \\
\hline $\begin{array}{l}\text { 4.2 Forderungen aus der Kreditfazilitat } \\
\text { Im Rahmen des WKM II }\end{array}$ & - & - & & ... & $\cdots$ & $\cdots$ & - \\
\hline $\begin{array}{l}5 \text { Forderungen in Euro an den Finanzsektor } \\
\text { im Euro-Wahrungsgebiet }\end{array}$ & 6465,1 & 2389,3 & 5062 & 1516 & 9000,3 & 249875,3 & 250079 \\
\hline 5.1 Hauptrefinanzierungsgeschafte & 2764,7 & 421,3 & 883 & 1283 & 4841,0 & 161986,7 & 161988 \\
\hline 52 Langerfristige Refinanzierungsgeschafte & 2707.5 & 1966,3 & 4179 & 230 & 3431,9 & 74996,7 & 74996 \\
\hline $\begin{array}{l}53 \text { Feinsteuenungsoperationen in Form von } \\
\text { befristeten Transaktionen }\end{array}$ & $\cdots$ & $\cdots$ & -.- & - & $\cdots$ & 31,5 & - \\
\hline $\begin{array}{l}54 \text { Strukturelle Operationen in Form von } \\
\text { befristeten Transaktionen }\end{array}$ & -- & - & $\ldots$ & - & - & $\ldots$ & $\ldots$ \\
\hline 55 Spitzenrefinanzıerungsfazilitat & - & -- & -.. & ... & 727,3 & 11796,0 & 11429 \\
\hline 56 Forderungen aus Margenausgleich & -.. & -.. & $\ldots$ & - & - & 4,8 & 404 \\
\hline 57 Sonstige Forderungen & 992,8 & 1,8 & 0 & 2 & $\ldots$ & 1058.6 & 1262 \\
\hline $\begin{array}{l}6 \text { Wertpapiere in Euro von Ansăssigen } \\
\text { Im Euro-Wăhrungsgebiet }\end{array}$ & 1744,1 & 3153,7 & 1941 & - & 199,4 & 23557,6 & 23521 \\
\hline 7 Forderungen in Euro an 8 ffentliche Haushalte & 221,4 & 144,1 & 167 & - & - & 58920,4 & 59180 \\
\hline 8 Intra-Eurosystem-Forderungen & 1297,7 & 2543,8 & 1396 & 768 & 82,1 & 100230,8 & - \\
\hline 81 Betelligungen an der FZB & 118,0 & 96,2 & 42 & 70 & 7,5 & 3952,9 & - \\
\hline $\begin{array}{l}82 \text { Forderungen aus der Ubertragung } \\
\text { von Wahrungsreserven an die EZB }\end{array}$ & 1179,7 & 961,6 & 425 & 699 & 74,6 & 39664,4 & $\ldots$ \\
\hline $\begin{array}{l}83 \text { Forderungen aus Schuldverschreibungen } \\
\text { zur Deckung der Emıssion von EZB- } \\
\text { Schuldverschreıbungen }\end{array}$ & -- & $\cdots$ & & - & $\ldots$ & - & -- \\
\hline $\begin{array}{l}84 \text { Sonstige Intra-Eurosystem- } \\
\text { Forderungen (netto) }\end{array}$ & - & 1486,0 & 929 & - & $\ldots$ & 56619,5 & $\ldots$ \\
\hline 9 Schwebende Verrechnungen & - & 0,0 & 345 & - & 0,0 & 2312,4 & k.A. \\
\hline Sonstige Aktiva & 3881,9 & 664,2 & 377 & 638 & 1109,5 & 81301,2 & 79844 \\
\hline 101 Scheidemunzen des Euro-Wahrungsgebiets & 98,3 & 20,3 &.- & 13 & ... & 1230,8 & k. A \\
\hline $\begin{array}{l}102 \text { Sachanlagen und immaterielle } \\
\text { Vermogensgegenstandc }\end{array}$ & 54,7 & 103.9 & 56 & k A & 40,7 & $\mathrm{KA}$ & $\mathrm{kA}$. \\
\hline 103 Sonstiges Finanzanlagevermogen & 2387,4 & 93,9 & 192 & $>320,5$ & 527,8 & $k A$ & k A. \\
\hline $\begin{array}{l}104 \text { Neubewertungsposten aus auBerbilanziellen } \\
\text { Geschaften }\end{array}$ & 0,4 & 111,8 & - & k A & - & k A & k A \\
\hline 10.5 Aktıve Rechnungsabgrenzungsposten & 305,9 & 195,7 & 86 & k A & 33,4 & k A & k A \\
\hline 106 Sonstıges & 1035,2 & 138,6 & 42 & $k$ A. & 507,7 & $\mathrm{k} \wedge$ & k. A \\
\hline Jahresverlust & - & - & $\cdots$ & - & - & 247,3 & k. A. \\
\hline 2 & 37846,0 & 26377,7 & 14782 & 14511 & 11211,0 & 931114,0 & 803192 \\
\hline
\end{tabular}


Noch Tabelle 11: Die Blianz des Eurosystems unterteilt nach EZB und NZBen zum 31.12.1999 in Mio. Euro

\begin{tabular}{|c|c|c|c|c|c|c|c|}
\hline $\begin{array}{l}\text { Passiva } \\
1 \text { Banknotenumlauf }\end{array}$ & EZB & $\begin{array}{c}\text { BBk } \\
140150\end{array}$ & $\underset{70614,0}{B d l}$ & $\begin{array}{c}\text { BdF } \\
\mathbf{4 6 2 6 1 , 4}\end{array}$ & $\begin{array}{c}\text { BdE } \\
\mathbf{5 8 9 1 1 , 2}\end{array}$ & $\begin{array}{l}\text { DNB } \\
17715\end{array}$ & $\begin{array}{c}\text { NBB } \\
12947,3\end{array}$ \\
\hline $\begin{array}{l}2 \text { Verbindlichkeiten in Euro gegenaber dem } \\
\text { Finanzsektor im Euro-Wuhrungsgebiet }\end{array}$ & $\cdots$ & 41896 & 9225,0 & 24268,8 & 12490,9 & 7481 & 3509,2 \\
\hline 21 Einlagen auf Girokonten & - & 39774 & 9100,8 & 24191,5 & 12462,0 & 7295 & 3458,8 \\
\hline 22 Einlagefazilitat & - & 2122 & 124,2 & 68,5 & 28,0 & 186 & 50,3 \\
\hline 23 Termineinlagen & $\cdots$ & - & - & - & - & - & - \\
\hline $\begin{array}{l}24 \text { Feinsteuerungsoperationen in Form } \\
\text { von befristeten Transaktionen }\end{array}$ & - & - & - & - & - & 一 & - \\
\hline 25 Verbindlichkeiten aus Margenausgleich & - & - & 一 & 8,8 & 0,9 & - & - \\
\hline $\begin{array}{l}3 \text { Verbindlichkeiten aus der Begebung } \\
\text { von Sehuldverschreibungen }\end{array}$ & - & - & - & - & 3301,8 & - & - \\
\hline $\begin{array}{l}4 \text { Verbindlichkeiten In Euro gegenđber sonstigen } \\
\text { Ansllssigen im Euro-Wahrungsgebiet }\end{array}$ & 1080,0 & 527 & 29465,5 & 3802,9 & 22082,7 & 59 & 95,9 \\
\hline 4 I Einlagen von offentlichen Haushalten & -- & 79 & 29078,4 & 1057.4 & 20947,7 & 9 & 64,3 \\
\hline 4.2 Sonstige Verbındlichkeiten & 1080,0 & 448 & 387,1 & 2745,5 & 1135,0 & 50 & 31,6 \\
\hline $\begin{array}{l}5 \text { Verbindlichkeiten in Euro gegen 0ber Anslissigen } \\
\text { auBerhalb des Euro-Wahrungsgebiets }\end{array}$ & 301,7 & 6167 & 5359,9 & 7112,2 & 451,1 & 424 & 6737,4 \\
\hline $\begin{array}{l}6 \text { Verbindlichkeiten in Fremdwalhrung gegenaber } \\
\text { Ansilssigen im Euro-W Whrungsgebiet }\end{array}$ & - & 17 & 38,9 & - & 2,7 & 1 & - \\
\hline $\begin{array}{l}7 \text { Verbindlichkeiten in Fremdwahrung gegenuber } \\
\text { Ansissigen auBerhalb des Euro-Wahrungsgebiets }\end{array}$ & 4709,0 & 2 & 926,4 & 495,2 & 548,4 & 116 & 569,9 \\
\hline $\begin{array}{l}71 \text { Einlagen, Guthaben und sonstige } \\
\text { Verbindlichkeiten }\end{array}$ & 4709,0 & 2 & 926,4 & 495,2 & 548,4 & 116 & 569,9 \\
\hline $\begin{array}{l}72 \text { Verbindlichkeiten aus der Kredit- } \\
\text { fazlitat im Rahmen des WKM II }\end{array}$ & - & - & - & - & - & - & $\cdots$ \\
\hline $\begin{array}{l}8 \text { Ausgleichsposten for vom IVF zugeteilte } \\
\text { Sonderziehungsrechte }\end{array}$ & $\cdots$ & 1653 & 958,8 & 1483,3 & 407,9 & 724 & 662,3 \\
\hline 9 Intra-Eurosystem-Verbindlichkelten & 41189.9 & $\cdots$ & 11293,4 & 18744,8 & - & 3389 & 10122,8 \\
\hline $\begin{array}{l}91 \text { Verbindlichkeiten gegenaber NZBen } \\
\text { aus abertragenen Wahrungsreserven }\end{array}$ & 39469,0 & - & - & -- & - & - & - \\
\hline $\begin{array}{l}92 \text { Verbindlichkeiten aus Schuldverschreibungen } \\
\text { zur Deckung der Emission von EZB- } \\
\text { Schuldverschreibungen }\end{array}$ & - & - & - & - & - & - & - \\
\hline $\begin{array}{l}93 \text { Sonstige Intra-Eurosystem- } \\
\text { Verbindlichkeiten (netto) }\end{array}$ & 1720.9 & - & 11293,4 & 18744,8 & $\cdots$ & 3389 & 10122,8 \\
\hline 10 Sehwebende Verrechnungen & $\cdots$ & 14 & 23,5 & 2,6 & 260,8 & - & - \\
\hline 11 Sonstige Passiva & 1540,3 & 100 & 2172,1 & 4270,8 & 2797,0 & 122 & 1046,9 \\
\hline $\begin{array}{l}\text { 11.1 Neubewertungsposten aus } \\
\text { auBerbilanzieilen Geschaften }\end{array}$ & - & - & - & - & 1,2 & - & 10,0 \\
\hline II 2 Passive Rechnungsabgrenzungsposten & 1237,7 & 42 & 15,7 & 335,0 & 2031,1 & 79 & 8,5 \\
\hline 113 Sonstiges & 302,6 & 58 & 2156,4 & 3935,8 & 764,6 & 43 & 1028,4 \\
\hline 12 Ruckstellungen & 21,9 & 7636 & 8734,3 & 21935,8 & 3796,8 & - & 798,1 \\
\hline 13 Ausgleichsposten aus Neubewertung & 6860,5 & 34953 & 24091,9 & 9714,0 & 9641,4 & 8633 & 3674,2 \\
\hline 14 Kapital und Rocklagen & 4027,1 & 5112 & 19413,8 & 2721,8 & 4,5 & 2886 & 1337,7 \\
\hline 14 I Kapital & 3999,6 & 2556 & 0,2 & 457,3 & 1,4 & 500 & 9,9 \\
\hline 142 Racklagen & 27,5 & 2556 & 19413,7 & 2264,4 & 3,2 & 2386 & 1327,8 \\
\hline 15 Jahresdberschub & $\cdots$ & 3903 & 535,0 & 153,5 & 2158,0 & 748 & 56,9 \\
\hline Inzsut & 59730,3 & 242130 & 182852,5 & 140967,1 & 116855,0 & 42298 & 41558,6 \\
\hline
\end{tabular}


Noch Tabelle 11: Die Bilanz des Eurosystems unterteilt nach EZB und NZBen zum 31.12.1999 in Mio. Euro

\begin{tabular}{|c|c|c|c|c|c|c|c|}
\hline $\begin{array}{l}\text { Passiva } \\
1 \text { Banknotenumlauf }\end{array}$ & $\begin{array}{c}\text { OeNB } \\
13328,1\end{array}$ & $\begin{array}{l}\text { BdP } \\
6932,7\end{array}$ & $\begin{array}{l}\text { CBI } \\
4524\end{array}$ & $\begin{array}{c}\text { BoF } \\
3008\end{array}$ & $\begin{array}{l}\mathbf{B C L} \\
585,3\end{array}$ & $\begin{array}{c}\text { EURS } \\
374976,9\end{array}$ & $\begin{array}{c}\text { Kons WA } \\
374953\end{array}$ \\
\hline $\begin{array}{l}2 \text { Verbindlichkeiten in Euro gegenuber dem } \\
\text { Finanzsektor im Euro-Wuhrungsgebiet }\end{array}$ & 3250,5 & 4009,1 & 2074 & 4884 & 4182,7 & 117271,6 & 117121 \\
\hline 21 Eınlagen auf Girokonten & 3235,2 & 3985,1 & 2074 & 4884 & 4182,7 & 114643,4 & 114493 \\
\hline 22 Eınlagefazılităt & 15,3 & 24,0 & - & 0 & - & 2618,4 & 2618 \\
\hline 23 Termineınlagen & $-\ldots$ & -- & - & - & $\ldots$ & $\ldots$ & -_ \\
\hline $\begin{array}{l}24 \text { Feinsteuerungsoperationen in Form } \\
\text { von befristeten Transaktionen }\end{array}$ & $\cdots$ & $\cdots$ & - & - & - & $\overline{-}$ & $\cdots$ \\
\hline 25 Verbındlıchkeiten aus Margenausgleıch & - & - & - & - & - & 9,8 & 10 \\
\hline $\begin{array}{l}3 \text { Verbindlichkeiten aus der Begebung } \\
\text { von Schuldverschreibungen }\end{array}$ & - & 4573,7 & - & - & - & 7875,5 & 7876 \\
\hline $\begin{array}{l}4 \text { Verbindlichkeiten in Euro gegenuber sonstigen } \\
\text { Anslassigen im Euro-Wahrungsgebiet }\end{array}$ & 19,1 & 2237,8 & 3558 & 1 & 503,4 & 63432,4 & 60614 \\
\hline 41 Einlagen von offentlichen Haushalten & 8,0 & 2235,7 & 2541 & - & 485,3 & 56505,4 & 56494 \\
\hline 4.2 Sonstige Verbındlichkeiten & 11,1 & 2,1 & 1018 & 1 & 18,0 & 6927,1 & 4120 \\
\hline $\begin{array}{l}5 \text { Verbindlichkeiten in Euro gegenuber Anslssigen } \\
\text { auDerhalb des Euro-Wuhrungsgcbicts }\end{array}$ & 237,3 & 825,7 & 1319 & 195 & 2161,6 & 31292,4 & 7834 \\
\hline $\begin{array}{l}6 \text { Verbindlichkciten in Fremdwăhrung gegenuber } \\
\text { Ansăssigen im Euro-WWăhungsgebiet }\end{array}$ & 375,2 & 491,7 & - & - & -- & 926,4 & 926 \\
\hline $\begin{array}{l}7 \text { Verbindlichkeiten in Fremdwăhrung gegenuber } \\
\text { Ansüssigen außerhalb des Euro-Wahrungsgebiets }\end{array}$ & 1339,7 & 2894,5 & 64 & 239 & - & 11904 & 11901 \\
\hline $\begin{array}{l}71 \text { Einlagen, Guthaben und sonstige } \\
\text { Verbindlichkeiten }\end{array}$ & 1339,7 & 2894,5 & 64 & 239 & - & 11904 & 11901 \\
\hline $\begin{array}{l}72 \text { Verbindlichkeiten aus der Kredit- } \\
\text { fazilıtat im Rahmen des WKM II }\end{array}$ & $\cdots$ & - & - & $\cdots$ & - & - & - \\
\hline $\begin{array}{l}8 \text { Ausgleichsposten fur vom IVF zugeteilte } \\
\text { Sonderziehungsrechte }\end{array}$ & 244,4 & 72,8 & 119 & 195 & 23,1 & 6543,7 & 6531 \\
\hline 9 Intra-Eurosystem-Verbindlichkeiten & 6724,1 & - & - & 1267 & 3451,3 & 96182,2 & - \\
\hline $\begin{array}{l}91 \text { Verbindlichkeıten gegenuber NZBen } \\
\text { aus ubertragenen Wahrungsreserven }\end{array}$ & -- & - & - & $\cdots$ & - & 39469,0 & - \\
\hline $\begin{array}{l}92 \text { Verbindlichkeiten aus Schuldverschreibungen } \\
\text { zur Deckung der Emission von EZB- } \\
\text { Schuldverschreibungen }\end{array}$ & - & $\cdots$ & - & $\cdots$ & - & - & - \\
\hline $\begin{array}{l}93 \text { Sonstıge Intra-Eurosystem- } \\
\text { Verbindlichketten (netto) }\end{array}$ & 6724,1 & $\cdots$ & $\cdots$ & 1267 & 3451,3 & 56713,2 & - \\
\hline 10 Schwebende Verrechnungen & - & - & - & - & 22,8 & 323,8 & k A \\
\hline 11 Sonstige Passiva & 887,8 & 238,4 & 440 & 11 & 52,1 & 13678,2 & 54714 \\
\hline $\begin{array}{l}11 \text { I Neubetwertungsposten aus } \\
\text { außerbilanzicllen Geschaften }\end{array}$ & 23,7 & 0,4 & - & k A & -- & 35,3 & $k A$ \\
\hline 112 Passive Rechnungsabgrenzungsposten & 59,2 & $\begin{array}{l}74,5 \\
163,5\end{array}$ & 20 & k. A. & 25,6 & 3928,8 & $k A$ \\
\hline 113 Sonstıges & 804,9 & 163,5 & 419 & k. A. & 26,4 & 9703,1 & k A \\
\hline 12 Ruckstellungen & 169,8 & 2300,1 & - & 2509 & 55,6 & 47957,4 & k A \\
\hline 13 Ausgleichsposten aus Neubewertung & 5195,0 & 1623,2 & 1151 & 1232 & 13,1 & 106782,0 & 107348 \\
\hline I4 Kapital und Rucklagen & 5989,1 & 122,8 & 1359 & 969 & 159,0 & 44102,1 & 53374 \\
\hline 141 Kapital & 12,0 & 1,0 & 0 & 841 & 25,0 & 8403,3 & k A. \\
\hline 142 Rucklagen & 5977,1 & 121,8 & 1359 & 129 & 134,0 & 35699,1 & k A \\
\hline 15 Jahresuberschuß & 85,9 & 55,1 & 173 & 0 & 0.9 & 7869.1 & k A \\
\hline 1 & 37846,0 & 26377,7 & 14781 & 14510 & 11211,0 & 931117,7 & 803192 \\
\hline
\end{tabular}

Quelle Eıgene Berechnungen Zur Zusammenstellung der Daten vgl die Erlauterungen zu den Tabellen 9 und 11 im Anhang 
Tabelle 12: Die Gewinn- und Verlustrechnungen der EZB und der NZBen fur das Jahr 1999 in Mio. Euro

1 Zinseinkunfe (brutto)

2 Zinsaufivendungen (brutto)

3 Nettozinsertrag (1+2)

4 Realisierte Gewinne (+)/

Verluste $(\cdot)$ aus Finanzoperationen

5 Abschreibungen auf Finanzanlagen

und -positionen

6 Zufuhrung ( - ) zu / Auflosung (+) von Rackstellungen fur Wahrungs- und Pressrisiken

7 Nettoergebnis aus Finanzoperationen, Abschreibungen und Risiokovorsorgen $(4+5+6)$

8 Ertrage aus Gebahren und Provisıonen

9 Aufwendungen aus Gebuhren und Provisionen

10 Nettoergebnis aus Gebuhren

und Provisionen (8+9)

11 Ertrige aus Beteiligungen

12 Nettoergebnis aus Monetilren

Eink0nften (vor EZB-Verlustanrechnung)

12 I Finanzierungsleistung fur Pool (brutto)

122 Partizipation am Pool (brutto)

13 Sonstige Ertralge

14 Gesamte Nettoertrăge

$(3+7+10+11+12+13)$

15 Finanzierungsbeitrag EZB-Verlust

151 Poolpartizipation der NZB

152 Direkter NZB-Beitrag zur Finanzierung des verbleibenden EZB-Verlusts

16 Personalaufwand

17 Andere administrative Aufwendungen

18 Abschreibungen auf Sachanlagen und immaterielle Vermogensgegenstünde

19 Aufwendungen for Banknotenproduktion

20 Sonstige Aufwendungen

21 "Vorbilanzielle" Gewinnausschuttungen an den Staat, davon:

21 I Korperschaftssteuer $u .8$

212 Gewinnantell vor Bilanzgewinn

213 Interımsdividende vor dem 31121999

22 JahresaberschuB / - fehlbetrag

\begin{tabular}{|c|c|c|c|c|c|c|}
\hline EZB & BBK & BdI & BdF & BdE & DNB & NBB \\
\hline 4872,2 & 6218 & 3971,5 & 3466,6 & 3091,8 & 1380 & 996,3 \\
\hline$-4118,1$ & -1206 & $-1848,0$ & $-1524,9$ & $-699,7$ & -573 & $-321,1$ \\
\hline 754,2 & 5012 & 2123,4 & 1941,8 & 2392,1 & 807 & 675,2 \\
\hline$-264,9$ & 3214 & $-185,2$ & k A. & 2304,8 & 370 & 152.6 \\
\hline $.604,9$ & -1052 & $-1629,6$ & k. A & $-398,2$ & -246 & - \\
\hline- & -2030 & 966,6 & k. A. & - & - & $-306,2$ \\
\hline$-869,9$ & 132 & $-848,2$ & $-115,7$ & 1906,6 & 124 & $-153,6$ \\
\hline 0,6 & 79 & 19,3 & 55.5 & 35,9 & 17 & 3,3 \\
\hline$-0,4$ & -7 & $-30,1$ & $-34,4$ & $-1,3$ & -4 & $-0,7$ \\
\hline 0,2 & 72 & $-10,8$ & 21,1 & 34,6 & 13 & 2,6 \\
\hline- & 21 & 931,4 & 19,1 & 1,6 & 8 & k. A. \\
\hline- & -3 & 4,3 & $-1,6$ & 2,1 & 1 & 0,2 \\
\hline- & -14 & $-2,3$ & $-9,1$ & $-1,8$ & -3 & $-1,1$ \\
\hline$\cdots$ & 11 & 6,6 & 7,5 & 3,9 & 2 & 1,3 \\
\hline 0,4 & 191 & 757,3 & 429,0 & 139,2 & 4 & 66,5 \\
\hline$-115,1$ & 5425 & 2957,6 & 2293,7 & 4476,2 & 957 & 590,9 \\
\hline- & -68 & $-41,5$ & $-46,9$ & $-24,8$ & -12 & $-8,0$ \\
\hline- & -11 & $-6,6$ & $-7,5$ & $-3,9$ & -2 & $-1,3$ \\
\hline$\cdots$ & -57 & $-34,8$ & $-39,4$ & $-20,8$ & -10 & $-6,7$ \\
\hline$-61,0$ & -862 & $-914,0$ & $-1277,7$ & $-170,4$ & -89 & $-175,3$ \\
\hline$-60,7$ & -290 & $-302,3$ & $-287,1$ & $-54,1$ & -72 & - \\
\hline$-10,5$ & -173 & $-146,9$ & $-148,4$ & $-16,2$ & -19 & $-30,5$ \\
\hline- & -89 & - & - & $-56,4$ & -17 & k. A. \\
\hline- & -39 & $-921,9$ & $-105,3$ & $-90,6$ & -0 & $-66,5$ \\
\hline- & - & $-96,0$ & $-274,8$ & $-1905,9$ & - & $-253,8$ \\
\hline- & - & $-96,0$ & $-274,8$ & - & - & $-130,3$ \\
\hline$\cdots$ & $\cdots$ & - & - & - & - & $-123,5$ \\
\hline$\cdots$ & - & - & - & $-1905,9$ & - & - \\
\hline-2473 & 3903 & 535,0 & 153,5 & 2158,0 & 748 & 56,9 \\
\hline
\end{tabular}


Noch Tabelle 12: Die Gewinn- und Verlustrechnungen der EZB und der NZBen fur das Jahr 1999 in Mio. Euro

\begin{tabular}{|c|c|c|c|c|c|c|}
\hline & OeNB & BdP & CBI & BoF & BCL & EURS \\
\hline I Zinscinkunfte (brutto) & 1148,5 & 712,8 & 437,5 & 485 & 310,4 & 27090,8 \\
\hline 2 Zinsaufwendungen (brutto) & $-385,9$ & $-407,6$ & $-186,7$ & -147 & $-283,5$ & $-11701,6$ \\
\hline 3 Nettozinsertrag $(1+2)$ & 762,6 & 305,2 & 250,8 & 338 & 26,9 & 15389,1 \\
\hline $\begin{array}{l}4 \text { Realısıerte Gewinne (+) / } \\
\text { Verluste (-) aus Finanzoperationen }\end{array}$ & 356,9 & 33,3 & 78,1 & 67 & 0,0 & k. A \\
\hline $\begin{array}{l}5 \text { Abschresbungen auf Finanzanlagen } \\
\text { und -positionen }\end{array}$ & $-212,3$ & $-78,7$ & $-44,0$ & - & $-9,5$ & k A \\
\hline $\begin{array}{l}6 \text { Zufuhrung ( ( ) zu / Auflosung ( + ) von Ruck- } \\
\text { stellungen fur Wahrungs- und Preisrisiken }\end{array}$ & 576,7 & $-67,9$ & -- & -- & $-9,8$ & k A \\
\hline $\begin{array}{l}7 \text { Nettoergebnis aus Finanzoperationen, } \\
\text { Abschreibungen und Risiokovorsorgen } \\
(4+5+6)\end{array}$ & 721,3 & $-113,3$ & 34,1 & 67 & $-19,4$ & 865,0 \\
\hline 8 Erträge aus Gebuhren und Provisionen & 1,2 & 4,2 & k A & k A & 2,6 & k A \\
\hline 9 Aufwendungen aus Gebuhren und Provisionen & $-1,8$ & $-7,1$ & k. A & k A & $-1,1$ & k A \\
\hline $\begin{array}{l}10 \text { Nettoergebnis aus Gebohren } \\
\text { und Provisionen }(8+9)\end{array}$ & $-0,6$ & $-2,9$ & 2,9 & k. A. & 1,4 & k. A. \\
\hline 11 Erträge aus Beteiligungen & 36,7 & 1,6 & 1,5 & k. A. & - & k. A. \\
\hline $\begin{array}{l}12 \text { Nettoergebnis aus Monetăren } \\
\text { Einkunften (vor EZB-Verlustanrechnung) }\end{array}$ & $-0,2$ & $-0,1$ & $-1,0$ & $\mathbf{0}$ & $-0,9$ & $0,2(0,0)$ \\
\hline 12 I Finanzierungslcistung fur Pool (brutto) & $-1,2$ & $-1,0$ & $-0,6$ & -1 & $-0,9$ & $36,0(35,2)$ \\
\hline 12.2 Partizıpation am Pool (brutto) & 1,1 & 0,9 & 0,4 & 1 & 0,1 & $35,8(35,2)$ \\
\hline 13 Sonstige Ertrăge & $\mathbf{7 6 , 4}$ & 17,7 & 0,3 & 33 & 11,2 & 1726,1 \\
\hline $\begin{array}{l}14 \text { Gesamte Nettoertrăge } \\
(3+7+10+11+12+13)\end{array}$ & 1596,1 & 208,3 & 288.6 & 437 & 19,3 & 19134,5 \\
\hline $\begin{array}{l}15 \text { Finanzierungsbeitrag EZB-Verlust } \\
151 \text { Poolpartizıpation der NZB }\end{array}$ & $\begin{array}{l}-6,6 \\
-11\end{array}$ & $\begin{array}{l}-5,4 \\
-0,9\end{array}$ & $\begin{array}{l}-2,4 \\
-0,4\end{array}$ & $-3,9$ & $-0,4$ & $\begin{array}{l}-219,6 \\
35\end{array}$ \\
\hline $\begin{array}{l}152 \text { Direkter NZB-Beitrag zur Finanzierung } \\
\text { des verbleibenden EZB-Verlusts }\end{array}$ & $-5,5$ & $-4,5$ & $-2,0$ & $-3,3$ & $-0,3$ & $-184,6$ \\
\hline 16 Personalaufwand & $-169,1$ & $-89,9$ & $-23,6$ & -50 & $-8,4$ & $-3890,3$ \\
\hline 17 Andere administrative Aufwendungen & $-67,2$ & $-27,0$ & $-9,0$ & -15 & $-5,2$ & $-1189,5$ \\
\hline $\begin{array}{l}18 \text { Abschreibungen auf Sachanlagen und } \\
\text { immaterielle Vermoggensgegenstănde }\end{array}$ & $-8,3$ & $-14,2$ & $-3,6$ & -0 & $-2,2$ & $-572,7$ \\
\hline 19 Aufwendungen fur Banknotenproduktion & $-26,9$ & $-2,0$ & $-2,4$ & -1 & -0.2 & k. A. \\
\hline 20 Sonstige Aufwendungen & $-16,3$ & $-14,7$ & $-34,6$ & -366 & $-2,2$ & $-1657,0$ \\
\hline $\begin{array}{l}21 \text { "Vorbilanzielle" Gewinnaus- } \\
\text { schuttungen an den Staat, davon: }\end{array}$ & $-1216,0$ & $-0,0$ & $-40,6$ & - & - & $-3787,0$ \\
\hline 211 Korperschaftssteucr u a & -442.6 & $-0,0$ & $\cdots$ & $\cdots$ & $\cdots$ & $-943,8$ \\
\hline 212 Gewinnantell vor Bilanzgewvinn & $-773,3$ & -- & - & - & - & $-896,8$ \\
\hline 21.3 Interimsdividende vor dem 31121999 & $\cdots$ & $\cdots$ & $-40,6$ & $\cdots$ & $\cdots$ & $-1946,5$ \\
\hline 22 Jahresuberschub / - fehlbetrag & $\mathbf{8 5 , 9}$ & $\mathbf{5 5 , 1}$ & 172,8 & $\mathbf{0}$ & 0,9 & 7621,8 \\
\hline
\end{tabular}

Quelle Eigene Berechnungen. Zur Zusammenstellung der Daten vgl dic Erlauterungen zu den Tabellen 10 und 12 im Anhang 


\section{V.2. Die Entstehung der NZB-Gewinne}

Der obige Verweis auf die unterschiedlichen Bilanzsummen allein vermag die Entstehung der NZB-Gewinne nicht zufriedenstellend zu erklären, da der Aktiva- und Passivabestand der NZBen nur Ausdruck der unterschiedlichen Tätigkeiten der NZBen ist. Diese beschränken sich aber keineswegs rein auf die Abwicklung der gemeinsamen Geldpolitik, sondern umfassen eine ganze Reihe anderer Aufgaben, die im Folgenden systematisch untersucht werden sollen. So lassen sich die Tätigkeiten der NZBen anhand der ESZB-Satzung in zwei Kategorien einteilen ${ }^{157}$. Zum einen sind bestimmte Aufgaben und Tätigkeiten der NZBen in der ESZB-Satzung konkret angesprochen und im einzelnen geregelt. Zum anderen dürfen die nationalen Zentralbanken auch andere als in der ESZB-Satzung bezeichneten Aufgaben übernehmen, es sei denn, der EZBRat stellt mit Zweidrittelmehrheit der abgegebenen Stimmen fest, daß diese Aufgaben nicht mit den Zielen und Aufgaben des ESZB/Eurosystems vereinbar sind. Derartige Aufgaben werden von den NZBen in eigener Verantwortung und auf eigene Rechnung wahrgenommen und gelten nicht als Aufgaben des ESZB/Eurosystems (Art. 14.4. ESZB-Satzung). In funktionaler Hinsicht beschränken sich diese „ESZB- bzw. Eurosystem-unabhängigen“ Tätigkeiten der NZBen jedoch nicht rein auf die in Art. 14.4. ESZB-Satzung erwähnten Aktivitäten, sondern sind in bestimmtem Umfang auch direkt in der ESZBSatzung verankert ${ }^{158}$. Als „Eurosystem-unabhängig“159 sollen deshalb alle Tätigkeiten der NZBen bezeichnet werden, bei denen die EZB kein Dispositionsrecht besitzt, solange die Ziele und Aufgaben des Eurosystems nicht beeinträchtigt werden. In Abgrenzung hierzu seien alle Tätigkeiten der NZBen, die auf Anweisung der EZB erfolgen, als „Eurosystem-spezifisch“ definiert. Abbildung 4 stellt diese funktionale der legalistischen Tätigkeitsabgrenzung gegenüber.

157 Die Zentralbank Griechenlands, die seit dem 1.1.2001 ebenfalls Mitglied des Eurosystems ist, kann in den folgenden Ausfuhrungen aus mangelnder Verfugbarkeit der entsprechenden Daten nur partiell berücksichtigt werden. Einen weiteren Überblick über verschiedene Tätigkeiten der NZBen geben auch Goetze (1999) und Tilch (2000).

Vgl. Rösl/Schäfer (1998a), S. 2, Rösl/Schäfer (1998b), S. 148 f. und Rösl/Schäfer (2000), S. 40.

159 Im Folgenden soll begrifflich nicht mehr zwischen „ESZB-unabhängigen“ und „Eurosystem-unabhängigen" Tätigkeiten der NZBen unterschieden werden, da sich die Analyse rein auf die Gewinnentstehung der an der dritten Stufe der EWU teilnehmenden NZBen beschränkt. 
Abbildung 4: Die Tätigkeiten der NZBen in legalistischer und funktionaler Hinsicht

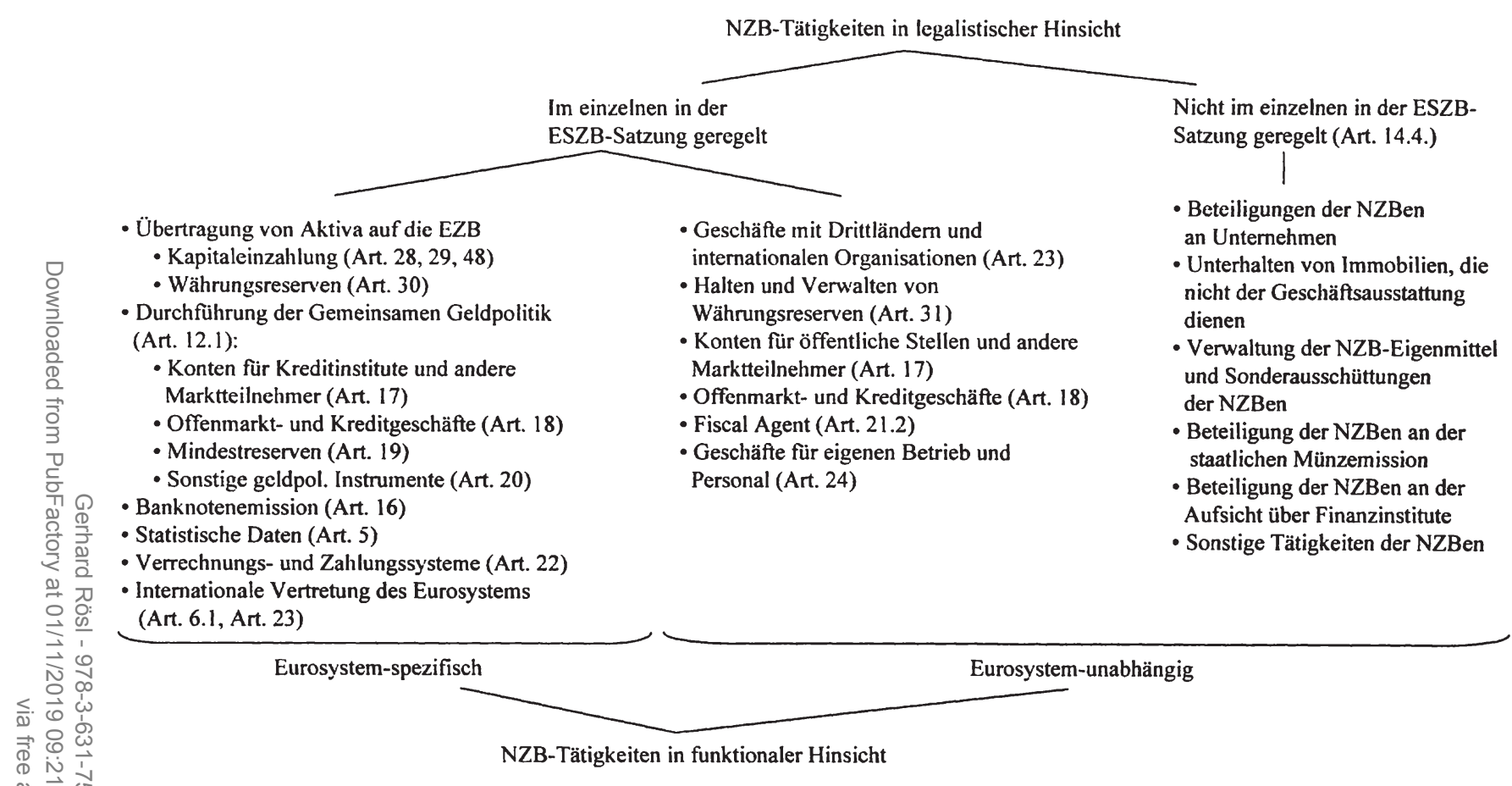

Quelle: Eigene Darstellung. 
In keinem Falle dürfen jedoch die Kompetenzen der NZBen zur Eurosystemunabhängigen Tätigkeitsausübung als autonomer Gestaltungsspielraum interpretiert werden. So besitzt die EZB jederzeit das Recht, die als Eurosystemunabhängig definierten Tätigkeiten der NZBen zu begrenzen. Bei den direkt in der ESZB-Satzung geregelten Eurosystem-unabhängigen Tätigkeiten stellt dies Art. 14.3. ESZB-Satzung sicher, der einerseits auf die Stellung der NZBen als integraler Bestandteil des ESZB verweist und andererseits die Verpflichtung der NZBen deutlich macht, gemäß den Leitlinien und Weisungen der EZB zu handeln. Im Falle der nicht im einzelnen in der ESZB-Satzung geregelten Eurosystem-unabhängigen Tätigkeiten der NZBen sichert - wie bereits erwähnt - Art. 14.4. ESZB-Satzung die Einflußmöglichkeit des EZB-Rates.

Dennoch verbleibt den NZBen ein Eurosystem-unabhängiger Gestaltungsspielraum. In welchem Umfang dieser nun die Gewinnentstehung der NZBen beeinflußt und welche Rolle die Eurosystem-spezifischen Tätigkeiten für die EWU-Notenbankgewinne spielen, soll im Folgenden untersucht werden. Dabei erfolgt die Analyse anhand der in Abbildung 4 aufgezeigten funktionalen Zuordnung der einzelnen NZB-Aktivitäten zum Eurosystem-spezifischen bzw. Eurosystem-unabhängigen Tätigkeitsbereich der NZBen.

\section{V.2.1. Die Analyse der Eurosystem-spezifischen Tätigkeiten der NZBen}

\section{Die satzungsgemäße Übertragung von Aktiva auf die EZB}

Die satzungsgemäße Übertragung von Aktiva auf die EZB in Form von Kapitalzahlungen und Währungsreserven wurde bereits im Rahmen der Analyse der EZB-Gewinnentstehung ausführlich analysiert. Dabei wurde klar, daß jeweils der gezeichnete EZB-Kapitalanteil den Umfang der von den NZBen auf die EZB zu transferierenden Ressourcen bestimmt. Für die Ertragslage der NZBen bedeuten diese Transfers zunächst einen Verzicht auf Zinserträge. Da diese entgangenen Zinseinkünfte allerdings im gleichen Verhältnis, wie sie von den NZBen finanziert wurden, auch an diese zurückfließen, sind keine besonderen Auswirkungen auf die NZB-Ertragslage zu erwarten. Dies gilt zumindest dann, wenn sich die Anlagestrategie der EZB und die der einzelnen NZBen prinzipiell ähnlich sind, was auch weitgehend der Fall ist ${ }^{160}$.

160 So beziehen sich die einschlägigen Angaben zur Anlagestrategie der EZB und der NZBen durchweg auf die Ertragsmaximierung im Rahmen vordefinierter Sicherheitskriterien. Vgl. hierzu z.B. Europäische Zentralbank (2000a), S. 57, Belgische Nationalbank (2000b), S. 12 und Bank of Finland (2000b), S. 60. 


\section{Die Beteiligung der NZBen an der Festlegung und Durchführung der gemeinsamen Geldpolitik}

\subsection{Die Beteiligung der NZBen an der Festlegung der gemeinsamen Geldpolitik}

Die Beteiligung der NZBen an der Festlegung und Durchführung der Gemeinsamen Geldpolitik ist unmittelbar in der ESZB-Satzung geregelt. So weist Artikel 12.1. der genannten Satzung die Kompetenz zur Festlegung der Geldpolitik des Eurosystems allein dem EZB-Rat zu. Allerdings sind die NZBen an der Entscheidungsfindung und Beschlußfassung des EZB-Rats beteiligt, da sie über ihre Präsidenten im EZB-Rat vertreten sind. Hierbei spielt jedoch die relative Größe der NZBen keine Rolle. So erfolgt gemäß Artikel 10.2. ESZBSatzung die Beschlußfassung bei geldpolitischen Entscheidungen ohne Stimmengewichtung und mit einfacher Mehrheit. Auch die Durchführung der Geldpolitik ist der Disposition der NZBen entzogen. Diese Kompetenz obliegt dem EZB-Direktorium, welches jedoch, soweit dies möglich und sachgerecht erscheint, die NZBen bei der operativen Abwicklung der geldpolitischen Geschäfte in Anspruch zu nehmen hat. Hierzu erteilt es den NZBen die erforderlichen Weisungen (Art. 12.1. ESZB-Satzung).

\subsection{Die Beteiligung der NZBen an der Durchführung der gemeinsamen Geldpolitik}

\subsubsection{Das geldpolitische Instrumentarium des Eurosystems}

Zur Durchführung der geldpolitischen Geschäfte steht dem Eurosystem eine Reihe von Instrumenten zur Verfügung. So können sowohl die EZB als auch die NZBen für Kreditinstitute, öffentliche Stellen und andere Marktteilnehmer Konten eröffnen (Art. 17 ESZB-Satzung), Offenmarkt- und Kreditgeschäfte durchführen (Art. 18 ESZB-Satzung) und unter bestimmten Voraussetzungen weitere geldpolitische Instrumente zur Anwendung bringen (Art. 20 ESZBSatzung). Weiterhin darf die EZB von Kreditinstituten die Haltung von Mindestreserven auf Konten bei der EZB und den NZBen verlangen (Art. 19 ESZB-Satzung). Allerdings verzichtet die EZB weitgehend darauf, geldpolitische Geschäfte selbst durchzuführen. Vielmehr trägt sie der in Art. 12.1. ESZB-Satzung verankerten Forderung nach einer möglichst dezentralen operativen Abwicklung der gemeinsamen Geldpolitik auch tatsächlich Rechnung. 
Tabelle 15: Die Beteiligung der NZBen an der Refinanzierung des Finanzsektors zum 1.1.1999 und 31.12.1999 in Mio. EUR

\begin{tabular}{|c|c|c|c|c|c|c|c|c|c|c|c|c|}
\hline & BBk & BdE & BdF & DNB & NBB & Bdl & CBI & OeNB & BdP & BCL & BoF & $\begin{array}{l}\text { Gesamte } \\
\text { NZBen }\end{array}$ \\
\hline $\begin{array}{l}\text { Forderungen in Euro an den } \\
\text { Finanzsektor zum 1.1.1999, davon: }\end{array}$ & 110422 & 26877 & 25477 & 8489 & 4980 & 3156 & 2241 & 1519 & 1231 & 233 & 3 & 184628 \\
\hline Hauptrefinanzierungsgeschafte & 83121 & 23135 & 19789 & 8454 & 4584 & 2130 & 2169 & 702 & - & - & $\cdots$ & 144084 \\
\hline $\begin{array}{l}\text { Lăngerfristige } \\
\text { Refinanzierungsgeschăfte }\end{array}$ & 24698 & - & $\cdots$ & - & $\cdots$ & - & $\cdots$ & $\cdots$ & - & - & - & 24698 \\
\hline Spitzenrefinanzierungs fazilităt & 2598 & 3711 & - & - & 4 & -- & 59 & $\cdots$ & - & - & $\cdots$ & 6372 \\
\hline Andere Forderungen ${ }^{1}$ & 5 & 31 & 5687 & 35 & 392 & 1026 & 13 & 817 & 1231 & 233 & 3 & 9473 \\
\hline Monetäre NZB-Basis zum 1.1.1999 & 159876 & 60142 & 60798 & 25064 & 18888 & 70218 & 6245 & 16243 & 6413 & 111 & 4823 & 428821 \\
\hline $\begin{array}{l}\text { Forderungen in Euro an den } \\
\text { Finanzsektor zum 1.1.1999 in vH. } \\
\text { der Monetăren NZB-Basis }{ }^{2}\end{array}$ & $69,1 \%$ & $44,7 \%$ & $41,9 \%$ & $33,9 \%$ & $26,4 \%$ & $4,5 \%$ & $35,9 \%$ & $9,4 \%$ & $19,2 \%$ & $210,4 \%$ & $0,1 \%$ & $43,1 \%$ \\
\hline $\begin{array}{l}\text { Forderungen in Euro an den } \\
\text { Finanzsektor zum 31.12.1999 }\end{array}$ & 90571 & 24184 & 44933 & 9443 & 20458 & 35852 & 5062 & 6465 & 2389 & 9000 & 1516 & 249875 \\
\hline Hauptrefinanzierungsgeschăfe & 48396 & 20348 & 37589 & 6861 & 5437 & 33163 & 883 & 2765 & 421 & 4841 & 1283 & 161987 \\
\hline $\begin{array}{l}\text { Lăngerfristige } \\
\text { Refinanzierungsgeschăfte }\end{array}$ & 32745 & 3379 & 6869 & 2581 & 15015 & 1892 & 4179 & 2708 & 1966 & 3432 & 230 & 74997 \\
\hline Spitzenrefinanzierungsfazilităt & 9417 & 453 & 399 & 1 & 5 & 794 & $\cdots$ & $\ldots$ & - & 727 & - & 11796 \\
\hline Andere Forderungen & 13 & 4 & 76 & $\cdots$ & 1 & 4 & 0 & 993 & 2 & - & 2 & 1095 \\
\hline $\begin{array}{l}\text { Monetăre NZB-Basis zum } \\
31.12 .1999\end{array}$ & 182046 & 71402 & 70530 & 25196 & 16456 & 79839 & 6598 & 16579 & 10942 & 4768 & 7892 & 492248 \\
\hline $\begin{array}{l}\text { Forderungen in Euro an den } \\
\text { Finanzsektor zum 1.1.1999 in vH. } \\
\text { der Monetären NZB-Basis }\end{array}$ & $49,8 \%$ & $33,9 \%$ & $63,7 \%$ & $37,5 \%$ & $124,3 \%$ & $44,9 \%$ & $76,7 \%$ & $39,0 \%$ & $21,8 \%$ & $188,8 \%$ & $19,2 \%$ & $50,8 \%$ \\
\hline
\end{tabular}

Quelle: Eigene Berechnungen. Die der Darstellung zugrunde liegenden Zahlen sind entnommen aus den Tabellen 9 und 11 . Differenzen in den Summen durch Runden der Zahlen.

\footnotetext{
${ }^{1}$ Dieser Posten setzt sich zusammen aus den NZB-Aktivposten „Feinsteuerungsoperationen in Form von befristeten Transaktionen“, „Strukturelle Operationen in Form von befristeten Operationen“, „Forderungen aus Margenausgleich“ und „sonstige Forderungen“" (an den heimischen Finanzsektor).

${ }^{2}$ Monetăre NZB-Basis als Summe aus Banknotenumlauf und Euro-Verbindlichkeiten der NZBen gegenaber dem im Euroraum ansăssigen Finanzsektor.
} 


\subsubsection{Die Beteiligung der NZBen an der Durchführung der Offenmarktgeschäfte des Eurosystems}

Die EZB unterschiedet - wie in der vorstehenden Tabelle 13 dargestellt hinsichtlich Zielsetzung, Rhythmus und Verfahren vier Kategorien von Offenmarktgeschäften des Eurosystems: Hauptrefinanzierungsgeschäfte, Längerfristige Refinanzierungsgeschäfte, Feinsteuerungsoperationen und strukturelle Operationen ${ }^{161}$. Zugelassene Geschäftspartner des Eurosystems sind hierbei nur Institute, die in das Mindestreservesystem einbezogen sind ${ }^{162}$.

Das für die Zentralbankgeldversorgung der Wirtschaft bedeutendste geldpolitische Instrument sind die Hauptrefinanzierungsgeschäfte („Haupttender"). Hierbei führt das Eurosystem in wöchentlichem Abstand dem Finanzsektor Liquidität in Form von befristeten Transaktionen („Repos“) mit einer Laufzeit von zwei Wochen zu. Die Schnittstelle zum Privatsektor bilden allein die NZBen, die diese Transaktionen in Abhängigkeit von der jeweiligen nationalen Rechtsordnung entweder als Pensionsgeschäfte oder in Form von „besicherten Krediten" durchführen ${ }^{163}$. Allerdings dürfen sich die Kreditinstitute gemäß dem „Heimatlandprinzip“ nur bei der jeweiligen nationalen Zentralbank des Mitgliedstaats refinanzieren, in dem das betreffende Institut niedergelassen ist $^{164}$. Unterhält ein Kreditinstitut in mehreren Mitgliedstaaten Niederlassungen, so kann dieses Institut über seine Auslandsniederlassungen bei verschiedenen NZBen an der Zentralbankgeldversteigerung des Eurosystems teilnehmen ${ }^{165}$.

161 Vgl. im Folgenden Europäische Zentralbank (2000g), S. 4 ff..

162 Die ESZB-Satzung würde auch Offenmarktgeschäfte mit privaten Nichtbanken zulassen (vgl. Art. 18.1. ESZB-Satzung), während der unmittelbare Erwerb von Schuldtiteln der öffentlichen Hand nach Art. 21.1. ESZB-Satzung strikt untersagt ist.

Bei Pensionsgeschäften wird im Zuge der NZB-Kreditgewährung das Eigentum an dem vom Kreditinstitut zur Besicherung aufzubringenden Vermögenswert auf die NZB übertragen, wobei gleichzeitig die NZB und das entsprechende Kreditinstitut vereinbaren, das Geschäft durch eine Rückübertragung des Vermögenswerts zu einem zukünftigen Zeitpunkt umzukehren. Bei besicherten Krediten hingegen bleibt das Kreditinstitut Eigentümer an dem zur Besicherung hinterlegten Vermögenswert. Allerdings erhält die NZB ein rechtswirksames Sicherungsrecht an den Vermögenswerten. Vgl. Europäische Zentralbank (2000g), S. 14.

164 Vgl. Europäische Zentralbank (2000g), S. 10. Die Geschäftspartner des Eurosystems können refinanzierungsfähige Sicherheiten jedoch grenzliberschreitend nutzen, sei es über das Korrespondenzzentralbankenmodell (CCBM) oder über zugelassene Verbindungen von herkömmlichen Wertpapierabwicklungssystemen. Vgl. hierzu European Central Bank (1998a), Europäische Zentralbank (2000g), S. 50 ff. und Europäische Zentralbank (2001d), S. 127.

165 Pro NZB ist jedoch nur jeweils ein Tendergebot pro Kreditinstitut gestattet. Zur Zentralbankgeldversteigerung (Tenderverfahren) des Eurosystems und der Zuteilung der 
Prinzipiell ähnlich wie die Hauptrefinanzierungsgeschäfte werden die Längerfristigen Refinanzierungsgeschäfte („Basistender") des Eurosystems abgewickelt. Diese werden ebenfalls ausschließlich von den NZBen durchgeführt und erfolgen in Form von befristeten Transaktionen (Pensionsgeschäfte bzw. besicherte Kredite) mit monatlichem Rhythmus und einer Laufzeit von drei Monaten. Dabei greift das Eurosystem gegenwärtig auf Zinstender mit amerikanischem Zuteilungsverfahren zurück, wobei auch eine Abwicklung über Mengentender bzw. über Zinstender mit holländischem Zuteilungsverfahren möglich ist. Die Zugangskriterien zu dieser Fazilität entsprechen denen der Hauptrefinanzierungsgeschäfte. Auch hier gilt das Heimatlandprinzip, d.h. eine Geschäftsbank darf sich nur bei einer NZB refinanzieren, in deren Land sie eine Niederlassung besitzt. Mehrfachgebote bei unterschiedlichen NZBen sind möglich, sofern die Geschäftsbank in diesen Ländern Niederlassungen unterhält. Zur generellen Bedeutung dieses Instruments kann gesagt werden, daß die Gesamthöhe des über den Basistender bereitgestellten Brutto-Zentralbankgeldes weit unter dem des Hauptrefinanzierungsinstruments liegt, wenngleich dies nicht notwendigerweise auch für eine einzelne NZB gelten muß. Des weiteren unterscheiden sich Haupt- und Basistender in der von den Kreditinstituten zu leistenden Zinsen. So ist der Zinssatz im Falle der Längerfristigen Refinanzierung wegen der relativ längeren Kreditlaufzeit naturgemäß höher.

Die Feinsteuerungsoperationen des Eurosystems dienen vor allem dazu, die Auswirkungen unerwarteter Liquiditätsschwankungen auf die Zinssätze auszugleichen. Hierzu kann das Eurosystem auf befristete Transaktionen (Repos bzw. Reverse-Repos), Devisenswaps, definitive Käufe und auf die Hereinnahme von Termineinlagen zurückgreifen, wobei die rasche Abwicklung dieser Geschäfte über Schnelltender oder bilaterale Geschäfte sichergestellt ist. Durchgeführt werden solche Transaktionen in der Regel von den NZBen, in Ausnahmefällen aber auch direkt durch die EZB. In jedem Falle tragen die durchführenden Zentralbanken selbst die anfallenden Kosten bzw. erhalten die entsprechenden Erträge aus diesen Maßnahmen.

Mit den sogenannten Strukturellen Operationen will das Eurosystem seine strukturelle Position gegenüber dem Finanzsektor beeinflussen. Dies kann entweder über befristete Transaktionen (Repos bzw. Reverse Repos), definitive (Ver-) Käufe von Wertpapieren oder über die Emission von EZBSchuldverschreibungen geschehen. Abgewickelt werden diese Geschäfte allein von den NZBen, d.h. auch hier stellen die NZBen die entstehenden

versteigerten Beträge zu den Kreditinstituten vgl. Europäische Zentralbank (2000g), S. 26 ff.. 
Aufwendungen bzw. die jeweiligen Erträge aus diesen Operationen in ihre GuVen ein ${ }^{166}$. Allerdings dürfte dies nicht für die Zinsverpflichtungen aus der Emission von EZB-Liquiditätspapieren gelten. Hier ist anzunehmen, daß die NZBen zwar die entsprechenden Papiere an die heimischen Geschäftsbanken ausgeben, die anfallenden Zinsaufwendungen aber der EZB über eine entsprechende Verrechnungsforderung in Rechnung stellen. Aktuell wird diese Frage jedoch erst dann, wenn das Eurosystem zum ersten Male Strukturelle Operationen durchführen wird.

Es kann folglich festgehalten werden, daß - sieht man von der Verzinsung der EZB-Liquiditätspapiere einmal ab - sämtliche Erträge und Aufwendungen aus der Offenmarktpolitik des Eurosystems gegenwärtig allein den NZBen zufallen. Dies gilt jedoch nicht unbedingt auch für etwaige vom Eurosystem verhängte Strafzinsen gegen Geschäftspartner, die im Rahmen der Offenmarktgeschäfte ihren vertraglichen oder öffentlich-rechtlichen Verpflichtungen gegenüber den NZBen (oder der EZB) nicht nachkommen ${ }^{167}$. Ob diese Strafgebühren auch letztendlich den NZBen zukommen oder ob diese wie die Strafzinsen auf die Nichterfüllung der Mindestreserve an die EZB weitergeleitet werden ${ }^{168}$, soll hier offenbleiben.

\subsubsection{Die Beteiligung der NZBen an der Bereitstellung der Ständigen Fazilitäten des Eurosystems}

Das Eurosystem bietet mit der Spitzenrefinanzierungsfazilität und der Einlagefazilität den Kreditinstituten zwei ständige Fazilitäten $a^{169}$. So können sich die Kreditinstitute über die Spitzenrefinanzierungsfazilität bei ihrer heimischen Zentralbank Übernachtliquidität gegen eine entsprechende Hinterlegung refinanzierungsfähiger Sicherheiten beschaffen. Kredithöchstgrenzen existieren hierbei im allgemeinen nicht. Allerdings soll dieser sehr kurzfristige Notenbankkredit nicht die Haupt- bzw. Längerfristigen Refinanzierungsgeschäfte des Eurosystems ersetzen, weshalb der Spitzenrefinanzierungssatz auch deutlich über den regulären Refinanzierungszinsen liegt. Vielmehr dient diese Fazilität als eine Art Ventilfunktion für die Zentralbankgeldnachfrage der Geschäftsbanken. So hat der grundsätzlich unbegrenzte

166 Vgl. Europäische Zentralbank (2000g), S. 16.

167 So werden beispielsweise Verstöße gegen die Regeln für Tenderoperationen, bilaterale Geschäfte und die Nutzung von refinanzierungsfähigen Sicherheiten mit einem Strafzins in Höhe von 2,5 Prozentpunkten auf den Spitzenrefinanzierunsgsatz geahndet. Vgl. Europäische Zentralbank (2000g), S. 99.

168 Vgl. Europäische Zentralbank (2001d), S. 203.

169 Vgl. Europäische Zentralbank (2000g), S. 5 f.. 
Zugang $\mathrm{zu}$ dieser Fazilität in Kombination mit dem vom Eurosystem festgelegten Zinssatz zur Folge, daß sich in aller Regel die Geldmarktzinsen (Tagesgeldsatz) unterhalb des Spitzenrefinanzierungssatzes bewegen. Die inhaltliche Umkehrung der Spitzenrefinanzierungsfazilität ist die Einlagefazilität. Hierbei können die Kreditinstitute Liquiditätsüberschüsse in prinzipiell beliebigem Umfang bei der heimischen Zentralbank bis zum nächsten Geschäftstag anlegen. Diese Positionen werden von den NZBen in Höhe des Satzes für die Einlagefazilität verzinst. Dieser Zinssatz ist der niedrigste Zinssatz des Eurosystems und bildet im allgemeinen die Untergrenze für den Tagesgeldsatz am Interbankenmarkt.

Die EZB selbst bietet die ständigen Fazilitäten nicht an, so daß die Zinseinkünfte des Eurosystems aus der Spitzenrefinanzierungsfazilität bzw. die Zinsaufwendungen des Eurosystems aus der Einlagefazilität allein den NZBen zufallen.

\subsubsection{Die Beteiligung der NZBen am Mindestreservesystem des Eurosystems}

Das Eurosystem verlangt von den an der Refinanzierung teilnehmenden Kreditinstituten, Mindestreserven bei den NZBen zu unterhalten ${ }^{170}$. Die EZB selbst ist an der Verwaltung des Mindestreservesystems nicht beteiligt. Die Höhe der von den Kreditinstituten zu unterhaltenden Mindestreserve errechnet sich aus der Mindestreservebasis und dem Mindestreservesatz. Die erste Komponente ist im wesentlichen abhängig von den Einlagen der Nichtbanken bei dem entsprechenden Kreditinstitut, aber auch ausgegebene Schuldverschreibungen und Geldmarktpapiere gehen in die Berechnungsgrundlage ein ${ }^{171}$. Dabei wird sowohl die Mindestreservebasis als auch die Höhe des Mindestreservesatzes vom EZB-Rat bestimmt. Allerdings hat dieser den vom Ministerrat (ECOFIN) festgelegten Rahmen zu beachten (Art. 19 ESZBSatzung). Dieser sieht auch die Erhebung von Strafzinsen vor, falls die Kreditinstitute ihrer Mindestreserveverpflichtung nicht ordnungsgemäß nachkommen ${ }^{172}$. Hierbei sind zwar die NZBen an der Überwachung der Einhaltungspflichten beteiligt und wirken auch an der Vollstreckung der ergriffenen Maßnahmen mit, die gegebenenfalls erhobenen Strafzinsen fallen jedoch der $\mathrm{EZB} \mathrm{zu}^{173}$.

$170 \mathrm{Vgl}$. im Folgenden Europäische Zentralbank (2000g), S. 56 ff. und Europäische Gemeinschaft (1998i), S. 1 ff..

171 Vgl. zur konkreten Berechnung Europäische Zentralbank (2000g), S. 58 und S. 93 ff..

172 Vgl. Europäische Gemeinschaft (1999f), S. 21 ff..

$173 \mathrm{Vgl}$. Europäische Zentralbank (2000h), S. 160. 
Die Mindestreserveverpflichtung der Kreditinstitute ist als sinnvolles geldpolitisches Instrument zu werten ${ }^{174}$. Dabei darf aber nicht verkannt werden, daß eine unverzinsliche bzw. eine unter dem Marktwert verzinste Mindestreserve als eine Art Sondersteuer auf die nicht freiwillig bei der Zentralbank gehaltenen Einlagen der Geschäftsbanken bzw. auf die Einlagen der Nichtbanken bei den Kreditinstituten interpretiert werden $\mathrm{kann}^{175}$. Um diese verzerrende Wirkung der Mindestreserve zu minimieren, zahlen die NZBen auf die Mindestreserveguthaben der Kreditinstitute eine Verzinsung in Höhe des durchschnittlichen Satzes für die Hauptrefinanzierungsgeschäfte ${ }^{176}$.

\subsection{Die Beteiligung der NZBen an der Durchführung der geldpolitischen Geschäfte des Eurosystems im ersten Jahr der EWU}

Obige Ausführungen haben gezeigt, daß nach der gegenwärtigen Aufgabenteilung im Eurosystem die operative Geldpolitik (fast) vollständig in den Aufgabenbereich der NZBen fällt. Bevor aber die konkrete Beteiligung der einzelnen NZBen an der Durchführung dieser Operationen und deren Auswirkung auf die NZB-Gewinnentstehung näher untersucht wird, soll zunächst der Umfang der vom Eurosystem im ersten Jahr der EWU durchgeführten geldpolitischen Operationen überblicksartig dargestellt werden. Die anschließenden Ausführungen beschäftigen sich mit der Verlagerung der Refinanzierung zwischen den NZBen des Eurosystems. In diesen Kontext läßt sich dann auch die Beteiligung der NZBen an der Netto-Zentralbankgeldbereitstellung des Eurosystems einordnen.

\subsubsection{Die geldpolitischen Geschäfte des Eurosystems im Überblick}

Wie die folgende Tabelle 14 zeigt, hat das Eurosystem in 1999 bei der Offenmarktpolitik nur auf Haupt- und Längerfristige Refinanzierungsgeschäfte zurückgegriffen $^{177}$. So teilte das EZB-Direktorium 52 Hauptrefinanzierungsgeschäfte mit einem Bruttovolumen von 69,4 Mrd. EUR pro Tender zu, was einem kumulierten Betrag von 3606,4 Mrd. EUR entspricht. Allerdings stehen diesen Werten rückläufige Tender in einem Gesamtvolumen von 3589,3 Mrd. EUR gegenüber, so daß die über die Hauptrefinanzierungsgeschäfte abgewickelte kumulierte Nettozuteilung von Zentralbankgeld insgesamt nur 17,1 Mrd. EUR beträgt.

174 Zur Diskussion des Instruments der Mindestreserve vgl. z. B. Menkhoff (1996), S. 45 ff..

175 Vgl. Issing (1995), S. 237.

176 Zur konkreten Berechnung vgl. Europäische Zentralbank (2000g), S. 60.

177 Vgl. auch Europäische Zentralbank (2000h), S. 50 ff.. 
Tabelle 14: Die geldpolitischen Geschäfte des Eurosystems im ersten Jahr der EWU'

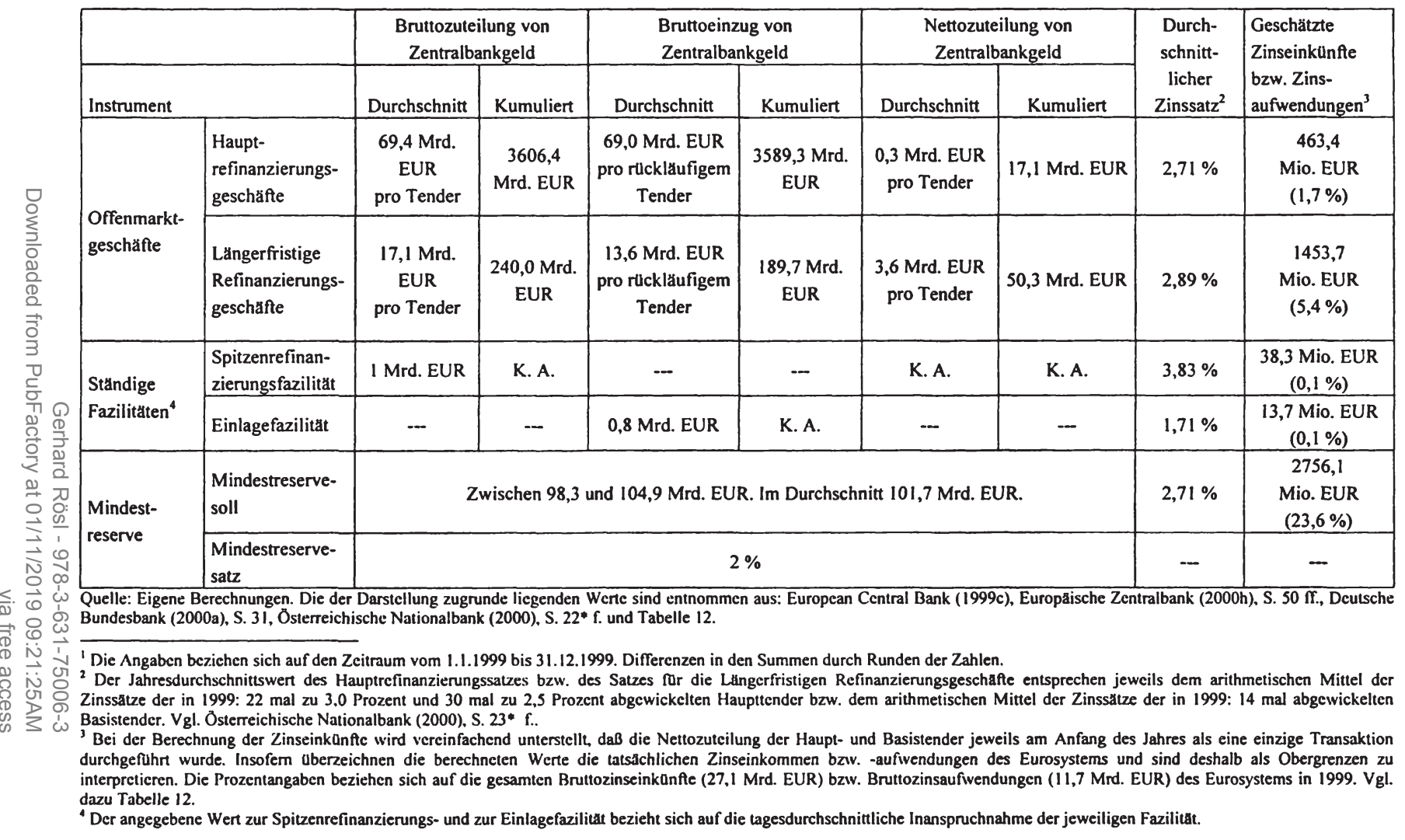


So ergibt sich beispielsweise ein nur als sehr grobe Näherung zu verstehender Zinsgewinn des Eurosystems aus den in 1999 über die Haupttender abgewickelten Nettozuteilungen in Höhe von 463 Mio. EUR, wenn man vereinfachend den jahresdurchschnittlichen Hauptrefinanzierungssatz von 2,71 Prozent auf die kumulierte Nettozuteilung ansetzt. In Relation zu den gesamten Bruttozinserträgen des Eurosystems (27,1 Mrd. EUR ${ }^{178}$ ) entspricht dieser Wert gerade einmal 1,7 Prozent. Diesbezüglich wichtiger erscheinen hier die Längerfistigen Refinanzierungsgeschäfte. Diese Operationen führte das Eurosystem in 1999 insgesamt 14 mal durch mit einem durchschnittlichem Bruttozuteilungsvolumen von 17,1 Mrd. EUR pro Tender, dem im Durchschnitt nur 3,6 Mrd. EUR an gleichzeitig auslaufenden Geschäften gegenüber standen. Über die Periode kumuliert stellten die nationalen Zentralbanken des Euroraums somit 50,3 Mrd. EUR über Basistender zur Verfügung, was rund 75 Prozent der gesamten über die Offenmarktpolitik abgewickelten kumulierten Nettozentralbankgeldzuteilungen entspricht. Multipliziert man auch hier den sich auf 2,89 Prozent belaufenden Jahresdurchschnittszins mit den in 1999 netto zugeteilten Basistendern, erhält man überschlagsweise einen Zinsgewinn des Eurosystems aus den Nettozentralbankgeldzuteilungen der im ersten Jahr der EWU abgewickelten Längerfristigen Refinanzierungsgeschäfte in Höhe von 1454 Mio. EUR. Dieser Betrag macht immerhin 5,4 Prozent der gesamten Bruttozinseinkünfte des Eurosystems aus.

Bezieht man nun aber neben diesen Forderungen, die das Eurosystem aus seinen in 1999 durchgeführten Haupt- und Basistendern gegenüber dem Finanzsektor netto neu erworben hat, auch diejenigen Forderungen aus Haupt- und Längerfristigen Refinanzierungsgeschäften, über die die NZBen bereits zu Beginn der EWU verfügten, in die Analyse mit ein, kehrt sich das oben geschilderte Bild um. So betrugen Ende 1999 die gesamten ausstehenden Forderungen des Eurosystems aus Hauptrefinanzierungsgeschäften 162 Mrd. EUR und aus Längerfristigen Refinanzierungsgeschäften 75 Mrd. EUR ${ }^{179}$. Setzt man auch hier zur überschlagsmäßigen Berechnung der Zinseinkommen aus diesen Aktiva den jeweiligen Jahresdurchschnittszins an, so erhält man Erträge aus Haupttendern in Höhe von 4390 Mio. EUR bzw. aus Basistendern im Betrag von 2168 Mio. EUR, was 15,9 \% bzw. 7,8 \% der Bruttozinsgewinne des Eurosystems entspricht.

Neben den Offenmarktgeschäften erzielte das Eurosystem in 1999 auch Zinseinkünfte aus der Bereitstellung der Spitzenrefinanzierungsfazilität. Allerdings zeigt die tagesdurchschnittliche Inanspruchnahme dieser Kredite in

\footnotetext{
178 Vgl. Tabelle 12.

179 Vgl. Tabelle 11.
} 
Höhe von 1 Mrd. EUR, daß die Geschäftsbanken bei ihrer Refinanzierung erwartungsgemä $\beta$ eher auf die relativ billigeren Haupt- und Basistender zurückgegriffen haben. So erwirtschaftete das Eurosystem in 1999 gerade einmal geschätzte 38,3 Mio. EUR aus dieser Fazilität. Ähnlich marginal sind die überschlagsweise berechneten Zinsaufwendungen des Eurosystems aus der Vergütung der Einlagefazilität in Höhe von 13,7 Mio. EUR. Diese fallen wegen ihrer nur relativ geringen Inanspruchnahme von durchschnittlich 800 Mio. EUR pro Geschäftstag und ihrer niedrigen Verzinsung kaum ins Gewicht. Dies gilt zumindest dann, wenn man sie zu den gesamten vom Eurosystem in 1999 finanzierten Bruttozinsaufwendungen in Relation setzt $(0,1 \text { Prozent })^{180}$.

Bedeutender hingegen sind die Kosten, die die NZBen aus der Verzinsung des Mindestreservesolls im ersten Jahr der EWU zu tragen hatten. So lassen sich diese Aufwendungen grob auf 2756 Mio. EUR beziffern, wenn man den Jahresdurchschnittszins der Hauptrefinanzierungsgeschäfte (2,71 Prozent p.a.) auf das durchschnittliche Mindestreservesoll in Höhe von 101,7 Mrd. EUR ansetzt. Dies bedeutet aber auch, daß das Eurosystem rund ein Viertel aller in 1999 finanzierten Bruttozinsaufwendungen zur Begleichung seiner Zinsverpflichtungen aufzuwenden hatte.

\subsubsection{Die Verschiebung der Refinanzierungsstruktur innerhalb des Eurosystems}

Bevor sich mit der Frage der Verschiebung der Refinanzierungsstruktur innerhalb des Eurosystems näher beschäftigt wird, soll kurz darauf hingewiesen werden, daß die nationalen Zentralbanken im Rahmen der Durchführung der gemeinsamen Geldpolitik selbst keinerlei Einfluß darauf haben, über welche NZB und in welcher Höhe die geldpolitischen Geschäfte des Eurosystems tatsächlich abgewickelt werden. Dies bestimmt sich jeweils aus dem Zusammenspiel der von der EZB festgelegten Parameter (Zinsen, Zuteilungsvolumen, Tenderlaufzeit, usw.) und dem Verhalten der Kreditinstitute in den einzelnen EWU-Ländern (Tendergebote). Die NZBen fungieren diesbezüglich folglich rein als operative Schnittstelle zwischen EZB und den nationalen Kreditinstituten, indem sie die kumulierten nationalen Tendergebote an die EZB weiterleiten und bei der Zuteilung des Zentralbankgelds als „Distributionskanal“ für die Zentralbankgeldversorgung der heimischen Geschäftsbanken dienen.

180 Die kumulierten Bruttozinsaufwendungen des Eurosystems betrugen in 1999: 11,7 Mrd. EUR. Vgl. Tabelle 12. 
Tabelle 15: Die Beteiligung der NZBen an der Refinanzierung des Finanzsektors zum 1.1.1999 und 31.12.1999 in Mio. EUR

\begin{tabular}{|c|c|c|c|c|c|c|c|c|c|c|c|c|}
\hline & BBk & BdE & BdF & DNB & NBB & BdI & CBI & OeNB & BdP & BCL & BoF & \begin{tabular}{|c|} 
Gesamte \\
NZBen
\end{tabular} \\
\hline $\begin{array}{l}\text { Forderungen in Euro an den } \\
\text { Finanzsektor zum 1.1.1999, davon: }\end{array}$ & 110422 & 26877 & 25477 & 8489 & 4980 & 3156 & 2241 & 1519 & 1231 & 233 & 3 & 184628 \\
\hline Hauptrefinanzierungsgeschäfte & 83121 & 23135 & 19789 & 8454 & 4584 & 2130 & 2169 & 702 & -- & - & -- & 144084 \\
\hline $\begin{array}{l}\text { Längerfristige } \\
\text { Refinanzierungsgeschăfte }\end{array}$ & 24698 & -- & $\cdots$ & $\cdots$ & - & - & -- & $\cdots$ & --- & $\cdots$ & - & 24698 \\
\hline Spitzenrefinanzierungsfazilităt & 2598 & 3711 & $\cdots$ & $\cdots$ & 4 & $-\cdots$ & 59 & -- & -- & - & - & 6372 \\
\hline Andere Forderungen ${ }^{1}$ & 5 & 31 & 5687 & 35 & 392 & 1026 & 13 & 817 & 1231 & 233 & 3 & 9473 \\
\hline Monetăre NZB-Basis zum 1.1.1999 & 159876 & 60142 & 60798 & 25064 & 18888 & 70218 & 6245 & 16243 & 6413 & 111 & 4823 & 428821 \\
\hline $\begin{array}{l}\text { Forderungen in Euro an den } \\
\text { Finanzsektor zum 1.1.1999 in vH. } \\
\text { der Monetären NZB-Basis }\end{array}$ & $69,1 \%$ & $44,7 \%$ & $41,9 \%$ & $33,9 \%$ & $26,4 \%$ & $4,5 \%$ & $35,9 \%$ & $9,4 \%$ & $19,2 \%$ & $210,4 \%$ & $0,1 \%$ & $43,1 \%$ \\
\hline $\begin{array}{l}\text { Forderungen in Euro an den } \\
\text { Finanzsektor zum 31.12.1999 }\end{array}$ & 90571 & 24184 & 44933 & 9443 & 20458 & 35852 & 5062 & 6465 & 2389 & 9000 & 1516 & 249875 \\
\hline Hauptrefinanzierungsgeschăfte & 48396 & 20348 & 37589 & 6861 & 5437 & 33163 & 883 & 2765 & 421 & 4841 & 1283 & 161987 \\
\hline $\begin{array}{l}\text { Längerfristige } \\
\text { Refinanzierungsgeschăfte }\end{array}$ & 32745 & 3379 & 6869 & 2581 & 15015 & 1892 & 4179 & 2708 & 1966 & 3432 & 230 & 74997 \\
\hline Spitzenrefinanzierungsfazilităt & 9417 & 453 & 399 & 1 & 5 & 794 & - & $\cdots$ & -- & 727 & $\cdots$ & 11796 \\
\hline Andere Forderungen & 13 & 4 & 76 & - & 1 & 4 & 0 & 993 & 2 & - & 2 & 1095 \\
\hline $\begin{array}{l}\text { Monetăre NZB-Basis zum } \\
\text { 31.12.1999 }\end{array}$ & 182046 & 71402 & 70530 & 25196 & 16456 & 79839 & 6598 & 16579 & 10942 & 4768 & 7892 & 492248 \\
\hline $\begin{array}{l}\text { Forderungen in Euro an den } \\
\text { Finanzsektor zum 1.1.1999 in vH. } \\
\text { der Monetären NZB-Basis }\end{array}$ & $49,8 \%$ & $33,9 \%$ & $63,7 \%$ & $37,5 \%$ & $124,3 \%$ & $44,9 \%$ & $76,7 \%$ & $39,0 \%$ & $21,8 \%$ & $188,8 \%$ & $19,2 \%$ & $50,8 \%$ \\
\hline
\end{tabular}

Quelle: Eigene Berechnungen. Die der Darstellung zugrunde liegenden Zahlen sind entnommen aus den Tabellen 9 und 11 . Differenzen in den Summen durch Runden der Zahlen.

'Dieser Posten setzt sich zusammen aus den NZB-Aktivposten „Feinsteuerungsoperationen in Form von befristeten Transaktionen“, „Strukturelle Operationen in Form von befristeten Operationen“, „Forderungen aus Margenausgleich“ und „sonstige Forderungen“ (an den heimischen Finanzsektor).

${ }^{2}$ Monetäre NZB-Basis als Summe aus Banknotenumlauf und Euro-Verbindlichkeiten der NZBen gegenuber dem im Euroraum ansässigen Finanzsektor. 
Abbildung 5: Die Forderungen der NZBen an den heimischen Finanzsektor zum 1.1.1999 und 31.12.1999 in Mio. Euro'

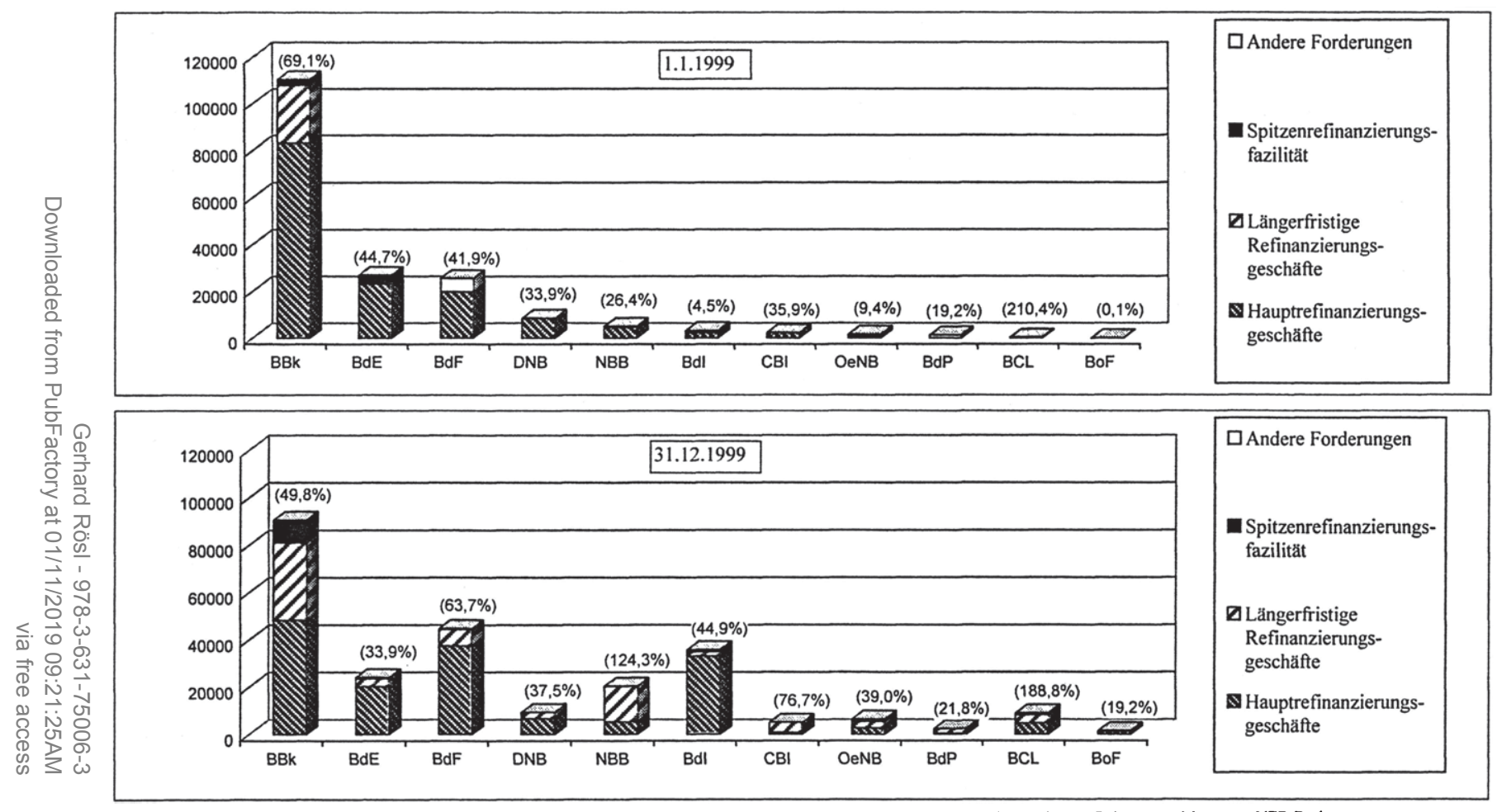

' Die in Klammern gesetzien Prozentangeben bezichen sich auf die Gesamthohe der jewelligen NZB-Forderungen an den heimischen Finanzsektor in Relation zur Monetaren NZB-Basis.

Quelle Eigene Darstellung Die der Darstellung zugrunde liegenden Daten sind entnommen aus den Tabellen 9 und II 
Die im ersten Jahr der EWU abgewickelten geldpolitischen Geschäfte des Eurosystems finden ihren bilanziellen Niederschlag im Aktivposten „Forderungen in Euro an Ansässige im Euro-Währungsgebiet" sowie in der Monetären NZB-Basis, die aus der Summe der Euroeinlagen der heimischen Kreditinstitute bei der jeweiligen NZB und dem ausgewiesenen Banknotenumlauf besteht. In der vorstehenden Tabelle 15 und in Abbildung 5 sind diese Bilanzposten zu Beginn der Währungsunion und zum 31.12.1999 zusammengestellt. Es zeigt sich eine bemerkenswerte Verschiebung der Refinanzierungsstruktur des Finanzsektors innerhalb des Eurosystems.

$\mathrm{Zu}$ Beginn der EWU verfügte einzig die Deutsche Bundesbank mit ihren ausstehenden Krediten aus dem Diskontgeschäft über Forderungen, die der Längerfristigen Refinanzierung des Eurosystems entsprachen. Und auch die den Hauptrefinanzierungsgeschäften des Eurosystems ähnlichen Wertpapierpensionsgeschäfte konzentrierten sich am 1.1.1999 überwiegend auf die Deutsche Zentralbank, da dieses geldpolitische Instrument bei fast allen anderen Notenbanken - wenn überhaupt vorhanden - nur eine vergleichsweise geringe Bedeutung hatte. Ähnliches gilt auch für die Ständigen Fazilitäten. Diese gehörten vor Beginn der Währungsunion nur vereinzelt zum geldpolitischen Instrumentarium der NZBen, weshalb auch kaum entsprechende Forderungen und/oder Verbindlichkeiten von den NZBen in die EWU eingebracht werden konnten. Am 31.12.1999 hat sich dieses Bild jedoch grundlegend geändert. So verteilten sich Ende 1999 sowohl die Hauptrefinanzierungsgeschäfte als auch die Längerfristige Refinanzierung über alle NZBen, wobei es allerdings keine aussagefähige Korrelation zwischen der Größe der nationalen Monetären NZBBasis und den entsprechenden Forderungen der jeweiligen NZBen aus Hauptbzw. Basistendern gab ${ }^{181}$. Besonders deutlich zeigt dies das Beispiel der „Überdeckung“" der Monetären NZB-Basis der Belgischen Nationalbank (NBB), welche zum 31.12.1999 über Forderungen an den heimischen Finanzsektor in Höhe von 20,5 Mrd. EUR verfügte, die gesamte Monetäre NZB-Basis Belgiens aber gerade einmal 16,5 Mrd. EUR betrug. Bei fast allen anderen NZBen hingegen reichte der Bestand an Finanzsektorforderungen Ende 1999 nicht aus, um die Monetäre NZB-Basis zu decken. Diese Beobachtungen lassen sich über drei Faktoren erklären.

Erstens zeigt bereits der kumulierte Stock an Euro-Forderungen an den Finanzsektor, den die NZBen bereits mit in die EWU eingebracht haben, daß nur 43,1 Prozent der gesamten Monetären NZB-Basen zum 1.1.1999 über solche Aktiva bereitgestellt wurden. Eine vollständige Deckung aller Monetären NZB-Basen durch diese Forderungen ist folglich nicht möglich. Zweitens wurde auch im

181 Vgl. Tabelle 15. 
ersten Jahr der EWU nicht der gesamte Zuwachs an Basisgeld allein über die geldpolitischen (Tender-) Operationen des Eurosystems zur Verfügung gestellt ${ }^{182}$. Drittens ist der grenzüberschreitende Überweisungsverkehr mit Zentralbankgeld zu berücksichtigen. So ist wegen des grenzüberschreitenden Basisgeld-Überweisungsverkehrs der Kausalzusammenhang zwischen den in der jeweiligen NZB-Bilanz ausgewiesenen „Euro-Forderungen an den Finanzsektor", die ja nur die ausstehenden Kredite an den heimischen Finanzsektor beinhalten ${ }^{183}$, und der nationalen Monetären NZB-Basis nicht mehr so eng wie vor dem Beitritt zur EWU ${ }^{184}$. Eine Analyse der Veränderung der Refinanzierungsstruktur des Eurosystems muß also grenzüberschreitende Zentralbankgeld-Überweisungen berücksichtigen.

Diese Transaktionen werden über das von den NZBen bereitgestellte TARGETZahlungsverkehrssystem abgewickelt und haben eine wichtige Auswirkung auf die NZB-Bilanzstruktur. Überweist beispielsweise der Geschäftsbankensektor in Land X Zentralbankgeld an die in Land $Y$ ansässigen Kreditinstitute, erhält die NZB des Zentralbankgeld importierenden Landes gegenüber der NZB des Zentralbankgeld exportierenden Landes eine entsprechende in Höhe des Satzes für die Hauptrefinanzierungsgeschäfte verzinste Verrechnungsforderung. Die folgende Darstellung verdeutlicht die buchungstechnische Erfassung dieses grenzüberschreitenden Überweisungsvorgangs ${ }^{185}$.

\section{Abbildung 6: Die bilanzielle Erfassung der grenzüberschreitenden Zentralbankgeld-Überweisungen in den NZB-Bilanzen}

Zentralbankgeld exportierende $\mathrm{NZB}_{\mathrm{X}}$ Zentralbankgeld importierende $\mathrm{NZB}_{\mathrm{Y}}$

A

$\mathrm{NZB}_{\mathrm{X}}$

- Einlagen der inländischen Geschäftsbanken

+ TARGETVerbindlichkeiten gegenüber der $\mathrm{NZB}_{\mathbf{Y}}$
A

$\mathrm{NZB}_{Y}$

$P$

\begin{tabular}{l|c}
\hline+ TARGET- & $+\begin{array}{l}\text { Einlagen der } \\
\text { inländischen }\end{array}$ \\
$\begin{array}{l}\text { Forderungen } \\
\text { gegenüber } \\
\text { der NZB }\end{array}$ & $\begin{array}{l}\text { Geschäfts- } \\
\text { banken }\end{array}$
\end{tabular}

${ }_{182}$ Vgl. hierzu auch die Tabelle 16.

183 Wie bereits oben erwähnt, gilt das Heimatlandprinzip bei der Teilnahme an den Tenderoperationen des Eurosystems.

Dies gilt im librigen auch, wenn man die Zentralbankgeldbereitstellung außerhalb der gemeinsamen Geldpolitik außen vor läßt.

185 Zur Funktionsweise von TARGET vgl. Europăische Gemeinschaft (2001b). 
Tabelle 16: Die Verteilung des in 1999 geschöpften (Netto-) Zentralbankgelds auf die cinzelnen NZBen und der grenzüberschreitende Überweisungsverkehr mit Basisgeld im ersten Jahr der EWU in Mio. Euro

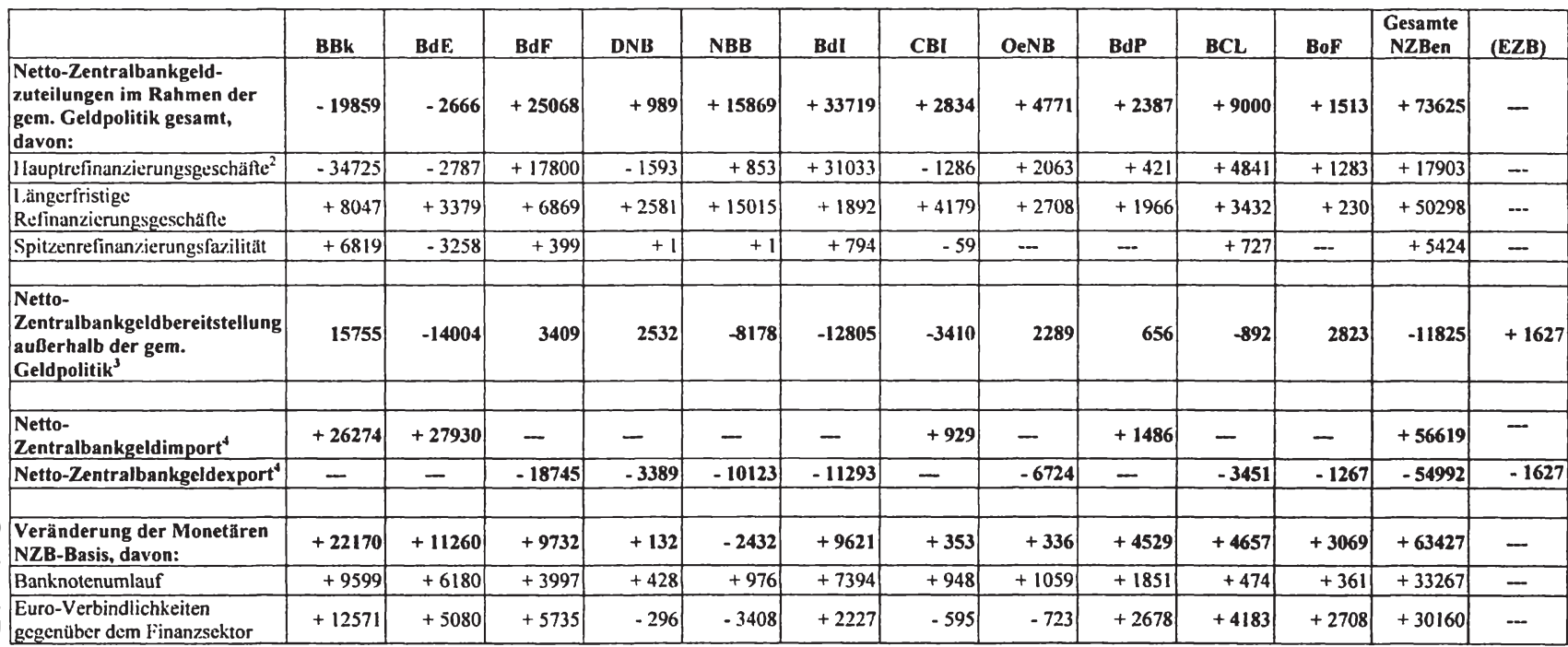

'Ermittelt durch die Verănderungswerte der zugehörigen Bilanzposten zwischen dem 31.12.1999 und dem 1.1.1999. Vgl. dazu die Tabellen 9 und I1.

Der kumulierte Wert der in 1999 über die Haupttender abgewickelten Netto-Zentralbankgeldzuteilungen weicht geringfügig von den Angaben des Eurosystems (17,1 Mrd. EUR) ab. Vgl. Tabelle 14. Zur Begründung der Abweichungen vgl. die Erläuterungen zu den Tabellen 9 und 11 im Anhang.

${ }^{3}$ Ermittelt als Differenz zwischen der Verănderung der Monetăren NZB-Basis und den Netto-Zentralbankgeldzuteilungen im Rahmen der gemeinsamen Geldpolitik korrigiert um den jeweiligen Saldo aus dem grenzuberschreitenden Netto-Zentralbankgeldimport bzw. -export.

Gemessen an „Sonstigen Intra-Eurosystem-Forderungen bzw. -Verbindlichkeiten (netto)“ der NZBen zum 31.12.1999. Vgl. Tabelle 9 und 11. Diese Posten enthalten neben den bilateralen Intra-Eurosy'stem-TARGET-Salden der NZBen in geringem Umfang auch Salden aus herkömmlichen Korrespondenzbankbeziehungen und andere bilaterale NZB-Forderungen. Die über die Konsolidierung der NZB-Angaben als Restgröße errechnete Netto-TARGET-Verbindlichkeit der EZB weicht vom tatsächlichen Wert (1721 Mio. EUR, vgl. Europăische Zentralbank $(2000 \mathrm{~h})$, S. 151) ab. Wegen der unterschiedlichen Erfassungsmethoden in den NZB-Bilanzen ist eine exakte Darstellung des grenzüberschreitenden Überweisungsverkehrs nicht möglich. $\mathrm{Vgl}$. dazu auch dic Erläuterungen zu den Tabellen 9 und 11 im Anhang. 
Anhand der vorstehenden Tabelle 16 wird nun deutlich, daß der grenzüberschreitende Handel mit Basisgeld im ersten Jahr der EWU substantielle Verschiebungen der Refinanzierungsstruktur der NZBen implizierte. So waren die deutsche und spanische Zentralbank mit 26,3 bzw. 27,9 Mrd. EUR in 1999 der mit Abstand größte Netto-Importeur von Basisgeld, während mit Ausnahme der Central Bank of Ireland (0,9 Mrd. EUR) und der Banco de Portugal (1,5 Mrd. EUR) alle anderen Notenbanken in 1999 einen Netto-Zentralbankgeldexport zu verzeichnen hatten. Der Grund für die ausgeprägten Basisgeldimporte der Deutschen Bundesbank und der Banco de España liegt im bereits erwähnten Rückgang ihrer Forderungen aus Hauptrefinanzierungsgeschäften. Dieser bedeutet für sich genommen nichts anderes als einen größengleichen Verlust an Zentralbankgeld der deutschen und spanischen Kreditinstitute, die wiederum versuchten, die über die rückläufigen Haupttender eingezogenen Basisgeldbestände über den europäischen Geldmarkt mit entsprechenden Zentralbankgeldimporten zu kompensieren. Bemerkenswert ist auch das Verhalten der belgischen Geschäftsbanken. So profitierten diese wegen ihres offensiven Bietungsverhaltens im ersten Jahr der EWU überproportional an den Nettozuteilungen der Längerfristigen Refinanzierungsgeschäfte des Eurosystems (15,0 Mrd. EUR) und verkauften zwei Drittel davon (10,1 Mrd. EUR) an das europäische „EWU-Ausland“"186. Die Begründung für dieses Verhalten könnte in unterschiedlichen Zinserwartungen im Vergleich $\mathrm{zu}$ den ausländischen Kreditinstituten liegen.

\subsubsection{Die Partizipation der NZBen an der Netto-Zentralbankgeld- bereitstellung des Eurosystems und deren Auswirkung auf die NZB- Gewinne}

Anhand der Tabelle 16 läßt sich auch verdeutlichen, in welchem Umfang die einzelnen NZBen an den Netto-Zentralbankgeldzuteilungen des Eurosystems im ersten Jahr der EWU beteiligt waren. So haben mit Ausnahme der deutschen und der spanischen Zentralbank alle NZBen in 1999 über die ausgeschriebenen Haupt- und Basistender ihrem heimischen Finanzsektor zusätzliches Zentralbankgeld netto zur Verfügung gestellt ${ }^{187}$. Der Grund für diese Asymmetrie liegt vor allem darin, daß die Zentralbanken Deutschlands und Spaniens bereits vor Beitritt zur EWU über einen beträchtlichen Bestand an „adäquaten“ Forderungen aus Hauptrefinanzierungsgeschäften verfügten, die deshalb auch

186 Vgl. auch Belgische Nationalbank (2000b), S. 85.

187 D.h. in diesen Ländern war die kumulierte Brutto-Zentralbankgeldzuteilung über das Jahr gesehen höher als die kumulierte Brutto-Zentralbankgeldvernichtung über die entsprechenden rückläufigen Tender. 
überproportional zur Brutto-Zentralbankgeldvernichtung im Rahmen von auslaufenden Haupttendern herangezogen wurden. Diese Beobachtung steht also nicht im Widerspruch $\mathrm{zu}$ der zweifellos richtigen Vermutung, da $\beta$ der überwiegende Teil der vom Eurosystem über die Tender abgewickelten BruttoZentralbankgeldzuteilungen den deutschen Geschäftsbanken zukam. Die NettoZentralbankgeldzuteilungen, die das Eurosystem über die Längerfristigen Refinanzierungsgeschäfte durchgeführt hat, sind hingegen gleichmäßiger auf die einzelnen NZBen verteilt, da zumindest alle NZBen ihre Basistenderforderungen in 1999 erhöhen konnten ${ }^{188}$. Allerdings gibt es große Unterschiede bei der Verteilung der Zuwächse. Die Tabelle 16 zeigt auch den Umfang desjenigen Zentralbankgelds, das die NZBen in 1999 außerhalb der Tenderoperationen (netto) geschöpft bzw. vernichtet haben. Insgesamt haben die NZBen auf diese Weise Zentralbankgeld in Höhe von 11,8 Mrd. EUR kumuliert eingezogen, wenngleich sich dies sehr heterogen auf die einzelnen NZBen verteilt. So hat die Hälfte der nationalen Währungsbehörden sogar zusätzliches Zentralbankgeld bereitgestellt, am meisten davon die Deutsche Bundesbank (15,8 Mrd. EUR). Solche Operationen laufen freilich nicht ohne Wissen der EZB ab, sind aber Ausdruck der vielschichtigen Tätigkeiten, die die NZBen auch außerhalb der gemeinsamen Geldpolitik wahrnehmen. Da der Umfang solcher Aktivitäten im weiteren Verlauf dieser Arbeit noch ausgiebig untersucht wird, soll an dieser Stelle der Hinweis genügen, daß ein Unterlaufen der Geldpolitik der EZB durch diese Operationen nicht möglich ist. Empirisch zu vernachlässigen sind diese Volumina jedoch nicht. Tabelle 16 läßt nun auch gewisse Rückschlüsse hinsichtlich der Auswirkung der in 1999 zu beobachtenden Verlagerung der Refinanzierung innerhalb des Eurosystems auf die einzelnen NZB-Gewinne zu. Insgesamt größter Profiteur aus den geldpolitischen Operationen des Eurosystems dürfte im ersten Jahr der EWU die italienische Zentralbank sein, die mit 33,7 Mrd. EUR fast die Hälfte der gesamten über die Tender abgewickelten Nettozuteilungen in 1999 auf sich vereinigen konnte. Die Deutsche Bundesbank hingegen hat aus den genannten Gründen einen deutlichen Rückgang ihrer Tenderforderungen und damit ihrer zugehörigen Zinserträge hinnehmen müssen. Allerdings darf in diesem Zusammenhang weder die Zentralbankgeldbereitstellung außerhalb der gemeinsamen Geldpolitk noch der grenzüberschreitende Basisgeld-Überweisungsverkehr übersehen werden.

Eine konkrete Berechnung der einzelnen Zinsgewinne und -verluste der NZBen, die auf die Verlagerung der Refinanzierung innerhalb des Eurosystems im Jahr

188 Die Inanspruchnahme der Spitzenrefinanzierungsfazilität bleibt im Folgenden außen vor, da die tagesdurchschnittliche Inanspruchnahme in 1999 insgesamt unbedeutend war. Vgl. Tabelle 14. 
1999 zurückzuführen waren, gestaltet sich allerdings sehr schwierig. So lassen die verfügbaren Jahresanfangs- und Jahresenddaten der NZB-Bilanzposten letztlich nur einen Vergleich zweier Zeitpunkte zu, sie sagen aber nichts über die Entwicklung innerhalb dieses Zeitraums aus. Deshalb soll als Behelfslösung wie folgt vorgegangen werden. So erfolgt die „Schätzung“ der Erträge der NZBen aus ihrer Beteiligung an den vom Eurosystem in 1999 über Haupt- und Basistender abgewickelten Netto-Zentralbankgeldzuteilungen durch Multiplikation der Veränderungswerte der Haupt- und Längerfristigen Refinanzierungsgeschäfte der NZBen mit den zugehörigen jahresdurchschnittlichen Zinssätzen (2,71\% bzw. 2,89\%). Ähnlich wird bei der Berechnung der Erträge aus der Netto-Basisgeldschöpfung außerhalb des geldpolitischen Instrumentariums sowie aus dem TARGET-Überweisungsverkehr verfahren, wobei hier der jahresdurchschnittliche Satz für Haupttender (2,71\%) angesetzt wird. Dieses Vorgehen unterstellt freilich, daß die den Veränderungswerten zugrunde liegenden Geschäfte jeweils als einzige Transaktion zum 1.1.1999 durchgeführt wurden. Zudem muß die relativ reichliche Ausstattung der Geschäftsbanken mit Zentralbankgeld zum 31.12.1999 berücksichtigt werden (Weihnachtsgeschäft und Jahr-2000-Problem). Deswegen dürfen die in der folgenden Tabelle 17 vorgestellten „Schätzungen“ der Zinserträge, die die NZBen aus der NettoZentralbankgelderhöhung des Eurosystems im ersten Jahr der EWU erwirtschaftet haben, auch nur als eine Art Beispielrechnung zur Darstellung grundsätzlicher Größenordnungen verstanden werden.

In jedem Falle wird jedoch deutlich, wie stark die Verzinsung der TARGETSalden dazu beiträgt, entgangene Zinseinkünfte der NZBen aus der Verschiebung der Refinanzierungsstruktur innerhalb des Eurosystems zu kompensieren. So erzielt beispielsweise die Bundesbank, die als einzige NZB Zinsverluste aus dem Rückgang von Haupt- und Basistendern in Höhe von sehr grob geschätzten 708 Mio. EUR zu verzeichnen hatte, bereits nach der Anrechnung ihrer Zinserträge aus Netto-TARGET-Forderungen (712 Mio. EUR) eine Nettozinsposition von 4 Mio. EUR. Zudem dürfte die Zentralbank Deutschlands auch über die größten Zinserträge aus der zusätzlichen Zentralbankgeldproduktion außerhalb der gemeinsamen geldpolitischen Operationen erzielt haben (als Orientierungsgröße 427 Mio. EUR). Bei den anderen NZBen zeigt sich ein sehr heterogenes Bild. Allerdings haben wohl alle nationalen Währungsbehörden bis auf die Belgische Nationalbank aus dem Zuwachs ihrer Monetären NZB-Basen entsprechende Bruttozinseinkünfte erwirtschaftet, wenngleich diese nicht allein auf die Partizipation an den Tendergeschäften des Eurosystems zurückzuführen sind. 
Tabelle 17: Geschätzte Zinserträge der NZBen aus der Netto-Zentralbankgelderhöhung des Eurosystems im ersten Jahr der EWU in Mio. Euro'

\begin{tabular}{|c|c|c|c|c|c|c|c|c|c|c|c|c|}
\hline & BBk & BdE & BdF & DNB & NBB & BdI & CBI & OeNB & BdP & BCL & BoF & \begin{tabular}{|c|} 
Gesamte \\
NZBen \\
\end{tabular} \\
\hline $\begin{array}{l}\text { Zinserträge (+), -aufwand (-) aus der } \\
\text { Beteiligung der NZBen an den vom } \\
\text { Eurosystem in } 1999 \text { über Haupt- und } \\
\text { Basistender abgewickelten Netto- } \\
\text { Zentralbankgeldzuteilungen, davon: }\end{array}$ & -708 & 22 & 681 & 31 & 457 & 896 & 86 & 134 & 68 & 230 & 41 & 1939 \\
\hline $\begin{array}{l}\text { Zinsertrag (+)/ verlust (-) aus Netto- } \\
\text { Zentralbankgeldzuteilung uber } \\
\text { Haupttender }\end{array}$ & -941 & -76 & 482 & -43 & 23 & 841 & -35 & 56 & 11 & 131 & 35 & 485 \\
\hline $\begin{array}{l}\text { Zinsertrag (+)/ verlust (-) aus Netto- } \\
\text { Zentralbankgeldzuteilung uber } \\
\text { Basistender }\end{array}$ & 233 & 98 & 199 & 75 & 434 & 55 & 121 & 78 & 57 & 99 & 7 & 1454 \\
\hline $\begin{array}{l}\text { Zinserträge (+), -aufwand (-) aus der } \\
\text { Netto-Zentralbankgeldschöpfung } \\
\text { außerhalb der gemeinsamen } \\
\text { Geldpolitik }\end{array}$ & 427 & -380 & 92 & 69 & -222 & -347 & -92 & 62 & 18 & -24 & 77 & -320 \\
\hline $\begin{array}{l}\text { Nettozinserträge }(+), \text {-aufwand }(-) \text { aus } \\
\text { TARGET }\end{array}$ & 712 & 757 & -508 & -92 & -274 & -306 & 25 & -182 & 40 & -94 & -34 & 44 \\
\hline $\begin{array}{l}\text { Zinserträge (+), -aufwand (-) aus } \\
\text { Netto-Zentralbankgelderhöhung }{ }^{3} \\
\text { (in vH. der Bruttozinseinkünfte in } \\
1999)^{4}\end{array}$ & $\begin{array}{c}431 \\
(6,9 \%)\end{array}$ & $\begin{array}{c}399 \\
(12,9 \%)\end{array}$ & $\begin{array}{c}265 \\
(7,7 \%)\end{array}$ & $\begin{array}{c}8 \\
(0,6 \%)\end{array}$ & $\begin{array}{c}-39 \\
(-3,9 \%)\end{array}$ & $\begin{array}{c}243 \\
(6,1 \%)\end{array}$ & $\begin{array}{c}19 \\
(4,3 \%)\end{array}$ & $\begin{array}{c}14 \\
(1,2 \%)\end{array}$ & $\begin{array}{c}126 \\
(17,7 \%)\end{array}$ & $\begin{array}{c}112 \\
(36,2 \%)\end{array}$ & $\begin{array}{c}83 \\
(17,1 \%)\end{array}$ & $\begin{array}{c}1663 \\
(7,7 \%)\end{array}$ \\
\hline
\end{tabular}

a) 6 (

Q

' Zur Herleitung und Interpretation der Schătzung vgl. die Ausführungen im Text.

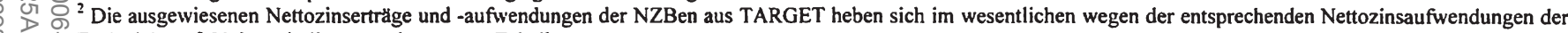
is $\leq \omega$ EZB nicht auf. Vgl. auch die Anmerkungen zu Tabelle 16.

${ }^{3}$ Ohne Berilcksichtigung der geschőpften Zentralbankgeldbestănde aufgrund der Inanspruchnahme der Spitzenrefianzierungsfazilităt.

${ }^{4}$ Zur Hobhe der Bruttozinseinkünfte der NZBen im Jahre 1999 vgl. Tabelle 12. 


\section{Die Beteiligung der NZBen an der Banknotenemission}

Die Zinserträge, die die NZBen aus der Emission von neu emittierten Banknoten erwirtschaften, wurden bereits im Rahmen der Analyse der geldpolitischen Operationen des Eurosystems implizit behandelt ${ }^{189}$. Deshalb sollen die folgenden Ausführungen die Beteiligung der NZBen an der Herstellung und der Ausgabe der Banknoten näher untersuchen.

\subsection{Die Beteiligung der NZBen an der Herstellung der Banknoten}

Die Herstellung der Euro-Banknoten obliegt den NZBen des Eurosystems. Die EZB beschränkt sich auf ihre Kompetenz, die Ausgabe von Banknoten innerhalb der Gemeinschaft zu genehmigen. Hierzu erstellt sie mit Hilfe der NZBen die erforderlichen Bedarfsschätzungen ${ }^{190}$. Die EWU-Staaten können jedoch selbst entscheiden, wo sie ihre Banknoten produzieren. So ziehen es Irland, Belgien, Frankreich, Italien und Griechenland vor, die benötigten Noten von ihren NZBen fertigen zu lassen, während die anderen Mitgliedstaaten entweder auf staatliche und/oder private Druckereien zurückgreifen ${ }^{191}$. Weiterhin muß die Herstellung der Banknoten nicht notwendigerweise im Inland erfolgen. So läßt beispielsweise Luxemburg seine Euro-Noten in Deutschland und in den Niederlanden produzieren. In jedem Falle haben aber die EWU-Länder ihre Herstellungskosten selbst zu tragen, wobei es letztlich die heimische NZB ist, die diese Aufwendungen finanziert. Allerdings ist eine vergleichende Darstellung dieser NZB-Fertigungskosten nicht möglich ${ }^{192}$. Um jedoch zumindest einen Eindruck von den Größenordnungen der herzustellenden Euro-Banknoten zu bekommen, sind in Tabelle 18 die von den EWU-12 Ländern für die Erstausstattungsmenge zu fertigenden Stückzahlen ausgewiesen.

189 Zur Diskussion der Erträge aus dem Stock der Banknoten, die die NZBen bereits mit in die EWU eingebracht haben vgl. auch die Ausführungen zum Pooling der Monetären Einkünfte in Kapitel V.3.1.2. Abschnitt 3.. Vgl. auch die theoretischen Überlegungen zum Totalen Banknotengewinn in Kapitel II. Abschnitt 4.1.2..

$190 \mathrm{Vgl}$. im Folgenden Europäische Zentralbank (2001d), S. 142 ff. und European Central Bank (2001c). Die EZB ermächtigte die NZBen, bis Ende 2001 ihre nationalen Banknoten nach den nationalen Gepflogenheiten zu emittieren, allerdings waren die zu emittierenden Bestände an die EZB zu melden. Vgl. European Central Bank (1999b).

191 Oft halten die NZBen jedoch Beteiligungen an den Druckereibetrieben. Vgl. z.B. die Unternehmensbeteiligungen der BdP, OeNB und BoF in Tabelle 29.

192 So enthalten die in den Jahresberichten ausgewiesenen „Aufwendungen für Banknotenproduktion" (vgl. Tabellen 10 und 12) sowohl Kosten aus der Produktion von nationalen Denominierungen des Euro als auch aus der Fertigung der Euro-Banknoten. 
Tabelle 18: Die Beteiligung der NZBen an der Herstellung der Erstausstattungsmenge an Euro-Banknoten

\begin{tabular}{|l|l|l|l|}
\hline $\begin{array}{l}\text { EWU- } \\
\text { Mitgliedstaat }\end{array}$ & $\begin{array}{l}\text { Herstellung der Euro- } \\
\text { Banknoten durch }\end{array}$ & $\begin{array}{l}\text { Hergestellte Euro- } \\
\text { Banknoten in Mio. } \\
\text { Stück (in vH. der } \\
\text { Gesamtmenge) }\end{array}$ & $\begin{array}{l}\text { Banknotenumlauf } \\
\text { Ende 1999 in Mio. } \\
\text { EUR (in vH. der } \\
\text { Gesamtmenge) }\end{array}$ \\
\hline Deutschland & $\begin{array}{l}\text { Bundesdruckerei, Berlin } \\
\text { Giesecke \& Devrient, } \\
\text { München }\end{array}$ & $4782,9(32,1 \%)$ & $140150(36,5 \%)$ \\
\hline Frankreich & $\begin{array}{l}\text { Banque de France, } \\
\text { Chamalières }\end{array}$ & $2265,0(15,2 \%)$ & $46261(12,0 \%)$ \\
\hline Italien & Banca d'Italia, Rom & $2439,7(16,4 \%)$ & $70614(18,4 \%)$ \\
\hline Spanien & $\begin{array}{l}\text { Fábrica Nacional y Timbre, } \\
\text { Madrid }\end{array}$ & $1924,1(12,9 \%)$ & $58911(15,3 \%)$ \\
\hline Niederlande & $\begin{array}{l}\text { Johan Enschedé \& Zn., } \\
\text { Haarlem }\end{array}$ & $659,0(4,4 \%)$ & $17715(4,6 \%)$ \\
\hline Griechenland & Bank of Greece, Athen & $617,0(4,1 \%)$ & $9101(2,4 \%)$ \\
\hline Österreich & $\begin{array}{l}\text { Österreichische Banknoten- } \\
\text { und Sicherheitdruck GmbH, } \\
\text { Wien }\end{array}$ & $550,0(3,7 \%)$ & $13328(3,5 \%)$ \\
\hline Portugal & Valora, Carregado & $537,5(3,6 \%)$ & $6932(1,8 \%)$ \\
\hline Belgien ${ }^{2}$ & $\begin{array}{l}\text { Belgische Nationalbank, } \\
\text { Brüssel }\end{array}$ & $550,0(3,7 \%)$ & $12947(3,4 \%)$ \\
\hline Finnland & Setec Oy, Vantaa & $225,0(1,5 \%)$ & $3008(0,8 \%)$ \\
\hline Irland & $\begin{array}{l}\text { Central Bank of Ireland, } \\
\text { Dublin }\end{array}$ & $293,7(2,0 \%)$ & $4524(1,2 \%)$ \\
\hline Luxemburg ${ }^{3}$ & $\begin{array}{l}\text { Bundesdruckerei, Berlin } \\
\text { Johan Enschedé \& Zn., } \\
\text { Haarlem }\end{array}$ & $46,0(0,3 \%)$ & $585(0,2 \%)$ \\
\hline Gesamt & --- & $14889,9(100,0 \%)$ & $384078(100,0 \%)$ \\
\hline
\end{tabular}

Quelle: Eigene Berechnungen. Die der Darstellung zugrunde liegenden Daten sind entnommen aus Bank of Greece (2000a), European Central Bank (2001b), Europäische Zentralbank (2001d), S. 148 und Tabelle 11. Differenzen in den Summen durch Runden der Zahlen.

${ }^{1}$ Inklusive einer logistischen Reserve in Höhe von rund einem Drittel der Erstausstattungsmenge. Vgl. European Central Bank (2001c).

${ }^{2}$ Der in der Bilanz der Belgischen Nationalbank zum 31.12.1999 ausgewiesene Banknotenumlauf (12947,3 Mio. EUR) entspricht dem ,theoretischen“ BEF-Umlauf in Belgien. Der Ende 1999 von der NBB emittierte Gesamtbestand an BEF-Banknoten (13432,1 Mio. EUR) schließt die in der BCL-Bilanz ausgewiesenen BEF-Noten (484,8 Mio. EUR) mit ein. Vgl. Belgische Nationalbank (2000b), S. 86. Letztere entsprechen dem geschätzten BEF-Umlauf in Luxemburg. Diese bilanzielle Aufsplittung ist auf die Lösung der belgisch-luxemburgischen Währungsunion zum 31.12.1998 zurückzuführen.

${ }^{3}$ Der in der BCL-Bilanz zum 31.12.1999 ausgewiesene Banknotenumlauf (585,3 Mio. EUR) setzt sich aus dem LUF-Banknotenumlauf (100,5 Mio. EUR) und dem „theoretischen“ BEF-Umlauf in Luxemburg (484,8 Mio. EUR) zusammen. Vgl. Banque Centrale du Luxembourg (2000c), S. 122. Die bis zum 31.12.1998 ebenfalls in Luxemburg umlaufenden Banknoten der Banque Internationale à Luxembourg (BIL) verloren mit Wirkung vom 1.1.1999 ihre Eigenschaft als gesetzliches Zahlungsmittel und werden in der BCL-Bilanz nicht erfaßt. Vgl. Art. 36 Abs. 2 BCL-Gesetz. 
Hierbei zeigt sich, daß Deutschland mit 4782,9 Mio. Stück die mit Abstand größte Anzahl an Euro-Banknoten zu produzieren hatte. Dies entspricht 32,1 Prozent der gesamten Euro-Banknotenmenge und ist etwa doppelt so viel wie der Anteil Frankreichs (15,2 Prozent) oder der Banca d'Italia (16,4 Prozent). Substantielle Bestände fertigte nur noch Spanien mit 1924,1 Mio. Stück (12,9 Prozent), während alle anderen EWU-Staaten jeweils weniger als fünf Prozent der gesamten Euro-Banknoten herstellten. Dabei verteilt sich die Herstellung der einzelnen Denominierungen der Euro-Banknoten nicht symmetrisch auf die EWU-Länder, sondern orientiert sich an den nationalen Zahlungsgewohnheiten ${ }^{193}$. So stellt allein Deutschland 59 Prozent aller zu produzierenden 500 EUR-Banknoten bzw. 45 Prozent der 200 EUR-Banknoten her, was freilich dazu führt, daß gemessen am Nominalwert des Euro-Banknotenumlaufs der deutsche Produktionsanteil entsprechend höher anzusetzen ist als der Stück bezogene deutsche Anteil ${ }^{194}$.

\subsection{Die Beteiligung der NZBen an der Ausgabe der Banknoten}

Nach Art. 16 ESZB-Satzung und Art. 106 Abs. 1 EGV sind sowohl die EZB als auch die NZBen zur Ausgabe von Banknoten befugt. Wie die nachstehende Tabelle 19 zeigt, entfallen dabei acht Prozent des gesamten Nennwerts der ausgegebenen Euro-Banknoten auf die EZB, während die restlichen 92 Prozent von den NZBen emittiert werden ${ }^{195}$.

Tabelle 19: Schlüssel zur Verteilung der Euro-Banknoten innerhalb des Eurosystems

\begin{tabular}{|l|r|l|r|}
\hline Europäische Zentralbank & $8 \%$ & Österr. Nationalbank & $2,6800 \%$ \\
\hline Deutsche Bundesbank & $27,8215 \%$ & Bank of Greece & $2,3360 \%$ \\
\hline Banque de France & $19,1210 \%$ & Banco de Portugal & $2,1845 \%$ \\
\hline Banca d'Italia & $16,9190 \%$ & Bank of Finland & $1,5845 \%$ \\
\hline Banco de España & $10,1020 \%$ & Central Bank of Ireland & $0,9650 \%$ \\
\hline $\begin{array}{l}\text { De Nederlandsche } \\
\text { Bank }\end{array}$ & $4,8595 \%$ & $\begin{array}{l}\text { Banque centrale du } \\
\text { Luxembourg }\end{array}$ & $0,1695 \%$ \\
\hline Belgische Nationalbank & $3,2550 \%$ & Gesamt & $100,000 \%$ \\
\hline
\end{tabular}

Quelle: Europäische Zentralbank (2001f), S. 6.

193 Vgl. European Central Bank (200lb).

194 Vgl. auch Tabelle 18 und Courtis (1999), S. 54.

$195 \mathrm{Vgl}$. im Folgenden Europäische Zentralbank (2001f), S. 4 ff.. 
Erklären läßt sich diese Aufteilung dahingehend, daß die EZB als eine von dreizehn Zentralbanken des Eurosystems ein Dreizehntel, also rund acht Prozent, der Euro-Banknoten ausgeben soll, während der verbleibende Anteil den einzelnen NZBen nach Maßgabe ihres gezahlten EZB-Kapitalanteils zusteht. Dieser Verteilungsschlüssel trägt einerseits den vertragsrechtlichen Kriterien des Art. 16 ESZB-Satzung bzw. des Art. 106 Abs. 1 EGV Rechnung und ist andererseits durch eine präventive Bilanzkosmetik begründet. So befürchtet man offensichtlich, daß es zu größeren Verlagerungen des jeweils in den NZB-Bilanzen ausgewiesenen „nationalen" Banknotenumlaufs innerhalb des Eurosystems kommen könnte ${ }^{196}$. Um eine solche Entwicklung, die zwar wegen des noch $\mathrm{zu}$ untersuchenden Poolings der Geldschöpfungsgewinne inhaltlich völlig unproblematisch ist, für die breite Öffentlichkeit etwas freundlicher $\mathrm{zu}$ gestalten, hat man sich seit dem 1.1.2002 auf folgendes buchungstechnische Vorgehen geeinigt. Zunächst wird der gesamte Wert aller umlaufenden Euro-Banknoten zum (monatlichen) Bilanzstichtag ermittelt. Dieser wird dann nach Maßgabe des genannten Verteilungsschlüssels auf die verschiedenen Zentralbanken aufgeteilt und jeweils in die Bilanzen als „Banknotenumlauf" eingestellt. Da die EZB im Gegensatz zu den NZBen keine Euro-Noten in Umlauf setzt, erhält sie eine entsprechende größengleiche verzinsliche Forderung gegenüber den NZBen, die sich im einzelnen nach dem gezahlten EZB-Kapitalanteil bestimmt. Die NZBen stellen ihrerseits entsprechende „Intra-Eurosystem-Verbindlichkeiten aus Banknoten“ gegenüber der EZB in ihre Bücher ein. Des weiteren haben diejenigen NZBen, bei denen der Wert der tatsächlich von ihnen emittierten Euro-Noten über ihrem jeweils zugeteilten Emissionsvolumen liegt, zusätzliche Intra-Eurosystem-Verbindlichkeiten gegenüber den anderen NZBen, "für die" sie die entsprechenden Banknoten in Umlauf gebracht haben, auszuweisen. Eine NZB, deren Wert an tatsächlich emittierten Euro-Noten jedoch unterhalb ihres Zuteilungsvolumens liegt, stellt als Ausgleichsposten entsprechende Forderungen an die anderen NZBen in ihre Bücher ein. $\mathrm{Zu}$ letzt werden die so ermittelten Intra-Eurosystem-BruttoForderungen und -Verbindlichkeiten verrechnet und als Nettoposten ausgewiesen ${ }^{197}$. Will man nun das tatsächliche Ausgabevolumen an Banknoten einer NZB bestimmen, so braucht man nur die ausgewiesenen „Intra-EurosystemNettosalden aus Euro-Banknoten“ mit dem jeweiligen Bilanzposten „Banknotenumlauf" zu verrechnen.

196 Theoretisch könnte eine NZB sogar einen negativen Banknotenumlauf ausweisen.

197 Die Verzinsung der Netto-Salden aus Euro-Banknoten erfolgt mit Hilfe des aktuellen Satzes für Hauptrefinanzierungsgeschäfte. Vgl. Europäische Zentralbank (2001g), S. 5. 
Neben den Herstellungskosten haben die NZBen u.U. auch die Aufwendungen für die Lagerung der Banknoten (inkl. Sicherheitspersonal) sowie die Emissionskosten (Verwaltungskosten, Logistik, usw.) zu finanzieren. Gerade letztere fallen naturgemäß bei denjenigen NZBen relativ stark ins Gewicht, die Euro-Banknoten auch in überseeischen Territorien ausgeben. In welchen Gebieten der Euro als gesetzliches Zahlungsmittel von den NZBen emittiert wird, ist in der folgenden Abbildung 7 aufgezeigt ${ }^{198}$.

Während in europäischen Gebieten der EWU-Staaten die Emissionskosten wohl bei den zuständigen Notenbanken verbleiben, werden die Aufwendungen der Banque de France bzw. der Banca d'Italia aus der Bereitstellung von Banknoten für den Zahlungsverkehr in Monaco bzw. in San Marino und Vatikanstadt vermutlich an die vor Ort ansässigen (Währungs-) Behörden der Kleinstaaten weitergereicht ${ }^{199}$.

In den außereuropäischen Territorien Frankreichs, Spaniens und Portugals sind ebenfalls die jeweiligen NZBen für den örtlichen Euro-Banknotenumlauf zuständig. In den französischen Überseegebieten erfolgt die Emission der EuroBanknoten jedoch nicht unmittelbar durch die Banque de France, sondern über das Institut d'Émission des Départements d'Outre-Mer (IEDOM). Hierzu stellt die Banque de France dem IEDOM auf Basis eines grundsätzlich unbegrenzten und zinsfreien Kredits die erforderlichen Banknoten zur Verfügung ${ }^{200}$. Funktional gesehen ist das IEDOM folglich - zumindest was die Emission der Euro-Banknoten betrifft - einer Niederlassung der französischen Zentralbank sehr ähnlich. Ob die Banque de France dem IEDOM auch entsprechende Aufwandsentschädigungen für die Erstausstattung an Euro-Banknoten zahlt, soll hier offenbleiben.

198 Des weiteren wird der Euro auch als gesetzliches Zahlungsmittel in Montenegro akzeptiert. Diese Region ist aber nicht dem Euro-Währungsraum zuzurechnen, da das Eurosystem dort keine Banknoten und Münzen emittiert.

199 Am einfachsten wäre es sicherlich, die produzierten Euro-Banknoten zum Nennwert zu verkaufen. Solche Fragen dürften in den jeweiligen bilateralen Vereinbarungen zwischen der Gemeinschaft und den angesprochenen Kleinstaaten geregelt sein. Vgl. Europäische Gemeinschaft (1999c), Europäische Gemeinschaft (1999d) und Europäische Gemeinschaft (1999e). Auch in Andorra wird der Euro zirkulieren, erhält aber nicht den Status eines gesetzlichen Zahlungsmittels. Vgl. European Central Bank (2001e), S. 43.

$200 \mathrm{Vgl}$. Banque de France (2000c), S. 248. Einem Abkommen zwischen dem IEDOM und der BdF zufolge soll sich die Höhe der BdF-Forderungen an das IEDOM jedoch am örtlichen Banknotenumlauf orientieren. Vgl. Banque de France (1999a), S. 214. 


\section{Abbildung 7: Die Euro-Banknotenemission in Europa und in außereuropäischen Territorien}

\begin{tabular}{|c|c|c|c|}
\hline \multicolumn{4}{|c|}{ Euro-Banknotenemission in } \\
\hline \multicolumn{2}{|c|}{$\underbrace{\text { Europa }}$} & \multicolumn{2}{|c|}{ Außereuropåische Territorien } \\
\hline EWU-Staaten & Nicht-EWU-Staaten & $\begin{array}{l}\text { Geltungsbereich des } \\
\text { Vertrages }\end{array}$ & $\begin{array}{l}\text { Kein Geltungsbereich des } \\
\text { Vertrages }\end{array}$ \\
\hline - Belgien & - Monaco & - Französische Gebiete: & - Französische Gebiete: \\
\hline - Deutschland & - San Marino & - Martinique & - Saint Pierre/Miquelon \\
\hline - Finnland & - Vatikanstadt & - Guadeloupe & - Mayotte \\
\hline - Frankreich & & - Reunion & \\
\hline - Griechenland & & - Franzossisch Guinea & \\
\hline - Irland & & - Spanische Gebiete: & \\
\hline - Italien & & - Kanaren & \\
\hline - Luxemburg & & - Ceuta & \\
\hline - Niederlande & & - Melilla & \\
\hline - Österreich & & - Portugiesische Gebiete: & \\
\hline - Portugal & & - Azoren & \\
\hline - Spanien & & - Madeira & \\
\hline
\end{tabular}

Quelle: Eigene Darstellung. Die der Darstellung zugrunde liegenden Angaben sind entnommen aus: Deutsche Bundesbank (1999d), S. 111 und European Central Bank (2001e), S. 43 ff.. 


\section{Die Beteiligung der NZBen an der Erstellung von Statistiken des Eurosystems}

Nach Art. 5.1. ESZB-Satzung sind die NZBen verpflichtet, die EZB bei der Erhebung von statistischen Daten zu unterstützen, die zur Wahrnehmung der ESZB-Aufgaben erforderlich sind. Hierzu nimmt die EZB die NZBen bei der Ausführung der in Art. 5.1. ESZB-Satzung bezeichneten Aufgaben ,soweit wie möglich" in Anspruch (Art. 5.2. ESZB-Satzung). Konkret bedeutet dies, daß die NZBen im Auftrag der EZB Daten von den Berichtspflichtigen erheben, die gewünschten nationalen Statistiken erstellen und diese an die EZB melden. Hierzu zählen im wesentlichen die Geld- und Bankenstatistik, die Zahlungsbilanzstatistik, die Finanzierungs- und Vermögensrechnung, die Statistik zur Finanzlage der öffentlichen Haushalte sowie eine Allgemeine Wirtschaftsstatistik $^{201}$. Die EZB hingegen beschränkt sich in der Regel auf die Aggregation der nationalen Statistiken.

Auf die Ertragslage der NZBen hat die beschriebene Aufgabenteilung innerhalb des Eurosystems unterschiedliche Auswirkungen. Dies liegt daran, daß die Zentralbanken nicht notwendigerweise alle von der EZB geforderten Daten selbst erheben müssen. So können die NZBen, solange die Erhebungstechnik dem EZB-Berichtsrahmen entspricht, auch auf die nationalen statistischen Ämter zurückgreifen und sich so die entsprechenden Erhebungskosten sparen. Im Gegenzug erbringen aber manche NZBen auch für die nationalen Statistikämter entsprechende Leistungen ${ }^{202}$. Diese Erhebungen, die von den NZBen in eigener Verantwortung durchgeführt werden, sollen jedoch an dieser Stelle nicht weiter untersucht werden, da diese Tätigkeit als Eurosystemunabhängig klassifiziert wird. Eine Quantifizierung der von den NZBen zu finanzierenden Eurosystem-spezifischen bzw. -abhängigen Statistikaufwendungen bzw. -gebühren ist nicht möglich.

\section{Die Beteiligung der NZBen an Verrechnungs- und Zahlungssystemen}

Nach Art. 3.1. Spstr. 4 ESZB-Satzung gehört es zu den grundlegenden Aufgaben des ESZB (bzw. des Eurosystems), das reibungslose Funktionieren der Zahlungssysteme zu fördern. Hierzu können die EZB und die NZBen entsprechende Einrichtungen entweder selbst zur Verfügung stellen oder Zahlungs- und Verrechnungssysteme, die von anderen Betreibern angeboten werden, auf Basis von einschlägigen EZB-Verordnungen überwachen (Art. 22

$201 \mathrm{Vgl}$. Europäische Zentralbank (2000d), Europäische Zentralbank (2000f) und Europäische Zentralbank (2001d), S. 152 ff..

202 Vgl. Europäische Zentralbank (2000g), S. 93 und Kapitel V.2.2.2. Abschnitt 6.. 
ESZB-Satzung). Die Zentralbanken der EU stellen mit dem bereits erwähnten TARGET-System ein entsprechendes EU-weites grenzüberschreitendes Zahlungsverkehrssystem bereit. Unter dem Aspekt der NZB-Gewinnentstehung sind hierbei vor allem der über TARGET abgewickelte grenzüberschreitende Zahlungsverkehr sowie die TARGET-Entgelte und-Ausgleichszahlungen von Bedeutung.

Da die grenzüberschreitenden Überweisungen innerhalb des Eurosystems bereits im Rahmen der Analyse der gemeinsamen Geldpolitik untersucht wurden, soll an dieser Stelle nur auf die Auswirkungen der TARGET-Teilnahme der Pre-InNZBen auf die Gewinnentstehung der EWU-NZBen eingegangen werden. Um ihren heimischen Geschäftsbanken Innertagesliquidität in Euro anbieten zu können, halten die Pre-In-NZBen beim Eurosystem Euro-Einlagen ${ }^{203}$. Bei welchen Zentralbanken und in welcher Höhe die Pre-In-NZBen ihre EuroDepositen unterhalten, gibt das Eurosystem jedoch nicht an. Deshalb lassen sich auch keine konkreten Aussagen treffen, in welchem Umfang die betreffenden NZBen (und die EZB) Zinsaufwendungen zu tragen haben: Insgesamt dürften diese wohl bei keiner NZB eine zentrale Rolle spielen, da die Verzinsung der Euro-Einlagen nur in Höhe des Satzes der Einlagefazilität erfolgt.

Die NZBen erhalten als Anbieter der nationalen RTGS-Systeme von den Kreditinstituten Entgelte für die Benutzung des TARGET-Zahlungssystems. Dabei wird die jeweilige Gebühr ausschließlich von der absendenden NZB erhoben und ist unabhängig vom Zielort oder vom Betrag der Zahlung EU-weit identisch. Die Höhe dieser Entgelte wird vom EZB-Rat bestimmt und deckt die anfallenden Bearbeitungs- und Abwicklungskosten ${ }^{204}$. Des weiteren wurde am 1.1.2001 ein Verfahren für Ausgleichszahlungen in TARGET eingeführt ${ }^{205}$. Diese Zahlungen sollen Teilnehmer für entstehende Mehrkosten entschädigen, die anfallen, wenn sie wegen systembedingten Störungen auf die Ständigen Fazilitäten des Eurosystems zurückgreifen müssen. Wie jedoch diese Entschädigungsleistungen im einzelnen finanziert werden, muß hier offenbleiben.

203 Für die Bank of England ist die Höhe der Einlage beim Eurosystem auf maximal 3 Mrd. EUR pro Tag und für die Zentralbanken Dänemarks und Schwedens jeweils auf höchstens $1 \mathrm{Mrd}$. EUR pro Tag festgelegt worden. Alle drei Pre-In-NZBen dürfen an ihren heimischen Finanzsektor Euro-Innertageskredite von maximal 1 Mrd. EUR vergeben. Vgl. Europäische Zentralbank (1998).

204 Vgl. Deutsche Bundesbank (1999d), S. 136 f..

205 Vgl. Europäische Zentralbank (2001d), S. 76. 
Auch bei der Überwachung von Zahlungssystemen, die von anderen Betreibern angeboten werden, sind die NZBen tätig. Dies betrifft sowohl die Aufsicht über Großbetragszahlungs- als auch über Massenzahlungssysteme ${ }^{206}$. Hierbei gibt der EZB-Rat die Kernprinzipien vor, in der Regel führen jedoch die NZBen die Überwachung aus. Die Aufwendungen, die die NZBen hierbei zu finanzieren haben, hängen naturgemäß von infrastukturellen Gegebenheiten ab. So haben beispielsweise nur die Deutsche Bundesbank, die Banque de France, die Banco de España und die Bank of Finland die Kosten aus der Überwachung ihrer nationalen Großbetragszahlungssysteme ${ }^{207}$ zu tragen, da die anderen EWULänder über keine entsprechenden Systeme verfügen. Allerdings wäre es denkbar, daß die NZBen in Analogie zur Vorgehensweise bei der Bankenaufsicht die überwachten Zahlungssysteme über Beiträge finanziell in die Pflicht nehmen, um die ihnen entstehenden Kosten zu decken.

\section{Die internationale Vertretung des Eurosystems durch die NZBen}

Wie bereits im Rahmen der Analyse der EZB-Tätigkeiten erwähnt, obliegt es nach Artikel 6.1. ESZB-Satzung der EZB zu entscheiden, wie das Eurosystem im Bereich der internationalen Zusammenarbeit vertreten wird. Dabei zeigte sich, daß die EZB selbst mehr oder weniger stark an den relevanten internationalen Finanzinstitutionen und Gremien beteiligt ist. Auf die NZBen hingegen greift die EZB bei der Außenvertretung des Eurosystems offenbar nicht direkt zurück. So findet man in den Berichten der NZBen keinen Hinweis darauf, daß die EZB internationale Aufgaben des Eurosystems auf eine oder mehrere NZBen überträgt. Gerade das Gegenteil ist der Fall. So mußten zum Beispiel alle vor der EWU bestehenden Wechselkurs- und Swapabkommen von den NZBen gekündigt werden ${ }^{208}$. Weiterhin ist auch im Rahmen der Wechselkurspolitik eine direkte Inanspruchnahme einer NZB durch die EZB nicht vorgesehen, da - wie bereits geschildert - die Devisenmarktinterventionen des Eurosystems allein durch Rückgriff auf die Währungsreserven der EZB erfolgen ${ }^{209}$. Zudem führte die EZB auch eine Zusammenlegung von IWF-

206 Vgl. im Folgenden European Central Bank (2000c) und Europäische Zentralbank (2001d), S. $122 \mathrm{ff}$.

207 Im einzelnen sind die genannten Großbetragszahlungssysteme Euro Access Frankfurt (EAF) in Deutschland, Paris Net Settlement (PNS) in Frankreich, Servicio de Pagos Interbancarios (SPI) in Spanien und Pankkien On-line Pikasiirrot ja Sekitjärjestelmä (POPS) in Finnland. Vgl. Europäische Zentralbank (2001d), S. 123.

$208 \mathrm{Vgl}$. Europäische Zentralbank (1999a), S. 97.

209 Vgl. Europäische Zentralbank (2000h), S. 57, Europäische Zentralbank (2000a), S. 60 und die Ausführungen zu Devisenmarktinterventionen der EZB in Kapitel IV.1. Abschnitt 2.2.. 
Reservepositionen und SZR der NZBen, die nach Artikel 30.5. ESZB-Satzung möglich wäre, bisher nicht durch. Vielmehr läßt sich eine funktionale Aufgabenverteilung zwischen der EZB und den NZBen im Bereich der internationalen Zusammenarbeit erkennen, die auf der einen Seite die direkte Außenvertretung des Eurosystems der EZB überläßt, und auf der anderen Seite den NZBen, als jeweiligen Vertreter der heimischen Regierung, einen bestimmten Spielraum eröffnet, um die internationalen vertraglichen Verpflichtungen ihrer Länder zu erfüllen, solange das Ziel der Gewährleistung der Preisstabilität nicht beeinträchtigt wird ${ }^{210}$. Eine Eurosystem-spezifische internationale direkte Vertretung des Eurosystems durch eine NZB findet offenbar gegenwärtig nicht statt.

${ }^{210}$ Vgl. auch Deutsche Bundesbank (1999c), S. 15 ff.. 


\section{V.2.2. Die Analyse der Eurosystem-unabhängigen Tätigkeiten}

Als „Eurosystem-unabhängig“ werden alle Tätigkeiten der NZBen bezeichnet, bei denen die EZB kein Dispositionsrecht besitzt, solange die Ziele und Aufgaben des Eurosystems nicht beeinträchtigt werden. Hierbei lassen sich in Abhängigkeit ihrer gemeinschaftsrechtlichen Verankerung zwei Bereiche unterscheiden $^{211}$ :

1. Eurosystem-unabhängige Tätigkeiten der NZBen, die im einzelnen in der ESZB-Satzung geregelt sind und

2. Eurosystem-unabhängige Tätigkeiten der NZBen, die nicht im einzelnen in der ESZB-Satzung geregelt sind (Art. 14.4. ESZB-Satzung).

Im Folgenden soll nun untersucht werden, in welchem Umfang die NZBen im ersten Jahr der EWU Eurosystem-unabhängige Tätigkeiten durchgeführt und welchen Einfluß diese Aktivitäten auf die Gewinnentstehung der einzelnen Zentralbanken haben.

\section{V.2.2.1. Eurosystem-unabhängige Tätigkeiten der NZBen, die im einzelnen in der ESZB-Satzung geregelt sind}

Anhand der ESZB-Satzung können folgende Kompetenzen der NZBen zur Eurosystem-unabhängigen Tätigkeitsausübung explizit identifiziert werden:

1. Geschäfte mit dritten Ländern und internationalen Organisationen (Art. 23 ESZB-Satzung),

2. Verfügung über die den NZBen nach der Übertragung an die EZB verbliebenen Währungsreserven (Art. 3.1. und 31 ESZB-Satzung),

3. Kontenverwaltung für private Nichtbanken und öffentliche Stellen (Art. 17 ESZB-Satzung),

4. Offenmarkt- und Kreditgeschäfte (Art. 18 ESZB-Satzung),

5. Fiscal Agent für öffentliche Stellen (Art. 21.2. ESZB-Satzung) und

6. Geschäfte für den eigenen Betrieb und für das Personal der NZBen (Art. 24 ESZB-Satzung).

211 Vgl. auch Abbildung 4. 


\section{Die Beteiligung der NZBen an internationalen Organisationen und bilaterale Geschäftsbeziehungen der NZBen mit Drittländern}

Nach Artikel 23 ESZB-Satzung sind die NZBen befugt, mit Zentralbanken und Finanzinstituten in dritten Ländern und, soweit zweckdienlich, mit internationalen Organisationen Beziehungen aufzunehmen, alle Arten von Devisen $^{212}$ und Edelmetalle per Kasse und per Termin zu kaufen und zu verkaufen, (...) Vermögenswerte zu halten und zu verwalten und alle Arten von Bankgeschäften, einschließlich der Aufnahme und Gewährung von Krediten, im Verkehr mit dritten Ländern sowie internationalen Organisationen zu tätigen. Dabei sind die im Rahmen dieser Auslandsgeschäfte anfallenden Aufwendungen und Erträge der NZBen als Eurosystem-unabhängig zu klassifizieren, solange die NZBen auf eigene Initiative und Rechnung handeln und ihre Tätigkeitsausübung von Weisungen der EZB unabhängig $\operatorname{sind}^{213} \cdot \mathrm{Da}-$ wie bereits geschildert ${ }^{214}$ - gegenwärtig die EZB offenbar allein die Außenvertretungskompetenz des Eurosystems wahrnimmt, trifft dies für alle im Folgenden untersuchten Kosten und Einkünfte aus den Beteiligungen der NZBen an internationalen Organisationen bzw. für alle Geschäftsbeziehungen der NZBen mit Drittländern zu.

\subsection{Die Beteiligungen der NZBen an internationalen Organisationen}

Die NZBen sind in unterschiedlicher Form an verschiedenen internationalen Organisationen beteiligt. Für die Analyse der Notenbankgewinnentstehung sind hierbei besonders die finanziellen Aufwendungen und Erträge interessant, die die NZBen in Erfüllung ihrer Verpflichtungen gegenüber dem Internationalen Währungsfonds (IWF) und der Bank für Internationalen Zahlungsausgleich (BIZ) zu leisten haben bzw. erwirtschaften.

212 Der Begriff „Devisen“ schließt Wertpapiere und alle sonstigen Vermögenswerte, die auf beliebige Währungen oder Rechnungseinheiten lauten, unabhängig von deren Ausgestaltung mit ein. Vgl. Art. 23 Spstr. 2 ESZB-Satzung.

213 Rechtsgrundlagen für Eurosystem-unabhängige Geschäfte der NZBen mit internationalen (Finanz-) Organisationen finden sich auch in Art. 307 EGV (Fortführung von Verträgen, die vor dem jeweiligen EG-Beitritt gegründet wurden, wie etwa die IWF-, BIZ-, oder OECD-Verträge der Mitgliedstaaten) und Art. 111 Abs. 5 EGV (Führung von Verhandlungen in internationalen Gremien und Treffen internationaler Vereinbarungen, unbeschadet der Gemeinschaftszuständigkeit und der Gemeinschaftsvereinbarungen uiber die Wirtschafts- und Währungsunion). Vgl. auch Deutsche Bundesbank (1999c), S. 15 ff..

214 Vgl. die Ausführungen zur internationalen Vertretung des Eurosystems durch die NZBen in Kapitel V.2.1. Abschnitt 6.. 
Tabelle 20: Die Beteiligung der NZBen an der Finanzierung der „originären“ Ressourcen des IWF zum 31.12.1999 in Mio. Euro

\begin{tabular}{|c|c|c|c|c|c|c|c|c|c|c|c|}
\hline & \multirow{5}{*}{ Land / NZB } & \multicolumn{10}{|c|}{.Originäre" Ressourcen des IWF } \\
\hline & & \multicolumn{7}{|c|}{ Quotenbasierte Ressourcen des IWF } & \multicolumn{3}{|c|}{ Zusătzliche Ressourcen des IWF } \\
\hline & & \multicolumn{3}{|c|}{ General Department' } & \multicolumn{4}{|c|}{ SZR-Department } & \multicolumn{2}{|c|}{ Sonderkreditvereinbarungen ${ }^{2}$} & \multirow[b]{2}{*}{$\begin{array}{c}\text { Zusatzliche } \\
\text { bilaterale } \\
\text { Kredite }\end{array}$} \\
\hline & & Quote & $\begin{array}{c}\text { Ziehungsrechte } \\
\text { (in vH der } \\
\text { Quote) }\end{array}$ & $\begin{array}{c}\text { Euro- } \\
\text { Guthaben } \\
\text { des IWF bei } \\
\text { der NZB }\end{array}$ & $\begin{array}{c}\text { SZR- } \\
\text { Forderungen }\end{array}$ & $\begin{array}{c}\text { Unentgcltlich } \\
\text { zugeteilte SZR }\end{array}$ & $\begin{array}{c}\text { Nettoposition im SZR- } \\
\text { Department } \\
\text { (in vH der unentgeltlich } \\
\text { zugeteilten SZR) }\end{array}$ & $\begin{array}{c}\text { SZR-Kauf- } \\
\text { verpflichtung der } \\
\text { NZB aufgrund } \\
\text { Designierung }\end{array}$ & AKV-Linie & NKV-Linie & \\
\hline & & 17756 & $\begin{array}{|ll|}6384 & (36 \%) \\
\end{array}$ & 11372 & 1948 & 1653 & $(17,9 \%)$ & 3011 & 3249 & 4855 & Nach Vereinb. \\
\hline ס & FR/BdF & 14658 & $\begin{array}{|ll|}5428 & (37 \%) \\
\end{array}$ & 9230 & 345 & 1483 & $-1138(-76,7 \%)$ & 4105 & 2321 & 3518 & Nach Vereinb. \\
\hline J & IT/BdI & 9631 & $\begin{array}{|ll|}3524 & (37 \%) \\
\end{array}$ & 6107 & 167 & 959 & $-792 \quad(-82,6 \%)$ & 2709 & 1508 & 2419 & Nach Vereinb. \\
\hline о & $\mathrm{NL} / \mathrm{DNB}$ & 7047 & $\begin{array}{|ll|}2566 & (36 \%) \\
\end{array}$ & 4481 & 1013 & 724 & $(40,0 \%)$ & 1158 & 1160 & 1796 & Nach Vereinb. \\
\hline 요 & $\mathrm{BE} / \mathrm{NBB}$ & 6286 & $\begin{array}{|ll|}2277 & (36 \%) \\
\end{array}$ & 4009 & 269 & 662 & $-393 \quad(-59,4 \%)$ & 1718 & 812 & 1320 & Nach Vereinb. \\
\hline 0 & ES/BdE & 4162 & $1517 \quad(36 \%)$ & 2645 & 259 & 408 & $\begin{array}{ll}-149 \quad(-36,5 \%) \\
\end{array}$ & 965 & - & 917 & Nach Vereinb. \\
\hline - & AT/OeNB & 2556 & $\begin{array}{|ll|}1057 & (41 \%) \\
\end{array}$ & 1499 & 145 & 244 & $-100 \quad(-40,8 \%)$ & 589 & - & 562 & Nach Vereinb. \\
\hline 3 & $\mathrm{FI} / \mathrm{BoF}$ & 1725 & \begin{tabular}{|l|l|}
634 & $(37 \%)$ \\
\end{tabular} & 1091 & 288 & 195 & $(48,1 \%)$ & 296 & $\ldots$ & 464 & Nach Vereinb. \\
\hline 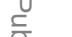 & $\mathrm{PT} / \mathrm{BdP}$ & 1184 & $\begin{array}{|ll|}375 & (32 \%) \\
\end{array}$ & 809 & 44 & 73 & $(-39,8 \%)$ & 174 & - & - & Nach Vereinb. \\
\hline 0 & $\mathrm{IE} / \mathrm{CBI}$ & 1144 & $\begin{array}{|ll|}414 & (36 \%) \\
\end{array}$ & 731 & 40 & 119 & $(-66.5 \%)$ & 317 & - & - & Nach Vereinb. \\
\hline$=3$ & $\mathrm{LU} / \mathrm{BCL}$ & 381 & $\begin{array}{|ll|}74 & (19 \%) \\
\end{array}$ & 307 & 2 & 23 & $\begin{array}{ll}-21 & (-89,5 \%)\end{array}$ & 67 & - & 464 & Nach Vereinb. \\
\hline$\stackrel{0}{2} \stackrel{0}{2}$ & EWU-11 & 66529 & \begin{tabular}{|l|}
$24249(36 \%)$ \\
\end{tabular} & 42280 & 4521 & 6543 & $-2022 \quad(-30,9 \%)$ & 15109 & 9050 & 16316 & - \\
\hline$\stackrel{2}{\cong} \frac{2}{0}$ & $\begin{array}{l}\text { IWF } \\
\text { gesamt }^{3}\end{array}$ & 286985 & \begin{tabular}{|l|l|}
$74044 \quad(26 \%)$ \\
\end{tabular} & 212941 & 24945 & 29256 & $-4311 \quad(-14,7 \%)$ & 62823 & 23205 & 46409 & $\overline{\text { K. A. }}$ \\
\hline 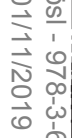 & Verzinsung & $\cdots$ & $\begin{array}{c}100 \% \text { des SZR- } \\
\text { Zinssatzes auf } \\
\text { vergateten Teil } \\
\text { der Reserve- } \\
\text { tranche }\end{array}$ & - & $\begin{array}{c}\text { SZR-Zinssatz } \\
\text { auf Brutto-SZR- } \\
\text { Forderungen }\end{array}$ & \begin{tabular}{c|} 
SZR-Zinssatz \\
auf unentgeltlich \\
zugeteilte SZR
\end{tabular} & $\begin{array}{l}\text { (SZR-Zinssatz auf } \\
\text { Netto-SZR-Position) }\end{array}$ & $\cdots$ & $\begin{array}{l}100 \% \text { des } \\
\text { SZR-Zins- } \\
\text { satzes auf } \\
\text { abgerufene } \\
\text { Beträge }\end{array}$ & $\begin{array}{c}100 \% \text { des SZR- } \\
\text { Zinssatzes auf } \\
\text { abgerufene } \\
\text { Betrage }\end{array}$ & Nach Vereinb. \\
\hline
\end{tabular}

Quelle: Eigene Berechnungen. Die der Darstellung zugrunde liegenden Angaben sind entnommen aus den Jahresberichten der NZBen, International Monetary Fund (2000a) und Internationaler Wăhrungsfonds (2000b), S. 71 ff.. Die vom IWF in SZR ausgewiesenen Angaben wurden mit Hilfe des SZR-EUR-Wechselkurses vom 31.12 .1999 umgerechnet (1 SZR = 1.364976 EUR).

$\sum \stackrel{1}{\infty}$

${ }_{1}$ Ohne Special Disbursement Account, da sich dieses Konto nicht aus den Subskriptionsverpflichtungen der Mitgliedstaaten finanziert.

${ }^{2}$ Die AKV-Kredite werden auf dic NKV-Kredite angerechnet, so daß der maximale von einer NZB im Rahmen dieser stăndigen Sonderkreditlinien zu finanzierende Gesamtbetrag auf das jeweilige NKV-Kreditvolumen begrenzt bleibt. Ende 1999 bestanden keine offenen AKV- und NKV-Forderungen der NZBen gg. dem IWF.

Angaben zum 31.1.2000. Die Differenz zwischen den gesamten SZR-Forderungen und den gesamten SZR-Zuteilungen der IWF-Mitgliedstaaten in Hobe von 431I Mio. EUR (= 3158 Mio. SZR) ist im wesentlichen auf die SZR-Bestande des General Resources Account im General Department zuruckzufuhren. Vgl. International Monetary Fund (2000a), S. 33. 


\subsubsection{Die Beteiligung der NZBen am Internationalen Währungsfonds (IWF)}

Die Finanzierungsleistungen der NZBen zugunsten des IWF lassen sich in zwei Gruppen einteilen. Die eine Gruppe umfaßt die Beiträge der NZBen zur Finanzierung der im Folgenden als "originäre" Ressourcen des IWF bezeichneten Mittel, mit denen der Fonds seinen satzungsgemäßen Verpflichtungen zur Gewährung von Zahlungsbilanzkrediten nachkommt. Die zweite Gruppe beschreibt die von den NZBen zu leistenden Zahlungen an die vom IWF verwalteten Sondervermögen, mit denen der Fonds unter anderem konzessionäre Zahlungsbilanzhilfen an anspruchsberechtigte Entwicklungsländer vergibt.

\subsubsection{Die Beteiligung der NZBen an der Finanzierung der „originären“ Ressourcen des IWF}

In der vorstehenden Tabelle 20 ist die Beteiligung der NZBen an der Finanzierung der „originären“ Ressourcen des IWF zum 31.12.1999 zusammengestellt. Hierbei zeigt sich, daß alle EWU-Regierungen ihre IWFVerpflichtungen aus dem General Department und dem SZR-Department vollständig auf die heimische Zentralbank übertragen haben ${ }^{215}$. So übernehmen die NZBen jeweils die Einzahlung der Quote (Subskription) auf das General Resource Account des General Departments, indem sie 25\% der Quote in Form von allgemein akzeptierten Reserveaktiva (z.B. SZR und USD) einzahlen und dem Fonds die restlichen $75 \%$ der Subskription in Form von Bargeld oder eines in heimischer Währung denominierten, nicht übertragbaren und unverzinslichen Wertpapiers, das auf Nachfrage gegen Reserveaktiva des Mitglieds eingelöst werden kann, zur Verfügung stellen ${ }^{216}$. Im Gegenzug räumt ihnen der IWF in Höhe der übertragenen Reserveaktiva und den vom IWF tatsächlich abgerufenen und zur Finanzierung eingesetzten Beständen an heimischer Währung Ziehungsrechte in der Reservetranche ein. Diesbezüglich zeigt die Empirie ein interessantes Bild. Zwar sind die Absolutbeträge der Reservepositionen zwischen den EWU-Staaten naturgemäß sehr unterschiedlich, da die Quoten die

215 Folglich stellen alle EWU-NZBen die entsprechenden Forderungen und Verbindlichkeiten aus dem General-Department (Ziehungsrechte), dem SZR-Department (SZRForderungen, Ausgleichsposten für unentgeltlich zugeteilte SZR), sowie etwaige AKVund NKV-Forderungen in ihre Bilanzen ein. Dies gilt jedoch nicht für die (nicht abgerufenen) Euro-Guthaben des IWF bei der NZB, die sich rechnerisch aus der Differenz zwischen der Quote und den Ziehungsrechten des Mitgliedstaats ergeben. 
relative Größe der einzelnen Volkswirtschaften widerspiegeln ${ }^{217}$, doch ist der jeweilige Anteil der Ziehungsrechte an der Quote zum Ende 1999 bei fast allen EWU-Ländern mit rund 36 Prozent nahezu identisch. Dies deutet darauf hin, daß einerseits die NZBen von (umfangreichen) Ziehungen in der Reservetranche absehen und andererseits der IWF bezüglich seiner Ziehungen bei den EWUStaaten versucht, die Finanzierungslasten grundsätzlich symmetrisch zu verteilen. Deutlich wird auch die Netto-Gläubigerstellung der EWU-Staaten im General Department, da die angesprochene durchschnittliche Relation aus Ziehungsrechten zur Quotensumme in Höhe von 39 Prozent 10 Prozentpunkte über dem gesamten IWF-Durchschnitt liegt ${ }^{218}$.

Für die Gewinnentstehung der NZBen ist vor allem die Verzinsung der Reserveposition von zentraler Bedeutung. Hierbei ist darauf hinzuweisen, daß der IWF nicht den gesamten Bestand an Ziehungsrechten der jeweiligen NZB verzinst. So wird für jedes Land die Differenz zwischen der Quote und der sogenannten Norm ${ }^{219}$ ermittelt und der so errechnete Betrag von der Reserveposition in Abzug gebracht ${ }^{220}$. Der verbleibende Wert (,vergüteter Teil der Reservetranche") wird dann mit der sich wöchentlich ändernden Remunerationsrate vergütet. Diese entspricht zur Zeit $100 \%$ des SZRZinssatzes. Die Zinsgutschriften erfolgen vierteljährlich.

Auch das Engagement im SZR-Department beeinflußt die Ertragslage der NZBen. So müssen die NZBen, deren SZR-Forderungen den Bestand der vom IWF unentgeltlich zugeteilten Sonderziehungsrechte ${ }^{221}$ unterschreitet, Zinsen an

217 Bei der Festlegung der Quoten orientiert sich der IWF an bestimmten volkswirtschaftlichen Schlüsselzahlen wie etwa dem Bruttoinlandsprodukt, der Höhe der Währungsreserven und den Transaktionen in der Bilanz der laufenden Posten. Vgl. Deutsche Bundesbank (1997a), S.17 und Jarchow/Rühmann (1989), S. 116.

Auf eine Analyse der Zinsaufwendungen bei Ziehungen der Mitgliedstaaten in den Kredittranchen des IWF soll hier verzichtet werden, da alle EWU-Staaten seit rund 20 Jahren keine Kredite mehr im General Department aufgenommen haben. $\mathrm{Zu}$ einer Übersicht der vom IWF bei der Kreditaufnahme erhobenen Gebühren vgl. Internationaler Währungsfonds (2000b), S. 78.

219 Die Norm eines Landes variiert aus historischen Gründen von Mitgliedstaat zu Mitgliedstaat und wird wie die Quote für jedes Land individuell festgelegt. Vgl. Deutsche Bundesbank (1997a), S. 36 und International Monetary Fund (2000e).

220 Vgl. Deutsche Bundesbank (1997a), S. 36. Allerdings nimmt die Differenz zwischen der Norm und der Quote jedes Mitglieds mit jeder allgemeinen Quotenerhöhung ab. So betrug Ende April 2000 die durchschnittliche Norm 96,2 \% der Quote. Vgl. International Monetary Fund (2000c), S. 189.

221 Die Höhe der unentgeltlichen SZR-Zuteilung richtet sich nach der Quote des Mitgliedstaats. Die letzte SZR-Zuteilung erfolgte 1981, wobei sich gegenwärtig eine neue "Gerechtigkeitszuteilung“ im Ratifizierungsverfahren befindet, die das bisherige Gesamtvolumen der kumulativen SZR-Zuteilungen von 21,4 Mrd. SZR auf 42,9 Mrd. SZR verdoppeln wird. Vgl. Internationaler Währungsfonds (2000b), S. 86 und $128 \mathrm{ff}$.. 
den IWF zahlen, während Teilnehmer mit positiver Nettoposition einen Zinsertrag erwirtschaften. Dabei erfolgt sowohl die Verzinsung der Nettoschuldnerals auch die Vergütung der Nettogläubigerpositionen mit dem SZR-Zinssatz, der sich seinerseits an den kurzfristigen Marktzinsen in Frankreich, Deutschland, Japan, Großbritannien und USA orientiert ${ }^{222}$. Anhand von Tabelle 20 wird deutlich, daß Ende 1999 nur die deutsche, niederländische und finnische Zentralbank entsprechende Zinsgutschriften erhalten, da alle anderen EWUNZBen Nettoschuldner im SZR-Department sind. Der Grund hierfür dürfte neben der Verwendung von SZR zur Finanzierung der Subskriptionsverpflichtungen vor allem in der freiwilligen Abgabe von SZR im Rahmen eines aktiven Währungsreservenmanagements der Nettoschuldner-NZBen liegen, da Transaktionen im Rahmen von Designierungen des IWF seit geraumer Zeit keine Rolle mehr spielen ${ }^{223}$.

Neben den genannten quotenbasierten Ressourcen des IWF stehen dem Fonds zur Zahlungsbilanzfinanzierung im Bedarfsfall noch weitere Mittel zur Verfügung $^{224}$. $\mathrm{Zu}$ erwähnen sind hierbei vor allem die Allgemeinen Kreditvereinbarungen (AKV) und die Neuen Kreditvereinbarungen (NKV) mit einem Volumen von $17 \mathrm{Mrd}$. bzw. $34 \mathrm{Mrd}$. SZR, an deren Finanzierung auch die meisten EWU-Staaten beteiligt sind ${ }^{225}$. So nehmen die Länder Deutschland, Belgien, Frankreich, Italien und die Niederlande an beiden Sonderkreditlinien teil, während Spanien, Luxemburg, Finnland und Österreich nur an den NKV partizipieren. Portugal und Irland hingegen stellen in keiner der genannten Kreditvereinbarungen Ressourcen zur Verfügung. Den an den AKV bzw. NKV teilnehmenden EWU-Staaten ist wiederum gemeinsam, daß sie die konkrete Finanzierung dieser Sonderkreditvereinbarungen auf die heimischen Zentralbank übertragen. Diese NZBen erwirtschaften dann gegebenenfalls die entsprechenden Zinseinkünfte ${ }^{226}$, wenngleich das Kreditausfallrisiko (wohl flächendeckend) von den heimischen Regierungen übernommen wird. Ende 1999 weisen die NZBen jedoch keine offenen AKV- bzw. NKV-Forderungen

222 Die Verzinsung der Nettopositionen der NZBen im SZR-Department erfolgt vierteljährlich. Vgl. International Monetary Fund (2000c), S. 203.

223 Als Designierung wird die Verpflichtung eines Mitglieds durch den IWF zum Ankauf von SZR gegen andere Währungen verstanden.

224 Neben der Kreditaufnahme bei den Mitgliedstaaten besitzt der IWF auch die Möglichkeit, Kredite auf den privaten Kapitalmärkten aufzunehmen und Bewertungsgewinne aufgrund von Goldverkäufen zu realisieren. Zur Funktionsweise der AKV und NKV vgl. Internationaler Währungsfonds (2000a), S. 1 ff. und Internationaler Währungsfonds (2000b), S. $76 \mathrm{ff}$..

226 So werden die jeweils vom IWF abgerufenen Beträge mit einem Satz, der gegenwärtig 100 Prozent des SZR-Zinssatzes p.a. entspricht, verzinst. Vgl. Internationaler Währungsfonds (2000a), S. 1 ff.. 
aus. Des weiteren steht den EWU-Mitgliedstaaten die Möglichkeit offen, unabhängig von den genannten Sonderkreditvereinbarungen zusätzliche bilaterale Kredite an den IWF zu gewähren. Auch hier kann eine Involvierung der NZBen nicht ausgeschlossen werden. Ähnliches trifft wohl auch auf die Übernahme bürgschaftsähnlicher Verpflichtungen aus Krediten dritter Parteien, wie etwa der Bank für Internationalen Zahlungsausgleich, an den IWF $\mathrm{zu}^{227}$. Hierbei ist jedoch davon auszugehen, daß sowohl bei der bilateralen Kreditvergabe als auch bei der Übernahme von Bürgschaften die jeweilige NZB verpflichtet ist, das jeweilige Ausfallrisiko durch entsprechende Bürgschaften der heimischen Regierung zu decken. Ob die im Zusammenhang dieser Transaktionen erzielten Zinseinkünfte bzw. Kommissionen eine gewisse quantitative Bedeutung erlangen können, soll hier offenbleiben.

\subsubsection{Die Beteiligung der NZBen an der Finanzierung des IWF- Sondervermögens}

Wichtigster Anhaltspunkt bei der Analyse der Beteiligung der NZBen an der Finanzierung der Beiträge ihres Landes zu den vom IWF verwalteten Sondervermögen sind zunächst die entsprechenden von den NZBen in ihren Jahresberichten ausgewiesenen Forderungen. Diese sind in Tabelle 21 zusammengestellt. Hier wird deutlich, daß zum 31.12.1999 nur die Zentralbanken Frankreichs, Italiens, Belgiens, Spaniens, Österreichs, Finnlands und Portugals derartige Forderungen besitzen. Bei diesen NZBen erfolgt der Ausweis allerdings meist pauschal als „Other claims on the IMF“ o.ä. und erlaubt in der Regel keine genaue Identifizierung der einzelnen Zahlungen auf die verschiedenen IWF-Sondervermögenskonten ${ }^{228}$. Um nun dennoch weitere Aussagen über die konkrete Finanzierungsleistungen der NZBen treffen zu können, werden den NZB-Angaben in Tabelle 21 die vom IWF zum 31.1.2000 veröffentlichten Zahlungen der EWU-Staaten in ausgewählte IWF-Sondervermögen (PRGF-Trust, PRGF-Administered Accounts und PRGF-HIPC-Trust and Related Accounts ${ }^{229}$ ) gegenübergestellt ${ }^{230}$.

227 Solche Bürgschaften gegenüber der BIZ hat die Deutsche Bundesbank bereits mehrfach übernommen. Vgl. Deutsche Bundesbank (1997a), S. 60.

$228 \mathrm{Vgl}$. Fußnote 1 in Tabelle 21.

229 Neben diesen Fonds führt der IWF noch folgende Sondervermögenskonten: Administered Accounts Established at the Request of Members, Trust Fund, Supplementary Financing Facility Subsidy Account und Retired Staff Benefits Investment Account. Vgl. International Monetary Fund (2000a), S. 55 ff..

230 Die benötigten Daten für eine zeitgleiche Gegenüberstellungen mit den NZB-Daten zum 31.12.1999 veröffentlicht der IWF nicht. 
Tabelle 21: Die Beteiligung der NZBen an der Finanzierung des IWF-Sondervermögens zum 31.12.1999 in Mio. Euro

\begin{tabular}{|c|c|c|c|c|c|c|c|c|c|}
\hline \multirow[b]{3}{*}{ Land / NZB } & \multirow{3}{*}{$\begin{array}{c}\text { Ausgewiesene } \\
\text { NZB-Forderungen an } \\
\text { IWF-Sonder- } \\
\text { vermogen zum } \\
31.12 .1999^{\prime}\end{array}$} & \multicolumn{5}{|c|}{$\begin{array}{l}\text { Identifizierte Zahlungen der EWU-Staaten in ausgewăhlte } \\
\text { IWF-Sondervermögen zum 31.1.2000 }\end{array}$} & \multirow{3}{*}{$\begin{array}{c}\text { IWF-Angaben } \\
\text { zum } \\
31.1 .2000 \\
\text { gesamt }\end{array}$} & \multirow{3}{*}{$\begin{array}{l}\text { Differenz zwischen } \\
\text { gesamten IWF- } \\
\text { Angaben zum } \\
\text { 31.1.2000 und NZB- } \\
\text { Angaben zum } \\
31.12 .1999\end{array}$} & \multirow{3}{*}{$\begin{array}{l}\text { Geschätzte Beteiligung } \\
\text { der NZB an der Finan- } \\
\text { zierung der identi- } \\
\text { fizierten Zahlungen des } \\
\text { eigenen Landes in IWF } \\
\text { Sondervermögen } \\
\end{array}$} \\
\hline & & \multicolumn{2}{|c|}{ PRGF-Trust ${ }^{2}$} & \multirow[b]{2}{*}{$\begin{array}{c}\text { PRGF- } \\
\text { Administered } \\
\text { Accounts }^{3}\end{array}$} & \multicolumn{2}{|c|}{$\begin{array}{c}\text { PRGF-HIPC Trust and Related } \\
\text { Accounts }\end{array}$} & & & \\
\hline & & $\begin{array}{l}\text { Subsidy } \\
\text { Account }\end{array}$ & Loan Account & & \begin{tabular}{|l|} 
PRGF-HIPC- \\
Trust Account
\end{tabular} & $\begin{array}{c}\text { Post-SCA-2 } \\
\text { Administered } \\
\text { Accounts }\end{array}$ & & & \\
\hline $\mathrm{DE} / \mathrm{BBk}$ & $\cdots$ & 164 & 1108 & $\cdots$ & -- & -- & 1272 & 1272 & - \\
\hline FR / BdF & 33 & - & 1296 & $\cdots$ & $\ldots$ & - & 1296 & 1263 & $2.5 \%$ \\
\hline $\mathrm{IT} / \mathrm{BdI}$ & 562 & 185 & 556 & $\cdots$ & $\cdots$ & 58 & 799 & 237 & $70.4 \%$ \\
\hline NL / DNB & $\cdots$ & 106 & -- & $\cdots$ & 9 & - & 116 & 106 & $\cdots$ \\
\hline $\mathrm{BE} / \mathrm{NBB}$ & 261 & 94 & 15 & 253 & $\cdots$ & - & 362 & 101 & $72,0 \%$ \\
\hline $\mathrm{ES} / \mathrm{BdE}$ & 158 & $\cdots$ & 207 & $\cdots$ & $\cdots$ & 36 & 243 & 85 & $65,0 \%$ \\
\hline AT/OeNB & 68 & 46 & - & 69 & $\cdots$ & 13 & 128 & 60 & $53.2 \%$ \\
\hline $\mathrm{FI} / \mathrm{BoF}$ & 8 & 31 & $\cdots$ & $\cdots$ & 3 & 8 & 42 & 34 & $19,0 \%$ \\
\hline $\mathrm{PT} i \mathrm{BdP}$ & 18 & - & - & 18 & 6 & - & 24 & 6 & $74,2 \%$ \\
\hline $\mathrm{IE} / \mathrm{CBI}$ & - & 3 & - & $\cdots$ & 5 & $\cdots$ & 9 & 3 & - \\
\hline $\mathrm{LU} / \mathrm{BCL}$ & $\cdots$ & 7 & - & - & 1 & -- & 8 & 7 & $\cdots$ \\
\hline Verzinsung & $\begin{array}{l}\text { Unterschiedliche } \\
\text { Verzinsung der } \\
\text { Teilpositionen }\end{array}$ & $\cdots$ & $\begin{array}{c}\text { Variable } \\
\text { Markt- } \\
\text { verzinsung }\end{array}$ & $0,5 \%$ & $\begin{array}{l}\text { Teilweise } \\
\text { Verzinsung } \\
\text { mit SDA- } \\
\text { Zinssatz }\end{array}$ & rd. $1.5 \%$ & -- & - & - \\
\hline
\end{tabular}

ㄴ. Quelle: Eigene Berechnungen. Die der Darstellung zugrunde liegenden Angaben sind entnommen aus den Jahresberichten der NZBen und aus International Monetary Fund (2000a). Die

$\Rightarrow$ fett gedruckten Zahlen zeigen jeweils die identifizierte Verwendung der Finanzierungsleistungen der NZBen an. Die in SZR ausgewiesenen IWF-Angaben wurden mit Hilfe des SZR-

EUR-Wechselkurs zum 31.12.1999 umgerechnet (I SZR = 1,364976 EUR).

' Vgl. Banca d'Italia (2000a), S. 272, Belgische Nationalbank (2000b), S. 77, Banque de France (2000c), S. 255, Banco de España (2000), S. 122, Banco de Portugal (2000a), S. 300 und Österreichische Nationalbank (2000), S. 127. Der für die Bank of Finland angegebene Wert ergibt sich als Residualgröße aus den von der BoF ausgewiesenen Gesamtforderungen an den IWF und den vom IWF ausgewiesenen Positionen im General Department und SZR-Department zum 31.12.1999. Vgl. Bank of Finland (2000b), S. 82 und International Monetary Fund (2000d).

2 Poverty Reduction and Growth Facility Trust. Ohne PRGF-Trust Reserve Account. Die Lănder Deutschland, Niederlande, Luxemburg, Finnland, Italien und Irland leisten direkte Zahlungen auf das PRGF-Trust-Subsidy Account. Belgien und Österreich uberweisen die Beiträge auf das PRGF-Trust Subsidy Account von ihren PRGF-Administered Accounts.

${ }^{3}$ Poverty Reduction and Growth Facility Administered Accounts. Hierbei handelt es sich jeweils ausschließlich um Einlagen der heimischen Zentralbank. Vgl. International Monetary Fund (2000a), S. 79. Die vom IWF zum 31.1.2000 ausgewiesene PRGF-Administered Account-Forderung uberzeichnet den von der NBB veröffentlichten Bilanzwert zum 31.12.1999 um 5 Mio. SZR ( = 6,8 Mio. EUR). Vgl. Belgische Nationalbank (2000b), S. 77.

${ }^{4}$ Poverty Reduction and Growth Facility-Heavily Indebted Poor Countries Trust and Related Accounts. Ohne Umbrella Account for HIPC Operations.

${ }^{s}$ Zinssatz des Special Disbursement Account (SDA). 
Es zeigt sich folgendes Bild. Die zum 31.12.1999 ausstehenden Forderungen der Banco de Portugal und der Österreichischen Nationalbank entsprechen offensichtlich den portugiesischen bzw. österreichischen Forderungen in den PRGF-Administered Accounts, da es sich nach IWF-Angaben bei diesen Einlagen ausschließlich um Einlagen der jeweiligen Zentralbank handelt ${ }^{231}$. Diese Einlagen werden mit 0,5 Prozent p.a. verzinst. Ebenfalls eindeutig erscheint die Beteiligung der Banque de France an der Finanzierung des französischen Beitrags für das Kreditkonto des PRGF-Trust, da Frankreich zum 31.1.2000 in den anderen Konten keine Forderungen besitz ${ }^{232}$. Auch im Falle Spaniens und Italiens dürften die NZB-Forderungen sich auf Zahlungen auf das PRGF-Trust Loan Account beschränken. Auf diese Depositen zahlt der IWF eine variable Marktverzinsung. Die Forderungen der Bank of Finland sind dagegen wohl den Post-SCA-2 Administered Accounts des im Rahmen des PRGF-HIPC Trust and Related Accounts verwalteten Sondervermögens zuzuordnen. Diese Einlagen verzinsen sich mit rund 1,5 Prozent p.a..

Es gilt folglich festzuhalten, daß die nationalen Regierungen der EWU-Staaten ihre NZBen in sehr unterschiedlicher Weise an der Finanzierung ihrer Beiträge zu den IWF-Sondervermögen beteiligen. So finanzierten Ende 1999 die NZBen Portugals, Italiens, Belgiens und Spaniens mit grob 70 Prozent, die Österreichische Nationalbank mit rund 53 Prozent und die Banque de France mit ca. 3 Prozent der identifizierten Zahlungen ihres Landes in die genannten IWFSondervermögen. In Deutschland, der Niederlande, in Luxemburg und in Irland hingegen erbrachten die NZBen keine Finanzierungsleistungen. So wird beispielsweise der deutsche Beitrag zum Loan Account des PRGF-Trust über die Bundesanstalt für Wiederaufbau (BfW) und die Zahlungen auf das (Zins-) Subventionskonto von Haushaltsmitteln der Bundesregierung finanziert ${ }^{233}$. Allerdings darf nicht übersehen werden, daß es sich bei der vorliegenden Analyse um eine Zeitpunktbetrachtung handelt und das beobachtete Verhalten der Regierungen, die heimische Zentralbank in die Finanzierung der Sondervermögen einzubeziehen, nicht ohne weiteres auf die Zukunft übertragen werden kann. Dies zeigt insbesondere das Beispiel der Deutschen Bundesbank, welche am 11.2.2000 in Absprache mit der Bundesregierung dem PRGF-HIPC-

231 Vgl. International Monetary Fund (2000a), S. 78 f..

232 Die Forderung Frankreichs aus dem French Technical Assistance Subaccount des IWFSondervermögens Administered Accounts Established at the Request of Members in Höhe von 0,54 Mio. US-Dollar sei hier wegen der geringen quantitativen Bedeutung vernachlässigt. Vgl. International Monetary Fund (2000a), S. 99. 
Trust Account einen zinslosen langfristigen 300 Mio. EUR Kredit überwiesen hat $^{234}$.

\subsubsection{Die Bedeutung der Zinseinkünfte der NZBen aus der IWF- Beteiligung für die NZB-Gewinne}

Bisher unbeantwortet blieb die Frage, welche quantitative Bedeutung die Beteiligung der NZBen am IWF für die Ertragssituation der Zentralbanken hat. Da die meisten NZBen in ihren Finanzausweisen jedoch weder ihre Zinserträge (bzw. Aufwendungen) aus den IWF-Departments und Sondervermögen im einzelnen angeben noch einen aggregierten (Netto-) Ertrag ausweisen, können die Einkünfte der NZBen aus den genannten IWF-Engagements nur geschätzt werden. Hierzu wird wie folgt vorgegangen. Bei der Berechnung der Verzinsung der Reserveposition im General Department wird vereinfachend unterstellt, daß die gesamten Ziehungsrechte (Stand 31.12.1999) mit einem Zinssatz in Höhe von $3,5 \%$ p. a. verzinst werden ${ }^{235}$. Ebenso wird bei der Schätzung der Nettozinseinkünfte bzw. -aufwendungen der NZBen aus dem SZR-Department verfahren. Die Bestimmung der GuV-wirksamen ${ }^{236}$ Zinserträge der NZBen aus der Finanzierung der IWF-Sondervermögen ergibt sich vereinfachend aus der Multiplikation der mit Hilfe der Tabelle 21 identifizierten Beteiligungen der NZBen an den IWF-Sondervermögen (Stand 31.12.1999) mit den zugehörigen Zinssätzen. In Tabelle 22 sind die überschlagsweise geschätzten (Netto-) Zinseinkünfte der NZBen aus den unterschiedlichen IWF-Beteiligungen zusammengestellt ${ }^{237}$.

234 Vgl. Deutsche Bundesbank (2000a), S. 35 und S. 123. Auch die Österreichische Nationalbank wird weitere 14,3 Mio. SZR für die HIPC-Initiative bereitstellen. Vgl. Österreichische Nationalbank (2000), S. 92.

235 Tatsächlich erfolgt - wie oben erläutert - die vierteljährliche Zinsgutschrift nur auf den vergüteten Teil der Reservetranche. Die zugrunde gelegte Remunerationsrate (100\% des SZR-Zinssatzes) wird überschlagsweise auf 3,5 Prozent angesetzt, da sich der SZRZinssatz in 1999 zwischen 3,2 und 3,9 Prozent p. a. bewegte. Vgl. Österreichische Nationalbank (2000), S. 126.

236 Nicht erfaßt werden hierbei die durch Zinsverzicht von den NZBen finanzierten Zuwendungen zu den IWF-Sondervermögen, die sich aus der Differenz zwischen der marktgerechten Verzinsung und der tatsächlichen unter Marktwert liegenden Zinseinkünfte ergeben. Solche nicht-GuV-wirksamen Transfers finanzierten Ende 1999 z.B die NBB, CBI, OeNB und BoF. Vgl. Tabelle 21. Der Gegenwartswert des Zinsverzichts aus dem Anfang 2000 gewährten zinslosen 300 Mio. EUR Kredit der Bundesbank beträgt rund 85 Mio. SZR. Vgl. Deutsche Bundesbank (2000a), S. 123.

237 Da die 11. Allgemeine Quotenerhöhung des IWF bereits Anfang des Jahres 1999 durchgeführt wurde und zugleich der IWF in 1999 keine (sehr ausgeprägten) Ziehungen bei den EWU-Staaten vorgenommen hat, erscheint dieses Vorgehen vertretbar.

Gerhard Rösl - 978-3-631-75006-3 
Tabelle 22: Geschätzte Zinseinkünfte der NZBen aus der IWF-Beteiligung zum 31.12.1999 in Mio. Euro'

\begin{tabular}{|c|c|c|c|c|c|}
\hline \multirow{12}{*}{ 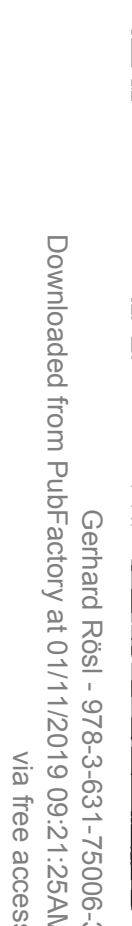 } & NZB & $\begin{array}{c}\text { Geschätzte } \\
\text { Zinseinkünfte aus } \\
\text { Ziehungsrechten }\end{array}$ & $\begin{array}{c}\text { Geschätzte Nettozinseinkünfte } \\
(+), \text { bzw. Zinsaufwendungen }(-) \\
\text { aus Beteiligung am SZR- } \\
\text { Department } \\
\end{array}$ & $\begin{array}{c}\text { Geschätzte Zinseinkünfte } \\
\text { aus Finanzierung des } \\
\text { IWF-Sondervermögens } \\
\end{array}$ & $\begin{array}{c}\text { Gesamte geschätzte } \\
\text { Nettozinseinkünfte der } \\
\text { NZBen aus der IWF- } \\
\text { Beteiligung } \\
\end{array}$ \\
\hline & \begin{tabular}{|l} 
Deutsche \\
Bundesbank
\end{tabular} & $\begin{array}{c}223 \\
(4,4 \%) \\
\end{array}$ & $\begin{array}{c}10 \\
(0,2 \%) \\
\end{array}$ & --- & $\begin{array}{c}234 \\
(4,7 \%) \\
\end{array}$ \\
\hline & Banque de France & $\begin{array}{c}190 \\
(9,8 \%)\end{array}$ & -40 & $\begin{array}{c}1 \\
(0,1 \%)\end{array}$ & $\begin{array}{c}151 \\
(7,8 \%)\end{array}$ \\
\hline & Banca d'Italia & $\begin{array}{c}123 \\
(5,8 \%)\end{array}$ & -28 & $\begin{array}{c}20 \\
(0,9 \%)\end{array}$ & $\begin{array}{c}115 \\
(5,4 \%)\end{array}$ \\
\hline & $\begin{array}{l}\text { De Nederlandsche } \\
\text { Bank }\end{array}$ & $\begin{array}{c}90 \\
(11,2 \%)\end{array}$ & $\begin{array}{c}10 \\
(1,2 \%)\end{array}$ & --- & $\begin{array}{c}100 \\
(12,4 \%)\end{array}$ \\
\hline & \begin{tabular}{|l|} 
Belgische \\
Nationalbank \\
\end{tabular} & $\begin{array}{c}80 \\
(11,8 \%) \\
\end{array}$ & -14 & $\begin{array}{c}2 \\
(0,3 \%) \\
\end{array}$ & $\begin{array}{c}68 \\
(10,1 \%)\end{array}$ \\
\hline & Banco de España & $\begin{array}{c}53 \\
(2,2 \%)\end{array}$ & -5 & $\begin{array}{c}6 \\
(0,3 \%)\end{array}$ & $\begin{array}{c}53 \\
(2,2 \%) \\
\end{array}$ \\
\hline & \begin{tabular}{|l|} 
Österreichische \\
Nationalbank \\
\end{tabular} & $\begin{array}{c}37 \\
(4,9 \%)\end{array}$ & -3 & $\begin{array}{c}0 \\
(0,0 \%) \\
\end{array}$ & $\begin{array}{c}34 \\
(4,5 \%)\end{array}$ \\
\hline & Bank of Finland & $\begin{array}{c}22 \\
(6,5 \%)\end{array}$ & $\begin{array}{c}3 \\
(0,9 \%)\end{array}$ & $\begin{array}{c}0 \\
(0,0 \%)\end{array}$ & $\begin{array}{c}26 \\
(7,7 \%)\end{array}$ \\
\hline & Banco de Portugal & $\begin{array}{c}13 \\
(4,3 \%)\end{array}$ & -1 & $\begin{array}{c}0 \\
(0,0 \%) \\
\end{array}$ & $\begin{array}{c}12 \\
(3,9 \%)\end{array}$ \\
\hline & $\begin{array}{l}\text { Central Bank of } \\
\text { Ireland }\end{array}$ & $\begin{array}{c}14 \\
(5,6 \%) \\
\end{array}$ & -3 & -- & $\begin{array}{c}12 \\
(4,8 \%)\end{array}$ \\
\hline & \begin{tabular}{|l|} 
Banque Centrale du \\
Luxembourg \\
\end{tabular} & $\begin{array}{c}3 \\
(11,2 \%)\end{array}$ & -1 & - & $\begin{array}{c}2 \\
(7,4 \%)\end{array}$ \\
\hline
\end{tabular}

Quelle: Eigene Berechnungen. Die der Darstellung zugrunde liegenden Angaben sind entnommen aus den Tabellen 12, 20 und 21.

'Die Prozentangaben beziehen sich auf die Nettozinserträge der NZBen. Vgl. dazu Tabelle 12. Ohne Zinseinkünfte aus AKV- und NKV-
Krediten, die von einigen NZBen in 1998 gewährt und in 1999 vollständig zurückgezahlt wurden. 
Zunächst kann konstatiert werden, daß die NZBen - gemessen in Absolutbeträgen - deutliche Unterschiede bezüglich der Höhe ihrer gesamten IWFNettozinseinkünfte verzeichnen. So dürften im Jahre 1999 die „großen“ Zentralbanken wie beispielsweise die Deutsche Bundesbank oder die Banque de France mit geschätzten 234 Mio. EUR bzw. 151 Mio. EUR durchaus bedeutende Nettoerträge erzielt haben, während die „kleineren“ Währungsbehörden Irlands und Luxemburgs mit veranschlagten 12 Mio. EUR bzw. 2 Mio. EUR wohl vergleichsweise geringe Nettozinseinkünfte vom IWF überwiesen bekommen haben. Dies ist nicht verwunderlich, da für jede NZB die Höhe ihrer gesamten IWF-Forderungen eindeutig durch die jeweilige Reservetrancheposition im General Department bestimmt und damit letztlich durch die Quote des Landes determiniert ist ${ }^{238}$. Die unterschiedlichen Verhaltensweisen der NZBen im SZRDepartment und die Finanzierungsleistungen der NZBen in den IWFSondervermögen schlagen somit nicht auf die gesamte IWF-Ertragssituation der NZBen durch. Die bisherige Analyse sagt jedoch noch nichts über die Bedeutung der vom IWF gezahlten Nettozinsen für die Gewinnentstehung der Zentralbanken selbst aus. Setzt man hierzu die jeweiligen (grob) geschätzten Nettoeinkünfte aus den drei genannten IWF-Beteiligungen der NZBen in Relation zu den gesamten am 31.12.1999 ausgewiesenen Nettozinserträgen der NZBen ${ }^{239}$, zeigt sich in der Tat ein völlig anderes Bild. So machten nach der vorliegenden Berechnung die IWF-Erträge der spanischen, deutschen, italienischen, irischen, portugiesischen und österreichischen NZB nur zwischen 2 und 5 Prozent der gesamten von diesen Währungsbehörden in 1999 erwirtschafteten Nettoerträge aus. Die Zentralbanken Luxemburgs, Finnlands und Frankreichs hingegen konnten immerhin zwischen 7 und 8 Prozent, die Währungsbehörden Belgiens und der Niederlande sogar 10 bzw. 12 Prozent der von ihnen erzielten Nettoerträge auf ihre IWF-Partizipation zurückführen.

\subsubsection{Die Beteiligung der NZBen an der Bank für Internationalen Zahlungsausgleich (BIZ)}

Die Bank für Internationalen Zahlungsausgleich (BIZ) mit Sitz in Basel ist die Bank der Zentralbanken. Sie besitzt die Rechtsform einer Aktiengesellschaft mit einem genehmigten Kapital von 1,5 Milliarden Goldfranken, das in 600.000 Aktien zu je 2.500 Goldfranken zerfällt ${ }^{240}$. Eigentümer der BIZ sind derzeit 49 Zentralbanken (Stand: 31.3.2001) entwickelter Länder, darunter alle Zentralbanken des Eurosystems mit Ausnahme der Banque Centrale du

238 Vgl. Tabellen 20 und 21.

239 Vgl. Tabelle 12.

240 Vgl. Art. 1 und 4 BIZ-Statut. 
Luxembourg ${ }^{241}$. Eine konkrete Identifizierung der NZB-Beteiligungen zum 31.12.1999 ist jedoch nicht ohne weiteres möglich, da die BIZ keinen Einblick in ihr Aktienregister gewährt ${ }^{242}$. Dennoch kann durch Kombination der in den Jahresberichten der NZBen und der BIZ veröffentlichten Daten die folgende Tabelle 23 erstellt werden. Es zeigt sich, daß im Gegensatz zu den Beteiligungen der NZBen an der EZB oder dem IWF, die Anteile der NZBen an der BIZ nicht der relativen Größe ihrer Länder entsprechen ${ }^{243}$. So besitzt beispielsweise die Belgische Nationalbank (NBB) mit 5 Prozent eine höhere BIZ-Beteiligung als die Banco de España mit 1,3 Prozent. Diese Beobachtung kann dahingehend erklärt werden, daß die NBB zusammen mit den anderen Gründungszentralbanken Deutschlands, Frankreichs, Großbritanniens, Italiens, Japans und einer Bankengruppe der USA über das Recht verfügt, bei jeder Neubegebung von BIZ-Aktien mindestens $55 \%$ der neu hinzukommenden Aktien zu gleichen Teilen zu zeichnen, weshalb alle später beigetretenen Zentralbanken i.d.R. weniger BIZ-Aktien besitzen ${ }^{244}$. Die Kapitalzeichnung bestimmt nun den Umfang der von den Zentralbanken einzuzahlenden Beträge und die Partizipation an der Dividendenausschüttung. Nach Artikel 7 Abs. 1 BIZ-Statut erfolgt die Kapitalzahlung in Höhe von 25 Prozent der gezeichneten Anteile, wobei die restlichen 75 Prozent bei Bedarf nachzuschießen sind. Die Dividendenzahlungen der BIZ sind in Schweizer Franken denominiert und variieren entsprechend mit der Ertragslage der BIZ. Am 1. Juli 1999 zahlte die BIZ pro begebener Aktie 320 SFr für das am 31.3.1999 endende Geschäftsjahr ${ }^{245}$. Allerdings waren diese Einkünfte, wie Tabelle 23 zeigt, für die NZBen eher unbedeutend. So betrug der Anteil der BIZ-Dividende an den Gesamten Nettoerträgen der jeweiligen NZBen nur maximal ein Prozent ${ }^{246}$. Relativ wichtiger für die NZB-Ertragslage könnten jedoch die Provisionen sein, die die BIZ als Vergütung für die Übernahme von Kreditgarantien bzw. Kreditdeckungen an ihre Gläubiger zahlt. So koordinierte die BIZ z.B. Ende 1998 eine multilaterale Kreditfazilität in Höhe von 13,3 Mrd. USD zugunsten der Banco Central do Brasil, die bereits im Dezember 1998 in Höhe von 4,2 Mrd. USD und erneut im April 1999 im Betrag von 4,5 Mrd. USD in Anspruch genommen wurde $^{247}$.

241 Vgl. Bank für Internationalen Zahlungsausgleich (2001), S. 204 und Banque Centrale du Luxembourg (2000b).

$242 \mathrm{Vgl}$. Bank für Internationalen Zahlungsausgleich (2000b).

243 Vgl. die Höhe der IWF-Quoten und EZB-Anteile der NZBen in den Tabellen 2 und 20.

$244 \mathrm{Vgl}$. Art. 8 Abs. 2 BIZ-Statut, Bank für Internationalen Zahlungsausgleich (2000a), S.

194 und Deutsche Bundesbank (1997a), S. 184. Bisher wurden drei Tranchen begeben.

$245 \mathrm{Vgl}$. Bank für Internationalen Zahlungsausgleich (1999), S. 187.

246 Zur Höhe der Gesamten Nettoerträge der NZBen des Jahres 1999 vgl. Tabelle 12.

247 Vgl. Banco Central do Brasil (1999), S. 209. 
Tabelle 23: Die Beteiligung der NZBen an der Bank für Internationalen Zahlungsausgleich zum 31.12.1999

\begin{tabular}{|c|c|c|c|c|c|c|c|c|c|}
\hline \multirow[b]{2}{*}{$\mathrm{NZB}$} & \multirow{2}{*}{$\begin{array}{c}\text { Anteil am } \\
\text { gesamten } \\
\text { genehmigten } \\
\text { BlZ-Kapital }\end{array}$} & \multicolumn{2}{|c|}{ Gezeichnete Aktien } & \multicolumn{2}{|c|}{ Gezahlte Aktien' } & \multicolumn{2}{|c|}{ Nachschußverpflichtung } & \multicolumn{2}{|c|}{ Dividende $^{2}$} \\
\hline & & Stück & Mio. EUR & Stück & Mio. EUR & Stück & Mio. EUR & Mio. EUR & $\begin{array}{c}\text { In vH. der Gesamten } \\
\text { Nettoerträge }\end{array}$ \\
\hline $\begin{array}{l}\text { Deutsche } \\
\text { Bundesbank }^{3}\end{array}$ & $<7,0 \%$ & $<42240$ & $<204$ & $<10560$ & $<51$ & $<31680$ & $<153,1$ & $<8,4$ & $<0,2 \%$ \\
\hline $\begin{array}{l}\text { Belgische } \\
\text { Nationalbank }\end{array}$ & $5,0 \%$ & 30000 & 144,9 & 7500 & 36,2 & 22500 & 111,3 & 6,0 & $1,0 \%$ \\
\hline Bank de France & $4,7 \%$ & 28440 & 137,4 & 7110 & 34,4 & 21330 & 103,1 & 5,7 & $0,2 \%$ \\
\hline $\begin{array}{l}\text { De Nederlandsche } \\
\text { Bank }\end{array}$ & $3,1 \%$ & 18660 & 90,2 & 4665 & 22,5 & 13995 & 67,6 & 3,7 & $0,4 \%$ \\
\hline Bank of Finland & $1,7 \%$ & 10000 & 48,3 & 2500 & 12,1 & 7500 & 36,2 & 2,0 & $0,5 \%$ \\
\hline Banco de España & $1,3 \%$ & 8000 & 38,7 & 2000 & 9,7 & 6000 & 29,0 & 1,6 & $0,0 \%$ \\
\hline Banco de Portugal & $1,3 \%$ & 8000 & 38,7 & 2000 & 9,7 & 6000 & 29,0 & 1,6 & $0,8 \%$ \\
\hline $\begin{array}{l}\text { Österreichische } \\
\text { Nationalbank }\end{array}$ & $1,3 \%$ & 8000 & 38,7 & 2000 & 9,7 & 6000 & 29,0 & 1,6 & $0,1 \%$ \\
\hline $\begin{array}{l}\text { Central Bank of } \\
\text { Ireland }\end{array}$ & $1,3 \%$ & 8000 & 38,7 & 2000 & 9,7 & 6000 & 29,0 & 1,6 & $0,6 \%$ \\
\hline $\begin{array}{l}\text { Banque Centrale du } \\
\text { Luxembourg }\end{array}$ & -- & --- & -- & $\cdots$ & -- & -- & - & $\cdots$ & -- \\
\hline
\end{tabular}

7 Quelle: Eigene Berechnungen. Verfugbare NZB-Daten aus: OeNB (2000), S. 93, DNB (2000b), S. 190, BdF (2000c), S. 258, CBI (2000c), S. 80 und 90, BdP (2001), NBB (2000b), S. 90, BdE (2000), S. 160, Bof (2000b), S. 85, BBk (2000a), S. 174 und 186, BCL (2000b). Angaben für die Banca d'Italia sind nicht verfugbar. Weitere Daten aus: BIZ (1999), S. 187, 194 und 198, BBk (2000a), S. 183 und 193, BBk (2000e), S. 11 und Tabelle 12.

$\overrightarrow{0}$

' Die Einzahlung der gezeichneten Aktien erfolgt zu 25\%. Dic Umrechnung des in Goldfranken (GFr) denominierten W'erts der BIZ-Aktien (2500 GFr/Aktie) zum 31.12.1999 in EUR ( $\mathrm{GFr}=1,9326$ EUR) erfolgt über USD-Äquivalent des Goldfranken (Seit 1979 unverändert: 1 GFr $=1,94149$ USD) und dem am 31.12.1999 gültigen EUR-USD-Wechselkurs (1 EUR = 1,0046 USD). Vgl. BZZ (1999), S. 194 ff. und BBk (2000a), S. 183. Die von der BoF und BdF in den Jahresberichten angegebenen Bilanzwerte ihrer BIZ-Beteiligungen (BoF: 11,1 Mio. EUR. BdF: 5,6 Mio. EUR) sind nicht mit den jeweils ebenfalls angegebenen Kapitalanteilen (BoF: 1,67\%, BdF: 4,74\%) kompatibel. Vgl. BdF (2000c), S. 258 und BoF (2000b) S. 85. Der Grund hierfür liegt in den nationalen Bilanzvorschriften, die es den NZBen im Bereich ihrer Finanzaktiva erlauben, eigene Wertansätze zu bilanzjeren. Vgl. European Central Bank (1998c).

${ }^{2}$ Die Dividendenausschüttung an die NZBen im Kalenderjahr 1999 für das am 31.3.1999 abgelaufene Geschäftsjahr der BIZ erfolgte am 1. Juli 1999 in Hohe von 320 SFr pro begebener Aktie. Die Berechnung des Euro-Gegenwerts der BIZ-Dividende erfolgt mit Hilfe des zum 31.12.1999 gültigen EUR-SFr-Wechselkurses $(1 \quad$ EUR $=1,6012 \mathrm{SFr})$. Vgl. Bank für Internationalen Zahlungsausgleich (1999), S. 198 ff. und Deutsche Bundesbank (2000e), S. 11.

${ }^{3}$ Far die BIZ-Beteiligung der Bundesbank kann nur eine Obergrenze angegeben werden, da die BBk nur die Gesamtsumme ihrer Beteiligungen (BIZ, Liquidităts-Konsortialbank und Swift) in Höhe von (gerundeten) 51 Mio. EUR ausweist. Vgl. Deutsche Bundesbank (2000a), S. 174 und 186. 
Tabelle 24: Dic Beteiligung der NZBen an den BIZ-Krediten zugunsten der Banco Central do Brasil

\begin{tabular}{|c|c|c|c|c|c|c|c|}
\hline \multirow[b]{2}{*}{ NZB } & \multirow{2}{*}{$\begin{array}{c}\begin{array}{c}\text { Von der NZB } \\
\text { garantierte } \\
\text { Kreditsummen' }\end{array} \\
\text { Mio. USD }\end{array}$} & \multicolumn{2}{|c|}{$\begin{array}{l}\text { Am } 31.12 .1999 \text { noch offene } \\
\text { Forderungen der NZBen an } \\
\text { BIZ aus Brasilien-Krediten in }\end{array}$} & \multicolumn{2}{|c|}{$\begin{array}{l}\text { Von BIZ in } 1999 \text { erhaltene } \\
\text { Provisionen }{ }^{2} \text { der NZBen in }\end{array}$} & \multicolumn{2}{|c|}{$\begin{array}{c}\text { Gesamte von der BIZ erhaltenen } \\
\text { Einkünfte der NZBen }{ }^{3}\end{array}$} \\
\hline & & Mio. USD & Mio. EUR & Mio. EUR & $\begin{array}{c}\text { In vH. der } \\
\text { Gesamten } \\
\text { Nettoerträge }\end{array}$ & Mio. EUR & $\begin{array}{l}\text { In vH. der } \\
\text { Gesamten } \\
\text { Nettoerträge }\end{array}$ \\
\hline Deutsche Bundesbank & 1364 & 324 & 322,5 & 30 & $0,6 \%$ & $30<x<38,4$ & $0,6 \%<x<0,7 \%$ \\
\hline Banco de España & $<1086$ & $<258$ & $<256,8$ & $<23,9$ & $<0,5 \%$ & $<25,5$ & $<0,6 \%$ \\
\hline Banco de Portugal & 350 & 83,1 & 82,7 & 7,7 & $3,7 \%$ & 9,3 & $4,5 \%$ \\
\hline Belgische Nationalbank & 300 & 71,2 & 70,9 & 6,6 & $1,1 \%$ & 12,6 & $2,1 \%$ \\
\hline De Nederlandsche Bank & 300 & 71,2 & 70,9 & 6,6 & $0,7 \%$ & 10,3 & $1,1 \%$ \\
\hline Central Bank of Ireland & 50 & 11,9 & 11,8 & 1,1 & $0,4 \%$ & 2,7 & $0,9 \%$ \\
\hline Bank of Finland & 50 & 11,9 & 11,8 & 1,1 & $0,3 \%$ & 3,1 & $0,7 \%$ \\
\hline Österreichische Nationalbank & 50 & 11,9 & 11,8 & 1,1 & $0,1 \%$ & 2,7 & $0,2 \%$ \\
\hline Banque Centrale du Luxembourg & 50 & 11,9 & 11,8 & 1,1 & $5,7 \%$ & 1,1 & $5,7 \%$ \\
\hline Banque de France & K. A. & K. A. & K. A. & K. A. & K. A. & $>5,7$ & $>0,2 \%$ \\
\hline
\end{tabular}

Quelle: Eigene Berechnungen. Daten bezüglich der Höhe der von den NZBen übernommenen Kreditgarantien aus: OeNB (1999), S. 88, CBI (1999), S. 70, DNB (1999), S. 96, BoF (2000), S. 67, NBB (2000), S. 89, BCL (2000), S. 125 und BdP (2000), S. 272. Angaben bezüglich der in 1999 von der gezahlten BIZ-Provisionen an CBI, BdE und BBk aus: CBI (2000), S. 79, BdE (2000), S. 130 und BBk (2000a), S. 193. Daten bezüglich der Höhe der Gesamten Nettoerträge der NZBen aus Tabelle 12. Angaben bezüglich der von der Banca d'Italia übernommenen Kreditgarantien sind nicht verfügbar.

'Anhand der Relation der von der CBI übernommenen Kreditgarantien (50 Mio. USD) und den von der CBI ausgewiesenen BIZ-Provisionszahlungen auf diese Kreditübernahmen (1,1 Mio. EUR) werden ausgehend von den BBk- und BdE-Angaben bezüglich ihrer erhaltenen BIZ-Provisionen die übernommenen Kreditgarantien der BBk und der BdE analog geschätzt. Hierbei ist für die BdE nur eine Obergrenze errechenbar, da die BdE auch nur eine Obergrenze für ihre BIZ-Provisionen veröffentlicht. Vgl. Banco de España (2000), S. 130. Die Bundesbank weist ihre von der BIZ in 1999 erhaltenen Provisionen in Höhe von 30 Mio. EUR nur auf Mio. EUR gerundet aus. Vgl. BBk (2000a), S. 193.

${ }^{2}$ Im Falle der OeNB, DNB, BoF, BCL und NBB sind die übernommenen Kreditgarantien bekannt. Die Schätzung der zugehörigen BIZ-Provisionen werden in Analogie zur Schätzung der Kreditübernahmen der BBk und BdE berechnet. Vgl. dazu Fußnote 1.

${ }^{3}$ Summe der Dividenden und Provisionen, die die jeweilige NZB von der BIZ in 1999 erhalten hat. Für die Banque de France und die Banco de España ist nur die Angabe einer Unter- bzw. einer Obergrenze möglich. Für die Deutsche Bundesbank kann nur ein Bereich angegeben werden. Zur Höhe der BIZDividenden der NZBen vgl. Tabelle 23. 
Die vorstehende Tabelle 24 zeigt, inwiefern die NZBen an der Finanzierung dieser Fazilität beteiligt waren und welche Bedeutung die hierfür erhaltenen Provisionen für die Ertragssituation der NZBen haben. Die umfangreichsten Kreditgarantien übernahm die Deutsche Bundesbank mit rund 1364 Mio. USD, gefolgt von der Banco de España mit maximal 1086 Mio. USD und den anderen NZBen mit jeweils weniger als 350 Mio. USD. Entsprechend verteilen sich auch die gewährten Kredite auf die einzelnen NZBen, wobei nur knapp ein Viertel des Kreditvolumens tatsächlich gezogen wurde. Mit Ausnahme der Zentralbank Luxemburgs und Portugals haben die hierfür erhaltenen Provisionen jedoch keine nennenswerten Auswirkungen auf die Ertragslage. Vergleicht man nun die gefundenen Ergebnisse mit den in Tabelle 23 ausgewiesenen BIZDividendenzahlungen, so wird deutlich, daß im Falle der Zentralbanken Belgiens, Portugals, Spaniens, Deutschlands und der Niederlande die in 1999 gezahlten BIZ-Provisionen die Dividendeneinkünfte dieser NZBen teilweise merklich übersteigen. Allerdings geschieht dies auf niedrigem Niveau. Diese Beobachtung läßt sich dahin gehend erklären, daß der Umfang der Kreditgarantien von der einzelnen NZB selbst, d.h. nach Absprache mit der heimischen Regierung, bestimmt wird und folglich unabhängig vom nationalen BIZ-Kapitalanteil ist. Insgesamt gesehen vermögen jedoch weder die BIZProvisionen noch die Gesamtsumme der von der BIZ erhaltenen Einkünfte für die Gewinnentstehung der einzelnen NZBen eine große Rolle zu spielen. Eine Ausnahme bilden hier nur die Banco de Portugal bzw. die Banque Centrale du Luxembourg bei denen immerhin 4,5 Prozent bzw. 5,7 Prozent der jeweiligen Gesamten Nettoerträge des Jahres 1999 auf ihre BIZ-Beteiligung zurückgeführt werden $\operatorname{kann}^{248}$.

\subsubsection{Die Beteiligung der NZBen an weiteren internationalen Organisationen}

Neben dem IWF und der BIZ existiert eine Reihe weiterer internationaler (Finanz-) Organisationen und Gremien, an denen sich die NZBen im Auftrag ihrer heimischen Regierungen beteiligen. Unter dem Aspekt der Finanzierungsleistungen der NZBen sind hier vor allem die Entwicklungsbanken wie die Weltbankgruppe, die Interamerikanische Entwicklungsbank, die Asiatische Entwicklungsbank, die Afrikanische Entwicklungsbank, sowie die Europäische Bank für Wiederaufbau und Entwicklung zu nennen ${ }^{249}$. Allerdings läßt sich hierbei aus Mangel an verfügbaren Daten keine vergleichende Analyse

248 Vgl. die Tabellen 12 und 24.

$249 \mathrm{Zu}$ den Zielen und Aufgaben der genannten Entwicklungsbanken vgl. Deutsche Bundesbank (1997a), S. 68 ff.. 
der NZB-Beteiligungen durchführen ${ }^{250}$. Man kann jedoch davon ausgehen, da $\beta$ die Finanzierungsleistungen der NZBen zugunsten der Entwicklungsbanken wohl ähnlich differenziert erfolgen wie die Beteiligung der NZBen an der Finanzierung der IWF-Sondervermögen. Auch die quantitative Bedeutung der in diesem Zusammenhang erzielten Einkünfte bzw. zu tragenden Aufwendungen dürften für die Gewinnsituation der NZBen wohl sehr begrenzt sein.

Letzteres gilt auch für die Partizipation der NZBen an der Organisation für wirtschaftliche Zusammenarbeit und Entwicklung (OECD). Hier sind alle NZBen im Auftrag ihrer Regierungen in den verschiedenen OECD-Komitees vertreten. Des weiteren nehmen auch Präsidenten bzw. Gouverneure der NZBen an Sitzungen informeller Gremien wie der Siebener- (G7), Zehner- (G10) und Zwanzigergruppe (G20) teil ${ }^{25 !}$.

\subsection{Bilaterale Geschäftsbeziehungen der NZBen mit Finanzinstituten und Zentralbanken in Drittländern}

Neben ihrer Beteiligung an internationalen Organisationen unterhalten die NZBen auch eine Reihe von bilateralen Geschäftsbeziehungen zu Finanzinstituten und Zentralbanken in dritten Ländern, wobei unter dem Aspekt der NZB-Gewinnentstehung vor allem etwaige Finanzierungsverpflichtungen der Notenbanken interessant sind. Diese könnten zum einen aus einer bilateralen Kreditvergabe an ausländische Währungsbehörden und zum anderen aus der NZB-Beteiligung an besonderen bilateralen Wechselkursabkommen entstehen. Des weiteren haben die NZBen Aufwendungen aus anderen Geschäftsbeziehungen mit Drittstaaten-Zentralbanken zu finanzieren.

\subsubsection{Bilaterale Kredite der NZBen an Zentralbanken und Finanzinstitute in Drittländern}

Die in den Geschäftsberichten der NZBen für das Jahr 1999 veröffentlichten Daten lassen eine genaue Identifizierung der bilateralen Kreditforderungen der NZBen an Zentralbanken und Finanzinstituten in Drittländern in der Regel nicht zu. So weisen als einzige Zentralbanken nur die Österreichische Nationalbank

250 So finden sich diesbezüglich in den NZB-Ausweisen nur vereinzelte Angaben. Vgl. z.B. Deutsche Bundesbank (1999d), S. 204 und Banco de Portugal (1999), S. 269.

251 Etwaige im Rahmen von G7- bzw. G10-Verhandlungen koordinierte Kreditabkommen zugunsten von Drittstaaten bzw. internationalen Finanzorganisationen (IWF, BIZ) sind bereits oben stehend analysiert worden und sollen diesen Gremien wegen des informellen Charakters derselben nicht funktional zugeordnet werden. 
und die Banco de España derartige Kredite explizit aus. Diese sind jedoch in ihrer Höhe nicht sehr bedeutend ${ }^{252}$. Insgesamt kann man wohl davon ausgehen, daß der Umfang solcher Kredite auch bei den anderen NZBen - sofern sie überhaupt existieren - sehr gering sein dürfte.

\subsubsection{Die Beteiligung der NZBen an besonderen bilateralen Wechselkursabkommen}

Frankreich hat sich bezüglich der Festsetzung der Paritäten des Euro gegenüber dem CFP-Franc, dem CFA-Franc und dem Komoren-Franc weitreichenden Handlungsspielraum zusichern lassen, obwohl die Kompetenz zur administrativen Festlegung des Euro-Wechselkurses nach Art. 111 EGV beim Ministerrat (ECOFIN) liegt. So besitzt Frankreich auch weiterhin das Recht, in seinen ehemaligen Pazifik-Kolonien Wallis und Futuna, Neukaledonien und Französisch-Polynesien den CFP-Franc zu emittieren und die Euro-Parität des CFP-Franc festzusetzen ${ }^{253}$. Die Banque de France ist jedoch an der Wahrnehmung dieser Tätigkeiten nicht beteiligt, da einerseits der örtliche Bargeldumlauf durch das in Paris ansässige Emissionsinstitut IEOM (Institut d'émission d'outre-mer) ${ }^{254}$ bedient wird und andererseits die CPF-Parität vom französischen Finanzminister festgelegt wird ${ }^{255}$. Eine Finanzierungsverpflichtung der Banque de France existiert hierbei nicht. Dies gilt auch für die Aufrechterhaltung der Parität des CFA- und des Komoren-Franc. So wird die Konvertierbarkeit dieser Währungen jeweils durch eine Haushaltsverpflichtung der französischen Staatskasse garantiert ${ }^{256}$. Auch Portugal ist ermächtigt, seine

252 Vgl. BdE-Kredite an die Dominikanische Republik (14,3 Mio. EUR) und an Äquitorial Guinea (4,2 Mio. EUR) sowie die Kredite der OeNB an die Türkei (2 Mio. EUR) in Österreichische Nationalbank (2000b), S. 127 und Banco de España (2000), S. 122.

$253 \mathrm{Vgl}$. das dem EGV beigefügte „Protokoll betreffend Frankreich“.

254 Entsprechend erzielt Frankreich im Zuge der CFP-Geldversorgung als einziger EWUStaat zusätzlich zu den Gewinnen aus der Euro-Emission auch einen Monetären Seigniorage aus der Emission von Nicht-Euro-Geldzeichen.

255 Die seit 1949 unveränderte Parität des CFP-Franc zum Französischen Franc (FRF) beträgt $100 \mathrm{~F} \mathrm{CFP}=5,5 \mathrm{FRF}$, was einem Eurogegenwert von 0,8 EUR entspricht. Vgl. Institut d'émission d'outre-mer (2001).

256 Vgl. Europäische Gemeinschaft (1998h), S. 58 ff.. Der CFA-Franc wird sowohl von der Banque des États de l'Afrique Centrale (Franc de la Coopération Financière en Afrique Central (XAF)) als auch von der Banque Centrale des États de l'Afrique de l'Quest (Franc de la Communauté Financière Africaine (XOF)) emittiert. Die derzeit gültige FRFbzw. Europarität entspricht $1 \mathrm{FRF}=100 \mathrm{XAF} / \mathrm{XOF}$ bzw. 1 EUR $=655,957 \mathrm{XAF} / \mathrm{XOF}$. Der Komoren Franc (KMF) wird vor der Banque Centrale des Comores emittiert. Die gültige FRF- bzw. Europarität des Komorenfranc beträgt derzeit $(1 \mathrm{FRF}=75 \mathrm{KMF}$ bzw. 1 EUR $=491,968 \mathrm{KMF})$. Vgl. Deutsche Bundesbank (2000b), S. 64 f.. 
traditionellen Wechselkursabkommen mit der Republik Kap-Verde in grundsätzlich alleiniger Verantwortung fortzuführen ${ }^{257}$. Allerdings darf auch hier kein Element dieser Vereinbarung dahingehend ausgelegt werden, daß sie eine Verpflichtung der Banco de Portugal (oder einer anderen Zentralbank des Eurosystems) beinhaltet, die Parität des Kap-Verde-Escudo zu stützen. Vielmehr wird die Konvertierbarkeit des Kap-Verde-Escudos durch eine vom portugiesischen Staat bereitgestellte beschränkte Kreditfazilität sichergestellt. Es kann folglich festgehalten werden, daß aus den genannten Wechselkursarrangements keine Finanzierungsverpflichtungen für die NZBen resultieren. Ob nun diese Regelungen auch ein Verbot zur Finanzierung beinhalten, soll hier offenbleiben. Für eine solche Interpretation spricht allerdings die Tatsache, daß Interventionsabkommen wie beispielsweise die bilateralen Swap-Abkommen der verschiedenen EWU-Länder mit dem Federal Reserve System der USA oder die Teilnahme der Bank of Finland am Nordic Agreement on Foreign Exchange Support zum 31.12.1998 ausgelaufen sind ${ }^{258}$.

\subsubsection{Andere Geschäftsbeziehungen der NZBen mit Zentralbanken und Finanzinstituten in Drittländern}

Die NZBen unterhalten weitere bilaterale Geschäftsbeziehungen zu Zentralbanken und Finanzinstituten in Drittländern. Diese dienen entweder dazu, die regionale Zusammenarbeit der beteiligten Institutionen $\mathrm{zu}$ fördern ${ }^{259}$, oder sie sind als partnerschaftliche Unterstützungsleistung für Zentralbanken in Transformations- bzw. Entwicklungsländern zu verstehen. Letztere umfassen insbesondere entgeltliche oder unentgeltliche Beratungsleistungen und Schulungen durch die NZBen, die teilweise auch durch spezielle Hilfsprogramme der EU, IWF und BIZ (z.B. Tacis-Programm und Phare-Programm der EU) koordiniert werden. Besonders engagiert scheinen hier neben der breit angelegten Technischen Zentralbankkooperation der Deutschen Bundesbank vor allem EWU-Länder mit ehemaligen Kolonien, wie Frankreich oder Portugal ${ }^{260}$. Die von den NZBen in diesem Zusammenhang zu tragenden Aufwendungen sind allerdings nicht quantifizierbar, dürften jedoch relativ begrenzt sein, da die angesprochenen Finanzierungsleistungen sich im wesentlichen auf Personalaufwendungen und ähnliches beschränken.

257 Vgl. im Folgenden Europäische Gemeinschaft (1998k), S. $111 \mathrm{ff} .$.

258 Vgl. Bank of Finland (1999), S. 72.

259 Vgl. z.B. die Teilnahme der BoF an der Nordic Financial Commission oder am NordicBaltic Monetary and Financial Committee. Vgl. Bank of Finland (2000b), S. 67.

260 Vgl. Deutsche Bundesbank (2000a), S. 164 ff.., Banque de France (2000c), S. 193 ff. und Banco de Portugal (2000a), S. 272. 


\section{Verfügung über die den NZBen nach der Übertragung auf die EZB verbliebenen Währungsreserven}

Nach Artikel 31 ESZB-Satzung sind die NZBen auch nach Übergang zur dritten Stufe der Europäischen Währungsunion befugt, mit ihren nach der Übertragung auf die EZB verbleibenden Währungsreserven, Eurosystem-unabhängige Geschäfte abzuschließen. So ist eine Zustimmung der EZB bei (Devisen-) Geschäften der NZBen zur Erfüllung ihrer Verpflichtungen gegenüber internationalen Organisationen nicht erforderlich ${ }^{261}$. Ebenfalls nicht zustimmungspflichtig sind Anlagegeschäfte der NZBen auf ausländischen Finanzmärkten, da sie keine Auswirkung auf die einheitliche Geldpolitik des Eurosystems haben ${ }^{262}$. Alle sonstigen Geschäfte der NZBen mit ihren Währungsreserven bedürfen jedoch oberhalb eines bestimmten der Öffentlichkeit nicht zugänglichen Betrags der Zustimmung der EZB, damit die Übereinstimmung mit der Wechselkurs- und Währungspolitik der Gemeinschaft gewährleistet ist (Art. 31.2. ESZB-Satzung). Dabei wird die Einhaltung dieser Vorgaben durch ein spezielles Monitoring-System der EZB überwacht ${ }^{263}$.

Wie bereits im Rahmen der internationalen Vertretung des Eurosystems erwähnt, führen die NZBen gegenwärtig auf eigene Rechnung keine Geschäfte mit Währungsreserven im Auftrag des Eurosystems/EZB durch. Dies gilt sowohl für Operationen an den Gold- bzw. Devisenmärkten als auch für Geschäfte, die die NZBen im Rahmen der internationalen Währungskooperation abwickeln. So werden etwaige Devisenmarktinterventionen des Eurosystems allein von der EZB bzw. von einer NZB in offener Stellvertretung und auf Rechnung der EZB durchgeführt. Auch die Partizipation der NZBen an internationalen (Finanz-) Organisationen wie dem Internationalen Währungsfonds (IWF) oder der Bank für Internationalen Zahlungsausgleich (BIZ) erfolgt ohne Weisung der EZB. Die einzige Ausnahme von diesen Überlegungen bildet die Übertragung von Währungsreserven auf die EZB, die die NZBen Anfang $1999 \mathrm{zu}$ leisten hatten ${ }^{264}$. Sieht man hiervon einmal ab, sind folglich sämtliche den NZBen in 1999 zugeflossenen Erträge aus ihren Währungsreserven als Eurosystem-unabhängig zu klassifizieren.

261 Vgl. Art. 31.1. ESZB-Satzung und Europäische Zentralbank (2000a), S. 60. Dies gilt auch für Transaktionen der Regierungen mit ihren Arbeitsguthaben in Fremdwährungen gegenüber internationalen Organisationen.

262 Vgl. Europäische Zentralbank (2000a), S. 60. Zu denken wäre beispielsweise an reine Portfolioumschichtungen von Guthaben der NZBen bei ausländischen Geschäftsbanken.

263 Vgl. European Monetary Institute (1995), S. 79 f., Europäische Zentralbank (1999a), S. 78 und Europäische Zentralbank (2000a), S. $60 \mathrm{f}$..

264 Vgl. Art. 30 ESZB-Satzung und die Ausführungen zu Kapitel IV.1. Abschnitt 1.4. und Kapitel V.2.1. Abschnitt 1.. 
Tabelle 25: Die Fremdwährungsaktiva der NZBen zum 31.12.1999'

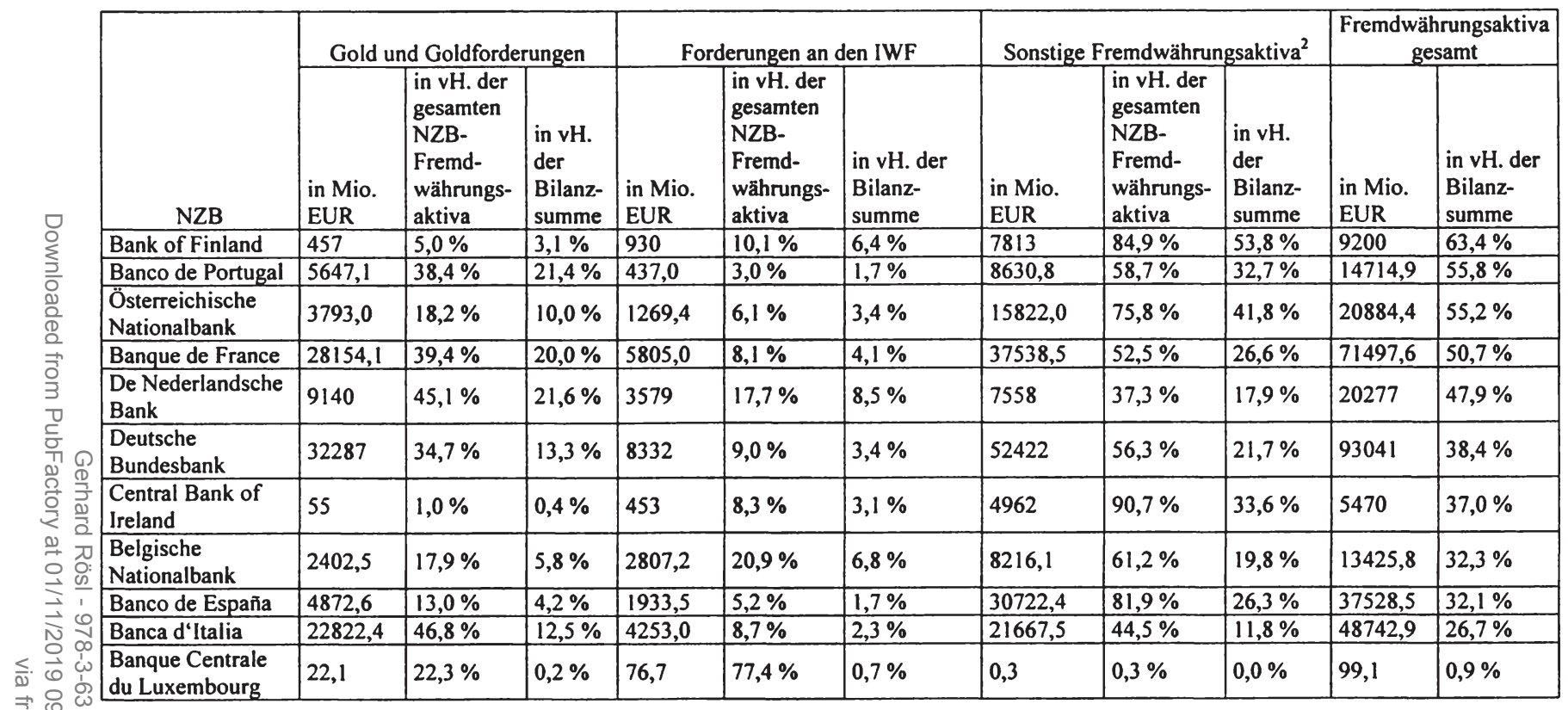

Quelle: Eigene Berechnungen. Die verwendeten Daten sind der Tabelle 11 entnommen.

' Die Deutsche Bundesbank, Bank of Finland, Central Bank of Ireland und De Nederlandsche Bank weisen in ihren Bilanzen nur auf Mio. EUR gerundete Werte aus.

2 Summe der standardisierten NZB-Bilanzposten „Forderungen in Fremdwahrung an Ansässige außerhalb des Euro-Wahrungsgebiets-Guthaben bei Banken, Wertpapieranlagen, Auslandskredite und sonstige Auslandsaktiva“ und „Forderungen in Fremdwăhrung an Ansässige im Euro-Wăhrungsgebiet“. Letztere dienen uberwiegend der Anlage von Wăhrungsreserven in Form von Repo-Geschăften mit im Euro-Wăhrungsgebiet ansässigen Geschăftsbanken. 
Eine empirische Quantifizierung der Einkünfte aus den NZB-Währungsreserven erweist sich jedoch als sehr schwierig, da die NZBen in ihren Gewinn- und Verlustrechnungen eine entsprechende Zuordnung nicht ausweisen. Um nun dennoch zumindest den Umfang der Währungsreserven und deren grundsätzliche Bedeutung für die Gewinnentstehung der NZBen aufzuzeigen, sind in der vorstehenden Tabelle 25 die verschiedenen NZB-Fremdwährungspositionen aus den Jahresausweisen zum 31.12.1999 zusammengestellt. Dabei erfolgt die Darstellung in Anlehnung an die NZB-Bilanzen getrennt nach Goldbeständen, IWF-Forderungen und „Sonstigen Fremdwährungsaktiva“ der NZBen. Allerdings darf nicht übersehen werden, daß der letztgenannte Posten zwar überwiegend aus Devisenreserven besteht, die die NZBen in Form von Geschäftsbankenguthaben und leicht monetisierbaren Wertpapieren halten. Diese Position beinhaltet aber auch Fremdwährungstitel wie z.B. Auslandskredite, die wegen ihrer eingeschränkten Liquidität üblicherweise nicht zu den Währungsreserven gezählt werden. Insofern überzeichnen die ausgewiesenen Werte etwas den Umfang der jeweiligen NZB-Währungsreserven, was aber die grundsätzliche Bedeutung derselben für die Gewinnentstehung der NZBen wohl nicht in Frage stellt ${ }^{265}$.

Ende 1999 vereinigen die Fremdwährungsaktiva der NZBen meist deutlich über 30 Prozent der jeweiligen NZB-Bilanzsummen auf sich. Einen diesbezüglich besonders hohen Anteil besitzt die Zentralbank Finnlands mit 63 Prozent, aber auch die Aktiva der Notenbanken Portugals (56 Prozent), Österreichs (55 Prozent), Frankreichs (51 Prozent) und der Niederlande (48 Prozent) bestehen ca. zur Hälfte aus Fremdwährungsforderungen. Die restlichen Zentralbanken investieren immerhin noch grob ein Drittel ihrer Aktiva in Fremdwährungstitel. Nur die Banque Centrale du Luxembourg hält in Relation zu ihrer Bilanzsumme so gut wie keine Auslandsaktiva (1 Prozent).

Keineswegs darf aber von den genannten Anteilen der Fremdwährungsaktiva an den NZB-Bilanzsummen vorschnell auf die Bedeutung der Währungsreserven für die Gewinnentstehung der NZBen geschlossen werden. Dies leuchtet schon deshalb ein, da die NZBen in ihren Fremdwährungsportfolios teilweise substantielle Bestände unverzinslicher Goldforderungen halten ${ }^{266}$. So machen

265 Ohnehin erübrigt sich diese begriffliche Differenzierung, wenn man den in Artikel 31.2. ESZB-Satzung genannten Begriff der Währungsreserven nicht in seinem ökonomischfunktionalen Sinne interpretiert, sondern ihn dem Begriff der Fremdwährungsaktiva gleichsetzt.

$266 \mathrm{Vgl}$. die Anteile der Goldbestände an den gesamten Fremdwährungsaktiva der NZBen in Tabelle 25. Die Kommentare der NZBen zu ihren Goldbeständen lassen die Vermutung zu, daß verzinsliche Goldforderungen kaum eine nennenswerte Rolle in ihren Währungsreservenportfolios spielen. 
Ende 1999 beispielsweise die Goldforderungen der Zentralbanken der Niederlande (22 Prozent), Portugals (21 Prozent) und Frankreichs (20 Prozent) rund ein Fünftel ihres gesamten Aktivabestandes aus, während im Gegensatz dazu die Central Bank of Ireland und die Banque Centrale du Luxembourg über praktisch kein Gold verfügen. Sinnvoller hingegen erscheint es deshalb, die Erträge der NZBen aus Forderungen an den IWF sowie aus Devisenreserven näher zu untersuchen. Da die Einkünfte aus den IWF-Beteiligungen der NZBen jedoch bereits analysiert wurden, sollen sich die folgenden Betrachtungen auf die Devisenreserven der NZBen beziehen. Allerdings ist eine Quantifizierung der Erträge aus den NZB-Devisenreserven nicht möglich, da in der Regel keine detaillierten Angaben zu den investierten Währungen bzw. zu den Anlageformen (Wertpapiere und/oder unverzinsliche und verzinste Einlagen bei Geschäftsbanken) verfügbar sind ${ }^{267}$. Dennoch deuten die in Tabelle 25 in Relation zur jeweiligen Bilanzsumme gesetzten „sonstigen“ Fremdwährungsaktiva darauf hin, daß besonders die finnische und österreichische Notenbank mit einem näherungsweise geschätzten Devisenanteil von 54 bzw. 42 Prozent am gesamten Aktivabestand dieser Währungsbehörden einen substantiellen Teil ihrer Einkünfte aus ihren Devisenreserven erwirtschaften. Dies gilt ebenfalls für die Zentralbanken Irlands (34 Prozent) und Portugals (33 Prozent) und in geringerem Umfang auch für die Notenbanken Frankreichs (27 Prozent), Spaniens (26 Prozent) sowie für die Zentralbanken Deutschlands, Belgiens und der Niederlande mit einem Devisenreservenanteil von rund 20 Prozent. Die Banca d'Italia hingegen erzielt mit einem Devisenanteil von 12 Prozent an ihrer Bilanzsumme offenbar nur relativ geringe Fremdwährungseinkünfte. Einen Extremfall markiert die Zentralbank Luxemburgs, die zum 31.12.1999 so gut wie keine Devisenreserven besitzt, was einerseits auf die Übertragung von Währungsreserven auf die EZB und andererseits auch auf die Finanzierung der deutlichen Quotenerhöhung Luxemburgs (von Ende 1998: 136 Mio. SZR auf Ende 1999: 279 Mio. SZR) im Internationalen Währungsfonds zurückzuführen ist. Unter dem Aspekt der Gewinnentstehung der NZBen ebenfalls interessant ist die Frage, in welchem Umfang die NZBen bei der Veranlagung ihrer Fremdwährungsbestände ein aktives Ertragsmanagement verfolgen. So scheint seit dem Übergang zur dritten Stufe der EWU der Spielraum der NZBen für eine stärker ergebnisorientierte Verwaltung der Währungsreserven größer geworden zu sein, vor allem da die Liquiditätsanforderungen an die Devisenreserven der NZBen nicht mehr so hoch sind wie noch zu den Zeiten nationaler Wechselkurspolitik. So werden die Fremdwährungsaktiva der NZBen für Devisenmarktinterventionen zur Beeinflussung des Euro-Wechselkurses

267 Vgl. Geschäftsberichte der NZBen für das Jahr 1999 und Klopfleisch (2000), S. 51 ff.. 
grundsätzlich nicht mehr benötigt, da diese - wie bereits erwähnt - von der EZB durchgeführt werden ${ }^{268}$. So nimmt nun auch die Deutsche Bundesbank bei der Formulierung der Anlagestrategie ihrer Währungsreserven auch konkret Bezug auf die Ertragsmaximierung, die allerdings unter Wahrung der Belange des ESZB erfolgen soll ${ }^{269}$. Auch die anderen NZBen scheinen bei ihrer zukünftigen Anlagepolitik ihrer Währungsreserven der Ertragskomponente mehr Aufmerksamkeit schenken zu wollen. So spricht etwa die finnische Zentralbank davon, kürzlich ihr Währungsreserven-Management signifikant in Richtung weniger liquider, dafür aber ertragreicherer Anlageformen geändert zu haben ${ }^{270}$. Und auch die in 1999 von der Österreichischen Nationalbank neu eröffnete Repräsen$\operatorname{tanz}$ in London wird mit einem aktiveren Management der Währungsreserven begründet $^{271}$. Vor diesem Hintergrund würde man nun zunächst vermuten, daß vor allen die Zentralbanken mit einem hohen Anteil an unverzinslichem Gold in ihren Währungsreservenportefeuilles versuchen, diese Bestände gegen verzinsliche Aktiva zu substituieren. Zumindest bis Oktober 2004 sind derartige Transaktionen jedoch nicht zu erwarten, da sich alle EWU-Zentralbanken und die Notenbanken Schwedens, Großbritanniens und der Schweiz darauf geeinigt haben, zur Stabilisierung des Goldmarktpreises nicht am Markt als Verkäufer von Gold auftreten zu wollen ${ }^{272}$.

\section{Kontenverwaltung für öffentliche Stellen und andere Marktteilnehmer}

Nach Art. 17 ESZB-Satzung haben die NZBen das Recht zur Durchführung ihrer Geschäfte für Kreditinstitute, öffentliche Stellen und andere Marktteilnehmer Konten zu eröffnen und zu verwalten. Diese Norm gilt nicht nur für die Abwicklung der Transaktionen aus der gemeinsamen Geldpolitik, sondern auch für Eurosystem-unabhängige Einlagengeschäfte. Der tatsächliche Umfang dieser Tätigkeiten wird jedoch maßgeblich durch die in den nationalen Zentralbankgesetzen geregelten Vorschriften festgelegt. So überrascht es nicht,

${ }^{268}$ Das Halten von Währungsreserven durch die NZBen könnte so gesehen nur noch über die in Art. 30.4. ESZB-Satzung erwähnte Verpflichtung zur Übertragung weiterer Währungsreserven auf die EZB bzw. über eine Art „window-dressing"-Funktion gegen spekulative Attacken auf den Euro-Wechselkurs begründet werden.

269 Vgl. Deutsche Bundesbank (1999b), S. 8. Die für die Bundesbank überraschend deutliche Zielformulierung der Ertragsmaximierung ist nicht zuletzt vor dem Hintergrund der aktuellen Diskussion der Übertragung des Währungsreservenmanagements auf eine externe Agentur zu verstehen. Vgl. dazu Döring, C./Burckhard C. (2000), S. 2 f..

270 Vgl. Bank of Finland (2000), S. 59.

271 Vgl. Österreichische Nationalbank (2000), S. 43.

272 Vgl. Europäische Zentralbank (2000a), S. 59. Dies gilt jedoch nicht für vor Abschluß des Goldabkommens beschlossene Goldverkäufe. 
daß die NZBen in unterschiedlichem Ausmaß Konten im Auftrag öffentlicher Stellen und bestimmter inländischer Privater (private Nichtbanken, Geschäftspartner aus dem Finanzsektor, die nicht der Mindestreserveverpflichtung unterliegen) verwalten. Ihren Niederschlag finden diese Aktivitäten in der jeweiligen NZB-Bilanz unter dem Posten „Verbindlichkeiten in Euro gegenüber sonstigen Ansässigen im Euro-Währungsgebiet", der auch die Grundlage für die folgende Analyse bildet. In Tabelle 26 sind die jeweiligen Bilanzstände der von den NZBen am Ende des Jahres 1999 verwalteten Konten der genannten inländischen Geschäftspartner zusammengefaßt. Es zeigt sich, daß eine Reihe von NZBen wie die Währungsbehörden Deutschlands, Frankreichs, Österreichs, Spaniens und Luxemburgs (Giro-) Konten für private Nichtbanken führen. Ob es sich hierbei im Einzelfall überwiegend um Unternehmen oder Privatkunden handelt, muß jedoch offenbleiben. In jedem Falle dürfte der Gesamtumfang dieser Einlagen sehr gering sein. Eine größere Rolle spielen hingegen die Konten von Geschäftspartnern aus dem Finanzsektor, die nicht der Mindestreserveverpflichtung unterliegen und keinen Zugang $\mathrm{zu}$ den ständigen Fazilitäten des Eurosystems haben. Als Beispiel seien hier die bei der Central Bank of Ireland (CBI) in Höhe von 1016 Mio. EUR gehaltenen Depositen des Eircom Pensionsfonds genannt, die Ende 1999 immerhin rund 18 Prozent der gesamten Euro-Sichtverbindlichkeiten der CBI gegenüber den Ansässigen des Euroraums ausmachten. Allerdings hatten diese Einlagen nach CBI-Angaben nur kurzfristigen Bestand ${ }^{273}$. Zu erwarten war deshalb, daß sich wie bei den anderen NZBen (mit Ausnahme der Zentralbank Frankreichs) die jeweilige Summe der Einlagen der genannten Finanzinstitute und privaten Nichtbanken in Relation zu den gesamten Euro-Verbindlichkeiten um die 1 Prozentmarke eingependelt haben. Für die Notenbankgewinnentstehung der NZBen bedeutet dies wiederum, daß für die einzelne Zentralbank etwaige Aufwendungen aus der Verzinsung der Depositen der privaten Nichtbanken und der erwähnten Finanzinstitute keine sehr große Bedeutung erlangen dürften, was auch für erhobene Kontoführungsgebühren zutrifft. Diesbezügliche Angaben veröffentlichen die NZBen jedoch nicht. Besser hingegen ist die Datenlage bezüglich der Kontenverwaltung, die die NZBen im Auftrag öffentlicher Stellen durchzuführen haben. Von besonderem Interesse ist hierbei die Frage, in welchem Umfang die jeweiligen Regierungen Girokonten bei ihren NZBen unterhalten. Diesbezüglich läßt sich folgende Zweiteilung vornehmen ${ }^{274}$.

273 Vgl. Central Bank of Ireland (2000c), S. 82.

274 Vgl. auch Europäische Zentralbank (1999c), S. 16 f., Europäische Zentralbank (2000e), S. $42 \mathrm{f}$. und European Central Bank (2000b). 
Tabelle 26: Eurosystem-unabhängige Kontenverwaltung der NZBen im Auftrag von inlăndischen Geschäftspartnern (keine Kreditinstitute mit Mindestreserveverpflichtung) (Angaben zum 31.12.1999)

\begin{tabular}{|c|c|c|c|c|c|c|c|c|c|}
\hline & & & & BBk & BdF & BdP & BoF & CBI & DNB \\
\hline & & 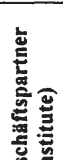 & $\begin{array}{l}\text { Konten von } \\
\text { Geschäftspartnern aus dem } \\
\text { Finanzsektor, die nicht der } \\
\text { Mindestreserve- } \\
\text { verpflichtung unterliegen } \\
\text { und sonstige Einlagen } \\
\end{array}$ & $\mathrm{Ja}$ & Ja & K. A. & 1 Mio. EUR & $\begin{array}{l}\text { (Kurzfristige) } \\
\text { Einlagen des } \\
\text { Eircom } \\
\text { Pensionsfonds in } \\
\text { Hobe von } 1016 \\
\text { Mio. EUR. } \\
\end{array}$ & K. A. \\
\hline & & 仓运 & $\begin{array}{l}\text { Konten für private } \\
\text { Nichtbanken }\end{array}$ & $\begin{array}{l}\text { Konten für } \\
\text { Unternehmen und } \\
\text { Privatkunden. }\end{array}$ & $\begin{array}{l}\text { Konten für Unternehmen } \\
\text { und Privatkunden. }\end{array}$ & K. A. & K. A. & K. A. & K. A. \\
\hline 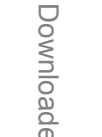 & 营 & 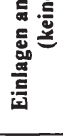 & $\begin{array}{l}\text { Einlagenhöhe gesamt } \\
\text { (in vH. der gesamten Euro- } \\
\text { Sichtverbindlichkeiten gg. } \\
\text { Ansässigen des } \\
\text { Euroraums) } \\
\end{array}$ & $\begin{array}{l}448 \text { Mio. EUR } \\
(1,1 \%)\end{array}$ & $\begin{array}{l}2745,5 \text { Mio. EUR } \\
(9,8 \%)\end{array}$ & $\begin{array}{l}2,1 \text { Mio. EUR } \\
(0,0 \%)\end{array}$ & $\begin{array}{l}1 \text { Mio. EUR } \\
(0,0 \%)\end{array}$ & $\begin{array}{l}\text { 1017,7 Mio. EUR } \\
(18,1 \%)\end{array}$ & $\begin{array}{l}50 \text { Mio. EUR } \\
(0,7 \%)\end{array}$ \\
\hline $\begin{array}{l}\stackrel{2}{2} \\
\stackrel{2}{0} \\
\frac{0}{3} \\
0 \\
\complement\end{array}$ & 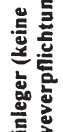 & & $\begin{array}{l}\text { Girokonten des Staates bei } \\
\text { NZB }\end{array}$ & $\begin{array}{l}\text { Ja, } \\
\text { aber Hauptkonto des } \\
\text { Staates bei } \\
\text { Geschåftsbanken. }\end{array}$ & $\begin{array}{l}\text { 1057,4 Mio. EUR, } \\
\text { aber Hauptkonto des } \\
\text { Staates bei } \\
\text { Geschäftsbanken }\end{array}$ & $\begin{array}{l}\text { Ca. 2235,7 Mio. } \\
\text { EUR. } \\
\text { aber seit März } 2000 \\
\text { Hauptkonto bei } \\
\text { Geschäftsbanken }\end{array}$ & $\begin{array}{l}\text { Ja, } \\
\text { aber Hauptkonto des } \\
\text { Staates bei } \\
\text { Geschaftsbanken }\end{array}$ & $\begin{array}{l}2540,3 \text { Mio. EUR, } \\
=\text { Hauptkonto des } \\
\text { Staates }\end{array}$ & $\begin{array}{l}\text { Ja, } \\
\text { aber Hauptkonto des } \\
\text { Staates bei } \\
\text { Geschaftsbanken }\end{array}$ \\
\hline 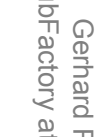 & 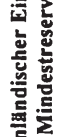 & 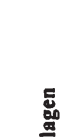 & Andere Staatliche Einlagen & $\begin{array}{l}\text { Depositen } \\
\text { gesetzlicher } \\
\text { Sozialversicherungen } \\
\text { und Sondervermōgen } \\
\text { des Bundes. } \\
\end{array}$ & K. A. & Ja, aber sehr gering & K. A. & $\begin{array}{l}\text { Einlagen des } \\
\text { "Official Assignee } \\
\text { in Bankruptcy" in } \\
\text { Hőhe von } 184463 \\
\text { EUR. } \\
\end{array}$ & K. A. \\
\hline 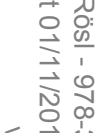 & 동 & 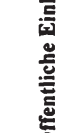 & $\begin{array}{l}\text { Einlagenhőhe gesamt } \\
\text { (in vH. der gesamten Euro- } \\
\text { Sichtverbindlichkeiten gg. } \\
\text { Ansässigen des } \\
\text { Euroraums) } \\
\end{array}$ & $\begin{array}{l}79 \text { Mio. EUR } \\
(0,2 \%)\end{array}$ & $\begin{array}{l}\text { 1057,4 Mio. EUR } \\
(3,8 \%)\end{array}$ & $\begin{array}{l}\text { 2235,7 Mio. EUR } \\
(35,8 \%) \\
\text { (Juli } 2000: 0,0 \% \text { ) }\end{array}$ & - & $\begin{array}{l}2540,5 \text { Mio. EUR } \\
(45,1 \%)\end{array}$ & $\begin{array}{l}9 \text { Mio. EUR } \\
(0,1 \%)\end{array}$ \\
\hline 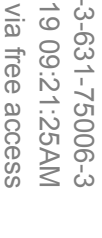 & 岑 & 5 & $\begin{array}{l}\text { Verzinsung der staatlichen } \\
\text { Einlagen }\end{array}$ & Nein & $\begin{array}{l}\text { Ja, in 1999: } 78,0 \text { Mio. } \\
\text { EUR. Verzinsung mit } \\
\text { Hauptrefinanzierungs- } \\
\text { satz bis zu einer } \\
\text { Einlagenhohe von } 1,5 \\
\text { Mrd. EUR. Ab dieser } \\
\text { Schwelle dann Satz fur } \\
\text { die Einlagefazilitat }\end{array}$ & $\begin{array}{l}\text { Ja, in } 1999 \text { in Hobe } \\
\text { von } 2 \text { Prozent. Aber } \\
\text { Staat hat seit Mitte } \\
2000 \text { die } \\
\text { Möglichkeit } \\
\text { zusătzliche Gelder } \\
\text { am Markt höher } \\
\text { verzinslich } \\
\text { anzulegen. }\end{array}$ & Nein & $\begin{array}{l}\text { Ja, in 1999: 82,6 } \\
\text { Mio. EUR. Dies } \\
\text { sind auf den } \\
\text { Jahresendstand der } \\
\text { staatlichen Einlagen } \\
\text { bezogen 3,25\%. }\end{array}$ & K. A. \\
\hline
\end{tabular}


Noch Tabelle 26: Eurosystem-unabhăngige Kontenverwaltung der NZBen im Auftrag von inländischen Geschåftspartnern (keine Kreditinstitute mit Mindestreserveverpflichtung) (Angaben zum 31.12.1999)

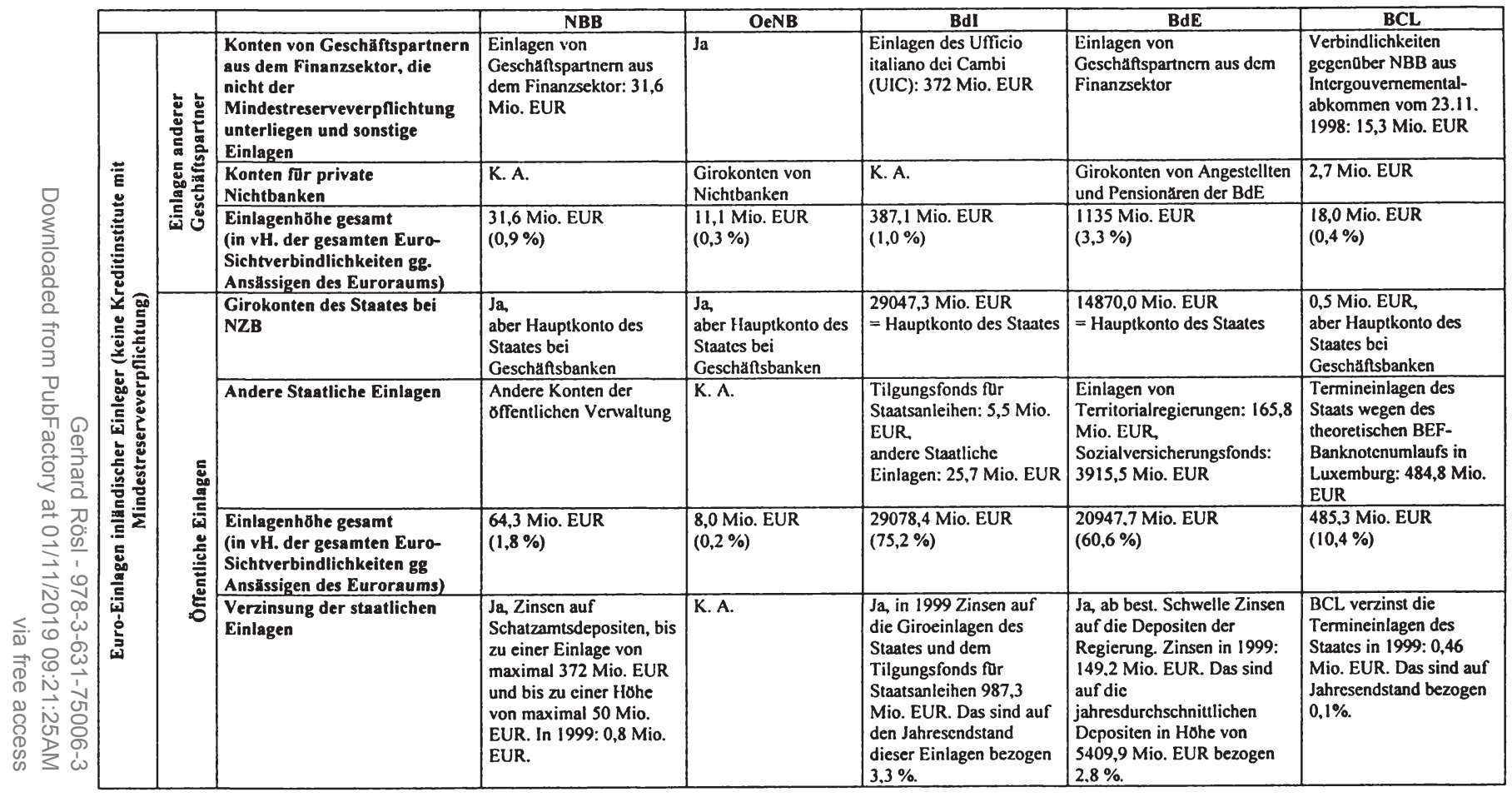

Quelle: Eigene Berechnungen. Die der Öbersicht zugrunde liegenden Daten sind entnommen aus den Geschånsberichten der NZBen fur 1999, European Central Bank (2000b), Europaische Zentralbank (1999c), S. 16 f., Europäische Zentralbank (2000c), S. 42 f., Banco de Portugal (2000b) und Banque de France (2000a). Fur die Deutsche Bundesbank (BBk), De Nederlandsche Bank (DNB) und Bank of Finland (BoF) sind nur auf Mio. EUR gerundete Werte verfugbar. 
Die erste Gruppe, bestehend aus den Regierungen Deutschlands, der Niederlande, Belgiens, Österreichs, Luxemburgs, Frankreichs und seit kurzem auch Portugals besitzen zwar Depositen bei ihrer NZB, unterhalten aber ihr Hauptkonto bei heimischen Geschäftsbanken. $\mathrm{Zu}$ dieser Gruppe ist auch die finnische Regierung zu zählen, die bei der Abwicklung ihrer Transaktionen traditionell nur sehr selten auf ihr Konto bei der Bank of Finland zurückgreift ${ }^{275}$. Ein völlig anderes Bild liefert dagegen das Verhalten der irischen, spanischen und italienischen Regierung, die ihr Haupteinlagenkonto jeweils bei der heimischen Zentralbank unterhalten. So wies die Central Bank of Ireland Ende 1999 Giraleinlagen des irischen Staates in Höhe von 2540 Mio. EUR aus, was zwar dem 32-fachen der Einlagen der deutschen Bundesregierung bei der Bundesbank entsprach, aber im Vergleich zu den Kontokorrenteinlagen der Regierungen Spaniens mit 14870 Mio. EUR und Italiens mit 29047 Mio. EUR immer noch relativ gering war. Es überrascht folglich nicht, daß die genannten Regierungseinlagen im Falle Spaniens 43 Prozent und im Falle Italiens 75 Prozent der Euro-Sichtverbindlichkeiten der heimischen NZBen gegenüber den Ansässigen des Euro-Währungsgebiets Ende 1999 auf sich vereinigten.

Die Begründung für diese erheblichen Unterschiede im Verhalten der Regierungen findet sich in den gesetzlichen Vorschriften für die jeweiligen NZBen einerseits und in der Verzinsung der Staatsdepositen andererseits ${ }^{276}$. Immer dann, wenn die Regierung das Recht besitzt, ihr Haupteinlagenkonto bei Geschäftsbanken zu führen und zugleich die Zentralbank auf die Staatseinlagen entweder keine Zinsen zahlt oder diese nur unter Marktwert verzinst, gibt es einen Anreiz für den Staat, seine Depositen zu den privaten Kreditinstituten umzuschichten. Die in Tabelle 26 aufgeführten Angaben bezüglich der Verzinsung der Staatseinlagen belegen diese Einschätzung unmittelbar. Dies bedeutet aber auch, daß entsprechende Auswirkungen auf die Höhe der Notenbankgewinne keinesfalls zu vernachlässigen sind. So zahlte etwa die Banca d'Italia in 1999 auf die gesamten Staatseinlagen 987 Mio. EUR Zinsen, was der Hälfte ihrer gesamten Zinsaufwendungen entsprach ${ }^{277}$. Andere NZBen hingegen wie zum Beispiel die Deutsche Bundesbank verzinsen ihre Staatseinlagen nicht. So betrug Ende 1999 die Höhe der staatlichen Einlagen bei der Bundesbank auch nur gerade einmal 79 Mio. EUR - ein Zwölftel dessen, was die italienische Zentralbank an Zinsen ihren staatlichen Einlegern in 1999 gutgeschrieben hat. Auch hinsichtlich der Frage nach den Kommissionen, die

275 Vgl. European Montary Institute (1995), S. 136, Bank of Finland (2000a) und Bank of Finland (2000b), S. 104 f..

276 Vgl. Europäische Zentralbank (1999c), S. 16 f., Europäische Zentralbank (2000b), S. 42 f. und European Central Bank (2000b).

277 Vgl. Banca d'Italia (2000a), S. 281 und Tabelle 12. 
die Währungsbehörden für die Kontenverwaltung des Staates erhalten, unterscheiden sich diese NZBen in beachtlicher Weise. So ist das italienische Schatzamt verpflichtet, an die Banca d'Italia für den geleisteten Zahlungsservice Kommissionen zu entrichten, während die Deutsche Bundesbank von der Bundesregierung keine entsprechenden Gebühren verlangen darf ${ }^{278}$.

\section{Eurosystem-unabhängige Offenmarkt- und Kreditgeschäfte der NZBen}

Artikel 18.1. ESZB-Satzung ermächtigt die NZBen zur Erreichung der Ziele des ESZB und zur Erfüllung seiner Aufgaben, Kreditgeschäfte mit Kreditinstituten und anderen Marktteilnehmern abzuschließen (...) und/oder auf den Finanzmärkten tätig zu werden, indem sie auf Gemeinschafts- oder Drittlandswährungen lautende Forderungen und börsengängige Wertpapiere (...) kaufen und verkaufen (...). Des weiteren dürfte diese Norm auch die Kompetenz zur Emission von NZB-Schuldverschreibungen umfassen ${ }^{279}$. Allerdings beschränkt sich Art. 18.1. ESZB-Satzung nicht rein auf die Offenmarkt- und Kreditgeschäfte, die die NZBen im Rahmen der gemeinsamen Geldpolitik durchführen, sondern schließt auch Eurosystem-unabhängige Transaktionen mit $e^{280}$. Im Folgenden soll nun untersucht werden, in welchem Umfang die NZBen im ersten Jahr der EWU Eurosystem-unabhängige Wertpapier(ver)käufe, Kreditgeschäfte sowie Geschäfte mit eigenen Schuldverschreibungen getätigt haben und ob diese Transaktionen für die NZB-Gewinnsituation von Bedeutung sind. Dabei werden an dieser Stelle nur in Euro denominierte Aktiva und Passiva berücksichtigt, da entsprechende Fremdwährungstransaktionen eher der bereits analysierten Veranlagung von Währungsreserven bzw. der Beteiligung der NZBen an internationalen Organisationen zuzuordnen sind.

\subsection{Eurosystem-unabhängige Wertpapiergeschäfte}

Die NZBen haben auch weiterhin die Möglichkeit, auf eigene Rechnung und Initiative Wertpapierkäufe und -verkäufe zu tätigen ${ }^{281}$. Die quantitative

278 Vgl. Banca d'Italia (2000a), S. 285 und $\S 20$ Abs. 1 BBankG.

279 Vgl. Smits (1999b), S. 617.

280 So ist die in den einleitenden Worten von Art. 18.1. ESZB-Satzung erwähnte Erreichung der Ziele des ESZB und dessen Aufgabenerfüllung nicht im Sinne einer Begrenzung auf Eurosystem-spezifische Offenmarkt- und Kreditgeschäfte der NZBen zu interpretieren, sondern erinnert vielmehr an die Ziele des ESZB (insbesondere an die Gewährleistung der Preisstabilität) und definiert damit den Handlungsrahmen der NZBen. Vgl. Smits (1999b), S. 617.

281 Vgl. auch Rösl/Schäfer (1998a), S. 3, Rösl/Schäfer (1998b), S. 149, Europäische Zentralbank (1999a), S. 72 und Rösl/Schäfer (2000), S. 40. 
Bedeutung dieser Aktivitäten im ersten Jahr der Währungsunion läßt sich prinzipiell anhand der transaktionsbedingten Veränderung der Wertpapierbestände in den Bilanzausweisen der NZBen aufzeigen, da die NZBen im Gründungsjahr der Währungsunion keine Wertpapiertransaktionen im Rahmen der gemeinsamen Geldpolitik durchgeführt haben. Allerdings erweist sich die konkrete Identifizierung dieser Wertpapierkäufe und -verkäufe als nicht einfach. Dies liegt zum einen daran, daß sich der Gesamtbestand an Euro-Wertpapieren in den NZB-Ausweisen auf die Bilanzposten „Wertpapiere in Euro von Ansässigen im Euro-Währungsgebiet", „Forderungen in Euro an Ansässige außerhalb des Euro-Währungsgebiets“ und „Sonstiges Finanzanlagevermögen“ verteilt $^{282}$. Da die beiden zu letzt genannten Positionen als Sammelposten fungieren, können für die Höhe der dort erfaßten Euro-Wertpapiere in der Regel nur Obergrenzen angegeben werden. Zum anderen müssen Wertpapierkursänderungen berücksichtigt werden. So kann, da die NZBen ihre Wertpapiere in der Regel zu Marktpreisen bewerten, z.B. bei einer Abnahme der jeweiligen Bilanzposten nicht ohne weiteres auf tatsächlich durchgeführte Verkaufstransaktionen geschlossen werden. Die in den Jahresberichten veröffentlichten Erläuterungen zu den NZB-Bilanzen erlauben es aber häufig dennoch, das entsprechende Transaktionsvolumen näherungsweise im Sinne von Ober- und Untergrenzen abzuschätzen ${ }^{283}$. Die Tabelle 27 zeigt ein sehr heterogenes Bild der im ersten Jahr der EWU von den NZBen durchgeführten Eurosystemunabhängigen Euro-Wertpapier-Transaktionen. Während beispielsweise die Deutsche Bundesbank (BBk) zu Beginn der EWU keine Bestände an heimischen Wertpapieren besa $\beta^{284}$ und sehr wahrscheinlich auch in der Folgezeit von entsprechenden Käufen absah, verkaufte die Banca d'Italia (BdI) in 1999 vermutlich einen beträchtlichen Teil ihrer Euro-Titel. Eine mögliche Erklärung für den geschätzten Abbau ihres Euro-Portfolios um bis zu 16 Prozent kann eine gewünschte Privatisierung der Reserven $\operatorname{sein}^{285}$.

282 V.gl. European Central Bank (1998c), S. $19 \mathrm{ff..}$

283 Zur Herleitung der einzelnen Schätzergebnisse vgl. die ausführlichen Erläuterungen zur Tabelle 27 im Anhang.

284 So veräußerte die Bundesbank ihre letzten Wertpapiere in 1996. Vgl. Deutsche Bundesbank (1997b), S. 178, Deutsche Bundesbank (1999d), S. 198 und die ausführlichen Erläuterungen im Anhang.

285 Vgl. hierzu auch die Analyse der als Finanzaktiva geearmarkten Euro-Wertpapiere der BdI in Tabelle 27 und die ausführlichen Erläuterungen im Anhang. Für eine solche Interpretation spricht auch das mit 15,4 Prozent vergleichsweise hohe Verhältnis der gesamten BdI-Reserven (inklusive Kapital) zur BdI-Bilanzsumme am 31.12.1999. Vgl. hierzu die Tabelle 30 . 
Tabelle 27: Eurosystem-unabhängige Transaktionen der NZBen mit Euro-Wertpapieren in 1999 in Mio. Euro

\begin{tabular}{|c|c|c|c|c|c|c|c|c|}
\hline \multicolumn{3}{|l|}{ NZB } & BBk & BdI & NBB & BdE & BCL & CBI \\
\hline \multirow{2}{*}{$\begin{array}{l}\text { NZB-Bılanzposten } \\
\text { "Wertpapicre in Euro von } \\
\text { Ansassigen im Euro- } \\
\text { Wahrungsgcbiet }\end{array}$} & \multicolumn{2}{|l|}{11.1999} & - & 2432,5 & 3779,4 & - & 16,5 & 1613,0 \\
\hline & \multicolumn{2}{|l|}{31121999} & - & 1483.1 & 3683,1 & - & 199,4 & 1941,1 \\
\hline \multicolumn{3}{|l|}{$\begin{array}{l}\begin{array}{l}\text { Differenz der Bilanzposten } \\
\text { (in \% gegenuber } 11.1999 \text { ) }\end{array} \\
\end{array}$} & - & $\begin{array}{c}-949,3 \\
(-39,0 \%) \\
\end{array}$ & $\begin{array}{c}-96,3 \\
(-2,5 \%) \\
\end{array}$ & - & $\begin{array}{c}+182,9 \\
(+1108,5 \%) \\
\end{array}$ & $\begin{array}{c}+328,1 \\
(+20,3 \%)\end{array}$ \\
\hline \multicolumn{3}{|c|}{$\begin{array}{l}\text { Geschatzter Transaktionswert in } 1999 \\
\text { (in \% gegenuber I } 1 \text { 1999) }\end{array}$} & $\begin{array}{c}T=0 \\
(\hat{T}=0 \%)\end{array}$ & $\begin{array}{l}T \approx 0 \\
(\hat{T} \approx 0)\end{array}$ & $\begin{array}{c}-96,3 \leq \leq T \leq 0,0 \\
(-2,5 \% \leq \leq \hat{T} \leq 0,0 \%)\end{array}$ & - & $\begin{array}{l}T=182,9 \\
(\hat{T} \approx 1108,5 \%) \\
\end{array}$ & $\begin{array}{c}T \geq 2328,1 \\
(\hat{T} \geq 220,3 \%) \\
\end{array}$ \\
\hline \multirow{4}{*}{$\begin{array}{l}\text { Identıfizicrte Bestande bzw. } \\
\text { Obergrenzen fur Euro- } \\
\text { Wertpapiere, die in den } \\
\text { NZB-Bilanzen als } \\
\text { "Forderungen in Euro an } \\
\text { Anstlssige außerhalb des } \\
\text { Euro-Wahrungssgebiets“ } \\
\text { verbucht werden } \\
\end{array}$} & \multirow{2}{*}{1.1 .1999} & $E-W P_{\max }$ & - & - & 927,6 & 43,1 & - & - \\
\hline & & $\epsilon-W P_{\text {sach }}$ & - & - & 0 & 0 & - & - \\
\hline & \multirow{2}{*}{ 31.12.1999 } & E-WP & 9149 & - & 255,9 & 38,4 & 720,6 & - \\
\hline & & $\epsilon-W P_{\text {mat }}$ & 0 & - & 0 & 0 & 0 & - \\
\hline \multicolumn{3}{|c|}{$\begin{array}{l}\begin{array}{l}\text { Differenz der identifizlerten Bestănde bzw Obergrenzen } \\
\text { (in \% gegenuber } 11 \text { 1999) }\end{array} \\
\end{array}$} & +9149 & - & $\begin{array}{c}-671,7 \\
(-72,4 \%)\end{array}$ & $\begin{array}{c}-4,7 \\
(-10,9 \%)\end{array}$ & $+720,6$ & - \\
\hline \multicolumn{3}{|c|}{$\begin{array}{l}\text { Geschatzter Transaktionswert in } 1999 \\
\text { (in \% gegenuber 1.1.1999) }\end{array}$} & $\begin{array}{c}T=0 \\
(\hat{T}=0 \%)\end{array}$ & $\begin{array}{c}T=0 \\
(\hat{T}=0 \%)\end{array}$ & $\begin{array}{c}T=0 \\
(\hat{T}=0 \%)\end{array}$ & $\begin{array}{c}T=0 \\
(\hat{T}=0 \%)\end{array}$ & $\begin{array}{c}T=0 \\
(\hat{T}=0 \%)\end{array}$ & $\begin{array}{c}T=0 \\
(\hat{T}=0 \%)\end{array}$ \\
\hline \multirow{4}{*}{\begin{tabular}{|l|} 
Identifizierte Bestande bzw. \\
Obergrenzen for Euro- \\
Wertpapiere, die in den \\
NZB-Bilanzen als \\
Sonstiges Finanzanlage- \\
vermogen" verbuche werden \\
\end{tabular}} & \multirow{2}{*}{ 1.1.1999 } & E-WP & - & 20509,4 & 1324,7 & \multirow{2}{*}{3687,6} & - & 17,5 \\
\hline & & $\epsilon-W P_{\text {a }}$ & - & K. A & K. A. & & - & K. A. \\
\hline & \multirow{2}{*}{31.12 .1999} & $\epsilon-W P_{\text {ma }}$ & - & 18174,1 & 1325.7 & \multirow{2}{*}{3534.5} & 431,5 & 40,3 \\
\hline & & $\epsilon-W P_{\infty}$ & - & K. A. & K. A. & & $\mathbf{K A}$ & K. A. \\
\hline \multicolumn{3}{|c|}{$\begin{array}{l}\text { Differenz der identifizierten Bestande bzw. Obergrenzen } \\
\text { (in \% gegenuber } 1.1 \text { 1999) }\end{array}$} & - & $\begin{array}{c}-2335,3 \\
(-11,4 \%)\end{array}$ & $\begin{array}{c}+1,0 \\
(+0,1 \%)\end{array}$ & $\begin{array}{l}-153,1 \\
(-4,2 \%) \\
\end{array}$ & $+431,5$ & $\begin{array}{c}+22,8 \\
(+132,3 \%) \\
\end{array}$ \\
\hline \multicolumn{3}{|c|}{$\begin{array}{l}\text { Geschatzter Transaktionswert in } 1999 \\
\text { (in \% gegenuber } 11.1999 \text { ) }\end{array}$} & $\begin{array}{c}T=0 \\
(\hat{T}=0 \%)\end{array}$ & $\begin{aligned}-3284,6 & \leq T \leq 0,0 \\
(-16,0 \% & \leq \hat{T} \leq 0,0 \%)\end{aligned}$ & $\begin{array}{c}0,0 \leq T \leq 1,0 \\
(0,0 \% \leq \hat{T} \leq 0,1 \%)\end{array}$ & $\begin{array}{c}-153,1 \leq \leq T \leq 0 \\
(-4,2 \% \leq \leq \hat{T} \leq 0)\end{array}$ & $0,0 \leq T \leq 431,5$ & K. A. \\
\hline \multicolumn{3}{|c|}{$\begin{array}{l}\text { Generelle Abschatzung der von den NZBen in } 1999 \\
\text { durchgefuhrten Wertpapiertransaktionen (bezogen auf die } \\
\text { Euro-Wertpapierbestande zu Beginn der EWU) }\end{array}$} & $\begin{array}{l}\text { Keine Trans- } \\
\text { aktionen }\end{array}$ & Deutlıche Nettoverkaufe & Geringe Nettoverkalufe & Geringe Nettoverkaufe & Deutliche Nettoklufe & $\begin{array}{l}\text { Deutliche } \\
\text { Nettokdufe }\end{array}$ \\
\hline
\end{tabular}


Noch Tabelle 27: Eurosystem-unabhăngige Transaktionen der NZBen mit Euro-Wertpapieren in 1999 in Mio. Euro

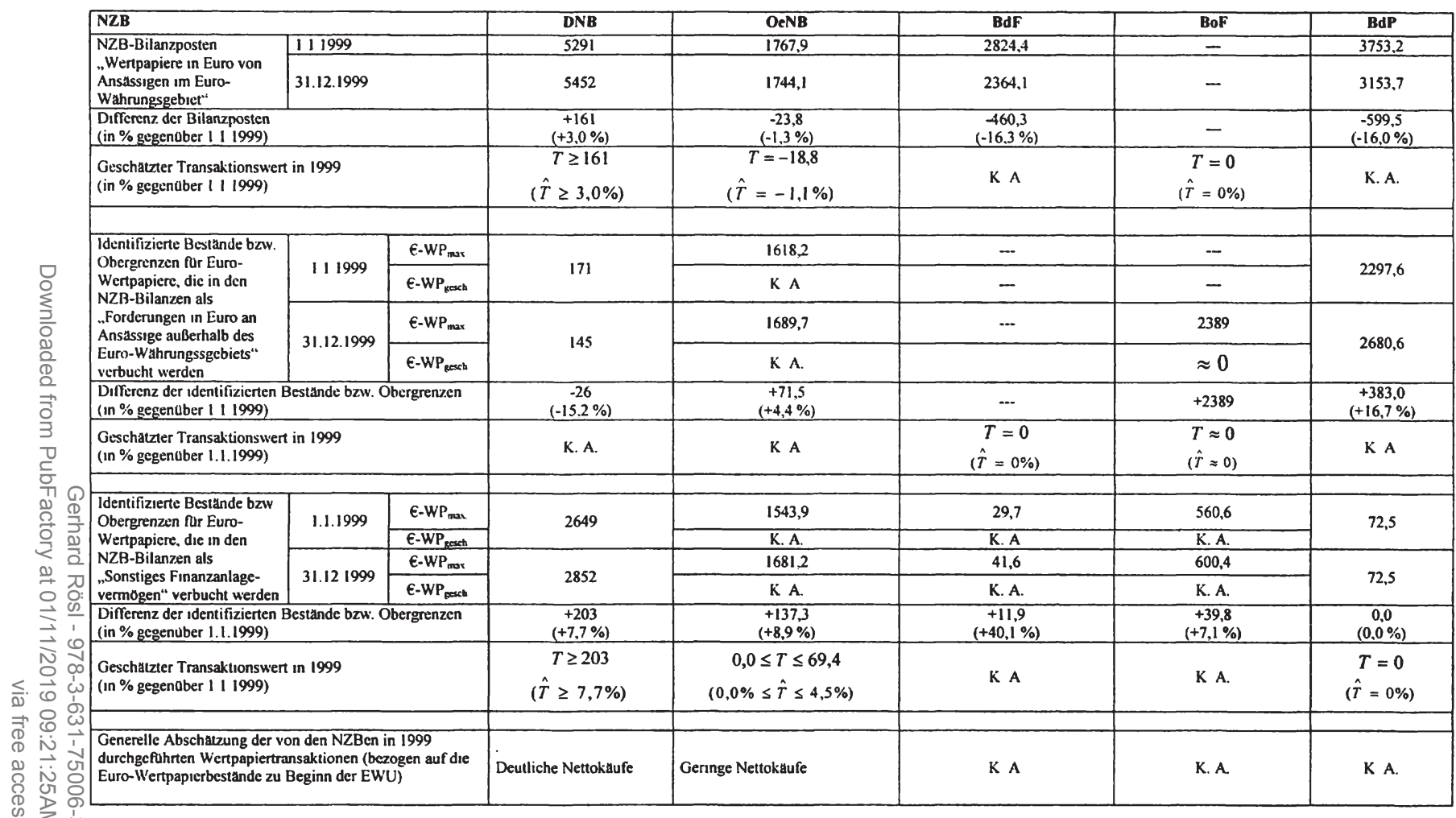

Quelle Eıgene Berechnungen Die der Darstellung zugrunde liegenden Daten sind den Geschaftsberichten der NZBen fur das Jahr 1999 entnommen. Zur Herleitung der Schatzergebnisse vgl. die Erlauterungen Im Anhang Angaben zum 1.1.1999, fur die BoF, CBI, Bdl, BCL, BdE und BdF zum 31.12.1998. 
In wohl nur relativ geringem Umfang veräußerten hingegen die Belgische Nationalbank (NBB) und die Banco de España (BdE) einen Teil ihrer Bestände an Euro-Wertpapieren, während die Währungsbehörden Luxemburgs, Irlands, der Niederlande und Österreichs ihr Euro-Wertpapierportefeuille erhöht haben dürften. Besonders auffällig ist hierbei das Engagement der Banque Centrale du Luxembourg, die den Bestand ihrer Euro-Titel in 1999 um bis zu 614,4 Mio. EUR aufstockte. Dies entspricht einer Zuwachsrate von mehr als tausend Prozent und kann mit dem generellen Aufbau eines Kapitalstocks erklärt werden $^{286}$. Im Falle der irischen (CBI) und niederländischen Zentralbank (DNB) hingegen sind die zu beobachtenden deutlichen Nettokäufe eher mit Bilanzstrukturinvestitionen $z u$ begründen. Die Käufe der Österreichischen Nationalbank dürften hingegen vergleichsweise geringer ausfallen. Diesen Schluß läßt zumindest die Analyse der einzelnen OeNB-Bilanzposten zu, auch wenn kein konkretes Gesamtvolumen für die Nettotransaktionen dieser Zentralbank berechnet werden kann. Für die Euro-Wertpapiertransaktionen der französischen, finnischen und portugiesischen Zentralbank hingegen sind auch Tendenzaussagen nicht möglich.

Die Entscheidung zur Durchführung Eurosystem-unabhängiger Wertpapiergeschäfte obliegt den Organen der NZBen, deren Kompetenzen wiederum in den nationalen Zentralbankgesetzen geregelt sind. Während beispielsweise in Belgien derartige Entscheidungen das Direktorium der NBB nach Konsultation des Regentenrats trifft, ist im Falle der italienischen Zentralbank der Gouverneur zuständig für das Management der im Besitz der BdI befindlichen Staatspapiere ${ }^{287}$. Die niederländische Zentralbanksatzung fordert zudem, daß das DNB-Governing Board bei der Aufstellung der internen Richtlinien für die Verwaltung von Wertpapieren den Interessen des Staates Rechnung tragen soll. Diese wohl mit Blick auf eine möglichst ertragreiche Veranlagung gerichtete Regelung darf jedoch die vertraglichen Vorschriften, insbesondere die Sicherung der finanziellen Autonomie, nicht beeinträchtigen. Ohnehin ist der Gestaltungsspielraum der NZBen bei Transaktionen in Euro-Wertpapieren durch EZB-interne Regeln begrenz ${ }^{288}$. Hierbei benötigen die NZBen - in Analogie zur Verfügung über die ihnen verbliebenen Währungsreserven - ab einem bestimmten Transaktionsvolumen die Zustimmung der EZB ${ }^{289}$. Somit ist auch

286 So brachte die erst zum 1. Juni 1999 gegründete BCL Aktiva im Gesamtwert von gerade einmal 500 Mio. EUR in die EWU mit ein. Vgl. Banque Centrale du Luxembourg (2000c), S. 114. Diese Aktiva stammen überwiegend aus der Liquidation des Luxemburgischen Währungsinstituts (IML - Institut Monetaire Luxembourgeois).

288 Vgl. Art. 29 Nr. 4 NBB-Statut und Art. 25 Abs. 3 BdI-Statut.

288 Vgl. Europäische Zentralbank (1999a), S. 72.

289 Vgl. De Nederlandsche Bank (2000b), S. 167. 
das Gewinnpotential, das die NZBen aus den entsprechenden Zinseinnahmen zusätzlicher Euro-Wertpapierkäufe erzielen können, limitiert. Auf eine quantitative Abschätzungen dieser Eurosystem-unabhängigen Notenbankgewinnentstehungskomponente soll hier jedoch verzichtet werden, da die NZBen weder die exakte Höhe noch die Zusammensetzung ihrer EuroPortefeuilles ausweisen. Die Richtung der jeweiligen Entwicklung läßt sich jedoch anhand der in Tabelle 27 geschätzten Transaktionen ablesen.

\subsection{Eurosystem-unabhängige Kreditgewährung der NZBen an Ansässige des Euro-Währungsgebiets}

Dieser Abschnitt beschäftigt sich mit der Frage, in welchem Umfang die NZBen auch nach Gründung der EWU die Möglichkeit haben, auf eigene Initiative und Rechnung Kredite an Ansässige des Euro-Währungsgebiets zu gewähren. Entscheidend ist hier wiederum, daß diese Transaktionen unabhängig von Weisungen der EZB durchgeführt werden. Es lassen sich zwei Bereiche unterscheiden: Kredite an den Staat einerseits und an die inländischen Privaten andererseits.

Art. 21.1. ESZB-Satzung und Art. 101 EGV verbieten es den NZBen, auch außerhalb der gemeinsamen Geldpolitik öffentlichen Haushalten und anderen staatlichen Stellen Kredite zu gewähren. Die Einhaltung dieser Vorgaben wird von der EZB überwacht und ist in 1999 auch befolgt worden ${ }^{290}$. Das Kreditvergabeverbot gilt jedoch nicht für Kreditinstitute in öffentlichem Eigentum, da diese bezüglich der Bereitstellung von Zentralbankgeld wie private Kreditinstitute behandelt werden (Art. 21.3. ESZB-Satzung und Art. 101 Abs. 2 EGV). Weiterhin sind zum Zwecke der reibungslosen Aufrechterhaltung des Zahlungsverkehrs Innertageskredite an den öffentlichen Sektor erlaubt, sofern sie auf den betreffenden Tag begrenzt bleiben und keine Verlängerung möglich ist ${ }^{291}$. Mit der gleichen Begründung dürfen die NZBen auch Sicherheitsbestände an Münzen halten, sofern sie weniger als 10 Prozent des nationalen Münzumlaufs ausmachen ${ }^{292}$. Eine besondere Ausnahme bildet jedoch die Kompetenz der Banco de Portugal (BdP), den autonomen Regionen Azoren und Madeira weiterhin eine zinsfreie Kreditfazilität nach geltendem

290 Vgl. Art. 237d EGV und Europäische Zentralbank (2000h), S. 126.

291 Vgl. Art. 4 Verordnung (EG) Nr. 3603/93 des Rates vom 13. Dezember 1993 in Europäische Gemeinschaft (1993), S. 1 - 3.

292 Vgl. Art. 6 Verordnung (EG) Nr. 3603/93 des Rates vom 13. Dezember 1993 in Europäische Gemeinschaft (1993), S. 1 - 3 und die Ausführungen zu Kapitel V.2.2.2. Abschnitt 4.. 
portugiesischen Recht zu gewähren ${ }^{293}$. Allerdings verpflichtet sich Portugal diese Regelung baldmöglichst $\mathrm{zu}$ beenden. So weist die portugiesische Währungsbehörde zum 31.12.1999 auch keine Kredite an die Azoren in ihrer Bilanz aus, obwohl das zinsfreie Kreditgewährungspotential der BdP an die Azoren Ende 1999 52,7 Mio. EUR beträgt. Dagegen schöpft Madeira zum 31.12.1999 die BdP-Kreditlinie in Höhe von 39,3 Mio. EUR vollständig aus ${ }^{294}$. Auch private (Nicht-) Banken kommen in bestimmtem Umfang in den Genuß von Eurosystem-unabhängigen Notenbankkrediten. An erster Stelle ist hierbei die Tätigkeit der Österreichischen Nationalbank (OeNB) im Zusammenhang mit der Finanzierung von European Recovery Program (ERP)-Krediten zu erwähnen. So ist die OeNB gemäß § 3 Abs. 2 des österreichischen ERP-FondsGesetzes verpflichtet, einen Plafonds zu finanzieren, der sich aus einem (von der Bundesschuld abgeschriebenen) Sockelbetrag in Höhe von 341,955 Mio. EUR zuzüglich der Summe angesammelter Zinsüberschüsse (Ende 1999: 497,542 Mio. EUR) errechnet ${ }^{295}$. Diese Mittel fließen dann den anspruchsberechtigten Firmen über ihre Hausbanken in Form von OeNB-Buchkrediten $\mathrm{zu}^{296}$. Weiterhin zeigt die Analyse der Zentralbankberichte, daß die NZBen zumindest bis zur Einführung der gemeinsamen europäischen Währung, die Möglichkeit besaßen, Unternehmen, an denen sie beteiligt sind, zinsfreie Kredite als Beitrag zu den Unternehmenskosten zu gewähren. Derartige Forderungen finden sich zum Beispiel in der Eröffnungsbilanz der österreichischen und irischen Zentralbank. Konkret leistete die OeNB ihrer 100-Prozent-Tochter „Münze Österreich AG“ eine Vorauszahlung zur Vorfinanzierung der Euromünzen-Produktion in Höhe von 145,3 Mio. EUR und auch die irische Notenbank wies eine zinsfreie Kreditforderung in Höhe von 97 Tsd. EUR an die Irish Interbank Settlement Company Limited (IRIS Co.) als Kostenbeitrag zur Errichtung des nationalen RTGS-Systems aus ${ }^{297}$. Es ist prinzipiell davon auszugehen, daß die NZBen diese Kompetenzen auch gegenwärtig besitzen, selbst wenn sich keine aktuellen Beispiele für solche Zahlungen anführen lassen. Hierfür spricht schon die Tatsache, daß die NZBen - wie an anderer Stelle noch ausführlich dargestellt werden wird - Unternehmensbeteiligungen halten dürfen und auch entsprechende Neugründungen seit dem 1.1.1999 zu beobachten sind. So ist es letztlich egal, ob eine NZB etwaige Jahresfehlbeträge ihrer Beteiligungen direkt

293 Vgl. im Folgenden Protokoll betreffend Portugal und 6. Erwägungsgrund der Verordnung (EG) Nr. 3603/93 des Rates vom 13. Dezember 1993 in Europäische Gemeinschaft (1993), S. 1 - 3.

$294 \mathrm{Vgl}$. Banco de Portugal (2000a), S. 259 und S. 304.

$295 \mathrm{Vgl}$. Österreichische Nationalbank (2000), S. 133.

296 Vgl. §83 OeNB-Gesetz und Österreichische Nationalbank (2000), S. 133.

297 Vgl. OeNB (2000), S. 133 und Central Bank of Ireland (2000c), S. 90. 
finanziert oder a priori einen Kostenbeitrag zur Vermeidung von entsprechenden Verlusten gewährt. Insgesamt gesehen dürfte das quantitative Ausmaß solcher Zahlungen jedoch sehr begrenzt bleiben, da die NZB-Unternehmensbeteiligungen grundsätzlich gering sind ${ }^{298}$.

Des weiteren gewähren einzelne NZBen auch Kredite an ihre Mitarbeiter. So räumen etwa die finnische, portugiesische und die spanische Zentralbank ihren Beschäftigten Kredite zum Kauf von Immobilieneigentum ein ${ }^{299}$. Quantitativ sind diese Kredite jedoch ebensowenig relevant wie Gehaltsvorschüsse, die die NZBen an ihre Dienstnehmer zahlen ${ }^{300}$.

Auch Geschäftsbanken können außerhalb der gemeinsamen Geldpolitik Kredite von den heimischen Währungsbehörden bekommen. Allerdings beschränkt sich diese Möglichkeit auf Überbrückungskredite, die die NZBen im Rahmen der „Emergency Liquidity Assistance“ (ELA) zahlungsunfähigen Institutionen und Märkten zur Abwehr von Finanzkrisen gewähren können ${ }^{301}$. Wegen des MoralHazard-Risikos darf eine solche Liquiditätsbereitstellung aber nur in Ausnahmefällen erfolgen. Über den Einsatz der ELA entscheidet die NZB grundsätzlich selbst und trägt hierfür sowohl die Verantwortung als auch die Kosten. Hierbei sei jedoch erwähnt, daß die jeweilige NZB nicht notwendigerweise allein die entsprechenden Aufwendungen $\mathrm{zu}$ tragen hat. So würde z.B. in Deutschland die Abwicklung solcher Transaktionen zunächst über die Eigenmittel (inkl. Nachschußverpflichtungen) der Liquiditäts-Konsortialbank (LiKo) laufen, an der neben der Bundesbank auch die Mitglieder von deutschen Bankenvereinigungen beteiligt sind ${ }^{302}$. Erst wenn diese Mittel nicht ausreichen sollten, kann die Sonderrediskontlinie der Deutschen Bundesbank in Anspruch genommen werden ${ }^{303}$. Generell kann zur empirischen Relevanz der ELA gesagt werden, daß der Einsatz dieses Instruments in den vergangenen Jahrzehnten nicht nur in Deutschland, sondern in allen Industrieländern nur in den seltensten Fällen zu beobachten gewesen war ${ }^{304}$.

Als Ergebnis kann folglich festgehalten werden, daß eine Eurosystemunabhängige Kreditgewährung der NZBen in gewissem Ausmaß möglich ist und

298 Vgl. Kapitel V.2.2.2. Abschnitt 1..

299 Vgl. Bank of Finland (1999), S. 90 ff., Banco de Portugal (2000a), S. 310 und Banco de España (2000), S. 133.

300 So betrugen z.B. die Forderungen der OeNB aus solchen Vorauszahlungen an ihre Mitarbeiter Ende 1999 gerade einmal 6,4 Mio. EUR. Vgl. Österreichische Nationalbank (2000), S. 133.

301 Vgl. im Folgenden Europäische Zentralbank (2000h), S. 102.

$302 \mathrm{Vgl}$. Liquiditäts-Konsortialbank GmbH (2000), S. 9 ff..

303 Dieses Vorgehen scheint bei allen NZBen üblich zu sein. Vgl. z.B. Banco de Portugal (2000a), S. 269 und Banco de España (2000), S. 132.

304 Vgl. Europäische Zentralbank (2000h), S. 102. 
von den NZBen in unterschiedlicher Intensität wahrgenommen wird. Allerdings ist der Umfang dieser Tätigkeiten quantitativ sehr begrenzt, so daß auch die Auswirkungen auf die Ertragssituation der NZBen eher qualitativ interessant sind.

\subsection{Eurosystem-unabhängige Emission und Einzug von NZB- Schuldverschreibungen}

$\mathrm{Zu}$ den weiterhin nach Gründung der EWU erlaubten Eurosystem-unabhängigen Geschäften ist auch die Emission von Schuldverschreibungen zu zählen, die die NZBen auf eigenen Namen, Rechnung und Initiative begeben können. Allerdings zeigt die Analyse der einschlägigen Geschäftsberichte, daß in 1999 wohl nur die italienische Zentralbank von dieser Möglichkeit Gebrauch gemacht hat. So wies die Banca d'Italia (BdI) zum 31.12.1999 Verbindlichkeiten aus BdI-Schuldverschreibungen in Höhe von 489 Mio. EUR aus ${ }^{305}$. Dies entsprach einem Anstieg gegenüber dem Vorjahr von 17 Mio. EUR und war vermutlich in engem Zusammenhang mit der aktiven Anlagepolitik der BdI-Reserven zu $\operatorname{sehen~}^{306}$. Angaben hinsichtlich der von der BdI hierfür zu zahlenden Zinsen werden nicht veröffentlicht. Eurosystem-unabhängige Zinsaufwendungen können den NZBen aber auch deshalb erwachsen, da sie noch über Restbestände von Schuldverschreibungen verfügen, die sie im Rahmen der damals noch nationalen Geldpolitik emittiert und in die EWU „mit hinein genommen“ haben. Dies trifft auf die NZBen Finnlands (823 Mio. EUR), Spaniens (6346 Mio. EUR) und Portugals (6657 Mio. EUR) $\mathrm{zu}^{307}$. Während die Bank of Finland ihre zum 1.1.1999 ausstehenden Liquiditätspapiere bereits im Laufe des Jahres 1999 vollständig zurückgekauft hat, zog die Banco de España ihre Schuldverschreibungen erst Ende 2000 gänzlich ein ${ }^{308}$. Im Falle der Banco de Portugal wird die Rückzahlung bis Ende 2004 erfolgen $^{309}$. Insgesamt gesehen dürfte die Eurosystem-unabhängige Emission von Schuldverschreibungen der NZBen in Zukunft sehr begrenzt sein und sich rein auf Geschäfte im Zusammenhang mit der Veranlagung von Reserven beschränken. Größere Auswirkungen auf die NZB-Gewinnsituation sind somit nicht zu erwarten.

305 Vgl. Banca d'Italia (2000a), S. 276. Die rechtliche Grundlage hierfür bildet Art. 42 Abs. 1 Spstr. 2 BdI-Statut.

306 Hierfür spricht auch die Verbuchung dieser Verbindlichkeiten in der BdI-Bilanz unter „Other liabilities“. Vgl. Banca d'Italia (2000a), S. 271 und European Central Bank (1998c), S. 46.

307 Vgl. European Central Bank (1999a), S. 2 und Tabelle 9.

$308 \mathrm{Vgl}$. Bank of Finland (2000b), S. 89 und Banco de España (2000), S. 125.

309 Vgl. Banco de Portugal (2000a), S. 311. 


\section{Fiscal Agent für öffentliche Stellen}

Artikel 21.2. ESZB-Satzung erlaubt es den NZBen für öffentliche Stellen als Fiskalagent tätig zu werden. Solche Tätigkeiten können neben der Bereitstellung von Einrichtungen zur Abwicklung der Emission von Staatspapieren (Auktionsverfahren, technische Abwicklungssysteme) auch Aktivitäten der NZBen im Rahmen der Markt- und Kurspflege, sowie Beratungs- und Koordinationsaufgaben umfassen ${ }^{310}$. Dabei dürfen die in diesem Rahmen von den NZBen durchgeführten Wertpapiertransaktionen keinesfalls auf eigene Rechnung erfolgen, da dies einer Kreditgewährung an den Staat gleichkäme. So ist den NZBen nach Artikel 21.1. ESZB-Satzung und Artikel 101 EGV der unmittelbare Erwerb von öffentlichen Schuldtiteln von den staatlichen Emittenten ebenso verboten wie die Übernahme des Zinsendienstes aus diesen Titeln. Dies gilt jedoch nicht für die administrativen Aufwendungen, die den NZBen aus ihrer Fiscal Agent-Tätigkeit entstehen. So darf beispielsweise die Deutsche Bundesbank nach $\S 20$ Abs. 1 BBankG dem Bund und den Ländern diesbezüglich keine Kosten und Gebühren berechnen. Daß dieses Vorgehen jedoch nicht repräsentativ für die anderen EWU-Zentralbanken ist, zeigt schon Artikel 15 Abs. 2 BdF-Statut, der der Banque de France zumindest Kostendeckung verspricht. Ohnehin sind gar nicht alle NZBen als Fiskalagent für ihre heimische Regierung tätig. So sind die Bank of Finland und die De Nederlandsche Bank in keiner Weise an der Emission heimischer Staatstitel beteiligt und auch die irische Zentralbank fungiert nur als Registrierungsstelle, während die komplette Schuldenverwaltung des irischen Staates von der National Treasury Managenent Agency organisiert wird ${ }^{311}$. Alle anderen NZBen besitzen zwar gemäß ihrer nationalen Zentralbankgesetze bzw. -statuten entsprechende Fiscal Agent-Kompetenzen, nehmen diese aber in sehr unterschiedlichem Umfang und meist in Zusammenarbeit mit nationalen Schuldenagenturen und dem heimischen Schatzamt wahr ${ }^{312}$. Da allerdings in der Regel keine Angaben hinsichtlich der Höhe der gegebenenfalls von den öffentlichen Emittenten an die NZBen zu entrichtenden Gebühren erhältlich sind, soll diese wahrscheinlich quantitativ ohnehin nicht allzu bedeutende Problematik nicht weiter verfolgt werden.

310 Vgl. Deutsche Bundesbank (2000a), S. 141.

311 Vgl. Central Bank of Ireland (2000b). In Finnland bringt das Schatzamt („Valtiokonttori“) selbst die Staatspapiere in Umlauf, während diese in den Niederlanden von der Schuldenagentur des Finanzministeriums emittiert werden. Vgl. Bank of Finland (2000a) und De Nederlandsche Bank (2000a).

312 Vgl. z.B. $\S 20$ Abs. 2 BBankG, Art. 15 BdF-Statut, Art. 22 NBB-Statut, $\S 42$ OeNBGesetz, Art. 43 BdI-Statut, Art. 7 BdE-Gesetz und Art. 24 BCL-Gesetz. 


\section{Die Geschäfte der NZBen für ihren eigenen Betrieb und für ihr Personal}

Nach Artikel 24 ESZB-Satzung sind die nationalen Zentralbanken befugt, Geschäfte für ihren eigenen Betrieb und für ihre Bediensteten zu tätigen. So bleibt es den NZBen auch nach Übergang zur dritten Stufe der EWU unbenommen, neben den erforderlichen Ausgaben für die Aufrechterhaltung des Geschäftsbetriebs eine von Weisungen der EZB unabhängige Personalpolitik zu betreiben $^{313}$. Diese Kompetenz schließt die Bezahlung der Löhne und Gehälter ihrer Bediensteten, gesetzliche und/oder freiwillige soziale (Zusatz-) Leistungen und Pensionszahlungen für ehemalige Angestellte mit ein. Um nun einen Überblick darüber zu bekommen, in welchem Umfang die NZBen im ersten Jahr der Europäischen Währungsunion von diesen Möglichkeiten Gebrauch gemacht haben, sind in Tabelle 28 die Personalentwicklung, Personalkosten und ausgewiesenen administrativen Aufwendungen der NZBen vergleichend zusammengestellt. Hierbei zeigt sich ein recht uneinheitliches Bild. Während mit Ausnahme der Deutschen Bundesbank $(+0,1 \%)$ die anderen relativ Personal-intensiven Zentralbanken Frankreichs $(-2,1 \%)$, Italiens $(-1,3 \%)$ und Spaniens (-0,8\%) die Anzahl ihrer Arbeitsplätze in 1999 leicht abgebaut haben, erhöhten - wenn auch auf niedrigem Niveau - besonders die „kleineren“ Währungsbehörden ihr Personal zum Teil deutlich (z. B. CBI: $+4,6 \%$, BCL: $+16,9 \%$ ). Auch hinsichtlich der Personalkosten, die die NZBen in $1999 \mathrm{zu}$ finanzieren hatten, ergeben sich beachtliche Unterschiede. So mögen zwar die Personalkosten pro Kopf schon deswegen erheblich differieren, da die NZBen in unterschiedlichem Umfang Pensionszahlungen an ehemalige Angestellte zu leisten haben ${ }^{314}$, doch zeigen beispielsweise die im Falle der Österreichischen Nationalbank (67961 EUR/Kopf) und Banco de Portugal (31763 EUR/Kopf) separat ausgewiesenen Lohn- und Gehaltskosten pro Kopf sehr unterschiedliche durchschnittliche Gehaltsniveaus zwischen den NZBen. Ähnliches gilt auch für den Vergleich der administrativen Aufwendungen. So können Zentralbanken mit relativ großem Geschäftsvolumen und deshalb relativ hohen Beschäftigtenzahlen offensichtlich Größenvorteile beispielsweise bei der Bezahlung neuer Geschäftsausstattung realisieren ${ }^{315}$. So überrascht es nicht, daß gerade die Deutsche Bundesbank und die Banque de France mit administrativen Aufwendungen in Höhe von jeweils rund 18000 EUR pro Kopf im Vergleich zu „kleineren“ Zentralbanken (vgl. z.B. OeNB: rd. 59000 EUR/Kopf) relativ niedrigere Kosten pro Beschäftigten zu tragen hat.

$313 \mathrm{Vgl}$. auch Hartmann (1997), S. 3ff. und Goetze (1999), S. 167f..

314 Vgl. z.B. Banque de France (2000c), S. 265 und Belgische Nationalbank (2000b), S. 97.

315 Ineffizienzprobleme seien an dieser Stelle vernachlässigt. $\mathrm{Zu}$ dieser Diskussion vgl. Vaubel (1999), S. 23 ff.. 
Tabelle 28: Personalentwicklung, Personalkosten und administrative Aufwendungen der NZBen in 1999

\begin{tabular}{|c|c|c|c|c|c|c|c|c|c|c|c|}
\hline & BBk & BdF & BdP & BoF & CBI & DNB & NBB & OeNB & BdI & BdE & $\overline{B C L}$ \\
\hline Personal zum 31.12.98 & 15891 & 15918 & 1828 & 782,5 & 638,5 & 1624 & 2357 & 1148 & 8914 & 3124 & 130 \\
\hline Personal zum 31.12.99 & 15905 & 15581 & 1826 & 785,5 & 668 & 1632 & 2445 & 1133 & 8802 & 3148 & 152 \\
\hline $\begin{array}{l}\text { Personalzuwachs in } 1999 \\
\text { (in vH. gegenüber 1998) }\end{array}$ & $\begin{array}{c}+14 \\
(+0,1 \%)\end{array}$ & $\begin{array}{c}-337 \\
(-2,1 \%)\end{array}$ & $\begin{array}{c}-2 \\
(-0,1 \%)\end{array}$ & $\begin{array}{c}+3 \\
(+0,4 \%)\end{array}$ & $\begin{array}{c}+29,5 \\
(+4,6 \%)\end{array}$ & $\begin{array}{c}+8 \\
(+0,5 \%)\end{array}$ & $\begin{array}{c}-88 \\
(-3,7 \%)\end{array}$ & $\begin{array}{c}-15 \\
(-1,3 \%)\end{array}$ & $\begin{array}{c}-112 \\
(-1,3 \%)\end{array}$ & $\begin{array}{c}-24 \\
(-0,8 \%)\end{array}$ & $\begin{array}{c}+22 \\
(+16,9 \%)\end{array}$ \\
\hline $\begin{array}{l}\text { Personalkosten in } 1999 \\
\text { gesamt in Mio. EUR' } \\
\text { Pro Kopf in EUR| }\end{array}$ & $\begin{array}{c}862 \\
{[54197]}\end{array}$ & $\begin{array}{c}1278 \\
{[82023]} \\
\end{array}$ & $\begin{array}{c}90 \\
{[49288]}\end{array}$ & $\begin{array}{c}50 \\
{[63654]}\end{array}$ & $\begin{array}{c}24 \\
{[37588]}\end{array}$ & $\begin{array}{c}89 \\
{[54534]}\end{array}$ & $\begin{array}{c}175 \\
{[71575]} \\
\end{array}$ & $\begin{array}{c}169 \\
{[149162]}\end{array}$ & $\begin{array}{c}914 \\
{[103840]}\end{array}$ & $\begin{array}{c}170 \\
{[54003]}\end{array}$ & $\begin{array}{c}8 \\
{[52632]}\end{array}$ \\
\hline $\begin{array}{l}\text { Löhne und Gehälter } \\
\text { [Pro Kopf in EUR] }\end{array}$ & 663 & $\begin{array}{c}729 \\
{[46788]}\end{array}$ & $\begin{array}{c}58 \\
{[31763]}\end{array}$ & $\begin{array}{c}34 \\
{[43285]}\end{array}$ & 21 & K. A. & K. A. & $\begin{array}{c}77 \\
{[67961]}\end{array}$ & 588 & $\begin{array}{c}124 \\
{[39390]}\end{array}$ & K. A. \\
\hline $\begin{array}{l}\text { Sozialabgaben } \\
\text { [Pro Kopf in EUR] }\end{array}$ & [41698] & $\begin{array}{c}148 \\
{[9499]}\end{array}$ & $\begin{array}{c}29 \\
{[15882]}\end{array}$ & $\begin{array}{c}5 \\
{[6365]}\end{array}$ & [32890] & K. A. & K. A. & $\begin{array}{c}10 \\
{[8826]}\end{array}$ & [66803] & $\begin{array}{c}30 \\
{[9530]}\end{array}$ & K. A. \\
\hline Pensionszahlungen & 191 & 376 & $\cdots$ & 11 & 2 & K. A. & K. A. & 76 & 262 & 2 & K. A. \\
\hline Sonstige Zahlungen & 8 & 25 & 2 & $\cdots$ & $=$ & K. A. & K. A. & 5 & 64 & -- & K. A. \\
\hline $\begin{array}{l}\text { Administrative } \\
\text { Aufwendungen in Mio. } \\
\text { EUR } \\
\text { |Pro Kopf in EUR }\end{array}$ & [18233] & [18420] & [14786] & [19096] & [14096] & [44118] & {$[--]$} & [59135] & [34310] & $\begin{array}{c}54 \\
{[17154]}\end{array}$ & [32895] \\
\hline
\end{tabular}

Quelle: Eigene Berechnungen. Die der Übersicht zugrunde liegenden Daten sind entnommen aus den Geschäftsberichten der NZBen für 1999.

○

' Personalstärke der BBk zum 1.1.1999 bzw. zum 1.1.2000, der NBB und der BCL jewveils zum 1.1.1999 bzw. zum 31.12.1999. Personal der BoF, NBB, CBI und DNB für die Jahre 1998 und 1999 jeweils in Vollzeitäquivalenten, im Falle der OeNB und Bdl jeweils in Jahresdurchschnittswerten. OeNB-Personalstärke ohne Direktoriumsund Präsidiumsmitglieder.

${ }^{2}$ Dieser Posten entspricht dem Posten „16 Personalaufwand“ in der Standard-GuV zum 31.12.1999. Vgl. dazu Tabelle 12. Personalkosten im Falle Frankreichs ohne

aे 6 Bezahlung der Organmitglieder in Höhe von 5,1 Mio. EUR. Vgl. Banque de France (2000c), S. 266.

$\overrightarrow{\vec{B}} \odot \mathrm{\omega}^{3}$ Dieser Posten entspricht dem Posten „17 Andere administrative Aufwendungen“ in der Standard-GuV zum 31.12.1999. Vgl. dazu Tabelle 12. Diese Position enthalt neben Sachaufwendungen z.B. für Geschäftsausstattung und Gebäudeinstandsetzung auch Aufwendungen fur das Sicherheitspersonal, Postgebühren, Personaltraining u.a., aber keine Zinsaufwendungen, Gebühren, Abschreibungen, sonstigen Aufwendungen, Körperschaftssteuern und sonstige Zahlungen an den Staat. Vgl. Bank of Finland (2000b), S. 90, Central Bank of Ireland (2000c), S. 81, Banca d'Italia (2000a), S. 286, Banque Centrale du Luxembourg (2000c), S. 128, Banco de Portugal (2000a), S. 288 und Banco de España (2000), S. 131. Im Falle der Deutschen Bundesbank und der Österreichischen Nationalbank beschränken sich die hier erfaßten Aufiwendungen auf Sachaufwendungen. Vgl. Deutsche Bundesbank (2000a), S. 176 und Osterreichische Nationalbank (2000), S. 120. Die NBB weist keinen entsprechenden Posten aus. 


\section{V.2.2.2. Eurosystem-unabhängige Tätigkeiten der NZBen, die nicht im einzelnen in der ESZB-Satzung geregelt sind}

Die zweite Säule der Eurosystem-unabhängigen Tätigkeiten bilden diejenigen Aktivitäten der NZBen, die sie im Zuge der Wahrnehmung anderer als in der ESZB-Satzung bezeichneten Aufgaben in eigener Verantwortung und auf eigene Rechnung ausüben. Diese sind nach Art. 14.4. ESZB-Satzung jedoch nur solange möglich, solange der EZB-Rat derartige Tätigkeiten mit Zweidrittelmehrheit der abgegebenen Stimmen nicht untersagt. Das Ziel dieser Bestimmung ist einerseits, die traditionell gewachsenen Aufgaben der NZBen nicht kategorisch zu verbieten, und andererseits, die Wirksamkeit der gemeinsamen Geldpolitik sicherzustellen ${ }^{316}$. Hierbei werden folgende Aktivitäten näher betrachtet:

1. Beteiligung der NZBen an Unternehmen (keine EZB-, IWF- und BIZBeteiligungen),

2. Unterhalten von Immobilien, die nicht direkt dem Geschäftsbetrieb der NZBen dienen,

3. Verwaltung der NZB-Eigenmittel und Sonderausschüttungen der NZBen,

4. Beteiligung der NZBen an der staatlichen Münzemission,

5. Beteiligung der NZBen an der Aufsicht über Finanzinstitute und

6. sonstige Tätigkeiten der NZBen.

\section{Die Beteiligungen der NZBen an Unternehmen (keine EZB-, IWF- und BIZ-Beteiligungen)}

Auch nach Einführung der gemeinsamen europäischen Währung haben die NZBen das Recht, neben ihren Anteilen an der EZB, dem IWF und der BIZ Beteiligungen an Unternehmen $\mathrm{zu}$ halten, zu erwerben und $\mathrm{zu}$ veräußern. Tabelle 29 zeigt, in welchem Umfang die NZBen zum 31.12.1999 solche Anteile besaßen.

Sofort ins Auge fallen die relativ großen Engagements der Österreichischen Nationalbank (OeNB) und der Banca d'Italia (BdI). So unterhält die österreichische Zentralbank neben Beteiligungen, die weitestgehend dem Zahlungsverkehr zuzurechnen sind, auch Anteile an Unternehmen, bei denen ein Bezug $\mathrm{zu}$ "originären" Notenbankaufgaben nur schwer herzustellen ist. Genannt sei hier beispielsweise die sich jeweils zu 100 Prozent im OeNB-Besitz befindliche „Hotelverwaltung $\mathrm{GmbH}^{\text {“ }}$ und „IG Immobilien $\mathrm{GmbH}^{\prime \prime}$.

316 Vgl. Liebscher (1998), S. 7, Goetze (1999), S. 161 und Gnan (1999), S. 605. 
Tabelle 29: Unternehmensbeteiligungen der NZBen zum 31.12.1999 (keine EZB-, IWF- und BIZ-Beteiligungen)

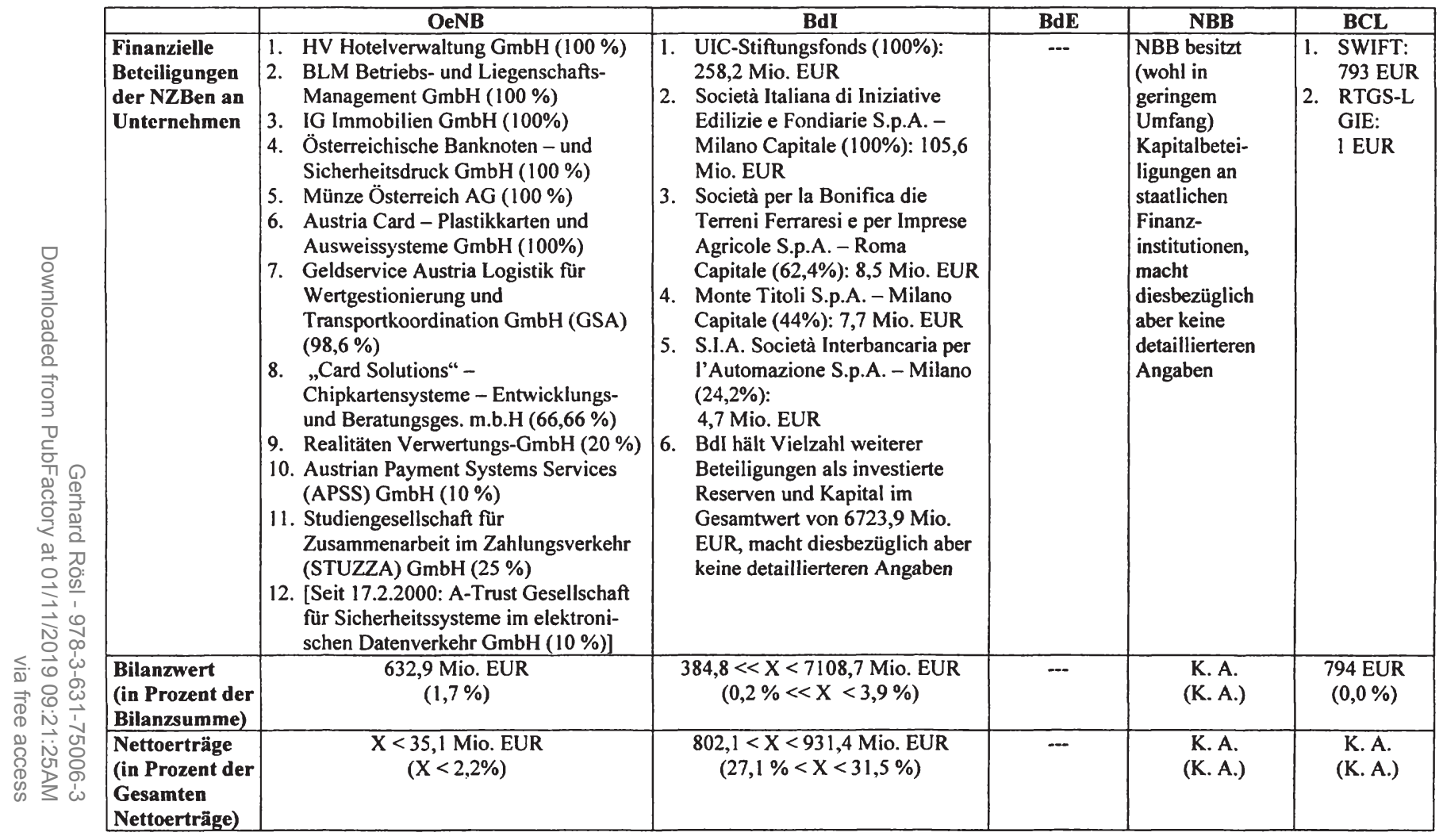


Noch Tabelle 29: Unternehmensbeteiligungen der NZBen zum 31.12.1999 (keine EZB-, IWF- und BIZ-Beteiligungen)

\begin{tabular}{|c|c|c|c|c|c|c|c|}
\hline & & BBk & BdF & BdP & BoF & CBI & DNB \\
\hline 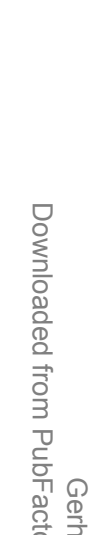 & $\begin{array}{l}\text { Finanzielle } \\
\text { Beteiligungen } \\
\text { der NZBen an } \\
\text { Unternehmen }\end{array}$ & $\begin{array}{l}\text { 1. Genossenschaft } \\
\text { SWIFT, La Hulpe, } \\
\text { Belgien } \\
\text { 2. Liquiditäts- } \\
\text { Konsortialbank } \\
\text { GmbH, Frankfurt } \\
\text { am Main }(30 \%)\end{array}$ & 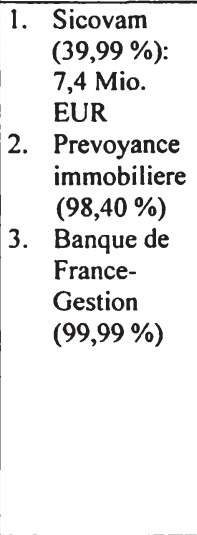 & 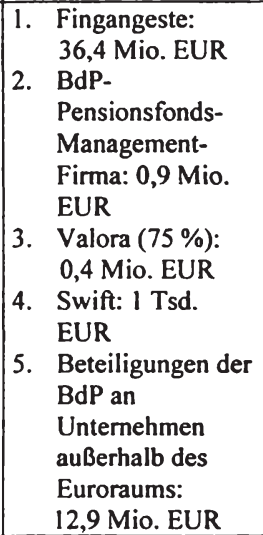 & 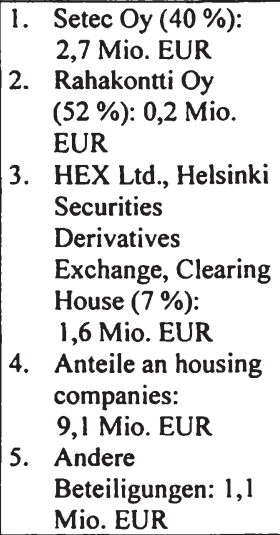 & \begin{tabular}{|ll} 
1. & Investor \\
& Compensation \\
& Company Ltd. \\
2. & Investor \\
& Compensation \\
& Administration \\
& Limited \\
& (ICAL) \\
& $(100 \%)$ \\
3. & Irish Realtime \\
& Interbank \\
Settlement Co. & Ltd. (IRIS \\
Co.) (7\%)
\end{tabular} & 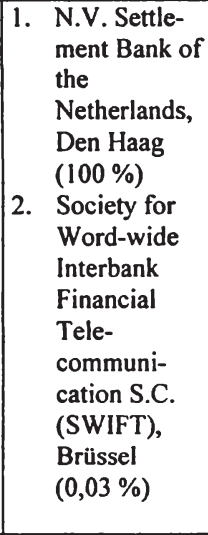 \\
\hline 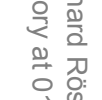 & \begin{tabular}{|l|} 
Bilanzwert \\
(in Prozent der \\
Bilanzsumme)
\end{tabular} & $\begin{array}{c}<<51 \text { Mio. EUR } \\
(0,0 \%)\end{array}$ & $\begin{array}{l}\text { 7,5 Mio. EUR } \\
(0,0 \%)\end{array}$ & $\begin{array}{l}\text { 50,6 Mio. EUR } \\
(0,2 \%)\end{array}$ & $\begin{array}{l}\text { 14,7 Mio. EUR } \\
(0,1 \%)\end{array}$ & $\begin{array}{l}\text { K. A. } \\
\text { (K. A.) }\end{array}$ & $\begin{array}{l}\text { 19,5 Mio. EUR } \\
(0,0 \%)\end{array}$ \\
\hline 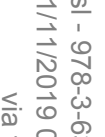 & $\begin{array}{l}\text { Nettoerträge } \\
\text { (in Prozent der } \\
\text { Gesamten } \\
\text { Nettoerträge) }\end{array}$ & $\begin{array}{c}8,4<X<21 \text { Mio. EUR } \\
(0,2 \%<X<0,4 \%)\end{array}$ & $\begin{array}{l}\text { 6,2 Mio. EUR } \\
(0,3 \%)\end{array}$ & $\begin{array}{l}41 \text { Tsd. EUR } \\
(0,0 \%)\end{array}$ & $\begin{array}{l}\text { K. A. } \\
\text { (K. A.) }\end{array}$ & $\begin{array}{l}\text { K. A. } \\
\text { (K. A.) }\end{array}$ & $\begin{array}{l}\text { 4,3 Mio. EUR } \\
(0,4 \%)\end{array}$ \\
\hline
\end{tabular}

Quelle: Eigene Berechnungen. Die der Übersicht zugrundeliegenden Daten sind den Jahresberichten der NZBen für 1999 entnommen. Vgl. dazu die Erläuterungen zur Tabelle 29 im Anhang. Die für die Gewichtung der Bilanzwerte und Nettoerträge der Beteiligungen verwendeten Bilanzsummen und Gesamten Nettoerträge der NZBen sind den Tabellen 11 und 12 entnommen. 
Insgesamt läßt sich der Bilanzwert der OeNB-Beteiligungen Ende 1999 auf rund 633 Mio. EUR beziffern, was im EWU-Vergleich recht hoch ist. Diese Beobachtung darf jedoch nicht überbewertet werden, da dieser Betrag gerade einmal 1,7 Prozent der OeNB-Bilanzsumme zum 31.12.1999 entspricht. Zudem sind die Nettoeinkünfte aus diesen Beteiligungen mit maximal 2,2 Prozent gemessen an den Gesamten Nettoerträgen der OeNB eher gering ${ }^{317}$. Dennoch sei darauf hingewiesen, daß die OeNB mit drei neuen Beteiligungen seit dem 1.1.1999 ihre Tätigkeiten relativ stark ausgeweitet hat ${ }^{318}$. Die mit weitem Abstand vor allen anderen NZBen größten Bestände an Unternehmensbeteiligungen hält die BdI. So beziffert die Zentralbank Italiens Ende 1999 den Wert ihrer Beteiligungen (ohne EZB, jedoch inklusive BIZ) auf rund 7,1 Mrd. EUR, was knapp 4 Prozent des Gesamtwerts der BdI-Aktiva entsprach ${ }^{319}$. Erklärt werden kann diese Beobachtung damit, daß die BdI bei der Anlage eines Teils ihrer vergleichsweise hohen Reserven ${ }^{320}$ eine Diversifizierungsstrategie verfolgt. Dennoch überrascht es, welche zentrale Bedeutung die Beteiligungserträge für die Bdl-Gewinnsituation besitzen. So läßt sich für 1999 ein diesbezüglich maximaler Ertrag von 931,4 Mio. EUR errechnen, der in Relation zu den Gesamten Nettoerträgen der BdI gesetzt, stolze 31,5 Prozent auf sich vereinigt. Verantwortlich sind hierfür vor allem die Nettoeinkünfte aus dem UIC-Stiftungsfonds, den die Banca Italia nicht erst seit der Eingliederung des bis zum 1.1.1999 noch selbständigen Ufficio italiano dei cambi (UIC) in ihre Bilanz eingestellt hat. Ein gänzlich anderes Bild zeigt die Analyse der Unternehmensbeteiligungen, die die anderen NZBen halten. So besaß die Banco de España Ende 1999 überhaupt keine derartigen Beteiligungen. Und auch bei den Währungsbehörden Deutschlands, Frankreichs, Finnlands, Luxemburgs, Portugals und der Niederlande überschritt der Bilanzwert der in Tabelle 29 aufgezeigten Unternehmensanteile nicht die 0,2 Prozentmarke, wenn man ihn in Relation zur jeweiligen NZB-Bilanzsumme setzt. Ähnliches gilt auch für den Anteil der Nettoerträge aus diesen Beteiligungen. So betrugen diese Einkünfte bei keiner der genannten Zentralbanken mehr als 0,4 Prozent ihrer Gesamten Nettoerträge des Jahres 1999. Auch bei den NZBen Belgiens und Irlands dürfte die quantitative Bedeutung der erzielten Nettoerträge sehr gering sein.

317 Zur Höhe der Gesamten Nettoerträge der NZBen in 1999 vgl. Tabelle 12.

318 Gründung der Betriebs- und Liegenschafts-Management GmbH durch die OeNB am 20. 9. 1999, OeNB-Beteiligungen an Geldservice Austria Logistik für Wertgestionierung und Transportkoordination und an A-Trust Gesellschaft für Sicherheitssysteme im elektronischen Datenverkehr GmbH am 28. 4. 1999 bzw. 17. 2. 2000. Vgl. OeNB (2000), S. 97.

319 Vgl. Banca d'Italia (2000a), S. 269 f..

320 So beträgt das Verhältnis von Kapital und Reserven zur Bilanzssumme der BdI Ende 1999 knapp über 15 Prozent. Ähnliches gilt auch für die OeNB. Vgl. Tabelle 30. 


\section{Unterhalten von Immobilien, die nicht direkt dem Geschäftsbetrieb dienen}

An dieser Stelle soll untersucht werden, inwiefern die NZBen Immobilien unterhalten, die nicht direkt dem Geschäftsbetrieb dienen. In Frage kommen hierbei insbesondere Gebäude oder Grundstücke, die die NZBen als investierte Reserven bzw. Kapital unterhalten, um entsprechende Mieteinnahmen zu erzielen. Entsprechende Angaben finden sich allerdings nur in den Geschäftsberichten der finnischen und italienischen Zentralbank ${ }^{321}$. Demnach besaßen die Bank of Finland Ende 1999 solche Immobilien im Wert von gerade einmal 0,2 Mio. EUR, weshalb - bei aller Abschreibung - die zugehörigen Mieteinnahmen auch sehr begrenzt sein durften. Die Banca d'Italia (BdI) hingegen investierte Personalrückstellungen in Gebäude im Wert von immerhin 354 Mio. EUR und erzielte dadurch Mieteinnahmen in Höhe von 15,6 Mio. EUR. In Relation zur Bilanzsumme belief sich der Bilanzwert dieser Immobilien jedoch auf nur 0,2 Prozent. Und auch der Anteil der in 1999 erzielten Mieteinnahmen an den Gesamten Nettoerträgen der BdI entsprach nur 0,5 Prozent ${ }^{322}$. Insgesamt gesehen sind diese Tätigkeiten also auch im Falle der Bdl eher weniger relevant. Einen Spezialfall bildet hingegen der Erwerb von Immobilien durch die Banco de Portugal. So ist die portugiesische Währungsbehörde gemäß Art. 25 lit. d) BdP-Gesetz ermächtigt, für „soziale Zwecke“ Immobilien zu erwerben. Allerdings ist auch hier der Umfang dieser Tätigkeit nicht sehr ausgeprägt. So hatte Ende 1998 die portugiesische Zentralbank Grundstücke für soziale Zwecke im Wert von 669,9 Mio. PTE (rund 3,3 Mio. EUR) in ihre Bilanz eingestellt, was einem Anteil von 0,02 Prozent der gesamten Bilanzsumme entsprach ${ }^{323}$. Zum 31.12.1999 verzichtet sie jedoch auf einen gesonderten Ausweis dieser Aktiva.

\section{Die Verwaltung der NZB-Eigenmittel und Sonderausschüttungen der NZBen}

Auch hinsichtlich der Gestaltung des Eigenkapitals und etwaiger Sonderausschüttungen verbleibt den NZBen ein Tätigkeitsfeld, welches im oben definierten Sinne als Eurosystem-unabhängig bezeichnet werden kann. So verfügt jede NZB im Rahmen der nationalen Zentralbankgesetze über das ihr zugewiesene Kapital bzw. die von ihr eingestellten Reserven grundsätzlich frei

321 Vgl. im Folgenden Bank of Finland (2000b), S. 85 und Banca d'Italia (2000a), S. 274 und S. 282.

322 Die Gesamten Nettoerträge der BdI betrugen in 1999: 2958 Mio. EUR. Vgl. Tabelle 12.

323 Vgl. Banco de Portugal (1999), S. 268. 
von Weisungen der EZB. Während die konkrete Investition dieser Ressourcen in entsprechende Aktiva bereits ausführlich analysiert wurde, sollen an dieser Stelle die Unterschiede in der Kapitalhöhe und in der Eigenkapitalstruktur der NZBen im Vordergrund stehen. Da letztere - wie aus den folgenden Analysen deutlich wird - als eine unmittelbare Reflexion der rechtlichen Organisationsform und der damit zusammenhängenden Kapitaleignerstruktur interpretiert werden kann, sollen diese Komponenten ebenfalls in die folgende Tabelle 30 eingehen.

Diesbezüglich lassen sich die NZBen in zwei Gruppen einteilen. Die erste Gruppe der eher „bankmäßig-organisierten“ Zentralbanken Belgiens (NBB), Österreichs (OeNB) und Italiens (BdI) ist dadurch gekennzeichnet, daß ihr Grundkapital entweder zur Hälfte (NBB und OeNB) bzw. gänzlich (BdI) privat finanziert ist. So überrascht es nicht, daß die NBB als $\mathrm{GmbH}$ und die OeNB als Aktiengesellschaft auch entsprechende Rechtsformen besitzen. Die italienische Zentralbank hingegen ist zwar seit 1936 eine Institution öffentlichen Rechts, dennoch reflektiert die Struktur der BdI auch heute noch ihren ursprünglichen Status als Aktiengesellschaft ${ }^{324}$. Gerade die Finanzierung des Kapitals über private Einlagen impliziert nun auch Eurosystem-unabhängige Aufwendungen für die jeweilige NZB, um entsprechende Investitionsanreize für die privaten Kapitalgeber zu bieten. So gewährt die NBB eine Mindestausschüttung in Höhe von 6 Prozent des eingezahlten Nominalkapitals, die wegen der Absicherung eines speziellen Reservefonds auch dann ausbezahlt wird, wenn die belgische Notenbank im laufenden Jahr einen Fehlbetrag erwirtschaftet ${ }^{325}$. Im Falle der italienischen Zentralbank wird zwar auf eine garantierte Mindestausschüttung verzichtet, die BdI besitzt jedoch die Möglichkeit gemäß Art. 56 BdI-Statut eine Zusatzausschüttung bis maximal 4 Prozent der Einkünfte aus den gesamten BdIReserven der Vorjahresbilanz zu gewähren ${ }^{326}$. Die OeNB hingegen verfügt über keine vergleichbaren Regelungen, zahlt aber in der Regel eine Verzinsung von 10 Prozent auf das Grundkapital ${ }^{327}$. Erwähnenswert erscheint auch die relativ hohe Eigenkapitalquote der OeNB mit 16,3 Prozent und der BdI mit 15,4 Prozent, was darauf zurückzuführen ist, daß diese NZBen ihren Aufgabenbereich traditionell etwas breiter definieren und zur Finanzierung dessen den gesetzlichen Rahmen zur Rücklagenbildung in der Vergangenheit relativ weit ausgeschöpft haben.

324 Vgl. auch die Einschätzung des Europäischen Währungsinstituts in European Monetary Institute (1995), S. 115. Vgl. Art. 50 Abs. 2 NBB-Statut.

326 In der Regel zahlt die BdI allerdings eine 10-prozentige Verzinsung auf ihr Grundkapital. Vgl. Banca d'Italia (2000a), S. 292.

327 Vgl. §69 OeNB-Gesetz und Österreichische Nationalbank (2000), S. 145. 
Tabelle 30: Organisationsform, Eigenkapital und Sonderausschüttungen der NZBen

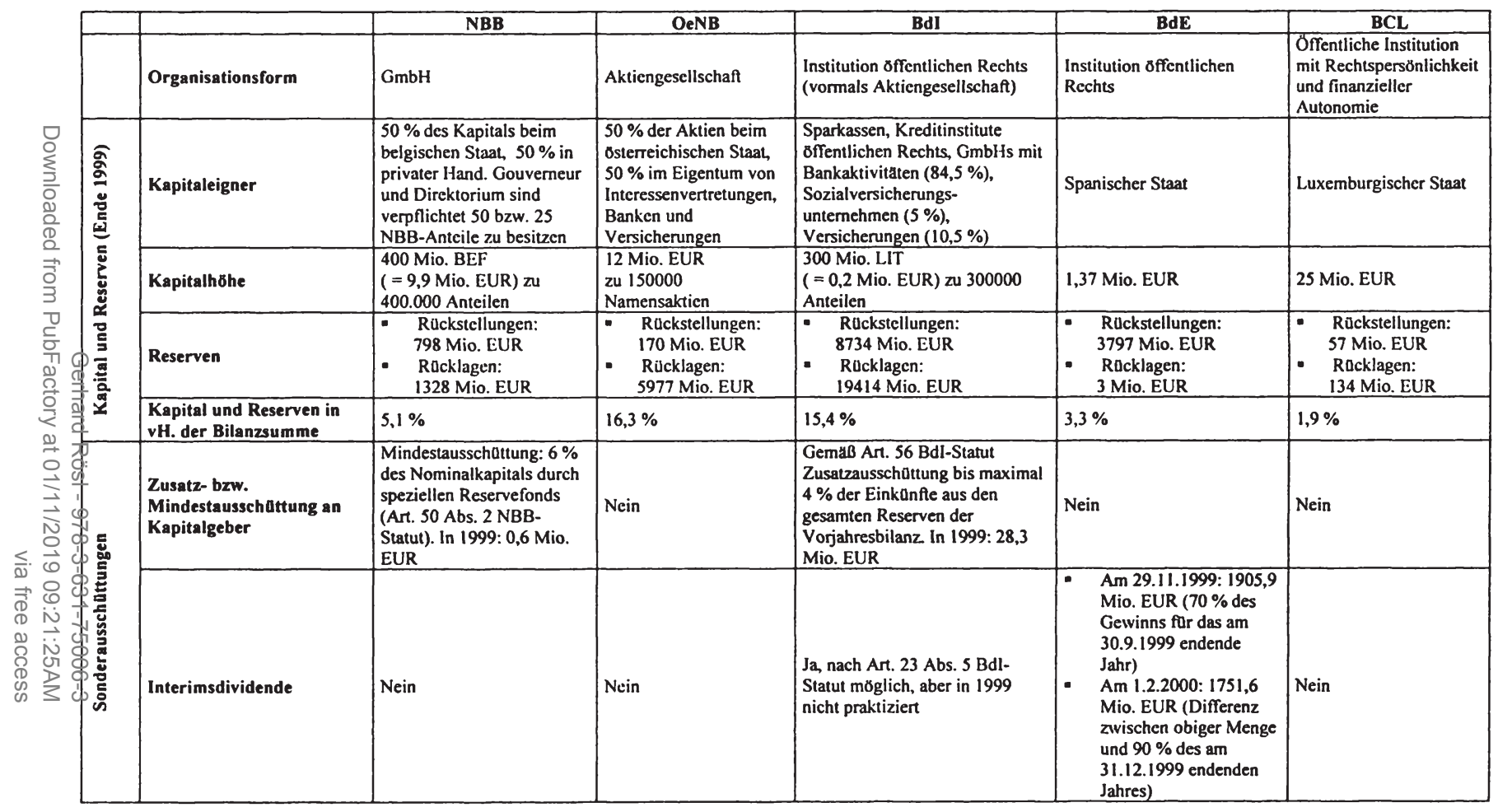


Noch Tabelle 30: Organisationsform, Eigenkapital und Sonderausschüttungen der NZBen

\begin{tabular}{|c|c|c|c|c|c|c|c|}
\hline & & BBk & BdF & BdP & BoF & CBI & DNB \\
\hline & Organisationsform & $\begin{array}{l}\text { Bundesunmittelbare } \\
\text { juristische Person } \\
\text { offentlichen Rechts }\end{array}$ & $\begin{array}{l}\text { Institution, deren Kapital } \\
\text { vom Staat gehalten wird }\end{array}$ & $\begin{array}{l}\text { Juristische Person } \\
\text { offentlichen Rechts } \\
\text { mit administrativer } \\
\text { und finanzieller } \\
\text { Autonomic und } \\
\text { eigenem Eigentum }\end{array}$ & $\begin{array}{l}\text { Unabhängige Institution } \\
\text { öffentlichen Rechts }\end{array}$ & $\begin{array}{l}\text { Rechtskörper mit } \\
\text { permanenter Nachfolge, } \\
\text { offiziellem Siegel (...) } \\
\text { und der Befugnis (...) } \\
\text { gerichtlich zu klagen, } \\
\text { verklagt zu werden, Land } \\
\text { zu besitzen und darüber } \\
\text { zu verfügen }\end{array}$ & $\begin{array}{l}\text { GmbH (Naamloze } \\
\text { Vennootschap) }\end{array}$ \\
\hline \multirow{4}{*}{ 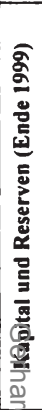 } & Kapitaleigner & Deutscher Staat & Französischer Staat & Portugiesischer Staat & Finnischer Staat & Irischer Staat & \begin{tabular}{|l|} 
Niederländischer \\
Staat
\end{tabular} \\
\hline & Kapitalhöhe & $\begin{array}{l}5 \text { Mrd. DEM } \\
(=2556 \text { Mio. EUR) }\end{array}$ & $\begin{array}{l}3 \text { Mrd. FRF } \\
\text { (=457 Mio. EUR), } \\
\text { Höhe des Kapitals ist } \\
\text { nicht gesetzlich } \\
\text { vorgeschrieben }\end{array}$ & $\begin{array}{l}200 \text { Mio. PTE } \\
(=1,0 \text { Mio. EUR })\end{array}$ & $\begin{array}{l}5 \text { Mrd. FIM } \\
\text { (=841 Mio. EUR), } \\
\text { Hohe des Kapitals ist } \\
\text { nicht gesetzlich } \\
\text { vorgeschricben }\end{array}$ & $\begin{array}{l}\text { Gezeichnetes Kapital: } \\
40000 \text { IEP ( = 50790 } \\
\text { EUR), } \\
\text { davon gezahltes Kapital: } \\
24000 \text { IEP ( = 30474 } \\
\text { EUR) } \\
\end{array}$ & $\begin{array}{l}500 \text { Mio. EUR zu } \\
500 \text { Anteilen }\end{array}$ \\
\hline & Reserven & $\begin{array}{l}\text { Rückstellungen: } \\
7636 \text { Mio. EUR } \\
\text { - Rücklagen: 2556 } \\
\text { Mio. EUR) }\end{array}$ & $\begin{array}{l}\text { - Rückstellungen: } \\
\text { 1936 Mio. EUR } \\
\text { Rücklagen: } \\
\text { 2264 Mio. EUR }\end{array}$ & $\begin{array}{l}\text { Rückstellungen: } \\
2300 \text { Mio. EUR } \\
\text { Rücklagen: } \\
122 \text { Mio. EUR }\end{array}$ & $\begin{array}{l}\text { Rückstellungen: } \\
\text { 2509 Mio. EUR } \\
\text { Rücklagen: } \\
\text { 129 Mio. EUR }\end{array}$ & $\begin{array}{l}\text { - Ruckstellungen: } \\
\text { - Rücklagen: } \\
\text { 1359 Mio. EUR }\end{array}$ & $\begin{array}{l}\text { - Rückstellungen: } \\
\text { - Rücklagen: } \\
\text { 2683 Mio. EUR }\end{array}$ \\
\hline & \begin{tabular}{|l|} 
Kapital und Reserven in \\
vH. der Bilanzsumme
\end{tabular} & $5,3 \%$ & $17,5 \%$ & $9,2 \%$ & $24,0 \%$ & $9,2 \%$ & $7,5 \%$ \\
\hline 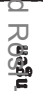 & \begin{tabular}{|l|} 
Zusatz- bzw. \\
Mindestausschüttung an \\
Kapitalgeber \\
\end{tabular} & Nein & Nein & Nein & Nein & Nein & Nein \\
\hline 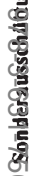 & Interimsdividende & Nein & Nein & Nein & Nein & $\begin{array}{l}\mathrm{Ja} \text {, in 1999: 40,6 Mio. } \\
\text { EUR, das sind ca. 1/5 } \\
\text { des auszuschüttenden } \\
\text { Jahresgewinns } \\
\text { (Anrechnung) }\end{array}$ & $\begin{array}{l}\text { Ja, nach Art. } 22 \text { Nr. } 3 \\
\text { DNB-Satzung } \\
\text { möglich, aber seit } \\
\text { 1.1.1999 nicht mehr } \\
\text { praktiziert }\end{array}$ \\
\hline
\end{tabular}

Quelle: Eigene Berechnungen. Die der Übersicht zugrundeliegenden Daten stammen aus den Jahresberichten der NZBen für 1998 und 1999 sowie den Zentralbankgesetzen bzw. Statuten der

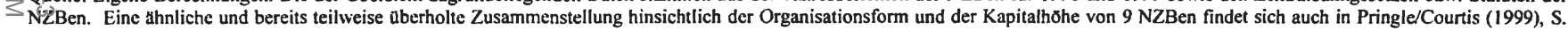
xvii ff.. 
Die anderen eher „behördlich-organisierten“ NZBen sind neben der weitgehend einheitlichen Rechtsform als Institution öffentlichen Rechts vor allem dadurch gekennzeichnet, daß ihr Grundkapital ausschließlich vom heimischen Staat gehalten wird. Die Höhe der Kapitalzahlungen variiert jedoch beträchtlich zwischen den NZBen. So beträgt z.B. die Höhe des gezahlten Kapitals der irischen Zentralbank gerade einmal 30 Tsd. EUR, während die Bundesbank über Kapitaleinlagen in Höhe von knapp 2,6 Mrd. EUR verfügt. Bezieht man allerdings zusätzlich Rückstellungen und Rücklagen in die Analyse mit ein und gewichtet die Summe aus Reserven und Kapital der einzelnen NZBen mit der jeweiligen Bilanzsumme, erscheint ein etwas homogeneres Bild. So liegt die Eigenkapitalquote dieser NZBen zwischen knapp 2 Prozent im Falle der luxemburgischen Zentralbank und etwas über 9 Prozent im Falle der irischen bzw. der portugiesischen Währungsbehörde. Eine Ausnahme bilden diesbezüglich nur die Banque de France mit 17,5 Prozent und die finnische Notenbank mit 24 Prozent $^{328}$. Neben der Eigenkapitalbildung ähneln sich die behördlich organisierten NZBen auch dahingehend, daß auf Zusatz- und Mindestausschüttungen gänzlich verzichtet wird. Die Zahlung von Interimsdividenden hingegen wird von der spanischen und der irischen Zentralbank praktiziert. Diese Ausschüttungen, die die NZBen im Einvernehmen mit den heimischen Finanzministern $\mathrm{zu}$ leisten haben ${ }^{329}$, können ebenfalls als Eurosystemunabhängige Aufwendungen interpretiert werden.

\section{Die Beteiligung der NZBen an der staatlichen Münzemission}

Nach Art. 106 Abs. 2 EGV liegt das Münzemissionsrecht bei den Mitgliedstaaten, wobei der Umfang der Münzausgabe der Genehmigung durch die EZB bedarf. Den EWU-Staaten steht es jedoch offen, die heimische NZB an der Münzemission zu beteiligen. In welchem Ausmaß die NZBen nun derartige Aufgaben wahrnehmen und welche Kosten sie dabei zu finanzieren haben bzw. welche Einkünfte sie erwirtschaften, soll im Folgenden untersucht werden. In jedem Fall sind diese Aufwendungen und Erträge als Eurosystem-unabhängig zu charakterisieren, da derartige Aktivitäten - sieht man von den von der EZB

328 Die relativ hohe Eigenkapitalrelation der französichen Zentralbank ist auf eine Regelung zurückzuführen, die die BdF verpflichtet, realisierte Bewertungsverluste bzw. als realisiert angesehene unrealisierte Bewertungsverluste ergebnisneutral $\mathrm{zu}$ halten. Vgl. Banque de France (2000c), S. 224 f.. Im Falle der BoF ist die hohe Eigenkapitalquote mit der Verpflichtung der finnischen Zentralbank zu erklären, gemäß Section 21 BoF-Gesetz grundsätzlich die Hälfte ihres Jahresüberschusses in die Reserven einzustellen, um etwaige Jahresfehlbeträge sofort finanzieren zu können.

Vgl. Section 23 Abs. 4 CBI-Gesetz von 1989 und Banco de España (2000), S. 128.

Gerhard Rösl - 978-3-631-75006-3 
festgesetzten Obergrenzen der Münzemission einmal ab - unabhängig von Weisungen der EZB durchgeführt werden und auf Basis nationaler Zentralbankgesetze erfolgen. Hierbei lassen sich die Beteiligung der NZBen an der Herstellung der Münzen einerseits und an der Münzausgabe andererseits unterscheiden. Bezüglich der Herstellung der Münzen kann festhalten werden, daß außer in Irland, Österreich und Luxemburg die nationalen Münzen in den staatlichen Münzprägeanstalten gefertigt werden. Dies gilt sowohl für normale Umlaufsmünzen als auch für Sammler- und Gedenkmünzen. Die Herstellungskosten tragen entsprechend die staatlichen Prägeanstalten. Die (Euro-) Münzen Luxemburgs werden hingegen in der niederländischen Münzstätte geprägt. Auch hier ist davon auszugehen, daß die Kosten der Münzherstellung nicht von der heimischen NZB zu übernehmen sind ${ }^{330}$. Anders verhält es sich im Falle Irlands. Hier stellt die Central Bank of Ireland (CBI) die irischen (Euro-) Münzen in ihrem Currency Centre selbst her. Dabei erfolgt die konkrete Finanzierung aller Kosten durch Rückgriff auf die sogenannte „Currency Reserve“ der $\mathrm{CBI}^{331}$. Prinzipiell ähnlich zur Vorgehensweise in Irland ist die Münzherstellung und deren Finanzierung in Österreich geregelt. Produziert werden die österreichischen (Euro-) Münzen von der Münze Österreich AG, einer 100 Prozent Tochter der OeNB, die in der Regel auch die Kosten der Münzherstellung selbst trägt $^{332}$. Allerdings zahlte die OeNB bereits in 1998 einen direkten Beitrag zu den Produktionskosten der ersten Euro-Münzserie ${ }^{333}$.

Weiterhin sind die NZBen an der Münzausgabe beteiligt. Dabei lassen sich drei Kostenarten unterscheiden, die die NZBen zu tragen haben: Ankaufs-, Lagerund Verwaltungskosten jeweils für Umlaufsmünzen einerseits und Sammlerund Gedenkmünzen andererseits. Hierbei zeigt die Analyse folgendes Bild.

Die für den Zahlungsverkehr bestimmten Umlaufsmünzen werden durchweg von den NZBen ausgegeben. Hierzu kaufen alle Zentralbanken des Eurosystems mit Ausnahme der Währungsbehörden Österreichs und Irlands, die ihre Münzen (zumindest indirekt) selbst herstellen, die Umlaufsmünzen zum Nennwert von

330 Hier sei jedoch erwähnt, daß die BCL nach Art. 18 BCL-Gesetz verpflichtet ist, für alle Kosten verantwortlich zu zeichnen, die mit der Münzemission in Verbindung stehen. Vermutlich betrifft diese Regelung jedoch nur die Verwaltungskosten zur Aufrechterhaltung eines einwandfreien Münzumlaufs.

331 Vgl. Central Bank of Ireland (2000c), S. 81. Die Currency Reserve entspricht im wesentlichen den in die CBI-Bilanz eingestellten Netto-Münzgewinnen. Eine buchungstechnische Verrechnung über die Gewinn- und Verlustrechnung der CBI findet allerdings nicht statt.

332 Vgl. Österreichische Nationalbank (2000), S. 131. Üblicherweise finanziert die Münze Österreich AG die Münz-Herstellungskosten dadurch, daß sie die hergestellten Münzen an die OeNB zum Nennwert verkauft.

333 Vgl. Österreichische Nationalbank (2000), S. 133. 
den heimischen Regierungen gegen Zentralbankgeld an ${ }^{334}$. Diese Anschaffungskosten werden dann an die Geschäftsbanken weiter gegeben, wenn diese die Münzen gegen Zentralbankgeld von der NZB erwerben. Dies gilt jedoch nicht für den gesamten Umlaufsmünzenbestand der NZBen. So halten die meisten NZBen entsprechende Sicherheitsbestände, um beschädigte gegen einwandfreie Münzen austauschen $\mathrm{zu}$ können und/oder eine gestiegene Nachfrage auch kurzfristig befriedigen zu können ${ }^{335}$. Die Kosten der Aufrechterhaltung des jeweiligen Sicherheitsbestands der NZBen in Höhe der kumulierten Anschaffungskosten verbleiben bei den NZBen. Dazu kommen noch diverse Verwaltungskosten, Lagerkosten, Aufwendungen für die Sicherheit, Kosten der Münzausgabe, die die NZBen unter Umständen vollständig zu tragen haben ${ }^{336}$, wenn in den jeweiligen Abkommen zwischen den NZBen und der nationalen Regierung nichts anderes geregelt ist. Gedenk- und Sammlermünzen hingegen werden jedoch nur teilweise durch die NZBen an Interessenten ausgegeben. Als Beispiele seien hier Finnland, Irland und Portugal genannt, die in Analogie zu den Umlaufsmünzen neben den Ankaufs-, und Verwaltungskosten auch die Aufwendungen der Münzausgabe zu finanzieren haben. In Deutschland hingegen wird die Emission von Sammlermünzen von der Bundesschuldenverwaltung bzw. in Frankreich und Österreich direkt von der Prägeanstalt durchgeführt, die jeweils auch die Emissionskosten tragen. Angaben, inwieweit die anderen NZBen bei der Ausgabe von Gedenk- und Sammlermünzen beteiligt sind, können aufgrund Datenmangels nicht gemacht werden. Eine empirische Quantifizierung der genannten Kosten, die die NZBen im Rahmen ihrer Beteiligung an der nationalen Münzemission zu tragen haben, erweist sich ebenfalls als schwierig. Um jedoch zumindest die quantitative Bedeutung der nationalen Münzemission aufzuzeigen, sind in Tabelle 31 die Münzumläufe (getrennt nach Umlaufsmünzen und Gedenk- bzw. Sammlermünzen) und Sicherheitsbestände an Münzen im Besitz der NZBen angeführt.

334 Im Falle Luxemburgs ist wohl davon auszugehen, daß die in den Niederlanden hergestellten luxemburgischen Euro-Münzen vom luxemburgischen Staat gegen einen mit Gewinnaufschlag versehenen Preis, der oberhalb der Herstellungskosten aber noch unterhalb des Nennwerts liegt, angekauft und an die BCL zum Umlaufswert veräußert werden.

$335 \mathrm{Vgl}$. dazu auch die Angaben in Tabelle 31. Hierbei sei angemerkt, daß die ausgewiesenen Sicherheitsbestände bei einigen NZBen auch Bestände an Gedenk- und Sammlermünzen beinhalten. So z.B. bei der Banco de Portugal. Vgl. Banco de Portugal (1999), S. 245. Der Umfang des Sicherheitsbestands an Münzen im Bestand der NZBen ist jeweils auf $10 \%$ des nationalen Münzumlaufs begrenzt. Vgl. Europäische Gemeinschaft (1993), S. 3. Während in Deutschland als Referenzmaß der aktuelle Münzumlauf herangezogen wird, bezieht man sich in Frankreich auf den Endstand des Münzumlaufs zum 31.12.1993. Vgl. Deutsche Bundesbank (2000a), S. 127 und Banque de France (2000c), S. 226. 
Tabelle 31: Sicherheitsbestănde an Mūnzen im Besitz der NZBen und nationaler Mūnzumlauf der Jahre 1998 und 1999 sowie genehmigte Münz-Neuemissionen für 2000

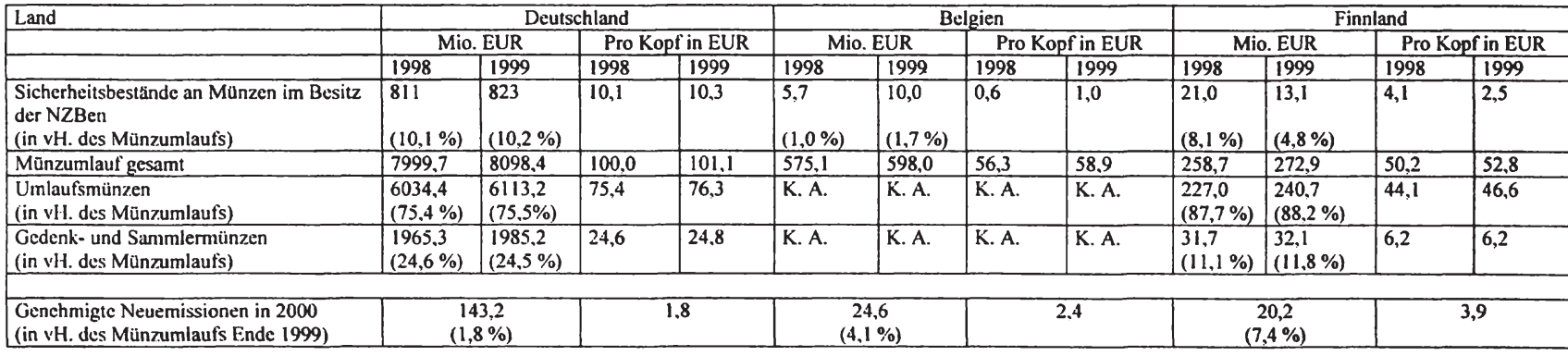

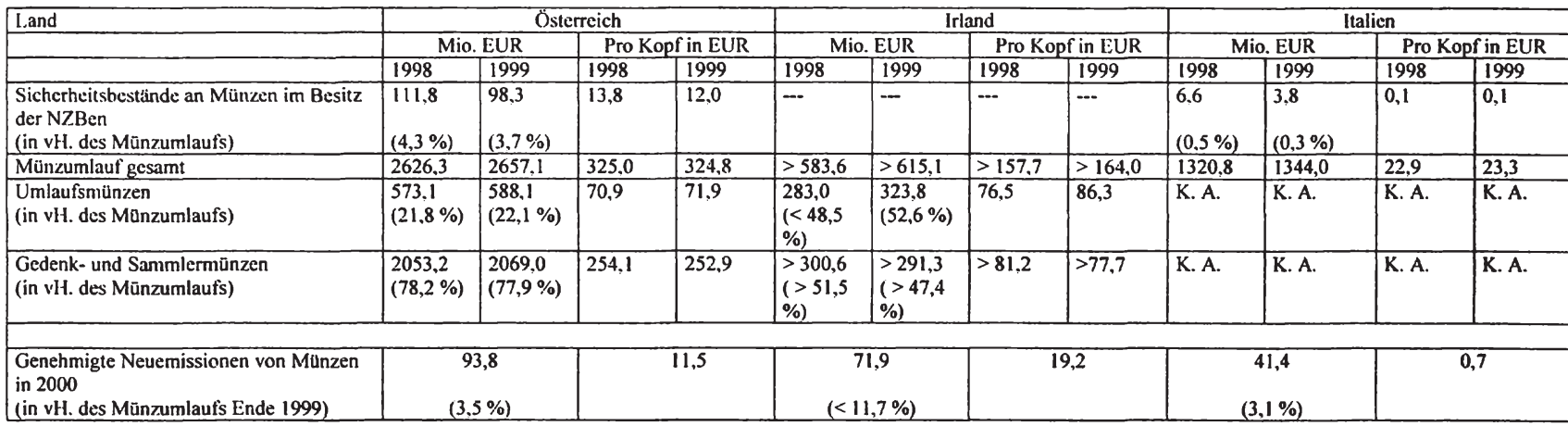

Angaben zur Darstellung: Die Sicherheitsbestände an Münzen sind den NZB-Bilanzen entnommen, wobei die BBk nur auf Mio. EUR gerundete Werte ausweist. Dic ausgewiesenen (1999d) (1999d), S. 130 und (2000c), Belgische Nationalbank (2000a) und (2000b), S. 70, Bank of Finland (1999), S. 90 f. und (2000b), S. 118 , Ősterreichische Nationalbank (2000), S. 118 und S. 11*. Für den irischen Münzumlauf können nur Untergrenzen angegeben werden. Vgl. Central Bank of Ireland (1999), S. 45 und (2000c), S. 44 ff.. Der Münzumlauf ltaliens in 1998 und 1999 ist als Differenz zwischen dem von der Bdl ausgewiesenen Bargeldumlauf abzüglich dem Banknotenumlauf angegeben. Vgl. Banca d'Italia (2000a), S. 290 f. und 324 f.. Angaben für den Umfang der genehmigten Neuemissionen aus Europłische Gemeinschaft (2000a). Bevölkerungszahlen aus International Monetary Fund (2000f). Differenzen in den relevanten Summen durch Runden der Zahlen. 
Noch Tabelle 31: Sicherheitsbestănde an Münzen im Besitz der NZBen und nationaler Munzumlauf der Jahre 1998 und 1999 sowie genehmigte Manz-Neuemissionen fur 2000

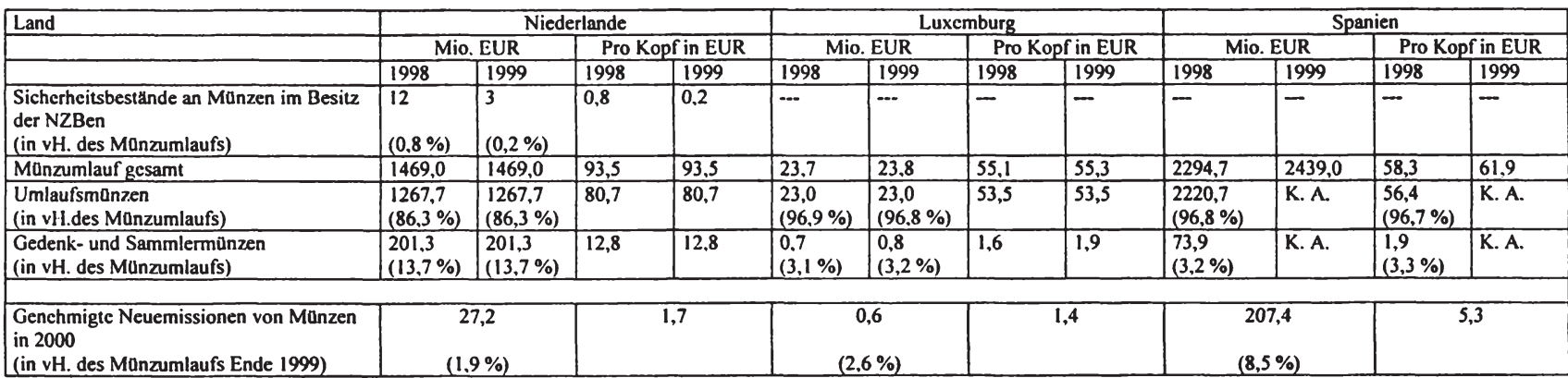

(in vH. des Manzumlaufs Ende 1999)

$(1.9 \%)$

$(2.6 \%)$

\begin{tabular}{|c|c|c|c|c|c|c|c|c|}
\hline & & & & & & & & \\
\hline $\begin{array}{l}\text { Sicherhcitsbestände an Manzen im Besitz } \\
\text { der NZBen } \\
\text { (in vH. des Manzumlaufs) }\end{array}$ & 259,3 & 259,3 & 4,4 & 4,4 & $\begin{array}{l}20,4 \\
(6,6 \%)\end{array}$ & $\begin{array}{l}20,3 \\
(6,3 \%)\end{array}$ & 2,0 & 2,0 \\
\hline Manzumlauf gesamt & $>2536.8$ & $>2624,0$ & $>43,1$ & $>44,4$ & 288.2 & 321,2 & 28,9 & 32,2 \\
\hline $\begin{array}{l}\text { Umlaufsmunzen } \\
\text { (in vH. des Manzumlaufs) }\end{array}$ & 2536,8 & 2624.0 & 43,1 & 44,4 & $\begin{array}{l}196,4 \\
(68,1 \%)\end{array}$ & $\begin{array}{l}216,4 \\
(67,4 \%)\end{array}$ & $\begin{array}{l}19,7 \\
(68,2 \%)\end{array}$ & $\begin{array}{l}21,7 \\
(67,4 \%)\end{array}$ \\
\hline $\begin{array}{l}\text { Gedenk- und Sammlermunzen } \\
\text { (in vH. des Münumlaufs) }\end{array}$ & K. A. & K. A. & K. A. & K. A. & $\begin{array}{l}91,9 \\
(31,9 \%)\end{array}$ & $\begin{array}{l}104,8 \\
(32,6 \%)\end{array}$ & $\begin{array}{l}9,2 \\
(31,8 \%)\end{array}$ & $\begin{array}{l}10,5 \\
(32,6 \%)\end{array}$ \\
\hline $\begin{array}{l}\text { Genehmigte Neuemissionen von Manzen } \\
\text { in } 2000 \\
\text { (in vH. des Münzumlaufs Ende 1999) }\end{array}$ & \multicolumn{2}{|c|}{83,7} & \multicolumn{2}{|c|}{1,4} & \multicolumn{2}{|c|}{36,4} & \multicolumn{2}{|c|}{3,7} \\
\hline
\end{tabular}

(in vH. des Münzumlaufs Ende 1999)

Quelle: Eigene Berechnungen. Angaben zur Darstellung: Die Sicherheitsbestande an Münzen sind den NZB-Bilanzen entnommen, wobei die DNB nur auf Mio. EUR gerundete Werte ausweist. Die ausgewiesenen Sicherheitsbestande enthalten in jewveils geringem Umfang auch Munzen aus anderen EWU-Staaten. Angaben bzgl. Manzumlauf fur NL und LU aus De Nederlandsche Bank (1999), S. 16 (Anhang) und (2000b), S. 162 ff., sowie Banque Centrale du Luxembourg (2000a). Munzumlauf Spaniens for 1998 aus Banco de España (1999), S. 113 , fur 1999 errechnet aus IFS-Linie 14a abzaglich Banknotenumlauf. Vgl. Banco de España (2000), S. 117 und International Monetary Fund (2000b). Angaben bzgl. FRFUmlaufsmünzenumlauf aus Banque de France $(2000 \mathrm{c})$, S. 236 und Banque de France (2000b). Zur Hobe des FRF-Gedenk- und Sammlerm0nzenumlaufs sind keine Angaben erhältlich, weshalb for den gesamten Munzumlauf nur eine Untergrenze angegeben iverden kann. Umlauf portugiesischer Manzen aus Banco de Portugal (1999), S. 245 und (2000a), S. 264. Angaben far den Umfang der genehmigten Neuemissionen aus Europäische Gemeinschaft (2000a). Bevölkerungszahlen aus International Monetary Fund (2000f). Differenzen in den relevanten Summen durch Runden der Zahlen. 
Zunächst fällt auf, daß Ende der Jahre 1998 und 1999 der Anteil der Gedenkund Sammlermünzen am gesamten Nennwert des nationalen Münzumlaufs mit ca. 50 Prozent in Irland und mit rund 78 Prozent im Falle Österreichs vergleichsweise hoch ist ${ }^{337}$. Dies ist um so erstaunlicher, wenn man bedenkt, daß gerade in diesen beiden Ländern die Regierungen sowohl ihr Recht zur Herstellung als auch zur Münzausgabe nicht selbst wahrnehmen und (un-) mittelbar auf die Zentralbank übertragen. Auf das Einnahmemotiv der Regierungen kann hier folglich nur eingeschränkt abgestellt werden. Dies gilt schon eher für die Situation in Portugal und in Deutschland. Bei den anderen EWULändern spielen Sammler- und Gedenkmünzen offenbar eine weniger bedeutende Rolle, wenngleich nicht für alle Länder entsprechende Daten verfügbar sind.

Die Höhe des für den Zahlungsverkehr bestimmten Umlaufs an Münzen hängt von den Zahlungsgewohnheiten der Geldverwender und den strukturellen Gegebenheiten, wie etwa der Verbreitung bargeldloser Zahlungssysteme für Kleinbeträge, in den einzelnen EWU-Ländern ab. Als grober Indikator hierfür mag der in Tabelle 31 aufgezeigte Umlaufsmünzenumlauf pro Kopf dienen. Hierbei zeigt sich, daß die Einwohner Frankreichs und Finnlands mit einem Betrag von ca. 44 EUR pro Kopf offenbar auf effizientere Kleinbetragzahlungssysteme (z.B. Geld Cards) zurückgreifen können als beispielsweise die Niederländer (Ende 1999: 80,7 EUR/Kopf) oder die Iren (Ende 1999: 86,3 EUR/Kopf). Allerdings läßt sich mit Hilfe dieser Beobachtung zumindest nicht dominant der Umfang der von der EZB in 2000 genehmigten Neuemissionen an Münzen pro Kopf erklären. So scheint beispielsweise das mit 11,5 EUR pro Kopf besonders hohe Münzemissionspotential Österreichs eher damit erklärbar $\mathrm{zu}$ sein, daß die nationale Emissionsstelle ihre ausgeprägte Tradition der Gedenk- und Sammlermünzen fortzusetzen gedenkt.

Hierbei darf jedoch nicht unerwähnt bleiben, daß zumindest die Genehmigung von Neuemissionen an nationalen Umlaufsmünzen durch die EZB einen gewissen Konfliktstoff in sich birgt. So werden die für den Zahlungsverkehr vorgesehenen Münzen von den nationalen Mitgliedstaaten emittiert, die dann die entsprechenden Münzgewinne erzielen ${ }^{338}$. Die ausgegebenen Münzen sind jedoch in allen EWU-Staaten als gesetzliches Zahlungsmittel anerkannt, so daß

337 Die herausragende Bedeutung der Sammler- und Gedenkmünzen in Irland und Österreich zeigt sich auch darin, daß diese beiden Länder ebenfalls die Spitzenplätze bei den genehmigten Münz-Neuemissionen des Jahres 2000 eingenommen haben. Vgl. Tabelle 31.

Wie die obige Analyse zeigt, fallen die Münzgewinne in einigen EWU-Staaten nicht unbedingt direkt bei der Regierung an. Sie verbleiben jedoch in jedem Falle im Mitgliedstaat. Vgl. dazu auch die theoretischen Überlegungen zum Fiskalischen Seigniorage in Kapitel II. Abschnitt 4.2.1.. 
die Neuemissionen an Münzen nicht rein auf die nationale Geldnachfrage beschränkt bleiben wird. Eine einzelne Regierung kann also, weil sie etwa aufgrund vergleichsweise solider Staatsfinanzen von den gesamten europäischen Geldverwendern als relativ vertrauenswürdig angesehen wird, mehr Münzen emittieren als für den nationalen Umlauf erforderlich wäre. Bei gegebenem gesamteuropäischen Emissionsvolumen käme es dann - etwas überspitzt ausgedrückt - zu Verteilungskämpfen im EZB-Rat. Diesen Schluß läßt zumindest die Neue Politische Ökonomie zu, welche die ZentralbankGouverneure als Vertreter der nationalen Interessen interpretiert. Zumindest dürfte ein politischer Druck auf den EZB-Rat, die Münzgewinne durch eine entsprechende Festlegung von nationalen Emissionskontingenten "gerecht" zu verteilen, nicht lange auf sich warten lassen. So sehen die vertraglichen Regelungen auch nur eine Umverteilung von Geldschöpfungsgewinnen aus der Banknotenproduktion, nicht aber aus der Münzproduktion vor ${ }^{339}$.

Die Frage ist nun, ob ein solches Verfahren für die Münzgewinne aus ökonomischer Sicht überhaupt wünschenswert ist. So lassen sich die Münzen im Gegensatz zu den Banknoten wegen ihrer ,nationalen Seite“ eindeutig dem Emittenten zuordnen. Warum soll nicht einfach der Wettbewerb entscheiden, welche Münzen sich als Zahlungsmittel durchsetzen und welche nicht ${ }^{340}$ ? In jedem Falle wäre ein so begründeter zusätzlicher, wenn auch zugegebenermaßen kleiner, Druck auf das Finanzgebaren der jeweiligen Regierungen nicht schädlich. Zudem wirkt auch der Wettstreit der Geldproduzenten um die unterschiedlichen Münz-Designes in seinem Ergebnis wohlfahrtserhöhend.

\section{Die Beteiligung der NZBen an der Aufsicht über Finanzinstitute}

Der Übergang zur gemeinsamen europäischen Währung und die sich zusehends integrierenden Geld- und Kapitalmärkte schafften einen Bedarf zur Koordinierung und Harmonisierung der Aufsicht über Finanzinstitute ${ }^{341}$. Dabei sehen die gemeinschaftsrechtlichen Regelungen vor, daß diese Aufgabe nicht vom Eurosystem oder anderen EU-Institutionen, sondern von den zuständigen nationalen Aufsichtsbehörden gemäß dem Prinzip „Heimatlandaufsicht und

339 Vgl. Art. 32.2. ESZB-Satzung. Es sei hier angemerkt, daß der Artikel 32.2. ESZBSatzung in der deutschen Fassung falsch ubersetzt wurde. Dort ist von „Bargeldumlauf“ die Rede, es handelt sich jedoch um den Banknotenumlauf. Vgl. dazu die Ausführungen zu Kapitel V.3.1..

340 Eine solche wettbewerbliche Regelung fordert allerdings die Aufhebung des Annahmezwangs der Münzen als gesetzliches Zahlungsmittel, sowie wegen des Grashamschen Gesetzes flexible Wechselkurse zwischen den Münzen.

$341 \mathrm{Vgl}$. im Folgenden Europäische Zentralbank (2000b), S. 53 ff.. 
gegenseitige Anerkennung" wahrgenommen wird ${ }^{342}$. Dies gilt sowohl für die Bankenaufsicht als auch für die Aufsicht über andere Finanzinstitutionen wie z.B. Investmentfonds. Dabei steht es den Mitgliedstaaten freilich offen, die Aufsichtskompetenzen ganz oder teilweise auf die heimische NZB zu übertragen. In welchem Umfang die NZBen bei der Erfüllung dieser Aufgabe mitwirken, soll im Folgenden untersucht werden. Die den NZBen hierbei entstehenden Aufwendungen und Erträge (erhobene Gebühren) werden entsprechend der nationalen Zuständigkeit als Eurosystem-unabhängig klassifiziert $^{343}$.

Bezüglich der Beteiligung der NZBen an der Bankenaufsicht lassen sich, wie in Tabelle 32 dargestellt, die untersuchten EWU-11-NZBen in drei Gruppen einteilen ${ }^{344}$. Die erste Gruppe bildet Belgien, Luxemburg und Finnland, die ihren NZBen keine spezifischen bankaufsichtlichen Tätigkeiten übertragen. Allerdings sind die belgische und finnische Zentralbank diesbezüglich nicht gänzlich ohne Einfluß, da das jeweilige NZB-Direktorium an der Entscheidungsfindung in den zuständigen staatlichen Aufsichtsbehörden mitwirkt. Die Deutsche Bundesbank, die Banque de France und die Österreichische Nationalbank hingegen sind auch in operativer Hinsicht weitreichend an der Bankenaufsicht beteiligt, wenngleich sich die genannten NZBen dieses Aufgabenfeld mit anderen zuständigen Stellen teilen müssen. Auch hier stellt zusätzlich eine Reihe von Koordinierungsvereinbarungen eine enge Zusammenarbeit zwischen den genannten NZBen und der nationalen Bankenaufsichtsstellen sicher. Die dritte Gruppe bestehend aus Irland, Italien, der Niederlande, Portugal und Spanien ist dadurch gekennzeichnet, daß die alleinige Zuständigkeit für die Bankenaufsicht bei der heimischen Zentralbank liegt. Dabei beschränkt sich deren Aufsichtsbefugnisse nicht nur auf den Bankensektor, sondern umfaßt teilweise auch die Überwachung von Wertpapier- und Investmentfirmen. Hierbei liegt in der Regel der Schwerpunkt der Aufsichtstätigkeit auf der Wahrung der Systemstabilität ${ }^{345}$.

342 So trägt nach Art. 3.3. ESZB-Satzung und Art. 105 Abs. 5 EGV das ESZB (Eurosystem) nur zur reibungslosen Durchführung der von den zuständigen Behörden auf dem Gebiet der Aufsicht über die Kreditinstitute und der Stabilität des Finanzsystems ergriffenen Maßnahmen bei. Vgl. dazu auch Europäische Zentralbank (2000b), S. 62. Eine Ausnahme von dieser Regel bildet Art. 25.2. ESZB-Satzung und Art. 105 Abs. 6 EGV, die den Rat ermächtigt, besondere Aufgaben im Zusammenhang mit der Aufsicht über Kreditinstitute und sonstige Finanzinstitute mit Ausnahme von Versicherungsunternehmen auf die EZB zu übertragen.

343 Vgl. auch Liebscher (1998), S. 7. Gnan faßt ebenfalls die Beteiligung der NZBen an der Bankenaufsicht unter Art. 14.4. ESZB-Satzung. Vgl. Gnan (1999), S. 605.

344 Vgl. Europäische Zentralbank (2000b), S. 63.

345 Vgl. Europäische Zentralbank (2000b), S. 66. 
Tabelle 32 : Die Beteiligungen der NZBen an der Aufsicht aber Finanzinstitute

\begin{tabular}{|c|c|c|c|c|}
\hline Land & $\begin{array}{l}\text { Fur die } \\
\text { Bankenaufsicht } \\
\text { zustandige Stelle }\end{array}$ & $\begin{array}{l}\text { Beteiligung der NZB an } \\
\text { der Bankenaufsicht }\end{array}$ & $\begin{array}{l}\text { Formelle } \\
\text { Koordinierungsverein- } \\
\text { barungen zwischen } \\
\text { Bankenaufsicht und } \\
\text { Zentralbank } \\
\end{array}$ & $\begin{array}{l}\text { Uber den Bankensektor } \\
\text { hinausgehende } \\
\text { Aufsichtsbefugnisse der } \\
\text { fur die Bankenaufsicht } \\
\text { zustllndigen Stelle }\end{array}$ \\
\hline Belgien & $\begin{array}{l}\text { Commission } \\
\text { Bancaire et } \\
\text { Financière } \\
\end{array}$ & $\begin{array}{l}\text { Keine spezifischen } \\
\text { bankaufsichtlichen } \\
\text { Aufgaben der NBB }\end{array}$ & $\begin{array}{l}\text { Beteiligung des } \\
\text { Direktoriums }\end{array}$ & $\begin{array}{l}\text { Wertpapierfirmen und } \\
\text { Investmentfonds, } \\
\text { Marktbeobachtung }\end{array}$ \\
\hline Luxemburg & $\begin{array}{l}\text { Commission de } \\
\text { Surveillance du } \\
\text { Secteur Financier }\end{array}$ & $\begin{array}{l}\text { Keine direkte } \\
\text { Beteiligung der } \mathrm{BCL}\end{array}$ & Keine & $\begin{array}{l}\text { Alle Finanzinstitute (außer } \\
\text { Versicherungs- } \\
\text { gesellschaften) und } \\
\text { Finanzmärkte }\end{array}$ \\
\hline Finnland & $\begin{array}{l}\text { Finanzaufsichs- } \\
\text { behorde }\end{array}$ & $\begin{array}{l}\text { Keine spezifischen } \\
\text { bankaufsichtlichen } \\
\text { Aufgaben der BoF }\end{array}$ & \begin{tabular}{|l|} 
Beteiligung des \\
Direktoriums und \\
Verwaltungsbeziehungen \\
\end{tabular} & $\begin{array}{l}\text { Wertpapierfirmen und } \\
\text { Borsen }\end{array}$ \\
\hline Deutschland & $\begin{array}{l}\text { Bundesaufsichtsamt } \\
\text { fur das Kreditwesen }\end{array}$ & $\begin{array}{l}\text { Weitreichende } \\
\text { Beteiligung der BBk an } \\
\text { der Überwachung der } \\
\text { Institute, hat in vielen } \\
\text { Fallen Recht auf } \\
\text { Anhörung }\end{array}$ & $\begin{array}{l}\text { Gesetzlich } \\
\text { vorgeschriebene enge } \\
\text { Zusammenarbeit }\end{array}$ & $\begin{array}{l}\text { Wertpapierfirmen und } \\
\text { offene Investmentfonds } \\
\text { sowie Finanzdienstleister } \\
\text { (auBer Versicherungs- } \\
\text { gesellschaften) }\end{array}$ \\
\hline Frankreich & $\begin{array}{l}\text { Commission } \\
\text { Bancaire }\end{array}$ & $\begin{array}{l}\text { Weit reichende } \\
\text { Betciligung der BdF }\end{array}$ & $\begin{array}{l}\text { Der Präsident der BdF } \\
\text { fuhrt den Vorsitz der } \\
\text { Commission Bancaire } \\
\text { und des CECEI' und ist } \\
\text { Mitglied des CRBF }{ }^{2} \text {, } \\
\text { Verwaltungsbeziehungen }\end{array}$ & Wertpapierfirmen \\
\hline Osterreich & Finanzministerium & $\begin{array}{l}\text { Weitreichende } \\
\text { Beteiligung der OeNB an } \\
\text { der Überwachung der } \\
\text { einzelnen Institute, hat in } \\
\text { viclen Fällen Recht auf } \\
\text { Anhorung }\end{array}$ & $\begin{array}{l}\text { Aus Vertretem des } \\
\text { Finanzministeriums und } \\
\text { der OeNB bestehende } \\
\text { Expertenkommission }\end{array}$ & $\begin{array}{l}\text { Versicherungs- } \\
\text { gesellschaften }\end{array}$ \\
\hline Irland & $\begin{array}{l}\text { Central Bank of } \\
\text { Ireland (CBI) }\end{array}$ & $\begin{array}{l}\text { Alleinige Zustandigkeit } \\
\text { der CBI }\end{array}$ & Nur eine Behörde & $\begin{array}{l}\text { Wertpapierfirmen, legt } \\
\text { Anforderungen an Borsen } \\
\text { und autorisierte } \\
\text { Mitgliedsunternehmen fest }\end{array}$ \\
\hline Italien & Banca d'Italia (BdI) & $\begin{array}{l}\text { Alleinige Zustandigkeit } \\
\text { der BdI }\end{array}$ & Nur eine Behorde & $\begin{array}{l}\text { Überwachung aller } \\
\text { Finanzinstitute (außer } \\
\text { Versicherungsgesell- } \\
\text { schaften) und Finanz- } \\
\text { markte im Hinblick auf } \\
\text { Stabilitat } \\
\end{array}$ \\
\hline Niederlande & \begin{tabular}{|l|} 
De Nederlandsche \\
Bank (DNB) \\
\end{tabular} & $\begin{array}{l}\text { Alleinige Zustandigkeit } \\
\text { der DNB }\end{array}$ & Nur eine Behorde & Investmentfonds \\
\hline \begin{tabular}{|l|} 
Portugal \\
\end{tabular} & $\begin{array}{l}\text { Banco de Portugal } \\
\text { (BdP) }\end{array}$ & $\begin{array}{l}\text { Alleinige Zustandigkeit } \\
\text { der BdP }\end{array}$ & Nur eine Behörde & Wertpapierfirmen \\
\hline Spanien & $\begin{array}{l}\text { Banco de Espafia } \\
\text { (BdE) }\end{array}$ & $\begin{array}{l}\text { Alleinige Zustandigkeit } \\
\text { der BdE }\end{array}$ & Nur eine Behorde & Keine \\
\hline
\end{tabular}

Quelle: Die der Obersicht zugrunde liegenden Daten sind entnommen aus Europđische Zentralbank (2000b), S. 64f..

\footnotetext{
' Das Comité des Etablissements de Crédit et des Entreprises d'Investissement (CECEI) ist neben der Commission Bancaire ebenfalls an der Erteilung bzw. Aufhebung der Erlaubnis zum Betreiben von Bankgeschăften beteiligt.

2 Das Comité de la Reglementation Bancaire et Financière (CRBF) ist eine weitere Institutionen mit bankenaufsichtsrechtlichen Befugnissen in Frankreich.
} 
Bezüglich der Aufwendungen, die die NZBen aus dem unterschiedlichen Umfang ihrer Aufsichtstätigkeiten zu tragen haben, lassen sich wegen der mangelnden Verfügbarkeit solcher Daten keine vergleichende Darstellungen aufzeigen. Allerdings ist wohl grundsätzlich davon auszugehen, daß die den NZBen entstandenen Kosten von den überwachten Instituten mittels Zwangsgebühren beglichen werden. $\mathrm{Ob}$ dies jedoch in allen Fällen kostendeckend erfolgt, soll hier offenbleiben. So erstatten beispielsweise die deutschen Geschäftsbanken dem Bundesaufsichtsamt für das Kreditwesen nur zum Teil die entstandenen Aufwendungen ${ }^{346}$.

\section{Sonstige Eurosystem-unabhängige Tätigkeiten der NZBen}

An dieser Stelle sollen die verbleibenden, noch nicht erfaßten Eurosystemunabhängigen Tätigkeitsbereiche der NZBen untersucht werden. Hierbei handelt es sich, wie Tabelle 33 zeigt, überwiegend um Dienstleistungen der Zentralbanken für die breite Öffentlichkeit. So unterhalten viele NZBen ein Geldmuseum, führen öffentliche Bibliotheken und vertreiben neben ihren Monatsund Geschäftsberichten auch Working Papers, geldgeschichtliche Schriften und andere Monographien (z.B. im Falle der Deutschen Bundesbank Kunstbände). Des weiteren sind manche NZBen intensiv mit der Erstellung von Statistiken befaßt, die den Umfang der vom Eurosystem geforderten Datenerhebung übersteigt. So ist etwa die Banque de France gemäß Art. 16 BdF-Statut dazu verpflichtet, die Zahlungsbilanz Frankreichs und die Auslandsvermögensposition des französischen Staates zu erstellen. Ähnliches gilt auch für die Nationalbank Belgiens. Weiterhin bieten die Zentralbanken Deutschlands und Spaniens Schlichtungs- und Beschwerdestellen für Geschäftsbanken und private Nichtbanken an. Andere NZBen erfüllen spezielle Aufgaben, die der Kreditsicherung zuzurechnen sind (Zentralen für Privat- und Unternehmenskredite, Beteiligung an der Einlagesicherung). Zudem managen die meisten Zentralbanken Bilanzzentralen. Weiterhin haben alle NZBen gegenüber den nationalen Regierungen eine Beratungs- und Kooperationspflicht, wobei in jedem Falle sichergestellt sein muß, daß die Unabhängigkeit der NZBen für den Bereich der gemeinsamen Geldpolitik unangetastet bleibt. Zuletzt sei noch erwähnt, daß einige NZBen der Förderung sozialer und kultureller Aktivitäten verpflichtet sind. Hierzu unterhalten $z$. B. die österreichische und spanische Zentralbank entsprechende Fonds. Leider lassen sich nur vereinzelt Angaben bezüglich der Kosten machen, die den NZBen in Ausübung der genannten Tätigkeiten zu tragen haben. Insgesamt dürften diese jedoch nicht zu hoch anzusetzen sein.

346 Vgl. Europäische Zentralbank (2000b), S. 64. 
Tabelle 33: Andere Eurosystem-unabhängige Tätigkeiten der NZBen

\begin{tabular}{|c|c|c|c|c|c|c|}
\hline & BBk & BdF & BdP & BoF & CBI & DNB \\
\hline 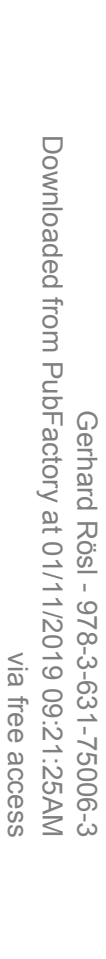 & 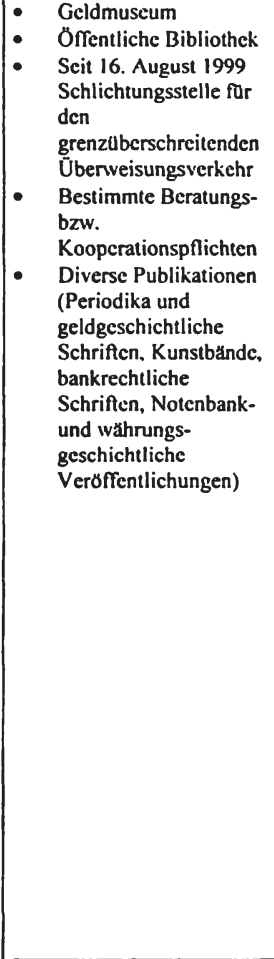 & $\begin{array}{l}\text { Auf Anweisung des } \\
\text { Staates } \\
\text { Dienstleistungen fur } \\
\text { den Staat oder fur } \\
\text { Dritte gegen volle } \\
\text { Vergütung (u.a. } \\
\text { Erstellung der } \\
\text { Zahlungsbilanz und } \\
\text { Bemessung der } \\
\text { Auslandsvermogenspos } \\
\text { ition des frz Staates) } \\
\text { Firmenanalyse und } \\
\text { Rating } \\
\text { Vervaltung der Central } \\
\text { Cheque Database und } \\
\text { der National Database } \\
\text { on Irregular Cheques } \\
\text { (FNCl) } \\
\text { Management des } \\
\text { Sekretariats der } \\
\text { Houschold Debt } \\
\text { Commissions inkl. } \\
\text { Führung des National } \\
\text { Register of Houschold } \\
\text { Credit Repayment } \\
\text { Incidents (FlCP) } \\
\text { Mitarbeit bei der Stock } \\
\text { Exchange Commission } \\
\text { (COB) } \\
\text { Management einer } \\
\text { Bilanzzentrale } \\
\text { Bestimmte Beratungs- } \\
\text { bziv. } \\
\text { Kooperationspflichten } \\
\text { Diverse Publikationen } \\
\text { (Pcriodika, } \\
\text { Monographien u.a.) }\end{array}$ & $\begin{array}{ll}- & \text { (Geld-) Museum } \\
\text { - } & \text { Öfentliche Bibliothek } \\
\text { - } & \text { Kunst-Kollektion } \\
\text { Wiedialfonds fur } \\
\text { Wiederaufbau von } \\
\text { Chiado } \\
\text { „Centralisation of } \\
\text { Credit Risks, Protected } \\
\text { Bills und Cheque } \\
\text { Defaulters“ } \\
\text { Management einer } \\
\text { Bilanzzentrale } \\
\text { Statistiken fur } \\
\text { EUROSTAT } \\
\text { Bestimmte Beratungs- } \\
\text { bzw. Kooperations- } \\
\text { pflichten } \\
\text { Diverse Publikationen } \\
\text { (Periodika. } \\
\text { Monographien u.a.) }\end{array}$ & $\begin{array}{l}\text { - Öffentliche Bibliothek } \\
\text { Institute for Economies } \\
\text { in Transition } \\
\text { Bestimmte Beratungs- } \\
\text { bzw. Kooperations- } \\
\text { pflichten } \\
\text { Diverse Publikationen } \\
\text { (Periodika, } \\
\text { Monographien u.a.) }\end{array}$ & $\begin{array}{l}\text { Beratung und Assistenz } \\
\text { fur Central Statistic } \\
\text { Office } \\
\text { Aufsicht aber Bureau } \\
\text { de Change } \\
\text { Aufsichts- und } \\
\text { Entscheidungs- } \\
\text { kompetenz. bezüglich } \\
\text { der Investor } \\
\text { Compensation } \\
\text { Company Limited } \\
\text { Bestimmte Beratungs- } \\
\text { bziv. Kooperations- } \\
\text { pflichten } \\
\text { Diverse Publikationen } \\
\text { (Periodika. } \\
\text { Monographien u.a.) }\end{array}$ & \begin{tabular}{|l} 
- Informationen für die \\
Offentlichkeit zur \\
Ërleichterung von \\
Investitions- \\
entscheidungen \\
(„Consumer affairs“) \\
Credit Registration \\
Bureau \\
Bestimmte Beratungs- \\
bzw. \\
Kooperationspflichten \\
Divcrse Publikationen \\
(Periodika, \\
Monographien u.a.)
\end{tabular} \\
\hline
\end{tabular}


Noch Tabelle 33: Andere Eurosystem-unabhängige Tätigkeiten der NZBen

\begin{tabular}{|c|c|c|c|c|}
\hline NBB & OeNB & BdI & BdE & BCL \\
\hline $\begin{array}{l}\text { Geldmuseum } \\
\text { Pflicht zur Konversion von } \\
\text { Auslandsverschuldung des } \\
\text { Staates in Euro } \\
\text { Zusammenarbeit mit dem } \\
\text { National Account Institute } \\
\text { (NAI) bzgl. Außenhandels- } \\
\text { und Zahlungsbilanzstatistik } \\
\text { für EUROSTAT } \\
\text { Seit 1999 Übernahme der } \\
\text { Aktivităten des Rediscount } \\
\text { und Guarantee Institute } \\
\text { (RGI) } \\
\text { Management des, ,Securities } \\
\text { Regulation Fund“ zur } \\
\text { Liquiditätsgarantie von } \\
\text { Staatsanleihen } \\
\text { Management einer } \\
\text { Bilanzzentrale } \\
\text { Management einer Zentrale } \\
\text { für Privatkredite } \\
\text { Management einer Zentrale } \\
\text { für Unternehmenskredite } \\
\text { Bestimmte Beratungs- bzw. } \\
\text { Kooperationspflichten } \\
\text { Diverse Publikationen } \\
\text { (Periodika, Monographien } \\
\text { u.a.) }\end{array}$ & $\begin{array}{ll}\text { - } & \text { Geldmuseum } \\
\text { Sammlung von } \\
\text { Streichinstrumenten } \\
\text { alter Meister: 24,5 Mio. } \\
\text { EUR } \\
\text { OeNB-Fonds zur } \\
\text { Förderung der } \\
\text { Forschungs- und } \\
\text { Lehraufgaben der } \\
\text { Wissenschaft: 7,3 Mio. } \\
\text { EUR (Auszahlungen in } \\
\text { 1999: 47, 3 Tsd. EUR) } \\
\text { Unterstützung des, ,Joint } \\
\text { Vienna Institute“ und } \\
\text { des, ,Austrian Bankers“ } \\
\text { College International“ } \\
\text { Bestimmte Beratungs- } \\
\text { bzw. } \\
\text { Kooperationspflichten } \\
\text { Diverse Publikationen } \\
\text { (Periodika, } \\
\text { Monographien u.a.) }\end{array}$ & $\begin{array}{l}\text { In den Ausweisen des } \\
\text { Jahres } 1999 \text { nicht explizit } \\
\text { erwähnt, aber vermutlich } \\
\text { auch weiterhin finanzielle } \\
\text { Beteiligung an } \\
\text { Wohltätigkeitsveranstaltun } \\
\text { gen und andere Arbeiten } \\
\text { des öffentlichen } \\
\text { Interesses, sowie } \\
\text { Förderung sozialer und } \\
\text { kultureller Aktivitäten (in } \\
\text { 1998: 2,1 Mio. EUR) } \\
\text { Bestimmte Beratungs- } \\
\text { bzw. } \\
\text { Kooperationspflichten } \\
\text { Diverse Publikationen } \\
\text { (Periodika, Monographien } \\
\text { u.a.) }\end{array}$ & $\begin{array}{l}\text { - Öffentliche Bibliothek } \\
\text { - } \\
\text { - } \text { Kunstorisches Archiv } \\
\text { BdE zahlt in Beneficent- } \\
\text { Social Fund: 1999: 8,1 } \\
\text { Mio. EUR } \\
\text { - Complaint Service für } \\
\text { Geschäftsbankenkunden } \\
\text { Bestimmte Beratungs- } \\
\text { bzw. } \\
\text { Kooperationspflichten } \\
\text { Diverse Publikationen } \\
\text { (Periodika. Monographien } \\
\text { u.a.) }\end{array}$ & $\begin{array}{l}\text { Erstellung der } \\
\text { Zahlungsbilanzstatistik } \\
\text { Bestimmte Beratungs- } \\
\text { bzw. } \\
\text { Kooperationspflichten } \\
\text { Diverse Publikationen } \\
\text { (Periodika, Monographien } \\
\text { u.a.) }\end{array}$ \\
\hline
\end{tabular}

Quelle: Eigene Darstellung. Die der Übersicht zugrundeliegenden Angaben stammen aus den Jahresberichten der NZBen furr 1999, den nationalen Zentralbankgesetzen bzw. Satzungen der NZBen, sowie den einschlägigen Internet-Seiten der NZBen. Ein Anspruch auf Vollstăndigkeit kann wegen der unterschiedlichen Informationsdichte nicht erhoben werden. 


\section{V.2.3. Zwischenergebnis}

Ziel der vorstehenden Analyse war es, die verschiedenen Tätigkeiten der NZBen zu systematisieren und deren Konsequenzen für die NZB-Gewinnentstehung aufzuzeigen. Dabei wurde klar, daß die NZBen einer Reihe von Tätigkeiten nachgehen, die sie aufgrund von Weisungen der EZB zu leisten haben („Eurosystem-spezifische“ Tätigkeiten). Hierzu ist insbesondere die Abwicklung der gemeinsamen Geldpolitik zu zählen, aber auch weitere Aktivitäten, die der Sicherung der Funktionsfähigkeit derselben dienen. Die NZBen können aber auch nach dem Übergang zur einheitlichen Währung eine Vielzahl anderer "Eurosystem-unabhängiger" Tätigkeiten ausüben, bei denen die EZB kein Dispositionsrecht besitzt, solange die Aufgaben und Ziele des Eurosystems nicht gefährdet sind. Auch wenn wegen der schwierigen Datenlage eine empirische Quantifizierung dieser Aktivitäten nicht immer gelingen kann, so wird doch deutlich, daß der Umfang derselben keinesfalls zu vernachlässigen ist. Aus politökonomischer Sicht ist diese Beobachtung freilich nicht überraschend. So waren ja die sich selbst entmachtenden Notenbänker direkt mit der Ausgestaltung der ESZB-Satzung betraut. Letztlich kann die ESZB-Satzung als das Ergebnis eines Verhandlungsprozesses interpretiert werden, die die Sicherung der Funktionsfähigkeit der gemeinsamen Geldpolitik mit anderen traditionellen Aufgaben der NZBen zu verbinden versucht. Die Dominanz der Geldpolitik steht hierbei jedoch nicht in Zweifel. 


\section{V.3. Die Verwendung der NZB-Gewinne}

Bevor die NZBen entsprechend ihrer nationalen Gesetzgebung über ihre Jahresüberschüsse verfügen können, sieht die ESZB-Satzung eine Umverteilung von Notenbankeinkünften zwischen den NZBen des Eurosystems vor. Dieses Umverteilungsverfahren soll im Folgenden ausführlich untersucht und kritisch gewürdigt werden. Der anschließende Abschnitt beschäftigt sich mit der „nationalen“ Verwendung der NZB-Gewinne.

\section{V.3.1. Die (Um-)Verteilung der Monetären Einkünfte}

Nach Artikel 32.1. ESZB-Satzung sind die Einkünfte, die den NZBen aus der Erfüllung der währungspolitischen Aufgaben des Eurosystems zufließen („Monetäre Einkünfte"), am Ende eines jeden Geschäftsjahres nach dem in Artikel 32 ESZB-Satzung geregelten Verfahren zu verteilen ${ }^{347}$. Hierbei sehen die vertraglichen Regelungen bezüglich der Ermittlung der Monetären Einkünfte zwei unterschiedliche Erfassungsmethoden vor. So kann nach Artikel 32.3. ESZB-Satzung in einem Zeitraum von maximal fünf Jahren nach Gründung der EWU ein Übergangsverfahren zur Anwendung kommen. Spätestens dann hat die Bemessung der Monetären Einkünfte nach dem sog. „EarmarkingVerfahren $^{6348}$ des Artikels 32.2. ESZB-Satzung zu erfolgen. Die Verteilung der Monetären Einkünfte ist hingegen unabhängig von der gewählten Erfassungsmethode geregelt. Sie erfolgt nach Maßgabe der von den NZBen eingezahlten EZB-Kapitalanteile in Form einer Ausschüttung an die nationalen Zentralbanken des Eurosystems, es sei denn der EZB-Rat hat nach einem entsprechenden Beschluß die Verwendung des Pools der Monetären Einkünfte zur Deckung anfallender EZB-Verluste vorgesehen (Art. 32.5. ESZB-Satzung) ${ }^{349}$. Die technische Abwicklung, also die Verrechnung und den Ausgleich der Salden aus der Verteilung der Monetären Einkünfte, übernimmt die EZB gemäß den Leitlinien des EZB-Rates (Art. 32.6. ESZB-Satzung).

347 Die nicht an der dritten Stufe der EWU teilnehmenden NZBen (Pre-In-NZBen) nehmen an diesem Verfahren nicht teil. Vgl. Art. 43.1. ESZB-Satzung.

348 In begrifflicher Anlehnung an Remsperger (1996), S. 1.

349 Vgl. auch die Ausführungen zur Finanzierung des EZB-Verlusts in Kapitel IV.2.. 


\section{V.3.1.1. Die Indirekte Methode in der Übergangsphase (1999 bis 2001)}

\section{Die vertraglichen Regelungen}

Das bis maximal Ende 2003 anwendbare Übergangsverfahren zur Ermittlung der Monetären Einkünfte ist in Artikel 32.3. ESZB-Satzung nicht näher ausgeführt und überläßt die konkrete Ausgestaltung desselben dem EZB-Rat. Hierbei muß jedoch eine entsprechende Beschlußfassung mit qualifizierter Mehrheit der abgegebenen Stimmen erfolgen, wobei die Stimmen der EZBDirektoriumsmitglieder unberücksichtigt bleiben und die Stimmen der NZBVertreter mit dem jeweiligen EZB-Kapitalanteil gewogen werden (Art. 10.3. ESZB-Satzung).

\section{Die Indirekte Methode nach dem Beschluß des EZB-Rats vom 3. November 1998}

In der Tat ist der EZB-Rat zu der Auffassung gekommen, daß die Bilanzstrukturen der NZBen die Anwendung des Earmarking-Verfahrens nicht bereits zu Beginn der EWU gestatten ${ }^{350}$. Deshalb erfolgte vom 1.1.1999 bis zum 31.12.2001 die Ermittlung der Monetären Einkünfte nach der sog. „Indirekte

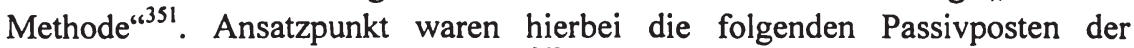
standardisiert erfaßten NZB-Bilanzen ${ }^{352}$ :

\begin{tabular}{|l|}
\hline NZB-Passivposten \\
Verbindlichkeiten in Euro gegenüber dem \\
Finanzsektor im Euro-Währungsgebiet \\
2.1 Einlagen auf Girokonten (inkl. Mindestreserveguthaben) \\
2.2 Einlagefazilität \\
2.3 Termineinlagen \\
2.4 Feinsteuerungsoperationen in Form \\
von befristeten Transaktionen \\
2.5 Verbindlichkeiten aus Margenausgleich \\
9.2 Verbindlichkeiten aus Schuldverschreibungen zur \\
Deckung der Emission von EZB-Schuldverschreibungen
\end{tabular}

350 Vgl. Europäische Gemeinschaft (2000e), S. 119 ff..

351 Zum Begriff der Indirekten Methode vgl. Europäisches Währungsinstitut (1997), S. 83.

352 Vgl. die Tabellen 9 und 11. Die EZB hat mittlerweile ihre Bilanzierungsleitlinie geändert. Der Punkt „Verbindlichkeiten der NZBen aus Schuldverschreibungen zur Deckung der Emission von EZB-Schuldverschreibungen" hat nun die neue Numerierung 10.2.. Vgl. Europäische Gemeinschaft (2000d), S. 119 ff. und die Tabelle 35 in Kapitel V.3.1.2. Abschnitt 2.1., die die ,alte" bis Ende 2000 gültige harmonisierte NZB-Bilanzstruktur der gegenwärtig gültigen ,neuen“ Bilanzstruktur gegenüberstellt. 
Dabei wird zunächst mit dem aktuellen Satz für Hauptrefinanzierungsgeschäfte ein einheitlicher Referenzzinssatz auf die definierten NZB-Passivpositionen angewendet. Zieht man hiervon die Zinsaufwendungen, die die NZB auf die Verbindlichkeiten der Bemessungsgrundlage gezahlt hat, ab, erhält man die Monetären Einkünfte der jeweiligen $\mathrm{NZB}^{353}$. Diese auf täglicher Basis ermittelten Beträge werden gepoolt und nach Abschluß des Geschäftsjahres auf die NZBen in Abhängigkeit des gezahlten EZB-Kapitalschlüssels verteilt.

\section{Umverteilungseffekte bei Anwendung der Indirekten Methode}

Die Höhe der Monetären Einkünfte und damit auch das Umverteilungspotential aus dem Notenbankgewinnpooling ist in der Übergangsphase sehr begrenzt. Dies liegt einerseits daran, daß die Mindestreserveeinlagen bei allen NZBen einen überragend großen Teil ihrer Bemessungsgrundlage ausmachen und andererseits sich die beim Pooling abzugsfähige Verzinsung der Mindestreserve wie auch der Referenzzinssatz zur Ermittlung der Monetären Brutto-Einkünfte jeweils am Satz für Hauptrefinanzierungsgeschäfte orientiert und so die effektive umverteilungsrelevante Bemessungsgrundlage um die Mindestreserveeinlagen reduziert. Einen positiven Poolfinanzierungsbeitrag leisten die NZBen folglich nur auf Basis derjenigen Bilanzposten, bei denen es positive Zinsdifferenzen zwischen dem Hauptrefinanzierungssatz und den von den NZBen gezahlten Zinssätzen gibt. Dies ist bei den unverzinslichen Überschußreserven bzw. bei der relativ niedrig verzinslichen Einlagefazilität gegeben. Im Falle der im Rahmen von Feinsteuerungsoperationen durchgeführten Reverse Repos bzw. der Hereinnahme von Termineinlagen oder der Emission von EZB-Schuldverschreibungen über die NZBen kommt es hingegen zu negativen Zinsdifferenzen, da den Kreditinstituten mit einer Verzinsung über dem Marktzins und damit über dem Satz für Hauptrefinanzierungsgeschäfte ein Anreiz gegeben werden muß, ihre liquiden Mittel bei der heimischen Zentralbank stillzulegen. Dies könnte bedeuten, daß eine NZB unter Umständen an einzelnen Geschäftstagen sogar einen negativen Beitrag zum Pool der Monetären Einkünfte leistet. Problematisch ist dies indes nicht. So wäre es theoretisch sogar vorstellbar, daß alle NZBen ständig negative Monetäre Einkünfte erzielen. Ein Pooling der negativen Monetären Einkünfte käme dann einer Umverteilung von NZBVerlusten gleich.

${ }^{353}$ Vgl. Europäische Zentralbank (2000h), S. 163. Des weiteren sieht Art. 32.4. ESZBSatzung vor, daß die NZBen für Kosten, die in Verbindung mit der Ausgabe von Banknoten stehen, einen Ausgleich erhalten können bzw. unter außergewöhnlichen Umständen für ESZB-spezifische Verluste entschädigt werden können. Von diesen Regelungen hat der EZB-Rat in der Übergangsphase keinen Gebrauch gemacht. 
Tabelle 34: Die Umverteilung der Monetären Einkünfte im Jahr 1999 in Mio. Euro.

\begin{tabular}{|c|c|c|c|c|c|c|}
\hline EWU-NZB & BBk & BdI & BdF & BdE & DNB & NBB \\
\hline $\begin{array}{l}\text { Nettoergebnis aus Monetären } \\
\text { Einkünften }\end{array}$ & -3 & 4,3 & $-1,6$ & 2,1 & 1 & 0,2 \\
\hline Finanzierungsleistung für $\mathrm{Pool}^{\prime}$ & 14 & 2,3 & 9,1 & 1,8 & 3 & 1,1 \\
\hline Partizipation am $\mathrm{Pool}^{2}$ & 11 & 6,6 & 7,5 & 3,9 & 2 & 1,3 \\
\hline EWU-NZB & OeNB & BdP & CBI & BoF & BCL & Gesamt $^{3}$ \\
\hline $\begin{array}{l}\text { Nettoergebnis aus Monetären } \\
\text { Einkünften }\end{array}$ & $-0,2$ & $-0,1$ & $-1,0$ & $\mathbf{0}$ & $-0,9$ & $0,2(0,0)$ \\
\hline Finanzierungsleistung für $\mathrm{Pool}^{\prime}$ & 1,2 & 1,0 & 0,6 & 1 & 0,9 & $36,0(35,2)$ \\
\hline Partizipation am $\mathrm{Pool}^{2}$ & 1,1 & 0,9 & 0,4 & 1 & 0,1 & $35,8(35,2)$ \\
\hline
\end{tabular}

Quelle: Eigene Berechnungen. Die der Darstellung zugrunde liegenden Daten sind den Jahresberichten der NZBen und der EZB für das Jahr 1999 entnommen.

${ }^{1}$ Direkte NZB-Angaben bzgl. der Finanzierungsleistung zum Pool der Monetären Einkünfte aus Deutsche Bundesbank (2000a), S. 194, Banca d'Italia (2000a), S. 284, Banque de France (2000c), S. 263, Banco de España (2000), S. 131 und Belgische Nationalbank (2000b), S. 94. Die Werte für die anderen NZBen wurden mit Hilfe der errechenbaren NZB-Poolpartizipation und den NZB-Angaben bezüglich ihrer Beteiligung an der EZB-Verlustfinanzierung des Jahres 1999 bestimmt. Hierbei sind allerdings wegen der schwierigen Datenlage detailliertere als auf eine Nachkommastelle gerundete Millionenbeträge nicht möglich. Vgl. hierzu die Erläuterungen zur Harmonisierung der GuVen der EZB und NZBen im Anhang sowie die NZB-Beiträge zur EZB-Verlustfinanzierung in Tabelle 8.

2 Direkte NZB-Angaben bzgl. der Poolpartizipation aus Deutsche Bundesbank (2000a), S. 194, Banca d'Italia (2000a), S. 284, Banque de France (2000c), S. 263, Banco de España (2000), S. 131 und Belgische Nationalbank (2000b), S. 94. Die Werte für die anderen NZBen wurden mit Hilfe der gezahlten EWU-NZB-Kapitalanteile (vgl. Tabelle 8) und dem von der EZB ausgewiesenen Gesamtbetrag der Monetären Einkünfte in Höhe von 35160676 EUR (vgl. Europäische Zentralbank (2000h), S. 163) errechnet. Vergleicht man zur Überprüfung der Berechnungen die für alle NZBen errechneten Angaben mit den verfügbaren, explizit ausgewiesenen NZB-Werten, so sind im Falle der $\mathrm{Bdl}$ und der $\mathrm{BdE}$ geringfügige Abweichungen festzustellen. Der Grund hierfür muß offen bleiben, da einerseits die Höhe der von der EZB publizierten Gesamtsumme der Monetären Einkünfte auf den EUR genau veröffentlicht ist und andererseits ein Vergleich der errechneten (gezahlten) EWU-NZBKapitalanteile mit den diesbezüglich explizit verfügbaren NZB-Angaben eine Übereinstimmung auf die vierte Nachkommastelle genau zeigt. Vgl. De Nederlandsche Bank (2000b), S. 195. In dieser Zusammenstellung der NZB-Poolpartizipation wird - soweit verfügbar - auf die vorhandenen NZB-Angaben zuruckgegriffen.

${ }^{3}$ In dieser Darstellung entsprechen sowohl die kumulierten NZB-Finanzierungsleistungen als auch die Summe der rückverteilten Poolbeträge nicht exakt der von der EZB ausgewiesenen Poolmasse in Höhe von 35,2 Mio. EUR (vgl. Europäische Zentralbank (2000h), S. 163), da einerseits die deutsche, niederländische und finnische NZB ihre Angaben nur auf Mio. EUR gerundet ausweisen und andererseits auch bei den restlichen NZBen Ungenauigkeiten durch die vorgenommenen Rundungen entstehen. Die tatsächlichen kumulierten Brutto- bzw. Nettobeträge sind deshalb in Klammern aufgeführt, um keinen Zweifel an der Existenz eines Nullsummenspiels zwischen den NZBen aufkommen zu lassen. 
Bezüglich der Frage, in welchem konkreten Ausmaß das Pooling der Monetären Einkünfte zu Umverteilungen zwischen den NZBen führt, muß sich die Analyse auf das Jahr 1999 beschränken, da das Eurosystem die Nettogewinner- bzw. Nettoverliererpositionen der einzelnen NZBen alles andere als transparent aufbereitet. So verbleibt nur der Weg über die Gewinn- und Verlustrechnungen der NZBen, deren Angaben nach einigen Berechnungen folgendes Bild gestatten $^{354}$.

Mit Abstand größter Gewinner war in 1999 die Banca d'Italia mit 4,3 Mio. EUR, gefolgt von der Banco de España mit 2,1 Mio. EUR und der De Nederlandsche Bank mit rund 1 Mio. EUR. Auch die Zentralbank Belgiens profitierte mit 0,2 Mio. EUR geringfügig am Pooling der Monetären Einkünfte des Jahres 1999. Finanziert wurden diese Positionen vor allem von der Deutschen Bundesbank mit rund 3 Mio. EUR und der Banque de France mit 1,6 Mio. EUR. Aber auch die irische (1,0 Mio. EUR), luxemburgische (0,9 Mio. EUR), österreichische (0,2 Mio. EUR) und portugiesische NZB (0,1 Mio. EUR) waren im ersten Jahr der EWU Nettozahler im System der Monetären Einkünfte. Im Falle der Bank of Finland ist diesbezüglich keine Aussage möglich, da nicht klar ist, ob die von der BoF veröffentlichten Nettoangaben von null Mio. EUR auf- oder abgerundet sind ${ }^{355}$.

Wie lassen sich die obigen Nettopositionen der NZBen nun erklären? Trivial ist die Feststellung, daß eine NZB immer dann Nettogewinnerin bzw. -verliererin ist, wenn ihr Anteil an der Finanzierung des Pools der Monetären Einkünfte geringer bzw. höher ist als ihr Anteil am gezahlten EZB-Kapital. Dabei wird bei den "Gewinner-NZBen“ die Höhe ihrer Poolzahlungen entweder durch eine relativ niedrige Haltung von Überschußreserven bzw. eine geringe Inanspruchnahme der Einlagefazilität und/oder durch eine relativ intensive Abwicklung von Termineinlagen, Reverse Repos und emittierten EZBSchuldverschreibungen bestimmt. Da jedoch - abgesehen von der Rückzahlung der Termineinlagen, die die Banque de France bereits mit in die EWU hinein brachte $^{356}$ - die NZBen im ersten Jahr der EWU keine Transaktionen mit Termineinlagen durchgeführt und auch von Feinsteuerungsmaßnahmen in Form von Reverse Repos und der Emission von EZB-Schuldverschreibungen abgesehen haben, muß die Position der „Gewinner-NZBen“ Italiens, Spaniens,

354 Vgl. Tabelle 34. Zur Herleitung der Ergebnisse vgl. die Fußnoten in Tabelle 34.

$355 \mathrm{Vgl}$. Bank of Finland (2000b), S. 84. Zudem ist eine Berechnung der genauen BoFNettoposition über die verbleibende Differenz aus der Gesamthöhe der Monetären Einkünfte und den kumulierten Nettopositionen der anderen NZBen wegen den von den NZBen in ihren GuVen ausgewiesenen Rundungsfehlern nicht möglich. Weiterhin stellt die BoF diese Information auch nicht auf Anfrage zur Verfügung.

356 Der Umfang dieser Termineinlagen belief sich auf 1885,8 Mio. EUR. Vgl. Tabelle 9. 
der Niederlande und Belgiens in einer relativ niedrigen Haltung von Überschußreserven und/oder einer relativ geringen Inanspruchnahme der Einlagefazilität durch die heimischen Kreditinstitute determiniert sein.

Obige Ausführungen zeigen, daß, solange das Indirekte Verfahren seine Anwendung findet, weder der Umfang des Pools der Monetären Einkünfte noch die Höhe der umverteilten Nettobeträge substantielle Größenordnungen erreichen. Deshalb konnte auch auf eine in Artikel 51 ESZB-Satzung zusätzlich vorgesehene optionale Poolkürzung verzichtet werden. Hierbei hat der EZB-Rat, wenn er nach dem Beginn der EWU feststellt, daß die Anwendung der vertraglichen Regelungen zum Pooling der Monetären Einkünfte für den relativen Stand der Einkünfte der NZBen wesentliche Änderungen zu Folge hat, für höchstens fünf Jahre nach Beginn der dritten Stufe der EWU die Möglichkeit, den Pool der Monetären Einkünfte nach einem einheitlichen Prozentsatz zu kürzen. Allerdings darf dieser Prozentsatz im ersten Jahr der EWU 60 Prozent nicht übersteigen und wäre in jedem darauffolgenden Jahr um mindestens 12 Prozentpunkte $\mathrm{zu}$ verringern $^{357}$.

\section{Kritische Würdigung der Indirekten Methode}

Als langfristige Vorgehensweise zur Ermittlung der Monetären Einkünfte ist die Indirekte Methode schon deshalb nicht geeignet, da dieses Verfahren den Banknotenumlauf aus der Bemessungsgrundlage ausnimmt und somit nur einen Bruchteil der NZB-Geldschöpfungsgewinne erfaßt ${ }^{358}$. Dies hat zur Folge, daß diejenigen Erträge, die die NZBen aus ihrer Banknotenemission erwirtschaften, keinem Umverteilungsproze $ß$ unterzogen werden und dadurch unvorhersehbare Umverteilungseffekte auftreten, die das Pooling der Monetären Einkünfte gerade verhindern will. Letzteres versucht die angefallenen Geldschöpfungsgewinne (grundsätzlich) ,gerecht“ auf die EWU-Bürger zu verteilen und zwar in Abhängigkeit davon, wie die EWU-Bürger diese Geldschöpfungsgewinne selbst finanziert haben ${ }^{359}$. Ohne vollständige Erfassung der Geldschöpfungsgewinne ist dies freilich nicht möglich, weshalb auch hier die Indirekte Methode nicht weiter analysiert werden soll.

357 Diese Regelung ist also höchstens bis Ende 2003 anwendbar. Vgl. Art. 52.2. ESZBSatzung. Die Terminierung auf den 1.1.2007 in Sinn/Feist (2000b), S. 17 ist unzutreffend.

358 Von der später noch ausführlich zu diskutierenden Problematik der faktischen Sozialisierung des Pre-EWU-Geldschöpfungsvermögens durch die Aufnahme der PreEWU-Banknotenumläufe in die Bemessungsgrundlage des Earmarking-Verfahrens sei an dieser Stelle abgesehen.

359 Vgl. auch die Ausführungen zur Rechtfertigung der Umverteilung von Geldschöpfungsgewinnen im Rahmen der Analyse des Earmarking-Verfahrens in Kapitel V.3.1.2. Abschnitt 3.1.. 


\section{V.3.1.2. Das Earmarking-Verfahren}

\section{Die vertraglichen Regelungen}

Nach der Übergangszeit sehen die vertraglichen Regelungen vor, daß die Ermittlung der Monetären Einkünfte nach dem in Artikel 32.2. ESZB-Satzung vorgesehenen Earmarking-Verfahren erfolgen soll. Hierbei entspricht der Betrag der Monetären Einkünfte jeder NZB ihren jährlichen Einkünften aus Vermögenswerten, die sie als Gegenposten zum Banknotenumlauf ${ }^{360}$ und $\mathrm{zu}$ ihren Verbindlichkeiten aus Einlagen der Kreditinstitute hält. Diese Vermögenswerte werden von den NZBen gemäß den vom EZB-Rat zu erlassenden Leitlinien $^{361}$ gesondert erfaßt. Von dem so ermittelten Betrag der Monetären Einkünfte einer jeden NZB sind nun die geleisteten Zinsaufwendungen aus der Verzinsung der Mindestreserveeinlagen der Kreditinstitute abzuziehen (Art. 32.4. Abs. 1 ESZB-Satzung). Des weiteren kann der EZB-Rat beschließen, daß die NZBen für Kosten in Verbindung mit der Ausgabe von Banknoten oder unter außergewöhnlichen Umständen für spezifische Verluste aus den von ihnen für das ESZB/Eurosystem unternommenen währungspolitischen Operationen entschädigt werden. In welcher Form dies geschieht, obliegt ebenfalls dem EZBRat. Eine Anrechnung auf die Monetären Einkünfte der betreffenden NZB ist hierbei möglich (Art. 34 Abs. 2 ESZB-Satzung). Die so ermittelten Finanzierungsbeiträge der NZBen werden gepoolt und in Abhängigkeit vom gezahlten EZB-Kapitalanteil auf die NZBen wieder verteilt (Art. 32.5. ESZB-Satzung). Die Verrechnung und den Ausgleich der Salden übernimmt erneut die EZB (Art. 32.6. ESZB-Satzung).

360 In der deutschen Fassung der ESZB-Satzung wird von „Bargeldumlauf“ gesprochen. Hierbei handelt es sich jedoch um einen Übersetzungsfehler des in englischer Sprache verhandelten ESZB-Protokolls, in der von „notes in circulation“ gesprochen wird. Vgl. European Community (1993). Ohnehin wird der nationale Münzumlauf nicht in den Bilanzen der NZBen erfaßt, da gemäß Artikel 106 Abs. 2 EGV das Recht zur Münzemission den Mitgliedstaaten zusteht. In den NZB-Ausweisen werden nur Sicherheitsbestände an Münzen (aktivisch) verbucht, die die NZBen von ihren Mitgliedstaaten gegen Einlagengewährung erworben haben. Vgl. Rösl/Schäfer (1998a), S. 7.

361 Auch hier ist die deutsche Übersetzung des Vertragstexts unpräzise, da sie hier von „Richtlinien“ spricht. Die EZB besitzt jedoch keine Kompetenz zum Erlaß von "Richtlinien“. Vielmehr erläßt sie „guidelines“, also Leitlinien, denen die NZBen nach Art. 14.3. ESZB-Satzung Folge zu leisten haben. Vgl. Art. 34 ESZB-Satzung, Art. 110 EGV und European Community (1993). Dieser begrifflichen Konfusion ausweichend spricht auch die EZB nur von „Leitlinien“. Vgl. z.B. Europäische Zentralbank (1999b), S. 78. 


\section{Das Earmarking-Verfahren nach dem Beschluß des EZB-Rats vom 6.Dezember 2001}

Bevor das seit dem 1.1.2002 gültige Earmarking-Verfahren im einzelnen vorgestellt wird, soll zunächst der Berichtsrahmen für diese Methode aufgezeigt werden. Daran anschließend gewährt die Analyse verschiedener anderer denkbarer Earmarking-Varianten konkrete Einsichten in bestimmte bisher in der wissenschaftlichen Diskussion noch nicht behandelte Problemstellungen, denen sich der EZB-Rat bei der Konstruktion der gültigen Earmarking-Methode gegenüber sah. Auf Basis dieser Untersuchung lassen sich Schlußfolgerungen ziehen, weshalb das seit Januar 2002 anzuwendende Earmarking-Verfahren vom EZB-Rat so und nicht anders konstruiert wurde.

\subsection{Der Berichtsrahmen für das Earmarking-Verfahren}

Es überrascht nicht, daß sich das Earmarking-Verfahren, wie auch die Indirekte Methode der Ermittlung der Monetären Einkünfte in der Übergangsphase, an dem Berichtsrahmen orientiert, der die Basis für den Konsolidierten Wochenausweis des Eurosystems bildet ${ }^{362}$. Allerdings hat der EZB-Rat die Leitlinie zur Erfassung der NZB-Bilanzen mittlerweile dreimal in geringem Umfang geändert. Dies hat zur Folge, daß auch die Bilanzstruktur, die die Grundlage für die bereits vorgestellte Disaggregation der Eurosystem-Bilanzen zum 1.1.1999 und 31.12.1999 bildete $^{363}$, wie folgt leicht angepaßt wurde. Die Änderungen betreffen die Ersetzung des Ausdrucks „Finanzsektor" durch „Kreditinstitute“ beim Aktivpostens 5 und Passivpostens 2, um die begriffliche Nähe zum Art. 32.2. ESZB-Satzung sicherzustellen ${ }^{364}$. Zudem wurde der bisherige Aktivposten „5.7 Sonstige Forderungen“ umbenannt in "Sonstige Forderungen in Euro an Kreditinstitute im Euro-Währungsgebiet" und ist als eigenständiger Aktivposten 6 auszuweisen. Der Grund hierfür liegt darin, daß der Aktivposten 5 ausschließlich geldpolitische Operationen des Eurosystems umfassen soll. Des weiteren wurde der Passivposten „Sonstige Verbindlichkeiten in Euro gegenüber Kreditinstituten im Euro-Währungsgebiet" als neue Passivposition 3 eingeführt. Diese soll die von den NZBen durchgeführten Geschäfte, die nicht mit den geldpolitischen Operationen mit Kreditinstituten in Verbindung stehen, separat widerspiegeln.

362 Vgl. Europäische Zentralbank (2001g), S. 1 ff..

$363 \mathrm{Vgl}$. Tabellen 9 und 11 in Kapitel V.1. sowie die Erläuterungen zu diesen Tabellen im Anhang.

364 Vgl. im Folgenden Europäische Zentralbank (2001i), S. 1 f.. 
Die restlichen Aktiv- und Passivposten bleiben inhaltlich unberührt. Aufgrund der neu eingefügten Bilanzpositionen ändert sich aber die Numerierung der jeweils nachfolgenden Posten. Deshalb kann für die weitere Analyse auch auf die disaggregierten Eurosystembilanzen der Tabellen 9 und 11 zurückgegriffen werden. Der „ausgelagerte" alte Aktivposten „5.7 Sonstige Forderungen“ und der neu einzufügende Passivposten „3 Sonstige Verbindlichkeiten in Euro gegenüber Kreditinstituten im Euro-Währungsgebiet", die jeweils auf Eurosystem-unabhängige Geschäfte der NZBen mit im Euroraum ansässigen Kreditinstituten abstellen, dürften zu keinen allzu großen Verzerrungen bei der Ermittlung der Monetären Einkünfte führen.

Die nachstehende Tabelle 35 stellt die bis Ende 2000 gültige NZBBilanzstruktur, die auch die Grundlage für die bereits vorgestellte Disaggregation der Eurosystembilanzen zum 1.1.1999 und 31.12.1999 bildet, der aktuellen Jahresausweis-Struktur gegenüber. Letztere bildet den Berichtsrahmen für die Ermittlung der Monetären Einkünfte. 
Tabelle 35: Gegenđberstellung der harmonisierten "alten" und "neuen" Bllanzastruktur des Eurosystems

Aktiva (alte Bilanzstruktur)

1 Gold und Goldforderungen

2 Forderungen in Fremdwährung an Anskssige auBerhalb des Euro-Wahrungsgebiets

21 Forderungen an den IWF

22 Guthaben bei Banken, Wertpapieranlagen, Auslandskredite und sonstige Auslandsaktıva

3 Forderungen in Fremdwăhrung an Ans\$sssige im Eura-Wurrungsgebiet

4 Forderungen in Euro an Ansassige auberhalb des Euro-Wahrungsgebiets

4.1 Guthaben bei Banken, Wertpapieranlagen und Kredite

4.2 Forderungen aus der Kreditfazilitat Im Rahmen des WKM II

5 Forderungen in Euro an den Finanzsektor im Euro-Wahrungsgebiet

51 Hauptrefinanzierungsgeschafte

52 Langerfristige Refinanzierungsgeschafte

53 Feinsteuerungsoperationen in Form von befrusteten Transaktionen

54 Strukturelle Operationen in Form von befristeten Transaktionen

55 Spitzenrefinanzierungsfazilitat

56 Forderungen aus Margenausgleıch

57 Sonsuge Forderungen

6 Wertpapiere in Euro von Ansłssigen

im Euro-Wwhrungsgebiet

7 Forderungen in Euro an offentliche Haushalte

8 Intra-Eurosystem-Forderungen

81 Beteiligungen an der EZB

82 Forderungen aus der Ubertragung von Wahrungsreserven an die EZB

83 Forderungen aus Schuldverschreibungen zur Deckung der Emıssion von EZB-

Schuldverschreibungen

84 Sonstige Intra-EurosystemForderungen (netto)

9 Schwebende Verrechnungen

10 Sonstige Aktiva

101 Scheidemanzen des Euro-Wahrungsgebiets

102 Sachanlagen und immaterielle Vermogensgegenstănde

103 Sonstiges Finanzanlagevermogen

104 Neubewertungsposten aus außerbılanziellen Geschanten

105 Aktive Rechnungsabgrenzungsposten

106 Sonstıges

II Jahresverlust

Bilanzsumme
Aktiva (neue Bilanzstruktur)

1 Gold und Goldforderungen

2 Forderungen in Fremdwhrung an Ansussige außerhalb des Euro-Wahrungsgebiets

2.I Forderungen an den IWF

22 Guthaben bei Banken, Wertpapieranlagen, Auslandskredite und sonstige Auslandsaktiva

3 Forderungen in Fremdwalhrung an Anslssige im Euro-Wunrungsgebiet

4 Forderungen In Euro an Ansăssige auBerhalb des Euro-Wuhrungsgebiets

4.1 Guthaben ber Banken, Wentpapieranlagen und Kredite

42 Forderungen aus der Kreditfazilitat im Rahmen des WKM II

5 Forderungen in Euro aus geldpol. Operationen an Kreditinstitute im Euro-Wuhrungsgebiet

51 Hauptrefinanzierungsgeschafte

52 Langerfristige Refinanzierungsgeschafte

53 Feinsteuenungsoperationen in Form von befristeten Transaktionen

54 Strukturelle Operationen in Form von befristeten Transaktionen

55 Spitzenrefinanzierungsfazslitat

56 Forderungen aus Margenausgleıch

6 Sonstige Forderungen in Euro gegen aber Kreditinstituten im Euro-Wahrungsgebiet

7 Wertpapiere in Euro von Anstussigen im Euro-Whhrungsgebiet

8 Forderungen in Euro an ofrentliche Haushalie

9 Intra-Eurosystem-Forderungen

91 Beterligungen an der EZB

92 Forderungen aus der Ubertragung von Wahrungsreserven an dic EZB

93 Forderungen aus Schuldverschreibungen zur Deckung der Emission von EZBSchuldverschreibungen

94 Sonstige Intra-EurosystemForderungen (netto)

10 Sehwebende Verrechnungen

11 Sonstige Aktiva

11 I Scheidemunzen des Euro-Wahrungsgebiets

112 Sachanlagen und immaterielle Vermogensgegenstande

113 Sonstıges Finanzanlagevermogen

11.4 Neubewertungsposten aus auBerbilanziellen Geschaften

II 5 Aktıve Rechnungsabgrenzungsposten

116 Sonstiges

12 Jahresverlust

Bilanzsumme 
Noch Tabelle 35: Gegenuberstellung der harmonisierten "alten" und "neuen" Bilanzstruktur des Eurosystems

\author{
Passiva (alte Bilanzstruktur) \\ 1 Banknotenumlauf \\ 2 Verbindlichkeiten in Euro gegenuber dem \\ Finanzsektor im Euro-Wăhrungsgebict \\ 2 I Einlagen auf Girokonten \\ 2.2 Einlagefazilităt \\ 23 Termineinlagen \\ 24 Feinsteuerungsoperationen in Form \\ von befristeten Transaktıonen \\ 25 Verbindlichketten aus Margenausgleich
}

3 Verbindlichkeiten aus der Begebung

von Schuldverschreibungen

4 Verbindlichkeiten in Furo gegenuber sonstigen Ansassigen im Euro-Wăhrungsgebiet

41 Einlagen von offentlichen Haushalten

42 Sonstıge Verbındlıchkeıten

5 Verbindlichkeiten in Euro gegenuber Ansăssigen auberhalb des Euro-Wahrungsgebiets

6 Verbindlichkeiten in Fremdwădhrung gegenaber Ansăssigen im Euro-Wahrungsgebiet

7 Verbindlichkeiten in Fremdwährung gegenuber Ansăssigen außerhalb des Euro-WHahrungsgebiets

7.1 Einlagen, Guthaben und sonstige Verbindlichkeiten

72 Verbındlıchkeıten aus der Kreditfazilitat Im Rahmen des WKM II

8 Ausgleichsposten fur vom IWF zugeteilte Sonderziehungsrechte

9 Intra-Eurosystem-Verbindlichkeiten

91 Verbindlichketten (gegenuber NZBen) aus ubertragenen Wathrungsreserven

92 Verbindlichkeiten aus Schuldverschresbungen zur Deckung der Emıssion von EZBSchuldverschreibungen

93 Sonstıge Intra-EurosystemVerbındiıchkeiten (netto)

10 Schwebende Verrechnungen

11 Sonstige Passiva

111 Neubewertungsposten aus außerbilanziellen Geschaften

II 2 Passive Rechnungsabgrenzungsposten

113 Sonstuges

\section{Ruckstellungen}

13 Ausgleichsposten aus Neubewertung

14 Kapital und RuckJagen

$$
14 \text { I Kapital }
$$

14.2 Rucklagen

\section{Jahresuberschuß}

Bilanzsumme

\author{
Passiva (neue Bilanzstruktur) \\ 1 Banknotenumlauf \\ 2 Verbindlichkeiten in Euro aus geldpolitischen \\ Operationen gegenUber Kreditinstituten \\ 21 Einlagen auf Girokonten \\ 2.2 Einlagefazilitat \\ 23 Termineınlagen \\ 24 Feinsteuerungsoperationen in Form \\ von befristeten Transaktionen \\ 2.5 Verbindlichkeiten aus Margenausgleich
}

3 Sonstige Verbindlichkeiten in Euro gegenuber Kreditinstituten im Euro-Wahrungsgeblet

4 Verbindlichkeiten aus der Begebung
von Schuldverschrcibungen

5 Verbindlichkeiten in Euro gegenuber sonstigen Ansăssigen im Euro-Wăhrungsgebiet

5.1 Einlagen von offentlichen Haushalten

52 Sonstige Verbındlıchkeiten

6 Verbindlichkeiten in Euro gegenuher Ansăssigen auBerhalb des Euro-Wahrungsgebiets

7 Verbindlichkeiten in Fremdwalhrung gegenüber Ansăssigen im Euro-Wăhrungsgebiet

8 Verbindlichkeiten in Fremdwahrung gegenuber Ansŭssigen auberhalb des Euro-Wahrungsgebiets

81 Einlagen, Guthaben und sonstıge Verbindlichkeiten

82 Verbindlichkeiten aus der Kreditfazılitat Im Rahmen des WKM II

9 Ausgleichsposten fur vom IWF zugeteilte Sonderziehungsrechte

10 Intra-Eurosystem-Verbindlichkeiten

101 Verbındlıchkeiten (gegenuber NZBen) aus ubertragenen Wahrungsreserven

102 Verbindlıchkeiten aus Schuldverschreıbungen zur Deckung der Emission von EZBSchuldverschreibungen

103 Sonstige Intra-EurosystemVerbindlıchkeiten (netto)

11 Schwebende Verrechnungen

12 Sonstige Passiva

12 I Neubewertungsposten aus außerbilanziellen Geschaften

122 Passive Rechnungsabgrenzungsposten

123 Sonstiges

13 Ruckstellungen

14 Ausgleichsposten aus Neubewertung

15 Kapital und Rucklagen

15.1 Kapital

152 Rucklagen

16 Jahresuberschuß

Bllanzsumme 


\subsection{Bestimmung der Bemessungsgrundlage zur Ermittlung der Monetären Einkünfte}

Die Bemessungsgrundlage zur Ermittlung der Monetären Einkünfte setzt sich ausschließlich aus folgenden Passivpositionen der aktuellen harmonisierten NZB-Bilanz (neuHB) zusammen ${ }^{365}$ :

1. Banknotenumlauf (Passivposition 1 der neuHB)

Allerdings gilt im Geschäftsjahr 2002 für jede NZB, daß der „Banknotenumlauf“

i) auch die von ihr ausgegebenen und die auf ihre nationale Währungseinheit lautenden Banknoten umfaßt und

ii) um den Wert der unverzinslichen Darlehen für vorzeitig abgegebene Euro-Banknoten, die noch nicht belastet wurden (Teil der Aktivaposition 6 der neuHB), vermindert wird.

Ab dem Geschäftsjahr 2003 umfaßt der „Banknotenumlauf“ für jede NZB ausschließlich auf Euro lautende Banknoten.

2. Verbindlichkeiten in Euro aus geldpolitischen Operationen gegenüber Kreditinstituten im Euro-Währungsgebiet (Passivposition 2 der neuHB).

3. Intra-Eurosystem-Verbindlichkeiten der NZBen aus der Emission von Schuldverschreibungen an die EZB zur Deckung der Emission von EZBSchuldverschreibungen (Passivposition 10.2. der neuHB).

4. Intra-Eurosystem-Nettoverbindlichkeiten aus TARGET-Transaktionen (Teil der Passivposition 10.3 der neuHB).

5. Intra-Eurosystem-Nettoverbindlichkeiten aus dem Banknotenumlauf einschließlich des noch zu erläuternden Ausgleichsbetrags ${ }^{366}$.

Der EZB-Rat hat die Punkte 3 bis 5 mit in die Bemessungsgrundlage aufgenommen, obwohl sie in Art. 32.2. ESZB-Satzung nicht direkt erwähnt werden. Dies ist jedoch nicht problematisch, da es hierdurch - wie an anderer Stelle noch gezeigt werden wird - zu keinen Netto- Umverteilungseffekten kommt.

$365 \mathrm{Vgl}$. Europäische Zentralbank (2001 g), S. 9.

366 Die Intra-Eurosystem-Salden aus dem Banknotenumlauf sind auf die bereits erlauterte spezielle Verbuchung des Euro-Banknotenumlaufs zurückzuführen. Vgl. hierzu die Ausführungen in Kapitel V.2.1. Abschnitt 3.2. Gegenwärtig besitzen die IntraEurosystem-Salden aus dem Banknotenumlauf wohl noch keine explizit definierte Bilanzposition. 


\subsection{Bestimmung der ,gesondert erfaßbaren Vermögenswerte“}

Bezüglich der „Vermögenswerte“ die als bilanzielle Gegenposten der jeweiligen NZB-Bemessungsgrundlage zugeordnet werden, äußert sich die ESZB-Satzung nicht konkret und überläßt diese Entscheidung dem EZB-Rat (Art. 32.7. ESZBSatzung). Folgende Positionen der aktuellen NZB-Bilanzaufstellung (neuHB) werden für das Earmarking einbezogen ${ }^{367}$ :

1. Forderungen in Euro aus geldpolitischen Operationen an Kreditinstitute im Euro-Währungsgebiet (Aktivaposition 5 der neuHB),

2. Intra-Eurosystem-Forderungen aus der Übertragung von Währungsreserven außer Gold an die EZB gemäß Artikel 30 ESZB-Satzung (Teil der Aktivaposition 9.2 der neuHB),

3. Intra-Eurosystem-Nettoforderungen aus TARGET-Transaktionen (Teil der Aktivaposition 9.4 der neuHB),

4. Intra-Eurosystem-Nettoforderungen aus dem Euro-Banknotenumlauf, einschließlich bestimmter (noch $\mathrm{zu}$ erläuternder) aktivisch verbuchter Ausgleichsbeträge,

5. Gold einschließlich der Forderungen im Hinblick auf an die EZB übertragenes Gold in einer Höhe, die einer jeden NZB die gesonderte Erfassung eines Teils ihres Goldes entsprechend der Anwendung ihres Anteils am Kapitalzeichnungsschlüssel auf den Gesamtbetrag des von allen NZBen gesondert erfaßten Goldes ermöglicht (Aktivaposition 1 und Teil der Aktivposition 9.2 der neuHB).

Diese Aufstellung zeigt, daß die NZBen keinen Gestaltungsspielraum bezüglich des Wertansatzes ihrer Earmarking-Aktiva besitzen. So handelt es sich mit der Ausnahme des gegebenenfalls anzurechnenden Goldes rein um Nominalwertforderungen ohne Kursschwankungen ${ }^{368}$. Auch die Höhe der Verzinsung dieser Forderungen wird allein vom EZB-Rat bestimmt und richtet sich überwiegend nach dem aktuellen Satz für Hauptrefinanzierungsgeschäfte ${ }^{369}$. Bleibt noch zu

367 Vgl. Europäische Zentralbank (2001g), S. 11. Vgl. hierzu die „neue“ Bilanzaufstellung in Tabelle 35.

368 Der EZB-Rat hat für die Berechnung der Monetären Einkünfte beschlossen, im Hinblick auf die Bilanzierung von Earmarking-fähigem Gold bis 2007 den Goldpreis in Euro pro Feinunze zum 31.12.2002 heranzuziehen. Vgl. Europäische Zentralbank (2001g), S. 11.

Zur Höhe der Verzinsung der Forderungen aus der Abwicklung der gemeinsamen Geldpolitik (Punkt 1) sowie der Verzinsung der bilateralen TARGET-Salden (Punkt 3) vgl. die Ausführungen zu Kapitel V.2.1. Abschnitt 2.. Zur Vergütung der IntraEurosystem-Nettoforderungen aus dem Banknotenumlauf (Punkt 4) vgl. Kapitel V.2.1. Abschnitt 3.2. und zur Vergütung der NZB-Forderungen aus übertragenen 
erwähnen, daß ein Earmarking der unverzinslichen bzw. als unverzinslich definierten Goldforderungen nur jeweils in Abhängigkeit des jeweiligen EZBKapitalanteils möglich ist. Hierzu wird auf Basis der ausgewiesenen NZBGoldreserven (inkl. Forderungen der NZBen aus den Goldübertragungen an die EZB) der maximale umverteilungsneutrale Goldbestand errechnet und anhand der EZB-Kapitalanteile auf die NZBen verteilt. NZBen, die zusätzlich zu ihrem Earmarking-fähigen Bestand an Gold noch über weitere Goldreserven verfügen, dürfen diese Volumina nicht zum Earmarking heranziehen. Die Höhe und Verteilung des Goldes innerhalb des Eurosystem hat also unmittelbaren Einfluß auf die Bestimmung des kumulierten Earmarking-fähigen Goldbestands aller NZBen und damit auf die absolute Höhe der Monetären Einkünfte. Wie an anderer Stelle jedoch noch gezeigt werden wird, bleiben aber hiervon sowohl die relativen als auch die absoluten Netto-Poolingpositionen der NZBen unberührt $^{370}$.

\subsection{Die Berechnung der Ausgleichsbeträge}

Die besonders in Deutschland intensiv geführte Diskussion des EarmarkingVerfahrens offenbarte erhebliche Umverteilungen der Geldschöpfungsgewinne zwischen den NZBen des Eurosystems ${ }^{371}$. Nicht zuletzt deshalb ist auch im EZB-Rat die Bereitschaft gestiegen, die „möglicherweise eintretenden wesentlichen Änderungen für den Stand der Einkünfte der NZBen auszugleichen “372. Deswegen wird für den Zeitraum von 2002 bis einschließlich 2007 ein Ausgleichsbetrag errechnet, der die prognostizierte substantielle Umverteilung der Notenbankeinkünfte abfedern soll. Der Ausgleichsbetrag bemißt sich nach folgender Formel:

$A B=(S-W) \times K$, mit:

AB der Ausgleichsbetrag,

$S$ der Betrag für eine jede NZB, der sich aus der Anwendung des Kapitalzeichnungsschlüssels auf den durchschnittlichen Wert des Banknotenumlaufs während des Zeitraums vom 1. Juli 1999 bis zum 30. Juni 2001 ergibt,

Währungsreserven an die EZB vgl. Kapitel IV.1. Abschnitt 1.3.. Gold wird in jedem Falle als unverzinst definiert, also auch bei verzinslichen Goldleihgeschäften.

$370 \mathrm{Vgl}$. hierzu die Ausfuhrungen zum Earmarking von Gold in Kapitel V.3.1.2. Abschnitt 3.2.2.1. sowie die Tabelle A5 im Anhang.

$371 \mathrm{Zu}$ dieser Diskussion vgl. Kapitel V.3.1.2. Abschnitt 3.2..

372 Europäische Zentralbank (2001g), S. 3. 
W der durchschnittliche Wert des Banknotenumlaufs für eine jede NZB während des Zeitraums vom 1. Juli 1999 bis zum 30. Juni 2001,

K der nachfolgende Koeffizient für jedes Geschäftsjahr.

\begin{tabular}{|c|c|}
\hline Geschäftsjahr & Koeffizient \\
\hline 2002 & 1 \\
\hline 2003 & 0,8606735 \\
\hline 2004 & 0,7013472 \\
\hline 2005 & 0,5334835 \\
\hline 2006 & 0,3598237 \\
\hline 2007 & 0,1817225 \\
\hline
\end{tabular}

Dies führt bei einem durchschnittlichen Wert des kumulierten Banknotenumlaufs vom 1. Juli 1999 bis 30 . Juni 2001 von ca. 357,5 Mrd. EUR näherungsweise zu folgenden individuellen Ausgleichsbeträgen der NZBen ${ }^{373}$ :

\begin{tabular}{|c|c|c|c|c|c|c|}
\hline \multicolumn{7}{|c|}{$\begin{array}{l}\text { Tabelle 36: Ausgleichsbeträge für die Berechnung der Monetären } \\
\text { Einkünfte im Zeitraum von } 2002 \text { bis } 2007 \text { in Mio. Euro }\end{array}$} \\
\hline Jahr & BBk & BdI & BdF & BdE & DNB & NBB \\
\hline 2002 & $-21692,0$ & $-1955,7$ & 30688,5 & $-15246,5$ & 2176,0 & 555,5 \\
\hline 2003 & $-18669,7$ & $-1683,3$ & 26412,8 & $-13122,3$ & 1872,8 & 478,1 \\
\hline 2004 & $-15213,6$ & $-1371,7$ & 21523,3 & $-10693,1$ & 1526,1 & 389,6 \\
\hline 2005 & $-11572,3$ & $-1043,4$ & 16371,8 & $-8133,8$ & 1160,9 & 296,4 \\
\hline 2006 & $-7805,3$ & $-703,7$ & 11042,4 & $-5486,1$ & 783,0 & 199,9 \\
\hline 2007 & $-3941,9$ & $-355,4$ & 5576,8 & $-2770,6$ & 395,4 & 100,9 \\
\hline Jahr & OeNB & BdP & CBI & BoF & BCL & BoG \\
\hline 2002 & $-2396,8$ & 3272,8 & $-410,5$ & 3449,0 & 79,3 & 1480,5 \\
\hline 2003 & $-2062,8$ & 2816,8 & $-353,3$ & 2968,5 & 68,2 & 1274,2 \\
\hline 2004 & $-1681,0$ & 2295,3 & $-287,9$ & 2418,9 & 55,6 & 1038,3 \\
\hline 2005 & $-1278,6$ & 1746,0 & $-219,0$ & 1840,0 & 42,3 & 789,8 \\
\hline 2006 & $-862,4$ & 1177,6 & $-147,7$ & 1241,0 & 28,5 & 532,7 \\
\hline 2007 & $-435,5$ & 594,7 & $-74,6$ & 626,8 & 14,4 & 269,0 \\
\hline
\end{tabular}

373 Zur Herleitung der Ergebnisse vgl. die Tabelle A2 im Anhang. Die vorliegende Schätzung basiert auf Monatsendwerten. Die EZB berechnet die Ausgleichsbeträge jedoch auf Tagesbasis. 
Allerdings sind gegebenenfalls folgende Sonderregelungen $\mathrm{zu}$ berücksichtigen $^{374}$ :

1. Falls der Wert der Euro-Banknoten, die die Banque Centrale du Luxembourg (BCL) im Jahr 2002 in Umlauf setzt, um zumindest $25 \%$ über dem durchschnittlichen Wert ihres Banknotenumlaufs im Zeitraum vom 1. Juli 1999 bis 30. Juli 2001 liegt (also über rd. 750 Mio. EUR) ${ }^{375}$, bezeichnet der Buchstabe „W“ der Formel zur Berechnung des Ausgleichsbetrags für die BCL den Wert der von der BCL 2002 in Umlauf gesetzten Banknoten bis zu einer Obergrenze von 2,2 Mrd. EUR. Bei Anwendung dieser Ausnahmeregelung werden die Ausgleichsbeträge nachträglich am Ende des Jahres 2002 angepaßt, um wieder ein Nullsummenspiel herzustellen. Maßgebend hierfür ist der EZB-Kapitalzeichnungsschlüssel der NZBen.

2. Sollte der Gesamtdurchschnitt des Banknotenumlaufs im Jahr 2002 unter dem Gesamtdurchschnitt der (noch auf nationale Währung lautenden) Banknoten der EWU-Länder im Zeitraum vom 1. Juli 1999 bis zum 30. Juni 2001 (also unter ca. 357,5 Mrd. EUR) liegen, so wird der Koeffizient „K“ für das Geschäftsjahr 2002 rückwirkend entsprechend der Verringerung des Gesamtdurchschnitts des Banknotenumlaufs vermindert. Allerdings darf bei dieser Verminderung der Koeffizient nicht unter 0,8606735 sinken. Bei Anwendung dieser Ausnahmeregelung wird ein Viertel der sich für die Ausgleichsbeträge der NZBen für das Jahr 2002 ergebenden Verminderung auf die sich für eine jede NZB für die Jahre 2004 bis 2007 ergebenden Ausgleichsbeträge aufgeschlagen.

3. Falls diejenigen NZBen, für die der Ausgleichsbetrag eine positive Zahl darstellt ${ }^{376}$, Nettozinsen auf die Intra-Eurosystem-Salden aus dem Banknotenumlauf zahlen, die bei entsprechender Verbuchung unter der Position „Nettoergebnis aus Monetären Einkünften“ in ihrer Gewinn- und Verlustrechnung zum Jahresende zu einer Nettoaufwendung führen, wird der Koeffizient „K“ für das Geschäftsjahr 2002 in dem für die Beseitigung dieses Umstands erforderlichen Umfang vermindert. Auch hier darf die Verminderung des Koeffizienten nicht unter 0,8606735 sinken, und bei Anwendung dieser Ausnahmeregelung wird ein Viertel der sich für die Ausgleichsbeträge der NZBen für das Jahr 2002 ergebenden Verminderung auf die sich für eine jede NZB für die Jahre 2004 bis 2007 ergebenden Ausgleichsbeträge aufgeschlagen.

374 Vgl. Europäische Zentralbank (2001g), S. 7 und 12.

$375 \mathrm{Vgl}$. Tabelle A2 im Anhang.

376 Banque de France (BdF), De Nederlandsche Bank (DNB), Belgische Nationalbank (NBB), Banco de Portugal (BdP), Bank of Finland (BoF), Banque Centrale du Luxembourg $(\mathrm{BCL})$ und Bank of Greece $(\mathrm{BoG})$. Vgl. hierzu Tabelle 36. 


\subsection{Die Ermittlung der Monetären Einkünfte durch das Earmarking- Verfahren}

Die Ermittlung der Monetären Einkünfte der NZBen nach dem EZBRatsbeschluß vom 6. Dezember 2001 läßt sich in drei Perioden unterteilen ${ }^{377}$. Die erste Periode betrifft das Jahr 2002, in der die Monetären Einkünfte noch prinzipiell ähnlich zum Indirekten Verfahren der Übergangsperiode (1999 2001) berechnet werden. Die zweite Periode umfaßt den Zeitraum zwischen 2003 bis einschließlich 2007, in dem bereits ein „echtes“ Earmarking durchgeführt, allerdings auch eine Einschleifregelung („Smoothing") praktiziert wird. Ab 2008 erfolgt das Earmarking in seiner reinen Form.

\subsubsection{Ermittlung der Monetären Einkünfte für das Jahr 2002}

Als erster Schritt wird für jede NZB der Eurowert der oben definierten Bemessungsgrundlage auf täglicher Basis ermittelt, wobei im Geschäftsjahr 2002 der NZB-Passivposten „Banknotenumlauf“ auch die noch umlaufenden auf nationale Währungseinheiten denominierten Banknoten umfaßt ${ }^{378}$. Auf diesen Betrag wird dann der für jede NZB unterschiedliche Ausgleichsbetrag angerechnet. Multipliziert man den so errechneten Wert der Bemessungsgrundlage (inkl. Ausgleichsbetrag) mit dem jeweils aktuellen Referenzzinssatz, der seinerseits dem aktuellen Satz für Hauptrefinanzzierungsgeschäfte entspricht, erhält man die Monetären (Brutto-) Einkünfte einer jeden NZB. Hiervon abzuziehen sind etwaige aufgelaufene oder bereits tatsächlich auf die Bemessungsgrundlage gezahlte Zinsen ${ }^{379}$. Zudem können nach erfolgtem EZB-Ratsbeschluß bestimmte Aufwendungen, die den NZBen in Verbindung mit der Ausgabe von Banknoten oder unter außergewöhnlichen für das Eurosystem unternommenen währungspolitischen Operationen entstanden sind, in Abzug gebracht werden (Art. 32.4. Abs. 2 ESZB-Satzung). Die Monetären (Netto-) Einkünfte jeder NZB werden gepoolt und am Ende eines jeden Geschäftsjahres zwischen den NZBen gemäß ihres gezahlten EZB-Kapitalanteils verteilt.

377 Vgl. im Folgenden Europäische Zentralbank (2001g), S. 4 ff..

$378 \mathrm{Vgl}$. Europäische Zentralbank (2001g), S. 9. Allerdings wird der Wert der unverzinslichen Darlehen für vorzeitig abgegebene Euro-Banknoten, die noch nicht belastet wurden (Teil der Aktivaposition 6 der neuHB), abgezogen. Diese Regelung berücksichtigt das sog. "lineare Belastungsmodell" der Verrechnung der vor dem 1.1.2002 an die Kreditinstutute abgegebenen Euro-Banknoten.

379 Angesprochen sind also hier vor allem die Aufwendungen der NZBen aus der Verzinsung der Mindestreserveeinlagen der Kreditinstitute. 


\subsubsection{Ermittlung der Monetären Einkünfte ab dem Jahr 2003 bis einschließlich 2007}

Im Zeitraum zwischen dem 1.1.2003 und dem 31.12.2007 erfolgt die Bemessung des Betrags der Monetären Einkünfte einer jeden NZB auf Grundlage der tatsächlichen Einkünfte, die sich aus den gesondert erfaßbaren Vermögenswerten ergeben. Geearmarktes Gold wirft hierbei keine Erträge ab.

Im einzelnen wird wie folgt vorgegangen. Im ersten Schritt ist zunächst die Bemessungsgrundlage, die aber im Gegensatz zu 2002 keine auf nationale Währungseinheiten denominierte Banknoten mehr enthält ${ }^{380}$, für jede NZB zu bestimmen und mit dem jeweiligen NZB-Ausgleichsbetrag zu verrechnen. Als zweiter Schritt wird dann der Wert der so ermittelten Bemessungsgrundlage (inkl. Ausgleichsbetrag) dem Wert der geearmarkten Aktiva gegenüber gestellt. Nun ist folgende Unterscheidung vonnöten:

a) Bei denjenigen NZBen, bei denen der Wert ihrer Bemessungsgrundlage (inkl. Ausgleichsbetrag) größer ist als der Wert der von ihr geearmarkten Vermögenswerte, ergibt sich der Wert der Monetären (Brutto-) Einkünfte zum einen aus den tatsächlich sich aus den geearmarkten Assets ergebenen Erträgen und zum anderen aus einem kalkulierten Einkunftsbetrag. Letzteren erhält man, wenn man den aus der (um den Ausgleichsbetrag angepaßten) Bemessungsgundlage und dem Wert der geearmarkten Vermögenswerte errechneten Differenzbetrag mit dem sog. „Durchschnittsertrag“ multipliziert. Dieser wiederum ergibt sich, wenn man den Gesamtbetrag der allen NZBen aus den geearmarkten Positionen zufließenden Einkünfte, allerdings ohne Berücksichtigung der Erträge der NZBen aus ihren Intra-EurosystemNettoforderungen aus TARGET-Transaktionen (Punkt 3. der gesondert erfaßbaren Vermögenswerte) und ohne Berücksichtigung sämtlicher Einkünfte aus Intra-Eurosystem-Nettoforderungen aus dem Euro-Banknotenumlauf, einschließlich Ausgleichsbetrag (Punkt 4. der gesondert erfaßbaren Vermögenswerte) durch den Durchschnittsbetrag aller gesondert erfaßbaren Vermögenswerte des Eurosystems teilt.

b) Bei denjenigen NZBen, bei denen der Wert ihrer Bemessungsgrundlage (inkl. Ausgleichsbetrag) kleiner ist als der Wert der von ihr geearmarkten Vermögenswerte, ergibt sich der Wert der Monetären (Brutto-) Einkünfte aus den tatsächlichen Erträgen der geearmarkten Assets, allerdings ist hier der analog zu berechnende kalkulatorische Einkunftsbetrag abzuziehen.

380 Vgl. Europäische Zentralbank (2001 g), S. 9. 
Diese Regelung sorgt folglich dafür, daß für die Berechnung der Monetären (Brutto-) Einkünfte einer jeden NZB die Höhe ihrer Bemessungsgrundlage entscheidend ist. Eine ertragsmäßig nicht unbedeutende Verzerrung, die sich aus einer entsprechenden Unter- bzw. Überdeckung der jeweiligen NZBBemessungsgrundlage durch die zugehörigen Earmarking-Aktiva ergeben würde, wird so vermieden.

Bevor die NZBen die Zahlungen an den Pool der Monetären (Netto-) Einkünfte abführen, dürfen diese wiederum aufgelaufene und bereits auf ihre $\mathrm{Be}$ messungsgrundlage gezahlte Zinsen abziehen. Aufwendungen, die in Verbindung mit der Ausgabe von Banknoten oder unter außergewöhnlichen Umständen aus für das Eurosystem unternommenen währungspolitischen Operationen entstanden sind, sind nach einem entsprechenden EZB-Ratsbeschluß ebenfalls abzugsfähig (Art. 32.4. ESZB-Satzung). Die so ermittelten Monetären (Netto-) Einkünfte werden gepoolt und nach Art. 32.5. ESZB-Satzung am Ende eines jeden Geschäftsjahres nach Maßgabe des gezahlten EZB-Kapitalschlüssels zwischen den NZBen des Eurosystems verteilt.

\subsubsection{Ermittlung der Monetären Einkünfte ab dem Jahr 2008}

Die Ermittlung der Monetären Einkünfte ab dem Jahr 2008 erfolgt wie die Berechnung im Zeitraum zwischen 2003 und 2007, allerdings mit dem Unterschied, daß kein Ausgleichsbetrag mehr auf die Bemessungsgrundlage angerechnet wird.

Da mit Ausnahme von Gold nur marktverzinsliche Aktiva geearmarkt werden und bei nicht ausreichender Deckung der jeweiligen NZB-Bilanz die „fehlenden“ Erträge durch das Ansetzen einer Durchschnittsverzinsung aufgefüllt werden, kommt dieses Verfahren inhaltlich der Indirekten Methode zur Ermittlung der Monetären Einkünfte (inkl. der Berücksichtigung des Banknotenumlaufs) weitgehend gleich. Dies gilt um so mehr, als gezeigt werden kann, daß die Ansetzung der Intra-Eurosystem-Verbindlichkeiten (Posten 3 bis 5 der Bemessungsgrundlage) rein „bilanz- bzw. konstruktionstechnisch“ bedingt ist und letztlich keine Auswirkung auf den ökonomisch relevanten NZBPoolfinanzierungsbeitrag hat ${ }^{381}$.

381 Vgl. hierzu die Analyse der Earmarking-Bemessungsgrundlage in Kapitel V.3.1.2. Abschnitt 2.6.2.. Der einfachen Fortschreibung der um den Banknotenumlauf erweiterten Indirekten Methode als Pooling-Regelverfahren stehen offensichtlich vertragsrechtliche Gründe entgegen. Vgl dazu Art. 32.2. und 32.3. ESZB-Satzung. 


\subsection{Analyse der Konstruktionselemente des Earmarking-Verfahrens}

Im Folgenden soll nun erläutert werden, warum das vorgestellte EarmarkingVerfahren so und nicht anders konstruiert wurde. So wird zunächst anhand der aktuellen harmonisierten NZB-Bilanzaufstellung eine Reihe von NZB-Aktiva identifiziert, die bereits aus prinzipiellen Überlegungen heraus für das Earmarking-Verfahren ungeeignet erscheinen. Nach dieser ersten Eingrenzung der Earmarking-Aktiva erfolgt dann die Analyse der vom EZB-Rat beschlossenen Earmarking-Bemessungsgrundlage. Die anschließenden Ausführungen untersuchen weitere ebenfalls mit der Regelung des Artikels 32.2. ESZBSatzung vereinbar scheinende Earmarking-Varianten und eröffnen so einen Einblick in verschiedene Problemstellungen, denen sich der EZB-Rat bei der Konstruktion des gültigen Earmarking-Verfahrens gegenüber sah.

\subsubsection{Eingrenzung der Earmarking-fähigen NZB-Aktiva}

Anhand der harmonisierten NZB-Bilanz lassen sich verschiedene Aktivposten identifizieren, die aus unterschiedlichen Gründen von vornherein für ein Earmarking ungeeignet erscheinen und wohl deshalb vom EZB-Rat auch nicht in den Katalog der "gesondert erfaßbaren Vermögenswerte“ aufgenommen wurden ${ }^{382}$. So können sowohl die „Sachanlagen und immateriellen Vermögenswerte" (Aktivposten (AP) der aktuellen harmonisierten Bilanzaufstellung (neuHB): 11.2) als auch das „Sonstige Finanzanlagevermögen“ (AP der neuHB: 11.3) nicht der Monetären NZB-Basis zugerechnet werden, da diese Posten bereits weitgehend für die Deckung der NZB-Kapitalreserven geearmarkt $\operatorname{sind}^{383}$. Zudem kommen auch die "Schwebenden Verrechnungen“ (AP der neuHB: 10), Sicherheitsbestände der NZBen an Scheidemünzen (AP der neuHB: 11.1), Neubewertungsposten aus außerbilanziellen Geschäften (AP der neuHB: 11.4), Rechnungsabgrenzungsposten (AP der neuHB: 11.5) und die „sonstigen“ Aktiva (AP der neuHB: 11.6) für das Earmarking-Verfahren nicht in Betracht, da aus diesen Posten kaum eine nachhaltige und funktionale Beziehung zur Bemessungsgrundlage hergestellt werden kann. Auch die Forderungen der NZBen an öffentliche Haushalte (AP der neuHB: 8) sind für ein Earmarking als eher ungeeignet einzustufen, da die Nähe zu den geldpolitischen Operationen nicht gegeben ist $^{384}$, und andererseits diese Aktiva mittelfristig durch die jeweiligen Regierungen getilgt werden. Bezüglich der in der „neuen“

382 Vgl. dazu die Tabelle 35.

383 Vgl. European Central Bank (1998c), S. 32 und Europäische Gemeinschaft (2001a), S. 44.

384 Vgl. Art. 21.1. ESZB-Satzung und Europäische Zentralbank (2001i), S. 1. 
Bilanzaufstellung explizit ausgegliederten ,sonstigen Forderungen in Euro gegenüber Kreditinstituten im Euro-Währungsgebiet" (AP 6 der neuHB) kann angeführt werden, daß gerade die Herauslösung dieses Postens von der "alten“ NZB-Aktivposition 5 „Forderungen in Euro an den Finanzsektor im EuroWährungsgebiet" die bilanztechnische Trennung der gemeinsam durchgeführten geldpolitischen Transaktionen von denjenigen Geschäften unterscheiden helfen soll, die die NZBen auf eigene Rechnung und Initiative mit den Kreditinstituten durchführen. Diese Trennung wäre freilich sinnlos, würde man diese Position für das Earmarking heranziehen wollen. Dementsprechend verzichtet der EZBRat auch auf eine Erfassung dieser NZB-Aktiva als „gesondert erfaßbare Vermögenswerte ${ }^{\text {3385. }}$.

Damit reduzieren sich die prinzipiell für ein Earmarking-Verfahren geeigneten NZB-Aktivpositionen auf die NZB-Währungsreserven (AP der neuHB: 1 - 3), sowie die Euro-Forderungen der NZBen gegenüber Ansässigen innerhalb und außerhalb des Euroraums (AP der neuHB: 4 - 5), Euro-Wertpapiere (AP der neuHB: 7) und Intra-Eurosystem-Forderungen (AP der neuHB: 9). Der EZB-Rat hat aber - wie oben beschrieben - den Kreis der nicht von vornherein als ungeeignet einzustufenden Earmarking-Aktiva noch weiter eingeengt, da er mit Ausnahme von Gold nur verzinsliche Nominalwertforderungen als ,gesondert erfaßbare Vermögenswerte" definiert. Erklärt werden kann diese Beobachtung mit der Befürchtung, daß die außerordentlich großen Heterogenitäten in den NZB-Aktivastrukturen zu nicht bzw. nur schwer kontrollierbaren Umverteilungseffekten führen würden. Dies zeigen die unten stehenden Ausführungen zu den Problematiken anderer denkbarer Earmarking-Varianten unmittelbar.

\subsubsection{Analyse der Earmarking-Bemessungsgrundlage}

Die Bemessungsgrundlage des Earmarking-Verfahrens umfaßt neben dem Banknotenumlauf und den Verbindlichkeiten der NZBen aus geldpolitischen Operationen gegenüber Kreditinstituten im Euro-Währungsgebiet auch verschiedene Intra-Eurosystem-Verbindlichkeiten (aus EZB-Schuldverschreibungen, aus TARGET-Transaktionen und aus dem Euro-Banknotenumlauf), die für sich genommen nichts anderes als Nostro-Guthaben zwischen den Zentralbanken des Eurosystems darstellen und als reine InterbankenTransaktionen keine ursächliche Beziehung zur Geldschöpfung und damit auch nicht zum Geldschöpfungsgewinn haben. Die Frage ist nun, ob durch Aufnahme dieser Posten in die Earmarking-Bemessungsgrundlage die Geldschöpfungs-

$385 \mathrm{Vgl}$. die Ausführungen $\mathrm{zu}$ den ,gesondert erfaßbaren Vermögenswerten“ in Kapitel V.3.1.2. Abschnitt 2.3.. 
gewinne des Eurosystems überhaupt adäquat erfaßt werden, oder ob es sich hierbei um „konstruktionstechnisch“ erklärbare und letzten Endes umverteilungsneutrale Durchlaufposten handelt.

Bezüglich der Intra-Eurosystem-Verbindlichkeiten der NZBen aus dem EuroBanknotenumlauf (Posten 5 der Bemessungsgrundlage) erscheint die Ansetzung zur Ermittlung der Monetären Einkünfte von vornherein unproblematisch. So ist die Verrechnung der Intra-Eurosystem-Verbindlichkeiten der NZBen aus dem Euro-Banknotenumlauf mit dem als eigenständigen Bilanzposten ausgewiesenen „Banknotenumlauf“, der ja letztlich nur eine der Bilanzkosmetik dienende Größe darstellt ${ }^{386}$, schon deshalb vonnöten, um die tatsächlich von der betreffenden NZB ausgegebenen Banknoten und damit den NZB-Beitrag zum Geldschöpfungsgewinn des Eurosystems ermitteln zu können.

Die Aufnahme der Intra-Eurosystem-Verbindlichkeiten der NZBen aus der Emission der EZB-Liquiditätspapiere (Posten 3 der Bemessungsgrundlage) und der Intra-Eurosystem-Netto-Verbindlichkeiten aus TARGET-Transaktionen (Posten 4 der Bemessungsgrundlage) in die Earmarking-Bemessungsgrundlage ist insofern gerechtfertigt, als durch die Ansetzung dieser Posten den NZBen die Möglichkeit eröffnet wird, die hierauf gezahlten Zinsen bei der Ermittlung der Monetären Einkünfte in Abzug zu bringen. So gelingt es, die parallel zum Earmarking abgewickelten Intra-Eurosystem-Ressourcentransfers, die sich auf die Emission der EZB-Liquiditätspapiere bzw. auf den grenzüberschreitenden TARGET-Zahlungsverkehr zurückführen lassen, über das EarmarkingVerfahren zu nivellieren. Dies zeigt auch das folgende Beispiel des grenzüberschreitenden TARGET-Überweisungsverkehrs ${ }^{387}$.

$386 \mathrm{Vgl}$. hierzu die Ausführungen zur Verbuchung des Euro-Banknotenumlaufs in Kapitel V.2.1. Abschnitt 3.2..

387 Die Intra-Eurosystem-Ressourcenübertragungen zwischen der EZB und den NZBen unterscheiden sich nicht grundsätzlich von den bilateralen Ressourcentransfers zwischen den NZBen, die sie aufgrund von TARGET-Operationen durchführen. Aus diesem Grund soll sich hier die Analyse auf die Auswirkungen des ubber TARGET abgewickelten grenzüberschreitenden Zahlungsverkehrs auf das Earmarking-Verfahren beschränkt werden. 
Abbildung 8: Die Auswirkungen des grenzüberschreitenden Überweisungsverkehrs auf die Umverteilungseffekte des Earmarking-Verfahrens

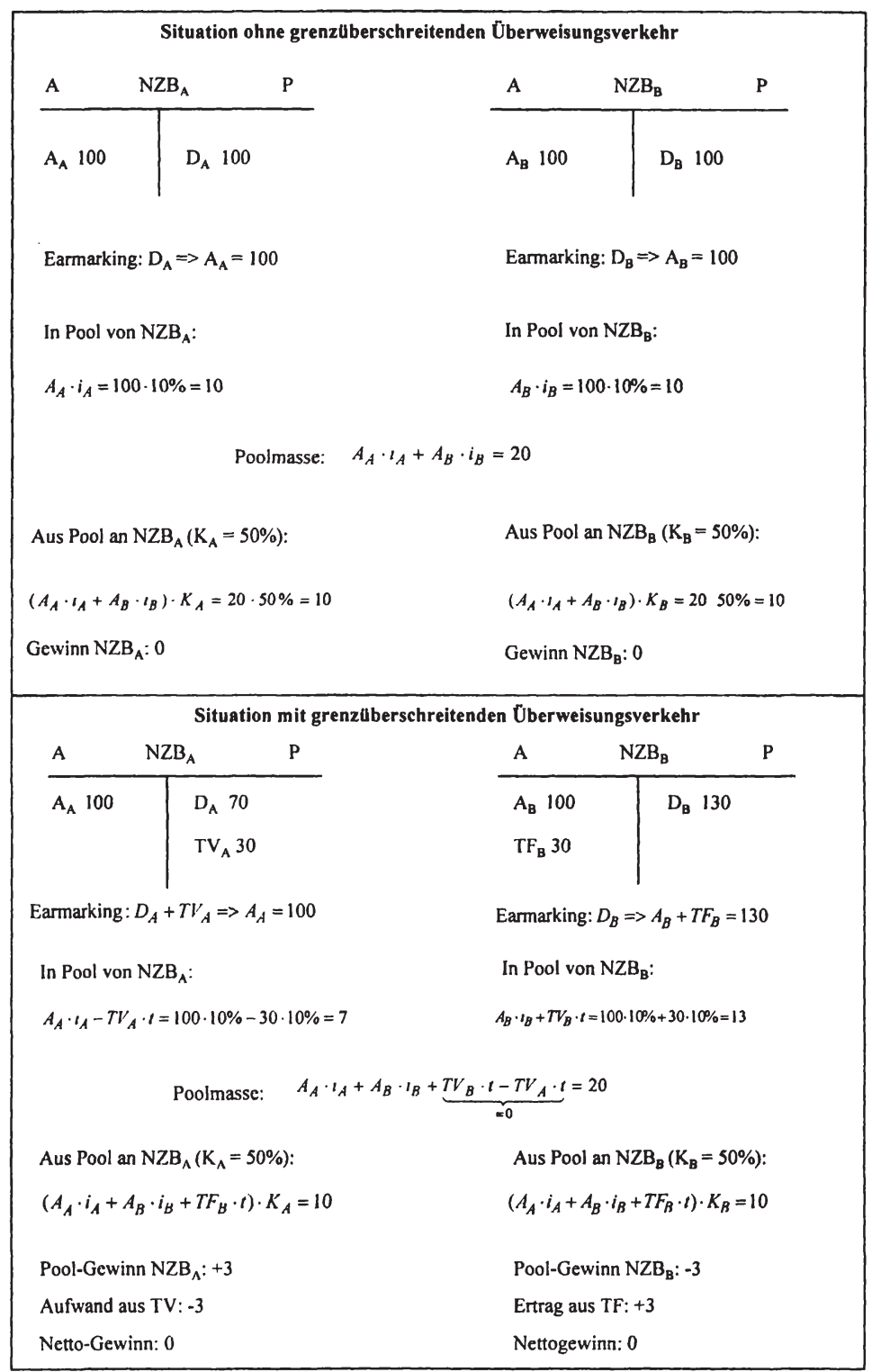


Dabei wird der Einfachheit halber angenommen, daß das Eurosystem (ohne EZB) nur aus zwei NZBen (A und B) besteht. Diese sollen jeweils einen EZBKapitalanteil von 50 Prozent besitzen und über identische Bilanzstrukturen verfügen. Die vollständig aus Earmarking-fähigen Positionen bestehenden Aktiva der NZBen $A_{A}$ und $A_{B}$ mögen jeweils 100 Einheiten betragen und sollen zu jeweils 10 Prozent verzinst werden $\left(\mathrm{i}_{A}=\mathrm{i}_{B}=\mathrm{i}=10 \%\right)$. Die Passivseiten sollen rein aus unverzinslichen Überschußreserven $\left(D_{A}\right.$ und $\left.D_{B}\right)$ bestehen. Von anrechenbaren Ausgleichsbeträgen wird ebenfalls abstrahiert. Es herrsche zunächst kein grenzüberschreitender Überweisungsverkehr. In diesem Fall hätte jede NZB dem EZB-Ratsbeschluß vom 6. Dezember 2001 zufolge die Verzinsung aus ihren geearmarkten Aktiva $\left(A_{A} \cdot i_{A}\right.$ bzw. $\left.A_{B} \cdot i_{B}\right)$ in Höhe von 10 Einheiten in den Pool der Monetären Einkünfte abzuführen und würde exakt den gleichen Betrag wieder ausgeschüttet bekommen, da jede NZB über einen EZBKapitalanteil von 50 Prozent verfügt. Es fände keine Umverteilung von Geldschöpfungsgewinnen statt. Ein solcher wäre auch nicht zu rechtfertigen.

Nun wird die Annahme grenzüberschreitender Zentralbankgeld-Überweisungen zugelassen. So soll der in Land A ansässige Geschäftsbankensektor den Kreditinstituten in Land B Zentralbankgeld in Höhe von 30 Einheiten über das TARGET-System überweisen. Dies führt zu entsprechenden TARGETVerbindlichkeiten (TV) bzw. TARGET-Forderungen (TF) zwischen den NZBen. Folgt man wiederum dem EZB-Ratsbeschluß dann bildet auch in diesem Beispiel für beide NZBen die gesamte Passivseite die Bemessungsgrundlage für die Bestimmung der Monetären Einkünfte, da im Falle der NZB A neben den Geschäftsbankeneinlagen auch die Netto-TARGETVerbindlichkeiten anzusetzen sind.

Entsprechend hat die NZB A die Verzinsung ihrer Earmarking-Aktiva $\left(A_{A} \cdot i_{A}=10\right)$ abzüglich der von ihr bereits an die NZB B im Zuge der Verzinsung des TARGET-Saldos gezahlten Zinsaufwendungen $\left(T V_{A} \cdot t=-3\right)$ in einer Gesamthöhe von 7 Einheiten in den Pool der Monetären Einkünfte abzuführen. Die NZB B zahlt ihrerseits neben den Einkünften, die sie aus dem Bestand ihrer Earmarking-Aktiva erzielt, die sie bereits vor der grenzüberschreitenden Überweisung besaß $\left(A_{B} \cdot i_{B}=10\right)$, auch die Erträge aus der bilateralen TARGET-Forderung gegenüber der NZB A $\left(T F_{B} \cdot 1=3\right)^{388}$ im Betrag von 13 Einheiten in den Pool ein. Dies ergibt eine Poolhöhe von 20 Einheiten, die

388 Die Verzinsung der TARGET-Salden erfolgt in Höhe des Satzes für Hauptrefinanzierungsgeschäfte und soll in diesem Beispiel mit der Verzinsung der jeweiligen Earmarking-Aktiva $A_{A}$ und $A_{B}$ identisch sein $\left(i_{A}=i_{B}=t=10 \%\right)$. Die NettoTARGET-Forderungen definiert der EZB-Rat als ,gesondert erfaßbare Vermögenswerte“ und damit dem Earmarking zugehörig. Vgl. hierzu Europăische Zentralbank (2001g), S. 11 und Kapitel V.3.1.2. Abschnitt 2.3.. 
gemäß des unterstellten EZB-Kapitalanteils von 50 Prozent zu je 10 Einheiten auf die NZBen A und B aufgeteilt werden. Hieraus ergibt sich dann ein PoolingGewinn der NZB A und ein korrespondierender Pooling-Verlust der NZB B in Höhe von 3 Einheiten. Bezieht man nun zusätzlich auch noch die Aufwendungen der NZB A, die diese aus der Verzinsung des TARGET-Saldos gegenüber der NZB B in Höhe von 3 Einheiten $\left(T F_{B} \cdot t=3\right)$ zu finanzieren hatte, in die Umverteilungsrechnung mit ein, so werden die entstandenen NettoPoolsalden wieder nivelliert.

Diese Ausführungen zeigen, daß das Earmarking-Verfahren nicht losgelöst von der bilateralen Verzinsung der TARGET-Salden gesehen werden kann $^{389}$. So ist die Verzinsung der TARGET-Salden als eine parallel zum Pooling der Monetären Einkünfte stattfindende Intra-Eurosystem-Ressoucenumverteilung zu verstehen, die die auf Basis früherer Geldschaffung erzielten Geldschöpfungsgewinne von der Zentralbankgeld exportierenden zur Basisgeld importierenden NZB schleust und diese auf direkte Weise finanziell so stellt, als ob die gesamte Monetäre NZB-Basis der Zentralbankgeld importierenden Notenbank (hier $D_{B}$ ) durch sie selbst geschöpft worden wäre. Diese Ressourcen führt die Basisgeld importierende NZB vollständig in den Pool der Monetären Einkünfte ab. Der Teil des Poolbeitrags jedoch, den die Zentralbankgeld importierende NZB aus ihrer TARGET-Forderung bestreitet, wird unter ökonomischen Gesichtspunkten von der Zentralbankgeld exportierenden NZB finanziert ${ }^{390}$. Eine Anrechnung dieser Finanzierungslast auf den Brutto-Beitrag dieser NZB zum Pool der Monetären Einkünfte ist somit zwingend erforderlich, wenn man die Zentralbankgeld exportierende NZB nicht zweimal, nämlich über die Verzinsung der TARGET-Verbindlichkeiten und zugleich über den Finanzierungsbeitrag zum Seigniorage-Pool, „zur Kasse bitten“ will. Dieser Problematik wird im Earmarking-Verfahren des EZB-Rats durch die Anrechnung der Zinsaufwendungen aus TARGET-Netto-Verbindlichkeiten an den Brutto-Poolfinanzierungsbeitrag der NZBen Rechnung getragen. Dies bedeutet jedoch nicht, daß nicht auch andere Earmarking-Varianten vorstellbar wären, die diese Probleme nicht ebenso adäquat lösen könnten.

Entschließt man sich beispielsweise dazu, die bilateralen TARGET-Salden in Zukunft nicht mehr zu verzinsen ${ }^{391}$, so bräuchte man z.B. nur die TARGETForderungen bzw. die TARGET-Verbindlichkeiten an die jeweilige Monetäre

389 Diese Ausführungen gelten analog für die Intra-Eurosystem-Salden aus der Emission der EZB-Schuldverschreibungen.

390 Die Zentralbankgeld exportierende NZB greift hierfür wieder auf diejenigen verzinslichen Aktiva $\left(A_{A}\right)$ zurück, die sie im Zuge früherer Geldschöpfung erworben hat.

391 Eine neben dem Earmarking-Verfahren parallel existierende Umverteilung von Geldschöpfungsgewinnen ist streng genommen auch nicht erforderlich. 
NZB-Basis anzurechnen. Im obigen Beispiel würde dies bedeuten, daß man die von der NZB A ,abgewanderten“ Zentralbankgeldbestände $\left(T_{\mathrm{A}}\right)$ zur Monetären Basis der NZB A $\left(D_{A}\right)$ hinzuzählt und im Falle der NZB B die TARGET-Forderungen $\left(T F_{B}\right)$ von den Einlagen der Kreditinstitute $\left(D_{B}\right)$ abgezogen werden.

Weiterhin könnte man auch ein „Asset-side-Earmarking“ dergestalt anwenden, daß man eine für alle Zeit gültige Zuweisung identifizierter Aktiva zur Monetären NZB-Basis vornimmt, und dann direkt die Erträge aus den so geearmarkten Assets vergemeinschaftet, ohne die Veränderung der Monetären NZB-Basen, die auf den grenzüberschreitenden Überweisungsverkehr zurückzuführen sind, zu berücksichtigen ${ }^{392}$. Auch hier müßten die TARGETForderungen und -Verbindlichkeiten der NZBen unverzinst bleiben. Zudem sollte das Anfangsearmarking bei allen NZBen vollständig mit marktverzinslichen Aktiva erfolgen, welches allerdings in der Praxis aufgrund der Heterogenitäten in den NZB-Bilanzen nicht ohne weiteres möglich ist.

Als Fazit kann man festhalten, daß die Berücksichtigung der Intra-EurosystemNettoverbindlichkeiten aus dem Banknotenumlauf (Posten 5 der Bemessungsgrundlage) zwingend für die Ermittlung der Geldschöpfungsgewinne erforderlich ist. Die Ansetzung der Intra-Eurosystem-(Netto-)Verbindlichkeiten aus TARGET-Transaktionen und aus der Emission von EZB-Schuldverschreibungen (Posten 3 und 4 der Bemessungsgrundlage) zur Ermittlung der Monetären Einkünfte wäre hingegen nicht unbedingt vonnöten, um die Geldschöpfungsgewinne in ihrer Gesamtheit zu erfassen. Solange jedoch das Eurosystem an der Verzinsung der Intra-Eurosystem-Salden festhält, muß die so induzierte, parallel zum Seigniorage-Pooling existierende Umverteilung von Geldschöpfungsgewinnen direkt im Earmarking-Verfahren verankert werden. Dies hat der EZB-Rat in seiner Earmarking-Methode berücksichtigt, indem er die erwähnten Posten 3 und 4 in die Bemessungsgrundlage aufgenommen hat und die auf diese Posten gezahlten Zinsen auf den Poolbeitrag jeder NZB anrechnen läßt.

392 Neu hinzukommende Aktiva des Eurosystems, welche durch zusätzliche Zentralbankgeldschöpfung erworben werden, werden bei Ankauf sofort geearmarkt. Vgl. auch das „Deadline-Earmarking“-Verfahren, welches abgesehen von der konzeptionellen Unterscheidung von Eurosystem-spezifischen und Eurosystem-unabhängigen Nettoerträgen im Kern ein Asset-Side-Earmarking darstellt. Vgl. Rösl/Schäfer (2000) und Rösl/Schäfer (2001). 


\subsubsection{Spezifische Probleme anderer denkbarer Earmarking-Varianten und deren Vermeidung durch die Earmarking-Methode des EZB- Rats}

Mit Hilfe anderer denkbarer Earmarking-Varianten lassen sich zusätzliche Erkenntnisse über die konkreten Probleme gewinnen, denen der EZB-Rat bei der Konstruktion des von ihm beschlossenen Earmarking-Verfahrens gegenüberstand. Im Folgenden werden deshalb auf Basis der (bis Ende 2000 gültigen) harmonisierten NZB-Bilanzen weitere mögliche EarmarkingMethoden vorgestellt und Aussagen bezüglich der prinzipiellen Umsetzbarkeit derselben getroffen. Dabei grenzen bereits die großen Heterogenitäten in der Zusammensetzung der NZB-Aktiva die tatsächlich durchführbaren EarmarkingMöglichkeiten stark ein. Um dies $\mathrm{zu}$ verdeutlichen, ist in Tabelle 37 die „Deckungsstruktur“ der verschiedenen Monetären NZB-Basen dergestalt aufgezeigt, daß für jede NZB ausgewählte NZB-Aktivposten in Relation zur jeweiligen Summe aus dem NZB-Banknotenumlauf und den Euro-Verbindlichkeiten der NZB gegenüber dem Finanzsektor zum 31.12.1999 gesetzt worden sind. Dabei hält sich die hier angesetzte Bemessungsgrundlage sehr eng an den Art. 32.2. ESZB-Satzung, d.h. die NZB-Verbindlichkeiten aus der Emission der EZB-Solawechsel sowie aus dem grenzüberschreitenden EuroZahlungsverkehr bleiben hier unberücksichtigt, um die Untersuchung nicht unnötig zu komplizieren ${ }^{393}$. Folgende alternative Earmarking-Varianten sollen nun unterschieden werden:

1. Einzelposten-Earmarking,

2. Sukzessives Earmarking,

3. Symmetrisches Earmarking,

4. Freies Earmarking.

393 Unberücksichtigt bleiben auch die Intra-Eurosystem-Nettoverbindlichkeiten der NZBen aus dem Euro-Banknotenumlauf, da diese Ende 1999 noch nicht existierten. Der jeweilige NZB-Bilanzposten „Banknotenumlauf“ erfaßt ausschließlich in heimischer Währung denominierte Banknoten. 
Tabelle 37: Die „Deckungsstrukturs der Monetären NZB-Basen zum 31.12.1999'

\begin{tabular}{|c|c|c|c|c|c|c|c|c|c|c|c|c|c|}
\hline & \begin{tabular}{|l|} 
NZB-Aktiva zum \\
31.12.1999 \\
\end{tabular} & BBk & BdI & BdF & BdE & DNB & NBB & OeNB & BdP & CBI & BoF & BCL & $\begin{array}{l}\text { Durch- } \\
\text { schnitt }^{2}\end{array}$ \\
\hline 1 & Gold und Goldforderungen & $17,7 \%$ & $28,6 \%$ & $39,9 \%$ & $6,8 \%$ & $36,3 \%$ & $14,6 \%$ & $22,9 \%$ & $51,6 \%$ & $0,8 \%$ & $5,8 \%$ & $0,5 \%$ & $22,3 \%$ \\
\hline 2 & $\begin{array}{l}\text { Forderungen in } \\
\text { Fremdwăhrung an Ansăssige } \\
\text { außerhalb des Euro- } \\
\text { Währungsgebiets }\end{array}$ & $33,4 \%$ & $28,0 \%$ & $56,7 \%$ & $45,7 \%$ & $40,3 \%$ & $66,1 \%$ & $90,3 \%$ & $75,0 \%$ & $80,6 \%$ & $102,3 \%$ & $1,6 \%$ & $43,4 \%$ \\
\hline 3 & $\begin{array}{l}\text { Forderungen in } \\
\text { Fremdwăhrung an Ansässige } \\
\text { im Euro-Wahhrungsgebiet }\end{array}$ & - & $4,5 \%$ & $4,7 \%$ & $0,0 \%$ & $3,9 \%$ & $0,8 \%$ & $12,8 \%$ & $7,9 \%$ & $1,4 \%$ & $8,5 \%$ & - & $2,4 \%$ \\
\hline 4 & $\begin{array}{l}\text { Forderungen in Euro an } \\
\text { Ansăssige außerhalb des } \\
\text { Euro-Wăhrungsgebiets }\end{array}$ & $5,0 \%$ & $1,5 \%$ & $0,7 \%$ & $5,8 \%$ & $3,3 \%$ & $1,6 \%$ & $20,2 \%$ & $25,3 \%$ & $0,4 \%$ & $30,3 \%$ & $15,1 \%$ & $5,1 \%$ \\
\hline 5 & $\begin{array}{l}\text { Forderungen in Euro an den } \\
\text { Finanzsektor im Euro- } \\
\text { Wahrungsgebiet }\end{array}$ & $49,8 \%$ & $44,9 \%$ & $63,7 \%$ & $33,9 \%$ & $37,5 \%$ & $124,3 \%$ & $39,0 \%$ & $21,8 \%$ & $76,7 \%$ & $19,2 \%$ & $188,8 \%$ & $50,8 \%$ \\
\hline 6 & $\begin{array}{l}\text { Wertpapiere in Euro von } \\
\text { Ansăssigen im Euro- } \\
\text { Wahrungsgebiet }\end{array}$ & - & $1,9 \%$ & $3,4 \%$ & - & $21,6 \%$ & $22,4 \%$ & $10,5 \%$ & $28,8 \%$ & $29,4 \%$ & $\cdots$ & $4,2 \%$ & $4,1 \%$ \\
\hline & $\begin{array}{l}\text { Forderungen in Euro an } \\
\text { offentliche Haushalte }\end{array}$ & $2,4 \%$ & $51,2 \%$ & $2,1 \%$ & $16,3 \%$ & - & - & $1,3 \%$ & $1,3 \%$ & $2,5 \%$ & - & $\cdots$ & $12,0 \%$ \\
\hline & $\begin{array}{l}\text { Intra-Eurosystem- } \\
\text { Forderungen }\end{array}$ & $21,8 \%$ & $10,3 \%$ & $13,4 \%$ & $46,0 \%$ & $9,3 \%$ & $9,6 \%$ & $7,8 \%$ & $23,2 \%$ & $21,2 \%$ & $9,7 \%$ & $1,7 \%$ & $20,4 \%$ \\
\hline & Schwebende Verrechnungen & $0,0 \%$ & $0,0 \%$ & $2,8 \%$ & $0,0 \%$ & - & - & $\cdots$ & $0,0 \%$ & $5,2 \%$ & $\cdots$ & $0,0 \%$ & $0,5 \%$ \\
\hline 10 & Sonstige Aktiva & $2,8 \%$ & $58,3 \%$ & $12,5 \%$ & $9,2 \%$ & $15,7 \%$ & $13,1 \%$ & $23,4 \%$ & $6,1 \%$ & $5,7 \%$ & $8,1 \%$ & $23,3 \%$ & $16,2 \%$ \\
\hline & Jahresverlust & - & - & - & - & - & - & - & - & - & -- & - & $-\cdots$ \\
\hline & Gesamte Aktiva & $133,0 \%$ & $229,0 \%$ & $199,9 \%$ & $163,7 \%$ & $167,9 \%$ & $252,5 \%$ & $228,3 \%$ & $241,1 \%$ & $224,0 \%$ & $183,9 \%$ & $235,1 \%$ & $177,0 \%$ \\
\hline
\end{tabular}

Quelle: Eigene Berechnungen. Die der Darstellung zugrunde liegenden Daten sind entnommen aus Tabelle 11. Die Numerierung der NZB-Aktivposten bezieht sich auf die bis zum Ende 2000 gulltige harmonisierte NZB-Bilanzstruktur, die auch der Tabelle 11 zugrunde liegt. Zur aktuellen NZB-Bilanzstruktur vgl. Tabelle 35.

\footnotetext{
' Ausgewăhlte NZB-Bilanzposten in Relation zur Summe aus dem jeweiligen NZB-Banknotenumlauf und den Euro-Verbindlichkeiten der NZB gegenuber dem Finanzsektor zum 31.12.1999.

${ }^{2}$ Summe der gleichlautenden NZB-Aktivposten in Relation zur Gesamtsumme der Monetăren NZB-Basen.
} 


\subsubsection{Einzelposten-Earmarking}

Anhand der Tabelle 37 kann leicht gezeigt werden, daß zwar für jede NZB erwartungsgemäß der Gesamtbestand ihrer Aktiva die Monetäre NZB-Basis weit übersteigt, mit Ausnahme der Euro-Forderungen der belgischen und luxemburgischen Zentralbank an den heimischen Finanzsektor jedoch keine der aufgeführten Aktivposten für sich genommen in der Lage ist, Ende 1999 die jeweilige Monetäre NZB-Basis zu decken. Es überrascht also nicht, daß der EZB-Rat mehrere Aktivpositionen für das Earmarking vorsieht.

\subsubsection{Sukzessives Earmarking}

Da ein einzelner standardisiert erfaßter NZB-Bilanzposten in der Regel nicht in der Lage ist, die jeweilige Monetäre NZB-Basis zu decken, hätte der EZB-Rat ein „sukzessives“ Earmarking beschließen können, welches bestimmte Gruppen von Aktiva schrittweise der Monetären NZB-Basis zuweist bis eine vollständige Deckung der Bemessungsgrundlage erreicht ist. Als primäres Zuordnungskriterium käme hierbei die Nähe der betreffenden Aktiva zu den „währungspolitischen Aufgaben“ (Art. 32.1. ESZB-Satzung), also insbesondere $\mathrm{zu}$ den geldpolitischen Operationen des Eurosystems, in Frage. Letztere finden ihren bilanziellen Niederschlag zur Zeit ausschließlich in der NZBAktivposition 5 „Forderungen in Euro aus geldpolitischen Operationen an Kreditinstitute im Euro-Währungsgebiet“, der weitgehend den „Forderungen in Euro an den Finanzsektor im Euro-Währungsgebiet" der „alten“ harmonisierten Bilanzaufstellung (altHB) entspricht. Als zweiten Schritt könnte auf die bilateralen TARGET-Forderungen der EWU-NZBen zurückgegriffen werden, da wegen des grenzüberschreitenden Überweisungsverkehrs ein unmittelbarer Bezug zur Monetären NZB-Basis besteht (überwiegender Teil des AP 8.4 der altHB bzw. 9.4 der neuHB) ${ }^{394}$. Sodann kämen die unter dem „alten“ bzw. „neuen“ Aktivposten 6 bzw. 7 verbuchten Euro-Wertpapiere in Frage, weil - der einschlägigen EZB-Leitlinie folgend - die hier erfaßten Bestände für geldpolitische Operationen des Eurosystems zur Verfügung stehen ${ }^{395}$. Im weiteren Verlauf könnte auf Fremdwährungsaktiva und auf die Forderungen an die EZB bzw. zur Not auch auf die ausstehenden Kredite an die heimischen öffentlichen Haushalte zurückgegriffen werden. Die anderen Aktivposten

394 Vgl. dazu die Ausführungen zur Abwicklung der gemeinsamen Geldpolitik in Kapitel V.2.1. Abschnitt 2. Dies würde wegen der Verzinsung der bilateralen TARGET-Salden bedeuten, daß die NZBen letztendlich in dem Maße an der Finanzierung des Pools beteiligt sind, wie sie die Monetäre NZB-Basis ursprünglich selbst geschöpft haben.

Vgl. European Central Bank (1998c), S. 31. 
kommen aus den oben genannten Gründen für das Earmarking-Verfahren nicht in Betracht.

Ein solches sukzessives Earmarking-Verfahren hat der EZB-Rat aber wohl aus dem Grund nicht gewählt, da - wie Tabelle 37 unmittelbar zeigt - die einzelnen zu earmarkenden Aktivpositionen nicht nur in absoluten Größen, sondern auch in relativer Hinsicht sehr unterschiedlich auf die NZBen verteilt sind. Eine solche Regelung würde freilich diejenigen NZBen bevorteilen, die, um ihre Monetäre NZB-Basis zu decken, möglichst umfangreich auf relativ niedrig verzinsliche oder sogar unverzinsliche Aktiva zurückgreifen. Es käme folglich zu Umverteilungseffekten, die ihre eigentliche Ursache nicht (nur) in der Verteilung der kumulierten Monetären NZB-Basis auf die NZBen findet, sondern in den außerordentlich heterogenen NZB-Aktivastrukturen.

Wie stark diese heterogenitätsinduzierten Umverteilungseffekte die Gewinnerbzw- Verliererposition der NZBen beim Pooling der Monetären Einkünfte beeinflussen könnten, wird an anderer Stelle noch mit Zahlen belegt werden. Hier jedoch soll zunächst geklärt werden, ob nicht mit Hilfe eines „symmetrischen“ Earmarking-Verfahren die erwähnten heterogenitätsinduzierten Umverteilungseffekte reduziert werden könnten.

\subsubsection{Symmetrisches Earmarking}

Anhand der Tabelle 37 wird schnell klar, daß auch ein durchgängiges „symmetrisches“ Earmarking, welches eine für alle NZBen gleiche prozentuale Zuordnung ausgewählter Aktiva zu ihrer Monetären NZB-Basis vorsehen könnte, nicht ohne weiteres möglich ist. So besaß etwa die Zentralbank Luxemburgs Ende 1999 keine oder nur vernachlässigbar geringe Bestände an Gold und Fremdwährungsaktiva (AP $1-3$ der altHB), die Bundesbank sowie die spanische und finnische NZB verfügten über keinen unter dem Posten 6 (der altHB) verbuchten Wertpapierbestand, und die Zentralbanken Belgiens, Finnlands, Luxemburgs und der Niederlande hielten keine Forderungen an die heimischen öffentlichen Haushalte (AP 7 der altHB). Auch die Aktivposten 4 (v.a. TARGET-Forderungen gegenüber den Pre-In-NZBen), 8 (Intra-Eurosystem-Forderungen) und 9 (Schwebende Verrechnungen) der damals gültigen Bilanzstruktur spielen in den Bilanzen verschiedener NZBen keine Rolle. Einzig die Euro-Forderungen der NZBen an den Finanzsektor im Euroraum (AP 5 der altHB) und die Sonstigen Aktiva (AP 10 der altHB) vereinigen bei allen NZBen nennenswerte Bestände, wenn man sie in Relation zur Monetären NZB-Basis setzt. Diese Volumina reichen jedoch nicht aus, ein symmetrisches Earmarking durchzuführen, welches die Monetären NZB-Basen voll deckt. 


\subsubsection{Freies Earmarking}

Anhand der Tabelle 37 läßt sich nun auch erkennen, warum die NZBen keinen Gestaltungsspielraum beim tatsächlich gültigen Earmarking-Verfahren besitzen. Ein solches Vorgehen (,freies Earmarking“) würde nämlich immer diejenigen NZBen bevorteilen, die über einen relativ hohen unverzinslichen Aktiva-, insbesondere Goldbestand verfügen. So käme eine solche Regelung besonders den Zentralbanken Portugals, Frankreichs und der Niederlande zugute, die Ende 1999: 51,6 Prozent, 39,9 Prozent bzw. 36,3 Prozent ihrer Monetären NZB-Basis durch Gold decken konnten, während die irische und luxemburgische Zentralbank quasi keine unverzinslichen Goldreserven besaßen. Zudem sind auch die meist deutlich unter Marktwert vergüteten bzw. unverzinsten Forderungen der NZBen an ihre noch ausstehenden Forderungen an ihre nationalen Haushalte zu berücksichtigen.

\subsubsection{Quantifizierung heterogenitätsinduzierter Umverteilungseffekte}

Wie bereits erwähnt, werden durch die Konstruktion des vom EZB-Rat beschlossenen Earmarking-Verfahrens die bei bestimmten anderen EarmarkingVarianten (insbesondere beim „freien“ und beim „sukzessiven“ Earmarking) auftretenden heterogenitätsinduzierten Umverteilungseffekte wegen der weitgehend einheitlichen Verzinsung der Earmarking-Aktiva recht klein gehalten. Deshalb kann auch zur näherungsweisen Berechnung der so verhinderten Umverteilungseffekte auf die (um den Banknotenumlauf in der Bemessungsgrundlage) erweiterte Indirekte Methode, die ihrerseits wegen der unterstellten Einheitsverzinsung solche Umverteilungseffekte völlig vermeidet, als Referenzmaß zurückgegriffen werden ${ }^{396}$. Im Folgenden sollen nun sowohl für das „freie“ und das „sukzessive“ Earmarking als auch für die erweiterte Indirekte Methode die jeweiligen Umverteilungsergebnisse berechnet und gegenübergestellt werden. Die jeweiligen Abweichungen der Umverteilungsergebnisse der angesprochenen Earmarking-Varianten zur erweiterten Indirekten Methode können dann als Grobmaß für die durch das vom EZB-Rat beschlossene Earmarking-Verfahren verhinderten heterogenitätsinduzierten Umverteilungseffekte herangezogen werden. Es sei jedoch explizit darauf

396 Von der Anrechenbarkeit der Ausgleichsbeträge sei im Folgenden abstrahiert. Zudem spielt die Nichtberücksichtigung der verschiedenen Intra-Eurosystem-Salden für die Berechnungen der Netto-Umverteilungseffekte keine Rolle, da Anfang 1999 der NZBPassivposten „Banknotenumlauf“ auch tatsächlich den jeweils von der NZB emittierten Banknoten entsprach und die Intra-Eurosystem-(Netto-)Verbindlichkeiten aus emittierten EZB-Liquiditätspapieren und aus dem TARGET-Zahlungsverkehr null waren. 
hingewiesen, daß die folgenden Berechnungen nur einen exemplarischen Charakter besitzen. So wird neben bestimmten vereinfachenden Annahmen (konstante Monetäre NZB-Basis, weitgehend einheitliche Verzinsung gleichlautender Aktivagruppen) ein Ceteris-paribus-Szenario unterstellt, welches freilich keinen Anspruch auf vollständige Realitätsnähe erheben kann ${ }^{397}$. Die Problematik der heterogenitätsinduzierten Umverteilungseffekte läßt sich auf diese Weise jedoch recht anschaulich verdeutlichen.

Die in der nachstehenden Tabelle 38 vorgestellten Netto-Poolingresultate, die sich aus der Anwendung der um den Banknotenumlauf erweiterten Indirekten Methode ergeben, basieren auf den zum 1.1.1999 existierenden Monetären NZB-Basen sowie dem in 1999 gültigen jahresdurchschnittlichen Referenzzinssatz von 2,71 Prozent p.a.. Entscheidendes Kriterium zur Ermittlung der Monetären Einkünfte ist hier die Verteilung der gesamten Monetären NZBBasis zu Beginn der EWU auf die NZBen ${ }^{398}$. Demzufolge wäre mit 827 Mio. Euro pro Jahr die Banque de France (BdF) größter Gewinner, größter Verlierer die Deutsche Bundesbank mit einem Poolverlust von 667 Mio. EUR pro Jahr. Dieser Verlust ist jedoch, wie oben ausführlich erläutert, in 1999 nicht zustande gekommen, da der EZB-Rat den jeweiligen Banknotenumlauf von der Bemessungsgrundlage der Berechnung der Monetären Einkünfte ausgenommen hat.

Beim „freien Earmarking“ sei es den NZBen gestattet, ihre Pre-EWU-Aktiva nach freier Wahl der Monetären NZB-Basis zuzuweisen, wobei die harmonisiert erfaßten Aktivposten 9 und 10 (Schwebende Verrechnungen, Sonstige Aktiva) unberücksichtigt bleiben sollen. Die NZBen werden folglich vor allem unverzinsliche und unter dem Marktwert vergütete Assets earmarken ${ }^{399}$. Dies bedeutet jedoch, daß vor allem die NZBen mit einem relativ reichlichen Bestand an Gold und (meist unverzinslichen) Kreditforderungen an die heimischen öffentlichen Haushalte deutlich weniger in den Pool der Monetären Einkünfte abzuführen haben, als wenn sie - weitgehend ähnlich zum EarmarkingVerfahren des EZB-Rats ${ }^{400}$ - ihre Monetäre NZB-Basis vollständig mit marktverzinslichen Aktiva decken müßten.

397 Zur Herleitung der Schätzergebnisse vgl. die Berechnungen im Anhang (Tabellen A3 und A4).

398 Vgl. dazu die Berechnungen der Tabelle A4 im Anhang.

399 Vgl. dazu die Berechnungen der Tabelle A3 im Anhang.

400 Es wurde bereits erwăhnt, daß die vorliegenden Berechungen von den im Zeitraum 2002 bis einschließlich 2007 anrechenbaren Ausgleichsbeträgen abstrahieren. 
Tabelle 38: Die Auswirkungen unterschiedlicher Earmarking-Verfahren auf die Umverteilung der Monetären Einkünfte aus den Pre-EWU-Aktiva der NZBen (Angaben in Mio. Euro)

Fortschreibung der Indirekten Methode mit Banknotenumlauf

in der Bemessungsgrundlage als Näherung für das Earmarking-Regelverfahren

\begin{tabular}{|c|c|c|c|c|c|c|c|c|c|c|c|c|}
\hline NZB & BBK & BdI & BdF & BdE & DNB & NBB & OeNB & BdP & CBI & BoF & BCL & Summe \\
\hline Monetäre Einkünfte (MEK) & 3538 & 1713 & 1145 & 1429 & 468 & 324 & 332 & 138 & 97 & 72 & 3 & 9260 \\
\hline $\begin{array}{l}\text { Anteile der NZBen an gesamten } \\
\text { MEK }\end{array}$ & $38,2 \%$ & $18,5 \%$ & $12,4 \%$ & $15,4 \%$ & $5,1 \%$ & $3,5 \%$ & $3,6 \%$ & $1,5 \%$ & $1,0 \%$ & $0,8 \%$ & $0,0 \%$ & $100,0 \%$ \\
\hline Aus Pool an NZB & 2871 & 1750 & 1972 & 1046 & 500 & 333 & 278 & 222 & 102 & 167 & 19 & 9260 \\
\hline Verteilung der MEK (netto) & $31,0 \%$ & $18,9 \%$ & $21,3 \%$ & $11,3 \%$ & $5,4 \%$ & $3,6 \%$ & $3,0 \%$ & $2,4 \%$ & $1,1 \%$ & $1,8 \%$ & $0,2 \%$ & $100,0 \%$ \\
\hline Gewinner (+)/Verlierer (-) & -667 & +37 & +827 & -383 & +32 & +9 & -55 & +85 & +5 & +95 & +16 & \\
\hline
\end{tabular}

Gewinner (+)/Verlierer (-)

$-383$

$+32$

$+9$

$-55+85$

$+5$

\section{Freies Earmarking}

\begin{tabular}{|c|c|c|c|c|c|c|c|c|c|c|c|c|}
\hline NZB & BBk & BdI & $\mathbf{B d F}$ & BdE & DNB & NBB & OeNB & BdP & CBI & BoF & BCL & Summe \\
\hline Monetäre Einkünfte (MEK) & 2748 & 461 & 550 & 156 & 310 & 340 & 306 & 1 & 117 & 90 & 1 & 5080 \\
\hline $\begin{array}{l}\text { Anteile der NZBen an gesamten } \\
\text { MEK }\end{array}$ & $54,1 \%$ & $9,1 \%$ & $10,8 \%$ & $3,1 \%$ & $6,1 \%$ & $6,7 \%$ & $6,0 \%$ & $0,0 \%$ & $2,3 \%$ & $1,8 \%$ & $0,0 \%$ & $100,0 \%$ \\
\hline Aus Pool an NZB & 1575 & 960 & 1082 & 574 & 274 & 183 & 152 & 122 & 56 & 91 & 10 & 5080 \\
\hline Verteilung der MEK & $31,0 \%$ & $18,9 \%$ & $21,3 \%$ & $11,3 \%$ & $5,4 \%$ & $3,6 \%$ & $3,0 \%$ & $2,4 \%$ & $1,1 \%$ & $1,8 \%$ & $0,2 \%$ & $100,0 \%$ \\
\hline Gewinner (+)/Verlierer (-) & -1173 & +499 & +532 & +418 & -36 & -157 & -154 & +121 & -61 & +1 & +9 & 0 \\
\hline
\end{tabular}

\section{Sukzessives Earmarking}

\begin{tabular}{|c|c|c|c|c|c|c|c|c|c|c|c|c|}
\hline NZB & BBk & BdI & BdF & BdE & DNB & NBB & OeNB & BdP & CBI & $\mathbf{B o F}$ & BCL & Summe \\
\hline Monetäre Einkünfte (MEK) & 3929 & 1805 & 2077 & 1718 & 1705 & 1239 & 825 & 977 & 472 & 110 & 3 & 14859 \\
\hline $\begin{array}{l}\text { Anteile der NZBen an gesamten } \\
\text { MEK }\end{array}$ & $26,4 \%$ & $12,1 \%$ & $14,0 \%$ & $11,6 \%$ & $11,5 \%$ & $8,3 \%$ & $5,6 \%$ & $6,6 \%$ & $3,2 \%$ & $0,7 \%$ & $0,0 \%$ & $100,0 \%$ \\
\hline Aus Pool an NZB & 4606 & 2808 & 3165 & 1679 & 802 & 535 & 446 & 357 & 163 & 267 & 30 & 14859 \\
\hline Verteilung der MEK (netto) & $31,0 \%$ & $18,9 \%$ & $21,3 \%$ & $11,3 \%$ & $5,4 \%$ & $3,6 \%$ & $3,0 \%$ & $2,4 \%$ & $1,1 \%$ & $1,8 \%$ & $0,2 \%$ & $100,0 \%$ \\
\hline Gewinner (+)/Verlierer (-) & +678 & +1004 & +1088 & -39 & -903 & -704 & -379 & -621 & -308 & +158 & +27 & 0 \\
\hline
\end{tabular}

Quelle: Eigene Berechnungen. Zur Herleitung der Ergebnisse vgl. die Berechnungen im Anhang (Tabellen A3 und A4). Differenzen in den Summen durch Runden der Zahlen. 
Die Folge hiervon ist eine im Vergleich zu den anderen Earmarking-Varianten drastische Reduktion der Umverteilungsmasse, wie Tabelle 38 unmittelbar zeigt. So sinkt beispielsweise der Brutto-Poolfinanzierungsbeitrag der Banca d'Italia (BdI) bei Anwendung der (um den Banknotenumlauf erweiterten) Indirekten Methode von 1903 Mio. EUR pro Jahr auf 461 Mio. EUR pro Jahr beim „freien“ Earmarking, da die italienische Zentralbank zu Beginn der EWU sowohl auf einen substantiellen Goldbestand (20,5 Mrd. EUR) als auch auf bedeutende, mit nur rund einem Prozent verzinste Forderungen an öffentliche Haushalte $(40,9$ Mrd. EUR) zurückgreifen kann. Da allein diese Aktiva bereits 87 Prozent der Monetären Pre-EWU-Basis Italiens auf sich vereinigen, würde die Banca d'Italia trotz ihres rund 16 prozentigen Anteils an der gesamteuropäischen Monetären Pre-EWU-Basis beim „freien Earmarking“ nur einen relativen Poolfinanzierungsbeitrag von etwas über 9 Prozent leisten ${ }^{401}$. Auch die von der Bundesbank abgeführten Seignioragebeträge wären vergleichsweise gering, dennoch ist sie beim „freien" Earmarking mit einem Defizit von 1173 Mio. EUR pro Jahr größter Verlierer. So würde allein die deutsche Zentralbank über die Hälfte des Seignioragepools finanzieren, aber nur 31 Prozent daraus wieder erhalten. Größter Gewinner wäre die französische Notenbank (BdF) mit einer positiven Netto-Poolingposition von 532 Mio. Euro pro Jahr.

Ein Vergleich der nach Anwendung des „freien" Earmarkings und der (um den Banknotenumlauf erweiterten) Indirekten Methode gefundenen Ergebnisse könnte nun die These erlauben, $\mathrm{da} ß$ es (mit Ausnahme der spanischen Zentralbank) für die prinzipielle Einstufung der NZBen als Poolinggewinner oder -verlierer generell egal ist, in welcher Form geearmarkt wird. Falls dies so wäre, dann würde die Netto-Poolposition der jeweiligen NZB rein über die Differenz zwischen dem jeweiligen NZB-Anteil an den kumulierten Monetären Pre-EWU-Basen und ihrem EZB-Kapitalanteil determiniert. Das EarmarkingVerfahren selbst würde dann nur über die Höhe der umverteilten Beträge entscheiden. $\mathrm{Da} ß$ dies jedoch nicht so ist, zeigen die Berechnungen für das „sukzessive" Earmarking-Verfahren, welches die betreffenden Aktiva der jeweiligen Monetären NZB-Basis in Abhängigkeit ihrer Nähe zu den geldpolitischen Operationen des Eurosystems zuordnet ${ }^{402}$. So kann - bei aller

401 Vgl. Tabelle 9 und Tabelle 39 in Kapitel V.3.1.2. Abschnitt 3.2..

402 Folgende Earmarking-Reihenfolge wurde unterstellt: Euro-Forderungen an den Finanzsektor (harmonisierter Aktivposten (AP) 5 der bis Ende 2000 gültigen harmonisierten NZB-Bilanzstruktur (altHB)), Euro-Wertpapiere (AP 6 der altHB), Fremdwährungsforderungen an Ansässige außerhalb des Euroraums (AP 2 der altHB), Fremdwährungsforderungen an Ansässige im Euroraum (AP 3 der altHB), Forderung aus Beteiligung an EZB (AP 8.1 der altHB), Forderungen an öffentliche Haushalte (AP 7 der altHB), Euroforderungen an Ansässige außerhalb des Euroraums (AP 4 der altHB) und 
gebotenen Zurückhaltung und berechtigten Kritik an den hier unterstellten Vereinfachungen - eine solche Earmarking-Methode sogar dazu führen, daß auf einmal die Deutsche Bundesbank, die sonst bei allen Umverteilungsberechnungen immer als Verlierer klassifiziert wird ${ }^{403}$, als Nettogewinner aus dem Seigniorage-Pooling hervorgeht. Die Erklärung hierfür ist einfach. So verfügt die Bundesbank in diesem Ceteris-paribus-Szenario zu Beginn der EWU über überproportional hohe Forderungen an den europäischen Finanzsektor, deren jahresdurchschnittliche Verzinsung mit 2,71\% in 1999 relativ niedriger anzusetzen ist als die hier veranschlagte Verzinsung der Euro-Wertpapiere $(3,81$ $\%)$ oder der Devisenreserven $(3,5 \%)^{404}$. Die Bundesbank könnte somit im Vergleich zu anderen NZBen beim Earmarking in relativ größerem Umfang auf vergleichsweise niedrig verzinsliche Assets zurückgreifen, während die anderen NZBen „mangels Masse“ relativ früh höher verzinsliche Aktiva earmarken müßten. Dies bedeutet aber, daß die Bundesbank beim Seigniorage-Pooling immer dann als Gewinner hervorgehen würde, wenn die so ermöglichte heterogenitätsinduzierte Zinsersparnis denjenigen Teil der deutschen Poolbeiträge, der sich aus der positiven Differenz zwischen dem deutschen Anteil an der gesamten Monetären Pre-EWU-Basis und dem deutschen EZB-Kapitalanteil ergibt, überkompensiert.

Es läßt sich also festhalten, daß es im Hinblick auf die Umverteilungseffekte entscheidend auf die Art des Earmarking-Verfahrens ankommt. Zwar werden im allgemeinen diejenigen NZBen, deren Anteil an der gesamten Monetären PreEWU-Basis ihren Anteil am EZB-Kapital übersteigt, zu Nettozahlern avancieren. Allerdings zeigen die Berechnungen unterschiedlicher EarmarkingVarianten, daß der relative NZB-Anteil an der gesamten Monetären NZB-Basis nicht notwendigerweise mit dem relativen Brutto-Poolfinanzierungsbeitrag einer NZB korrespondieren muß. Verantwortlich hierfür sind heterogenitätsinduzierte Umverteilungseffekte, die je nach Konstruktion des Earmarking-Verfahrens mehr oder weniger stark in Erscheinung treten. Letzten Endes kommt also neben der Unterschiedlichkeit in den Quantitäten der von den NZBen eingebrachten Pre-EWU-Aktiva auch der Wahl des Earmarking-Verfahrens und damit den Qualitäten der NZB-Pre-EWU-Aktiva selbst eine entscheidende Bedeutung für

Gold (AP 1 der altHB). Vgl. auch die Berechnungen zum ,sukzessiven“ Earmarking in Tabelle A4 im Anhang.

$403 \mathrm{Vgl}$. die Übersichtsdarstellung der verschiedenen Seigniorage-Studien in Kapitel V.3.1.2. Abschnitt 3.2.1..

404 Zur Ansetzung der Verzinsung vgl. die Erläuterungen zu den Berechnungen der verschiedenen Earmarking-Varianten in Tabelle A3 und A4 im Anhang. 
die Umverteilungseffekte aus dem Seigniorage-Pooling $\mathrm{zu}^{405}$. Durch das vom EZB-Rat am 6. Dezember 2001 beschlossene Earmarking-Verfahren werden diese heterogenitätsinduzierten Umverteilungseffekte weitgehend ausgeblendet. Einzig die unterschiedlichen Forderungen der NZBen aus Haupt- und Längerfristigen Refinanzierungsgeschäften könnten diesbezüglich eine gewisse Rolle spielen.

\subsection{Zwischenergebnis}

Die Analyse der Konstruktionselemente des vom EZB-Rat beschlossenen Earmarking-Verfahrens zeigte, daß schon von vornherein bestimmte NZBAktivpositionen (Sonstige Euro-Forderungen gegenüber dem Finanzsektor, Forderungen an Haushalte, Schwebende Verrechnungen und „sonstige“ Aktiva (Positionen 6, 8, 10 und 11 der neuHB)) wegen ihrer bereits zweckgebundenen Verwendung beziehungsweise aufgrund des Fehlens einer dauerhaften und funktionalen Beziehung zur Monetären NZB-Basis für ein Earmarking nicht in Frage kommen und wohl deshalb auch nicht vom EZB-Rat berücksichtigt wurden. Des weiteren wurde anhand der Analyse anderer denkbarer Earmarking-Varianten klar, warum mit Ausnahme von Gold ausschließlich nur Nominalwertforderungen mit einer vom EZB-Rat festgelegten Verzinsung als „gesondert erfaßbare Vermögenswerte" für die Ermittlung der Monetären Einkünfte deklariert wurden und weshalb der EZB-Rat den NZBen beim Earmarking keinen Gestaltungsspielraum läßt. Der Grund hierfür liegt offensichtlich in der weitgehenden Vermeidung von heterogenitätsinduzierten Umverteilungseffekten, die sich aus den großen quantitativen und qualitativen Unterschiedlichkeiten der NZB-Aktiva ergeben.

Bezüglich der bilanztechnischen Erfassung der Geldschöpfungsgewinne auf der Passivseite der NZB-Bilanzen zeigte die Analyse, daß obwohl in die Bemessungsgrundlage zur Ermittlung der Monetären Einkünfte auch Komponenten eingehen, deren Existenz nicht ursächlich auf die Geldschöpfung des Eurosystems zurückzuführen ist, die Gewinne des Eurosystem aus der Schaffung von Basisgeld vollständig erfaßt werden. Etwaige Verzerrungen, die aus bestimmten parallel zum Seigniorage-Pooling stattfindenden IntraEurosystem-Ressourcentransfers resultieren können, werden durch die Konstruktion des Earmarking-Verfahrens vermieden. Alternative Vorgehensweisen könnten dies jedoch ebenso leisten.

${ }_{405}$ Vgl. Hasse (1997). 


\section{Umverteilungseffekte des Earmarking-Verfahrens}

Zunächst soll geklärt werden, warum eine Umverteilung von Geldschöpfungsgewinnen im Eurosystem erforderlich ist und wie der in der ESZBSatzung vorgesehene Verteilungsschlüssel ökonomisch begründet werden kann. Die dann anschließenden Analysen beschäftigen sich mit den als unerwünscht definierten Umverteilungseffekten des Earmarking-Verfahrens.

\subsection{Rechtfertigung der Umverteilung von Geldschöpfungsgewinnen im Eurosystem}

Die Rechtfertigung für eine Umverteilung von Geldschöpfungsgewinnen im Eurosystem liegt in der grenzüberschreitenden Nutzung von Zentralbankgeld und dessen Auswirkung auf die Gewinne der einzelnen NZBen. So sind die Geldverwender in der EWU nicht mehr darauf angewiesen, sich ihre offiziellen Zahlungsmittel bei der heimischen NZB zu besorgen. Relevant erscheint dies vor allem für die Urlaubsländer der EWU, die gerade in der Ferienzeit mit einem Zustrom an Euro-Banknoten, die von ausländischen EWU-NZBen emittiert wurden, rechnen müssen ${ }^{406}$. Theoretisch könnte es sogar soweit kommen, daß sich die Nettoerträge des Eurosystems, die aus der Emission von Zentralbankgeld entstehen, bei nur einer einzigen NZB konzentrieren. In diesem Fall würden ohne einen Umverteilungsmechanismus dann aber auch nur diejenigen Bürger ${ }^{407}$ in den Genuß der Geldemissionsgewinne kommen, bei dessen NZB die auszuschüttenden Nettoerträge gerade anfallen, während die Wirtschaftssubjekte in anderen Teilräumen des Eurogebiets leer ausgehen, obwohl sie diese effektiv mitfinanziert haben. Deshalb erscheint es grundsätzlich wünschenswert, die Geldschöpfungsgewinne des Eurosystems auf die gesamten EWU-Bürger zu verteilen ${ }^{408}$.

Als Verteilungskriterium kommt hierbei aus naheliegenden Gründen die effektive Finanzierungsleistung der jeweils in den EWU-Staaten ansässigen Geldverwender in Frage. Dabei bestimmt sich die effektive Finanzierungsleistung wegen der marktgerechten Verzinsung der Mindestreserve vor allem

406 Vgl. auch Gros (1998), S. 33.

407 Der Begriff Bürger ist hier ungeachtet der staatsbürgerlichen Zugehörigkeit im ökonomischen Sinn als Wirtschaftssubjekt mit Wohnsitz im Inland zu verstehen.

408 EWU-Ausländer sollten hingegen nicht an den Notenbankgewinnen des Eurosystems partizipieren, da diese zwar in Höhe der Zinseinkünfte aus der Auslandszirkulation der Euro-Banknoten einen Teil der Notenbankgewinne effektiv mitfinanzieren, aber im Gegensatz zu den EWU-Inländern nicht die Last zu tragen haben, im Falle einer als zu hoch empfundenen Inflation die Euros als gesetzliches Zahlungsmittel akzeptieren zu müssen. 
durch den Zinsverzicht, den die in den einzelnen EWU-Staaten ansässigen Banknotenverwender leisten. Da aber der in der jeweiligen NZB-Bilanz ausgewiesene Banknotenumlauf nicht notwendigerweise der tatsächlichen Banknoten-Zirkulation in den einzelnen EWU-Staaten entsprechen muß und letztere auch nicht ohne weiteres bestimmbar ist, bietet es sich an, als Verteilungskriterium anerkannte ökonomische Determinanten der Transaktionskasse heranzuziehen. Diese umfassen im wesentlichen das Volkseinkommen sowie Zinsen für alternative Vermögensanlagen ${ }^{409}$. Da sich jedoch eine empirische Schätzung der Zinselastizität der Geldnachfrage nicht ohne Probleme gestaltet und dieser Parameter für die langfristige Entwicklung des Zentralbankgeldumlaufs ohnehin nicht dominant ist, überrascht es nicht, daß die Gewinnverteilungsregel der ESZB-Satzung gerade die erste Determinante der Transaktionskasse im Blickfeld hat. So erfolgt die Verteilung der gepoolten Monetären Einkünfte nach Maßgabe der eingezahlten EZB-Kapitalanteile, die sich ihrerseits jeweils zur Hälfte am relativen Anteil der Bevölkerung und dem Bruttoinlandsprodukt des betreffenden Landes an der gesamten Gemeinschaft orientiert $^{410}$. Insgesamt gesehen ist der in der ESZB-Satzung verankerte Gewinnverteilungsschlüssel also ökonomisch begründbar.

\subsection{Unerwünschte Umverteilungseffekte des Earmarking-Verfahrens}

Allgemein wird unterstellt, daß nur diejenigen Geldschöpfungsgewinne einem Umverteilungsverfahren unterzogen werden sollten, die das Eurosystem seit Aufnahme seiner Tätigkeit am 1.1.1999 erwirtschaftet hat. Das Geldschöpfungsvermögen jedoch, das die NZBen bereits mit in die EWU eingebracht haben, soll hingegen nicht vergemeinschaftet werden, da dieses noch der nationalen Geldpolitik zuzurechnen ist ${ }^{411}$. Eine solche Trennung ist in der ESZB-Satzung aber nicht vorgesehen.

Am besten nähert man sich dieser Diskussion, indem man - wie in Tabelle 39 geschehen - die Anteile der jeweiligen NZBen an der gesamten europäischen Monetären NZB-Basis zum 1.1.1999 den entsprechenden EZB-Kapitalanteilen der NZBen gegenüberstellt.

409 Vgl. hierzu z.B. Issing (1995), S. 22 ff..

410 Vgl. Art. 29.1. und Art. 32.5. ESZB-Satzung.

411 Vgl. z.B. Remsperger (1996), S. 3, Sinn/Feist (1997a), S. 24, Gros (1998), S. 34, Rösl/Schäfer (1998a), S. 11 und Sinn/Feist (2000c), S. 19. 
Tabelle 39: EZB-Kapitalanteil der EWU-11-NZBen und die Verteilung der Monetären NZB-Basen zum 1.1.1999

\begin{tabular}{|c|c|c|c|c|c|}
\hline EWU-11 & $\begin{array}{c}\text { Kapitalanteil der } \\
\text { NZB am gezahlten } \\
\text { EZB-Kapital }^{1}\end{array}$ & $\begin{array}{c}\text { Anteil der NZB an } \\
\text { der gesamten } \\
\text { Monetären } \\
\text { NZB-Basis } \\
\end{array}$ & $\begin{array}{l}\text { Differenz zwischen dem } \\
\text { Anteil der NZB an der } \\
\text { gesamten Monetären NZB- } \\
\text { Basis und dem Anteil der } \\
\text { NZB am gezahlten EZB- } \\
\text { Kapital in Prozentpunkten }\end{array}$ & $\begin{array}{c}\text { Anteil der NZB am } \\
\text { gesamten } \\
\text { Banknotenumlauf }\end{array}$ & \begin{tabular}{|c} 
Differenz zwischen \\
dem Anteil der NZB \\
am gesamten \\
Banknotenumlauf und \\
dem Anteil der NZB \\
am gezahlten EZB- \\
Kapital in \\
Prozentpunkten
\end{tabular} \\
\hline Deutsche Bundesbank & $31,0 \%$ & $37,3 \%$ & 6,3 & $38,2 \%$ & 7,2 \\
\hline Banque de France & $21,3 \%$ & $14,2 \%$ & $-7,1$ & $12,4 \%$ & $-8,9$ \\
\hline Banca d'Italia & $18,9 \%$ & $16,4 \%$ & $-2,5$ & $18,5 \%$ & $-0,4$ \\
\hline Banco de España & $11,3 \%$ & $14,0 \%$ & 2,7 & $15,4 \%$ & 4,1 \\
\hline De Nederlandsche Bank & $5,4 \%$ & $5,8 \%$ & 0,4 & $5,1 \%$ & $-0,3$ \\
\hline Belgische Nationalbank & $3,6 \%$ & $4,4 \%$ & 0,8 & $3,5 \%$ & $-0,1$ \\
\hline $\begin{array}{l}\text { Österreichische } \\
\text { Nationalbank }\end{array}$ & $3,0 \%$ & $3,8 \%$ & 0,8 & $3,6 \%$ & 0,6 \\
\hline Banco de Portugal & $2,4 \%$ & $1,5 \%$ & $-0,9$ & $1,5 \%$ & $-0,9$ \\
\hline Bank of Finland & $1,8 \%$ & $1,1 \%$ & $-0,7$ & $0,8 \%$ & $-1,0$ \\
\hline Central Bank oflreland & $1,1 \%$ & $1,5 \%$ & 0,4 & $1,0 \%$ & $-0,1$ \\
\hline $\begin{array}{l}\text { Banque Centrale du } \\
\text { Luxembourg }\end{array}$ & $0,2 \%$ & $0,0 \%$ & $-0,2$ & $0,0 \%$ & $-0,2$ \\
\hline Gesamt & $100,0 \%$ & $100,0 \%$ & 0,0 & $100,0 \%$ & 0,0 \\
\hline
\end{tabular}

Quelle: Eigene Berechnungen. Die der Darstellung zugrunde liegenden Daten sind aus Tabelle 9 und Europäische Zentralbank (2001d), S. 200 entnommen. Differenzen in den Summen durch Runden der Zahlen.

${ }^{1}$ Von den EWU-11-NZBen finanziertes EZB-Kapital. Bei der Berechnung dieser Kapitalanteile bleiben die Kapitalzahlungen der Pre-In-NZBen unberücksichtigt. 
Während die NZBen der Niederlande, Belgiens, Österreichs, Portugals, Finnlands, Irlands und Luxemburgs jeweils weniger als einen Prozentpunkt zwischen ihrem gezahlten EZB-Kapitalanteil und ihrem Anteil an der gesamten Monetären NZB-Basis aufweisen, fielen die Unterschiede bei den Zentralbanken Deutschlands, Frankreichs, Italiens und Spaniens besonders deutlich aus. So brachte zum Beispiel die Deutsche Bundesbank 37,3 Prozent der gesamten Monetären NZB-Basis in die EWU mit ein, verfügte aber nur über einen gezahlten EZB-Kapitalanteil von 31,0 Prozent. Anders herum verhält es sich bei der Zentralbank Frankreichs, die bei einem gezahlten EZB-Kapitalanteil von 21,3 Prozent nur 14,2 Prozent der gesamten Monetären NZB-Basis auf sich vereinigen konnte. Diese Unterschiede lassen sich vor allem über die Verteilung der nationalen Banknotenumläufe erklären, wie Tabelle 39 unmittelbar erkennen läßt. Dabei liegt die Ursache für den relativ hohen DEM-Umlauf vor allem in der umfangreichen internationalen Verwendung der D-Mark ${ }^{412}$, wogegen der relativ hohe Umlauf an spanischen Peseten neben den traditionell engen Beziehungen zu den ehemaligen Kolonien auch auf hohe SchwarzmarktAktivitäten zurückzuführen sein dürfte ${ }^{4 / 3}$. Die relativ geringe Banknotenverwendung in Frankreich hingegen hat ihre Ursache vor allem in der intensiven Nutzung elektronischer Zahlungsmittel wie Geld- und Kreditkarten ${ }^{414}$.

Wegen der allgemeinen Pflicht der NZBen, beim Earmarking-Verfahren des EZB-Rats (fast) ausschließlich verzinsliche Aktiva zu earmarken, führt die Unterschiedlichkeit der Verteilung der (Pre-EWU-) Monetären NZB-Basen und der EZB-Kapitalanteile nun dazu, daß diejenigen NZBen, deren Anteil an der gesamten Monetären NZB-Basis zu Beginn der EWU höher war als ihr Anteil am gezahlten EZB-Kapital, beim Pooling der Monetären Einkünfte einen Verlust erleiden werden, während die anderen NZBen entsprechend von der Umverteilung profitieren. Dies impliziert eine (faktische) Sozialisierung von Geldschöpfungsvermögen, welches die NZBen bereits mit in die EWU eingebracht haben und das somit noch der ehemals nationalen Geldpolitik zuzurechnen ist. Eine solche Regelung ist jedoch kaum zu begründen ${ }^{415}$.

412 So zirkulierten Ende 1994 ca. 30 - 40 Prozent des DEM-Notenumlaufs im Ausland. Vgl. Deutsche Bundesbank (1995), S. 67, Seitz (1995), S. 54 und Deutsche Bundesbank (1999a), S. 44.

$413 \mathrm{Vgl}$. Schneider/Ernste (2000), S. 199.

$414 \mathrm{Vgl}$. hierzu insbesondere die Strukturdaten zum Zahlungsverkehr in den einzelnen Industrieländern in Deutsche Bundesbank (1999a), S. 43.

415 Vgl. z.B. Remsperger (1996), S. 2, o.V. (1996), S. 7, Sinn/Feist (1997d), S. 8 und Gros (1998), S. 19. 


\subsubsection{Die empirischen Seigniorage-Studien im Überblick}

Die kritisierten Umverteilungswirkungen könnten allerdings toleriert werden, wenn die umverteilten Beträge keine bedeutenden Ausmaße annähmen. Gerade dieser Fragestellung widmete sich in jüngerer Vergangenheit eine Vielzahl von empirischen Untersuchungen, die aber zu höchst unterschiedlichen Ergebnissen kommen. Es läßt sich jedoch zeigen, daß die gefundenen Resultate weit weniger widersprüchlich sind als vielfach angenommen, da sie entweder unterschiedliche Fragestellungen beantworten und/oder unterschiedliche Meßverfahren verwenden ${ }^{416}$. Am deutlichsten wird dies, wenn man - wie in Tabelle 40 geschehen - die einschlägigen Studien in drei Kategorien einteilt ${ }^{417}$.

Die erste Gruppe untersucht die gepoolten Erträge aus den Pre-EWU-Aktiva der NZBen und mißt die umverteilten Beträge auf Jahresbasis. Je nach Berechnungsmethode differieren hierbei die gefundenen Ergebnisse, da sie entweder unterschiedliche Teilnehmerszenarien unterstellen und/oder verschiedene Datenbasen zugrunde legen. So wird zum Beispiel der Verlust der Bundesbank aus der Sozialisierung ihres Pre-EWU-Aktivabestandes auf einen Betrag zwischen 0,9-2,3 Mrd. EUR pro Jahr geschätzt ${ }^{418}$. Allerdings vermochten diese zum Teil bereits 1996 veröffentlichten Ergebnisse keine allzu große Öffentlichkeitswirkung zu entfalten. Nicht so die Untersuchungen von Sinn und Feist, die zwar inhaltlich die gleiche Fragestellung wie die bis dato vorliegenden Seigniorage-Studien im Blickfeld haben, die Poolgewinne bzw. -verluste der NZBen aber nicht über die jährlich anfallenden Beträge, sondern über den Barwert derselben beschreiben ${ }^{419}$. Die Folge hiervon sind ungleich höhere Gewinner- und Verliererpositionen der NZBen; im Falle der Bundesbank Verluste zwischen 29 und 46 Mrd. EUR. Dabei erweisen sich - jeweils im Rahmen der getroffenen Annahmen - auch die mit der „Barwertmethode“ gefundenen Ergebnisse als recht robust.

416 Vgl. auch Sinn (1997), S. 44 und Maennig (1999), S. 86.

417 Eine Übersichtsdarstellung von drei bzw. vier relevanten Seignioragestudien findet sich auch in Maennig (1999), S. 87, Larbig (1997), S. 18 f. und Larbig (1999), S. 212 f..

$418 \mathrm{Je}$ nach unterstelltem USD- bzw. ECU-Wechselkurs können die prognostizierten deutschen Verluste bei einzelnen Studien sogar über 2,3 Mrd. EUR liegen. Zudem sei erwähnt, daß die Untersuchung der Dresdner Bank eine wachsende Monetäre NZB-Basis unterstellt. Die Geldschöpfungsgewinne des Eurosystems aus dem Zuwachs an Monetärer NZB-Basis wären in diesem Zusammenhang als „erwünscht“ zu klassifizeren. Da aber die gefundenen Ergebnisse weitestgehend von dem Pre-EWU-Aktivastock dominiert werden, sollen die Erträge aus dem Zuwachs des Geldschöpfungsvermögens hier nicht im einzelnen berücksichtigt werden. 
Tabelle 40: Seigniorage-Studien im Überblick

\begin{tabular}{|c|c|c|c|c|}
\hline Autor & Untersuchungsgegenstand & Zentrale Annahmen & Berechungsmethode & Verlust Deutschlands \\
\hline $\begin{array}{l}\text { Remsperger } \\
\text { (1996) }\end{array}$ & $\begin{array}{l}\text { Jăhrliche Zinscrtragsverluste bzw. } \\
\text {-gewinne der NZBen aus dem Pre- } \\
\text { EWU-Aktivabestand durch das } \\
\text { Pooling der Monetăren Einkunfte }\end{array}$ & $\begin{array}{l}\text { - Unterstellter Bundesbankgewinn in Höhe } \\
\text { von } 7 \text { Mrd. DEM } \\
\text { - Verschicdene Teilnchmerszenarien }\end{array}$ & $\begin{array}{l}\text { Singuläre Beispielrechnung fur die } \\
\text { Verluste der Deutschen Bundesbank } \\
\text { aber die Differenz zwischen } \\
\text { relativen Poolfinanzierungs- und } \\
\text { Auszahlungsbetrag }\end{array}$ & $\begin{array}{l}\text { - 2,6 Mrd. DEM (1,3 Mrd. EUR) pro } \\
\text { Jahr bei EWU } 15 \\
\text { - 1,7 Mrd. DEM (0,9 Mrd. EUR) pro } \\
\text { Jahr bei „Kern-EWU“ }\end{array}$ \\
\hline $\begin{array}{l}\text { O.V. in Central } \\
\text { Banking (1996) }\end{array}$ & $\begin{array}{l}\text { Jährliche Zinsertragsverluste bzw. } \\
\text {-gewinne der NZBen aus dem Pre- } \\
\text { EWU-Aktivabestand durch das } \\
\text { Pooling der Monetăren Einkünfte }\end{array}$ & $\begin{array}{l}\text { - EWU } 15 \\
\text { - Weitgehend harmonisiert erfaßte } \\
\text { Zentralbankgewinne des Jahres } 1995\end{array}$ & $\begin{array}{l}\text { Verteilung der kumulierten } \\
\text { Zentralbankgewinne des Jahres } 1995 \\
\text { mit EZB-Kapitalanteil und Vergleich } \\
\text { mit dem aktuellen harmonisierten } \\
\text { Notenbankgewinn } \\
\end{array}$ & 2,6 Mrd. USD pro Jahr \\
\hline $\begin{array}{l}\text { O.V. in Central } \\
\text { Banking (1997) }\end{array}$ & $\begin{array}{l}\text { Jahrrliche bzw. kumulierte } \\
\text { Zinsertragsverluste bzw. -gewinne } \\
\text { der NZBen durch das Pooling der } \\
\text { Monetären Einkunfte im Zeitraum } \\
\text { von } 1999 \text { bis } 2004\end{array}$ & $\begin{array}{l}\text { - } \quad \text { EWU } 12 \\
\text { - } \quad \text { Zinssatz: 3,1 \% p.a. } \\
\text { Monetare NZB-Basen: Werte fur } 1996\end{array}$ & $\begin{array}{l}\text { Indirektes Verfahren mit } \\
\text { Banknotenumlauf }\end{array}$ & $\begin{array}{l}\text { 2,1 Mrd. USD pro Jahr oder } \\
\text { kumuliert (1999- 2004): 10,4 Mrd. } \\
\text { USD } \\
\text { Mit Kappung nach Art. 51 ESZB- } \\
\text { Satzung kumuliert (1999-2004): } \\
\text { 6,8 Mrd. USD }\end{array}$ \\
\hline $\begin{array}{l}\text { Dresdner Bank } \\
\text { (1997) }\end{array}$ & $\begin{array}{l}\text { Jahhrliche bzov. kumulierte } \\
\text { Zinsertragsverluste bzw. -gewinne } \\
\text { der NZBen durch das Pooling der } \\
\text { Monetăren Einkanfte im Zeitraum } \\
\text { von } 1999 \text { bis } 2004\end{array}$ & $\begin{array}{l}\text { - } \quad \text { EWU } 15 \\
\text { - } \quad \text { Kachstumsrate der Geldbasis: } 4 \text { \% p.a. } \\
\text { wachsender Anteil der NZBen an } \\
\text { - Zinssatz: 3-4,5\% \%.a. } \\
\text { - } \quad \text { Monetare Basen: Werte für } 1996\end{array}$ & $\begin{array}{l}\text { Indircktes Verfahren mit } \\
\text { Banknotenumlauf }\end{array}$ & $\begin{array}{l}\text { 2,5 bis 4,5 Mrd. DEM (1,3 bis 2,3 } \\
\text { Mrd. EUR) pro Jahr oder kumuliert } \\
\text { (1999-2004) ca. } 25 \text { Mrd. DEM } \\
\text { (13 Mrd. EUR) } \\
\text { - Mit Kappung nach Art. 51 ESZB- } \\
\text { Satzung kumuliert (1999-2004) } \\
\text { ca. 17.5 Mrd. DEM (8,9 Mrd. EUR) }\end{array}$ \\
\hline Schobert (1998) & $\begin{array}{l}\text { Jahrliche Zinsertragsverluste bzw. } \\
\text {-gewinne der NZBen aus dem Pre- } \\
\text { EWU-Aktivabestand durch das } \\
\text { Pooling der Monetären Einkanfte } \\
\end{array}$ & $\begin{array}{l}\text { - } \quad \text { EWU } 11 \\
\text { - Zinssatz: 6,34 \% p.a. } \\
\text { - Monetăre NZB-Basen: Werte furr } 1996\end{array}$ & $\begin{array}{l}\text { Indirektes Verfahren mit } \\
\text { Banknotenumlauf }\end{array}$ & 1,93 Mrd. ECU pro Jahr \\
\hline Gros (1998) & $\begin{array}{l}\text { Jahrliche Zinsertragsverluste bzw. } \\
\text {-gevinne der NZBen aus dem Pre- } \\
\text { EWU-Aktivabestand durch das } \\
\text { Pooling der Monetären Einkanfte }\end{array}$ & $\begin{array}{l}\text { - } \quad \text { EWU } 11 \\
\text { - Zinssatz: 6,34\% p.a. } \\
\text { - Monetare NZB-Basen: Werte für } 1996\end{array}$ & $\begin{array}{l}\text { Indirektes Verfahren mit } \\
\text { Banknotenumlauf }\end{array}$ & 1,93 Mrd. ECU pro Jahr \\
\hline Blau (1998) & $\begin{array}{l}\text { Jahrliche Zinsertragsverluste bzw. } \\
\text {-gewinne der NZBen aus } \\
\text { prognostizierten Monetăren } \\
\text { Einkünten bei verschiedenen } \\
\text { Szenarien }\end{array}$ & $\begin{array}{l}\text { EWU 15 } \\
\text { Datenbasis: } 1979 \text { - } 1995 \\
\text { - Alternative Szenarien der nationalen } \\
\text { Basisgeldnachfragen: „begrenzte“(BK) } \\
\text { und „vollstandige“ Konvergenz (VK) } \\
\text { - Altemative geldpolitische Szenarien: } \\
\text { "stabilitats“- und „kompromißorientiert“ }\end{array}$ & $\begin{array}{l}\text { Berechnung der Monetăren } \\
\text { Einkünfte in Abhăngigkeit der } \\
\text { verschiedenen Szenarien }\end{array}$ & $\begin{array}{l}\text { 1,8-3,1 Mrd. ECU pro Jahr bei } \\
\text { BK und unterschiedlichen } \\
\text { geldpolitischen Szenarien } \\
\text { - 1,0-1,7 Mrd. ECU pro Jahr bei } \\
\text { VK und unterschiedlichen } \\
\text { geldpolitischen Szenarien }\end{array}$ \\
\hline
\end{tabular}




\section{Noch Tabelle 40: Seigniorage-Studien im Überblick}

\begin{tabular}{|c|c|c|c|c|}
\hline Autor & Untersuchungsgegenstand & Zentrale Annahmen & Berechungsmethode & Verlust Deutschlands \\
\hline $\begin{array}{l}\text { Sinn/Feist } \\
(1997 \mathrm{a}),(1997 \mathrm{~b}) \\
(1997 \mathrm{c}),(1997 \mathrm{~d}) \\
\text { und Sinn }(1997)\end{array}$ & $\begin{array}{l}\text { Faktische Vergemeinschaftung eines Teils } \\
\text { des Pre-EWU-Aktivabestands der NZBen } \\
\text { durch das Earmarking-Verfahren }\end{array}$ & $\begin{array}{l}\text { - Verschiedene Teilnchmerszenarien } \\
\text { (v.a. EWU 15) } \\
\text { - Mit und ohne harmonisierte } \\
\text { Mindestreserve } \\
\text { - Konstante Pre-EWU-Geldhasis } \\
\text { - Earmarking: nur verzinsliche Aktiva }\end{array}$ & $\begin{array}{l}\text { Barwert der zukünftigen Erträge aus } \\
\text { dem geearmarkten Pre-EWU- } \\
\text { Aktivabestand der NZBen } \\
\text { (kapitalisierte Zinserträge bzw. } \\
\text {-verluste durch das Pooling der } \\
\text { Monetären Einkünfte) }\end{array}$ & $\begin{array}{l}90 \text { Mrd. DEM ( } 46 \text { Mrd. } \\
\text { EUR) bei EWU } 15 \text { ohne } \\
\text { harm. MR } \\
64 \text { Mrd. DEM ( } 33 \text { Mrd. } \\
\text { EUR bei EWU } 15 \text { mit } \\
\text { harm. MR bei } 2 \%\end{array}$ \\
\hline $\begin{array}{l}\text { L.äufer (1997), } \\
\text { (1998) }\end{array}$ & $\begin{array}{l}\text { Seigniorageverluste für Deutschland aus } \\
\text { dem Verlust des Wettbewerbsvorsprungs auf } \\
\text { dem internationalen Markt für Basisgeld }\end{array}$ & $\begin{array}{l}\text { - EWU } 15 \\
\text { - Konstante Pre-EWU-Geldbasis } \\
\text { Verschiebung der Verteilung der Pre- } \\
\text { EWU-Geldbasis } \\
\text { - Earmarking: nur verzinsliche Aktiva }\end{array}$ & $\begin{array}{l}\text { Übernahme der von Sinn/Feist (1997a) } \\
\text { errechncten Ergebnisse, aber inhaltlich } \\
\text { (vermeintlich) andere Begrilndung für } \\
\text { dic Verluste }\end{array}$ & $\begin{array}{l}90 \text { Mrd. DEM ( } 46 \text { Mrd. EUR) } \\
\text { bei EWU } 15\end{array}$ \\
\hline $\begin{array}{l}\text { Wenger/Kaserer } \\
(1997)\end{array}$ & $\begin{array}{l}\text { Berechnung der dt. Verluste wie Sinn/Feist } \\
\text { (1997a), dazu: Verluste aus Sozialisierung } \\
\text { der Erträge aus dem geschätzten Zuwachs } \\
\text { des DEM-Banknotenumlaufs ohne EWU }\end{array}$ & $\begin{array}{l}\text { Wie Sinn/Feist (1997a), aber: } \\
\text { - Nur Banknotenumlauf } \\
\text { - Geschătzte Wachstumsrate des DEM- } \\
\text { Notenumlaufs ohne EWU: } 4 \text { \% p.a. } \\
\text { - Zinssatz: k. A. }\end{array}$ & $\begin{array}{l}\text { Wie Sinn/Feist (1997a), dazu: } \\
\text { Kapitalisierung der Erträge aus dem } \\
\text { geschătzten Zuwachs des DEM- } \\
\text { Banknotenumlaufs ohne EWU }\end{array}$ & $\begin{array}{l}>150 \mathrm{Mrd} . \mathrm{DEM} \text { ( > } 77 \mathrm{Mrd} . \\
\text { EUR) }\end{array}$ \\
\hline Wenger (1997) & $\begin{array}{l}\text { Berechnung der dt. Verluste wie Sinn/Feist } \\
\text { (1997a), dazu: Verluste aus Sozialisierung } \\
\text { der Erträge aus dem geschätzten Zuwachs } \\
\text { des DEM-Banknotenumlaufs ohne EWU }\end{array}$ & $\begin{array}{l}\text { Wic Sinn/Feist (1997a), aber: } \\
\text { - Nur Banknotenumlauf } \\
\text { - Geschătzte Wachstumsrate des DEM- } \\
\text { Notenumlaufs ohne EWU: } 4 \text { \% p.a. } \\
\text { - Zinssatz: } 6 \text { \% p.a. }\end{array}$ & $\begin{array}{l}\text { Wie Sinn/Feist (1997a), dazu: } \\
\text { Kapitalisierung der Erträge aus dem } \\
\text { geschătzten Zuwachs des DEM- } \\
\text { Banknotenumlaufs ohne EWU }\end{array}$ & $\begin{array}{l}180 \text { Mrd. DEM ( } 92 \text { Mrd. } \\
\text { EUR), davon aus Pre-EWU- } \\
\text { Stock: } 60 \text { Mrd. DEM (31 Mrd. } \\
\text { EUR) }\end{array}$ \\
\hline Sinn/Feist (2000a) & Wie Sinn/Feist (1997a) & $\begin{array}{l}\text { Wie Sinn/Feist (1997a), aber: } \\
\text { - EWU } 12 \\
\text { - Nur Banknotenumlauf }\end{array}$ & Wie Sinn/Feist (1997a) & 59 Mrd. DEM (30 Mrd. EUR) \\
\hline $\begin{array}{l}\text { Sinn/Feist } \\
(2000 b),(2000 c)\end{array}$ & Wie Sinn/Feist (1997a) & $\begin{array}{l}\text { Wie Sinn/Feist (1997a), aber: } \\
\text { - Verschiedene Teilnehmerszenarien } \\
\text { (v.a. EWU 11) } \\
\text { - Nur Banknotenumlauf } \\
\end{array}$ & Wie Sinn/Feist (1997a) & $\begin{array}{l}57 \text { Mrd. DEM ( } 29 \text { Mrd. EUR) } \\
\text { bei EWU } 11\end{array}$ \\
\hline Feist (200I) & Wie Sinn/Feist (1997a) & $\begin{array}{l}\text { Wie Sinn/Feist (1997a), aber: } \\
\text { - EWU } 27 \\
\text { - Nur Banknotenumlauf }\end{array}$ & Wie Sinn/Fcist (1997a) & 96 Mrd. DEM (49 Mrd. EUR) \\
\hline
\end{tabular}




\section{Noch Tabelle 40: Seigniorage-Studien im Ũberblick}

\begin{tabular}{|c|c|c|c|c|}
\hline \multicolumn{5}{|c|}{$\begin{array}{l}\text { Seignioragegewinne und -verluste der NZBen durch Vergleich der geschătzten Seigniorageniveaus bei europåischer und nationaler Geldpolitik unter } \\
\text { teilweiser Berücksichtigung der Umverteilungseffekte zwischen den NZBen aus dem Pooling der Monetären Einkünfte }\end{array}$} \\
\hline Autor & Untersuchungsgegenstand & Zentrale Annahmen & Berechungsmethode & Verlust Deutschlands \\
\hline \multirow[t]{2}{*}{$\begin{array}{l}\text { Maennig/ } \\
\text { Hunger (1996) }\end{array}$} & $\begin{array}{l}\text { Seignioragezugetvinne bzw. -einbußen durch } \\
\text { Vergleich der Seigniorages bei autonomer } \\
\text { Geldpolitik in der Vergangenheit und der } \\
\text { Partizipation am prognostierten europalischen } \\
\text { Seigniorage }\end{array}$ & $\begin{array}{l}\text { - EWU } 14 \text { und EWU } 10 \\
\text { - } \pi=3 \% \\
\text { - } y=0 \%\end{array}$ & $\begin{array}{l}\text { Schătzung des europarischen } \\
\text { Seigniorages mit der Summe von } 14 \\
\text { nationalen realen Geldmengen der } \\
\text { Jahre } 1998 \text { - } 1992\end{array}$ & $\begin{array}{l}\text { - } 0,33 \% \text { des BIP bei EWU } 14 \\
\text { - } 0,39 \% \text { des BIP bei EWU } 10\end{array}$ \\
\hline & $\begin{array}{l}\text { Auswirkung der verănderten } \\
\text { Seigniorageausschuttung auf die nationalen } \\
\text { Haushalte }\end{array}$ & $\begin{array}{l}\text { Ausschattungsquote: } 35 \% \text { des } \\
\text { prognostizierten europäischen } \\
\text { Seigniorages }\end{array}$ & $\begin{array}{l}\text { Verteilung des Ausschattungsbetrags } \\
\text { nach EZB-Kapitalanteilen }\end{array}$ & $\begin{array}{l}\text { - } 1,3 \% \text { des Etats bei EWU } 14 \\
\text { - 1,4\% des Etats bei EWU } 10\end{array}$ \\
\hline $\begin{array}{l}\text { Lange/Nolte } \\
\text { (1997), (1998) }\end{array}$ & $\begin{array}{l}\text { Seignioragezugetvinne bzw. -einbußen durch } \\
\text { Vergleich der Seigniorages bei autonomer } \\
\text { Geldpolitik in der Vergangenheit und der } \\
\text { Partizipation am prognostierten Seigniorage } \\
\text { der EZB }\end{array}$ & $\begin{array}{l}\text { - EWU Is } \\
\text { - Geldpolitik wird operativ von der } \\
\text { EZB durchgefuhrt } \\
\text { - Alternative Inflations- und } \\
\text { Wachstumsszenarien }\end{array}$ & $\begin{array}{l}\text { Berechnungen mit } \\
\text { Opportunitătskostenseigniorage } \\
\text { (OppS) und Monetärem Seigniorage } \\
\text { (MonS) }\end{array}$ & $\begin{array}{l}\text { - } 0,35 \% \text { des BIP pro Jahr (Opps } \\
\text { bei } \pi=2 \%, y=0 \% \text { ) } \\
\text { - } 0,27 \% \text { des BIP (=Zugewinn) } \\
\text { pro Jahr (MonS bei } \pi=7 \% \text {, } \\
y=3,5 \% \text { ) }\end{array}$ \\
\hline Noltc (1998) & $\begin{array}{l}\text { Seignioragezugetwinne bzw. -einbußen durch } \\
\text { Vergleich der Seigniorages bei autonomer } \\
\text { Geldpolitik in der Vergangenheit und der } \\
\text { Partizipation am prognostierten Seigniorage } \\
\text { der EZB }\end{array}$ & $\begin{array}{l}\text { - EWU IS } \\
\text { - Geldpolitik wird operativ von der } \\
\text { EZB durchgefuhrt } \\
\text { - Altemative Inflationsszenarien }\end{array}$ & $\begin{array}{l}\text { Berechnungen mit } \\
\text { Opportunitătskostenseigniorage }\end{array}$ & $\begin{array}{l}\text { - } 0,29 \% \text { des BIP pro Jahr bei } \\
\pi=2 \% \\
-0,01 \% \text { des BIP (=Zugewinn) } \\
\text { bei } \pi=7 \% \text { pro Jahr }\end{array}$ \\
\hline $\begin{array}{l}\text { Klopfleisch } \\
\text { (1999) }\end{array}$ & $\begin{array}{l}\text { Untersuchung folgender Effekte auf den } \\
\text { Seigniorage der NZBen: } \\
\text { - Konvergenzprozeß hin zur EWU } \\
\text { (Konvergenzeffekt) } \\
\text { - Änderung des geldpolitischen } \\
\text { Instrumentariums (Übergangseffekt) } \\
\text { - Poolings der Monetăren Einkünfte } \\
\text { (Verteilungseffekt) }\end{array}$ & $\begin{array}{l}\text { - EWU } 11 \\
\text { - Unterschiedliche Varianten des } \\
\text { fiskalischen, monetăren und des } \\
\text { Opportunitätskostenseigniorages } \\
\text { - Beobachtungszeitraum } 1992-1997\end{array}$ & $\begin{array}{l}\text { Berechnungen des Konvergenzeffekts } \\
\text { aber Zins-, Preisstabilităts- und } \\
\text { Mindestreserveeffekte, Ermittlung des } \\
\text { Übergangs- und Verteilungseffekts } \\
\text { aber Opportunitatskostenseigniorage }\end{array}$ & $\begin{array}{l}\text { - Konvergenzeffekt: } 0,81 \% \text { des } \\
\text { BIP pro Jahr } \\
\text { - Übergangseffekt: } 0,11 \% \text { des } \\
\text { BIP pro Jahr } \\
\text { - Verteilungseffekt: } 0,03 \% \text { des } \\
\text { BIP pro Jahr }\end{array}$ \\
\hline \multirow[t]{2}{*}{ Maennig (1999) } & $\begin{array}{l}\text { Seignioragezugewinne bzw. -cinbußen durch } \\
\text { Vergleich der Seigniorages bei autonomer } \\
\text { Geldpolitik in der Vergangenheit und der } \\
\text { Partizipation am prognostierten europaischen } \\
\text { Seigniorage }\end{array}$ & $\begin{array}{l}\text { - EWU } 14 \text { und EWU } 10 \\
\text { - } \pi=3 \% \\
\text { - } y=0 \%\end{array}$ & $\begin{array}{l}\text { Schatzung des europarischen } \\
\text { Seigniorages mit der Summe von } 14 \\
\text { nationalen realen Geldmengen der } \\
\text { Jahre } 1998-1992\end{array}$ & $\begin{array}{l}-0,33 \% \text { des BIP bei EWU } 14 \\
\text { - } 0,39 \% \text { des BIP bei EWU } 10\end{array}$ \\
\hline & $\begin{array}{l}\text { Auswirkung der verłnderten } \\
\text { Seigniorageausschultung auf die nationalen } \\
\text { Haushalte }\end{array}$ & $\begin{array}{l}\text { Ausschuttungsquote: } 80 \% \text { des } \\
\text { prognostizierten europäischen } \\
\text { Seigniorages }\end{array}$ & $\begin{array}{l}\text { Verteilung des Ausschattungsbetrags } \\
\text { nach EZB-Kapitalanteilen }\end{array}$ & $\begin{array}{l}-0,9 \% \text { des Etats bei EWU } 14 \\
\text { - } 1,0 \% \text { des Etats bei EWU } 10\end{array}$ \\
\hline
\end{tabular}


Daran ändern auch die Berechnungen Wengers nichts, der den Barwert des deutschen Verlusts zwar auf bis zu 92 Mrd. EUR beziffert, aber die SinnFeistschen Überlegungen nur erweitert. So schätzt Wenger die (faktische) Vergemeinschaftung des Pre-EWU-Aktivabestandes ähnlich wie Sinn und Feist auf $31 \mathrm{Mrd}$. EUR ${ }^{420}$, bezieht aber zusätzlich auch die Sozialisierung der Erträge, die die Bundesbank erst nach dem Übergang zur dritten Stufe der EWU aus dem geschätzten Zuwachs des Geldschöpfungsvermögens annahmegemäß erzielen wird (61 Mrd. EUR), in seine Analyse mit ein ${ }^{421}$. Auch die jüngst von Feist vorgestellte Prognose des deutschen Verlustes in Höhe von $49 \mathrm{Mrd}$. EUR steht nicht im Widerspruch zu den von Sinn und Feist gefundenen Ergebnissen. So unterstellt Feist wie die Sinn-Feistschen-Berechnungen eine konstante Monetäre Pre-EWU-Basis, erweitert aber die EWU-Teilnehmerzahl auf 27 Staaten und zeigt so grundsätzliche Probleme einer sich vergrößernden EWU auf.

Die dritte Gruppe von Seigniorageuntersuchungen ist hingegen mit den beiden erstgenannten nur in Ansätzen vergleichbar. So sprechen diese Studien zwar das Pooling der Monetären Einkünfte an. Die Berechnungen haben aber vor allem die allgemeine Seigniorageniveauveränderung im Blickfeld, die sich aus der europäischen im Vergleich zur vormals nationalen Geldpolitik ergeben können. Bildlich gesprochen geht es bei diesen Untersuchungen also nicht ausschließlich um die Verteilung des „Pre-EWU-Seigniorage-Kuchens“ in Form eines Nullsummenspiels der Gewinner- und Verlierer-NZBen, sondern weitgehend um die im Rahmen verschiedener Szenarien prognostizierte Höhe des sich in Zukunft ergebenden europäischen "Seigniorage-Kuchens“, dessen Verteilung auf die NZBen und die Bezugsetzung der ausgeschütteten Beträge zu den geschätzten nationalen Seigniorageeinnahmen der NZBen ohne $\mathrm{EWU}^{422}$. Es

420 Wenger legt seinen Berechnungen nur den DEM-Banknotenumlauf zugrunde, während Sinn und Feist in ihrer ersten Studie zusätzlich verschiedene Mindestreserveszenarien untersuchen, die bei einem Satz von 2 Prozent einen deutschen Seigniorageverlust von 64 Mrd. DEM bzw. 33 Mrd. EUR impliziert. Vgl. Wenger (1998), S. 1 und Sinn/Feist (1997a), S. 20. Diese Ausführungen gelten auch für die Schätzungen Wengers und Kaserers. Vgl. Wenger/Kaserer (1997).

Da die Sozialisierung des Zuwachses an zukünftigen Geldschöpfungsgewinnen, die die NZBen ohne ihre Pre-EWU-Aktiva erzielen, als wünschenswert angesehen werden können, sollen an dieser Stelle die Überlegungen Wengers und Kaserers nicht weiter verfolgt werden.

422 Diese Untersuchungen stehen also eher in der Tradition der Analysen von Gubitz (1989), Grilli (1989a), Grilli (1989b), Cornelius (1990b), Gros (1990), Gros (1993), Gros/Vandille (1995), Hofner (1994) und Balke/Dejonckheere/Masseti (1996), die sich unter anderem mit der Frage beschäftigen, welche Bedeutung die nationalen Seigniorages für einzelnen $\mathrm{E}(\mathrm{W}) \mathrm{U}$-Staaten in der Vergangenheit besaßen und welche Auswirkungen bestimmte Faktoren (u.a. die Konvergenzkriterien) auf die zukünftige Seigniorageentwicklung haben werden. 
überrascht also nicht, daß diese Studien den Großteil der NZBen überwiegend als „Seigniorageverlierer" bezeichnen, ohne daß es entsprechend größengleiche Seignioragegewinner gibt, da bei stabilitätsorientierter Geldpolitik der EZB der europäische Seigniorage annahmegemäß niedriger ist als die kumulierten nationalen Seigniorages bei nationaler, also zumindest teilweise weniger stabiler Geldpolitik der NZBen.

$\mathrm{Da}$ an dieser Stelle aber nur die ,ungerechtfertigten“ Umverteilungen der Erträge der NZBen, die auf ihrem Pre-EWU-Geldschöpfungsvermögen beruhen, untersucht werden sollen, wird im Folgenden nur auf die ersten beiden Gruppen von Seigniorage-Studien Bezug genommen.

\subsubsection{Kritische Würdigung der Seigniorage-Studien}

Zunächst gilt es, darauf hinzuweisen, daß die Seigniorage-Studien, die die kritisierte Vergemeinschaftung der Erträge aus dem Pre-EWU-Seignioragevermögen auf Jahresbasis berechnen, grundsätzlich nicht weniger aussagekräftig sind, als die Untersuchungen, die sich der Barwertmethode bedienen. Unter bestimmten Voraussetzungen unterscheidet beide Varianten ja nur der Zeithorizont. Die konkrete Quantifizierung der Umverteilungseffekte auf Jahresbasis gestaltet sich jedoch vergleichsweise schwieriger, da hier konkret entschieden werden muß, in welcher Form geearmarkt und welche Verzinsung unterstellt werden soll.

\subsubsection{Seigniorage-Studien, die die Umverteilungseffekte auf Jahresbasis berechnen}

Wie Tabelle 40 erkennen läßt, greift ein Teil der Studien, die die kritisierten Umverteilungseffekte auf Jahresbasis berechnen, auf das Indirekte Verfahren zur Ermittlung der Monetären Einkünfte zurück, wobei jeweils der Banknotenumlauf in die Bemessungsgrundlage mit eingeht. Ein solches Vorgehen ist mit dem (ab 2008 gültigen) Earmarking-Regelverfahren dann inhaltlich identisch, wenn - wie dies nach dem einschlägigen EZB-Ratsbeschluß auch weitgehend der Fall ist - ausschließlich zum (einheitlichen) Marktzins vergütete Aktiva geearmarkt werden und die bis 2007 gültigen Übergangsregelungen nicht mehr greifen. Für die Berechnung der tatsächlichen (Pre-EWUAktiva-basierten) Umverteilungseffekte des Seigniorage-Pooling im Zeitraum vom 1.1.1999 bis zum 31.12.2007 ist die Verwendung der Indirekten-Methode (inkl. Banknotenumlauf in der Bemessungsgrundlage) jedoch ungeeignet, da in dieser Zeit unterschiedliche Maßnahmen die kritisierten Umverteilungswirkungen erheblich reduzieren. Diesbezüglich sei auf die bereits 
vorgenommene Analyse des Seigniorage-Poolings in der „Übergangsphase“ (1999 bis 2001) und auf die noch folgenden Ausführungen zu den von 2002 bis 2007 anzurechnenden Ausgleichsbeträgen verwiesen ${ }^{423}$.

Weiterhin kann angemerkt werden, daß die genannten Seigniorage-Studien nicht die Verzinsung der Mindestreserve und deren Abzugsfähigkeit vom NZBPoolbeitrag berücksichtigen ${ }^{424}$. Welche Auswirkungen die Anrechnungsfähigkeit der Mindestreserveaufwendungen für die Netto-Poolpositionen der einzelnen NZBen hat, zeigt die Tabelle 41. So würde sich z.B. in einem EWU11-Szenario für die Deutsche Bundesbank (BBk) bei unverzinster Mindestreserve und einem unterstellen Referenzzins von 2,71 Prozent ein zusätzlicher Netto-Poolingverlust aus Pre-EWU-Aktiva in Höhe von 63 Mio. EUR pro Jahr ergeben, der allerdings gegenwärtig wegen der Verzinsung und Abzugsfähigkeit der Mindestreserve nicht zum Tragen kommt. Für die Bundesbank bedeutet dies immerhin eine Reduktion der maximal möglichen unerwünschten Umverteilungseffekte von rund 9 Prozent.

Interessant ist nun die Frage, ob nicht auch das Earmarking von Gold zu einer Reduktion der kritisierten Umverteilungseffekte führt. So verringert das Earmarking der (Earmarking-fähigen) unverzinslichen Goldbestände den jeweiligen NZB-Poolbetrag und damit auch die Höhe der umverteilten Beträge. Eine Auswirkung auf die unerwünschten Umverteilungseffekte hat diese Regelung jedoch nicht. Dies liegt daran, daß die Aufnahme des Goldes in die Earmarking-Aktiva - im Gegensatz zur Verteilung der Pre-EWU-Einlagen der Kreditinstitute bei der Anrechnung der Mindestreserveverzinsung - nur nach Maßgabe des EZB-Kapitalschlüssels erfolgen darf und der EZB-Kapitalschlüssel zugleich der Verteilungsschlüssel des Pools der Monetären Einkünfte bildet. Im Endeffekt wird durch diese Regelung nur die Poolhöhe und damit auch die Absoluthöhe der umverteilten Seigniorage-Einkünfte gekürzt. Diese Kürzung läßt jedoch sowohl die relative als auch die absolute NettoPoolingposition der NZBen unberührt. Die errechenbare Zinsersparnis aus dem Earmarking von Gold darf letztlich gar nicht als echte Ersparnis interpretiert werden, da die einzelnen NZBen durch Verzicht auf Pooleinzahlung nur diejenigen Nettobeträge „sparen“, die sie ohnehin wieder ausgeschüttet bekommen hätten. Sparen kann man sich allerdings das Earmarking von Gold, was auch die vergleichenden Umverteilungsrechungen der Tabelle 41 unmittelbar belegen.

423 Vgl. Kapitel V.3.1.1. Abschnitt 3. und Kapitel V.3.1.2. Abschnitt 3.2.3.2..

424 Die Verzinsung der Mindestreserve war allerdings zum Zeitpunkt der Erstellung der Studien auch nicht unbedingt vorhersehbar. 
Tabelle 41: Die Auswirkungen der Verzinsung der Mindestreserve sowie des Earmarkings unverzinslicher Goldbestănde auf die Umverteilung der Monetăren Einkünfte' Monetüre Einkanfte aus Monetürer Pre-EWU-Basis (Banknotenumlauf und Einlagen der Kreditinstitute) zum 1.1.1999, verzinste anrechenbare Mindestreserve

\begin{tabular}{|c|c|c|c|c|c|c|c|c|c|c|c|c|}
\hline NZB & BBk & BdI & BdF & BdE & DNB & NBB & OeNB & BdP & CBI & BoF & $\overline{B C L}$ & EURS \\
\hline Monetare NZB-Basis & 159876 & 70218 & 60798 & 60142 & 25064 & 18888 & 16243 & 6413 & 6245 & 4823 & 110,8 & 428820 \\
\hline Monetare Einkunfte brutto & 4333 & 1903 & 1648 & 1630 & 679 & 512 & 440 & 174 & 169 & 131 & 3 & 11621 \\
\hline Verzınsung der MR & .795 & -190 & -502 & .201 & -211 & -187 & -108 & -36 & .72 & -59 & 0 & 2361 \\
\hline Monetare Eınkianfte (netto) & 3538 & 1713 & 1145 & 1429 & 468 & 324 & 332 & 138 & 97 & 72 & 3 & 9260 \\
\hline Aus Pool an NZB & 2871 & 1750 & 1972 & 1046 & 500 & 333 & 278 & 222 & 102 & 167 & 19 & 9260 \\
\hline Gewinner $(+) /$ Verlierer $(-)$ & .667 & +37 & +827 & .383 & +32 & +9 & .55 & +85 & +5 & +95 & +16 & 0 \\
\hline
\end{tabular}

Monet⿱艹re Einkunfte aus Mindestreserve-Guthaben der Kreditinstitute zum 1.1.1999

\begin{tabular}{|c|c|c|c|c|c|c|c|c|c|c|c|c|}
\hline NZB & BBk & BdI & BdF & BdE & DNB & NBB & OeNB & $\mathbf{B d P}$ & CBI & BoF & BCL & EURS \\
\hline Euro-Eınlagen der Kreditınstitute & 29325 & 6998 & 18534 & 7411 & 7777 & 6916 & 3974 & 1331 & 2669 & 2176 & - & 87112 \\
\hline Monetare Eınkunfte & 795 & 190 & 502 & 201 & 211 & 187 & 108 & 36 & 72 & 59 & 0 & 2361 \\
\hline Aus Pool an NZB & 732 & 446 & 503 & 267 & 127 & 85 & 71 & 57 & 26 & 42 & 5 & 2361 \\
\hline Gewinner $(+)$ / Verlierer $(-)$ & -63 & +257 & +1 & +66 & -83 & -102 & -37 & +21 & -46 & -16 & +5 & 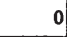 \\
\hline
\end{tabular}

Monetäre EinkUnfte und Goldearmarking zum 1.1.1999

B

BBk BdI Bd

Earmarking-Pahiger Goldbestand'

Antcil des Earmarking-Pahıgen NZB-

Goldbestandes am gesamten Earmarking- $\quad 31,0 \%$
rahigen Goldbestand

3128

1907

BdF
2149

BdE

DNB

$31,0 \%$

$18,9 \% \quad 21,3 \%$

1140

$545 \quad 363$

NBB
363

OeNB

\section{(B)}

CBI BOF BCL EURS

Monetare Eınkanfte (brutto)

Verzinsung der Mindestreserve

Zinserspamis aus Goldcarmarking ${ }^{6}$

Monetäre Einkunfte (verzinsliche MR und

\begin{tabular}{rrr}
4333 & 1903 \\
.795 & -190 \\
-85 & -52 \\
3453 & 1662 \\
2786 & 1699 \\
-667 & +37 \\
\hline
\end{tabular}

Goldearmarkıng)

Poolpartizipation

Gewinner $(+) /$ Verlierer (-)

Quelle. Eıgene Berechnungen Die der Darstellung zugrunde liegenden Daten sind der Tabelle 9 entnommen

' Angaben in Mio EUR

${ }^{2} \mathrm{Vgl}$ auch Tabelle 38 und die Tabelle $\mathrm{A} 4$ im Anhang

${ }^{3}$ Angaben zum I 1.1999. Zur Berechnung des Earmarking-Pahigen Goldbestands vgl. Tabelle A5 im Anhang

- Entsprncht wie der Poolverteilungsschlussel dem gezahlten EZB-Kapitalanteil (hier EWU-11).

' Vgl. Tabelle 38 und die Tabelle A4 im Anhang

'Ermittlung der Zinserspamis durch Multiplikation des Earmarking-fahigen Goldbestands zum 11.1999 mit dem jahresdurchschnittlichen Zinssatz fur Hauptrefinanzierungsgeschafte des Jahres 1999 (2,71 \% p.a). 
Es läßt sich folglich festhalten, daß die vorgestellten Seigniorage-Studien, die die unerwünschten Umverteilungseffekte auf Jahresbasis messen, die kritisierte Umverteilung von Pre-EWU-Ressourcen wegen der Nichtberücksichtigung der Verzinsung der Mindestreserve grundsätzlich zu hoch ansetzen. Die Tatsache, $\mathrm{da} ß$ das Earmarking-Verfahren des EZB-Rats in bestimmtem Umfang auch ein Earmarking von unverzinslichem Gold zuläßt, spielt hingegen für die Prognose der unerwünschten Umverteilungseffekte keine Rolle. Eine genaue Quantifizierung der kritisierten Umverteilungswirkungen des ab 2008 gültigen EarmarkingRegelverfahrens ist aber schon deshalb schwierig, da die zukünftige Verzinsung der Earmarking-Aktiva nicht exakt prognostiziert werden kann. Bei einem unterstellten Zinssatz von 2,71 Prozent ${ }^{425}$ läßt sich in einem EWU-11-Senario der unerwünschte Pooling-Verlust der Deutschen Bundesbank auf 667 Mio. EUR pro Jahr ansetzen. Der Beitritt Griechenlands zum Eurosystem am 1.1.2001 ändert - wie die Berechnungen im Anhang zeigen ${ }^{426}$ - an den jährlichen Verlusten Deutschlands (675 Mio. EUR) nichts Gravierendes. Insgesamt gesehen ist der angegebene Wert für die deutschen Verluste wegen der veranschlagten relativ niedrigen Verzinsung dennoch eher als Untergrenze zu interpretieren. So würde der Netto-Poolingverlust der Bundesbank in einer EWU der 12 und einer unterstellten durchschnittlichen Verzinsung der Earmarking-Aktiva von 3,7 Prozent pro Jahr schon immerhin 922 Mio. EUR betragen $^{427}$.

\subsubsection{Seigniorage-Studien, die die Umverteilungseffekte mit der Barwertmethode berechnen}

Die zweite Gruppe der empirischen Seigniorage-Studien versucht, die auf das Earmarking-Verfahren zurückzuführenden „ungerechtfertigten“ Umverteilungen von Erträgen, die die NZBen aufgrund ihres Pre-EWU-Aktivabestands erwirtschaften, mit Hilfe der Barwertmethode zu messen. In die Diskussion eingeführt wurde diese Vorgehensweise 1997 von Sinn und Feist, die mittlerweile in mehreren Untersuchungen ihre Ergebnisse präzisiert haben ${ }^{428}$. In dieser Arbeit sollen nun vor allem die aktuellen Schätzungen der genannten Autoren

425 Dieser Zinssatz entspricht dem durchschnittlichen Satz für Hauptrefinanzierungsgeschäfte des Eurosystems im ersten Jahr der EWU.

426 Vgl. Tabelle A6 im Anhang.

427 Zur Berechnung vgl. Tabelle A6 im Anhang. Der unterstellte Zinssatz von 3,70 Prozent p.a. entspricht dem durchschnittlichen Satz für Hauptrefinanzierungsgeschäfte des Eurosystems in den ersten drei Jahren der EWU.

Vgl. Sinn/Feist (1997a), Sinn/Feist (1997b), Sinn/Feist (1997c), Sinn/Feist (1997d), Sinn (1997), Sinn/Feist (2000a), Sinn/Feist (2000b), Sinn/Feist (2000c) und Feist (2001). 
im Vordergrund stehen, weshalb sich die folgenden Ausführungen auch überwiegend auf die von Sinn und Feist prognostizierten Umverteilungen der EWU-11- bzw. EWU-12-Teilnehmerstaaten konzentrieren.

Nach Ansicht von Sinn und Feist besitzen die Seigniorage-Studien, die die unerwünschten Umverteilungseffekte des Earmarking-Verfahrens auf Jahresbasis ermitteln (Stromansatz), den Nachteil, daß sie wegen ihres beschränkten Zeithorizonts die quantitative Dimension der ungerechtfertigterweise umverteilten Pre-EWU-Geldschöpfungsgewinne nur eingeschränkt erfassen $^{429}$. Zwar könnte man mit dieser Methode prinzipiell auch die in weiterer Zukunft umverteilten Beträge quantifizieren, man müßte dann aber Aussagen über die zukünftige Zinsentwicklung der geearmarkten Aktiva treffen, was freilich recht spekulativ ist. Um diese Probleme zu umgehen, stellen die Autoren bei ihren Berechnungen nun direkt auf den Wert der zu earmarkenden PreEWU-Vermögenstitel, dem sog. Pre-EWU-Geldschöpfungsvermögen, selbst ab (Bestandsansatz). Hinter dieser Vorgehensweise steht die Überlegung, daß es aus ökonomischer Sicht keinen Unterschied macht, ob die NZBen für alle Ewigkeit die Erträge aus ihren geearmarkten Pre-EWU-Aktiva in den Pool der Monetären Einkünfte abzuführen haben oder die geearmarkten Aktiva selbst an die Währungsgemeinschaft abtreten. Mit anderen Worten läßt sich die Gesamtheit der in Zukunft umzuverteilenden Pre-EWU-Geldschöpfungsgewinne direkt am Bestand des Pre-EWU-Seignioragevermögens der NZBen ablesen, da der Marktwert der geearmarkten Pre-EWU-Aktiva der Summe der gegenwärtigen und abdiskontierten zukünftigen Erträge (Barwert der Erträge) dieser Aktiva entspricht. Da nun das Pre-EWU-Geldschöpfungsvermögen der NZBen seinen größengleichen Part in der jeweils von den NZBen zum 1.1.1999 in die EWU eingebrachten Monetären NZB-Basen findet, soll es nach Auffassung der Autoren wegen der exakten numerischen Verfügbarkeit dieser Daten gelingen, die durch das Seigniorage-Pooling umverteilten Beträge vollständig und präzise $\mathrm{zu}$ quantifizieren, und zwar unabhängig von der Prognose des Zeitpfads der Zinserträge. Allerdings ist bei der Quantifizierung der unerwünschten Umverteilungseffekte dem Umstand Rechnung zu tragen, daß das Eurosystem die Mindestreserveeinlagen der Kreditinstitute zum Satz für Hauptrefinanzierungsgeschäfte vergütet. $\mathrm{Da}$ diese Zinsaufwendungen der NZBen beim Pooling der Monetären Einkünfte jeweils in Abzug gebracht werden dürfen (Art. 32.4. ESZB-Satzung), reduziert sich somit das umverteilungsrelevante Pre-EWU-Geldschöpfungsvermögen wertmäßig auf den jeweiligen Banknotenumlauf der NZBen zum 1.1.1999 ${ }^{430}$.

429 Vgl. im Folgenden Sinn/Feist (2000b), S. 1 ff. und Sinn/Feist (2000c), S. 14 ff..

430 Im Folgenden sollen die Umverteilungseffekte aus Pre-EWU-Überschußreserven wegen mangelnder Relevanz vernachlässigt werden. Vgl. dazu Kapitel V.3.1.1. Abschnitt 3.. 
Tabelle 42: Die Gewinner und Verlierer der Umverteilung des Pre-EWUGeldschöpfungsvermögens nach der Barwertmethode von Sinn und Feist

Die Berechnungen von Sinn und Feist (EWU-11-Szenario)

\begin{tabular}{|l|r|r|r|r|r|r|}
\hline & \multicolumn{2}{|c|}{$\begin{array}{c}\text { Beigetragenes } \\
\text { Geldschöpfungs- } \\
\text { vermögen }\end{array}$} & \multicolumn{2}{c|}{$\begin{array}{c}\text { Erhaltenes } \\
\text { Geldschöpfungs- } \\
\text { vermögen }\end{array}$} & $\begin{array}{c}\text { Gewinn/ } \\
\text { Verlust } \\
\text { absolut }\end{array}$ & $\begin{array}{c}\text { Gewinn/ } \\
\text { Verlust } \\
\text { pro Kopf }\end{array}$ \\
\hline EWU-11 & Mrd. EUR & Anteil \% & Mrd. EUR & Anteil \% & Mrd. EUR & EUR \\
\hline Deutschland & 138,6 & 39,4 & 109,2 & 31,0 & $-29,3$ & -358 \\
\hline Frankreich & 43,8 & 12,4 & 75,1 & 21,3 & $+31,3$ & +535 \\
\hline Italien & 64,5 & 18,3 & 66,4 & 18,9 & $+1,9$ & +34 \\
\hline Spanien & 50,7 & 14,4 & 39,7 & 11,3 & $-11,0$ & -281 \\
\hline Niederlande & 18,6 & 5,3 & 19,1 & 5,4 & $+0,5$ & +33 \\
\hline Belgien & 12,5 & 3,6 & 12,8 & 3,6 & $+0,2$ & +24 \\
\hline Österreich & 12,3 & 3,5 & 10,5 & 3,0 & $-1,8$ & -222 \\
\hline Portugal & 4,6 & 1,3 & 8,6 & 2,4 & $+4,0$ & +401 \\
\hline Finnland & 3,0 & 0,8 & 6,2 & 1,8 & $+3,3$ & +634 \\
\hline Irland & 3,4 & 1,0 & 3,8 & 1,1 & $+0,4$ & +97 \\
\hline Luxemburg & 0,1 & 0,0 & 0,7 & 0,2 & $+0,6$ & +1319 \\
\hline Gesamt & 352,0 & 100,0 & 352,0 & 100,0 & 0,0 & - \\
\hline Legand & & & & & \\
\hline
\end{tabular}

Legende: Kapitalanteil der EZB zum 1.1.1999, Anteil am Bargeldumlauf und Angaben zur Bevölkerung zum 31.12.1998.

Quelle: Sinn/Feist (2000b), S. 11.

Korrigierte Berechnungen (nur Banknotenumlauf) (EWU-11-Szenario)

\begin{tabular}{|l|r|r|r|r|r|r|}
\hline & \multicolumn{2}{|c|}{$\begin{array}{c}\text { Beigetragenes } \\
\text { Geldschöpfungs- } \\
\text { vermögen }\end{array}$} & \multicolumn{2}{c|}{$\begin{array}{c}\text { Erhaltenes } \\
\text { Geldschöpfungs- } \\
\text { vermögen }\end{array}$} & $\begin{array}{c}\text { Gewinn/ } \\
\text { Verlust } \\
\text { absolut }\end{array}$ & $\begin{array}{c}\text { Gewinn/ } \\
\text { Verlust } \\
\text { pro Kopf }\end{array}$ \\
\hline EWU-11 & Mrd. EUR & Anteil \% & Mrd. EUR & Anteil \% & Mrd. EUR & EUR \\
\hline Deutschland & 130,6 & 38,2 & 105,9 & 31,0 & $-24,6$ & -308 \\
\hline Frankreich & 42,3 & 12,4 & 72,8 & 21,3 & $+30,5$ & +519 \\
\hline Italien & 63,2 & 18,5 & 64,6 & 18,9 & $+1,4$ & +24 \\
\hline Spanien & 52,7 & 15,4 & 38,6 & 11,3 & $-14,1$ & -359 \\
\hline Niederlande & 17,3 & 5,1 & 18,5 & 5,4 & $+1,2$ & +74 \\
\hline Belgien & 12,0 & 3,5 & 12,3 & 3,6 & $+0,3$ & +32 \\
\hline Osterreich & 12,3 & 3,6 & 10,3 & 3,0 & $-2,0$ & -250 \\
\hline Portugal & 5,1 & 1,5 & 8,2 & 2,4 & $+3,1$ & +313 \\
\hline Finnland & 2,6 & 0,8 & 6,2 & 1,8 & $+3,5$ & +680 \\
\hline Irland & 3,6 & 1,0 & 3,8 & 1,1 & $+0,2$ & +49 \\
\hline Luxemburg & 0,1 & 0,0 & 0,7 & 0,2 & $+0,6$ & +1331 \\
\hline Gesamt & 341,7 & 100,0 & 341,7 & 100,0 & 0,0 & - \\
\hline Legent & & 119 & Ant & \\
\hline
\end{tabular}

Legende: Kapitalanteil der EZB zum 1.1.1999, Anteil am Banknotenumlauf und Angaben zur Bevölkerung zum 31.12.1998. Differenzen in den Summen durch Runden der Zahlen.

Quelle: Eigene Berechnungen in Anlehnung an Sinn/Feist (2000b), S. 11. Daten aus Europäische Zentralbank (2000h), S. 158, International Monetary Fund (2000f) und Tabelle 9. 
Noch Tabelle 42: Die Gewinner und Verlierer der Umverteilung des Pre-EWUGeldschöpfungsvermögens nach der Barwertmethode von Sinn und Feist

\begin{tabular}{|c|c|c|c|c|c|c|}
\hline \multirow[b]{3}{*}{ EWU-12 } & \multicolumn{6}{|c|}{ Die Berechnungen von Sinn und Feist (EWU-12-Szenario) } \\
\hline & \multicolumn{2}{|c|}{$\begin{array}{l}\text { Beigetragenes } \\
\text { Geldschöpfungs- } \\
\text { vermögen }\end{array}$} & \multicolumn{2}{|c|}{$\begin{array}{l}\text { Erhaltenes } \\
\text { Geldschöpfungs- } \\
\text { vermögen }\end{array}$} & \multirow{2}{*}{\begin{tabular}{|l|}
$\begin{array}{l}\text { Gewinn/ } \\
\text { Verlust } \\
\text { absolut }\end{array}$ \\
Mrd. EUR \\
\end{tabular}} & \multirow{2}{*}{\begin{tabular}{|l|}
$\begin{array}{l}\text { Gewinn/ } \\
\text { Verlust } \\
\text { pro Kopf }\end{array}$ \\
EUR
\end{tabular}} \\
\hline & Mrd. EUR & Anteil \% & Mrd. EUR & Anteil $\%$ & & \\
\hline Deutschland & 138,6 & 38,6 & 108,6 & 30,2 & $-30,0$ & -366 \\
\hline Frankreich & 43,8 & 12,2 & 74,6 & 20,8 & $+30,9$ & +527 \\
\hline Italien & 64,5 & 18,0 & 66,0 & 18,4 & $+1,5$ & +26 \\
\hline Spanien & 50,7 & 14,1 & 39,4 & 11,0 & $-11,3$ & -287 \\
\hline Niederlande & 18,6 & 5,2 & 19,0 & 5,3 & $+0,4$ & +26 \\
\hline Belgien & 12,5 & 3,5 & 12,7 & 3,5 & $+0,2$ & +16 \\
\hline Österreich & 12,3 & 3,4 & 10,5 & 2,9 & $-1,9$ & -230 \\
\hline \begin{tabular}{|l|} 
Portugal \\
\end{tabular} & 4,6 & 1,3 & 8,5 & 2,4 & $+3,9$ & +396 \\
\hline Finnland & 3,0 & 0,8 & 6,2 & 1,7 & $+3,2$ & +627 \\
\hline Irland & 3,4 & 1,0 & 3,8 & 1,0 & $+0,3$ & +91 \\
\hline Luxemburg & 0,1 & 0,0 & 0,7 & 0,2 & $+0,5$ & +1309 \\
\hline Griechenland & 6,9 & 1,9 & 9,1 & 2,5 & $+2,2$ & +209 \\
\hline Gesamt & 359,0 & 100,0 & 359,0 & 100,0 & 0,0 & \\
\hline
\end{tabular}

Quelle: Sinn/Feist (2000a), S. 28

Korrigierte Berechnungen (nur Banknotenumlauf) (EWU-12-Szenario)

\begin{tabular}{|l|r|r|r|r|r|r|}
\hline \multirow{2}{*}{ EWU-12 } & \multicolumn{2}{|c|}{$\begin{array}{c}\text { Beigetragenes } \\
\text { Geldschöpfungs- } \\
\text { vermögen }\end{array}$} & \multicolumn{2}{c|}{$\begin{array}{c}\text { Erhaltenes } \\
\text { Geldschöpfungs- } \\
\text { vermögen }\end{array}$} & $\begin{array}{l}\text { Gewinn/ } \\
\text { Verlust } \\
\text { absolut }\end{array}$ & $\begin{array}{l}\text { Gewinn/ } \\
\text { Verlust } \\
\text { pro Kopf }\end{array}$ \\
\cline { 2 - 7 } & Mrd. EUR & Anteil \% & Mrd. EUR & Anteil \% & Mrd. EUR & EUR \\
\hline Deutschland & 130,6 & 37,4 & 105,6 & 30,2 & $-24,9$ & -311 \\
\hline Frankreich & 42,3 & 12,1 & 72,6 & 20,8 & $+30,3$ & +515 \\
\hline Italien & 63,2 & 18,1 & 64,2 & 18,4 & $+1,0$ & +18 \\
\hline Spanien & 52,7 & 15,1 & 38,4 & 11,0 & $-14,4$ & -365 \\
\hline Niederlande & 17,3 & 4,9 & 18,4 & 5,3 & $+1,2$ & +74 \\
\hline Belgien & 12,0 & 3,4 & 12,4 & 3,5 & $+0,4$ & +39 \\
\hline Österreich & 12,3 & 3,5 & 10,2 & 2,9 & $-2,1$ & -260 \\
\hline Portugal & 5,1 & 1,5 & 8,3 & 2,4 & $+3,2$ & +321 \\
\hline Finnland & 2,6 & 0,8 & 6,0 & 1,7 & $+3,4$ & +653 \\
\hline Irland & 3,6 & 1,0 & 3,7 & 1,0 & $+0,1$ & +34 \\
\hline Luxemburg & 0,1 & 0,0 & 0,7 & 0,2 & $+0,6$ & +1286 \\
\hline Griechenland & 7,6 & 2,2 & 8,9 & 2,5 & $+1,2$ & +118 \\
\hline Gesamt & 349,3 & 100,0 & 349,3 & 100,0 & \multicolumn{2}{c|}{0,0} \\
\hline Legende: Kapitalanteil der EZB zum 1.1.1999, Anteil am Banknotenumlauf und Angaben zur \\
Bevölkerung zum 31.12.1998. Differenzen in den Summen durch Runden der Zahlen.
\end{tabular}

Quelle: Eigene Berechnungen in Anlehnung an Sinn/Feist (2000a), S. 28. Daten aus Bank of Greece (1999a), S. 253, Europäische Zentralbank (2000h), S. 158, International Monetary Fund (2000f) und Tabelle 9. 
Die vorstehende Tabelle 42 zeigt die von Sinn und Feist prognostizierten unerwünschten Umverteilungseffekte aus der Umverteilung des Pre-EWUGeldschöpfungsvermögens in einem EWU-11- und EWU-12-Szenario ${ }^{431}$. Dabei wird klar, daß nach den Berechnungen von Sinn und Feist jeweils Deutschland mit einem Netto-Poolingverlust von 29,3 Mrd. EUR (EWU-11) bzw. 30,0 Mrd. EUR (EWU-12) der mit Abstand größte Verlierer von Pre-EWUSeignioragevermögen sein wird. Aber auch Spanien wird mit 11,0 Mrd. EUR (EWU-11) bzw. 11,3 Mrd. EUR (EWU-12) sich einer erheblichen Umverteilung von Pre-EWU-Geldschöpfungsgewinnen gegenüber sehen. Im Falle Österreichs beträgt der Netto-Poolingverlust zwar „nur“ 1,8 Mrd. EUR (EWU-11) bzw. 1,9 Mrd. EUR (EWU-12), pro Kopf sind dies jedoch immerhin 222 bzw. 230 Euro pro Einwohner. Die restlichen Länder hingegen werden nach der Prognose von Sinn und Feist als Gewinner aus dem Seigniorage-Pooling hervorgehen. Hierbei ragt besonders die Zentralbank Frankreichs hervor, die einen prognostizierten Betrag von 31,3 Mrd. EUR (EWU-11) bzw. 30,9 Mrd. EUR (EWU-12) gewinnen wird, aber auch die Notenbanken Portugals und Finnlands dürfen sich über Nettotransfers zwischen 3,2 und 4,0 Mrd. EUR freuen.

Würdigt man nun die vorgestellten Berechnungen von Sinn und Feist kritisch, so ist zunächst darauf hinzuweisen, daß die Autoren mit Werten der nationalen Bargeldumläufe gerechnet haben ${ }^{432}$, anstatt auf die erforderlichen Angaben der nationalen Banknotenumläufe zurückzugreifen. Berücksichtigt man diese Anmerkung, so ergeben sich die ebenfalls in Tabelle 42 aufgezeigten korrigierten Gewinner- und Verliererpositionen der einzelnen EWU-11- bzw. EWU-12-Länder. Ein Vergleich der Berechnungen mit den Schätzungen von Sinn und Feist zeigt, da $\beta$ in den korrigierten Szenarien wegen der jetzt unberücksichtigten nationalen Münzumläufe das kumulierte Seignioragevermögen jeweils um rund $10 \mathrm{Mrd}$. EUR sinkt. Entsprechend nehmen auch die errechneten Nettoumverteilungen zugunsten bzw. zu Lasten der einzelnen EWU-Mitgliedstaaten ab. So sinkt beispielsweise der deutsche Verlust im EWU-11-Szenario um 4,7 Mrd. EUR auf nunmehr 24,6 Mrd. EUR. Auch in einer EWU der 12 ist der Verlust Deutschlands um 5,1 Mrd. EUR auf 24,9 Mrd. EUR nach unten zu korrigieren, was immerhin einer relativen Verringerung von

431 Das EWU-12-Szenario unterstellt, daß die Bank of Greece (BoG) bereits zum 1.1.1999 Mitglied des Eurosystems gewesen ist. Wegen des raschen Beitritts der BoG zum Eurosystem am 1.1.2001 dürften hierdurch keine allzu großen Verzerrungen auftreten.

432

Dies merken Sinn und Feist auch explizit an. Vgl. Sinn/Feist (2000c), S. 17. Anstelle der Banknotenumläufe arbeiten sie mit der IFS-Linie 14 ,currency in circulation“, die neben dem jeweiligen Banknotenumlauf auch den nationalen Münzumlauf (u.U. inkl. umlaufsfähige Gedenk- und Sammlermünzen) enthält. Vgl. International Monetary Fund (2000f). 
17 Prozent gegenüber der Sinn-Feistschen Prognose gleichkommt. Dennoch vermögen die korrigierten Berechnungen die Ergebnisse von Sinn und Feist nicht substantiell zu erschüttern. Bleibt nun die Frage offen, ob die Verwendung der Barwertmethode an sich geeignet ist, die kritisierten Umverteilungen aus dem Earmarking-Verfahren richtig zu prognostizieren.

Zunächst läßt sich festhalten, daß die prinzipielle Vorgehensweise von Sinn und Feist, die kritisierten Umverteilungseffekte anstatt über die laufende Umverteilung über den Barwert derselben zu messen, nicht ernsthaft in Frage zu stellen ist ${ }^{433}$. So ist es aus ökonomischer Sicht in der Tat egal, ob für immer und ewig die Erträge eines Aktivums oder bereits heute das Aktivum selbst vergemeinschaftet wird $^{434}$. Allerdings ist die Anwendung dieser Äquivalenzbeziehung zur Schätzung der kritisierten Nettoumverteilungen des EarmarkingVerfahrens nur im Rahmen bestimmter Voraussetzungen zutreffend. Sinn und Feist unterstellen diesbezüglich folgende Annahmen, die nun herausgelöst und hinterfragt werden sollen:

1. Earmarking ausschließlich marktverzinslicher Wertpapiere ${ }^{435}$,

2. die Gesamtheit der Monetären NZB-Basen, die die NZBen in die EWU eingebracht haben, bleibt konstant ${ }^{436}$,

3. das Earmarking-Verfahren tritt bereits zum 1.1.1999 ohne Übergangsregelungen in $\mathrm{Kraft}^{437}$,

4. das Eurosystem behält eine konstante Teilnehmerzahl.

$\mathrm{Zu}$ 1. Earmarking ausschließlich marktverzinslicher Wertpapiere.

Wie bereits oben ausführlich geschildert, trifft die Annahme des Earmarkings ausschließlich marktverzinslicher Wertpapiere nicht $\mathrm{zu}$, da neben unverzinslichem Earmarking-fähigen Gold nur marktverzinsliche Nominalwertforderungen als "gesondert erfaßbare Vermögenswerte“ vom EZB-Rat anerkannt werden. Dennoch läßt sich die Sinn-Feistsche Argumentation aufrechterhalten. So konnte im Rahmen der Analyse der Studien, die die kritisierten Umverteilungseffekte aus dem Pre-EWU-Aktivabestand auf Jahres-

433 Zu einer anderen Auffassung vgl. Dresdner Bank (1997).

434 Aus juristischer Sicht werden freilich nach wie vor nur die Erträge der geearmarkten Aktiva vergemeinschaftet, während die Aktiva an sich rechtlich bei den NZBen verbleiben. Vgl. dazu auch Sinn (1997). Vgl. z.B. Sinn/Feist (2000c), S. 21.

436 Vgl. z.B. Sinn (1997), S. 44. Diese Annahme ergibt sich unmittelbar aus dem BarwertAnsatz.

437 Vgl. Sinn/Feist (2000c), S. 21. 
basis zu messen versuchen, gezeigt werden, daß die Anrechenbarkeit des unverzinslichen Goldbestandes die unerwünschten Umverteilungseffekte unberührt läßt. Entscheidend für die Überlegungen von Sinn und Feist ist vielmehr, daß - wie auch tatsächlich vom EZB-Rat zwingend vorgeschrieben - die nach Abzug der umverteilungsneutralen Goldbestände verbleibende Bemessungsgrundlage vollständig durch marktverzinsliche Aktiva gedeckt ist. Dies wäre bei einem Earmarking ausschließlich marktverzinslicher Wertpapiere freilich der $\mathrm{Fall}^{438}$. Die vom EZB-Rat vorgeschriebenen marktverzinslichen Nominalwertforderungen erfüllen diese Bedingung jedoch ebenso. Zudem muß man zur Begründung des Barwertansatzes nicht zwingend auf die Marktpreisbewertung der NZB-Aktiva als quasi sichtbare Inkorporierung der abdiskontierten zukünftigen Erträge dieser Assets abstellen, es genügt der Hinweis auf den Barwert der periodisch anfallenden Opportunitätskosten der Pre-EWUBanknotenverwender. Dieser beschreibt den in Höhe des Nennwerts der emittierten Banknoten anfallenden intertemporalen Zinsverzicht der Banknotenhalter und ist unabhängig von der Art und Weise, wie die NZBen ihre Assets im einzelnen veranlagen, als intertemporaler Ressourcentransfer zu den Geldproduzenten zu verstehen ${ }^{439}$. Im Hinblick auf das Pooling der Geldschöpfungsgewinne und die prognostizierten unerwünschten Umverteilungseffekte ist allerdings $\mathrm{zu}$ berücksichtigen, daß die NZBen vom EZB-Rat - wie es gegenwärtig auch der Fall ist - (praktisch) unabhängig von der tatsächlichen Investition ihrer Aktiva gezwungen werden, den durch Zinsverzicht der Pre-EWU-Banknotenverwender finanzierten periodisch anfallenden Ressourcentransfer auch tatsächlich auf immer und ewig über die Abführung der marktverzinslichen Zinserträge in den Seignioragepool einzuzahlen. Solange dies zutrifft, kann die Barwertmethode von Sinn und Feist als grundsätzlich sinnvoller Ansatz zur Messung der unerwünschten Umverteilungseffekte verwendet werden.

Zu 2. Die Gesamtheit der Monetären NZB-Basen, die die NZBen in die EWU eingebracht haben, bleibt konstant.

Die zweite implizite Annahme in den Sinn-Feistschen Überlegungen ist die Unterstellung, daß die Monetären NZB-Basen, die die NZBen mit in die EWU eingebracht haben, in ihrer Summe konstant bleiben ${ }^{440}$. Trifft diese Annahme zu,

438 Die Bilanzstrukturanalyse zeigte, daß mangels Masse eine vollständige Deckung der Monetären NZB-Basis durch marktverzinsliche Wertpapiere der NZBen in der Regel nicht möglich ist. Vgl. dazu die Tabelle 37.

439 Vgl. auch die theoretischen Überlegungen zum Opportunitätskostenseigniorage in Kapitel II Abschnitt 5 ..

440 Vgl. Läufer (1997), S. 2, Gros (1998), S. 32 ff. und Läufer (1998), S. 3. 
dann spielt es für die Höhe der von Sinn und Feist prognostizierten Seigniorageverluste und -gewinne der NZBen allerdings keine Rolle, ob sich die Verteilung der Pre-EWU-Monetären Basen (insbesondere des Pre-EWUBanknotenumlaufs) zwischen den NZBen verändert oder nicht ${ }^{44 !}$. Dies zeigt folgendes Beispiel. Angenommen der (in Euro umgetauschte) Pre-EWUBanknotenumlauf der Deutschen Bundesbank "wandert" teilweise zu anderen NZBen ab, da - aus welchen Gründen auch immer - bei der Bundesbank überproportional viele Euros zurückgegeben werden und diese in gleicher Höhe bei einer anderen NZB nachgefragt werden (konstantes kumuliertes Pre-EWUSeignioragevermögen). Dies hätte zur Folge, daß die Bundesbank im Vergleich zur Situation ohne abgewanderten Banknotenumlauf beim Pooling der Monetären Einkünfte nun relativ weniger verlieren würde oder sogar gewinnen würde, da bei gegebener Gesamthöhe der Monetären Pre-EWU-Basis die Monetäre Basis der Bundesbank gesunken wäre. Die effektive, ökonomisch relevante Poolingfinanzierungslast der Bundesbank bleibt aber von der Umschichtung des Eurosystem-Banknotenumlaufs unberührt, da bereits die Verlagerung des Banknotenumlaufs einen entsprechenden Ressourcentransfer zwischen den NZBen beinhaltet (Umverteilung des Pre-EWU-Seignioragevermögens vor Pooling). So finanziert in diesem Beispiel die Bundesbank zusätzlich zu ihrem Bruttopoolbeitrag auch die vergleichsweise gestiegenen "Vor-Pooling-Seigniorageeinnahmen" der anderen NZBen durch Zinsverzicht auf die Erträge der „abgewanderten“ Aktiva. Dies bedeutet aber, daß - im Rahmen der von Sinn und Feist getroffenen Annahmen - die ökonomisch relevanten Umverteilungseffekte aus dem Pooling der Pre-EWU-Geldschöpfungsgewinne der NZBen unabhängig von der sich einstellenden Allokation des Pre-EWU-Banknotenumlaufs bestimmt werden ${ }^{442}$. Aus diesen Gründen kann per se auch nicht von der aktuellen Gewinn- bzw. Verlustsituation der NZBen beim Pooling der Monetären Einkünfte auf die ökonomisch relevante Umverteilung von Pre-EWU-Seignioragevermögen geschlossen werden $^{443}$.

Die Annahme eines in alle Ewigkeit konstanten, kumulierten Pre-EWUSeignioragevermögens ist jedoch kritisiert worden, da die zukünftige Nachfrage

441 Vgl. hierzu Läufer (1997) und Läufer (1998). Es sei darauf hingewiesen, daß im Gegensatz zur Verlagerung der Pre-EWU-Banknotenumläufe, die automatisch eine entsprechende Umverteilung von Zinseinkünften zwischen den NZBen impliziert, beim grenzüberschreitenden Überweisungsverkehr erst die Verzinsung der bilateralen TARGET-Salden den entsprechenden Transfer der Zinseinkünfte sicherstellt.

442 Bei der marktgerechten Verzinsung der bilateralen TARGET-Salden gilt diese Aussage auch für die gesamte Monetäre Pre-EWU-Basis.

443 Vgl. Läufer (1997), S. 1 und Läufer (1998), S. 3 ff.. 
nach Basisgeld nicht eindeutig vorhergesagt werden kann. So benötigt bei gegebenen Zahlungsgewohnheiten die europäische Wirtschaft zur Finanzierung ihres Wachstums zwar zusätzliches Basisgeld. Ändert sich jedoch gleichzeitig die Neigung zur Bargeldhaltung, da die Wirtschaftssubjekte zukünftig verstärkt auf elektronische Zahlungsmittel wie Geld- und Kreditkarten zurückgreifen, kann es dazu kommen, daß trotz Wirtschaftswachstums die Nachfrage nach Banknoten sinkt. Eine so erklärte Reduktion des Pre-EWU-Seignioragevermögens wäre daher nicht auszuschließen ${ }^{444}$. Eine Reduktion des Pre-EWUSeignioragevermögens kann auch darin begründet sein, daß der Euro im Ansehen der EWU-Ausländer weniger Vertrauen auf sich vereinigen kann, als die kumulierte Auslandszirkulation der einzelnen EWU-Währungen vor dem Übergang zum Euro ${ }^{445}$. Ob der Euro jedoch so erfolgreich wie seine ehemals nationalen Denominierungen sein wird, bleibt letztlich Spekulation ${ }^{446}$. Es spricht jedoch die starke ökonomische und politische Präsenz der EWU-Länder im europäischen Ausland dafür, daß der Euro als Transaktionswährung langfristig mindestens so stark wird, wie die kumulierten ehemaligen EWU-Währungen waren.

Tatsächlich ist der Euro-Banknotenumlauf Mitte 2002 (299 Mrd. EUR) geringer als die kumulierten NZB-Banknotenumläufe zu Beginn der EWU (342 Mrd. EUR). Auf die Berechnungen der kritisierten Umverteilungseffekte hat diese Beobachtung jedoch keine Auswirkungen. Entscheidend ist allein die Frage, ob sich (als Referenzszenario) die kumulierten NZB-Banknotenumläufe in einer Welt ohne EWU rückläufig entwickelt hätten. Nur dann wären die deutschen Verluste aus dem Seignioragepooling entsprechend nach unten zu korrigieren, da die in- und ausländische DEM-Verwendung ohnehin abgenommen hätte. Sollte dies jedoch nicht der Fall sein, kann trotz des vergleichsweise gesunkenen Euro-Banknotenumlaufs die Barwertmethode mit dem expliziten Hinweis auf das erwähnte Referenzszenario aufrechterhalten werden. So teilt sich z.B. der prognostizierte deutsche Verlust nur anders auf. Zum einen finanziert die Bundesbank die gegenwärtig zu beobachtende Reduzierung des Seignioragepools durch Verzicht auf die Nutzung der Erträge aus dem ehemaligen DEMAuslandsumlauf. Zum anderen hat sie u.U. immer dann weitere Transfers zu finanzieren, wenn nach der Poolverkleinerung ihr Anteil an der Finanzierung der verbleibenden Pre-EWU-Aktiva basierten Erträge des Eurosystems immer noch größer ist als ihr EZB-Kapitalanteil.

444 Vgl. z.B. Apholte/Von Köppen-Mertes (1997), S. 6, Dresdner Bank (1997), S. 2 und Gros (1998), S. 32.

445 Vgl. Läufer (1997), S. 2, Läufer (1998), S. 2 und Maennig (1999), S. 90.

446 Zur Entwicklung des Euro als internationale Reserve-, Vehikel-, Finanzierungs-, Anker-, und Interventionswährung vgl. European Central Bank (2001e). 
Zu 3. Das Earmarking-Verfahren tritt bereits ab dem 1.1.1999 in Kraft.

Wie Sinn und Feist selbst darauf hinweisen, sind bei ihren Umverteilungsrechnungen immer noch diejenigen Zinsersparnisse zu berücksichtigen, die die „Verlierer"-NZBen erzielen, wenn verschiedene Übergangsregelungen das sofortige Inkrafttreten des Earmarking-Verfahrens verhindern ${ }^{447}$. So wurde in der sogenannten Übergangsphase der Jahre 1999 bis einschließlich 2002 der Banknotenumlauf aus der Bemessungsgrundlage zur Ermittlung der Monetären Einkünfte ausgenommen und so nahezu keine Umverteilung von (Pre-EWU-) Geldschöpfungsgewinnen durchgeführt ${ }^{448}$. Für den Zeitraum von 2003 bis 2007 reduzieren die vorgestellten Ausgleichsbeträge die unerwünschten Umverteilungseffekte ${ }^{449}$. In welcher Höhe die identifizierten „Verlierer"-NZBen aus dem Pre-EWU-Seigniorage-Pooling solche Einsparungen erzielen, verdeutlicht die folgende Tabelle 43. Hierbei wird klar, daß erwartungsgemäß die Deutsche Bundesbank (BBk) in der Übergangsperiode zwischen 1999 und 2001 die größten Zinsersparnisse in einer Höhe von ca. 2559 Mio. EUR erzielt hat ${ }^{450}$. "Finanziert" wurde diese Ersparnis vor allem durch die Banque de France (BdF), die auf Pre-EWU-Seignioragegewinne anderer NZBen in Höhe von 3009 Mio. EUR verzichten mußte, da in dieser Zeit die Erträge aus dem Banknotenumlauf beim Pooling unberücksichtigt geblieben sind. Etwas höher sollte hingegen die Poolingersparnis der „Verlierer“-NZBen aus der Anwendung der Ausgleichsbeträge beim Earmarking-Verfahren zwischen 2002 und 2007 ausfallen. So läßt sich bei einem unterstellten Zinssatz von 3,7 Prozent p.a. in diesem Zeitraum etwa für die Bundesbank eine kumulierte Zinsersparnis von 2919 Mio. EUR berechnen ${ }^{451}$. Auch hier hat die französische Zentralbank mit 4130 Mio. EUR den mit Abstand größten Zinsverzicht auf die Pre-EWUbasierten Erträge der anderen NZBen zu finanzieren. Problematisch ist dies indes nicht, da diese Erträge ihr nach den obigen Überlegungen ohnehin nicht zustehen.

447 Vgl. Sinn/Feist (2000c), S. 21.

$448 \mathrm{Vgl}$. die Ausführungen zu Kapitel V.3.1.1. Abschnitt 3..

$449 \mathrm{Vgl}$. die Ausführungen zu Kapitel V.3.1.2. Abschnitt 2.4..

450 Mit diesen Beträgen müßten freilich noch die sehr geringen Netto-Poolingpositionen der NZBen für die Jahre 1999 bis 2001 verrechnet werden. Da hierfür jedoch kaum Daten erhältlich sind, soll hierauf verzichtet werden.

45) Die veranschlagte 3,7-prozentige Durchschnittverzinsung der Earmarking-Aktiva entspricht dem durchschnittlichen Zinssatz für Hauptrefinanzierungsgeschäfte des Eurosystems im Zeitraum vom 7.1.1999 bis 5.12.2001. 
Tabelle 43: Geschätzte Zinsersparnisse bzw. entgangene Gewinne der NZBen aus dem Pre-EWU-Seignioragepooling im Zeitraum von 1999 bis 2007

Geschätzte Zinsersparnisse (-) bzw. entgangene Gewinne der NZBen aus dem Pre-EWU-Seignioragepooling durch Anwendung der Indirekten Methode in der Übergangsphase vom 1.1.1999 bis 31.12.2001 in Mio. EUR'

\begin{tabular}{|c|c|c|c|c|c|c|c|c|c|c|c|c|c|c|}
\hline Jahr & $\begin{array}{r}\text { Referenz- } \\
\text { zinssatz } \\
\end{array}$ & BBk & BdI & BdF & BdE & DNB & NBB & OeNB & BdP & CBI & BoF & BCL & $\mathrm{BoG}^{3}$ & $\begin{array}{r}\text { EWU } 11 \\
\text { bzw. } 12\end{array}$ \\
\hline 1999 & $2,71 \%$ & -667 & 37 & 827 & -383 & 32 & 9 & -55 & 85 & 5 & 95 & 16 & - & 0 \\
\hline 2000 & $4,07 \%$ & -1002 & 56 & 1242 & -575 & 47 & 13 & -82 & 127 & 7 & 143 & 23 & - & 0 \\
\hline $2001^{4}$ & $3,27 \%$ & -890 & -12 & 940 & -497 & 25 & 4 & -76 & 99 & 2 & 106 & 18 & 284 & 0 \\
\hline & Summe & -2559 & 81 & 3009 & -1455 & 104 & 26 & -213 & 311 & 14 & 344 & 57 & 284 & 0 \\
\hline
\end{tabular}

Geschătzte Zinsersparnisse (-) bzw. entgangene Gewinne der NZBen aus dem Pre-EWU-Seignioragepooling durch Anwendung der Ausgleichsbeträge beim EarmarkingVerfahren vom 1.1.2002 bis 31.12.2007 in Mio. EUR

\begin{tabular}{|c|c|c|c|c|c|c|c|c|c|c|c|c|c|c|}
\hline Jahr & $\begin{array}{r}\text { Referenz- } \\
\text { zinssatz }^{6}\end{array}$ & BBk & BdI & BdF & BdE & DNB & NBB & OeNB & BdP & CBI & BoF & BCL & BoG & EWU 12 \\
\hline 2002 & $3,70 \%$ & -803 & -72 & 1135 & -564 & 81 & 21 & -89 & 121 & -15 & 128 & 3 & 55 & 0 \\
\hline 2003 & $3.70 \%$ & -691 & -62 & 977 & -486 & 69 & 18 & -76 & 104 & -13 & 110 & 3 & 47 & 0 \\
\hline 2004 & $3,70 \%$ & -563 & -51 & 796 & -396 & 56 & 14 & -62 & 85 & -11 & 90 & 2 & 38 & 0 \\
\hline 2005 & $3,70 \%$ & -428 & -39 & 606 & -301 & 43 & 11 & -47 & 65 & -8 & 68 & 2 & 29 & 0 \\
\hline 2006 & $3,70 \%$ & -289 & -26 & 409 & -203 & 29 & 7 & -32 & 44 & -5 & 46 & 1 & 20 & 0 \\
\hline 2007 & $3,70 \%$ & -146 & -13 & 206 & -103 & 15 & 4 & -16 & 22 & -3 & 23 & 1 & 10 & 0 \\
\hline & Summe & -2919 & -263 & 4130 & -2052 & 293 & 75 & -323 & 440 & -55 & 464 & 11 & 199 & 0 \\
\hline
\end{tabular}

Kumulierte Geschätzte Zinsersparnisse (-) bzw. entgangene Gewinne der NZBen aus dem Pre-EWU-Seignioragepooling im Zeitraum von 1999 bis 2007 in Mio. EUR

\begin{tabular}{|c|c|c|c|c|c|c|c|c|c|c|c|c|c|c|}
\hline Jahr & NZB & BBk & BdI & BdF & BdE & DNB & NBB & OeNB & BdP & CBI & BoF & BCL & BoG & EWU 12 \\
\hline $\begin{array}{r}1999 \mathrm{bis} \\
2007\end{array}$ & $\begin{array}{r}\text { Gesamt- } \\
\text { summe }\end{array}$ & -5478 & -182 & 7139 & -3507 & 397 & 101 & -536 & 751 & -41 & 808 & 68 & 483 & 0 \\
\hline
\end{tabular}

Quelle: Eigene Berechnungen. Differenzen in den Summen durch Runden der Zahlen.

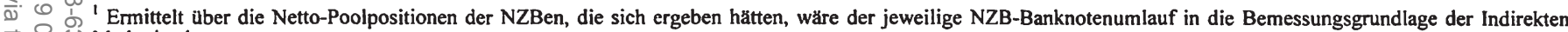
Methode eingegangen.

${ }^{2}$ Referenzzinssatz für die Anwendung der Indirekten Methode (exklusive Banknotenumlauf in der Bemessungsgrundlage) furr 1999 bis 2002 als jahresdurchschnittlicher Satz für Hauptrefinanzierungsgeschäfte des Eurosystems.

${ }_{3}^{3}$ Pooling-Position der Bank of Greece aus Konsistenzgründen mit Hilfe des GRD-Banknotenumlaufs zum 1.1.1999

In 2001 gilt wegen des Beitritts Griechenlands zum Euroraum ein gegenuber 1999 und 2000 leicht veränderter gezahlter EZB-Kapitalschlussel fur die NZBen. Vgl. hierzu die Tabelle 45.

${ }^{5}$ Ermittelt durch Multiplikation der einzelnen NZB-Ausgleichsbetråge mit dem unterstellten Referenzzinssatz. Vgl. Dazu die Tabelle 36.

${ }^{6}$ Durchschnittlicher Zinssatz fur Hauptrefinanzierungsgeschäfte des Eurosystems vom 7.1.1999 bis 5. Dezember 2001. 
$\mathrm{Zu}$ 4. Konstante EWU-Teilnehmerzahl.

Will man nun die effektiven Nettopositionen der NZBen aus dem Pooling der Erträge des Pre-EWU-Seignioragevermögens quantifizieren, so sind für jede NZB die in Tabelle 43 vorgestellten kumulierten Zinsersparnisse bzw. Zinsverzichte mit den in Anlehnung an Sinn und Feist kalkulierten (korrigierten) Netto-Poolingpositionen zu verrechnen. Dies läßt sich jedoch nicht ohne Einschänkung durchführen, da die Barwertmethode zur Berechnung der NettoPoolpositionen der NZBen auf einem Ceteris-paribus-Szenario basiert ${ }^{452}$. Letzteres impliziert aber einen auf immer und ewig konstanten Datenkranz, insbesondere darf sich die Anzahl der EWU-Länder nicht ändern. So wirkt sich zwar der Beitritt der Bank of Greece (BoG) zum Eurosystem am 1.1.2001 wegen des vergleichsweise geringen Abstands zwischen dem griechischen Anteil am eingebrachten kumulierten Seignioragevermögen (2,2 Prozent) und dem EZB-Kapitalanteil als relativen Poolanspruch der BoG (2,5 Prozent) von nur 0,3 Prozentpunkten ${ }^{453}$ nicht allzu stark auf die einzelnen NettoPoolpositionen der NZBen im EWU-11- und EWU-12-Szenario aus. Wie die Ausführungen der Umverteilungungseffekte der EWU-Erweiterung jedoch zeigen werden, wird dies nicht so bleiben. Die im Folgenden vorgestellte Prognose der unerwünschten effektiven Netto-Umverteilungseffekte aus dem Pre-EWU-Seignioragevermögen gilt - bei Außerachtlassung aller anderen vorgetragenen Einwände - somit nur für den Fall, die EWU wäre bis an das Ende aller Tage eine Veranstaltung der gegenwärtigen Mitglieder des Eurosystems. Wie Tabelle 44 zeigt, vermögen auch die im Zeitraum von Anfang 1999 bis Ende 2007 anwendbaren Übergangsregelungen es nicht, die kritisierten unerwünschten Umverteilungseffekte des Pooling der Monetären Einkünfte befriedigend zu beheben. So dürfte sich der langfristige effektive Verlust der Deutschen Bundesbank trotz der geschätzten kumulierten Zinsersparnisse von 5478 Mio. EUR immer noch in einer Größenordnung zwischen 19 und $20 \mathrm{Mrd}$. EUR bewegen. Auch Spanien und Österreich werden trotz der vorgestellten Übergangsregelungen noch erhebliche Pooling-Verluste um die $10 \mathrm{Mrd}$. EUR bzw. 1 bis 2 Mrd. EUR hinzunehmen haben. Rechnet man diese Beträge in ProKopf-Werte um, so dürften die spanischen Bürger mit einem Verlust von 276 EUR pro Kopf sogar noch vor den Einwohnern Deutschlands mit 243 Mio. EUR liegen, während die Österreicher sich einem Pro-Kopf-Fehlbetrag von 194 EUR gegenüber sehen.

452 Vgl. auch Gros (1998), S. 32.

$453 \mathrm{Vgl}$. die korrigierten Berechnungen der EWU-11 - und EWU-12-Szenarien in Tabelle 42. Es sei darauf hingewiesen, daß die Berechnungen des EWU-12-Senarios unterstellen, die Bank of Greece wăre schon am 1.1.1999 Mitglied des Eurosystems gewesen. 
Tabelle 44: Effektive Nettopositionen der NZBen aus dem Pooling von Pre-EWUGeldschöpfungsgewinnen

\begin{tabular}{|l|c|c|c|c|c|c|}
\hline NZB & BBk & BdI & BdF & BdE & DNB & NBB \\
\hline $\begin{array}{l}\text { Korrigierte Gewinne (+) / } \\
\text { Verluste (-) aus Pre-EWU- } \\
\begin{array}{l}\text { Seigniorage-Pooling in Mio. } \\
\text { EUR }\end{array}\end{array}$ & -24910 & +1024 & +30329 & -14374 & +1158 & +395 \\
\hline $\begin{array}{l}\text { Zinsersparnisse aus Übergangs- } \\
\text { regelungen (1999-2007) in Mio. } \\
\text { EUR }\end{array}$ & +5478 & +182 & -7139 & +3507 & -397 & -101 \\
\hline $\begin{array}{l}\text { Effektive Netto-Poolingposition } \\
\text { in Mio. EUR }\end{array}$ & -19432 & +1206 & +23190 & -10867 & +761 & +294 \\
\hline $\begin{array}{l}\text { Effektive Netto-Poolingposition } \\
\text { pro Kopf in EUR }\end{array}$ & -243 & +21 & +394 & -276 & +48 & +29 \\
\hline
\end{tabular}

\begin{tabular}{|l|c|c|c|c|c|c|}
\hline NZB & OeNB & BdP & CBI & BoF & BCL & BoG \\
\hline $\begin{array}{l}\text { Korrigierte Gewinne (+) / } \\
\text { Verluste (-) aus Pre-EWU- } \\
\text { Seigniorage-Pooling in Mio. } \\
\text { EUR }\end{array}$ & -2103 & +3198 & +127 & +3362 & +553 & +1241 \\
\hline $\begin{array}{l}\text { Zinsersparnisse aus Übergangs- } \\
\text { regelungen (1999-2007) in Mio. } \\
\text { EUR }\end{array}$ & +536 & -751 & +41 & -808 & -68 & -483 \\
\hline $\begin{array}{l}\text { Effektive Netto-Poolingposition } \\
\text { in Mio. EUR }\end{array}$ & -1567 & +2447 & +168 & +2554 & +485 & +758 \\
\hline $\begin{array}{l}\text { Effektive Netto-Poolingposition } \\
\text { pro Kopf in EUR }\end{array}$ & -194 & +245 & +45 & +496 & +1128 & +72 \\
\hline
\end{tabular}

Quelle: Eigene Berechnungen. Verwendete Daten aus den Tabellen 42 und 43, sowie International Monetary Fund (2000f). Differenzen in den Summen durch Runden der Zahlen. 
Die restlichen EWU-Länder werden allesamt vom Pooling der Pre-EWUGeldschöpfungsgewinne profitieren. Frankreich wird mit einem Gewinn von rund $23 \mathrm{Mrd}$. EUR erneut am stärksten gewinnen. Am meisten werden sich aber wohl die Bürger Luxemburgs mit 1128 EUR pro Kopf über die umverteilten Pre-EWU-Seignioragegewinne aus Deutschland, Spanien und Österreich freuen. An dieser Stelle soll jedoch noch einmal explizit darauf hingewiesen werden, daß die vorgestellten Berechnungen nur im Rahmen der getroffenen Annahmen gelten. Würde man beispielsweise unterstellen, daß sich der deutsche Banknotenumlauf in einem Szenario ohne EWU rückläufig entwickelt hätte, müßten die prognostizierten Verluste Deutschlands entsprechend nach unten korrigiert werden. Derartige Entwicklungen wären zugegebenermaßen wegen der gegenwärtig im internationalen Vergleich recht rückständigen Verwendung elektronischer Zahlungsmittel in Deutschland nicht gänzlich auszuschließen. Es spricht allerdings auch vieles dafür, daß solche rückläufigen Effekte durch eine verstärkte DEM-Auslandsverwendung (v.a. in Süd-Osteuropa) überkompensiert worden wären. Zudem werden die Ausführungen zur EWU-Erweiterung zeigen, daß bei einer zahlenmäßigen Zunahme der Währungsunion sich die geschätzte Verliererposition Deutschlands eher vergrößern wird. Eine Kritik an der Ceterisparibus-Annahme zur Schätzung der EWU-11- bzw. der EWU-12-NettoPoolposition Deutschlands bleibt diesbezüglich zwar prinzipiell korrekt, sollte aber dann dahin gehend interpretiert werden, daß diese Prognosen den deutschen Verlust eher unter- als überschätzen.

\subsubsection{Lösungsansätze zur Vermeidung der unerwünschten Umverteilungseffekte des Earmarking-Verfahrens}

\subsubsection{Anrechnung der Monetären Pre-EWU-Basen auf das Geldschöpfungsvermögen der NZBen}

Sowohl die auf Jahresbasis als auch die mit Hilfe der Barwertmethode durchgeführten Berechnungen der unerwünschten Umverteilungseffekte legen es nahe, den Anfangsstock der von den NZBen in die EWU eingebrachten Aktiva und Passiva aus dem Umverteilungsmechanismus der Monetären Einkünfte auszunehmen ${ }^{454}$. Dies könnte zum Beispiel durch einen bilanziellen Kunstgriff erfolgen, der es den NZBen jeweils erlaubt, ihren Pre-EWUBanknotenumlauf (inklusive unverzinster Pre-EWU-Überschußreserven der

454 Vgl. Remsperger (1996), S. 3, Sinn/Feist (1997d), S. 25 und Gros (1998), S. 34. 
Geschäftsbanken) $)^{455}$ vollständig durch unverzinsliche Forderungen zu decken. Hierzu bräuchten sich die NZBen nur jeweils gegenseitig in Höhe ihrer PreEWU-Banknotenumläufe und unverzinster Pre-EWU-Überschußreserven ertraglose nicht rückzahlbare „Kredite“ gewähren und diese Forderungen earmarken ${ }^{456}$. Allerdings sollten dann alle anderen zur Deckung der Monetären NZB-Basen herangezogenen Aktiva verzinslich $\operatorname{sein}^{457}$. Eine solche Regelung würde die unerwünschten Umverteilungen von Pre-EWU-Geldschöpfungsgewinnen vermeiden und zugleich die erwünschten Umverteilungseffekte des Earmarking-Verfahrens gewährleisten. Letztere umfassen nämlich nicht nur die Verteilung derjenigen Geldschöpfungsgewinne, die das Eurosystem durch Neuemission von Zentralbankgeld seit dem 1.1.1999 erwirtschaftet hat. Auch die Umverteilung von Pre-EWU-Geldschöpfungsvermögen, welches nicht auf das Pooling der Monetären Einkünfte, sondern auf den grenzüberschreitenden Zahlungsverkehr (Verlagerung der Pre-EWU-Banknotenumlaufs und der unverzinslichen Pre-EWU-Giraleinlagen der Geschäftsbanken) zurückzuführen ist, wird so vermieden. Allerdings impliziert eine solche Vorgehensweise eine Art „Einfrieren“ bzw. „Grandfathering" des Pre-EWU-Seignioragevermögens $^{458}$. Dies wäre aber nur dann gerechtfertigt, wenn das Pre-EWUGeldschöpfungsvermögen in einem Szenario ohne EWU konstant, zumindest aber nicht gesunken wäre. Wäre letzteres der Fall, weil sich etwa die Zahlungsgewohnheiten in den Bargeld-intensiven EWU-Ländern in Richtung einer verstärkten Nutzung elektronischer Zahlungsmittel entwickelt hätte, dann wären für solche Länder die kritisierten unerwünschten Umverteilungseffekte aus dem Pre-EWU-Seignioragevermögen freilich geringer anzusetzen, da ihre Monetäre NZB-Basis in Zukunft ohnehin abgenommen hätte. Unterstellt man weiter, daß die kumulierte Monetäre Basis des Eurosystems zukünftig ansteigt, käme das „Einfrieren“ des Pre-EWU-Geldschöpfungsvermögens einer Bevorteilung dieser Länder gleich. Deshalb kann es erforderlich erscheinen, den künstlich generierten unverzinslichen „Pre-EWU-Deckungsposten“ der NZBen jeweils einen individuellen, zeitabhängigen Korrekturfaktor hinzuzufügen. Die operative Festlegung desselben ist allerdings ohne Willkür nicht möglich.

${ }^{455}$ Falls die Mindestreserve nicht mehr verzinst werden sollte, wäre freilich die gesamte Monetäre Pre-EWU-Basis der NZBen durch eine derartig künstlich geschaffene Forderung zu decken.

Vgl. auch die Überlegungen von Sinn und Feist, die ein Earmarking speziell hierfür emittierter unverzinslicher NZB-Schuldverschreibungen vorschlagen. Vgl. Sinn/Feist (1997a), S. 24.

457 Ein zusätzliches umverteilungsneutrales Earmarking von Gold wäre auch hier nicht problematisch, bliebe jedoch letztlich überflüssig. 


\subsubsection{Anrechnung der Ausgleichsbeträge im Zeitraum von 2002 bis 2007}

Die Anrechenbarkeit der Ausgleichsbeträge auf die jeweilige NZBBemessungsgrundlage zur Ermittlung der Monetären Einkünfte im Zeitraum von 2002 bis 2007 greift die obigen Überlegungen im gewissen Sinne auf ${ }^{459}$. Zwar setzt man hierbei nicht direkt an den Eröffnungsbilanzen der NZBen zum 1.1.1999 an, bezieht sich aber immerhin auf den jeweiligen durchschnittlichen Wert des NZB-Banknotenumlaufs im Zeitraum vom 1. Juli 1999 bis zum 30. Juni 2001, der durch den Pre-EWU-Banknotenumlauf weitestgehend bestimmt ist $^{460}$. Zudem ist unter einer bestimmten Voraussetzung die Anrechnung der Ausgleichsbeträge auf die Bemessungsgrundlage der NZBen dem oben vorgeschlagenen Earmarking unverzinslicher Aktiva inhaltlich gleichzusetzen, wie die folgende Beispielrechnung zeigt.

Der Einfachheit halber soll das Eurosystem (ohne EZB) nur aus den zwei NZBen $A$ und $B$ mit einem jeweiligen EZB-Kapitalanteil von 50 Prozent $\left(K_{A}=\right.$ $\mathrm{K}_{\mathrm{B}}=50 \%$ ) bestehen ${ }^{461}$. Die Passiva der NZBen bestehen nur aus Banknoten, wobei die NZB A über einen Pre-EWU-Banknotenausweis von 100 Einheiten bzw. die NZB B über 150 Einheiten verfügt. Die Pre-EWU-Aktiva der NZBen seinen qualitativ identisch mit einer Einheitsverzinsung von 10 Prozent. Zudem soll das Eurosystem im ersten Jahr der Währungsunion keine Bilanztransaktionen durchführen. Am Ende dieses Jahres würde sich dann nach erfolgtem Earmarking eine Poolmasse von 25 Einheiten ergeben, die einen Pooling-Gewinn für die NZB A in Höhe von 2,5 Einheiten (pro Jahr) impliziert. Finanziert wird dieser unerwünschte Ressourcentransfer von der NZB B durch Rückgriff auf ihre Pre-EWU-Geldschöpfungsgewinne. Die oben vorgeschlagene Deckung der Pre-EWU-Banknotenumläufe durch eine Anrechnung künstlich geschaffener unverzinslicher Aktiva würde diese unerwünschten Umverteilungseffekte verhindern, da die NZB-Poolbeiträge und damit auch die Poolmasse null wäre.

459 In den Jahren 1999 bis einschließlich 2001, in der die Indirekte Methode zur Ermittlung der Monetären Einkünfte zur Anwendung kam, wurde praktisch keine Umverteilung von Pre-EWU-Seignioragegewinnen vorgenommen, da in dieser Zeit der Banknotenumlauf aus der Bemessungsgrundlage ausgenommen wurde. Vgl. dazu die Ausführungen zur Indirekten Methode in Kapitel V.3.1.1. Abschnitt 3..

460 So ist die Verteilung der durchschnittlichen Banknotenumläufe im Zeitraum von Juli 1999 bis Juni 2002 (vgl. Tabelle A2 im Anhang) fast identisch mit der Verteilung der PreEWU-Banknotenumläufe ( Vgl. Tabelle 9). Vgl. Abbildung 9. 
Abbildung 9: Umverteilung von Pre-EWU-Geldschöpfungsvermögen und die Anrechnung der Ausgleichsbeträge

Umverteilung der Pre-EWU-Aktiva-basierten Monetären Einkünfte der NZBen

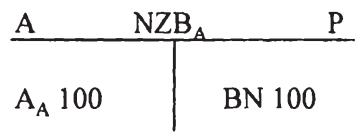

Earmarking: $\mathrm{BN} \Rightarrow \mathrm{A}_{\mathrm{A}}=100$

In Pool von $\mathrm{NZB}_{\mathrm{A}}$ :

$$
A_{A} \cdot i=100 \cdot 10 \%=10
$$

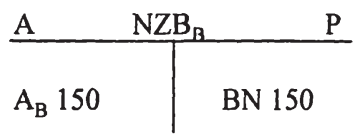

Earmarking: $\mathrm{BN}=>\mathrm{A}_{\mathrm{B}}=150$

In Pool von $\mathrm{NZB}_{\mathrm{B}}$ :

$A_{B} \cdot i=150 \cdot 10 \%=15$

Poolmasse: $\mathrm{P}=25$

Aus Pool in $\mathrm{NZB}_{\mathrm{A}}\left(\mathrm{K}_{\mathrm{A}}=50 \%\right)$ :

Aus Pool in $\mathrm{NZB}_{\mathrm{B}}\left(\mathrm{K}_{\mathrm{B}}=50 \%\right)$ :

$P \cdot K_{A}=12,5$

$P \cdot K_{H}=12,5$

Gewinn $\mathrm{NZB}_{\mathrm{A}}:+2,5$

Gewinn $\mathrm{NZB}_{\mathrm{B}}:-2,5$

Umverteilung der Pre-EWU-Aktiva-basierten Monetären Einkünfte der NZBen inklusive Ausgleichbetrag

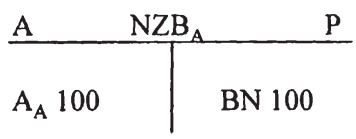

Earmarking: $\mathrm{BN}+\mathrm{AB}=>\mathrm{A}_{\mathrm{A}}+\mathrm{AB}_{\mathrm{A}}$

In Pool von $\mathrm{NZB}_{\mathrm{A}}$ :

$$
\begin{aligned}
A_{A} \cdot i+A B \cdot i & =100 \cdot 10 \%+25 \cdot 10 \% \\
& =12,5
\end{aligned}
$$

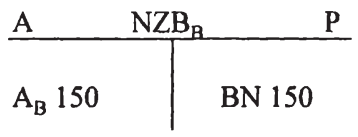

Earmarking: $\mathrm{BN}-\mathrm{AB} \Rightarrow \mathrm{A}_{\mathrm{B}}-\mathrm{AB}_{\mathrm{B}}$ In Pool von $\mathrm{NZB}_{\mathrm{B}}$ :

$$
\begin{aligned}
A_{B} \cdot i-A B \cdot i & =150 \cdot 10 \%-25 \cdot 10 \% \\
& =12,5
\end{aligned}
$$

Poolmasse: $\mathrm{P}=25$

Aus Pool in $\mathrm{NZB}_{\mathrm{A}}\left(\mathrm{K}_{\mathrm{A}}=50 \%\right)$ :

$$
P \cdot K_{A}=12,5
$$

Gewinn $\mathrm{NZB}_{\Lambda}: 0$
Aus Pool in $\mathrm{NZB}_{\mathrm{B}}\left(\mathrm{K}_{\mathrm{B}}=50 \%\right)$ :

$P \cdot K_{B}=12,5$

Gewinn $\mathrm{NZB}_{\mathrm{B}}: 0$ 
Die Anrechnung des Ausgleichsbetrags nach Maßgabe des EZBRatsbeschlusses vom 6. Dezember 2001 leistet dies - jedoch nur bei einem Koeffizienten von eins - ebenso ${ }^{462}$. So sind zunächst die Ausgleichsbeträge zu berechnen, die sich bei unterstellter gleicher Verteilung der durchschnittlichen Banknotenumläufe (im Zeitraum von Juli 1999 bis Juni 2001) mit der Verteilung der Pre-EWU-Banknotenumläufe ${ }^{463}$ in diesem Beispiel wie folgt ergeben:

\begin{tabular}{|c|c|c|}
\hline NZB & $\mathbf{N Z B}_{\mathbf{A}}$ & $\mathbf{N Z B}_{\mathbf{B}}$ \\
\hline Pre-EWU-Banknotenumlauf & $\mathrm{W}_{\mathrm{A}}=100$ & $\mathrm{~W}_{\mathrm{B}}=150$ \\
\hline EZB-Kapitalanteil & $\mathrm{K}_{\mathrm{A}}=50 \%$ & $\mathrm{~K}_{\mathrm{B}}=50 \%$ \\
\hline $\begin{array}{l}\text { Verteilung des kumulierten Pre- } \\
\text { EWU-Banknotenumlaufs gemäß }\end{array}$ & $\mathrm{S}_{\mathrm{A}}=\left(\mathrm{W}_{\mathrm{A}}+\mathrm{W}_{\mathrm{B}}\right)^{*} \mathrm{~K}_{\mathrm{A}}$ & $\begin{array}{c}\mathrm{S}_{\mathrm{B}}=\left(\mathrm{W}_{\mathrm{A}}+\mathrm{W}_{\mathrm{B}}\right)^{*} \mathrm{~K}_{\mathrm{B}} \\
=\end{array}$ \\
\hline EZB-Kapitalanteil & $250 * 50 \%=125$ & $250 * 50 \%=125$ \\
\hline $\begin{array}{l}\text { Ausgleichsbetrag mit } \\
\text { Koeffizient } 1= \\
\mathrm{AB}^{1}=(\mathrm{S}-\mathrm{W}) \times 1\end{array}$ & $\mathrm{AB}_{\mathrm{A}}=25$ & $A B_{B}=-25$ \\
\hline
\end{tabular}

Die so ermittelten individuellen Ausgleichsbeträge werden nun für jede NZB mit ihrer Bemessungsgrundlage (hier nur Banknotenumlauf) verrechnet. Die NZB A hat folglich zusätzlich zu ihren Erträgen, die ihr aus ihren Pre-EWUAktiva $\left(A_{A} \cdot i=10\right)$ zufließen, auch die kalkulatorischen Zinseinkünfte aus dem Ausgleichsbetrag $\left(A_{B} \cdot i=2,5\right)$ in den Seignioragepool abzuführen. Hierzu spiegelbildlich verhält es sich bei der NZB B, die die kalkulatorischen Zinseinkünfte aus dem Ausgleichsbetrag von ihren Monetären Einkünften abziehen darf und somit ebenfalls einen Poolbeitrag von 12,5 Einheiten leistet. Die Aufteilung der Poolmasse von 25 Einheiten je zur Hälfte auf die NZBen zeigt, daß keine Umverteilung von Pre-EWU-Geldschöpfungsvermögen stattgefunden hat. Letztlich erhält jede NZB genau den Betrag aus dem Pool zurück, den sie selbst finanziert hat. Dies gilt jedoch nur für das Jahr 2002, in dem der Koeffizient zur Berechnung der Ausgleichsbeträge den Wert eins annimmt. Die schrittweise Verringerung dieses Multiplikators bis einschließlich 2007 läßt hingegen die kritisierte Umverteilung von Pre-EWU-Geldschöpfungsvermögen wieder relevant werden. Dies wäre jedenfalls dann zu befürchten, wenn sich die Pre-EWU-Banknotenumläufe der NZBen in einer Situation ohne EWU nicht genau in dem Zeitpfad angeglichen hätten, der durch

462 Zur Berechnung der Ausgleichsbeträge und deren Anrechnung auf die Bemessungsgrundlage der Monetären Einkünfte vgl. Kapitel V.3.1.2. Abschnitt 2.4. und Kapitel V.3.1.2. Abschnitt 3.2.3.2.

463 Daß diese Annahme weitestgehend auch tatsächlich gilt, wurde bereits erwähnt. 
die über sechs Jahre verteilte sukzessive Reduktion des Koeffizienten zur Berechnung der Ausgleichsbeträge beschrieben wird ${ }^{464}$.

Letztlich muß wohl die vom EZB-Rat beschlossene sechsjährige stufenweise Reduktion der Ausgleichsbeträge als Kompromiß zwischen zwei Extrempositionen gesehen werden. So dürften vor allem die Vertreter der Gewinner-NZBen den Standpunkt vertreten haben, daß mit der Aufgabe einer eigenständigen nationalen Geldpolitik auch die anfallenden Geldschöpfungsgewinne europäisch sind und bestimmte nationale Vorgriffsrechte schon aus diesem Grunde abzulehnen sind ${ }^{465}$. Dem läßt sich die oben vorgestellte Analyse entgegenhalten, die eine faktische Umverteilung von Pre-EWU-Geldschöpfungsvermögen wegen der klaren Zurechenbarkeit zur ehemals nationalen Geldpolitik nicht gerechtfertigt sieht. So dürften die Verlierer-NZBen Deutschlands, Spaniens und Österreichs wohl nur eine Vergemeinschaftung der Geldschöpfungsgewinne vorgeschlagen haben, die auf den Aktiva basiert, die das Eurosystem erst nach dem Übergang zur dritten Stufe der EWU durch neue Geldschöpfung erworben hat. Wie oben gezeigt, würde dies bei unterstellter konstanter Monetärer Pre-EWU-Basis der NZBen einer Forderung nach einer ewigen Anwendung der Earmarking-Ausgleichsbeträge mit einem Koeffizienten von eins gleichkommen. Dieser Vorschlag war jedoch, wenn er überhaupt so deutlich formuliert wurde, nicht durchsetzbar, wie die im Anhang aufgeführte Stimmverteilung des EZB-Rats vermuten läßt ${ }^{466}$. Demzufolge können die Verlierer-NZBen Deutschlands, Spaniens und Österreichs nur 44 Prozent der gewogenen Stimmanteile auf sich vereinigen, was auch den relativ kurzen Zeitraum der Übergangsregelung von nur sechs Jahren erklärt.

Aus deutscher Sicht befriedigt diese Regelung nicht. So konnte gezeigt werden, daß auch nach der Anrechnung der verschiedenen Übergangsregelungen in einem EWU-12-Szenario immer noch deutliche Pre-EWU-Seigniorageverluste von rund $19 \mathrm{Mrd}$. EUR zu erwarten sind. Bei einer sich vergrößernden EWU ist diese Schätzung wahrscheinlich sogar nach oben zu korrigieren, wie die folgenden Ausführungen vermuten lassen.

464 Zur zeitlichen Anpassung des Koeftizienten zur Berechnung der Ausgleichsbeträge vgl. Kapitel V.3.1.2. Abschnitt 2.4..

465 Diese Auffassung vertritt auch Klopfleisch. Vgl. Klopfleisch (2000), S. 168.

466 Vgl. Tabelle A7 im Anhang. Gemäß Artikel 10.3. ESZB-Satzung werden für alle Beschlüsse des EZB-Rats, die die Erfassung und Verteilung der Monetären Einkünfte betreffen, die Stimmen im EZB-Rat nach Maßgabe des gezahlten EZB-Kapitalanteils gewogen. Die Stimmen der Direktoriumsmitglieder werden hierbei mit null gewogen und bleiben somit unberücksichtigt. Vgl. Art. 10.3. ESZB-Satzung. 


\subsection{Die Auswirkungen der EWU-Erweiterung auf die Umverteilung der Geldschöpfungsgewinne durch das Earmarking-Verfahren}

Ein Beitritt von neuen Mitgliedstaaten zum Euroverbund führt freilich zu keinen grundsätzlich neuen Problemen oder relativiert die vormals existierenden. Es erhöht sich jedoch das absolute Niveau der Monetären Einkünfte, und auch die Umverteilung zwischen den bereits im Eurosystem befindlichen NZBen wird sich verschieben. Letzteres hängt im einzelnen von der jeweiligen Differenz zwischen dem Anteil der Beitritts-NZB an der gesamten Monetären EWU-Basis und ihrem EZB-Kapitalanteil ab. Anhand der Tabelle 45 ist ersichtlich, wie sich die Gewinner- und Verliererpositionen der NZBen eingestellt hätten, wenn alle EWU-Staaten bereits zum 1.1.1999 dem Euroverbund beigetreten wären und das Earmarking-Verfahren ohne Übergangsregelungen sofort zur Anwendung gekommen wäre. Dann würden alle damaligen Pre-Ins (Griechenland, Schweden, Dänemark und Großbritannien) als Gewinner beim Pooling der Monetären Einkünfte hervorgehen, weshalb sich jeweils die Nettoverlustposition Deutschlands und Spaniens gegenüber dem EWU-11 bzw. EWU-12-Szenarien deutlich erhöhen würde ${ }^{467}$. Dazu würde Frankreich vergleichsweise weniger gewinnen. Der Grund hierfür ist in der Tatsache zu suchen, daß die damals nicht beigetretenen EU-Staaten durchweg einen im Vergleich zu ihrer EZB-Kapitalbeteiligung niedrigeren Anteil am gesamten EWU-europäischen Banknotenumlauf vorzuweisen gehabt hätten. Es wird schnell klar, daß mit einer noch weitergehenden Vergrößerung der EWU sich erneut die Gewinner- und Verliererpositionen der sich bereits im Euroverbund befindlichen Länder verschieben werden ${ }^{468}$. Diese Problematik soll aber an dieser Stelle nicht weiter verfolgt werden, da ein Ceteris-paribus-Szenario, wie es die Barwertmethode darstellt, von einer Konstanz des Banknotenumlaufs der Beitrittsländer ausgeht und eine solche Annahme kaum mit der für den Beitritt erforderlichen Beseitigung des nationalen Geldüberhangs vereinbar scheint. Zudem kann nicht exakt prognostiziert werden, wie sich das Wirtschaftswachstum der osteuropäischen Beitrittskanditaten entwickeln wird. Letzteres bestimmt bei gegebener Bevölkerungsentwicklung den zu zeichnenden EZB-Kapitalanteil der Beitrittsländer und hat somit unmittelbare Auswirkungen auf die Partizipation am Seignioragepoo ${ }^{469}$. Die Berechnung von Feist deuten jedoch darauf hin, daß sich die Pre-EWU-Seigniorageverluste Deutschlands eher vergrößern als verkleinern dürften.

$467 \mathrm{Vgl}$. dazu die Tabelle 42.

$468 \mathrm{Vgl}$. hierzu Feist (2001).

469 Vgl. Art. 29.1. und Art. 32.5. ESZB-Satzung. 
Tabelle 45: Umverteilung von Seignioragevermögen und EWU-Erweiterung

\begin{tabular}{|l|r|r|r|r|r|r|}
\hline & \multicolumn{2}{|c|}{$\begin{array}{c}\text { Beigetragenes } \\
\text { Geldschöpfungs- } \\
\text { vermögen }\end{array}$} & \multicolumn{2}{|c|}{$\begin{array}{c}\text { Erhaltenes } \\
\text { Geldschøpfungs- } \\
\text { vermögen }\end{array}$} & $\begin{array}{l}\text { Gewinn/ } \\
\text { Verlust } \\
\text { absolut }\end{array}$ & $\begin{array}{l}\text { Gewinn/ } \\
\text { Verlust pro } \\
\text { Kopf }\end{array}$ \\
\cline { 2 - 7 } & Mrd. EUR & Anteil \% & Mrd. EUR & Anteil \% & Mrd. EUR & EUR \\
\hline Deutschland & 130,6 & $32,7 \%$ & 97,6 & $24,5 \%$ & $+32,9$ & +411 \\
\hline Frankreich & 42,3 & $10,6 \%$ & 67,1 & $16,8 \%$ & $-24,8$ & -422 \\
\hline Italien & 63,2 & $15,9 \%$ & 59,4 & $14,9 \%$ & $+3,8$ & +67 \\
\hline Spanien & 52,7 & $13,2 \%$ & 35,5 & $8,9 \%$ & $+17,3$ & +439 \\
\hline Niederlande & 17,3 & $4,3 \%$ & 17,1 & $4,3 \%$ & $+0,2$ & +15 \\
\hline Belgien & 12,0 & $3,0 \%$ & 11,4 & $2,9 \%$ & $+0,5$ & +53 \\
\hline Österreich & 12,3 & $3,1 \%$ & 9,4 & $2,4 \%$ & $+2,9$ & +354 \\
\hline Portugal & 5,1 & $1,3 \%$ & 7,7 & $1,9 \%$ & $-2,6$ & -259 \\
\hline Finnland & 2,6 & $0,7 \%$ & 5,6 & $1,4 \%$ & $-2,9$ & -567 \\
\hline Irland & 3,6 & $0,9 \%$ & 3,4 & $0,8 \%$ & $+0,2$ & +51 \\
\hline Luxemburg & 0,1 & $0,0 \%$ & 0,6 & $0,1 \%$ & $-0,5$ & -1126 \\
\hline Großbritannien & 35,3 & $8,8 \%$ & 58,5 & $14,7 \%$ & $-23,3$ & -400 \\
\hline Schweden & 9,1 & $2,3 \%$ & 10,6 & $2,7 \%$ & $-1,5$ & -171 \\
\hline Griechenland & 7,6 & $1,9 \%$ & 8,2 & $2,1 \%$ & $-0,6$ & -54 \\
\hline Dänemark & 5,0 & $1,3 \%$ & 6,7 & $1,7 \%$ & $-1,7$ & -313 \\
\hline Gesamt & 398,7 & $100,0 \%$ & 398,7 & $100,0 \%$ & 0,0 & - \\
\hline Legende: Kapitalanteil der EZB zum 1.1 .1999$, Anteil am Banknotenumlauf und Angaben \\
zur Bevölkerung zum 31.12 .1998$. & & & & \\
\hline
\end{tabular}

Quelle: Eigene Berechnungen und Darstellung in Anlehnung an Sinn/Feist (1997d), S. 13. Die der Darstellung zugrunde liegenden Daten sind entnommen aus Tabelle 9, Danmarks Nationalbank (1999), S. 119, Bank of Greece (1999a), S. 253, Schwedische Reichsbank (1999), S. 34, Bank of England (2001), S. 87 und Europäische Zentralbank (2001d), S. 200 und International Monetary Fund (2000f). Banknotenumlauf der Bank of England zum 28.2.1999. Umrechnung der in nationaler Währung ausgewiesenen Banknotenumläufe der Zentralbanken Griechenlands, Dänemarks, Schwedens und des Vereinigten Königreichs mit dem jeweiligen monatsdurchschnittlichen Wechselkurs gegenüber dem Euro im Januar 1999. Vgl. Europäische Zentralbank (2001b), S. 38*. Differenzen in den Summen durch Runden der Zahlen. 


\section{Analyse des Earmarking-Verfahrens unter konzeptionellen Gesichtspunkten}

\subsection{Konzeptionelle Begründung des Earmarking-Verfahrens}

An dieser Stelle soll untersucht werden, wie das Earmarking-Verfahren konzeptionell begründet werden kann. Dabei steht im Mittelpunkt dieser Betrachtung nicht die Rechtfertigung für das Pooling von Notenbankeinkünften an sich, sondern die Frage, aus welchen Gründen die vertraglichen Regelungen nur Teile und nicht die gesamten NZB-Einkünfte einem Umverteilungsprozeß unterziehen. Die Erklärung hierfür könnte im Aufgabenspektrum der NZBen zu sehen sein. So sind die NZBen einerseits als integraler Bestandteil des Eurosystems verpflichtet, ihren Beitrag zur Erfüllung der Aufgaben des Eurosystems zu leisten (Art. 14.3. ESZB-Satzung). Andererseits dürfen die NZBen auch andere als in der ESZB-Satzung bezeichneten Aufgaben wahrnehmen, es sei denn, der EZB-Rat stellt mit Zweidrittelmehrheit der abgegebenen Stimmen fest, daß diese Aufgaben nicht mit den Zielen und Aufgaben des ESZB/Eurosystems vereinbar sind. Derartige Aufgaben werden von den NZBen in eigener Verantwortung und auf eigene Rechnung wahrgenommen und gelten nicht als Aufgaben des ESZB/Eurosystems (Art. 14.4. ESZB-Satzung). Es leuchtet ein, die Erträge und Aufwendungen dieser in Eigenregie durchgeführten Tätigkeiten nicht $\mathrm{zu}$ vergemeinschaften. Entsprechend sieht die ESZB-Satzung auch vor, daß nur die (Netto-) Erträge, die den NZBen aus der „Erfüllung der währungspolitischen Aufgaben des ESZB/Eurosystems" zufließen, sozialisiert werden sollen ${ }^{470}$.

\subsection{Konzeptionelle Kritik an der Umsetzung des Earmarking-Verfahrens}

Die Frage ist nun, ob es mit Hilfe des Earmarking-Verfahrens auch tatsächlich gelingt, die gewünschte Trennung zwischen den ,währungspolitischen“ Erträgen und Aufwendungen einerseits und den anderen Einkünften und Kosten der NZBen andererseits zu verwirklichen. Dabei ist zunächst zu klären, ob die in Artikel 14.4. ESZB-Satzung angesprochenen Tätigkeiten der NZBen, die sich auf die Wahrnehmung von anderen als in der ESZB-Satzung bezeichneten Aufgaben beziehen und expressis verbis „nicht als Aufgaben des ESZB/Eurosystems" (Art. 14.4. ESZB-Satzung) gelten, in funktionaler Hinsicht überhaupt eine Negativabgrenzung zu den „währungspolitischen“ Aufgaben der NZBen bilden. So zeigt die Analyse der NZB-Gewinnentstehung, daß auch

${ }^{470} \mathrm{Vgl}$. Art. 32.1. und Art. 32.4. ESZB-Satzung. 
direkt in der ESZB-Satzung eine Reihe von Tätigkeiten der NZBen beschrieben sind, die unter funktionalen Aspekten den in Art. 14.4. ESZB-Satzung erwähnten Aktivitäten gleichzusetzen sind, da diese ebenfalls in eigener Verantwortung und auf eigene Rechnung erfolgen, ohne daß die EZB diese Tätigkeiten ohne weiteres unterbinden kann. Will man die Eigenverantwortlichkeit als Abgrenzungskriterium heranziehen, so erscheint es nur konsequent, diesen Maßstab auch für die in der ESZB-Satzung unmittelbar geregelten Tätigkeiten anzuwenden. Demzufolge wurden als Ausdruck dieser funktionalen Zuordnung die NZB-Tätigkeiten in eine „Eurosystem-spezifische“ und in eine „Eurosystem-unabhängige" Komponente unterteilt.

Allerdings folgt das Earmarking-Verfahren dieser funktionalen Tätigkeitsabgrenzung nicht, sondern definiert alle Aktivitäten der NZBen, die die Monetäre NZB-Basis tangieren, als Pooling-relevant und damit den währungspolitischen Aufgaben des Eurosystems zugehörig. Diese Vorgehensweise untergräbt jedoch in bestimmtem Umfang die Rechtfertigung für die eigene Existenz. Diese liegt ja gerade in einer Aufgaben- bzw. Tätigkeits-basierten funktionalen Trennung zwischen "währungspolitischen“ (Art. 31.1. ESZBSatzung) bzw. „Eurosystem-spezifischen“ Erträgen und Aufwendungen auf der einen Seite und den „anderen“ (Art. 14.4. ESZB-Satzung) bzw. „Eurosystemunabhängigen" Einkünften und Kosten auf der anderen Seite, je nachdem, ob man die Zuordnung zu diesen Bereichen im „legalistischen“ oder im streng funktionalen Sinne interpretieren mag. Für die im Vertrag vorgesehene Anwendung des Earmarking-Verfahrens ist es aber egal, ob sich die Monetäre Basis nun beispielsweise aufgrund von eindeutig der gemeinsamen Geld- und damit auch der Währungspolitik zuzuordnenden NZB-Aktivitäten verändert oder ob diese auf Transaktionen zurückzuführen ist, die, wie z.B. die An- und Verkäufe von Unternehmensbeteiligungen, unter den Art. 14.4. ESZB-Satzung fallen und damit expressis verbis nicht den Aufgaben des ESZB/Eurosystems zuzurechnen sind. Ein konzeptioneller Widerspruch in der ESZB-Satzung dürfte wohl nicht zu leugnen sein. Dieser läßt sich jedoch in zweifacher Hinsicht lösen, wenngleich beide Vorgehensweisen dann wohl nicht mehr unbedingt mit den bestehenden Vertragsregelungen vereinbar wären.

Entweder verzichtet man auf die in der ESZB-Satzung direkt angesprochene Trennung zwischen ESZB-Satzungs-basierten und Nicht-ESZB-Satzungsbasierten Aufgaben der NZBen ${ }^{471}$, spart sich als Folge daraus das Earmarking und poolt die gesamten NZB-Gewinne. Oder man nimmt die funktionale Begründung des Earmarking ernst und läßt dann aber nicht nur die in Art. 14.4. ESZB-Satzung angesprochenen Aufgaben, sondern auch die in der ESZB-

471 Vgl. Art. 3 und Art. 14.4. ESZB-Satzung sowie Abbildung 4. 
Satzung im einzelnen geregelten „Eurosystem-unabhängigen“ Tätigkeiten bei einem Umverteilungsmechanismus außen vor. Hierzu wäre allerdings unter Umständen ein anderes Verfahren zur Ermittlung der „Eurosystem-spezifischen" Einkünfte der NZBen erforderlich" ${ }^{472}$.

\section{V.3.2. Die Gewinnverwendung der NZBen nach dem Pooling der Monetären Einkünfte}

Die Verwendung der Gewinne, die den NZBen nach dem Pooling der Monetären Einkünfte verbleiben, erfolgt nach nationalen Regelungen. Es überrascht somit nicht, daß die folgende Tabelle 46 ein sehr heterogenes Bild der NZB-Gewinnverwendung des Jahres 1999 zeigt. So greift eine Reihe von Regierungen über Körperschaftssteuern, Interimsdividenden und anderen satzungsgemäßen Regularien bereits vor der bilanziellen Feststellung des "Jahresüberschusses“ auf den heimischen NZB-Gewinn $\mathrm{zu}^{473}$. Derartige Regelungen dienen vor allem dazu, den Regierungen, die nicht alleiniger Eigentümer der NZBen sind, den mit Abstand größten Teil des NZB-Gewinns zukommen zu lassen. Dies wird insbesondere anhand der Gewinnverwendung der österreichischen und belgischen Notenbank deutlich. Inhaltlich unterscheiden sich diese Vorgehensweisen freilich nicht von einer Ausschüttung nach Feststellung des Bilanzgewinns. Sie zeigen jedoch, daß die von den NZBen in ihren Gewinn- und Verlustrechnungen veröffentlichten Jahresüberschüsse nicht ohne weiteres vergleichbar sind, was oftmals übersehen wird ${ }^{474}$. Die Zuführung zu den verschiedenen Reserven der NZBen ist ebenfalls sehr unterschiedlich in den Zentralbankgesetzen geregelt. Besonders ausgeprägt ist hierbei die quasi automatische Reservenbildung der finnischen Zentralbank, die in der Regel 50 Prozent ihres Jahresüberschusses in die Reserven einzustellen hat $^{475}$. Nach erfolgter Dotierung der Reserven kommen in der Regel die Kapitaleigner der NZBen in den Genuß der auszuschütteten Beträge. Im Falle Deutschlands, Frankreichs, Spaniens, Portugals, Irlands, Finnlands, Luxemburg und der Niederlande ist dies jeweils ausschließlich die heimische Regierung.

$472 \mathrm{Zu}$ einem Versuch, diese funktionale Trennung auch innerhalb der bestehenden Vertragsregelungen zu gewährleisten, vgl. die Ausführungen zum „Deadline-Earmarking“ in Rösl/Schäfer (2000).

473 Solche Zugriffe werden in den GuVen der NZBen als Aufwand erfaßt und auf die Bruttoeinkünfte angerechnet.

474 Dies wäre auch für eine Analyse der Partizipation der EWU-Regierungen am Totalen Seigniorage von Bedeutung. Vgl. dazu die theoretischen Überlegungen Fiskalischen Seigniorage in Kapitel II. Abschnitt 4.2.1.. 
Tabelle 46: Die Verwendung der NZB-Bilanzgewinne des Jahres $1999^{1}$

\begin{tabular}{|c|c|c|c|c|c|}
\hline NZB & BBk & BdI & BdF & BdE & DNB \\
\hline $\begin{array}{l}\text { "Vorbilanzielle" Gewinn- } \\
\text { schüttungen an den }\end{array}$ & - & $-96,0$ & $-274,8$ & $-1905,9$ & - \\
\hline $\begin{array}{l}\text { Staat, davon: } \\
\text { Korperschaftssteuer u.ä. }\end{array}$ & $\ldots$ & $-96,0$ & $-274,8$ & ...- & ... \\
\hline Gewinnanteil vor & $\ldots$ & -- & -- & - & -.- \\
\hline $\begin{array}{l}\text { Interimsdividende vor dem } \\
31.12 .1999\end{array}$ & $\cdots$ & $\cdots$ & $\cdots$ & $-1905,9$ & -.- \\
\hline $\begin{array}{l}\text { Jahresũberschuß / } \\
\text { - fehlbetrag }\end{array}$ & 3903 & 535,0 & 153,5 & 2158,0 & 748 \\
\hline Zufuhrung zu Reserven & $\ldots^{2}$ & $-160,5$ & $-24,2$ & - & -297 \\
\hline $\begin{array}{l}\text { Ausschüttung an } \\
\text { Kapitaleigner }^{3}\end{array}$ & $-3903^{4}$ & $-0,0$ & $-72,9$ & $-2158,0^{5}$ & -451 \\
\hline Andere Verwendung & - & $-374,5^{6}$ & $-22,9^{7}$ & - & - \\
\hline Gewinnvortrag & -- & -- & $-33,5$ & - & -- \\
\hline $\begin{array}{l}\text { Verwendung GuV- } \\
\text { unwirksamer Gewinne }\end{array}$ & - & $(-28,3)^{8}$ & $(-46,3)^{9}$ & - & - \\
\hline & & & & & \\
\hline Kapitaleigner der NZB & $\begin{array}{l}\text { Deutscher } \\
\text { Staat } \\
(100 \%)\end{array}$ & \begin{tabular}{|l} 
Kreditinstitute \\
$(84,5 \%)$, \\
Sozial- \\
versicherungen \\
$(5 \%)$, \\
Versicherungen \\
$(10,5 \%)$ \\
\end{tabular} & $\begin{array}{c}\text { Französischer } \\
\text { Staat } \\
(100 \%)\end{array}$ & $\begin{array}{l}\text { Spanischer } \\
\text { Staat } \\
(100 \%)\end{array}$ & $\begin{array}{c}\text { Nieder- } \\
\text { ländischer } \\
\text { Staat (100\%) }\end{array}$ \\
\hline
\end{tabular}

1 Angaben in Mio. EUR. Die BBk, DNB und BoF weisen nur auf Mio. EUR gerundete Betrage aus. Diese Darstellung schließt sich an die harmonisierte GuV des Eurosystems zum 31.12.1999 an (vgl. Tabelle 12 und die entsprechenden Erläuterungen zu dieser Tabelle). Ein Minuszeichen kennzeichnet folglich die Verwendung des Jahresuberschusses bzw. „vorbilanzielle“" Gewinnausschuttungen.

${ }^{2}$ Zufuhrung zu der gesetzlichen Reserve nur bis zu ihren Hochststand von 2556 Mio. EUR ( $=5000$ Mio. DM). Vgl. Art. 27 BBankG und Deutsche Bundesbank (2000a), S. 192.

${ }^{3} \mathrm{Vgl}$. dazu auch die Tabelle 30.

${ }^{4}$ Enthalt auch die zweckgebundene Verwendung von 30 Mio. DM zugunsten des Fonds zum Ankauf von Ausgleichsforderungen bis zur Auflosung desselben Ende 2034.

${ }_{5}^{5}$ Die Ausschuttung erfolgte in Form einer zweiten Interimsdividende in Höhe von 1751,6 Mio. EUR am 1.2.2000, die restlichen 406,4 Mio. EUR wurden nach Feststellung des Jahresabschlusses an die Regierung abgefuhrt. Vgl. Banco de España (2000), S. 132.

${ }^{6}$ Ausschüttung an das italienische Schatzamt. Vgl. dazu auch Art. 54 BdI-Statut, Art. 57 BdI-Statut und Banca d'Italia (2000a), S. 287.

${ }^{7}$ Zufuhrung zum Pensionsfonds des BdF-Personals. Vgl. Banque de France (2000c), S. 234.

${ }^{8}$ Die Banca d'Italia hat eine weitere Zusatzausschulttung aufgrund von Art. 56 BdI-Statut in Höhe von 28,3 Mio. EUR beschlossen, die sich ebenfalls auf das Geschäftsjahr 1999 bezog, aber zum Zeitpunkt der Aufstellung der Jahreskonten noch nicht in die GuV einging. Vgl. Banca d'Italia (2000a), S. 288.

9 Die Banque de France erzielte aufgrund der Verwendung der harmonisierten Bilanzierungsregeln des Eurosystems zusătzlich einen Bewertungsgewinn aus der Erstellung der Eröffungsbilanz in Höhe von 43,3 Mio. EUR. Dieser Betrag wurde von der BdF nicht GuV-wirksam verbucht, sondern direkt in der Bilanz erfaßt und als Gewinn fortgeschrieben. Vgl. Banque de France (2000c), S. 234 und S. 244. 
Noch Tabelle 46: Die Verwendung der NZB-Bilanzgewinne des Jahres 1999

\begin{tabular}{|c|c|c|c|c|c|c|}
\hline NZB & NBB & OeNB & $\overline{B d P}$ & CBI & BoF & BCL \\
\hline $\begin{array}{l}\text { "Vorbilanzielle" } \\
\text { Gewinn- }\end{array}$ & -2538 & -121600 & -0.0 & -40.6 & $\ldots$ & - \\
\hline $\begin{array}{l}\text { schuttungen an } \\
\text { den Staat, davon: }\end{array}$ & & & & & & \\
\hline $\begin{array}{l}\text { Körperschaftssteuer } \\
\text { u.a. }\end{array}$ & $-130,3$ & $-442,6$ & $-0,0$ & $\cdots$ & $\cdots$ & $\cdots$ \\
\hline \begin{tabular}{|l|} 
Gewinnanteil vor \\
Bilanzgewinn
\end{tabular} & $-123,5$ & $-773,3$ & $\cdots$ & $\cdots$ & $\cdots$ & $\ldots$ \\
\hline $\begin{array}{l}\text { Interimsdividende } \\
\text { vor dem 31.12.1999 }\end{array}$ & $\cdots$ & -.. & $\cdots$ & $-40,6$ & $\cdots$ & $\cdots$ \\
\hline $\begin{array}{l}\text { JahresuberschuB / } \\
\text { - fehlbetrag }\end{array}$ & 56,9 & 85,9 & 55,1 & 172,8 & 0 & 0,9 \\
\hline $\begin{array}{l}\text { Zufuhrung zu } \\
\text { Reserven }\end{array}$ & $-24,2$ & $-19,3$ & $-27,6$ & - & k. $A .^{10}$ & k. A. \\
\hline $\begin{array}{l}\text { Ausschüttung an } \\
\text { Kapitaleigner }\end{array}$ & $-23,9$ & $-1,2$ & $-27,6$ & $-172,8$ & k. A. & k. A. \\
\hline \begin{tabular}{|l} 
Andere \\
Verwendung
\end{tabular} & $-8,7^{11}$ & $-65,4^{12}$ & - & $\cdots$ & - & - \\
\hline Gewinnvortrag & $\cdots$ & - & - & - & - & - \\
\hline $\begin{array}{l}\text { Verwendung GuV- } \\
\text { unwirksamer } \\
\text { Gewinne }\end{array}$ & - & - & $\cdots$ & $\cdots$ & - & - \\
\hline $\begin{array}{l}\text { Kapitaleigner der } \\
\text { NZB }\end{array}$ & $\begin{array}{l}\text { Belgischer } \\
\text { Staat } \\
(50 \%) \\
\text { Private } \\
(50 \%)\end{array}$ & \begin{tabular}{|l} 
Österr. Staat \\
$(50 \%)$ \\
Interessen- \\
vertretungen, \\
Banken, \\
Versicher- \\
ungen $(50 \%)$
\end{tabular} & $\begin{array}{l}\text { Portugie- } \\
\text { sischer Staat } \\
(100 \%)\end{array}$ & $\begin{array}{l}\text { Irischer } \\
\text { Staat } \\
(100 \%)\end{array}$ & $\begin{array}{l}\text { Finnischer } \\
\text { Staat } \\
(100 \%)\end{array}$ & $\begin{array}{c}\text { Luxem- } \\
\text { burgischer } \\
\text { Staat } \\
(100 \%)\end{array}$ \\
\hline
\end{tabular}

Quelle: Eigene Berechnungen. Die der Darstellung zugrunde liegenden Daten sind den Geschăftsberichten der NZBen fur das Jahr 1999 sowie den einschlägigen Zentralbankgesetzen bzw. NZB-Statuten entnommen. Differenzen in den Summen durch Runden der Zahlen.

${ }^{10}$ Der Gewinn der Bank of Finland betrug in 1999 weniger als 500.000 EUR und wird nicht detaillierter als 0 Mio. EUR ausgewiesen. Vgl. Bank of Finland (2000b), S. 84. Dies gilt auch fur dessen Verwendung. Section 21 Abs. 2 BoF-Gesetz schreibt allerdings eine Regelgewinnverwendung von $50 \%$ zu den Reserven und $50 \%$ zur Regierung vor.

"Ausschuttung an das Personal der Belgischen Nationalbank (2,8 Mio. EUR) sowie eine weitere Dividendenunabhăngige Ausschüttung an den Staat (5,8 Mio. EUR). Vgl. Art. 49 NBB-Statut und Belgische Nationalbank (2000b), S. 74.

12 Zuweisung zum Jubilaumsfonds der OeNB zur Förderung der Forschungs- und Lehraufgaben der Wissenschaft. Vgl. Österreichische Nationalbank (2000), S. 145. 
Die Dividendenzahlungen der NZBen Belgiens, Österreichs und Italiens, deren Kapitalausstattung teilweise bzw. vollständig privat finanziert ist, sind wegen der bereits angesprochenen „vorbilanziellen“ Gewinnzugriffe der heimischen Regierungen erwartungsgemäß gering. Die verbleibenden Jahresüberschüsse gehen hier entweder zusätzlich zum heimischen Schatzamt (Italien und teilweise auch Belgien) oder unterliegen einer anderen zweckgebundenen Verwendung wie der Finanzierung von Pensions- oder Wissenschaftsfonds (Frankreich bzw. Österreich).

Interessant ist die Gewinnausschüttung der belgischen Nationalbank an ihr eigenes Personal. In 1999 betrug dieser Wert 2,8 Mio. EUR und entspricht einem durchschnittlichen Kopfgeld von immerhin 1145 EUR $^{476}$. Diese Praxis ist aber wohl weniger außergewöhnlich als man zunächst vermuten könnte. So bietet auch die Banque de France ihren Mitarbeitern einen Anreizplan mit Gewinnbeteiligung an. In 1999 schüttete sie - unter Personalaufwand verbucht 24,8 Mio. EUR an ihr Personal aus, was einem durchschnittlichen Betrag von 1592 EUR pro Kopf gleichkommt ${ }^{477}$.

476 Vgl. Tabelle 28.

477 Vgl. Banque de France (2000c), S. 265 und Tabelle 28. 


\section{ZUSAMMENFASSUNG}

Die theoretischen Überlegungen zum staatlichen Geldschöpfungsgewinn zeigen, daß den institutionellen Arrangements sowohl bei der Entstehung als auch bei der Verteilung des Seigniorages eine entscheidende Bedeutung zukommt. Dies gilt freilich auch für die Europäische Währungsunion. So hat die Entnationalisierung der Geldpolitik unmittelbare Konsequenzen für die Gewinnentstehung und -verwendung der teilnehmenden Zentralbanken und damit für die einzelnen EWU-Staaten.

Dies liegt zum einen daran, daß mit der Europäischen Zentralbank eine supranationale Institution geschaffen wurde, die nach den vertraglichen Regelungen jederzeit selbst in die operative Abwicklung der Geld- und Devisenpolitik eingreifen kann. Allerdings zeigt die Analyse, daß die EZB von dieser Kompetenz bisher weitgehend absieht und somit gegenwärtig auch keine allzu ausgeprägten Gewinne erzielt. Nicht nur deshalb sind keine problematischen Umverteilungseffekte aus der Verteilung der EZBNotenbankgewinne zu erwarten. So erfolgt sowohl die für die EZBGewinnentstehung besonders wichtige Ausstattung der EZB mit Kapital und Währungsreserven als auch die Gewinnverteilung bzw. Verlustfinanzierung der EZB auf bzw. durch die NZBen streng nach Maßgabe der jeweiligen NZBKapitalanteile. Auch der Umstand, daß die auf eigene Rechnung durchgeführten geld- und devisenpolitischen Operationen der EZB über die Konten der im Euroraum ansässigen Kreditinstitute bei den NZBen abgewickelt und dabei die einzelnen NZBen abweichend von ihrem EZB-Kapitalanteil in Anspruch genommen werden, ändert an dieser Einschätzung nichts.

Vergleichsweise größere Volumina an Notenbankgewinnen erzielen die nationalen Zentralbanken des Eurosystems. Dies zeigt vor allem die durchgeführte Disaggregation der Eurosystembilanzen zum 1.1.1999 und 31.12.1999 mit den zugehörigen Gewinn- und Verlustrechnungen. Da eine solche Zusammenstellung jedoch nur ein Abbild der verschiedenen NZB-Tätigkeiten ist, wurden die verschiedenen Aufgaben und Aktivitäten der NZBen systematisch untersucht. Als grundsätzliches Abgrenzungskriterium ist hierbei die Gebundenheit der NZBen an die Weisungen der EZB gewählt worden. So gehen die NZBen neben den weisungsgebundenen, „Eurosystem-spezifischen“ Tätigkeiten einer Reihe von „Eurosystem-unabhängigen“ Aktivitäten nach, bei denen die EZB kein Dispositionsrecht besitzt, solange die Ziele und Aufgaben des Eurosystems nicht beeinträchtigt werden. Während bei der Analyse der Eurosystem-spezifischen NZB-Tätigkeiten vor allem die Abwicklung der gemeinsamen Geldpolitik und die damit einhergehende Veränderung der Refinanzierungsstruktur innerhalb des Eurosystems im Vordergrund stand, 
zeigte die Untersuchung der Eurosystem-unabhängigen Aktivitäten eine überraschende Vielfalt. So wurden neben den im Auftrag der heimischen Regierung durchgeführten Geschäften der NZBen mit internationalen Organisationen (insbesondere IWF und BIZ) auch andere Formen der internationalen Zusammenarbeit der nationalen Währungsbehörden (bilaterale Kreditvergabe u.ä.) untersucht. Die weitere Analyse beschäftigte sich mit der in bestimmten Umfang im Kompetenzbereich der NZBen verbleibenden eigenständigen Verwaltung ihrer Aktiva. Zudem wurde die Durchführung verschiedener Einlagengeschäfte außerhalb der gemeinsamen Geldpolitik und die Beteiligung der NZBen an der heimischen Münzemission, der Aufsicht über Kreditinstitute (als zuständige nationale Behörde) und die Beteiligung an heimischen Unternehmen untersucht. Ein Unterlaufen der gemeinsamen Geldpolitik mit Hilfe dieser Tätigkeiten ist wegen der letztlichen Entscheidungskompetenz der EZB nicht zu erwarten. Quantitativ zu vernachlässigen sind diese Aktivitäten jedoch nicht.

Bevor die NZBen die Bilanzgewinne ihrer satzungsgemäßen Verwendung zuführen können, sehen die gemeinschaftsrechtlichen Regelungen erst eine Umverteilung der Geldschöpfungsgewinne der NZBen vor. Diesbezüglich waren zwei Varianten zu unterscheiden. So wurden in einer von 1999 bis einschließlich 2001 gültigen Übergangsphase die „Monetären Einkünfte“ der NZBen nach der sog. Indirekten Methode ermittelt und nach Maßgabe des EZBKapitalschlüssels auf die einzelnen NZBen verteilt. Die umverteilten Beträge nahmen jedoch kein bedeutendes $A$ usma $ß$ an, was auch die vorgenommenen Berechnungen der "Gewinner"- und „Verliererpositionen“ der NZBen bestätigten. Zukünftig sind jedoch deutlich höhere Umverteilungsvolumina zu erwarten, da das Eurosystem Anfang 2002 zum sog. Earmarking-Verfahren übergegangen ist. Diese facettenreiche Methode zur Ermittlung der Monetären Einkünfte wurde ausführlich beschrieben und deren Konstruktionselemente eingehend analysiert. Dabei wurde klar, daß bereits die sehr heterogenen Aktivastrukturen in den NZB-Bilanzen die Möglichkeiten für ein funktionsfähiges Earmarking bereits von vornherein stark einschränkten. Demzufolge gewährt der EZB-Rat den NZBen auch keinen Gestaltungsspielraum bei der Wahl ihrer Earmarking-Aktiva, um so (letztlich willkürliche) heterogenitätsinduzierte Umverteilungseffekte zu vermeiden. Bezüglich der bilanztechnischen Erfassung der Geldschöpfungsgewinne auf der Passivseite der NZB-Bilanzen zeigte die Analyse, daß obwohl in die Bemessungsgrundlage zur Ermittlung der Monetären Einkünfte auch Komponenten eingehen, deren Existenz nicht ursächlich auf die Geldschöpfung des Eurosystems zurückzuführen ist, die Gewinne des Eurosystems aus der Schaffung von Basisgeld vollständig erfaßt werden. Etwaige Verzerrungen, die aus bestimmten parallel zum Seigniorage- 
Pooling stattfindenden Intra-Eurosystem-Ressourcentransfers resultieren können, werden durch die Konstruktion des Earmarking-Verfahrens vermieden. Die anschließende Analyse beschäftigte sich mit den Umverteilungseffekten des Earmarking-Verfahrens. So kann das Seigniorage-Pooling des EZB-Rats insofern gerechtfertigt werden, als es durch diese Maßnahme grundsätzlich gelingen kann, die angefallenen Geldschöpfungsgewinne des Eurosystems zu seinen ursprünglichen (inländischen) Finanziers in Abhängigkeit der geleisteten Finanzierungsintensität zurück zu transferieren. Die Kritik an der EarmarkingMethode ist daher eher konzeptionell begründet. So führt das EarmarkingVerfahren dazu, da $\beta$ auch diejenigen Geldschöpfungsgewinne zwischen den NZBen verteilt werden, deren Existenz auf Aktiva beruhen, die die NZBen bereits mit in die EWU eingebracht haben und deshalb noch der vormals nationalen Geldpolitik zuzurechnen sind. Um diese in der Literatur sehr kontrovers diskutierte Debatte zu strukturieren, wurden zunächst die relevanten Seigniorage-Untersuchungen in Abhängigkeit ihrer Fragestellungen und/oder Meßverfahren in drei Gruppen aufgeteilt. Hierbei zeigte sich, daß die zum Teil sehr heterogenen Ergebnisse dieser Analysen weit weniger widersprüchlich sind, als man auf den ersten Blick annehmen könnte. Besondere Aufmerksamkeit wurde den Seigniorage-Studien gewidmet, die die kritisierten Umverteilungseffekte aus dem Pre-EWU-Seignioragevermögen der NZBen auf Jahresbasis bzw. mit der sog. Barwertmethode messen. Dabei wurde klar, daß beide Vorgehensweisen im Rahmen bestimmter Annahmen intertemporal äquivalent sind. Die Quantifizierung der kritisierten Umverteilungseffekte erweist sich jedoch bei den auf Jahresbasis bezogenen Berechnungen als vergleichsweise schwierig. So müssen hier Aussagen über die zukünftige Zinsentwicklung getroffen werden, was freilich recht spekulativ ist. Zudem sind aktuelle institutionelle Regelungen wie die Anrechenbarkeit der Mindestreserveverzinsung auf den NZB-Poolbeitrag zu berücksichtigen, was letztlich dazu führt, daß die bisherigen Seigniorage-Studien die deutschen Verluste grundsätzlich $\mathrm{zu}$ hoch ansetzen. Ein korrigierter Wert für die Verliererposition Deutschlands in einer Höhe zwischen 670 und 920 Mio. EUR pro Jahr erscheint je nach unterstellter Verzinsung realistisch. Ungleich höhere Umverteilungseffekte sagen die von Sinn und Feist mit Hilfe der Barwertmethode ermittelten Berechnungen voraus. Diese Schätzungen, die in einem EWU-12-Szenario deutsche Verluste in Höhe von 30,0 Mrd. EUR prognostizieren, können jedoch auf 19,4 Mrd. EUR deutlich nach unten korrigiert werden. So reduziert bereits die Verwendung des aktuellen Datensatzes die deutsche Verlustposition um 5,1 Mrd. EUR und auch die kumulierte geschätzte Zinsersparnis, die der Bundesbank aus der Anwendung verschiedener Übergangsregelungen in Höhe von 5,5 Mrd. EUR zukommt, 
verringert den prognostizierten deutschen Fehlbetrag. Dennoch bleibt dieses Volumen substantiell. Dabei zeigte die Analyse der impliziten Annahmen der Barwertmethode, daß diese Vorgehensweise zur Berechnung der unerwünschten Umverteilungseffekte durchaus vertretbar ist. Zwar bleibt diese Methode wegen der unterstellten Ceteris-paribus-Bedingung prinzipiell angreifbar, letztlich sollten die gefundenen Ergebnisse aber wohl dahin gehend interpretiert werden, daß sie die deutschen Verluste eher unter- als überschätzen. Dies gilt vor allem deshalb, da bei einer wachsenden EWU sich die Pre-EWU-Seigniorageverluste erhöhen dürften und eine rückläufige in- und ausländische DEM-Banknotenverwendung in einem Szenario ohne EWU nicht recht plausibel erscheint. Diese Probleme ließen sich allerdings lösen, wenn man die Erträge aus dem Pre-EWUSeignioragevermögen keinem Umverteilungsprozeß unterzöge. Der vorgestellte Lösungsansatz scheint dies zu leisten. Demgegenüber mildert der vom EZB-Rat beschlossene Ausgleichsmodus die kritisierten Umverteilungseffekte nur ab, beseitigt jedoch das Problem zumindest für Deutschland nicht im erforderlichen Ausmaß.

Auch die grundsätzliche Frage nach der konzeptionellen Begründung des Earmarking-Verfahrens bleibt nicht unbeantwortet. So kann der Sinn einer solchen Regelung nur in einer Trennung zwischen den „währungspolitischen“ Aufgaben, die dem ESZB bzw. Eurosystem zugerechnet werden, und den Aktivitäten, die die NZBen auf eigene Rechnung und Initiative durchführen, liegen. Allerdings zeigen die Ausführungen, daß diese Trennung nicht konsequent umgesetzt wird.

Schließlich wurde die Gewinnverwendung der NZBen untersucht, die sich nach den nationalen Vorschriften ergibt. Wie nicht anders zu erwarten, zeigt sich hierbei ein sehr heterogenes Bild. Es bleibt jedoch kein Zweifel daran, daß in der Regel jeweils die heimische Regierung in den Genuß der Notenbankgewinne kommt. Dies gilt freilich auch, wenn die nationale Regierung keine Kapitalanteile an der heimischen NZB besitzt. 


\section{Anhang}

Tabellen im Anhang

Tabelle A1: Die Bilanz der Europäischen Zentralbank zum 31.12.1999 und 31.12.2000 in Mio. Euro

Tabelle A2: Die Berechnung der Ausgleichsbeträge für die Ermittlung der Monetären Einkünfte der Jahre 2002 bis 2007 in Mrd. Euro.

Tabelle A3: „Freies Earmarking“ zum 1.1.1999 (Angaben in Mio. EUR)....288

Tabelle A4: Die Ermittlung der Monetären Einkünfte durch die Indirekte Methode (inkl. Banknotenumlauf) und durch „sukzessives“ Earmarking (Angaben in Mio. EUR).

Tabelle A5: Berechnung des Earmarking-fähigen Goldbestandes der NZBen zum 1.1.1999.

Tabelle A6: Berechnungen der Netto-Poolingpositionen der EWU-12NZBen auf Jahresbasis mit unterschiedlichen Zinshöhen 293

Tabelle A7: Die Verteilung der gewogenen Stimmen der NZBen im EWU-12-EZB-Rat. 294

Erläuterungen zu bestimmten Tabellen im Text

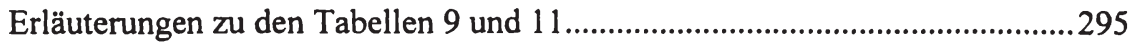

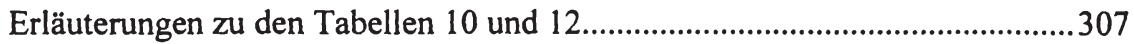

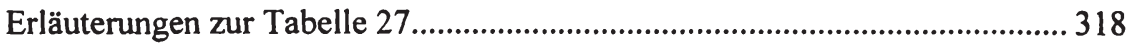

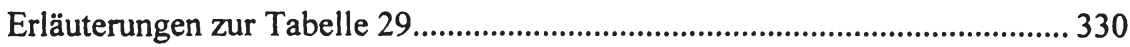


Tabelle A1: Die Bilanz der Europäischen Zentralbank zum 31.12.1999 und 31.12.2000 in Mio. Euro

\begin{tabular}{|c|c|c|}
\hline Aktiva & 1999 & 2000 \\
\hline 1 Gold und Goldforderungen & 6957,0 & 7040,9 \\
\hline $\begin{array}{l}2 \text { Forderungen in Fremdwährung an Ansässige } \\
\text { außerhalb des Euro-Währungsgebiets }\end{array}$ & 41923,0 & $\mathbf{3 7 4 7 5 , 0}$ \\
\hline $\begin{array}{l}\text { Guthaben bei Banken, Wertpapier- } \\
\text { anlagen, Auslandskredite und sonstige } \\
\text { Auslandsaktiva }\end{array}$ & 41923,0 & 37475,0 \\
\hline $\begin{array}{l}3 \text { Forderungen in Fremdwährung an Ansässige } \\
\text { im Euro-Währungsgebiet }\end{array}$ & 2595,1 & 3824,5 \\
\hline $\begin{array}{l}4 \text { Forderungen in Euro an Ansässige } \\
\text { außerhalb des Euro-Währungsgebiets }\end{array}$ & 3002,6 & 698,3 \\
\hline $\begin{array}{l}\text { Guthaben bei Banken, Wertpapier- } \\
\text { anlagen und Kredite }\end{array}$ & 3002,6 & 698,3 \\
\hline $\begin{array}{l}5 \text { Forderungen in Euro an Kreditinstitute } \\
\text { im Euro-Währungsgebiet }\end{array}$ & 565,7 & 288,1 \\
\hline $\begin{array}{l}6 \text { Wertpapiere in Euro von Ansässigen } \\
\text { im Euro-Währungsgebiet }\end{array}$ & 3537,1 & 3667,7 \\
\hline $\begin{array}{l}7 \text { Intra-Eurosystem-Forderungen } \\
\text { Sonstige Forderungen innerhalb } \\
\text { des Eurosystems (netto) }\end{array}$ & -- & 13080,8 \\
\hline 8 Sonstige Aktiva & 902,5 & 1263,6 \\
\hline 8.1 Sachanlagen und immaterielle Anlagewerte & 42,6 & 64,2 \\
\hline 8.2 Sonstiges Finanzanlagevermögen & 76,1 & 81,8 \\
\hline $\begin{array}{l}\text { 8.3 Neubewertungsposten aus außerbilanziellen } \\
\text { Geschäften }\end{array}$ & $-\cdots$ & 251,6 \\
\hline 8.4 Rechnungsabgrenzungsposten & 777,0 & 862,3 \\
\hline 8.5 Sonstiges & 6,8 & 3,7 \\
\hline 9 Jahresfehlbetrag & 247,3 & --- \\
\hline Aktiva insgesamt & 59730,3 & 67339,0 \\
\hline \multicolumn{3}{|l|}{ Nachrichtlich: } \\
\hline Terminforderungen in Euro & -- & 2885,7 \\
\hline
\end{tabular}


Noch Tabelle A1: Die Bilanz der Europäischen Zentralbank zum 31.12.1999 und 31.12.2000 in Mio. Euro

\begin{tabular}{|c|c|c|}
\hline Passiva & 1999 & 2000 \\
\hline $\begin{array}{l}1 \text { Verbindlichkeiten in Euro gegenüber } \\
\text { Kreditinstituten im Euro-Währungsgebiet }\end{array}$ & 265,7 & 288,1 \\
\hline $\begin{array}{l}2 \text { Verbindlichkeiten in Euro gegenüber sonstigen } \\
\text { Ansässigen im Euro-Währungsgebiet }\end{array}$ & 1080,0 & 1080,0 \\
\hline $\begin{array}{l}3 \text { Verbindlichkeiten in Euro gegenüber Ansässigen } \\
\text { außerhalb des Euro-Währungsgebiets }\end{array}$ & 301,7 & 3421,1 \\
\hline $\begin{array}{l}4 \text { Verbindlichkeiten in Fremdwährung gegenüber } \\
\text { Ansässigen außerhalb des Euro-Währungsgebiets }\end{array}$ & 4709,0 & 4803,4 \\
\hline $\begin{array}{l}\text { Einlagen, Guthaben und sonstige } \\
\text { Verbindlichkeiten }\end{array}$ & 4709,0 & 4803,4 \\
\hline 5 Intra-Eurosystem-Verbindlichkeiten & 41189,9 & 39469,0 \\
\hline $\begin{array}{l}5.1 \text { Verbindlichkeiten aus der Übertragung } \\
\text { von Währungsreserven }\end{array}$ & 39469,0 & 39469,0 \\
\hline $\begin{array}{l}\text { 5.2 Sonstige Verbindlichkeiten innerhalb } \\
\text { des Eurosystems (netto) }\end{array}$ & 1720,9 & $\cdots$ \\
\hline 6 Sonstige Passiva & 1274,6 & 1678,0 \\
\hline 6.1 Rechnungsabgrenzungsposten & 1237,7 & 1626,0 \\
\hline 6.2 Sonstiges & 36,9 & 52,0 \\
\hline 7 Rückstellungen & 21,9 & 2637,0 \\
\hline 8 Ausgleichsposten aus Neubewertung & 6860,5 & 7972,6 \\
\hline 9 Grundkapital und Rücklagen & 4027,1 & 3999,6 \\
\hline 9.1 Grundkapital & 3999,6 & 3999,6 \\
\hline 9.2 Rücklagen & 27,5 & -- \\
\hline 10 Jahresüberschuß & $\cdots$ & 1990,1 \\
\hline Passiva insgesamt & 5973,3 & 67339,0 \\
\hline $\begin{array}{l}\text { Nachrichtlich: } \\
\text { Terminverbindlichkeiten in Fremdwährung }\end{array}$ & & 2885,7 \\
\hline
\end{tabular}

Quelle: Europäische Zentralbank (2001d), S. 190 f.. 
Tabelle A2: Die Berechnung der Ausgleichsbetrăge for die Ermittlung der Monetăren Einkünfte der Jahre 2002 bis 2007 in Mrd. Euro

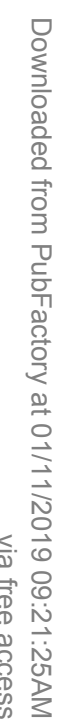

\begin{tabular}{|c|c|c|c|c|c|c|c|c|c|c|c|c|c|c|}
\hline & $\begin{array}{l}\text { Banknoten- } \\
\text { umlauf }\end{array}$ & $\begin{array}{r}\begin{array}{r}\text { Eurosystem } \\
\text { der } 12^{2}\end{array} \\
\end{array}$ & BBk & Bdl & $\mathrm{BdF}$ & BdE & DNB & NBB & OeNB & $\mathrm{BdP}$ & CBI & BoF & $\mathrm{BCL}$ & BoG \\
\hline 1999 & Juli & 353,3 & 130,2 & 64,5 & 43,8 & 53,8 & 17,1 & 11,8 & 12,3 & 5,4 & 3,7 & 2,7 & 0,6 & 7,5 \\
\hline & Aug. & 347,8 & 129,7 & 62,7 & 43,1 & 53,0 & 16,9 & 11,7 & 12,2 & 4,5 & 3,6 & 2,6 & 0,6 & 7,2 \\
\hline & Sept. & 347,4 & 129,7 & 63,4 & 42,6 & 53,3 & 16,8 & 11,8 & 12,3 & 3,6 & 3,6 & 2,6 & 0,6 & 7,1 \\
\hline & Okt. & 350,6 & 130,2 & 64,2 & 43,0 & 53,2 & 16,7 & 12,0 & 12,4 & 5,0 & 3,7 & 2,6 & 0,6 & 7,0 \\
\hline & Nov. & 350,2 & 131,0 & 64,1 & 42,7 & 53,6 & 16,9 & 12,0 & 12,5 & 3,5 & 3,8 & 2,6 & 0,6 & 6,9 \\
\hline & Dez. & 384,1 & 140,2 & 70,6 & 46,3 & 58,9 & 17,7 & 12,9 & 13,3 & 6,9 & 4,5 & 3,0 & 0,6 & 9,1 \\
\hline 2000 & Jan. & 355,3 & 131,8 & 65,8 & 43,0 & 53,8 & 16,8 & 11,9 & 12,3 & 5,4 & 3,8 & 2,7 & 0,6 & 7,3 \\
\hline & Feb. & 352,0 & 130,9 & 65,3 & 42,8 & 53,5 & 16,7 & 11,8 & 12,3 & 4,6 & 3,9 & 2,6 & 0,6 & 7,0 \\
\hline & Mrz. & 354,9 & 131,2 & 66,0 & 42,9 & 54,3 & 16,7 & 11,9 & 12,3 & 5,4 & 3,9 & 2,6 & 0,6 & 7,0 \\
\hline & Apr. & 362,4 & 132,5 & 68,0 & 44,0 & 54,8 & 17,1 & 12.1 & 12,7 & 5,7 & 4,1 & 2,7 & 0,6 & 8,1 \\
\hline & Mai & 358,3 & 130,9 & 67,1 & 44,5 & 54,4 & 17,0 & 12,4 & 12,7 & 4,5 & 4,1 & 2,7 & 0,6 & 7,4 \\
\hline & Jun. & 363,5 & 131,5 & 68,1 & 44,4 & 55,8 & 17,3 & 12,4 & 12,9 & 5,7 & 4,2 & 2,8 & 0,6 & 7,8 \\
\hline & Jul. & 366,7 & 131,4 & 69,3 & 45,5 & 56,6 & 17,3 & 12,2 & 13,0 & 5,6 & 4,3 & 2,8 & 0,6 & 8,2 \\
\hline & Aug. & 361,6 & 130,9 & 67,4 & 45,1 & 55,7 & 16.9 & 12,1 & 12,9 & 5,2 & 4,3 & 2,8 & 0,6 & 7,8 \\
\hline & Sep. & 362,6 & 131,3 & 67,9 & 44,3 & 55,7 & 16,8 & 12,1 & 13,2 & 5,9 & 4,3 & 2,7 & 0,6 & 7,8 \\
\hline & Okt. & 359,7 & 130,1 & 68,0 & 44,3 & 55,1 & 16,7 & 12,2 & 13,4 & 4,7 & 4,4 & 2,7 & 0,6 & 7,6 \\
\hline & Nov. & 357,5 & 129,3 & 68,7 & 44,1 & 55,0 & 16,7 & 12,1 & 13,4 & 3,2 & 4,4 & 2,7 & 0,6 & 7,4 \\
\hline & Dez. & 380,3 & 133,9 & 75,1 & 46,1 & 57,2 & 17,4 & 12,9 & 13,9 & 6,3 & 5,0 & 3,0 & 0,6 & 8,9 \\
\hline 2001 & Jan. & 355,6 & 126,8 & 69,0 & 43,5 & 53,8 & 16,3 & 11.9 & 13,0 & k. A. & 4,4 & 2,6 & 0,6 & k. A. \\
\hline & Feb. & 352,0 & 126,2 & 68,8 & 42,8 & 53,4 & 16,1 & 11,8 & 12,8 & k. A. & 4,4 & 2,6 & 0,6 & k. A. \\
\hline & Mrz. & 351,7 & 125,3 & 69,5 & 42,0 & 53,5 & 15,8 & 11,7 & 12,8 & k.A. & 4,4 & 2,6 & 0,6 & k. A. \\
\hline & Apr. & 352,7 & 125,0 & 70,7 & 42,2 & 53,5 & 15,8 & 11,8 & 13,0 & k. A. & 4,5 & 2,7 & 0,6 & k. A. \\
\hline & Mai & 350,2 & 124,1 & 70,1 & 42,0 & 53,0 & 16,0 & 12,0 & 12,9 & k. A. & 4,5 & 2,7 & 0,6 & k.A. \\
\hline & Jun. & 350,2 & 121,9 & 70,5 & 41,5 & 53,7 & 15,8 & 12,0 & 12,9 & k. A. & 4,6 & 2,7 & 0,6 & k. A. \\
\hline
\end{tabular}

9 Hinweis Die der Darstellung zugrunde liegenden Angaben sind entnommen aus Deutsche Bundesbank (200la), S. 18*, Banca d'ltalia (2000c), Banca d'Italia (2001), Banque de France (1999b), Banque de France (2000d). Banque de France (2001). Banco de España (2001), De Nederlandsche Bank (2001). Belgische Nationalbank (1999), Belgische Nationalbank (2000c), Belgische Nationalbank (2001), Osterreıchische Nationalbank (2001), Central Bank of Ireland (2000d), S 32, Central Bank of Ireland (2001), S 28, Bank of Finland (2000b), S. 104 f., Bank of Finland (2001a), S. 104 f., Bank of Finland (2001b), Banque Centrale du Luxembourg (2001), Bank of Greece (1999b), Bank of Greece (2000b) und Bank of Greece (2001) BCL-Banknotenumlauf als Summe aus LUF-Umlauf und theoretischem Wert des in Luxemburg zirkulierenden BEF-Umlaufs (konstant 484,4 Mio EUR). Angaben bezuglich des Umlaufs portugiesischer Banknoten als Differenz aus den verfogbaren Angaben errechnet. Die Banco de Portugal veroffentlicht keinen Monatsausiveis ihrer Bilanz

'Monatsendwerte. Vereinzelt geringe Abweichungen bel BdF und DNB wegen Datenmangels (Verwendung von Kalenderwochen-Endwerten) BoF-Werte fur September und Oktober 1999 aufgrund Datenmangels auf Basis der August- und Novemberangaben linear geschatzt

Von Juli 1999 bis Dezember 2000 als Summe des kumulierten Banknotenumlaufs des Eurosystems der 1 I plus Banknotenumlauf der Bank of Greece (BoG) Ab Januar 2001 kumulierter Banknotenumlauf des Eurosystems der 12. 
Noch Tabelle A2: Die Berechnung der Ausgleichsbetrăge für die Berechnung der Monetăren Einkünfte der Jahre 2002 bis 2007 in Mrd. Euro

\begin{tabular}{|c|c|c|c|c|c|c|c|c|c|c|c|c|c|}
\hline NZBen & $\begin{array}{l}\text { Eurosystem } \\
\text { der } 12\end{array}$ & BBK & BdI & BdF & BdE & DNB & NBB & OeNB & BdP & CBI & BoF & $\mathrm{BCL}$ & BoG \\
\hline $\begin{array}{l}\text { Durchschnittlicher } \\
\text { Banknotenumlauf": w }\end{array}$ & 357,5 & 129,8 & 67,7 & 43,6 & 54,5 & 16,7 & 12,1 & 12,8 & 5,2 & 4,2 & 2,7 & 0,6 & 7,6 \\
\hline $\begin{array}{l}\text { Gezahlter EZB- } \\
\text { Kapitalanteil der } \\
\text { EWU-12-NZBen } \\
\end{array}$ & $100 \%$ & $30.24 \%$ & $18,39 \%$ & $20.78 \%$ & $10,98 \%$ & $5,28 \%$ & $3,54 \%$ & $2,91 \%$ & $2,37 \%$ & $1,06 \%$ & $1,72 \%$ & $0,19 \%$ & $2,54 \%$ \\
\hline $\begin{array}{l}\text { Produkt aus W und } \\
\text { EZB-Kapitalantcil: S }\end{array}$ & 357,5 & 108,1 & 65.7 & 74,3 & 39,3 & 18,9 & 12,7 & 10,4 & 8,5 & 3,8 & 6,1 & 0,7 & 9,1 \\
\hline & & & & & & & & & & & & & \\
\hline \multicolumn{14}{|c|}{ Ausgleichsbeträge in Mio. EUR } \\
\hline Jahr & $\begin{array}{l}\text { Koeffizient } \\
\text { (k) }\end{array}$ & BBk & BdI & Bdf & BdE & DNB & NBB & OeNB & BdP & CBI & BoF & $\mathrm{BCL}$ & BoG \\
\hline 2002 & 1 & $-21692,0$ & $-1955,7$ & 30688,5 & $-15246,5$ & 2176,0 & 555,5 & -2396.8 & 3272,8 & $-410,5$ & 3449,0 & 79,3 & 1480.5 \\
\hline 2003 & 0,8606735 & $-18669,7$ & $-1683,3$ & 26412,8 & $-13122,3$ & 1872,8 & 478,1 & $-2062,8$ & 2816,8 & $-353,3$ & 2968,5 & 68,2 & 1274,2 \\
\hline 2004 & 0,7013472 & $-15213,6$ & $-1371,7$ & 21523,3 & $-10693,1$ & 1526,1 & 389,6 & $-1681,0$ & 2295,3 & $-287,9$ & 2418,9 & 55,6 & 1038,3 \\
\hline 2005 & 0,5334835 & $-11572,3$ & $-1043,4$ & 16371,8 & $-8133,8$ & 1160.9 & 296,4 & $-1278,6$ & 1746,0 & $-219,0$ & 1840,0 & 42,3 & 789,8 \\
\hline 2006 & 0,3598237 & $-7805,3$ & $-703,7$ & 11042,4 & $-5486,1$ & 783,0 & 199,9 & $-862,4$ & 1177,6 & $-147,7$ & 1241,0 & 28,5 & 532,7 \\
\hline 2007 & 0,1817225 & $-3941,9$ & $-355,4$ & 5576,8 & $-2770,6$ & 395,4 & 100,9 & $-435,5$ & 594,7 & $-74,6$ & 626,8 & 14,4 & 269,0 \\
\hline
\end{tabular}

D: Quelle: Eigene Berechnungen. Differenzen in den Summen durch Runden der Zahlen.

${ }^{3}$ Die vorliegende Rechnung darf nur als Naherungslosung verstanden werden, da sich die offiziclle Berechnung der Ausgleichsbeträge an den Tagesausweisen der NZB-Banknotenumläufe orientiert. Diese Daten sind der Offentlichkeit nicht zugänglich.

4 Arithmetisches Mittel der ausgewiesenen Monatsentwerte im Zeitraum von Juli 1999 bis Juni 2001 . Fur die Banco de Portugal und die Bank of Greece aufgrund Datenmangels nur von Januar 1999 bis Dezember 2000. Die Kumulierung der jewcils fur die NZBen errechneten Durchschnittswerte weicht vom Durchschnittswert des kumulierten (EWU-12-) EurosystemBanknotenumlauf (357,5 Mrd. EUR) um eine Nachkommastelle ab (357,4 Mrd. EUR), weshalb der Durchschnittswert fur Portugal um 0,1 Mrd. EUR von 5,1 auf 5,2 Mrd. EUR erhöt wurde.

${ }^{3}$ Errechnet anhand der Formel zur Berechnung der jahrlichen Ausgleichsbeträge $(S-W) \times K$. 
Tabelle A3: „Freies Earmarking" zum 1.1.1999 (Angaben in Mio. Euro)

Deutsche Bundesbank

Earmarking

MB

$M B$ - G

$\mathrm{MB}-\mathrm{G}-\mathrm{EZB}$

$\mathrm{MB}-\mathrm{G}$ - EZB - $8 \mathrm{HH}$

$\mathrm{MB}$ - G - EZB - $8 \mathrm{HH}$ - EFo

$\mathrm{MB}-\mathrm{G}-\mathrm{EZB}-\mathrm{\sigma HH}-\mathrm{EFo}-\mathrm{DEV}$

$\begin{array}{rl}\text { Mio. EUR } & \\ 159876 & \text { Zinseinnahmen aus } \\ 130564 & \text { G } \\ 129339 & \text { EZB } \\ 124899 & 6 \mathrm{HH} \\ 14349 & \text { EFo } \\ -50225 & \text { DEV } \\ & \text { EWP }\end{array}$

Monetăre Bruttoeinkanfte

Verzinsung der Mindestreserve

Monetăre Einkünfte (netto)

Mio. EUR

\section{Earmarking}

MB

$M B \cdot G$

MB - G - EZB

MB - G - EZB - $\measuredangle H H$

$\mathrm{MB}-\mathrm{G}$ - EZB - $\diamond \mathrm{HH}-€ \mathrm{Fo}$

$\mathrm{MB}$ - G - EZB - $6 \mathrm{HH}$ - $\mathrm{EFO}$ - DEV
$\mathrm{MB}$ - G - EZB - EFo - DEV

Earmarking
$M B$
$M B-G$
$M B-G-E Z B$
$M B-G-E Z B-E F o$
$M B-G$ - EZB - EFo - DEV

\section{Banco de Espafia}

Earmarking

$\mathrm{MB}$

$M B-G$

$\mathrm{MB}-\mathrm{G}$ - EZB

$\mathrm{MB}-\mathrm{G}-\mathrm{EZB}-\varnothing \mathrm{HH}$

$\mathrm{MB}-\mathrm{G}-\mathrm{EZB}-\varnothing \mathrm{HH}-\mathrm{EFo}$

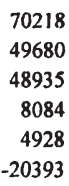

$-20393$

Zinseinnahmen aus
G
EZB
6HH
EFo
DEV
EWP

Monetare Brutto Einkünfte

Verzinsung der Mindestreserve

Moneture Einkünfte (netto)

Mio. EUR

60798

35196

34354

8877

$-25900$

Zinseinnahmen aus
G
EZB
EFo
DEV
EWP
øHH

Monetăre Brutto Einkunfte

Verzinsung der Mindestreserve

Monetăre Einkünfte (netto)

Mio. EUR

60142

55328

54883

12182

$-14738$

Zinseinnahmen aus
G
EZB
ठHH
EFo
DEV
EWP

Monetăre Brutto Einkunfte

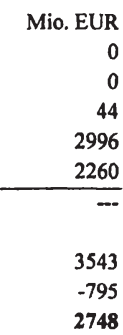

\begin{tabular}{rr} 
Mio. EUR & Zinssatz \\
0 & $0,00 \%$ \\
0 & $0,00 \%$ \\
392 & $0,96 \%$ \\
86 & $2,71 \%$ \\
886 & $3,50 \%$ \\
\hline$(101)$ & $3,81 \%$
\end{tabular}

650

$-190$

461

\begin{tabular}{rr} 
Mio. EUR & Zinssatz \\
0 & $0,00 \%$ \\
0 & $0,00 \%$ \\
690 & $2,71 \%$ \\
1217 & $3,50 \%$ \\
\hline$(108)$ & $3,81 \%$ \\
$(91)$ & $5,00 \%$
\end{tabular}

1001

$-451$

550

\begin{tabular}{rr} 
Mio. EUR & Zinssatz \\
0 & $0,00 \%$ \\
0 & $0,00 \%$ \\
0 & $0,00 \%$ \\
730 & $2,71 \%$ \\
\hline$(1661)$ & $3,50 \%$ \\
\hline..-
\end{tabular}


De Nederlandsche Bank

Earmarking

MB

MB - G

$\mathrm{MB} \cdot \mathrm{G}-\mathrm{EZB}$

$\mathrm{MB}-\mathrm{G} \cdot \mathrm{EZB}-\mathrm{EF} \mathrm{O}$

$\mathrm{MB}-\mathrm{G}-\mathrm{EZB}$ - $€ F \mathrm{~F}$ - DEV
Mio. EUR

25064

17049

16835

8175

$-2404$

Zinseinnahmen aus
G
EZB
EFo
DEV
EWP
oHH

Monetăre Bruttoeinkünfte

Verzinsung der Mindestreserve

Monetăre Einkünfte (netto)

Mio. EUR

18888

16541

16398

10490

$-456$

Belgische Nationalbank
Earmarking
MB
MB - G
MB - G - EZB
$M B-G-E Z B-E F o$
$M B-G-E Z B-E F o-D E V$

Zinseinnahmen aus
G
EZB
EFo
DEV
EWP
OHH

Monetare Bruttoeinklinfte 527

Verzinsung der Mindestreserve

Moneture Einkänfte (netto)

Mio. EUR

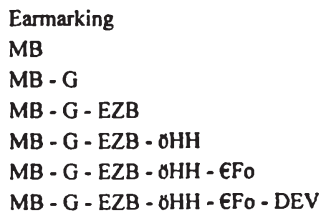

Österreichische Nationalbank

Banco de Portugal

Earmarking

$\mathrm{MB}$

$\mathrm{MB}-\mathrm{G}$

$\mathrm{MB} \cdot \mathrm{G} \cdot \mathrm{EZB}$

$\mathrm{MB}$ - G - EZB - $6 \mathrm{HH}$

$\mathrm{MB}-\mathrm{G}-\mathrm{EZB}-8 \mathrm{HH}-\mathrm{EF}$

16243
12839
12721
12526
9389
-6587

Monetăre Bruttoeinkunfte

Verzinsung der Mindestreserve

Monetăre Einkanfte (netto)

Mio. EUR

$\begin{array}{ll}6413 & \text { Zinseinnahmen aus } \\ 1464 & \text { G } \\ 1367 & \text { EZB } \\ 1190 & \text { oHH } \\ -2341 & \text { EFo } \\ & \text { DEV } \\ & \text { EWP }\end{array}$

Monetăre Bruttoeinkünfte

Verzinsung der Mindestreserve

Monetăre Einkünfte (netto)

Zinseinnahmen aus
G
EZB
oHH
EFo
DEV
EWP

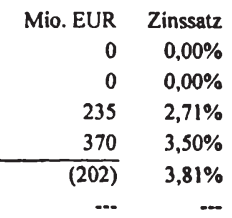

521

$-211$

310 Zinssatz $0,00 \%$ $0,00 \%$ $2,71 \%$ $3,50 \%$ $3,81 \%$

... -

Mio. EUR Zinssatz $0,00 \%$ $0,00 \%$ $0,00 \%$ $2,71 \%$ $3,50 \%$ $3,81 \%$

1




\section{Central Bank of Ireland}

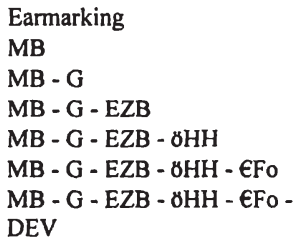

\begin{tabular}{|c|c|c|c|}
\hline \multicolumn{4}{|l|}{ Mio. EUR } \\
\hline 6245 & Zinseinnahmen aus & Mio. EUR & Zinssatz \\
\hline 6134 & G & 0 & $0,00 \%$ \\
\hline 6092 & EZB & 0 & $0,00 \%$ \\
\hline 5925 & бHH & 0 & $0,00 \%$ \\
\hline 3671 & €Fo & 61 & $2,71 \%$ \\
\hline-2711 & DEV & 223 & $3,50 \%$ \\
\hline & $€ W P$ & $(61)$ & $3,81 \%$ \\
\hline \multicolumn{2}{|c|}{ Monetăre Bruttoeinkunfte } & 190 & \\
\hline \multicolumn{2}{|c|}{ Verzinsung der Mindestreserve } & -72 & \\
\hline \multicolumn{2}{|c|}{ Monetäre Einkünfte (netto) } & 117 & \\
\hline
\end{tabular}

\section{Bank of Finland}

$\begin{array}{lr}\text { Earmarking } & \text { Mio. EUR } \\ \text { MB } & 4823 \\ \text { MB - G } & 4330 \\ \text { MB - G - EZB } & 4260 \\ \text { MB - G - EZB - GFo } & 4257 \\ \text { MB - G - EZB - EFo - DEV } & -4272\end{array}$

Zinseinnahmen aus
G
EZB
EFo
DEV
EWP
øHH

Monetäre Bruttoeinkunfte

Verzinsung der Mindestreserve Monetăre Einkünfte (netto)

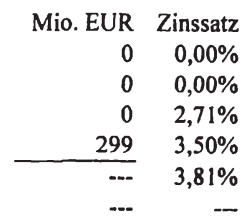

149

$-59$

\author{
Banque Centrale du \\ Luxembourg \\ Earmarking \\ MB \\ $M B$ - $G$ \\ $M B-G-E Z B$ \\ $M B$ - G - EZB - ठHH \\ $\mathrm{MB}-\mathrm{G}-\mathrm{EZB}-\diamond \mathrm{HH}-€ \mathrm{Fo}$
}

Mio. EUR

$\begin{aligned} 111 & \text { Zinseinnahmen aus } \\ 79 & \text { G } \\ 72 & \text { EZB } \\ 48 & \text { oHH } \\ -185 & \text { GFo } \\ & \text { DEV } \\ & \in W P\end{aligned}$

Monetäre Bruttoeinkünte

Verzinsung der Mindestreserve

Monetäre Einkünfte (netto)

\begin{tabular}{rr} 
Mio. EUR & Zinssatz \\
0 & $0,00 \%$ \\
0 & $0,00 \%$ \\
0 & $0,00 \%$ \\
6 & $2,71 \%$ \\
\hline$(5)$ & $3,50 \%$ \\
$(1)$ & $3,81 \%$
\end{tabular}

1

$-0$

1

Anmerkungen zu „Freies Earmarking“. Berechnung der jeweilıgen Zinseinnahmen durch Multiplikatıon des betreffenden Pre-EWU. Aktivums zum 11.1999 mit dem zugehorigen Zinssatz des Jahres 1999. Zinssatze: Gold (G) unverzinst (harmonisierter Aktivposten 1), EZB-Beteiligung (EZB) ertragslos (harmonisierter Aktivposten 81), da in 1999 EZB-Verlust; Verzinsung der Kredite an offentliche Haushalte $(6 \mathrm{HH})$ (harmonisierter Aktivposten 7) aus NZB-Jahresberichten fur 1999; vercinfachende Annahmen: jahresdurchschnittliche Zinssatze fur Hauptrefinanzierungsgeschafte (HRG) in 1999. 2,71 \% fur Verzinsung der gesamten Euro denominierten Forderungen (EFo) der NZBen (harmonisierte Aktivposten $4+5$ ); Verzinsung der NZB-Fremdwahrungsforderungen an Ansassige außerhalb des Euroraums (DEV) (harmonisicrte Aktivposten $2+3$ ) zu jahresdurchschnttllichen SZR-Zinssatz in 1999. 3,5\%; jahresdurchschnittliche Umlaufsrendite fur Dreimonatsgeld $(2,96 \%)$ bzw. fur 10-jathrige Euro-Staatsanleihen $(4,66 \%)$ in 1999 angewendet jeweils auf $50 \%$ des betreffenden NZB-Bestandes an Euro-Wertpapıeren ( $(W \mathrm{P})$ bzw Durchschnittsverzinsung der gesamten Euro-Wertpapıere (harmonisıerter Aktıvposten 6) von 3,81\%; die harmonisierten Aktivposten 82 bis 11 seien vom Earmarking ausgenommen Vgl. dazu Anmerkungen im Text Anrechenbarer Zinsaufwand der NZBen aufgrund der Verzinsung der Mindestreserve zum Satz fur HRG (2,71 \%) auf Giraleinlagen beı der jeweıligen NZB (harmonisierter Passivposten 2 1) Bilanzposten der NZBen zum 111999 aus Tabelle 9 Hınweis Die Ermittlung der Monetaren Bruttoeinkunfte brıcht bei vollstandiger Deckung der jewesligen Monetaren NZB-Basis (MB) ab Die Bilanzposten bezıehen sıch auf die bis zum Ende des Jahres 2000 gultige harmonisıerte NZB-Bılanzstruktur.

Quelle. Eigene Berechnungen 
Tabelle A4: Die Ermittlung der Monetären Einkünfte durch die Indirekte Methode (inkl. Banknotenumlauf) und durch „sukzessives“ Earmarking (Angaben in Mio. EUR)

\begin{tabular}{|c|c|c|c|c|c|c|c|c|c|c|c|}
\hline & BBk & BdI & BdF & BdE & DNB & NBB & OeNB & BdP & CBI & BoF & BCL \\
\hline Monetäre Basis & 159876 & 70218 & 60798 & 60142 & 25064 & 18888 & 16243 & 6413 & 6245 & 4823 & 111 \\
\hline Monetare Einkanfte (brutto) & 4333 & 1903 & 1648 & 1630 & 679 & 512 & 440 & 174 & 169 & 131 & 3 \\
\hline Verzinsung der Mindestreserve & 795 & 190 & 502 & 201 & 211 & 187 & 108 & 36 & 72 & 59 & $\mathbf{0}$ \\
\hline Monetăre Einkünfte (netto) & 3538 & 1713 & 1145 & 1429 & 468 & 324 & 332 & 138 & 97 & 72 & 3 \\
\hline
\end{tabular}

Anmerkung: Berechnung der Monetăren Einkūnfte (brutto) durch Multiplikation der Monetăren NZB-Basis zum 1.1.1999 mit jahresdurchschnittlichem Referenzzinssatz in 1999: 2,71

$\%$. Berechnung der Verzinsung der Mindestreserve durch Multiplikation des harmonisierten Passivpostens 2.1 (Giraleinlagen der Kreditinstitute) mit 2,71 \% p.a.

\section{Sukzessives Earmarking}$$
\text { MB }
$$$$
M B \text { - FFS }
$$$$
M B \text { - FFS - EWP }
$$

$M B$ - FFS - EWP - FWFA

MB - FFS - EWP - FWFA - FWFI

MB - FFS - EWP - FWFA - FWFI - EZB

MB - FFS - EWP - FWFA - FWFI - EZB - $8 \mathrm{HH}$

MB - FFS - EWP - FWFA - FWFI - EZB - $8 \mathrm{HH}$ - EFA

MB - FFS - EWP - FWFA - FWFI - EZB - $8 \mathrm{HH}$ - EFA -G

\begin{tabular}{cccc} 
BBk & BdI & BdF & BdE \\
159876 & 70218 & 60798 & 60142 \\
49454 & 67062 & 35321 & 33265 \\
49454 & 64422 & 32497 & 33265 \\
-15120 & 39101 & -2281 & -14188 \\
& 39101 & & \\
\cline { 2 - 3 } & 38356 & & \\
& -2495 & &
\end{tabular}

\begin{tabular}{ccccccc|}
\hline DNB & NBB & OeNB & BdP & CBI & BoF & BCL \\
25064 & 18888 & 16243 & 6413 & 6245 & 4823 & 111 \\
16575 & 13908 & 14724 & 5182 & 4004 & 4820 & -122 \\
11284 & 10128 & 12956 & 1429 & 2391 & 4820 & \\
705 & -770 & -1834 & -5378 & -3903 & -3061 & \\
705 & & & & & &
\end{tabular}

Zinseinnahmen aus FFS

Zinseinnahmen aus EWP

Zinseinnahmen aus DEV

Ertrage aus Beteiligung an EZB

Zinseinnahmen aus Kredite an $8 \mathrm{HH}$

Zinseinnahmen aus $\in F A$

Zinseinnahmen aus Gold

Monetăre Einkanfte (brutto)

Verzinsung der Mindestreserve

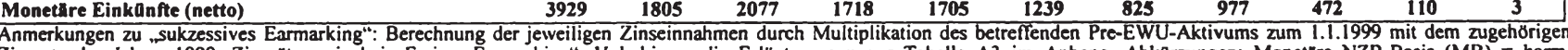

\begin{tabular}{cccc}
2992 & 86 & 690 & 728 \\
0 & 654 & 700 & 0 \\
2260 & 886 & 1217 & 1661 \\
0 & \\
394 & \\
\hline
\end{tabular}

491

491

320

$-7695$ Zinssatz des Jahres 1999. Zinssatze wie bei Freiem Earmarking". Vgl. hierzu die Erläuterungen zur Tabelle A3 im Anhang. Abkarzungen: Monetäre NZB-Basis (MB) = harm. Passivposten (PP) 1 + 2; Forderungen an den Finanzsektor (FFS) $=$ harm. Aktivposten $(A P)$; Euro-Wertpapiere (EWP) $=$ AP 6; Fremdwăhrungsforderungen an Ansässige außerhalb des Euroraum (FWFA) = AP 2; Fremdivăhrungsforderungen an Ansässige im Euroraum (FWFI) = AP 3; Beteiligung an EZB (EZB) = AP 8.1; Kredite an 8 ffentliche Haushalte (סHH) = AP 7; Euroforderungen an Ansässige außerhalb des Euroraums $(E F A)=A P$; Gold $(G)=A P 1$; Anrechenbarer Zinsaufwand der NZBen aufgrund der Verzinsung der Mindestreserve zum Satz for HRG (2,71\%) auf Giraleinlagen bei der jetveiligen NZB (AP 2.1). Bilanzposten der NZBen zum 1.1.1999 aus Tabelle 9. Hinweis: Die Ermittlung der Monetăren Bruttoeinkünfe bricht bei vollstandiger Deckung der jeiveiligen Monetären NZB-Basis ab. Die Bilanzposten beziehen sich auf die bis zum Ende des Jahres 2000 gältige harmonisierte NZB-Bilanzstruktur (altHB). Quelle: Eigene Berechnungen. 
Tabelle A 5: Berechnung des Earmarking-fahigen Goldbestandes der NZBen zum 1.1.1999

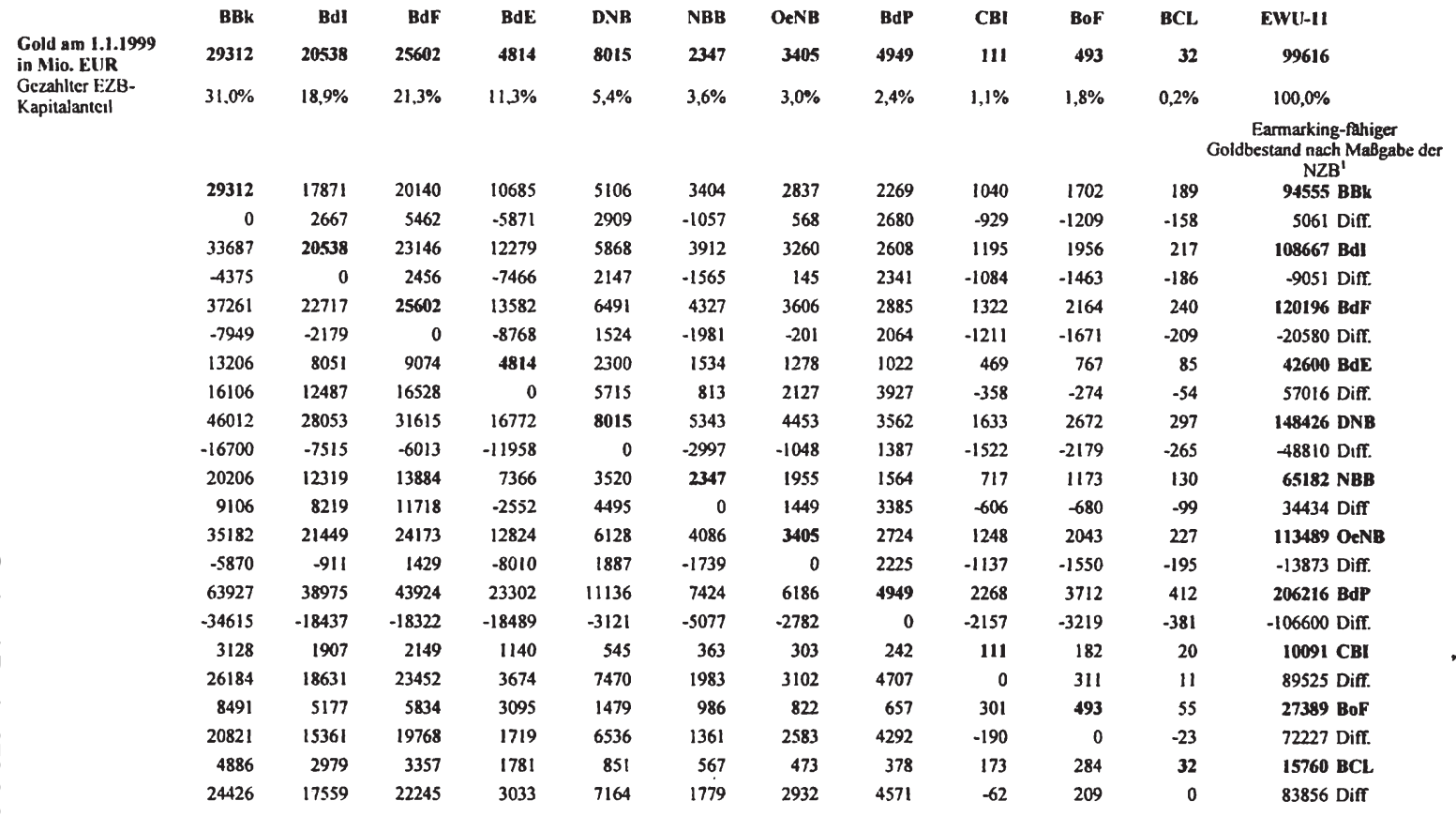

Quelle Eigene Berechnungen Die der Darstellung zugrunde liegenden Daten sind der Tabelle 9 entnommen.

' Angaben in Mio EUR Der fett gedruckte Wert des nach Maßgabe der jeweiligen NZB ermittelten Gesamtwerts des Earmarking-Pahigen Goldbestands des Eurosysterns ergibt sich durch die Division des tatsachlıchen NZB-Goldbestandes durch den zugehorigen gezahlten EZB-Kapitalantell (z B. BBK. 29312 Mio. EUR / 31,0\%=94555 Mio EUR) Bei diesem Betrag würde die betreffende NZB (z.B. BBk) ihren gesamten tatsachlich existierenden Goldbestand earmarken durfen und zugleich würde der so ermittelte Earmarking-Pahige Goldbestand in Relation gesetzt zur Gesamtheit des von allen NZBen geearmarkten Goldes dem individuelien EZB-Kapitalanteil der betreffenden NZB entsprechen Verfugt jedoch nur eine der anderen NZBen (ZB. die BdE) tatsachlich aber weniger Gold, als sie nach MaBgabe der betreffenden NZB (z B BBk) earmarken durfte (Differenz negativ z B. BdE -587I Mio. EUR) wird der Gesamtbestand des Earmarking-fahigen Goldes notwendigerweise von einer anderen NZB bestimmt. Bei der am
1111999 zu bcobachtenden Goldverteilung innerhalb des Eurosystems ist die Central Bank of lreland (CBI) die „kritische“ Zentralbank, die 100 Prozent thres tatskchlich am 1.1.1999 existierenden Goldbestandes earmarken dorfte Fur die anderen NZBen ergibt sich ihr Anteil durch die Multiplikation ihres gezahiten EZB-Kapitalanterls mit der Gesamtsumme des Earmarking-fahigen umverteilungsneutralen Goldbestandes (zB. fur die BBk. 3128 Mio. EUR). 
Tabelle A6: Berechnungen der Netto-Poolingpositionen der EWU-12-NZBen auf Jahresbasis mit unterschiedlichen Zinshöhen

\begin{tabular}{|c|c|c|c|c|c|c|c|c|c|c|c|c|c|}
\hline \multicolumn{14}{|c|}{ Berechnungen der Netto-Poolingpositionen der NZBen auf Jahresbasis für EWU-12 mit unterschiedlichen Zinshöhen' } \\
\hline $\begin{array}{l}\text { NZBen (EWU-12) } \\
\text { bei } 2,71 \%\end{array}$ & Bk & BdI & $\mathbf{d F}$ & dE & NB & BB & OeNB & 3dP & BI & 3oF & CL & BoG & U 1 \\
\hline $\begin{array}{l}\text { Banknotenumlauf zum } \\
\text { 1.1.1999 in Mio. EUR }\end{array}$ & 130551 & 63220 & 264 & 52731 & 17287 & 971 & 2269 & 5082 & 3576 & 2647 & 111 & 7632 & 49341 \\
\hline Poolbeitrag bei $2,71 \%$ & & 13 & 45 & 1429 & 468 & 324 & 332 & 138 & 97 & 72 & & 207 & 9467 \\
\hline EZB-Kapit & $30,2 \%$ & $18,4 \%$ & $20,8 \%$ & $11,0 \%$ & $5,3 \%$ & $3,5 \%$ & $2,9 \%$ & $2,4 \%$ & $1,1 \%$ & $1,7 \%$ & $2 \%$ & $2,5 \%$ & $0,0 \%$ \\
\hline Aus Pool & 863 & 1741 & 1967 & 1039 & 500 & 335 & 275 & 224 & 100 & 163 & 18 & 240 & 9467 \\
\hline $\begin{array}{l}\text { Gewi } \\
\text { in } \mathrm{Mi}\end{array}$ & -675 & +28 & +822 & -390 & +31 & +1 & -57 & +87 & +3 & +91 & +15 & +34 & 0 \\
\hline $\begin{array}{l}\text { N2 } \\
\text { bei }\end{array}$ & Bk & BdI & dF & BdE & NB & BB & OeNB & BdP & CBI & BoF & CL & BoG & EWU 12 \\
\hline $\begin{array}{l}\text { uf zum } \\
\text { EUR }\end{array}$ & 130551 & 63220 & 42264 & 52731 & 17287 & 11971 & 12269 & 5082 & 3576 & 2647 & 111 & 7632 & נדודי \\
\hline $0 \%$ & 30 & 2339 & 1564 & 1951 & 640 & 443 & 454 & 188 & 132 & 98 & 4 & 282 & 1292 \\
\hline EZB-K & $30,2 \%$ & $18,4 \%$ & $20,8 \%$ & $11,0 \%$ & $5,3 \%$ & $3,5 \%$ & $2,9 \%$ & $2,4 \%$ & $1,1 \%$ & $1,7 \%$ & $2 \%$ & $2,5 \%$ & $100,0 \%$ \\
\hline Aus Pool & 3909 & 2377 & 2686 & 1419 & 682 & 458 & 376 & 306 & 137 & 222 & 25 & 328 & 1292 \\
\hline $\begin{array}{l}\text { Gewinn (+) / Verlust (-) } \\
\text { in Mio. EUR pro Jahr }\end{array}$ & 922 & +38 & +1122 & -532 & +43 & $|5|$ & -78 & +118 & +5 & +124 & +20 & + & \\
\hline
\end{tabular}

Quelle: Eigene Berechnungen. Verwendete Daten aus Tabelle 9 und Bank of Greece (1999a), S. 253. Differenzen in den Summen durch Runden der Zahlen.

\footnotetext{
'Wegen der Anrechenbarkeit der Verzinsung der Mindestreserve auf die Monetären Bruttoeinkünfte wird sich hier auf die Umverteilungseffekte aus dem Pre-EWU-Banknotenumlauf beschränkt. Angaben in Mio. EUR.
} 
Tabelle A7: Die Verteilung der gewogenen Stimmen der NZBen im EWU-12-EZB-Rat

\begin{tabular}{|c|c|c|c|c|}
\hline EWU-12-NZBen & $\begin{array}{c}\text { Gezahlter } \\
\text { EZB- } \\
\text { Kapitelanteil }^{1}\end{array}$ & $\begin{array}{l}\text { Stimme ohne } \\
\text { Gewichtung } \\
\text { und ohne } \\
\text { EZB- } \\
\text { Direktorium }\end{array}$ & $\begin{array}{l}\text { Stimme mit } \\
\text { Gewichtung }\end{array}$ & $\begin{array}{c}\text { Pooling- } \\
\text { Gewinner (G) } \\
\text { bzw. - Verlierer } \\
\text { (V) }\end{array}$ \\
\hline Deutsche Bundesbank & $30,2410 \%$ & 1 & 3,6288 & $\mathrm{~V}$ \\
\hline Banque de France & $20,7838 \%$ & 1 & 2,4936 & $\mathrm{G}$ \\
\hline Banca d'Italia & $18,3902 \%$ & 1 & 2,2068 & G \\
\hline Banco de España & $10,9804 \%$ & 1 & 1,3176 & V \\
\hline $\begin{array}{l}\text { De Nederlandsche } \\
\text { Bank }\end{array}$ & $5,2819 \%$ & 1 & 0,6336 & G \\
\hline $\begin{array}{l}\text { Belgische } \\
\text { Nationalbank }\end{array}$ & $3,5383 \%$ & 1 & 0,4248 & G \\
\hline $\begin{array}{l}\text { Österreichische } \\
\text { Nationalbank }\end{array}$ & $2,9130 \%$ & 1 & 0,3492 & V \\
\hline $\begin{array}{l}\text { Bank von } \\
\text { Griechenland }\end{array}$ & $2,5389 \%$ & 1 & 0,3048 & G \\
\hline Banco de Portugal & $2,3745 \%$ & 1 & 0,2844 & $\mathrm{G}$ \\
\hline Bank of Finland & $1,7248 \%$ & 1 & 0,2064 & $\mathrm{G}$ \\
\hline $\begin{array}{l}\text { Central Bank of } \\
\text { Ireland }\end{array}$ & $1,0490 \%$ & 1 & 0,1272 & $\mathrm{G}$ \\
\hline $\begin{array}{l}\text { Banque Centrale du } \\
\text { Luxembourg }\end{array}$ & $0,1842 \%$ & 1 & 0,0228 & G \\
\hline $\begin{array}{l}\text { Summe EWU-12- } \\
\text { NZBen }\end{array}$ & $100,00 \%$ & 12 & 12 & - \\
\hline $\begin{array}{l}\text { Summe der Verlierer- } \\
\text { NZBen }\end{array}$ & $44,1344 \%$ & 9 & 5,2961 & - \\
\hline $\begin{array}{l}\text { Summe der Gewinner- } \\
\text { NZBen }\end{array}$ & $55,8656 \%$ & 3 & 6,7039 & - \\
\hline
\end{tabular}

Quelle: Eigene Berechnungen.

\footnotetext{
${ }^{1}$ Art. 10.3. ESZB-Satzung spricht von einer Gewichtung der Stimmen nach „gezeichnetem EZB-Kapitalanteil“". Art. 43.6. ESZB-Satzung stellt jedoch sicher, daß inhaltlich die Stimmgewichtung nach gezahlten EZB-Kapitalanteil der im Eurosystem vereinigten NZBen erfolgt.

${ }^{2}$ Bei Entscheidungen des EZB-Rats bezüglich der Verteilung der Monetären Einkünfte der NZBen (Art. 32 ESZB-Satzung) bleiben die Stimmen des EZB-Direktoriums unberücksichtigt, da diese mit dem Faktor null gewogen werden (Art. 10.3. ESZB-Satzung) 
Erläuterungen zu den Tabellen 9 und 11: Die Bilanz des Eurosystems unterteilt nach EZB und NZBen zum 1.1.1999 und 31.12.1999 in Mio. Euro

\section{Allgemeine Bemerkungen}

Die EZB hat ihre Bilanzierungsleitlinie mittlerweile dreimal geändert (vgl. Europäische Gemeinschaft (2001a)). Die Struktur der Tabellen 9 und 11 orientiert sich an der Bilanzaufstellung (im folgenden als "Standardbilanz" bezeichnet), die die EZB den NZBen bis Ende 2000 empfohlen hat (vgl. European Central Bank (1998c), S. 49). Wie bereits im Text erwähnt, besitzen die von der EZB empfohlenen Bilanzierungsleitlinien für die von den NZBen in Eigenregie erstellten Jahresausweise keinen bindenden Charakter (vgl. European Central Bank (1998c), S. 16 ff. und Europäische Gemeinschaft (2001a), S. 28 ff.). Im allgemeinen folgen die NZBen jedoch dem EZB-Vorschlag, so daß die vorgenommene Disaggregation der Eurosystembilanzen zum 1.1.1999 und 31.12.1999 aussagekräftig ist. Folgende generelle Bemerkungen seien vorweg geschickt.

Einige EWU-Zentralbanken weisen ihre Bilanzen zum 1.1.1999 aus, andere greifen hingegen auf Bilanzen zum 31.12.1998 zurück. Die Vergleichbarkeit zwischen den Bilanzen zum 31.12.1998 und den „klassischen“ Eröffnungsbilanzen ist jedoch nicht beeinträchtigt.

Weiterhin weisen einige Zentralbanken ihre Bilanzen nach der Gewinnverwendung aus, obwohl die EZB-Empfehlung eine separate Darstellung der Jahresüberschüsse vorsieht. Bei anderen NZBen kommt hinzu, daß Interimsausschüttungen und andere „vorbilanzielle“ Gewinnverwendungen zu berücksichtigen sind. $\mathrm{Da}$ jedoch die Gewinnverwendung jeweils bekannt ist, lassen sich die entsprechenden Beträge für die standardisierte Bilanzaufstellung zurückrechnen. Dabei soll der in der Standardbilanz ausgewiesene Passivposten „15 Jahresüberschuß ${ }^{\text {“ }}$ nur diejenigen Zentralbankgewinne erfassen, die den Zentralbanken zum Zeitpunkt des Bilanzierungstermins nach Abzug aller „vorbilanziellen Gewinnausschüttungen“, wie etwa Körperschaftssteuern u.ä., verbleiben. Der Standard-Passivposten „15 Jahresüberschuß“ darf also nicht mit der Gesamtheit der Gewinne der Zentralbanken gleichgesetzt werden, die die Notenbanken an ihre Kapitaleigner ausschütten bzw. einer anderweitigen Verwendung zuführen. Eine diesbezüglich vergleichende Aufstellung findet sich in der jeweils zugehörigen Gewinn- und Verlustrechnung (vgl. Tabellen 10 und 12). Anders ist wegen den großen Heterogenitäten eine durchgängige Vergleichbarkeit zwischen den EWU-Zentralbankbilanzen wohl kaum herzustellen. 
2. Erläuterungen zu den in den Tabellen 9 und 11 aufgefuihrten Bilanzpositionen der verschiedenen Zentralbanken

\subsection{Europäische Zentralbank (EZB)}

2.1.1. Bewertungsansätze und Bilanzstruktur der EZB

Die EZB hält sich bei ihren Jahresausweisen sowohl an die von ihr empfohlene Bilanzstruktur als auch an die von ihr vorgeschlagenen Bewertungsansätze. Sie weist aber nur die für sie relevanten Posten aus (vgl. Europäische Zentralbank (2000h), S. $150 \mathrm{ff}$.$) .$

2.1.2. Besonderheiten der EZB-Bilanz zum 31.12.1998

Keine.

2.1.3. Besonderheiten der EZB-Bilanz zum 31.12.1999

Keine.

\subsection{Deutsche Bundesbank (BBk)}

\subsubsection{Bewertungsansätze und Bilanzstruktur der BBk}

Die BBk übernimmt in ihren Bilanzausweisen zum 1.1.1999 und 31.12.1999 weitestgehend sowohl die von der EZB empfohlene Bilanzstruktur als auch die von der EZB vorgeschlagenen Bewertungsansätze (vgl. Deutsche Bundesbank (2000a), S. 174 ff.).

2.2.2. Besonderheiten der BBk-Eröffnungsbilanz zum 1.1.1999

Die BBk weist in ihrer Eröffnungsbilanz nur auf Mio. EUR gerundete Beträge aus.

\subsubsection{Besonderheiten der BBk-Bilanz zum 31.12.1999}

Die BBk weist in ihrer Bilanz zum 31.12.1999 nur auf Mio. EUR gerundete Beträge aus.

\subsection{Banca d'Italia (BdI)}

\subsubsection{Bewertungsansätze und Bilanzstruktur der BdI}

Die BdI übernimmt in ihren Bilanzausweisen zum 1.1.1999 und 31.12.1999 weitgehend sowohl die von der EZB empfohlene Bilanzstruktur als auch die von der EZB vorgeschlagenen Bewertungsansätze (vgl. Banca d'Italia (2000a), S. $263 \mathrm{ff}$.). Weiterhin bietet sie in vielen Fällen zusätzliche Informationen, indem sie zahlreiche Unterposten in der Bilanz ausweist. Für die Standardbilanz müssen folgende Anpassungen vorgenommen werden:

- Folgende BdI-Posten werden für die Standardbilanz zusammengefaßt:

- BdI-Aktivposten „2.2 Securities (other than shares)“, „2.3 Reverse operations“ und „2.4 Other claims“ zu Standard-Aktivposten „2.2 Guthaben bei Banken, Wertpapieranlagen, Auslandskredite und sonstige Auslandsaktiva“, 
- BdI-Aktivposten „10.2 UIC endowment fund“ und „10.3 Investments of reserves and provisions (including shares)" zu Standard-Aktivposten „10.3 Sonstiges Finanzanlagevermögen“,

- BdI-Aktivposten „10.4 Intangible fixed assets“, „10.5 Deferred charges“ und „10.6 Tangible fixed assets (net of depreciation)" zu StandardAktivposten „10.2 Sachanlagen und immaterielle Vermögensgegenstände",

- BdI-Passivposten „10.1 Bank of Italy drafts“, „10.2 Cashier's department services" und „10.4 Sundry“ zu Standard-Passivposten „11.3 Sonstiges“,

- BdI-Passivposten „13 Provision for general risks“, „14.2 Ordinary and extraordinary reserves" und „14.3 Other reserves" zu StandardPassivposten „14.2 Rücklagen“.

\subsubsection{Besonderheiten der BdI-Eröffnungsbilanz zum 1.1.1999}

Keine.

\subsubsection{Besonderheiten der BdI-Bilanz zum 31.12.1999}

Keine.

\subsection{Banque de France (BdF)}

\subsubsection{Bewertungsansätze und Bilanzstruktur der BdF}

Die BdF übernimmt in ihren Bilanzausweisen weitestgehend die von der EZB empfohlenen Bewertungsgrundsätze. Allerdings weicht die BdF, was die Bilanzstruktur betrifft, zum Teil deutlich von der EZB-Empfehlung ab (vgl. Banque de France (2000c), S. 235 ff.). Deshalb müssen für die Standardbilanz folgende Anpassungen vorgenommen werden:

- Folgende BdF-Bilanzposten (Unterposten) werden den entsprechenden Standardbilanz-Positionen zugeordnet:

- BdF-Aktivposten „2.2 Foreign exchange assets held with euro area residents“ zu Standard-Aktivposten ,3 Forderungen in Fremdwährung an Ansässige im Euro-Währungsgebiet",

- BdF-Aktivposten „9.1 Claims on the French Treasury - For Coins“ zu Standard-Aktivposten „10.1 Scheidemünzen des Euro-Währungsgebiets“,

- BdF-Aktivposten „9.2 Claims on the French Treasury - Under the Agreement of 10 June 1993“ zu Standard-Aktivposten „7 Forderungen in Euro an öffentliche Haushalte",

- BdF-Aktivposten „12.1 Tangible and intangible assets“ zu StandardAktivposten „10.2 Sachanlagen und immaterielle Vermögensgegenstände",

- BdF-Aktivposten „12.2 Equity interests and portfolio securities (other than interest in the ECB)“ zu Standard-Aktivposten „10.3 Sonstiges Finanzanlagevermögen", 
- Unterposten „Accruals“ des BdF-Aktivposten „11.2 Miscellaneous transactions“ zu Standard-Aktivposten „10.5 Aktive Rechnungsabgrenzungsposten",

- Unterposten „Accruals“ des BdF-Passivposten „9.2 Other liabilities Other" zu Standard-Passivposten „11.2 Passive Rechnungsabgrenzungsposten",

- BdF-Passivposten „9.1 Banking transactions“ zuzüglich des unter „9.2 Other liabilities - Other" verbuchten Unterpostens "Miscellaneous“ zu Standard-Passivposten „11.3 Sonstiges“,

- BdF-Passivposten „9.4 Revaluation accounts“ zu Standard-Passivposten „13 Ausgleichsposten aus Neubewertung“.

- Folgende BdF-Posten werden für die Standardbilanz zusammengefaßt:

- BdF-Aktivposten „11.1 Banking transactions“, „8 Advances to IEDOM and IEOM" und der Unterposten „Miscellaneous“ des BdF-Aktivposten

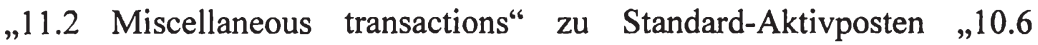
Sonstiges",

- BdF-Aktivposten „2.1 Foreign exchange assets held with non-euro area residents“ und „3 Relations with the IMF“ zu Standard-Aktivposten „2 Forderungen in Fremdwährung an Ansässige außerhalb des EuroWährungsgebiets",

- BdF-Passivposten „9.3 Provisions for liabilites and charges“, „10 Reserve for general banking risks", „11 Revaluation Reserve of State gold reserves" und "12 Revaluation reserve of States foreign exchange reserves" zu Standard-Passivposten „12 Rückstellungen“,

- Unterposten „Reserves“ und „Retained earnings“ des BdF-Passivpostens „13 Capital, reserves and retained earnings“ zu Standard-Passivposten "14.2 Rücklagen“.

- Die „Related liabilities“, die die BdF in ihren Notes zum BdF-Passivposten „2 Euro-denominated liabilities to the monetary financial institutions of the euro area" separat ausweist, werden durch Vergleich mit den BdFBilanzdaten den entsprechenden BdF-Posten ,2.1 Current accounts" und „2.2 Other liabilities“ bzw. den zugehörigen Standard-Passivposten 2.1. bis 2.5. zugewiesen.

\subsubsection{Besonderheiten der BdF-Bilanz zum 31.12.1998}

Keine.

\subsubsection{Besonderheiten der BdF-Bilanz zum 31.12.1999}

- Der Wert des BdF-Passivposten „4 Foreign exchange liabilities“ wird in der Standardbilanz zum 31.12.1999 dem Standard-Passivposten „7 Verbindlichkeiten in Fremdwährung gegenüber Ansässigen außerhalb des Euro-Währungsgebiets“ zugeordnet, da ein Vergleich der aggregierten 
Eurosystembilanzen mit dem Konsolidierten Wochenausweis eine eindeutige Zuweisung zuläßt.

- Die BdF weist im Gegensatz zu allen anderen NZBen sowohl ihre Beteiligung an der EZB als auch ihre Forderungen aus der Übertragung von Währungsreserven an die EZB (Standard-Aktivposten 8.1 und 8.2) nicht in Höhe des Euro(gegen-)werts bei Übertragung, sondern wertberichtigt aus (vgl. Banque de France (2000c), S. 256).

\subsection{Banco de España (BdE)}

\subsubsection{Bewertungsansätze und Bilanzstruktur der $\mathrm{BdE}$}

Die BdE übernimmt in ihren Bilanzausweisen weitestgehend sowohl die von der EZB empfohlene Bilanzstruktur als auch die von der EZB vorgeschlagenen Bewertungsansätze (vgl. Banco de España (2000), S. 113 ff.).

\subsubsection{Besonderheiten der BdE-Bilanz zum 31.12.1998}

Die BdE weist ihren Bilanzgewinn zum 31.12.1998 inklusive einer Interimsausschüttung aus, die bereits am 29.11.1998 an die heimische Regierung gezahlt wurde (vgl. Banco de España (2000), S. 128). Da aber in der Standardbilanz der Passivposten „15 Jahresüberschuß“ nur diejenigen Überschüsse erfassen soll, die erst nach dem 31.12.1998 ausgeschüttet bzw. anderweitig verwendet werden sollen, ist die am 29.11.1998 gezahlte Interimsausschüttung in Höhe von 2256,8 Mio. EUR dem passivischen Standard-Rechungsabgrenzungsposten zuzurechnen. Der von der BdE in Höhe von 6468,5 Mio. EUR ausgewiesene Bilanzgewinn vermindert sich in der Standardbilanz entsprechend auf 4211,7 Mio. EUR.

\subsubsection{Besonderheiten der BdE-Bilanz zum 31.12.1999}

Die BdE weist ihren Bilanzgewinn zum 31.12.1999 inklusive einer Interimsausschüttung aus, die bereits am 29.11.1999 an die heimische Regierung gezahlt wurde (vgl. Banco de España (2000), S. 128). Da aber in der Standardbilanz der Passivposten „15 Jahresüberschuß“ nur diejenigen Überschüsse erfassen soll, die erst nach dem 31.12.1999 ausgeschüttet bzw. anderweitig verwendet werden sollen, ist die am 29.11.1999 gezahlte Interimsausschüttung in Höhe von 1905,85 Mio. EUR dem passivischen Standard-Rechungsabgrenzungsposten zuzurechnen. Der von der BdE in Höhe von 4063,83 Mio. EUR ausgewiesene Bilanzgewinn vermindert sich in der Standardbilanz entsprechend auf 2157,98 Mio. EUR. 


\subsection{De Nederlandsche Bank (DNB)}

\subsubsection{Bewertungsansätze und Bilanzstruktur der DNB}

Die DNB übernimmt in ihren Bilanzausweisen sowohl die von der EZB empfohlene Bilanzstruktur als auch die von der EZB vorgeschlagenen Bewertungsansätze (vgl. De Nederlandsche Bank (2000b), S. 180 ff.).

\subsubsection{Besonderheiten der DNB-Eröffnungsbilanz zum 1.1.1999}

- Die DNB weist in ihrer Eröffnungsbilanz nur auf Mio. EUR gerundete Beträge aus.

- Die DNB weist im Gegensatz zu allen anderen NZBen in ihrer Eröffnungsbilanz Forderungen aus der Übertragung von Währungsreserven an die EZB (2139 Mio. EUR) aus, obwohl diese Aktiva zum 1.1.1999 noch nicht abschließend auf die EZB übertragen worden sind. Tatsächlich fand die Übertragung erst zwischen dem 4. und 7. Januar 1999 statt (vgl. Europäische Zentralbank (2000h), S. 157).

- Die DNB weist ihre Eröffnungsbilanz nur nach der Gewinnverwendung aus. In der Standardbilanz sollen aber mit Hilfe des Passivpostens „15 Jahresüberschuß“ diejenigen NZB-Überschüsse separat erfaßt werden, die nach dem 31.12.1998 ausgeschüttet bzw. anderweitig verwendet wurden. Nach Anwendung der neuen Bilanzierungsregeln beträgt der DNBBilanzgewinn des Jahres 1998: 334 Mio. EUR, der zum Teil bereits am 17.9.1998 im Wege einer Interimsausschüttung in Höhe von 296 Mio. EUR an die holländische Regierung ausgeschüttet wurde (vgl. De Nederlandsche Bank (1999), S. 189 und De Nederlandsche Bank (2000b), S. 180 ff.). Der verbleibende restliche Ausschüttungsbetrag in Höhe von 38 Mio. EUR soll nun vom passivischen DNB-Rechungsabgrenzungsposten „17.1 Accruals and deferred income" abgezogen werden. Dieser Posten verringert sich somit von 838 Mio. EUR (DNB-Bilanz) auf 800 Mio. EUR (Standardbilanz). Der noch auszuschüttende Betrag wird in der Standardbilanz separat als „15 Jahresüberschuß" ausgewiesen.

\subsubsection{Besonderheiten der DNB-Bilanz zum 31.12.1999}

- Die DNB weist in ihrer Bilanz zum 31.12.1999 nur auf Mio. EUR gerundete Beträge aus.

- Die DNB weist ihre Bilanz zum 31.12.1999 nur nach der Gewinnverwendung aus. Zur separaten Darstellung des Jahresüberschusses für 1999 in Höhe von 748 Mio. EUR sind folgende Operationen erforderlich: 297 Mio. EUR des Bilanzgewinns, die nach DNB-Angaben der Allgemeinen Reserve zugeführt wurden (vgl. De Nederlandsche Bank (2000b), S. 183), werden vom DNB-Passivposten „19.2 General reserve“, abgezogen. In der Standardbilanz beträgt der Passivposten „14.2 Rücklagen“ somit nur 2386 Mio. EUR, während der entsprechende Posten der DNB-Bilanz „19.2 
General reserve": 2683 Mio. EUR ausweist. Die restlichen 451 Mio. EUR werden, in Analogie zur Vorgehensweise in 1998, vom DNB-Bilanzposten „17.1 Accruals and deferred income“ (530 Mio. EUR) abgezogen, weshalb der entsprechende Passivposten „11.2 Passive Rechnungsabgrenzungsposten" in der Standardbilanz nur 79 Mio. EUR beträgt. Von Interimsausschüttungen sah die DNB in 1999 ab.

\subsection{Belgische Nationalbank (NBB)}

\subsubsection{Bewertungsansätze und Bilanzstruktur der NBB}

Die NBB übernimmt in ihren Bilanzausweisen die von der EZB empfohlene Bilanzstruktur und weitgehend die von der EZB vorgeschlagenen Bewertungsansätze (vgl. Belgische Nationalbank (2000b), S. 59 ff.).

\subsubsection{Besonderheiten der NBB-Eröffnungsbilanz zum 1.1.1999}

Keine.

\subsubsection{Besonderheiten der NBB-Bilanz zum 31.12.1999}

Die NBB weist in ihrer Bilanz zum 31.12.1999 den Bilanzposten „7.3 Other Claims within the Eurosystem" im Gegensatz zum sonst üblichen Nettoausweis in der Bruttoform in Höhe von 3855,2 Mio. Euro aus (vgl. Belgische Nationalbank (2000b), S. 70). Da die NBB innerhalb des Eurosystems zum 31.12.1999 im Betrag von 13978,0 Mio. EUR Brutto-Schuldner war, ist in der Standardbilanz der Aktivposten „8.4 Sonstige Intra-Eurosystem-Forderungen (netto)“ mit einem Strich auszuweisen, während sich sowohl der Passivposten „9.3 Sonstige Intra-Eurosystem-Verbindlichkeiten (netto)“ als auch die Bilanzsumme zum 31.12.1999 um 3855,2 Mio. EUR im Vgl. zum NBB-Ausweis verringert.

\section{8. Österreichische Nationalbank (OeNB)}

\subsubsection{Bewertungsansätze und Bilanzstruktur der OeNB}

Die OeNB übernimmt in ihren Bilanzausweisen sowohl die von der EZB empfohlene Bilanzstruktur als auch die von der EZB vorgeschlagenen Bewertungsansätze (vgl. Österreichische Nationalbank (2000), S. 116 ff.).

\subsubsection{Besonderheiten der OeNB-Eröffnungsbilanz zum 1.1.1999}

Zur separaten Darstellung des OeNB-Jahresüberschusses für 1998 ist folgende Operation erforderlich: Der Bilanzgewinn des Jahres 1998 in Höhe von 82,8 Mio. EUR, der nach OeNB-Angaben fast vollständig den Rücklagen zugeführt wurde (vgl. Österreichische Nationalbank (1999), S. 135), wird vom OeNBPassivposten „14.2 Rücklagen“ abgezogen. In der Standardbilanz beträgt der Passivposten „14.2 Rücklagen“ somit nur 5729,4 Mio. EUR, während der entsprechende Posten der OeNB-Bilanz 5812,2 Mio. EUR ausweist.

\subsubsection{Besonderheiten der OeNB-Bilanz zum 31.12.1999}

Keine. 


\subsection{Banco de Portugal (BdP)}

\subsubsection{Bewertungsansätze und Bilanzstruktur der BdP}

Die BdP übernimmt in ihren Bilanzausweisen sowohl die von der EZB empfohlene Bilanzstruktur als auch die von der EZB vorgeschlagenen Bewertungsansätze (vgl. Banco de Portugal (2000a), S. 284 ff.).

\subsubsection{Besonderheiten der BdP-Eröffnungsbilanz zum 1.1.1999} Keine.

\subsubsection{Besonderheiten der BdP-Bilanz zum 31.12.1999}

Keine.

\subsection{Central Bank of Ireland (CBI)}

\subsubsection{Bewertungsansätze und Bilanzstruktur der CBI}

Die CBI übernimmt in ihren Bilanzausweisen weitgehend sowohl die von der EZB empfohlene Bilanzstruktur als auch die von der EZB vorgeschlagenen Bewertungsansätze (vgl. Central Bank of Ireland (2000c), S. 73 ff.). Die CBI veröffentlicht jedoch eine andere als die von der EZB vorgeschlagene Untergliederung des Aktivpostens "Other assets“. Deshalb müssen für die Standardbilanz folgende Anpassungen vorgenommen werden:

- Folgende CBI-Posten werden für die Standardbilanz zusammengefaßt:

- CBI-Aktivposten "Shares in the Bank for International Settlements“, „Loan to Irish Realtime Interbank Settlement Co. Ltd“ und „AIB plc/ICAROM Interest Bearing Loan“ zu Standard-Aktivposten „10.3 Sonstiges Finanzanlagevermögen“",

- CBI-Aktivposten „Stocks of materials for Note Production“ und „Other“ zu Standard-Aktivposten „10.6 Sonstiges“.

- Folgende CBI-Aktivposten werden den entsprechenden StandardbilanzPositionen zugeordnet:

- der CBI-Aktivposten „Accrued income“ zu Standard-Aktivposten „10.5 Aktive Rechnungsabgrenzungsposten",

- der CBI-Aktivposten „Fixed assets“ zu Standard-Aktivposten „10.2 Sachanlagen und immaterielle Vermögensgegenstände“.

2.10.2. Besonderheiten der CBI-Bilanz zum 31.12.1998

- Die CBI weist in ihrer Bilanz zum 31.12.1998 nur auf Mio. EUR gerundete Beträge aus.

- Die CBI weist ihre Bilanz zum 31.12.1998 nur nach Verwendung des Bilanzgewinns aus. Dieser beträgt in 1998: 193,4 Mio. EUR (,surplus income"), wobei die CBI im Laufe des Jahres 1998 dem irischen Schatzamt eine Vorauszahlung in Höhe von 40,6 Mio. EUR gezahlt hat und dieser Betrag bei der restlichen Gewinnausschüttung angerechnet wird. Dieser Restbetrag in Höhe von 152,8 Mio. EUR wird in der CBI Bilanz unter dem 
Passivposten „Other liabilities - Profit and loss appropriations" verbucht und entspricht dem Standardbilanz-Passivposten „15 Jahresüberschuß“ (vgl. Central Bank of Ireland (1999), S. 67 und Central Bank of Ireland (2000c), S. 83). Der CBI-Sammelposten „Other liabilities“ weist folglich einen um 153 Mio. EUR höheren Wert aus als der Standardbilanz-Passivposten „11 Sonstige Passiva".

\subsubsection{Besonderheiten der CBI-Bilanz zum 31.12.1999}

- Die CBI weist in ihrer Bilanz zum 31.12.1999 nur auf Mio. EUR gerundete Beträge aus.

- Die CBI weist ihre Bilanz zum 31.12.1999 nur nach Verwendung des Bilanzgewinns aus. Dieser beträgt in 1999: 213,4 Mio. EUR („surplus income"), wobei die CBI im Laufe des Jahres 1999 dem irischen Schatzamt eine Vorauszahlung in Höhe von 40,6 Mio. EUR gezahlt hat und dieser Betrag bei der restlichen Gewinnausschüttung angerechnet wird. Dieser Restbetrag in Höhe von 172,8 Mio. EUR wird in der CBI Bilanz unter dem Passivposten „Other liabilities - Profit and loss appropriations“ verbucht und entspricht dem Standardbilanz-Passivposten „15 Jahresüberschuß“ (vgl. Central Bank of Ireland (2000c), S. 82). Der CBI-Sammelposten „15 Other liabilities" weist folglich einen um 173 Mio. EUR höheren Wert aus als der Standardbilanz-Passivposten „11 Sonstige Passiva“.

\subsection{Bank of Finland (BoF)}

\subsubsection{Bewertungsansätze und Bilanzstruktur der BoF}

Die BoF übernimmt in ihren Bilanzausweisen weitgehend sowohl die von der EZB empfohlene Bilanzstruktur als auch die von der EZB vorgeschlagenen Bewertungsansätze (vgl. Bank of Finland (2000b), S. 82 ff.). Die BoF veröffentlicht jedoch keine Untergliederung Aktivpostens „Other claims“, wie von der EZB empfohlen. Deshalb können für den Aktivposten „10 Sonstige Aktiva" der Standardbilanz nur partielle Angaben gemacht werden.

\subsubsection{Besonderheiten der BoF-Bilanz zum 31.12.1998}

- Die BoF weist in ihrer Bilanz zum 31.12.1998 nur auf Mio. EUR gerundete Beträge aus.

- Folgende Unterposten des Standardbilanz-Aktivpostens „10 Sonstige Aktiva“ können quantifiziert werden:

- „10.1 Scheidemünzen des Euro-Währungsgebiets“: Mit Hilfe der verfügbaren BoF-Angaben (vgl. Bank of Finland (1999), S. 90 f. und Bank of Finland (2000b), S. 55, 82 und 105) läßt sich der Sicherheitsbestand der BoF an finnischen Münzen in Höhe von 124,7 Mio. FIM (= 21 Mio. EUR) errechnen. 
- „10.3 Sonstiges Finanzanlagevermögen“: Die BoF gibt den Wert ihrer Beteiligungen mit 30,4 Mio. Euro und die Höhe ihrer investierten Pensionsreserven im Betrag von 284,2 Mio. EUR an, weshalb sich eine Untergrenze der BoF-Finanzaktiva von 314,6 Mio. EUR veranschlagen läßt (vgl. Bank of Finland (2000b), S. 85).

\subsubsection{Besonderheiten der BoF-Bilanz zum 31.12.1999}

- Die BoF weist in ihrer Bilanz zum 31.12.1999 nur auf Mio. EUR gerundete Beträge aus.

- Folgende Unterposten des Standardbilanz-Aktivpostens „10 Sonstige Aktiva“ können quantifiziert werden:

- „10.1 Scheidemünzen des Euro-Währungsgebiets": Nach BoF-Angaben betrug der Umlauf von finnischen Münzen Ende 1999: 1622,3 Mio. FIM = 272,9 Mio. Euro. Berücksichtigt man weiterhin, daß die BoF Ende 1999 einen Sicherheitsbestand von 4,8 Prozent des Münzumlaufs besitzt, kann der Sicherheitsbestand an Münzen zum 31.12.1999 auf 13 Mio. Euro beziffert werden (vgl. Bank of Finland (2000b), S. 58 und S. 118).

- „10.3 Sonstiges Finanzanlagevermögen“: Die BoF gibt den Wert ihrer Beteiligungen mit 26,0 Mio. Euro und die Höhe ihrer investierten Pensionsreserven im Betrag von 294,5 Mio. EUR an, weshalb sich eine Untergrenze der BoF-Finanzaktiva von 320,5 Mio. EUR veranschlagen läßt (vgl. Bank of Finland (2000b), S.85).

\subsection{Banque Centrale du Luxembourg (BCL)}

2.12.1. Bewertungsansätze und Bilanzstruktur der BCL

Die BCL übernimmt in ihren Bilanzausweisen zum 31.12.1998 und 31.12.1999 weitestgehend sowohl die von der EZB empfohlene Bilanzstruktur als auch die vorgeschlagenen Bewertungsansätze (vgl. Banque Centrale du Luxembourg (2000c), S. 114 ff.).

\subsubsection{Besonderheiten der BCL-Bilanz zum 31.12.1998} Keine.

2.12.3. Besonderheiten der BCL-Bilanz zum 31.12.1999

Keine. 


\subsection{Kumulierte Aktiv- und Passivposten der EZB und NZBen}

\subsubsection{Generelle Bemerkungen}

Aufgrund folgender Punkte weichen die kumulierten Aktiv- und Passivposten der EZB und der NZBen vom Konsolidierten Wochenausweis ab:

- Nicht immer einheitliche Bewertungsansätze in den Jahresausweisen der Zentralbanken,

- Revision von Daten, die noch zur Erstellung des Konsolidierten Wochenausweises an die EZB gemeldet wurden, aber in den erst später aufgestellten NZB-Bilanzen rückwirkend berichtigt wurden,

- Verbuchung von Transaktionen, die zum Bilanzierungszeitpunkt noch nicht durchgeführt worden sind, als bereits durchgeführte Geschäfte (solche Transaktionen werden sonst üblich unter "Rechnungsabgrenzungsposten“ erfaßt),

- Rundungsfehler.

\subsubsection{Besonderheiten der aggregierten EZB- und NZB-Bilanzen zum}

31.12.1998 bzw. zum 1.1.1999

Aufgrund folgender Faktoren heben sich die in der Standardbilanz ausgewiesenen kumulierten „Intra-Eurosystem-Forderungen und Verbindlichkeiten" nicht auf:

- Die DNB weist im Gegensatz zu allen anderen NZBen in ihrer Eröffnungsbilanz ihre Forderungen aus der Übertragung von Währungsreserven an die EZB (2139 Mio. EUR) bereits aus, obwohl diese Aktiva zum 1.1.1999 noch nicht abschließend auf die EZB übertragen worden sind,

- der bilanzielle Gegenposten zu den von den NZBen eingezahlten „Beteiligungen (der NZBen) an der EZB" wird in der Standardbilanz unter dem Passivposten „14.1 (EZB-) Kapital“" erfaßt.

\subsubsection{Besonderheiten der aggregierten EZB- und NZB-Bilanzen zum} 31.12.1999

Aufgrund folgender Faktoren heben sich die in der Standardbilanz ausgewiesenen kumulierten „Intra-Eurosystem-Forderungen und -Verbindlichkeiten" nicht auf:

- Die BdF weist im Gegensatz zu allen anderen NZBen sowohl ihre Beteiligung an der EZB als auch ihre Forderungen aus der Übertragung von Währungsreserven an die EZB (Standard-Aktivposten 8.1 und 8.2) nicht in Höhe des Euro(gegen-)werts bei Übertragung, sondern wertberichtigt aus (vgl. Banque de France (2000c), S. 256),

- der bilanzielle Gegenposten zu den von den NZBen eingezahlten „Beteiligungen (der NZBen) an der EZB“ wird in der Standardbilanz unter dem Passivposten „14.1 (EZB-) Kapital“ erfaßt. 


\subsection{Konsolidierter Wochenausweis des Eurosystems}

\subsubsection{Bewertungsansätze und Bilanzstruktur des Konsolidierten Wochenausweises des Eurosystems}

- Die NZBen sind verpflichtet zur Erstellung des Konsolidierten Wochenausweises Daten an die EZB zu melden. Diese basieren auf einer einheitlichen Bilanzstruktur sowie auf grundsätzlich einheitlichen Bewertungsmaßstäben und Bilanzierungsrichtlinien. So dürfen die NZBen nur bei den Standard-Aktivposten „10.2 Sachanlagevermögen und immaterielle Vermögensgegenstände", „10.3 Sonstiges Finanzanlagevermögen“ und „10.6 Sonstiges“ sowie bei den Standard-Passivposten „11.3 Sonstiges" und „12 Rückstellungen“ eigene Bewertungsansätze anwenden (vgl. European Central Bank (1998c), S. 34).

- Der Aktivposten des Konsolidierten Wochenausweises „8 Other assets“ enthält keine Untergliederung wie der entsprechende Posten "10 Sonstige Aktiva" in der Standardbilanz.

- Der Passivposten des Konsolidierten Wochenausweises „9 Other liabilities“ setzt sich aus den Standardbilanzposten „10 Schwebende Verrechnungen“, „11 Sonstige Passiva“, „12 Rückstellungen“ und „15 Jahresüberschuß“ zusammen.

- Der Konsolidierte Wochenausweis des Eurosystems enthält keine IntraEurosystem-Forderungen bzw. -Verbindlichkeiten, da diese bei der Konsolidierung herausfallen.

\subsubsection{Besonderheiten des Konsolidierten Wochenausweises zum 1.1.1999} Keine.

\subsubsection{Besonderheiten des Konsolidierten Wochenausweises zum} 31.12.1999

- Das Eurosystem ist im Gegensatz zum Eröffnungsausweis offenbar dazu übergegangen, den Aktiv- bzw. Passivposten „Forderungen bzw. Verbindlichkeiten in Euro an Ansässige außerhalb des Euro-Währungsgebiets" in der Nettoform auszuweisen. Diese Vermutung bestätigt auch der Vergleich der Differenz der kumulierten Brutto-,,Forderungen und Verbindlichkeiten der EWU-Zentralbanken in Euro an Ansässige außerhalb des Euro-Währungsgebiets" (2980 Mio. EUR) mit der Differenz der entsprechenden Posten des Konsolidierten Wochenausweises zum 31.12.1999 (3012 Mio. EUR). 
Erläuterungen zu den Tabellen 10 und 12: Die Gewinn- und Verlustrechnungen der EZB und der NZBen für das Jahr 1998 und 1999 in Mio. Euro

\section{Allgemeine Bemerkungen}

Ähnlich wie bei der Veröffentlichung der Bilanzen sind die NZBen auch beim Ausweis ihrer in Eigenregie erstellten Gewinn- und Verlustrechnungen nicht an die von der EZB vorgeschlagene GuV-Struktur gebunden (vgl. European Central Bank (1998c), S. 19). Deshalb weicht auch ein Teil der NZBen von diesem Aufbau ab. Dennoch soll hier der Versuch unternommen werden, durch entsprechende Umgruppierungen die GuVen auf eine einheitliche Struktur, die im folgenden als "Standard-GuV" bezeichnet werden soll, zu bringen. Dabei orientiert sich die Standard-GuV sehr eng an der von der EZB empfohlenen Struktur. Allerdings werden zusätzliche Informationen hinsichtlich des Ausweises der "Monetären Einkünfte" der NZBen und der Finanzierung des EZB-Verlusts des Jahres 1999 bereitgestellt. Weiterhin soll eine Vergleichbarkeit der von den Zentralbanken erwirtschafteten Jahresgewinne erreicht werden, indem in der Standard-GuV „vorbilanzielle“ Gewinnverwendungen wie Körperschaftssteuerzahlungen, Interimsdividenden und andere steuerähnliche Zugriffe auf den Brutto-Jahresüberschuß separat ausgewiesen werden. Die verbleibenden in der Standard-GuV als „Jahresüberschuß“ bezeichneten Gewinnbeträge dürfen also nicht mit der Gesamtheit der Zentralbankgewinne, die die Notenbanken entweder an ihre Kapitaleigner ausschütten bzw. einer anderweitigen Verwendung zuführen, gleichgesetzt werden.

Die Zentralbanken weisen ihre Angaben unterschiedlich genau aus. Einige Zentralbanken stellen nur Angaben in Mio. EUR zur Verfügung, andere weisen diese bis auf den letzten Euro-Cent aus. Wegen dieser unterschiedlichen Informationsdichte (inklusive Rundungsfehlern) summieren sich die Angaben bezüglich der Finanzierung und Verwendung der Monetären Einkünfte des Jahres 1999 jeweils nicht zum Wert von 35,2 Mio. EUR auf. Die Saldierung derselben ergibt somit nicht 0,0 Mio. EUR. Dies ist in der Tabelle 12 durch entsprechende Klammersetzung verdeutlicht.

Ein Vergleich mit einer vom Eurosystem veröffentlichten $\mathrm{GuV}$, die, ähnlich wie der Konsolidierte Wochenausweis für die Eurosystembilanz, kumulierte Aufwands- und Ertragsposten ausweist, ist nicht möglich, da das Eurosystem keine entsprechenden Daten zur Verfügung stellt. 
2. Erläuterungen zu den GuV-Positionen der in den Tabellen $\mathbf{1 0}$ und $\mathbf{1 2}$ aufgeführten Zentralbanken

\subsection{Europäische Zentralbank (EZB)}

\subsubsection{GuV-Struktur der EZB}

Die EZB hält sich an die von ihr empfohlene GuV-Struktur. Sie weist aber nur die für sie relevanten Posten aus (vgl. Europäische Zentralbank (2000h), S. 152). 2.1.2. Besonderheiten der EZB-GuV zum 31.12.1998 Keine.

\subsubsection{Besonderheiten der EZB-GuV zum 31.12.1999}

Keine.

\subsection{Deutsche Bundesbank (BBk)}

\subsubsection{GuV-Struktur der BBk}

Die BBk übernimmt die von der EZB empfohlene GuV-Struktur (vgl. Deutsche Bundesbank (2000a), S. 176).

\subsubsection{Besonderheiten der BBk-GuV zum 31.12.1998}

- Die BBk weist ihre GuV nur auf Mio. EUR gerundete Beträge aus.

- Die BBk unterscheidet begrifflich zwischen dem GuV-Ergebnis „Jahresüberschuß“ in Höhe von 6447 Mio. EUR und dem „Bilanzgewinn“ im Betrag von 8295 Mio. EUR (vgl. Deutsche Bundesbank (1999d), S. 186 und Deutsche Bundesbank (2000a), S. 176). Diese Unterscheidung soll hier aus Konsistenzgründen aufgegeben werden. Deshalb wird der BBk-GuV-Posten „13 Jahresüberschuß“ (6447 Mio. EUR) mit dem nicht in der BBk-GuV ausgewiesenen „Entnahme aus den Rücklagen“ (1848 Mio. EUR) zu dem Standard-GuV-Posten „22 Jahresüberschuß/-fehlbetrag“ (8295 Mio. EUR) zusammengefaßt. Der Standard-GuV-Posten „13 Sonstige Erträge“ (1958 Mio. EUR) ist entsprechend um die „Entnahme aus den Rücklagen“ (1848 Mio. EUR) höher auszuweisen, als der BBk-Posten „6 Sonstige Erträge“ (110 Mio. EUR). Dies gilt ebenfalls auch für den Ausweis des StandardGuV-Postens „14 Gesamte Nettoerträge“ (BBk-GuV: 7926 Mio. EUR, Standard-GuV: 9774 Mio. EUR).

\subsubsection{Besonderheiten der BBk-GuV zum 31.12.1999}

- Die BBk weist ihre GuV nur auf Mio. EUR gerundete Beträge aus.

- Der BBk-Posten „5 Nettoergebnis aus Monetären Einkünften“ (72 Mio. EUR) enthält nach BBk-Angaben neben dem „Nettoaufwand aus Monetären Einkünften vor EZB-Verlustanrechnung" (3 Mio. EUR) auch den zur teilweisen Finanzierung des EZB-Verlusts an die EZB abgetretenen Poolanspruch der BBk (11 Mio. EUR) und den direkten BBk-Aufwand zur Finanzierung des EZB-Verlusts in Höhe von 57 Mio. EUR (vgl. Deutsche 
Bundesbank (2000a), S. 194). Diese Posten werden in der Standard-GuV separat ausgewiesen, weshalb sich auch der Standard-GuV-Posten „14 Gesamte Nettoerträge“ (5425 Mio. EUR) vom gleichnamigen BBk-Posten (5356 Mio. EUR) um 69 Mio. EUR unterscheidet.

\subsection{Banca d'Italia (BdI)}

\subsubsection{GuV-Struktur der BdI}

Die BdI hält sich wesentlich an die EZB-Empfehlung zur GuV-Struktur, allerdings trennt sie beim Ausweis ihrer Einkünfte zwischen „Net income from institutional operations" und "Other income" (vgl. Banca d'Italia (2000a), S. $280 \mathrm{ff}$.). Deshalb sind folgende Anpassungen erforderlich:

- Der in der BdI-GuV unter „B) Other income - Income from the investment of reserves and provisions" verbuchte Unterposten „Interest income" und der BdI-GuV-Posten „A) Net income from institutional operations - Interest income" werden zum Standard-GuV-Posten "1 Zinseinkünfte (Brutto)“ zusammengefaßt,

- der in der BdI-GuV unter „B) Other income - Income from the investment of reserves and provisions" verbuchte Unterposten „Dividends on equity shares and participating interests" und der BdI-GuV-Posten „A) Net income from institutional operations - Income from equity shares and participating interests" werden zum Standard-GuV-Posten „11 Erträge aus Beteiligungen“ zusammengefaßt.

- Der Standard-GuV-Posten „13 Sonstige Erträge“ entspricht dem BdI-GuVPosten „B) Other Income“ abzüglich der oben genannten Zinseinkünfte und Erträge aus Beteiligungen. Von weiteren Zuordnungen wird wegen mangelnder Relevanz abgesehen.

- Zur separaten Darstellung der von der BdI an den italienischen Staat gezahlten Körperschaftssteuer, die die BdI unter dem GuV-Posten „Taxes on income for the year and productive activities" ausweist, wird der jeweilige Körperschaftssteuerbetrag herausgerechnet und unter dem Standard-GuVPosten „21.1 Körperschaftssteuer u.ä.“ verbucht. Der Restbetrag wird dem Standard-GuV-Posten „20 Sonstige Aufwendungen“ zugeordnet. Neben diesem Restbetrag gehen in den Standard-GuV-Posten "20 Sonstige Aufwendungen“ auch die unter dem BdI-Aufwandsposten verbuchten „Other costs" ein.

\subsubsection{Besonderheiten der BdI-GuV zum 31.12.1998} Keine.

\subsubsection{Besonderheiten der BdI-GuV zum 31.12.1999}

Der BdI-GuV-Posten „Net result of the pooling of monetary income“ zeigt einen BdI-Nettoaufwand in Höhe von 37,1 Mio. EUR. Dieser setzt sich aus dem BdI- 
Beitrag zur Finanzierung des EZB-Verlustes in Höhe von 41,5 Mio. EUR (Summe aus an EZB abgetretene BdI-Poolpartizipation (6,6 Mio. EUR) und dem direkten BdI-Beitrag zur Finanzierung des verbleibenden EZB-Fehlbetrags (34,8 Mio. EUR)) abzüglich des „Nettoertrags aus Monetären Einkünften vor EZB-Verlustanrechnung" im Betrag von 4,3 Mio. EUR zusammen (vgl. Banca d'Italia (2000a), S. 281). Diese Posten werden in der Standard-GuV separat ausgewiesen.

\subsection{Banque de France (BdF)}

\subsubsection{GuV-Struktur der BdF}

Die BdF hält sich prinzipiell an die von der EZB empfohlene GuV-Struktur (vgl. Banque de France (2000c), S. 238), unterteilt jedoch den Ausweis der Nettoerträge in zwei Bereiche: „1 Net income on financial activities within the ESCB“ und „2 Net income on other activities“. Deshalb sollen für die Standard$\mathrm{GuV}$ die nachstehenden Anpassungen vorgenommen werden.

- Folgende BdF-GuV-Positionen werden zu den entsprechenden StandardGuV-Posten zusammengefaßt:

" „1.1.1 Interest and related income“ und „2.1.1 Interest and related income" $\mathrm{zu}, 1$ Zinseinkünfte (brutto),

- „1.1.2 Interest and related expenses“ und „2.1.2 Interest and related expenses“ $\mathrm{zu}, 2$ Zinsaufwandungen (brutto),

- „1.4 Commissions“ und „2.3 Commissions“ mit den zugehörigen Bruttowerten zu „10 Nettoergebnis aus Gebühren und Provisionen“,

- „1.7 Net of other income and expenses“ und „2.5 Other income and expenses" zu „13 Sonstige Erträge“,

- „3.2 Taxes“, „4 Net charge to the reserve for general banking risks“ und „5 Exceptional expenses“ zu „20 Sonstige Aufwendungen“,

- „1.2 Net income/loss on securities transactions“, „1.3 Net gain/loss on foreign exchange and gold" und „2.2 Net income on financial transactions“ zu „7 Nettoergebnis aus Finanzoperationen, Abschreibungen und Risikovorsorgen". Eine genauere Zuordnung erscheint hier nicht möglich.

- Folgende BdF-Positionen werden den entsprechenden Standard-GuV-Posten zugewiesen:

- „1.6 Net result of pooling of monetary income“ $\mathrm{zu}, 12$ Nettoergebnis aus Monetären Einkünften (vor EZB-Verlustanrechnung)“,

- „1.5 Expenses arising on participating interest in the ECB“ $\mathrm{zu}, 15$ Finanzierungsbeitrag EZB-Verlust",

- ,2.4 Income on equity interests (excl. ECB) and portfolio securities“ zu „11 Erträge aus Beteiligungen“. 


\subsubsection{Besonderheiten der BdF-GuV zum 31.12.1998}

Keine.

\subsubsection{Besonderheiten der BdF-GuV zum 31.12.1999 \\ Keine.}

\subsection{Banco de España (BdE)}

\subsubsection{GuV-Struktur der BdE}

Die BdE hält sich weitgehend an die von der EZB empfohlene GuV-Struktur (vgl. Banco de España (2000), S. 118), weist aber einen zusätzlichen Posten "Transfers and additions to other funds and provisions" aus, der in der StandardGuV mit dem BdE-GuV-Posten „Other expenses“ zum Standard-Posten „20 Sonstige Aufwendungen" zusammengefaßt wird. Weiterhin werden in der Standard-GuV die Interimsdividenden, die von der BdE vor dem jeweiligen Bilanztermin gezahlt wurden, separat ausgewiesen.

\subsubsection{Besonderheiten der BdE-GuV zum 31.12.1998 Keine.}

\subsubsection{Besonderheiten der BdE-GuV zum 31.12.1999}

Der BdE-GuV-Posten "Net result of the pooling of monetary income" zeigt einen BdE-Nettoaufwand in Höhe von 22,6 Mio. EUR. Dieser setzt sich aus dem BdE-Beitrag zur Finanzierung des EZB-Verlustes in Höhe von 24,8 Mio. EUR (Summe aus der an die EZB abgetretenen BdE-Poolpartizipation (3,9 Mio. EUR) und dem direkten BdE-Beitrag zur Finanzierung des verbleibenden EZBFehlbetrags (20,8 Mio. EUR)) abzüglich des „Nettoertrags aus Monetären Einkünften vor EZB-Verlustanrechnung" im Betrag von 2,1 Mio. EUR zusammen (vgl. Banco de España (2000), S. 131). Diese Posten werden in der Standard-GuV separat ausgewiesen.

\subsection{De Nederlandsche Bank (DNB) \\ 2.6.1. GuV-Struktur der DNB}

Die DNB hält sich weitgehend an die von der EZB empfohlene GuV-Struktur (vgl. De Nederlandsche Bank (2000b), S. 182). Allerdings unterscheidet sich die Struktur der DNB-GuV von der EZB-Empfehlung dahingehend, daß sie ihre Zinserträge und Dividendeneinkünfte unter dem DNB-GuV-Posten „Interest income and dividend" zusammenfaßt. Folgende Aufteilungen sind erforderlich: Der DNB-GuV-Unterposten „Income from participating interests and loans included in Other financial assets" wird dem Standardposten „11 Erträge aus Beteiligungen“ zugeordnet. Der restliche Teil des GuV-Postens „Interest income and dividend" wird in der Standard-GuV als „1 Zinseinkünfte (brutto)“ erfaßt.

\subsubsection{Besonderheiten der DNB-GuV zum 31.12.1998}

- Die DNB weist ihre GuV nur auf Mio. EUR gerundete Beträge aus. 
- Die von der DNB am 17.9.1998 in Höhe von 296 Mio. EUR gezahlte Interimsdividende an den holländischen Staat wird in der Standard-GuV separat ausgewiesen. Deshalb unterscheidet sich der Standard-GuV-Posten „22 Jahresüberschuß“ (38 Mio. EUR) vom DNB-Posten „Net-Profit“ (334 Mio. EUR).

\subsubsection{Besonderheiten der DNB-GuV zum 31.12.1999}

- Die DNB weist ihre GuV nur auf Mio. EUR gerundete Beträge aus.

- Nach DNB-Angaben ist der DNB-Beitrag zur EZB-Verlustfinanzierung (12 Mio. EUR) unter dem GuV-Unterposten „Income from participating interests and loans included in Other financial assets" (-4 Mio. EUR) verbucht (vgl. De Nederlandsche Bank (2000b), S. 194). Da der Standardposten „11 Erträge aus Beteiligungen“ jedoch nur die Nettoerträge aus den DNB-Beteiligungen ohne EZB-Verlustfinanzierungsbeitrag erfaßt, ist hier folglich ein Betrag von 8 Mio. EUR auszuweisen. Der DNB-Beitrag zur EZB-Verlustfinanzierung (12 Mio. EUR) wird als eigenständiger Standard-Aufwandsposten erfaßt.

- Der DNB-GuV-Posten „7 Net result from allocation of monetary income“ (1 Mio. EUR) entspricht dem Standard-Posten „12 Nettoergebnis aus Monetären Einkünften (vor EZB-Verlustanrechnung)“. Die Angaben zur Bruttofinanzierungsleistung zum Pool der Monetären Einkünfte bzw. zur Poolpartizipation werden von der DNB nicht zur Verfügung gestellt, können aber mit Hilfe von EZB-Angaben errechnet werden (vgl. Kapitel IV.2. Abschnitt 1.2. und Kapitel V.3.1.1. Abschnitt 2.).

\subsection{Belgische Nationalbank (NBB)}

\subsubsection{GuV-Struktur der NBB}

Die NBB hält sich nicht an die von der EZB empfohlene GuV-Struktur (vgl. Belgische Nationalbank (2000b), S. 72). Zahlreiche Anpassungen sind deshalb erforderlich.

- Folgende NBB-GuV-Posten werden den entsprechenden Standard-GuVPositionen zugeordnet:

- „I.1. Interest income“ zu „1 Zinseinkünfte (brutto)“,

- „I.2. Interest expenses“ zu „2 Zinsaufwendungen (brutto)“,

- „I.4. Allocation of monetary income from the Eurosystem" mit den zugehörigen Bruttopositionen zu „12 Nettoergebnis aus Monetären Einkünften (vor EZB-Verlustanrechnung",

- „III Commission“ mit den zugehörigen Bruttopositionen zu „10 Nettoergebnis aus Gebühren und Provisionen“,

- „I.5 Appropriation to the provision for covering loss from the ECB“ zu „15 Finanzierungsbeitrag EZB-Verlust“,

- „IX.1. Remuneration and social costs“ $\mathrm{zu}, 16$ Personalaufwand“, 
- „XI. Deprecation of tangible fixed assets“ $\mathrm{zu}$ „18 Abschreibungen auf Sachanlagen und immaterielle Vermögensgegenstände“,

- „XIII. Taxes and dues“ zu „21.1 Körperschaftssteuer u.ä.“,

- „VII. State share“ zu „21.2 Gewinnanteil vor Bilanzgewinn“.

- Folgende NBB-GuV-Positionen werden zu den entsprechenden StandardGuV-Posten zusammengefaßt:

- „I.3 Capital gains / losses on securities“ und „II.1 Foreign exchange difference gains" (dies sind jeweils wohl überwiegend realisierte Bewertungsgewinne, vgl. Belgische Nationalbank (2000b), S. 93 f.) zu „4 Realisierte Gewinne/Verluste aus Finanzoperationen",

- "II.2 Allocation to / Write-back of provision for future exchange losses", „XII.2 Allocation to / write back of provisions - For contingences" und „VIII. Transfer to the unavailable reserve of capital gains on gold“ $\mathrm{zu}, 6$ Zuführung / Auflösung von Rückstellungen für Währungs- und Preisrisiken",

- „VI. Other proceeds“, „XII. Allocation to / Write-back of provisions for new premises" und „IV. Amounts recovered from third parties" zu „13 Sonstige Erträge",

- „IX.2 Other expenses“ und „X. Exceptional costs“ zu „20 Sonstige Aufwendungen".

- Weitere Bemerkungen:

- Hinsichtlich des Standard-Postens „11 Erträge aus Beteiligungen“ können keine Angaben gemacht werden. Die NBB weist jedoch darauf hin, daß sie über entsprechende Beteiligungen verfügt (vgl. Belgische Nationalbank (2000b), S. 81).

- Die NBB weist die Kosten für die Banknotenproduktion nicht explizit aus, erwähnt aber, daß sie im Posten „IX.2 Other expenses“ enthalten sind (vgl. Belgische Nationalbank (2000b), S. 97).

- Der von der NBB ausgewiesene „Net profit for the financial year“ ist mit dem „Jahresüberschuß“ der Standard-GuV identisch.

\subsubsection{Besonderheiten der NBB-GuV zum 31.12.1998}

Keine.

\subsubsection{Besonderheiten der NBB-GuV zum 31.12.1999}

Keine.

\section{8. Österreichische Nationalbank (OeNB)}

\subsubsection{GuV-Struktur der OeNB}

Die OeNB übernimmt die von der EZB empfohlene GuV-Struktur (vgl. Österreichische Nationalbank (2000), S. 120 und 140). Der zusätzlich angegebene OeNB-GuV-Posten "Allgemeiner Reservefonds“ wird in der 
Standard-GuV dem Posten „Sonstige Aufwendungen“ zugerechnet. Der OeNBPosten „Körperschaftssteuer und Gewinnanteil des Bundes" wird in der Standard-GuV in seiner Zusammensetzung ausgewiesen.

\subsubsection{Besonderheiten der OeNB-GuV zum 31.12.1998}

Die OeNB weist keine Untergliederung der GuV-Posten „Nettozinsertrag“, „Nettoergebnis aus Finanzoperationen, Abschreibungen und Risikovorsorgen" und „Nettoergebnis aus Gebühren und Provisionen“ aus (vgl. Österreichische Nationalbank (2000), S. 140).

\subsubsection{Besonderheiten der OeNB-GuV zum 31.12.1999}

- Der OeNB-GuV-Posten „12 Netto-Ergebnis aus Monetären Einkünften“ entspricht dem Standard-Posten „12 Nettoergebnis aus Monetären Einkünften (vor EZB-Verlustanrechnung)“.

- Die Angaben zur Bruttofinanzierungsleistung zum Pool der Monetären Einkünfte bzw. zur Poolpartizipation werden von der OeNB nicht zur Verfügung gestellt, können aber mit Hilfe von EZB-Angaben errechnet werden (vgl. Kapitel IV.2. Abschnitt 1.2. und Kapitel V.3.1.1. Abschnitt 2.).

- Die OeNB weist in ihrer GuV den Finanzierungsbeitrag zum EZB-Verlust nicht explizit aus, erwähnt aber, daß sie in entsprechender Höhe Rückstellungen gebildet hat (vgl. Österreichische Nationalbank (2000), S. 137). Um in der Standard-GuV den OeNB-Finanzierungsbeitrag in Höhe von 6,6 Mio. EUR separat darstellen zu können, wird vom OeNB-GuVPosten „Sonstige Aufwendungen“ der entsprechende Betrag abgezogen.

\subsection{Banco de Portugal (BdP)}

\subsubsection{GuV-Struktur der BdP}

Die BdP übernimmt die von der EZB empfohlene GuV-Struktur (vgl. Banco de Portugal (2000a), S. 288).

\subsubsection{Besonderheiten der BdP-GuV zum 31.12.1998}

Der BdP-GuV-Posten „3 Net interest income“ ist nicht vollständig mit der Summe der ausgewiesenen Bruttozinseinkünfte bzw. -aufwendungen kompatibel. Diese Werte gehen unverändert in die Standard-GuV ein.

\subsubsection{Besonderheiten der BdP-GuV zum 31.12.1999}

- Der BdP-GuV-Posten „12 Net result of pooling of monetary income“ entspricht dem Standard-Posten „12 Nettoergebnis aus Monetären Einkünften (vor EZB-Verlustanrechnung)“.

- Die Angaben zur Bruttofinanzierungsleistung zum Pool der Monetären Einkünfte bzw. zur Poolpartizipation werden von der BdP nicht zur Verfügung gestellt, können aber mit Hilfe von EZB-Angaben errechnet werden (vgl. Kapitel IV.2. Abschnitt 1.2. und Kapitel V.3.1.1. Abschnitt 2.). 
- Die BdP weist in ihrer GuV den Finanzierungsbeitrag zum EZB-Verlust nicht explizit aus, verbucht ihn aber vermutlich unter dem Posten „19 Other expenses" (vgl. Banco de Portugal (2000a), S. 318). Um nun in der StandardGuV den BdP-Finanzierungsbeitrag (5,4 Mio. EUR) separat darstellen zu können, wird vom BdP-GuV-Posten „19 Other expenses“ der entsprechende Betrag abgezogen.

\subsection{Central Bank of Ireland (CBI)}

\subsubsection{GuV-Struktur der CBI}

Die CBI hält sich weitgehend an die von der EZB empfohlene GuV-Struktur (vgl. Central Bank of Ireland (2000c), S. 75). Dennoch sind folgende Anpassungen an die Standard-GuV erforderlich:

- Der CBI-GuV-Posten „Interest income“ und der Wert der BruttoZinseinkünfte, die die CBI aus der Verzinsung der auf die EZB übertragenen Währungsreserven erhält und in der CBI-GuV unter „Income from equity shares and participating interests" verbucht, werden zum Standardposten „1 Zinseinkünfte (brutto)" zusammengefaßt.

- Der CBI-GuV-Posten „Interest expense“ enthält nach CBI-Angaben auch den Netto-Beitrag zu den gepoolten Monetären Einkünften (ohne EZBVerlustanrechnung). Dieser wird in der Standard-GuV separat ausgewiesen. Die zugehörigen Bruttobeträge der Poolfinanzierung und Poolpartizipation werden von der CBI nicht angegeben, können aber mit Hilfe von EZBAngaben errechnet werden (vgl. Kapitel IV.2. Abschnitt 1.2. und Kapitel V.3.1.1. Abschnitt 2.).

- Nach CBI-Angaben enthält der Posten „Income from equitiy shares and participating interests" neben dem direkten Beitrag der CBI zur EZBVerlustfinanzierung auch die Zinserträge aus den an die EZB übertragenen Währungsreserven. Diese beiden Posten werden separat in der Standard-GuV ausgewiesen.

- Der CBI-GuV-Posten "Transfers to other reserves“ wird dem StandardPosten „20 Sonstige Aufwendungen“ zugeordnet.

- Der CBI-GuV-Posten „Surplus income payable to the exchequer" wird in der Standard-GuV auf die Posten „21.3 Interimsdividende vor dem 31.12. (des entsprechenden Jahres)" und „22 Jahresüberschuß" aufgeteilt.

2.10.2. Besonderheiten der CBI-GuV zum 31.12.1998 Keine.

2.10.3. Besonderheiten der CBI-GuV zum 31.12.1999

Keine. 


\subsection{Bank of Finland (BoF)}

\subsubsection{GuV-Struktur der BoF}

Die BoF hält sich weitgehend an die von der EZB empfohlene GuV-Struktur (vgl. Bank of Finland (2000b), S.84). Sie weist allerdings ihre „Erträge aus Gebühren und Provisionen“ und „Erträge aus Beteiligungen“ nicht extra aus, sondern verbucht diese zusammen mit anderen, nicht näher erläuterten Einkünften unter dem BoF-GuV-Posten „Other central banking income“ (vgl. Bank of Finland (2000b), S. 90). Folgende Anpassungen sind für die Standard$\mathrm{GuV}$ erforderlich:

- Die BoF-GuV-Posten „Realized gains related to foreign exchange rate movements" und Realized securities price differences" werden zum Standard-Posten „4 Realisierte Gewinne / Verluste aus Finanzoperationen“ zusammengefaßt,

- der BoF-GuV-Posten „Other central banking income“ wird dem StandardPosten „13 Sonstige Erträge“ zugeordnet,

- die BoF-GuV-Posten „Other expenses" und „Changes in provisions" werden zum Standard-Posten „20 Sonstige Aufwendungen“ zusammengefaßt,

- der BoF-GuV-Posten „Net share of monetary income“ entspricht dem Standard-Posten „12 Nettoergebnis aus Monetären Einkünften (vor EZBVerlustanrechnung)“.

\subsubsection{Besonderheiten der BoF-GuV zum 31.12.1998}

Die BoF weist ihre GuV nur auf Mio. EUR gerundete Beträge aus.

\subsubsection{Besonderheiten der BoF-GuV zum 31.12.1999}

- Die BoF weist ihre GuV nur auf Mio. EUR gerundete Beträge aus.

- Die Angaben zur Bruttofinanzierungsleistung zum Pool der Monetären Einkünfte bzw. zur Poolpartizipation werden von der BoF nicht zur Verfügung gestellt, können aber mit Hilfe von EZB-Angaben errechnet werden (vgl. Kapitel IV.2. Abschnitt 1.2. und Kapitel V.3.1.1. Abschnitt 2.). Die Netto-Partizipation der BoF am Pool der Monetären Einkünfte (ohne EZB-Verlustanrechnung) beläuft sich auf einen gerundeten Wert von null Mio. EUR (vgl. Bank of Finland (2000b), S. 84 und 90).

- Die BoF weist in ihrer GuV den Finanzierungsbeitrag zum EZB-Verlust nicht explizit aus. Um nun in der Standard-GuV den BoFFinanzierungsbeitrag in Höhe von 3,9 Mio. EUR separat darstellen zu können, wird vom BoF-GuV-Posten „Other expenses“ der entsprechende Betrag abgezogen. 


\subsection{Banque Centrale du Luxembourg (BCL)}

\subsubsection{GuV-Struktur der BCL}

Die BCL hält sich an die von der EZB empfohlene GuV-Struktur (vgl. Banque Centrale du Luxembourg (2000c), S.117).

2.12.2. Besonderheiten der BCL-GuV zum 31.12.1998 Keine.

\subsubsection{Besonderheiten der BCL-GuV zum 31.12.1999}

Der BCL-GuV-Posten „Résultat net provenant de la répartition du revenu monétaire" (1,3 Mio. EUR) entspricht dem Nettoaufwand der BCL aus Monetären Einkünften inklusive EZB-Verlustfinanzierung. Dieser Posten wird in der Standard-GuV getrennt nach dem Beitrag der BCL zur EZBVerlustfinanzierung (0,4 Mio. EUR) und dem Nettoergebnis aus Monetären Einkünften (ohne EZB-Verlustanrechnung) ausgewiesen. Die Angaben zur Bruttofinanzierungsleistung zum Pool der Monetären Einkünfte bzw. zur Poolpartizipation werden von der BCL nicht zur Verfügung gestellt, können aber mit Hilfe von EZB-Angaben errechnet werden (vgl. Kapitel IV.2. Abschnitt 1.2. und Kapitel V.3.1.1. Abschnitt 2.). 
Erläuterungen zur Tabelle 27 „Eurosystem-unabhängige Transaktionen der NZBen in Euro-Wertpapieren"

\section{A ) Generelle Bemerkungen:}

- Zu den Bilanzierungsgrundsätzen der NZBen vgl. European Central Bank (1998c) und die Erläuterungen zu den Tabellen 9 und 11 im Anhang.

- Die Zentralbanken Deutschlands, Finnlands und der Niederlande weisen ihre Angaben nur auf Mio. EUR gerundete Beträge aus.

\section{B) Analyse der Transaktionen der NZBen in 1999 mit Euro-Wertpapieren:}

1. Deutsche Bundesbank (BBk):

1.1.Euro-Wertpapiere, die in der BBk-Bilanz als „Wertpapiere in Euro von Ansässigen im Euro-Währungsgebiet" verbucht werden:

Die Bundesbank hält weder zum 1.1.1999 noch zum 31.12.1999 entsprechende Wertpapiere (vgl. Deutsche Bundesbank (2000a), S. 174).

1.2.Euro-Wertpapiere, die in der BBk-Bilanz als „Forderungen in Euro gegenüber Ansässigen außerhalb des Euro-Währungsgebiets" verbucht werden:

Zum 1.1.1999 besteht der BBk-Aktivposten „Forderungen in Euro gegenüber Ansässigen außerhalb des Euro-Währungsgebiets" in Höhe von 128 Mio. EUR ausschließlich aus Krediten der Bundesbank an die Weltbank (vgl. Deutsche Bundesbank (1999d), S. 204). Auch zum 31.12.1999 kann man davon ausgehen, daß der BBk-Aktivposten „Forderungen in Euro gegenüber Ansässigen außerhalb des EuroWährungsgebiets" in Höhe von 9149 Mio. EUR keine Wertpapiere enthält, da ein Zukauf von Wertpapieren der seit Jahren zu beobachtenden Praxis der Bundesbank widerspräche, sich sukzessive von allen in inländischer Währung denominierten Wertpapieren zu trennen (vgl. Deutsche Bundesbank (1997b), S. 178). Zudem verweist die Bundesbank bei der Erläuterung zu diesem Posten rein auf ihre TARGET-Forderungen gegen die Pre-In-NZBen (vgl. Deutsche Bundesbank (2000a), S. 183). Da jedoch nicht gänzlich auszuschließen ist, daß dieser Posten auch Euro-Wertpapiere beinhaltet, wird der Bilanzwert dieses Postens in Tabelle 27 als Obergrenze für gegebenenfalls hier verbuchte Euro-Wertpapiere angegeben. Dennoch wird der Umfang der hier verbuchten Wertpapierbestände und damit auch das Transaktionsvolumen auf null geschätzt.

1.3.Euro-Wertpapiere, die in der BBk-Bilanz unter dem Posten „Finanzanlagen“" verbucht werden: 
Die Finanzaktiva der Bundesbank enthalten keine Wertpapiere, da diese sowohl zum 1.1.1999 als auch zum 31.12.1999 ausschließlich aus den Beteiligungen der Bundesbank an der Liquiditäts- und Konsortialbank $\mathrm{GmbH}$, an der Bank für Internationalen Zahlungsausgleich und an der Genossenschaft SWIFT bestehen (vgl. Deutsche Bundesbank (1999d), S. 205 f. und Deutsche Bundesbank (2000a), S. 193).

\section{Banca d'Italia (BdI):}

2.1.Euro-Wertpapiere, die in der BdI-Bilanz als „Securities issued by euroarea residents (other than shares)" verbucht werden:

Nach Angaben der BdI ist in 1999 die Abnahme dieser Position um 949,3 Mio. EUR hauptsächlich auf eine Umbuchung zu den Finanzaktiva der BdI zurückzuführen, so daß die tatsächlichen transaktionsbedingten Abgänge dieses Postens sehr klein sein dürften (vgl. Banca d'Italia (2000a), S. 273).

2.2.Euro-Wertpapiere, die in der BdI-Bilanz als „Claims on non-euro-area residents" verbucht werden:

Der BdI-Bilanzposten „Claims on non-euro-area residents“ wird zum 31.12.1998 von der BdI wegen mangelnder Relevanz nicht explizit ausgewiesen. Ende 1999 bestand dieser Posten in Höhe von 1214,2 Mio. EUR gänzlich aus TARGET-Forderungen an Pre-In-NZBen (vgl. Banca d'Italia (2000a), S. 272).

2.3.Euro-Wertpapiere, die in der BdI-Bilanz als „Investments of reserves and provisions (including shares) - Government securities“ und „Investments of reserves and provisions (including shares) - Other secutities" ausgewiesen werden:

Hier verbuchte Wertpapiere werden zu Marktpreisen bilanziert (vgl. Banca d'Italia (2000a), S. 266). Die BdI gibt jeweils den Wert ihrer als Finanzaktiva geearmarkten Wertpapiere an: Ende 1998 hielt die BdI Wertpapiere in Höhe von 20509,4 Mio. EUR, die sich aus Regierungspapieren (20301,8 Mio. EUR) und anderen Wertpapieren (207,6 Mio. EUR) zusammensetzten. Ende 1999 hielt die BdI Wertpapiere in Höhe von 18174,1 Mio. EUR, die sich aus Regierungspapieren (17787,4 Mio. EUR) und anderen Wertpapieren (386,7 Mio. EUR) zusammensetzten (vgl. Banca d'Italia (2000a), S. 269). Da die BdI die Denominierung der ,anderen Wertpapiere“ nicht ausweist, sind die in der Tabelle 27 notierten Werte als Obergrenzen für die als Finanzaktiva geearmarkten Euro-Wertpapiere im Bestand der BdI zu betrachten. Wie bereits erwähnt, enthält der für 1999 angegebene Wert auch die vom Bilanzposten „Wertpapiere in Euro von Ansässigen im 
Euro-Währungsgebiet“ zugebuchten Beträge in Höhe von ca. 949,3 Mio. EUR, so daß die Differenz der ausgewiesenen Jahresendstände in Höhe von -2335,3 Mio. EUR nur als Ausgangswert zu einer näheren Abschätzung der Euro-Wertpapierverkäufe im Rahmen des Finanzaktivamanagements der BdI dienen kann. Ohne die zugebuchten 949,3 Mio. EUR würde die entsprechende Differenz der Bilanzwerte -3284,6 Mio. EUR betragen. Berücksichtigt man weiterhin, daß die italienischen Regierungspapiere in 1999 Kursrückgänge (vgl. International Monetary Fund (2000b), S. 418f.) verzeichneten, dann kann der umbuchungsbereinigte Bilanzdifferenzwert jedoch nur als Obergrenze für die in 1999 von der BdI durchgeführten Verkäufe interpretiert werden. Die tatsächlichen Euro-Wertpapierverkäufe dürften folglich weniger als der umbuchungsbereinigte Bilanzdifferenzwert betragen. Dennoch kann man davon ausgehen, daß die BdI (als Finanzaktiva geearmarkte) EuroWertpapiere in einer bedeutenden Größenordnung veräußert hat, da sie die Höhe der in 1999 durchgeführten Nettoverkäufe ihrer gesamten Finanzaktiva (Wertpapiere und Beteiligungen) auf 3562 Mio. EUR beziffert (vgl. Banca d'Italia (2000a), S. 273 f.).

\section{Belgische Nationalbank (NBB):}

3.1.Euro-Wertpapiere, die in der NBB-Bilanz als "Securities of euro area residents denominated in euro" verbucht werden:

Die Abnahme des NBB-Aktivpostens „Securities of euro area residents denominated in euro" in Höhe von 96,3 Mio. EUR gegenüber der Eröffnungsbilanz ist nach NBB-Angaben auf den starken Anstieg der Zinsen am Euro-Bondsmarkt zurückzuführen (vgl. Belgische Nationalbank (2000b), S. 80). Der Transaktionswert der von der NBB durchgeführten Verkäufe ist deshalb deutlich niedriger als die Differenz der ausgewiesenen Jahresendstände.

3.2.Euro-Wertpapiere, die in der NBB-Bilanz unter dem Posten „Claims on non-euro area residents denominated in euro" verbucht werden:

Die von der NBB zum 1.1.1999 in Höhe von 927,6 Mio. EUR und zum 31.12.1999 im Betrag von 255,9 Mio. EUR ausgewiesenen „Forderungen in Euro gegenüber Ansässigen außerhalb des Euro-Währungsgebiets“ enthalten mit großer Wahrscheinlichkeit keine Euro-Wertpapiere. So verweist die NBB in ihren Kommentaren zu diesem Bilanzposten ausschließlich auf Termineinlagen und TARGET-Forderungen gegenüber Pre-In-NZBen (vgl. Belgische Nationalbank (2000b), S. 79 f.). Zudem spricht sie in ihren Notes zum (oben erwähnten) Bilanzposten „Securities of euro area residents denominated in euro" explizit von 
ihrem „Bank's portfolio of euro securities“ (Belgische Nationalbank (2000b), S. 80). Dennoch kann nicht ausgeschlossen werden, daß der NBB-Bilanzposten „Claims on non-euro area residents denominated in euro" nicht auch Euro-Wertpapiere enthält. Deshalb sind die Bilanzwerte zum 1.1.1999 und 31.12.1999 in Tabelle 27 als Obergrenzen für die Euro-Wertpapiere angegeben. Aufgrund obiger Überlegungen ist jedoch davon auszugehen, daß das hier verbuchte Transaktionsvolumen in EuroWertpapieren null ist.

3.3.Euro-Wertpapiere, die in der NBB-Bilanz unter dem Posten „Other financial assets" verbucht werden:

Die Finanzaktiva der NBB entsprechen den investierten Reserven (inkl. Kapital) der NBB (,Statutory investments“ bzw. „Other financial assets“) und setzen sich aus Staatsanleihen, kurzfristigen Wertpapieren, Beteiligungen der $\mathrm{NBB}$ an staatlichen Finanzinstitutionen und an der Bank für Internationalen Zahlungsausgleich (BIZ) sowie anderen Wertpapieren zusammen (vgl. Belgische Nationalbank (2000b), S. 70 und 81). Nähere Angaben macht die NBB nicht, so daß die diesbezüglich in der Tabelle 27 angegebenen Werte jeweils als Obergrenze für die geearmarkten Euro-Wertpapiere interpretiert werden müssen. Da die NBB ihre Finanzaktiva entgegen der EZB-Empfehlung zu Anschaffungskosten und nicht zu Marktpreisen bewertet (vgl. Belgische Nationalbank (2000b), S. 63), sind entsprechende Änderungen im Bilanzausweis auf Transaktionen zurückzuführen. Deshalb fanden auch Euro-Wertpapierverkäufe in 1999 in Höhe von nur maximal 1 Mio. EUR statt. Dies trifft zumindest dann zu, wenn man unterstellt, daß die NBB von Umschichtungen innerhalb ihres Finanzaktiva-Portfolios absah.

\section{Banco de España (BdE):}

4.1.Euro-Wertpapiere, die in der BdE-Bilanz als „Securities of euro area residents denominated in euro" verbucht werden:

Die BdE weist keine „Securities of euro area residents denominated in euro" aus (vgl. Banco de España (2000), S. 116).

4.2.Euro-Wertpapiere, die in der BdE-Bilanz als "Claims on non-euro area residents denominated in euro" verbucht werden:

Die BdE hielt Ende 1998 „Forderungen in Euro gegenüber Ansässigen außerhalb des Euro-Währungsgebiets" in Höhe von 43,08 Mio. EUR und Ende 1999 im Betrag von 4118,98 Mio. EUR (vgl. Banco de España (2000), S. 116). Dabei setzten sich diese Forderungen Ende 1999 aus TARGET-Forderungen an Pre-In-NZBen in Höhe von 4080,55 Mio. EUR und „Forderungen aus bilateralen Abkommen“ in Höhe von 38,43 
Mio. EUR zusammen. Da letztere mit großer Wahrscheinlichkeit Einlagen aus Korrespondenzbankbeziehungen sein dürften, kann man davon ausgehen, daß die BdE zum 31.12.1999 unter diesem Posten keine Euro-Wertpapiere verbucht hat. Da dies jedoch nicht mit Sicherheit behauptet werden kann, ist der angesprochene Wert (38,4 Mio. EUR) als Obergrenze für Euro-Wertpapiere angegeben. Desweiteren dürften auch die zum 31.12.1998 ausgewiesenen Euro-Forderungen der BdE gegenüber Ansässigen außerhalb des Euro-Währungsgebiets in Höhe von 43,08 Mio. EUR Einlagen aus Korrespondezbankbeziehungen darstellen und keine Euro-Wertpapiere enthalten. Da dies jedoch nicht mit Sicherheit behauptet werden kann, ist der zum 31.12.1998 ausgewiesene Bilanzwert des BdE-Postens "Claims on non-euro area residents denominated in euro" als Obergrenze für die gegebenenfalls hier EuroWertpapiere angegeben.

4.3.Euro-Wertpapiere, die in der BdE-Bilanz unter dem Posten „Other financial assets" verbucht werden:

Die Banco de España bilanziert ihre als Finanzaktiva geearmarkten Wertpapiere zu Marktpreisen (vgl. Banco de España (2000), S. 119 f.). Die Finanzaktiva der BdE bestanden sowohl Ende 1998 als auch Ende 1999 zu $99 \%$ aus mittel- und langfristigen Staatsanleihen (vgl. Banco de España (1999), S. 112 und Banco de España (2000), S. 125). Die Abnahme dieses Postens ist nach BdE-Angaben hauptsächlich auf unrealisierte Bewertungsverluste aufgrund steigender Zinsen zurückzuführen (vgl. Banco de España (2000), S. 125). Dies bedeutet, daß der Transaktionswert der von der BdE durchgeführten Verkäufe der unter diesem Posten ausgewiesenen Euro-Wertpapiere deutlich niedriger war, als die Differenz der Jahresendstände zeigt.

\section{Banque Centrale du Luxembourg (BCL):}

5.1.Euro-Wertpapiere, die in der BCL-Bilanz als „Titres en euro émis par des résidents de la zone euro" verbucht werden:

Die Differenz der ausgewiesenen Jahresendwerte in Höhe von 182,9 Mio. EUR kann als brauchbare Näherung für die tatsächlichen Käufe der $\mathrm{BCL}$ gesehen werden, da etwaige Kurswertänderungen des am Ende des Jahres $1998 \mathrm{zu}$ Buche stehenden Bestands an Euro-Wertpapieren von gerade mal 16,5 Mio. EUR kaum zu Verzerrungen führen.

5.2. Euro-Wertpapiere, die in der BCL-Bilanz als „Créances en euro sur des non-résidents de la zone euro" verbucht werden:

Die BCL hielt zum 31.12.1998 keine „Forderungen in Euro gegenüber Ansässigen außerhalb des Euro-Währungsgebiets“. Hinsichtlich der Ende 
1999 ausgewiesenen Forderungen in Höhe von 720,6 Mio. EUR gibt die $\mathrm{BCL}$ an, daß dieser Posten TARGET-Forderungen gegenüber Pre-InNZBen und Giroeinlagen bei internationalen Organisationen enthält (vgl. Banque Centrale du Luxembourg (2000c), S. 120). Die Existenz von hier verbuchten Euro-Wertpapieren wird nicht erwähnt, ist allerdings auch nicht gänzlich auszuschließen. Deshalb wird in Tabelle 27 für die gegebenenfalls hier verbuchten Euro-Titel als Obergrenze 720,6 Mio. EUR angesetzt, wenngleich davon auszugehen ist, daß dieser Posten keine derartigen Titel enthält.

5.3.Euro-Wertpapiere, die in der BCL-Bilanz unter dem Posten „Autres actifs financiers" verbucht werden:

Hier verbuchte Wertpapiere werden zu Marktpreisen bilanziert (vgl. Banque Centrale du Luxembourg (2000c), S. 122). Die BCL gibt die Höhe des geearmarkten Wertpapierportfolios mit 431,5 Mio. EUR an, äußert sich aber nicht, ob dieses Portfolio ausschließlich aus EuroAnlagen besteht (vgl. Banque Centrale du Luxembourg (2000c), S. 122). Deshalb wird der entsprechende Wert als Obergrenze für die EuroWertpapieranlagen ausgewiesen. Die Zunahme dieses Postens um 431,5 Mio. EUR ist rein mengenbedingt, da die BCL Ende 1998 keine entsprechenden Wertpapiere ausweist.

\section{Central Bank of Ireland (CBI):}

6.1.Euro-Wertpapiere, die in der CBI-Bilanz als „Securities of euro area residents in euro" verbucht werden:

Die von der CBI ausgewiesenen "Securities of euro area residents in euro" sind Wertpapiere mit einer Laufzeit bis zu fünf Jahren und bestehen zum Teil aus ehemaligen DEM-Währungsreserven (vgl. Central Bank of Ireland (2000c), S. 89). Da in 1999 neben deutschen Treasury bills und deutschen Staatsanleihen auch die Anleihen aller anderen EWU-Staaten einen deutlichen Anstieg ihrer Umlaufsrenditen verzeichneten (vgl. Deutsche Bundesbank (2000d), S. 3, Central Bank of Ireland (2000a), S. 22 f. und International Monetary Fund (2000b)) und der Anstieg derselben entsprechende Kurswertverluste implizierte, kann man davon ausgehen, daß das tatsächliche Volumen an EuroWertpapierkäufen durch die CBI in 1999 deutlich höher war als die reine Differenz der ausgewiesenen Bilanzendstände der Jahre 1998 und 1999.

6.2.Euro-Wertpapiere, die in der CBI-Bilanz als „Claims on non-euro area residents in euro" verbucht werden:

Nach CBI-Angaben besteht der Bilanzposten „Claims on non-euro area residents in euro" sowohl zum 31.12.1998 als auch Ende 1999 
ausschließlich aus Übernachteinlagen. Er enthält also keine EuroWertpapiere (vgl. Central Bank of Ireland (2000c), S. 88).

6.3.Euro-Wertpapiere, die in der CBI-Bilanz unter "Other assets - other" ausgewiesen werden:

Die CBI weist alle Wertpapiere in ihrem Bestand zu Marktpreisen aus (vgl. Central Bank of Ireland (2000c), S.74). Die CBI weicht in ihrem Bilanzausweis von der Struktur, die die EZB empfiehlt, insofern ab, da sie den Sammelposten „Andere Aktiva“ (Other Assets) in einer anderen, aber nicht minder detaillierteren Zusammenstellung untergliedert. Im Finanzausweis der CBI finden sich jedoch keine direkten Hinweise auf Euro-Wertpapiere, die als Finanzaktiva geearmarkt sind (vgl. Central Bank of Ireland (2000c), S. 77 und 90). Allerdings weist sie einen Posten „Other assets - other" (Ende 1998: 17,5 Mio. EUR, Ende 1999: 40,3 Mio. EUR) aus, der Euro-Wertpapiere enthalten könnte (vgl. Central Bank of Ireland (2000c), S. 77). Die entsprechenden Werte werden in die Tabelle 27 als mögliche Obergrenzen für die in Euro denominierten, als Finanzaktiva geearmarkten Wertpapiere der CBI aufgenommen. Die Veränderung dieses Postens läßt jedoch keinen Schluß hinsichtlich durchgeführter Wertpapierkäufe zu.

\section{De Nederlandsche Bank (DNB):}

7.1.Euro-Wertpapiere, die in der DNB-Bilanz als „Securities of euro area residents denominated in euro" verbucht werden:

Die unter diesem Posten verbuchten Wertpapiere bestehen hauptsächlich aus Teilen des früheren DEM-Portfolios der DNB (vgl. De Nederlandsche Bank (1999), S. 213 und De Nederlandsche Bank (2000b), S. 190). Da sowohl bei langfristigen Staatsanleihen Deutschlands als auch bei deutschen kurzfristigen Treasury bills in 1999 die Umlaufsrenditen gestiegen sind (vgl. International Monetary Fund (2000b), S. 568 f.), was entsprechende Kursverluste impliziert, ist die ausgewiesene Differenz der Jahresendstände in Höhe von 161 Mio. EUR als Untergrenze für die von der DNB getätigten Euro-Wertpapierkäufe anzusetzen.

7.2.Euro-Wertpapiere, die in der DNB-Bilanz als „Claims on non-euro area residents denominatd in euro" verbucht werden:

Die DNB hielt Euro-Wertpapiere, die sie unter dem Bilanzposten „Claims on non-euro area residents denominatd in euro - Fixed-income securities" ausweist, zum 1.1.1999 in Höhe von 171 Mio. EUR und Ende 1999 in Höhe von 145 Mio. EUR (vgl. De Nederlandsche Bank (1999), S. 189). Zur Frage, ob die Abnahme dieses Postens kursbedingt ist oder 
auf Verkäufe der DNB zurückzuführen ist, macht die DNB keine Angaben. Desweiteren gibt sie im Gegensatz $\mathrm{zu}$ den anderen Bilanzposten auch nicht an, in welche Wertpapiere sie investiert hat. Deshalb kann auch keine Schätzung vorgenommen werden, ob die Abnahme des DNB-Bilanzposten "Claims on non-euro area residents denominated in euro - Fixed-income securities" in Höhe von 26 Mio. EUR kurs- oder transaktionsbedingt war.

7.3.Euro-Wertpapiere, die in der DNB-Bilanz unter dem Posten „Other financial assets" verbucht werden:

Hier verbuchte Wertpapiere werden zu Marktpreisen bilanziert (vgl. De Nederlandsche Bank (2000b), S. 185 und 198). Die unter diesem Posten verbuchten Wertpapiere bestehen ebenfalls aus Teilen des früheren DEM-Portfolio der DNB (vgl. De Nederlandsche Bank (1999), S. 213 und De Nederlandsche Bank (2000b), S. 190). Dieses verzeichnete - wie bereits oben erwähnt - in 1999 deutliche Kurswertverluste. Berücksichtigt man weiterhin, daß die als Finanzaktiva geearmarkten Euro-Wertpapiere grundsätzlich längerfristige Papiere sind und sämtliche Bonds der EWU-Staaten in 1999 ebenfalls Kursverluste hinnehmen mußten, ist die ausgewiesene Differenz der Jahresendstände in Höhe von 203 Mio. EUR eher als Untergrenze für die von der DNB getätigten Euro-Wertpapierkäufe anzusehen.

\section{8. Österreichische Nationalbank (OeNB):}

8.1.Euro-Wertpapiere, die in der OeNB-Bilanz als „Wertpapiere in Euro von Ansässigen im Euro-Währungsgebiet" verbucht werden:

Die OeNB weist neben den Jahresendständen auch explizit die transaktionsbedingten Veränderungen der „Wertpapiere in Euro von Ansässigen im Euro-Währungsgebiet" des Jahres 1999 in Höhe von 18,8 Mio. EUR aus (vgl. Österreichische Nationalbank (2000), S. 130).

8.2.Euro-Wertpapiere, die in der OeNB-Bilanz als „Forderungen in Euro an Ansässige außerhalb des Euro-Währungsgebiets" verbucht werden:

Die OeNB gibt an, daß ihr Bilanzposten „Forderungen in Euro an Ansässige außerhalb des Euro-Währungsgebiets" zum 1.1.1999 in Höhe von 1618,2 Mio. EUR ausschließlich aus „Wertpapier- und sonstigen Veranlagungen" bestand (vgl. Österreichische Nationalbank (2000), S. 128). Ende 1999 enthielt dieser Posten in Höhe von 3351,5 Mio. EUR neben TARGET-Forderungen an Pre-In-NZBen (1661,8 Mio. EUR) auch „Wertpapier- und sonstigen Veranlagungen“ im Betrag von 1689,7 Mio. EUR (vgl. Österreichische Nationalbank (2000), S. 128). Da die OeNB aber die konkrete Höhe der Euro-Wertpapiere nicht angibt, ist der 
jeweilige Sammelposten „Wertpapier- und sonstigen Veranlagungen“ als Obergrenze für die hier verbuchten Euro-Wertpapiere zu interpretieren. Ob die Zunahme dieses Postens um 71,5 Mio. EUR kursbedingt war oder durch Zukäufe von Euro-Wertpapieren bzw. „sonstigen Veranlagungen“ erzielt wurde, gibt die OeNB nicht an. Aussagen hinsichtlich des Transaktionsvolumens sind folglich nicht möglich.

8.3.Euro-Wertpapiere, die in der OeNB-Bilanz unter dem Posten „Sonstiges Finanzanlagevermögen" verbucht werden:

Die hier verbuchten Wertpapiere sind zu Marktpreisen bewertet (vgl. Österreichische Nationalbank (2000), S. 121). Die OeNB gibt die Höhe ihrer als Finanzaktiva veranlagten Wertpapiere zum 1.1.1999 in Höhe von 1543,9 Mio. EUR und zum 31.12.1999 im Betrag von 1681,2 Mio. EUR explizit an (vgl. Österreichische Nationalbank (2000), S. 132). Allerdings differenziert sie hierbei nicht zwischen Euro-Wertpapieren und in Auslandswährung denominierten Titeln, so daß die ausgewiesenen Werte als Obergrenzen für Euro-Wertpapiere zu interpretieren sind. Das Transaktionsvolumen der hier erfaßten Wertpapiere, läßt sich auf 69,4 Mio. EUR beziffern, da der Zunahme dieses Bilanzunterpostens um 137,3 Mio. EUR nach OeNB-Angaben unrealisierte NettoBewertungsgewinne in Höhe von 67,9 Mio. EUR gegenüberstanden (vgl. Österreichische Nationalbank (2000), S. 132). Der so errechnete Differenzwert in Höhe von 69,4 Mio. EUR bildet gleichzeitig die Obergrenze für die geschätzten Euro-Wertpapierkäufe, zumindest dann, wenn man unterstellt, daß die OeNB keine Portfolioumschichtungen zwischen Fremdwährungs- und Euro-Titeln vorgenommen hat.

\section{Banque de France (BdF):}

9.1. Euro-Wertpapiere, die in der BdF-Bilanz als „Euro-denominated securities" verbucht werden:

Die unter diesem Posten verbuchten Euro-Wertpapiere der BdF bestehen zu fast 100 Prozent aus Staatspapieren, wobei wiederum knapp 60 Prozent in festverzinslichen Wertpapieren mit einer Laufzeit von weniger als drei Monaten angelegt sind (vgl. Banque de France (2000c), S. 256) . Allerdings verzichtet die $\mathrm{BdF}$ darauf anzugeben, in wie fern die Abnahme des BdF-Postens „Euro-denominated securities“ um 460,3 Mio. EUR gegenüber 1998 kurs- oder transaktionsbedingt ist (vgl. Banque de France (2000c), S. 248). Da weiterhin die BdF keine Angaben macht, welche kurzfristigen Titel sie in ihrem Euro-Wertpapierportfolio hält, können wegen der in 1999 unterschiedlichen Zinsentwicklungen für Treasury bills in den einzelnen EWU-Staaten (z.B. Anstieg der Treasury bill-Zinsen in 
Deutschland und Rückgang in Frankreich (vgl. International Monetary Fund (2000b)) auch keine Schätzungen bezüglich der von der BdF durchgeführten Wertpapiertransaktionen durchgeführt werden.

9.2. Euro-Wertpapiere, die in der BdF-Bilanz als „Euro-denominated claims on non-euro area residents" verbucht werden:

Die BdF gibt an, daß der Bilanzposten „Euro-denominated claims on noneuro area residents" vor allem aus TARGET-Forderungen gegen Pre-InNZBen besteht, aber auch Forderungen gegen Geschäftsbanken mit Sitz außerhalb des Euroraums beinhaltet (vgl. Banque de France (2000c), S. 247). Euro-denominierte Wertpapiere enthält dieser Posten folglich nicht.

9.3. Euro-Wertpapiere, die in der BdF-Bilanz unter „Equity interests and portfolio securities (other than interest in the ECB) - Long term equity holdings" verbucht werden:

Die BdF weicht bei ihrem Bilanzausweis teilweise von der von der EZB empfohlenen Bilanzstruktur ab. So verbucht sie die als Finanzaktiva geearmarkten BdF-Beteiligungen und Wertpapiere unter dem Posten A 12.2 „Equity interests and portfolio securities (other than interest in the ECB) - Long term equity holdings" (vgl. Banque de France (2000c), S. 236 und S. 258). Allerdings bleibt unklar, ob die erwähnten „Long term equity holdings" (bzw. "portfolio securities") ausschließlich in Euro denominiert sind, so daß die Jahresendstände auch nur als Obergrenze für Euro-Wertpapiere interpretiert werden können. Desweiteren macht die $\mathrm{BdF}$ keine näheren Angaben, ob die Zunahme dieses Postens gegenüber 1998 um 11,9 Mio. EUR transaktions- oder kursbedingt war. Allerdings erwähnt sie, daß der Veränderungswert auch Umbuchungen zu anderen Posten enthält (vgl. Banque de France (2000c), S. 258). Nicht zuletzt deswegen können auch hier keine Folgerungen bezüglich möglicher Wertpapiertransaktionen gezogen werden.

\section{Bank of Finland (BoF):}

10.1. Euro-Wertpapiere, die in der Standard-Bilanz (vgl. Tabellen 9 und 11 dieser Arbeit) als „Wertpapiere in Euro von Ansässigen im EuroWährungsgebiet" verbucht werden:

Die BoF weist weder zum 31.12.1998 noch Ende 1999 einen entsprechenden Bilanzposten aus (vgl. Bank of Finland (2000b), S. 82).

10.2. Euro-Wertpapiere, die in der BoF-Bilanz als „Claims on non-euro area residents denominated in euro" verbucht werden:

Die BoF hielt Ende 1998 keine „Forderungen in Euro gegenüber Ansässigen außerhalb des Euro-Währungsgebiets“ und damit auch keine hier zu verbuchenden Euro-Wertpapiere (vgl. Bank of Finland (2000b), S. 
82). Ende 1999 war der Wert solcher Papiere, wenn überhaupt vorhanden, sehr gering, da nach BoF-Angaben der genannte BoF-Aktivposten „hauptsächlich aus Einlagen bei Pre-In-NZBen besteht" (Bank of Finland (2000b), S. 88). Deshalb dürfte auch der Transaktionswert möglicher Zukäufe von Euro-Wertpapieren, falls überhaupt vorhanden, sehr gering gewesen sein.

10.3. Euro-Wertpapiere, die in der Standard-Bilanz (vgl. Tabellen 9 und 11 dieser Arbeit) als Finanzaktiva ausgewiesen werden:

Die BoF besitzt entsprechende Wertpapiere, die sie als Finanzaktiva earmarkt und zu Marktpreisen bewertet (vgl. Bank of Finland (2000b), S. 87 und 88). Die BoF weist jedoch weder den Wert ihrer als Finanzaktiva geearmarkten Wertpapiere noch den Gesamtwert ihrer Finanzaktiva explizit aus. Der von der BoF angegebene Posten „Other Assets“, der neben dem Münzbestand, Sachanlagevermögen, Neubewertungsposten aus außerbilanziellen Geschäften, Rechnungsabgrenzungsposten und anderen Aktiva auch die Finanzaktiva der BoF enthält, beläuft sich Ende 1998 auf 612 Mio. EUR und Ende 1999 auf 638 Mio. EUR. Zieht man jeweils von diesen Werten den von der BoF gehaltenen Sicherheitsbestand an Münzen (1998: 21 Mio. EUR, 1999: 11,6 Mio. EUR) und die ausgewiesenen Beteiligungen der BoF (1998: 30,4 Mio. EUR, 1999: 26,0 Mio. EUR) ab, ergibt sich für Ende 1998 eine Höchstgrenze der in Form von Euro-Wertpapieren angelegten Finanzaktiva in Höhe von 232,8 Mio. EUR und für Ende 1999 in Höhe von 600,4 Mio. EUR (vgl. Bank of Finland (2000b), S. 58 und 85). Dennoch dürfte die tatsächliche Höhe dieser Titel vor allem wegen des hier ebenfalls erfaßten Sachanlagevermögens deutlich unterhalb dieser Grenzen liegen. Die Differenz der jeweiligen Höchstgrenzen beträgt 39,8 Mio. EUR. Dieser Veränderungswert läßt jedoch hinsichtlich der in 1999 durchgeführten Euro-Wertpapiertransaktionen keine Aussagen zu.

\section{Banco de Portugal (BdP)}

11.1.Euro-Wertpapiere, die in der BdP-Bilanz als „Securities of euro area residents denominated in euro" verbucht werden:

Die BdP weist ihre als „Wertpapiere in Euro von Ansässigen im EuroWährungsgebiet" verbuchten Bestände an Euro-Wertpapieren zum 1.1.1999 in Höhe von 3753,2 Mio. EUR und zum 31.12.1999 im Betrag von 3153,7 Mio. EUR explizit aus (vgl. Banco de Portugal (2000a), S. 303). Diese Titel bestehen aus Treasury bills (21,8 Prozent), Staatsanleihen (36,3 Prozent), anderen Anleihen (0,2 Prozent) und anderen Wertpapiere (41,7 Prozent). Da zwar die Staatsanleihen aller 
EWU-Staaten in 1999 generell Kursverluste erlitten, die Zinsentwicklung bei den Treasury bills der EWU-Staaten jedoch uneinheitlich war (vgl. International Monetary Fund (2000b)) und auch die Kursentwicklungen der anderen Anlageformen unbekannt bleiben, können keine Aussagen hinsichtlich des Transaktionswerts der in 1999 von der BdP veräußerten Euro-Wertpapiere getroffen werden.

11.2.Euro-Wertpapiere, die in der BdP-Bilanz als „Claims on non-euro area residents denominated in euro" verbucht werden:

Die BdP weist ihre als „Claims on non-euro area residents denominated in euro" verbuchten Bestände an Euro-Wertpapieren zum 1.1.1999 in Höhe von 2297,6 Mio. EUR und zum 31.12.1999 im Betrag von 2680,6 Mio. EUR explizit aus (vgl. Banco de Portugal (2000a), S. 303). Da diese überwiegend in kurzfristigen Wertpapieren internationaler Finanzorganisationen investiert waren, hier aber keine Aussagen über etwaige Kursgewinne bzw. -verluste dieser Titel möglich sind, ist trotz dieser detaillierten Angaben eine Schätzung der von der BdP durchgeführten Kauf- bzw. Verkaufstransaktionen nicht möglich.

11.3.Euro-Wertpapiere, die in der BdP-Bilanz unter dem Posten „Other financial assets" verbucht werden

Die BdP weist ihre als „Other financial assets“ verbuchten Bestände an Euro-Wertpapieren zum 1.1.1999 und zum 31.12.1999 in Höhe von jeweils 72,462 Mio. EUR explizit aus (vgl. Banco de Portugal (2000a), S. 308). Dies Tatsache, daß sich der Betrag dieses Postens gegenüber der Eröffnungsbilanz nicht verändert hat, deutet zum einen darauf hin, daß diese Werte zu historischen Anschaffungskosten bilanziert werden und zum anderen, daß die BdP keine Transaktionen vorgenommen hat. 
Erläuterungen zu Tabelle 29: Unternehmensbeteiligungen der NZBen zum 31.12.1999 (keine EZB-, IWF- und BIZ-Beteiligungen)

\section{Allgemeine Bemerkung:}

Der Einfachheit halber soll in diesem Abschnitt der Begriff „Unternehmensbeteiligungen“ alle NZB-Beteiligungen außer die Beteiligungen der NZBen an der EZB, dem IWF und der BIZ erfassen.

\section{Analyse der NZB-Unternehmesbeteiligungen}

1. Deutsche Bundesbank (BBk): Die Bundesbank gibt nur den Gesamtwert ihrer Beteiligungen, die sich aus den Anteilen an der Genossenschaft SWIFT, der Liquiditäts- und Konsortialbank (LiKo) und der Bank für Internationalen Zahlungsausgleich (BIZ) zusammensetzen, in Höhe von 51 Mio. EUR bekannt (vgl. Deutsche Bundesbank (2000a), S. 186). Deshalb kann der in Tabelle 29 ausgewiesene Betrag nur als Obergrenze für die Unternehmensbeteiligungen der Bundesbank (LiKo und SWIFT) gesehen werden. Der tatsächliche Wert dürfte deutlich unterhalb von 51 Mio. EUR liegen. Bezüglich der Erträge aus ihren Beteiligungen (BIZ, Liko, SWIFT) gibt die Bundesbank nur einen Gesamtwert in Höhe von 21 Mio. EUR an (vgl. Deutsche Bundesbank (2000a), S. 193). Allerdings lassen sich zusätzliche Erkenntnisse hinsichtlich der Mindesthöhe derjenigen Erträge gewinnen, die der Bundesbank aus ihren Unternehmensbeteiligungen (LiKo und SWIFT) zufließen. Errechnet man die in 1999 zu erhaltende BIZDividende, die sich ergeben würde, wenn die gesamten Finanzaktiva der Bundesbank in Höhe von 51 Mio. EUR allein aus der BIZ-Beteiligung bestünden, ergibt sich ein Betrag in Höhe von 8,4 Mio. EUR (vgl. hierzu die Ausführungen zu NZB-Beteiligungen an der BIZ und Tabelle $23 \mathrm{im}$ Text). Der so errechnete Wert entspricht gleichzeitig der Höhe der Mindesterträge aus den Beteiligungen der Bundesbank an den genannten Unternehmen (LiKo und SWIFT).

2. Bank of Finland (BoF): Die BoF weist den Bilanzwert ihrer Unternehmesbeteiligungen im einzelnen aus (vgl. Bank of Finland (2000b), S. 85), hinsichtlich der Erträge aus diesen Beteiligungen macht sie jedoch keinerlei Angaben.

3. Central Bank of Ireland (CBI): Die CBI gibt an, daß sie in 1998 zwei Firmen "The Investor Compensation Company Limited" und "Investor Compensation Administration Limited". gegründet hat (vgl. Central Bank of 
Ireland (1999), S. 70 und Central Bank of Ireland (2000c), S. 93). Dabei weist sie den Bilanzwert der Beteiligungen an diesen $\mathrm{GmbHs}$ genauso wenig aus, wie die 7 prozentige Beteiligung an der IRIS Co. Allerdings stellt sie den Wert einer ausstehenden unverzinslichen Kreditforderung an die IRIS Co. in Höhe von 0,1 Mio. EUR in ihre Jahreskonten ein (vgl. Central Bank of Ireland (2000c), S. 90). Die CBI weist keine entsprechenden Erträge bzw. Aufwendungen aus den oben genannten Unternehmensbeteiligungen aus (vgl. Central Bank of Ireland (2000c), S. 80).

4. De Nederlandsche Bank (DNB): Die DNB gibt den Gesamtwert ihrer Beteiligungen an der Bank für Internationalen Zahlungsausgleich, der N.V. Settlement Bank of the Netherlands und der Society for Interbank Financial Telecommunications S. C. (SWIFT) in Höhe von 42 Mio. EUR an (vgl. De Nederlandsche Bank (2000b), S. 190). Nach Abzug des BIZ-Anteils (22,5 Mio. EUR, vgl. Tabelle 23) erhält man den Bilanzwert der beiden Unternehmensbeteiligungen in Höhe von 19,5 Mio. EUR. Die Nettoerträge aus den Beteiligungen der DNB den Unternehmensbeteiligungen errechnen sich wie folgt: Die DNB weist unter dem GuV-Posten „Interest from participating interests and loans included in Other financial assets" einen Nettoaufwand in Höhe von 4 Mio. EUR aus (vgl. De Nederlandsche Bank (2000b), S. 190). Da dieser Wert nach DNB-Angaben neben der BIZDividende (3,7 Mio. EUR) auch den Gesamtbeitrag der DNB zur EZBVerlustfinanzierung (12 Mio. EUR) enthält, kann für die Höhe des Nettoertrag aus den DNB-Unternehmensbeteiligungen ein Betrag von 4,3 Mio. EUR angegeben werden (vgl. De Nederlandsche Bank (2000b), S. 190 ff. und Tabelle 23.

5. Belgische Nationalbank (NBB): Die NBB gibt zwar an, daß sie Kapitalbeteiligungen an staatlichen Finanzinstitutionen hält, macht aber weder hinsichtlich des Bilanzwerts dieser Anteile noch hinsichtlich der Erträge aus diesen Beteiligungen genaueren Angaben (vgl. Belgische Nationalbank (2000b), S. 81.)

6. Österreichische Nationalbank (OeNB): Der in Tabelle 29 angegebene Bilanzwert errechnet sich aus der Differenz des von der OeNB ausgewiesenen Gesamtwerts der OeNB-Beteiligungen (ohne EZB und IWF) in Höhe von 642,6 Mio. EUR und dem Beteiligungswert der OeNB an der BIZ im Betrag von 9,7 Mio. EUR (vgl. Österreichische Nationalbank (2000), S. 132 und Tabelle 23). Der Wert der Einkünfte aus diesen Beteiligungen errechnet sich aus der Differenz des von der OeNB ausgewiesenen „Erträge 
aus den Beteiligungen" (ohne EZB) (36,7 Mio. EUR) und den Erträgen aus der BIZ-Beteiligung der OeNB (1,6 Mio. EUR). Da von der OeNB in Höhe von 36,7 Mio. EUR ausgewiesene Gesamtwert der Erträge aus den OeNBBeteiligungen (ohne EZB) auch Erträge aus der IWF-Beteiligung enthält, ist der errechnete Wert als Obergrenze zu interpretieren (vgl. Österreichische Nationalbank (2000), S. 120 und Tabelle 23. Die erwähnten Erträge aus der IWF-Beteiligung sind jedoch nicht mit den vom IWF gezahlten Zinserträgen gleichzusetzen, sondern entsprechen mit großer Wahrscheinlichkeit den in 1999 erhaltenen Einkünften aus der Auflösung von IWF-Rücklagen (SCA-2 Konto der OeNB).

7. Banca d'Italia (BdI): Die in Tabelle 29 angegebene Obergrenze für den Bilanzwert der BdI-Unternehmensbeteiligungen setzt sich zusammen aus der 100\%-Beteiligung der BdI am UIC-Stiftungsfonds im Betrag von 258,2 Mio. EUR plus die als investierte Reserven und Kapital geearmarkten Beteiligungen der BdI in Höhe von 6850,45 Mio. EUR (vgl. Banca d'Italia (2000a), S. 269). Der sich ergebende Gesamtwert in Höhe von 7108,7 Mio. EUR ist deshalb nur als Obergrenze zu betrachten, da die geearmarkten Beteiligungen auch die Anteile der BdI an der BIZ enthalten dürften. Als Untergrenze für die Unternehmensbeteiligungen der BdI kann die Summe der Bilanzwerte der in Tabelle 29 explizit angegebenen Beteiligungen in Höhe von 384,8 Mio. EUR errechnet werden. Die Höhe der Erträge aus den Beteiligungen läßt sich abschätzen mit Hilfe der Summe des BdI-GuVPostens „Income from equity shares and participating interests“ in Höhe von 802,1 Mio. EUR, der den Einkünften aus der Beteiligung am UICStiftungsfonds entspricht, und des BdI-GuV-Postens „Other income dividends on equity shares and participating interests" in Höhe von 129,4 Mio. EUR, der den Erträgen aus den Beteiligungen entspricht, die die BdI als gearmarkte Reserven und Kapital hält (vgl. Banca d'Italia (2000a), S. 269 und S. 281 f. und vgl. Banca d'Italia (2000b), S. 47*). Da der zu letzt genannte Betrag auch die Erträge aus der Beteiligungen der BdI an der BIZ enthalten dürfte, ist der ausgewiesenen Wert als Obergrenze zu betrachten. Die angegeben Erträge aus dem UIC-Stiftungsfonds (802,1 Mio. EUR) kann entsprechend als Untergrenze interpretiert werden.

8. Banque Centrale du Luxembourg (BCL): Die BCL weist den jeweiligen Bilanzwert ihrer Beteiligungen an Unternehmen des Euroraums unmittelbar aus (vgl. Banque Centrale du Luxembourg (2000c), S. 122). Angaben zu den Erträgen aus diesen Anteilen macht die BCL nicht, diese dürften auch quasi Null sein. 
9. Banco de España (BdE): Die BdE besitzt außer der ihren Anteilen an der $\mathrm{BIZ}$, der EZB und dem IWF keine weitere Beteiligungen (vgl. Banco de España (2000), S. 113 ff.).

10.Banque de France (BdF): Die BdF weist den Bilanzwert ihrer Beteiligung an Sicovam in Höhe von 7,426 Mio. EUR aus, wogegen sie für die Beteiligungen an der Prévovance immobilière und an der Banque de France Gestion nur angibt, daß der jeweilige Bilanzwert in seiner Höhe nicht signifikant sei (vgl. Banque de France (2000c), S. 258). Mit Hilfe der in der BdF-Tabelle T.9.A., die den Gesamtwert der „Non-ECB participating interests (gross)“ angibt, läßt sich jedoch der Gesamtwert für die beiden genannten Beteiligungen in Höhe von 0,06 Mio. EUR errechnen (vgl. Banque de France (2000c), S. 258), so daß sich der Gesamtwert der BdFUnternehmensbeteiligungen auf 7,5 Mio. EUR beziffern läßt. Die entsprechenden im Jahre 1999 angefallenen Erträge aus diesen Beteiligungen dürften rund 6,2 Mio. EUR betragen, wenn man unterstellt, daß die jeweiligen Gewinne der BdF-Beteiligungen in Abhängigkeit der Kapitalanteile ausgeschüttet werden. So würde die BdF 39,99 Prozent vom Sicovam-Gewinn (13,31 Mio. EUR), 98,4 Prozent vom Gewinn der Prévoyance immobilière (0,214 Mio. EUR) und 99,99 Prozent vom Gewinn der Banque de France Gestion (0,680 Mio. EUR) erhalten, was insgesamt 6,2 Mio. EUR entspricht (vgl. Banque de France (2000c), S. 258).

11. Banco de Portugal (BdP): Die BdP gibt die Bilanzwerte ihrer Unternehmensbeteiligungen unmittelbar an (vgl. Banco de Portugal (2000a), S. 308). Die Höhe der von der BdP gehaltenen Anteile weist sie nur für Valora (75 Prozent) aus (vgl. Banco de Portugal (2000a), S. 263. Die Erträge aus diesen Beteiligungen errechnen sich wie folgt. Die BdP weist ihren Posten "Income from equity shares and participating interests" in Höhe von 1,637 Mio. EUR aus (vgl. Banco de Portugal (2000a), S. 288). Zieht man hiervon die in 1999 in Höhe von 1,596 Mio. EUR erhaltenen BIZDividendeneinkünfte ab (vgl. Tabelle 23), verbleibt als Residualgröße ein Betrag von 0,041 Mio. EUR. 
Gerhard Rösl - 978-3-631-75006-3

Downloaded from PubFactory at 01/11/2019 09:21:25AM

via free access 


\section{Literaturverzeichnis:}

Apholte, A./von Köppen-Mertes, I. (1997): Währungsreserven auf dem Weg in die EWU, in: Dresdner Bank (Hrsg.): Wirtschaftsanalysen - Trends, 3. Quartal 1997, S. 3-8.

Auernheimer, L. (1974): The Honest Government's Guide to the Revenue from the Creation of Money, in: Journal of Political Economy, Vol. 82, S. 93 110.

Bailey, M. (1956): The Welfare Cost of Inflationary Finance, in: Journal of Political Economy, Vol. 64, S. $93-110$.

Balke, B./Dejonckheere, F./Masseti, F. (1996): Potential Seigniorage in Europe: The Effects of the EMU, Working Paper No. 287, Institut für Weltwirtschaft, Kiel.

Baltensperger, E./Jordan T.J. (1997): Principles of Seigniorage, in: Swiss Journal of Economics and Statistics, Vol. 133, S. $133-152$.

Baltensperger, E./Jordan T.J. (1998): Seigniorage and the Transfer of Central Bank Profits to the Government, in: Kyklos, Vol. 51, S. $73-88$.

Banca d'Italia (2000a): Abridged Report for the Year 1999, Rom.

Banca d'Italia (2000b): Relazione Annuale: Amministrazione e bilancio della Banca d'Italia 1999, Rom.

Banca d'Italia (2000c): Statistical Bulletin, verschiedene Ausgaben, Rom.

Banca d'Italia (2001): Statistical Bulletin, verschiedene Ausgaben, Rom.

Banco Central do Brasil (1999): Boletim do Banco Central do Brasil - Annual Report 1998, Brasilia.

Banco de España (1999): Annual Report 1998, Madrid.

Banco de España (2000): Annual Report 1999, Madrid.

Banco de España (2001): Spanischer Banknotenumlauf von Juli 1999 bis Juni 2001 in http://www.bde.es (Boletin Estadistico: Billets y monedas en circulatión; Zeitreihe unter CSV).

Banco de Portugal (1999): Annual Report 1998, Lissabon.

Banco de Portugal (2000a): Annual Report 1999, Lissabon.

Banco de Portugal (2000b): End-of-month figures - General government, in: Banco de Portugal (2001): Mitteilung der Banco de Portugal an den Verfasser.

Bank für Internationalen Zahlungsausgleich (1999): 69. Jahresbericht (1. April 1998 - 31. März 1999), Basel.

Bank für Internationalen Zahlungsausgleich (2000a): 70. Jahresbericht (1. April 1999 - 31. März 2000), Basel.

Bank für Internationalen Zahlungsausgleich (2000b): Mitteilung der Bank für Internationalen Zahlungsausgleich an den Verfasser. 
Bank für Internationalen Zahlungsausgleich (2001): 71. Jahresbericht (1. April 2000 - 31. März 2001), Basel.

Bank of England (2001): Annual Report 2000, London.

Bank of Finland (1999): Annual Report 1998, Helsinki.

Bank of Finland (2000a): Mitteilung der Bank of Finland an den Verfasser.

Bank of Finland (2000b): Annual Report 1999, Helsinki.

Bank of Finland (2001a): Annual Report 2000, Helsinki.

Bank of Finland (2001b): Monthly Balance Sheet of the Bank of Finland, in: http://www.bof.fi/env/rhinden.htm

Bank of Greece (1999a): Annual Report 1998, Athen.

Bank of Greece (1999b): Monthly Statistical Bulletin, verschiedene Ausgaben, Athen.

Bank of Greece (2000a): Annual Report 1999, Athen.

Bank of Greece (2000b): Monthly Statistical Bulletin, verschiedene Ausgaben, Athen.

Banque Centrale du Luxembourg (2000a): Circulation de pièces courantes en LUF -Circulation de frappes numismatiques de pièces courantes et de monnaies commémoratives en LUF émises par l'etat, in: http://www.bcl.lu/html/en/index_billets_pieces.html.

Banque Centrale du Luxembourg (2000b): Mitteilung der Banque Centrale du Luxembourg an den Verfasser.

Banque Centrale du Luxembourg (2000c): Rapport Annuel 1999, Luxemburg.

Banque Centrale du Luxembourg (2001): LUF-Umlauf für die Jahre 1999 bis 2001, in: http://www.bcl.lu/html/en/index_billets_pieces.html.

Banque de France (1999a): Annual Report 1998, Paris.

Banque de France (1999b): Bulletin Digest, verschiedene Ausgaben, Paris.

Banque de France (2000a): The weekly return of the Banque de France as at 1

September, in: http://www.banque-france.fr/gb/actu/ecofi/1.htm.

Banque de France (2000b): Mitteilung der Banque de France an den Verfasser.

Banque de France (2000c): Annual Report 1999, Paris.

Banque de France (2000d): Bulletin Digest, verschiedene Ausgaben, Paris.

Banque de France (2001): Bulletin Digest, verschiedene Ausgaben, Paris.

Barro, R. (1982): Measuring the Fed's Revenue from Money Creation, in: Economics Letters, Vol. 10, S. 327 - 332.

Belgische Nationalbank (1999): Statistical bulletin of the National Bank of Belgium, verschiedene Ausgaben, Brüssel.

Belgische Nationalbank (2000a): Mitteilung der Belgischen Nationalbank an den Verfasser. 
Belgische Nationalbank (2000b): Annual Report for the Year 1999, Part II: Activities and Annual Accounts, Brüssel.

Belgische Nationalbank (2000c): Statistical bulletin of the National Bank of Belgium, verschiedene Ausgaben, Brüssel.

Belgische Nationalbank (2001): Statistical bulletin of the National Bank of Belgium, verschiedene Ausgaben, Brüssel.

Black, S.W. (1992): Seigniorage, in: Newman, P./Milgate, M./Eatwell, J. (Hrsg.): The Palgrave Dictionary of Money and Finance, London.

Blau, J.-O. (1998): Die Bedeutung des Seigniorage im EWS und in der zukünftigen Europäischen Währungsunion, Forschungsbericht 9811, Europa-Institut, Sektion Wirtschaftswissenschaft, Abteilung VWL, Saarbrücken.

Boeschoten, W.C./Hebbink G.E. (1996): Electronic money, currency demand and seigniorage loss in the G10 countries, DNB-Staff reports, Amsterdam.

Bofinger, P./Reischle, J./Schächter, A. (1996): Geldpolitik - Ziele, Institutionen, Strategien und Instrumente, München.

Calvo, G. (1978): Optimal Seigniorage from Money Creation - An Analysis in Terms of the Optimum Balance of Payments Deficit Problem, in: Journal of Monetary Economics, Vol. 4, S. 503 - 517.

Central Bank of Ireland (1999): Annual Report 1998, Dublin.

Central Bank of Ireland (2000a): Bulletin, Spring 2000, Dublin.

Central Bank of Ireland (2000b): Mitteilung der Central Bank of Ireland an den Verfasser.

Central Bank of Ireland (2000c): Annual Report 1999, Dublin.

Central Bank of Ireland (2000d): Quarterly Bulletin, Spring 2000, Dublin

Central Bank of Ireland (2001): Quarterly Bulletin, Autumn 2001, Dublin.

Chamley, C. (1991): Taxation of Financial Assets in Developing Countries, in: The World Bank Economic Review, Vol. 5, No. 3, S. 513 - 533.

Cornelius, P. (1990a): Münzgewinne und Haushaltsfinanzierung in der offenen Volkswirtschaft, in: Wirtschaftswissenschaftliches Studium (WiSt), H. 12, S. $615-616$.

Cornelius, P. (1990b): Münzgewinneffekte der europäischen Währungsunion, in: Wirtschaftswissenschaftliches Studium (WiSt), H. 12, S. 617-619.

Courtis, N. (1999): Commission eyes juicy ESCB profits, in: Central Banking, Vol. 9, No. 3, S. $52-54$.

Danmarks Nationalbank (1999): Report and Accounts 1998, Kopenhagen.

De Nederlandsche Bank (1999): Annual Report 1998, Amsterdam.

De Nederlandsche Bank (2000a): Mitteilung der De Nederlandsche Bank an den Verfasser.

De Nederlandsche Bank (2000b): Annual Report 1999, Amsterdam. 
De Nederlandsche Bank (2001): Niederländischer Banknotenumlauf (Wochenausweis) der Jahre 1999 bis 2001 in http://www.statistics.dnb.nl./ indexuk.html.

Deutsche Bundesbank (1995): Der DM-Bargeldumlauf im Ausland, in: Monatsbericht der Deutschen Bundesbank, Juli 1995, S. 67 - 73.

Deutsche Bundesbank (1997a): Weltweite Organisationen und Gremien im Bereich von Währung und Wirtschaft, Frankfurt am Main.

Deutsche Bundesbank (1997b): Geschäftsbericht 1996, Frankfurt am Main.

Deutsche Bundesbank (1999a): Neuere Entwicklungen beim elektronischen Geld, in: Monatsbericht der Deutschen Bundesbank, Juni 1999, S. 41 58.

Deutsche Bundesbank (1999b): Überlegungen und Vorschläge zur künftigen Organisationsstruktur der Deutschen Bundesbank, in: Monatsbericht der Deutschen Bundesbank, Juli 1999, S. 5 - 16, Frankfurt am Main.

Deutsche Bundesbank (1999c): Die Beziehungen Deutschlands zum Internationalen Währungsfonds nach Einführung des Euro, in: Monatsbericht der Deutschen Bundesbank, September 1999, S. 15 - 25.

Deutsche Bundesbank (1999d): Geschäftsbericht 1998, Frankfurt am Main. Deutsche Bundesbank (2000a): Geschäftsbericht 1999, Frankfurt am Main.

Deutsche Bundesbank (2000b): Statistische Beihefte zum Monatsbericht Devisenkursstatistik, Januar 2000, Frankfurt am Main.

Deutsche Bundesbank (2000c): Mitteilung der Deutschen Bundesbank an den Verfasser.

Deutsche Bundesbank (2000d): Statistische Beihefte zum Monatsbericht Kapitalmarktstatistik, September 2000, Frankfurt am Main.

Deutsche Bundesbank (2000e): Statistische Beihefte zum Monatsbericht Devisenkursstatistik, September 2000, Frankfurt am Main.

Deutsche Bundesbank (2001a): Monatsbericht der Deutschen Bundesbank, Februar 2001, S. 18* - 19*.

Deutsche Bundesbank (2001b): Monatsbericht der Deutschen Bundesbank, Oktober 2001, S. 18* - 19*

Döring, C./Burckhard C. (2000): Bundesbank nicht auf reine Geld-Kompetenz schrumpfen lassen, in: Deutsche Bundesbank, Auszüge aus Presseartikeln, Nr. 10, vom 25. 2. 2000, S. 2 - 3.

Dornbusch, R. (1988): The European Monetary System, the Dollar and the Yen, in: Giavazzi, F./Miller, S./Miller M. (Hrsg.): The European Monetary System, Cambridge, S. $23-47$.

Drazen, A. (1985): A general measure of inflation tax revenues, in: Economics letters, Vol. 17, S. 327 - 333.

Dresdner Bank (1997): Sinn und Unsinn zum Euro (mimeo.). 
Easterly, W./Mauro P./Schmidt-Hebbel, K. (1995): Money Demand and Seigniorage-Maximazing Inflation, in: Journal of Money, Credit, and Banking, Vol. 27, No. 2, S. $583-603$.

Euba, N. (1978): Der „Münzgewinn“ der Geldschöpfung und seine Verteilung, in: Wirtschaftswissenschaftliches Studium (WiSt), H. 2, S. 49 - 54.

Europäische Gemeinschaft (1993): Verordnung Nr. 3603/93 des Rates vom 13. Dezember 1993 zur Festlegung der Begriffsbestimmungen für die Anwendung der in Artikel 104 und Artikel 104b Absatz 1 des Vertrages vorgesehenen Verbote, in: Amtsblatt (EG) Nr. L 332 vom 31.12.1993, S. $1-3$.

Europäische Gemeinschaft (1997a): Entschließung des Europäischen Rates über die Einführung eines Wechselkursmechanismus in der dritten Stufe der Wirtschafts- und Währungsunion, Amsterdam, 16. Juni 1997 (97/C 236/03), in: Amtsblatt (EG) Nr. C 236 vom 2.8.1997, S. 5-6.

Europäische Gemeinschaft (1997b): Verordnung Nr. 1103/97 des Rates vom 17. Juni 1997 über bestimmte Vorschriften im Zusammenhang mit der Einführung des Euro, in: Amtsblatt (EG) Nr. L 162 vom 19.6.1997, S. 1 3.

Europäische Gemeinschaft (1998a): Beschluß der Europäischen Zentralbank vom 9. Juni 1998 über die Methode zur Festlegung der prozentualen Anteile der nationalen Zentralbanken im Schlüssel für die Zeichnung des Kapitals der Europäischen Zentralbank (EZB/1998/1), in: Amtsblatt (EG) Nr. L 8 vom 14.1.1999, S. 31 - 32.

Europäische Gemeinschaft (1998b): Beschluß der Europäischen Zentralbank vom 9. Juni 1998 zur Bestimmung der Maßnahmen, die zur Einzahlung des Kapitals der Europäischen Zentralbank erforderlich sind (EZB/1998/2), in: Amtsblatt (EG) Nr. L 8 vom 14.1.1999, S. 33 - 35.

Europäische Gemeinschaft (1998c): Beschluß der Europäischen Zentralbank vom 1. Dezember 1998 zur Bestimmung der Maßnahmen, die zur Einzahlung des Kapitals der Europäischen Zentralbank durch die nationalen Zentralbanken nicht teilnehmender Mitgliedstaaten erforderlich sind (EZB/1998/14), in: Amtsblatt (EG) Nr. L 110 vom 28.4.1999, S. 33 34.

Europäische Gemeinschaft (1998d): Beschluß der Europäischen Zentralbank vom 1. Dezember 1998 über die prozentualen Anteile der nationalen Zentralbanken im Schlüssel für die Zeichnung des Kapitals der Europäischen Zentralbank (EZB/1998/13), in: Amtsblatt (EG) Nr. L 125 vom 19.5.1999, S. 33.

Europäische Gemeinschaft (1998e): Beschluß des Rates vom 5. Juni 1998 über die zur Festlegung des Schlüssels für die Zeichnung des Kapitals der 
Europäischen Zentralbank benötigten statistischen Daten (98/382/EG), in: Amtsblatt (EG) Nr. L 171 vom 17.06.1998, S. 33 - 34.

Europäische Gemeinschaft (1998f): Abkommen vom 1. September 1998 zwischen der Europäischen Zentralbank und den nationalen Zentralbanken der nicht dem Euro-Währungsgebiet angehörenden Mitgliedstaaten über die Funktionsweise eines Wechselkursmechanismus in der dritten Stufe der Wirtschafts- und Währungsunion (98/C 345/05), in: Amtsblatt (EG) Nr. C 345 vom 13.11.1998, S. 6-12.

Europäische Gemeinschaft (1998g): Verordnung Nr. 2532/98 des Rates vom 23. November 1998 über das Recht der EZB, Sanktionen zu verhängen, in: Amtsblatt (EG) Nr. L 318 vom 27.11.1998, S. 4 - 7.

Europäische Gemeinschaft (1998h): Entscheidung des Rates vom 23. November 1998 über Wechselkursfragen in Zusammenhang mit dem CFA-Franc und dem Komorenfranc (98/683/EG), in: Amtsblatt (EG) Nr. L 320 vom 28.11 .1998 , S. $58-59$.

Europäische Gemeinschaft (1998i): Verordnung Nr. 2818/98 der Europäischen Zentralbank vom 1. Dezember 1998 über die Auferlegung einer Mindestreservepflicht (EZB/1998/15), in: Amtsblatt (EG) Nr. L 356 vom 30.12.1998, S. $1-6$.

Europäische Gemeinschaft (1998j): Empfehlung der Europäischen Zentralbank für eine Verordnung (EG) des Rates über die Grenzen und Bedingungen für Kapitalerhöhungen der Europäischen Zentralbank (vorgelegt am 3. November 1998) (EZB/1998/11), in: Amtsblatt (EG) Nr. C 411 vom 31.12.1998, S. 10.

Europäische Gemeinschaft (1998k): Entscheidung des Rates vom 21. Dezember 1998 über Wechselkursfragen in Zusammenhang mit dem KapVerde-Escudo (98/744/EG), in: Amtsblatt (EG) Nr. L 358 vom 31.12.1998, S. $111-112$.

Europäische Gemeinschaft (1999a): Empfehlung der Kommission vom 13. Januar 1999 zu Sammlermünzen, Medaillen und Marken (1999/63/EG), in: Amtsblatt (EG) Nr. L 20 vom 27.1.1999, S. 61 - 62.

Europäische Gemeinschaft (1999b): Entscheidung des Rates vom 31. Dezember 1998 über die Währungsregelungen in den französischen Gebieten St. Pierre und Miquelon und Mayotte (1999/95/EG), in: Amtsblatt (EG) Nr. L 30 vom 4.2.1999, S. 29 - 30.

Europäische Gemeinschaft (1999c): Entscheidung des Rates vom 31. Dezember 1998 über den von der Gemeinschaft zu vertretenden Standpunkt bezüglich einer Vereinbarung über Währungsbeziehungen zum Fürstentum Monaco (1999/96/EG), in: Amtsblatt (EG) Nr. L 30 vom 4.2.1999, S. $31-32$. 
Europäische Gemeinschaft (1999d): Entscheidung des Rates vom 31. Dezember 1998 über den von der Gemeinschaft zu vertretenden Standpunkt bezüglich einer Vereinbarung über Währungsbeziehungen zur Republik San Marino (1999/97/EG), in: Amtsblatt (EG) Nr. L 30 vom 4.2.1999, S. $33-34$.

Europäische Gemeinschaft (1999e): Entscheidung des Rates vom 31. Dezember 1998 über den von der Gemeinschaft zu vertretenden Standpunkt bezüglich einer Vereinbarung über Währungsbeziehungen zur Vatikanstadt (1999/98/EG), in: Amtsblatt (EG) Nr. L 30 vom 4.2.1999, S. $35-36$.

Europäische Gemeinschaft (1999f): Verordnung Nr. 2157/1999 der Europäischen Zentralbank vom 23. September 1999 über das Recht der Europäischen Zentralbank, Sanktionen zu verhängen (EZB/1999/4), in: Amtsblatt (EG) Nr. L 264 vom 12.10.1999, S. $21-26$.

Europäische Gemeinschaft (2000a): Entscheidung der Europäischen Zentralbank vom 23. Dezember 1999 über die Genehmigung des Umfangs der Ausgabe von Münzen in 2000 (EZB/1999/11), in: Amtsblatt (EG) Nr. L 4 vom 7.1.2000, S. 18.

Europäische Gemeinschaft (2000b): Verordnung (EG) Nr. 1009/2000 des Rates vom 8. Mai 2000 über Kapitalerhöhungen der Europäischen Zentralbank, in: Amtsblatt (EG) Nr. L 115 vom 16.5.2000, S. 1.

Europäische Gemeinschaft (2000c): Verordnung (EG) Nr. 1010/2000 des Rates vom 8. Mai 2000 über die Einforderung weiterer Währungsreserven durch die Europäische Zentralbank, in: Amtsblatt (EG) Nr. L 115 vom 16.5.2000, S. 2 - 3 .

Europäische Gemeinschaft (2000d): Verordnung (EG) Nr. 1478/2000 des Rates vom 19. Juni 2000 zur Änderung der Verordnung (EG) Nr. 2866/98 über die Umrechnungskurse zwischen dem Euro und den Währungen der Mitgliedstaaten, die den Euro einführen, in: Amtsblatt (EG) Nr. L 167 vom 7.7.2000, S. 1.

Europäische Gemeinschaft (2000e): Beschluß der Europäischen Zentralbank vom 3. November 1998 geändert durch den Beschluß vom 14. Dezember 2000 über die Verteilung der monetären Einkünfte der nationalen Zentralbanken der teilnehmenden Mitgliedstaaten und der Verluste der EZB für die Geschäftsjahre 1999 bis 2001 (EZB/2000/19), in: Amtsblatt (EG) Nr. L 336 vom 30.12.2000, S. $119-121$.

Europäische Gemeinschaft (2000f): Abkommen vom 16. November 2000 zwischen der Europäischen Zentralbank und der Bank von Griechenland über die Forderung, die der Bank von Griechenland gemäß Artikel 30.3 der Satzung durch die Europäische Zentralbank gutgeschrieben wird, und 
damit zusammenhängende Fragen, in: Amtsblatt (EG) Nr. L 336 vom 30.12.2000, S. $122-123$.

Europäische Gemeinschaft (2001a): Leitlinie der Europäischen Zentralbank vom 1. Dezember 1998 über die Rechnungslegungsgrundsätze und das Berichtswesen im Europäischen System den Zentralbanken in der geänderten Fassung vom 15. Dezember 1999 und 14. Dezember 2000 (EZB/2000/18), in Amtsblatt (EG) Nr. L 33 vom 2.2.2001, S. 21 - 64.

Europäische Gemeinschaft (2001b): Leitlinie der Europäischen Zentralbank vom 26. April 2001 über ein transeuropäisches automatisches EchtzeitBrutto-Express-Zahlungsverkehrssystem (Target) (EZB/2001/3), in: Amtsblatt (EG) Nr. L 140 vom 24.5.2001, S. 72 - 82.

Europäische Kommission (2000): Mitteilung der Kommission an das Europäische Parlament, den Rat, den Wirtschafts- und Sozialausschuß, den Ausschuß der Regionen und die Europäische Zentralbank. Praktische Aspekte des Euro: Aktueller Stand und künftige Aufgaben, in: http://www.europa.eu.int/eur-lex/de/com/pdf/2000/ com2000_0443de01.pdf.

Europäische Zentralbank (1998): Bedingungen für die Teilnahme von nationalen Zentralbanken und Kreditinstituten außerhalb des EuroWährungsraums an TARGET, in: http://www.bundesbank.de/ewi/de/ presse/pressenotizen/archiv98/notizen/bedtarget080798.htm.

Europäische Zentralbank (1999a): Jahresbericht 1998, Frankfurt am Main.

Europäische Zentralbank (1999b): Compendium, Sammlung von Rechtsinstrumenten, Juni 1998 - Mai 1999, Frankfurt am Main.

Europäische Zentralbank (1999c): Einlagen der öffentlichen Hand und ihre Auswirkungen auf die Liquiditätslage im Eurogebiet, in: Monatsbericht der Europäischen Zentralbank, Juli 1999, S. 16-17.

Europäische Zentralbank (1999d): Der institutionelle Rahmen des Europäischen Systems der Zentralbanken, in: Monatsbericht der Europäischen Zentralbank, Juli 1999, S. 59-67.

Europäische Zentralbank (2000a): Währungsreserven und Devisengeschäfte des Eurosystems, in: Monatsbericht der Europäischen Zentralbank, Januar 2000, S. $55-61$.

Europäische Zentralbank (2000b): WWU und Bankenaufsicht, in: Monatsbericht der Europäischen Zentralbank, April 2000, S. 53 - 70.

Europäische Zentralbank (2000c): Jahresabschluß der EZB zum 31. Dezember 1999, Pressemitteilung vom 12. April 2000, Frankfurt am Main. 
Europäische Zentralbank (2000d): Erhebung und Aufbereitung statistischer Daten durch das ESZB, Mai 2000, in: http://www.ecb.int/ pub/pdf/statinf0005de.pdf.

Europäische Zentralbank (2000e): Die Umstellung auf Zinstender bei den Hauptrefinanzierungsgeschäften, in: Monatsbericht der Europäischen Zentralbank, Juli 2000, S. $39-44$.

Europäische Zentralbank (2000f): Anforderungen im Bereich der allgemeinen Wirtschaftsstatistik, August 2000, in: http://www.ecb.int/pub/pdf/ strateqgen_de.pdf.

Europäische Zentralbank (2000g): Die einheitliche Geldpolitik in Stufe 3 Allgemeine Regelungen für die geldpolitischen Instrumente und Verfahren des Eurosystems, November 2000, Frankfurt am Main.

Europäische Zentralbank (2000h): Jahresbericht 1999, Frankfurt am Main.

Europäische Zentralbank (2001a): Statistik des Euro-Währungsgebiets, in: Monatsbericht der EZB, Januar 2001, S. 1* - 84*.

Europäische Zentralbank (2001b): Statistik des Euro-Währungsgebiets, in: Monatsbericht der EZB, Februar 2001, S. 1* - 84*.

Europäische Zentralbank (2001c): Statistik des Euro-Währungsgebiets, in: Monatsbericht der EZB, in: Monatsbericht der Europäischen Zentralbank, Juli 2001, S. 1* - 98*.

Europäische Zentralbank (2001d): Jahresbericht 2000, Frankfurt am Main.

Europäische Zentralbank (2001e): Jahresabschluß der EZB zum 31 . Dezember 2000, Pressemitteilung vom 29. März 2001, Frankfurt am Main.

Europäische Zentralbank (2001f): Beschluß der Europäischen Zentralbank vom 6. Dezember 2001 über die Ausgabe von Euro-Banknoten (EZB/2001/15), in: http://www.ecb.int/pub/legal/ecb200115de.pdf.

Europäische Zentralbank (2001g): Beschluß der Europäischen Zentralbank vom 6. Dezember 2001 über die Verteilung der monetären Einkünfte der Nationalen Zentralbanken der teilnehmenden Mitgliedstaaten ab dem Geschäftsjahr 2002 (EZB/2001/16), in: http://www.ecb.int/pub/legal/ ecb200116de.pdf.

Europäische Zentralbank (2001h): Beschlüsse über die Ausgabe von EuroBanknoten und die Verteilung der monetären Einkünfte, Pressemitteilung der EZB vom 6. Dezember 2001, Frankfurt am Main.

Europäische Zentralbank (2001i): Konsolidierter Ausweis des Eurosystems zum 29. Dezember 2000, Pressemitteilung vom 4. Januar 2001, Frankfurt am Main.

Europäisches Währungsinstitut (1997): Jahresbericht 1996, Frankfurt am Main. 
European Central Bank (1998a): Correspondent Central Banking Model (CCBM), Frankfurt am Main.

European Central Bank (1998b): Third Progress Report on the TARGET Project, November 1998, Frankfurt am Main.

European Central Bank (1998c): Guideline of the European Central Bank of 1 December 1998 on the Legal Framework for Accounting and Reporting in the European System of Central Banks (ECB/1998/NP22), Frankfurt am Main.

European Central Bank (1998d): Euro central rates and intervention rates in ERM II, Press release 31 December 1998, in: http://www.ecb.int/press/ pr981231_3.htm.

European Central Bank (1999a): Consolidated opening financial statement of the European System of Central Banks (Eurosystem) as at 1 January 1999, Press release 5 January 1999, in: http://www.ecb.int/press/ pr990105_2.htm.

European Central Bank (1999b): Guideline of the European Central Bank of 22 April 1999 on the authorisation to issue national banknotes during the transitional period (ECB/1999/NP11), in: http://www.ecb.int/pub/legal/ ecb1999np11.htm.

European Central Bank (1999c): Weekly financial statements for 1999, ECB press releases, in: http://www.ecb.int/press/fs/prfs 1999.htm.

European Central Bank (2000a): Euro central rates and intervention rates in ERM II, Press release 17 January 2000, in: http://www.ecb.int/press/00/ pr000117.htm.

European Central Bank (2000b): Treasury activities affecting liquidity in the euro area, 13.7.2000, in: http://www.ecb.int/home/treas_info.htm.

European Central Bank (2000c): Role of the Eurosystem in the field of payment systems oversight, in: http://www.ecb.int/pub/pdf/

paysysover.pdf.

European Central Bank (2001a): TARGET Annual Report, May 2001, Frankfurt am Main.

European Central Bank (2001b): Euro banknotes to be produced until 31 December 2001, ECB press release 5 October 2001, in: http://www.ecb.int/press/01/pr011005.htm.

European Central Bank (2001c): The euro banknotes: Answers to frequently asked questions, in: http://www.ecb.int/change/eurobnfaq_en.htm.

European Central Bank (2001d): Template on international reserves and foreign currency liquidity, in: http://www.ecb.int/stats/reserves.

European Central Bank (2001e): Review of the International Role of the Euro, Frankfurt am Main. 
European Central Bank (2001f): Swap agreement with the Federal Reserve, ECB press release 13 September 2001, in: http://www.ecb.int/press/01/ pr010913_1.htm.

European Community (1993): Protocol (No 3) on the Statute of the European System of Central Banks and of the European Central Bank, Brussels.

European Monetary Institute (1995): Progress towards convergence - Report prepared in accordance with article 7 of the EMI statute.

Feist, H. (2001): The Enlargement of the European Union and the Redistribution of Seigniorage Wealth, in: CESifo Working Paper Series, Working Paper 408.

Filc, W. (1986): Zinsloser und tilgungsfreier Notenbankkredit zur Finanzierung öffentlicher Investitionen: 10 Thesen, in: Dohnanyi, K. v. (Hrsg.): Notenbankkredit an den Staat? Beiträge und Stellungnahmen zu dem Vorschlag, öffentliche Investitionen mit zins- und tilgungsfreien Notenbankkrediten zu finanzieren, S. $47-65$.

Fischer, S. (1982): Seigniorage and the Case for a National Money, in: Journal of Political Economy, Vol. 90, S. $295-313$.

Friedman, M. (1953): Discussion of the Inflationary Gap, in: Essays in Positive Economics, Chicago, S. $251-262$.

Friedman, M. (1971): Government Revenue from Inflation, in: Journal of Political Economy, Vol. 79, S. 846 - 856.

Fry, M. (1981): Government Revenue from Monopoly Supply of Currency and Deposits, in: Journal of Monetary Economics, Vol. 8, S. 261 - 270.

Fry, M. (1993): The fiscal abuse of central banks, in: International Monetary Fund Working paper, No. 93/58.

Gnan, Ernest (1999): Kommentar zu Artikel 14 der Satzung des ESZB und der EZB, in: Von der Groeben, H./Thiesing, J./Ehlermann C.-D. (Hrsg.): Kommentar zum EU-/EG-Vertrag, Bd. 3, Artikel 102a - 136a EGV, Baden-Baden, S. 595 - 606.

Goetze, H. (1999): Die Tätigkeit der nationalen Zentralbanken in der Wirtschafts- und Währungsunion, Frankfurt am Main.

Grilli, V. (1989a): Exchange Rates and Seigniorage, in: European Economic Review, Vol. 33, S. $580-587$.

Grilli, V. (1989b): Seigniorage in Europe, in: Cecco, M. de/Giovannini, A. (Hrsg.): A European Central Bank? - Perspectives on monetary unification after ten years of the EMS, Cambridge, S. 53 - 79 .

Gros, D. (1989): Seigniorage in the EC: The Implications of the EMS and Financial Market Integration, in: IMF Working Paper Nr. 7. 
Gros, D. (1990): Seigniorage and EMS Discipline, in: De Grauwe, P./Papademos, L. (Hrsg.): The European Monetary System in the 1990s, New York, S. $162-181$.

Gros, D. (1993): Seigniorage and EMU. The fiscal implications of price stability and financial market integration, in: European Journal of Political Economy, Vol. 9, S. $581-601$.

Gros, D. (1998): Distributing Seigniorage under EMU, in: ifo Schnelldienst 17 $18 / 1998$, S. $29-39$.

Gros, D./Vandille, G. (1995): Seigniorage and EMU: The fiscal implications of price stability and financial market integration, in: Journal of Common Market Studies, Vol. 33, Nr. 2, S. 175 - 196.

Gubitz, A. (1989): Seigniorage - Hindernis auf dem Weg zur Europäischen Währungsunion?, in: Konjunkturpolitik, H. 5, S. $288-296$.

Hartmann, Wendelin (1997): The European Central Bank and its relationship with national central banks, speech on the occasion of the „Athens Summit 97 " on August 30, in: Deutsche Bundesbank, Auszüge aus Presseartikeln Nr. 49 v. 3.9.1997, S. 3.

Hasse, R. (1997): Die Saga vom Transfer des Rheingolds an Europa, in: Handelsblatt vom 13.8.1997, Nr. 154, S. 8.

Hochreiter, E./Rovelli, R./Winckler, G. (1996): Montary and financial policies in the economies in transition, central banks and seigniorage: A study of three economies in transition, in: European Economic Review, Vol. 40, S. $629-643$.

Hofner, G. (1994): Geldemission, Staatsbudget und monetäre Integration in Europa, Fuchsstadt.

Honohan, P. (1996): Does it matter how seigniorage is measured?, in: Applied Financial Economics, Vol. 6, No. 3, S. 293 - 300.

http://www.bportugal.pt/stats/frstats_e.htm.

Institut d'émission d'outre-mer (2001): La mise en circulation de la monnaie fiduciaire, in: http://www.inst-ieom.fr/monnaiefid.htm.

Institut Monetaire Luxembourgeois (1998): Rapport Annuel 1997, Luxemburg.

International Monetary Fund (2000a): Financial Statements, Quarter Ended January 31 , Washington, D.C..

International Monetary Fund (2000b): International Financial Statistics, June 2000, Washington, D.C..

International Monetary Fund (2000c): Annual Report 2000, Washington, D.C..

International Monetary Fund (2000d): Finland: Position in the Fund as of December 31, 1999, in http://www.imf.org/np/tre/tad/exfund2.cfm. 
International Monetary Fund (2000e): Financial Organization and Operations of the IMF, in: http://www.imf.org/external/pubs/ft/pam/pam45/ APPENDIX/APII.htm.

International Monetary Fund (2000f): International Financial Statistics, December 2000, Washington, D.C..

Internationaler Währungsfonds (2000a): Die Allgemeinen Kreditvereinbarungen (AKV), die Neuen Kreditvereinbarungen (NKV), Informationsblatt, 31. Juli 2000, in: http://www.imf.org/external/np/exr/facts/deu/ gabnabd.htm.

Internationaler Währungsfonds (2000b): Jahresbericht 2000, Washington, D.C..

Issing, O. (1995): Einführung in die Geldtheorie, 10. Auflage, München.

Jarchow, H.-J./Rühmann P. (1989): Monetäre Außenwirtschaft, II. Internationale Währungspolitik, 2. Auflage, Göttingen.

Klein, M. (1989): Monetary and Fiscal Seigniorage: Theory and Evidence. Sonderforschungsbereich 303, Projektbereich B, Discussion Paper No. B123, Rheinische Friedrich-Wilhelms-Universität Bonn.

Klein, M./Neumann, M.J.M. (1990): Seigniorage: What Is It and Who Gets It?, in: Weltwirtschaftliches Archiv, Bd. 126, H. 2, S. 205 -221.

Klopfleisch, R. (2000): Fiskalische Konsequenzen der Europäischen Währungsunion - Die Veränderung des Seigniorage und dessen Bedeutung für die nationalen EWU-11 Haushalte, Frankfurt am Main.

Lange, C. (1995): Seigniorage - Eine theoretische und empirische Analyse des staatlichen Geldschöpfungsgewinnes, Berlin.

Lange, C., F. Nolte (1997): Geldschöpfungsgewinne in einer Europäischen Währungsunion, Diskussionspapier No. 205, Universität Hannover, Fachbereich Wirtschaftswissenschaften, Hannover.

Lange, C./Nolte, F. (1998): Konsequenzen der Europäischen Währungsunion für den Geldschöpfungsgewinn der Mitgliedsländer, in: Kredit und Kapital, H. 4, S. $494-519$.

Larbig, G. A. (1999): Seigniorage-Verteilung in der Europäischen Währungsunion, in: List Forum für Wirtschafts- und Finanzpolitik, Bd. 25, H. 2, S. $199-221$.

Larbig, G.A. (1997): Zur aktuellen Diskussion des Just-Retour in der EWU: Seigniorage-Wettbewerb und Verteilungsspielräume aus fiskalischer Sicht, Diskussionspapier Serie B, No. 97/07, Universität Jena, Fachbereich Wirtschaftswissenschaften, Jena.

Läufer, N. K. A. (1997): Die Seigniorage-Kosten des Euro für Deutschland Eine Kritik an Sinn und Feist, in: http://www.uni-konstanz.de/fuF/ wiwi/laufer/seigniorage/seigniorage-main.html. 
Läufer, N.K.A. (1998): The Seigniorage costs of the Euro for Germany, A critique of Sinn and Feist, in: http://www.uni-konstanz.de/fuF/wiwi/ laufer/seigniorage/sinn-oder-unsinn.pdf.

Liebscher, K. (1998): Die Rolle einer nationalen Zentralbank im ESZB am Beispiel der OeNB, in: http://www.oenb.co.at/tagung/refer17.htm.

Liquiditäts-Konsortialbank (2000): Geschäftsbericht 1999, Frankfurt am Main.

Maennig, W. (1999): Notenbankgewinn-Einbußen - ernsthaftes Hindernis für die Währungsunion?, in: Hasse, R./Schenk, K./Wass von Czege, A. (Hrsg.): Herausforderungen der Europäischen Währungsunion, Schriftenreihe des Europa-Kollegs Hamburg zur Integrationsforschung, Bd. 22, Baden-Baden, S. $77-93$.

Maennig, W./Hunger, A. (1996): Seigniorageverluste - Hemmnis für die Europäische Währungsunion?, in: Wirtschaftswissenschaftliches Studium (WiSt), H. 5, S. $227-232$.

Mankiw, N. (1987): The Optimal Collection of Seigniorage, Theory and Evidence, in: Journal of Monetary Economics, Vol. 20, S. 327 - 341.

Marty, A. (1968): The Optimal Rate of Growth of Money, in: Journal of Political Economy, Vol. 76, S. $860-873$.

Menkhoff, L. (1996): Geldpolitische Instrumente der Europäischen Zentralbank - Eine Analyse unter den Aspekten Effizienz, Wettbewerbsneutralität und Dezentralität, 2. Auflage, Stuttgart.

Neldner, M. (1984): Seigniorage, inflationäre Staatshaushaltsfinanzierung und das Problem der optimalen Geldmenge, in: Das Wirtschaftsstudium (WISU), S. $411-418$.

Neumann, M.J.M. (1992): Seigniorage in the United States: How Much Does the U.S. Government Make from Money Production?, in: Federal Reserve Bank of Saint Louis Review, March/April, S. 32 - 40.

Neumann, M.J.M. (1995): A Comparative Study of Seigniorage: Japan and Germany, Sonderforschungsbereich 303, Projektbereich B, Discussion Paper No. B-304, Rheinische Friedrich-Wilhelms-Universität Bonn.

Nolte (1998): Geldschöpfungsgewinne in einer Europäischen Währungsunion, in: Lange, C. et al. (Hrsg.): Monetäre Aspekte der europäischen Integration, Berlin.

O. V. (1996): The winners and losers from EMU, in: Central Banking (1996), Vol. 7, No. 2, Autumn 1996, S. 6 - 10, London.

O. V. (1997): Dispute over ESCB profits, in: Central Banking (1997), Vol. 7, No. 4, Spring 1997, S. 7 -10, London.

Österreichische Nationalbank (1999): Geschäftsbericht 1998, Wien. Österreichische Nationalbank (2000): Geschäftsbericht 1999, Wien. 
Österreichische Nationalbank (2001): Mitteilung der Österreichischen Nationalbank an den Verfasser.

Phelps, E. (1972): Inflation Policy and Unemployment Theory, New York.

Phelps, E. (1973): Inflation in the Theory of Public Finance, in: Swedish Journal of Economics, Vol. 75, S. $867-882$.

Pringle, R./Courtis N. (1999): Objectives Governance and Profits of Central Banks, Central Banking Publications, London.

Remsperger, P. (1996): Umverteilung der Notenbankgewinne in der Währungsunion - Milliardenverluste für den Bundeshaushalt?, in: Wirtschaftsdienst der BHF-Bank, Nr. 181, S. 1 - 3.

Rösl, G./Schäfer W. (1998a): Notenbankgewinnentstehung und-verwendung im Euro-Währungsraum, Diskussionsbeiträge aus dem Institut für Theoretische Volkswirtschaftslehre 3/1998, Universität der Bundeswehr Hamburg.

Rösl, G./Schäfer W. (1998b): Notenbankgewinnentstehung und -verwendung in der WWU, in: Caesar, R./Scharrer, H.-E. (Hrsg.): Die Europäische Wirtschafts- und Währungsunion - regionale und globale Herausforderungen, Europäische Schriften des Instituts für Europäische Politik, Bd. 76, S. $147-168$.

Rösl, G./Schäfer W. (2000): A Conceptual Approach to the Creation and Allocation of Central Bank Profits in the Euro Area, in: Kredit und Kapital, H. 1, S. $39-61$.

Rösl, G./Schäfer W. (2001): Creation and Allocation of Central Bank Profits in the Euro Area, in: Caesar, R./Scharrer, H.-E. (eds.): European Economic and Monetary Union: Regional and Global Challenges, HWWA Studies, Vol. 62, in cooperation with Institut für Europäische Politik, S. $157-174$.

Rovelli, R. (1994): Reserve requirements, seigniorage and the financing of the government in an economic and monetary union, in: European Economy, Notes and Reports, No. 1, S. $11-55$.

Schneider, F./Ernste, D.H. (2000): Shadow Economies - Size, Causes, and Consequences, in: Journal of Economic Literature, Vol. 38, S. 77 - 114.

Schobert, F. (1998): Seigniorage: Potential Measurement and Distribution in the European Monetary Union (mimeo.).

Schwedische Reichsbank (1999): Annual Report 1998, Stockholm.

Seitz, F. (1995): Der DM-Umlauf im Ausland, Volkswirtschaftliche Forschungsgruppe der Deutschen Bundesbank, Diskussionspapier 1/95, Frankfurt am Main.

Sinn, H.-W. (1997): Die Kühe des Bauern Buba, in: Wirtschaftswoche, Nr. 49 vom 27.11.1997, S. $42-44$. 
Sinn, H.-W./Feist, H. (1997a): Eurowinners and Eurolosers: The Distribution of Seigniorage Wealth in EMU, CES Working Paper, No. 134.

Sinn, H.-W./Feist, H. (1997b): Eurowinners and Eurolosers: The Distribution of Seigniorage Wealth in EMU, in: European Journal of Political Economy, Vol. 13, S. $665-689$.

Sinn, H.-W./Feist, H. (1997c): Gewinne der EZB gerecht verteilen, in: EU Magazin, Nr. 12/1997, S. $20-21$.

Sinn, H.-W./Feist, H. (1997d): Eurowinners and Eurolosers: The Distribution of Seigniorage Wealth in EMU, in: Discussion Paper Series, No. 1747, Dezember 1997.

Sinn, H.-W./Feist, H. (2000a): The Accidental Redistribution of Seigniorage Wealth in the Eurosystem, in: Cesifo Forum, Vol.1, No. 3, S. 27 - 29.

Sinn, H.-W./Feist, H. (2000b): Seigniorage wealth in the eurosystem: eurowinners and eurolosers revisited, CESifo Working Paper Series, Working Paper No. 353, November 2000.

Sinn, H.-W./Feist, H. (2000c): Der Euro und der Geldschöpfungsgewinn: Gewinner und Verlierer durch die Währungsunion, in: ifo Schnelldienst $31 / 2000$, S. $14-22$.

Smits (1999a): Kommentar zu Artikel 6 der Satzung des ESZB und der EZB, in: Von der Groeben, H./Thiesing, J./Ehlermann C.-D. (Hrsg.): Kommentar zum EU-/EG-Vertrag, Bd. 3, Artikel 102a - 136a EGV, 5. Auflage, Baden-Baden, S. 562 - 567.

Smits (1999b): Kommentar zu Artikel 18 der Satzung des ESZB und der EZB, in: Von der Groeben, H./Thiesing, J./Ehlermann C.-D. (Hrsg.): Kommentar zum EU-/EG-Vertrag, Bd. 3, Artikel 102a - 136a EGV, 5. Auflage, Baden-Baden, S. 615 - 621.

Tilch, S. (2000): Europäische Zentralbank und Europäisches System der Zentralbanken, Frankfurt am Main.

Vaubel, R. (1999): The Future of the Euro: A Public Choice Perspective, Beiträge zur angewandten Wirtschaftsforschung, Institut für Volkswirtschaftslehre und Statistik, Universität Mannheim: Discussion Paper 570-99, in: http://www.uni-manheim.de/vaubel/vaubel/future.html, Mannheim.

Weber, K. (1999): Kommentar zu Artikel 32 der Satzung des ESZB und der EZB, in: Von der Groeben, H./Thiesing, J./Ehlermann C.-D. (Hrsg.): Kommentar zum EU-/EG-Vertrag, Bd. 3, Artikel 102a - 136a EGV, 5. Auflage, Baden-Baden, S. 615 - 621 .

Wenger, E. (1997): Warum Deutschland an der Einführung des Euro zu den sich derzeit abzeichnenden Bedingungen kein Interesse haben kann (mimeo.). 
Wenger, E./Kaserer, C. (1997): o.T. (ungekürzte Fassung eines Leserbriefes an die F.A.Z. vom 21.6.1997), in: http://www.wifak.uni-wuerzburg.de/ wilan/wifak/bwl/bwl4/faz_fett.html.

Wesche, K./Weidmann, J. (1995): Central Bank Independence and Seigniorage: The Banque de France, Sonderforschungsbereich 303, Projektbereich B, Discussion Paper No. B-307, Rheinische FriedrichWilhelms-Universität Bonn. 


\title{
SCHRIFTEN ZUR WIRTSCHAFTSTHEORIE UND WIRTSCHAFTSPOLITIK
}

\author{
Herausgegeben von Rolf Hasse, Jörn Kruse, Wolf Schäfer, \\ Thomas Straubhaar, Klaus W. Zimmermann
}

Band 1 Lars Bünning: Die Konvergenzkriterien des Maastricht-Vertrages unter besonderer Berücksichtigung ihrer Konsistenz. 1997.

Band 2 Andreas Henning: Beveridge-Kurve, Lohnsetzung und Langzeitarbeitslosigkeit. Eine theoretische Untersuchung unter Berücksichtigung des Insider-Outsider-Ansatzes und der Entwertung des Humankapitals. 1997.

Band 3 Iris Henning: Die Reputation einer Zentralbank. Eine theoretische Untersuchung unter besonderer Berücksichtigung der Europäischen Zentralbank. 1997.

Band 4 Rüdiger Hermann: Ein gemeinsamer Markt für Elektrizität in Europa. Optionen einer Wettbewerbsordnung zwischen Anspruch und Wirklichkeit. 1997.

Band 5 Alexander Tiedtke: Japan und der Vorwurf des Trittbrettfahrerverhaltens in der US-amerikanisch-japanischen Allianz. 1997.

Band 6 Wolfgang Grimme: Ordnungspolitisches Konzept der Regionalpolitik. Darstellung der Defizite und des Reformbedarfs der Regionalpolitik am Beispiel Mecklenburg-Vorpommems. 1997.

Band 7 Christian Ricken: Determinanten der Effektivität der Umweltpolitik. Der nationale Politikstil im Spannungsfeld von Ökonomie, Politik und Kultur. 1997.

Band 8 Christian Schmidt: Real Convergence in the European Union. An Empirical Analysis. 1997.

Band 9 Silvia Marengo: Exchange Rate Policy for MERCOSUR: Lessons from the European Union. 1998.

Band 10 Jens Kleinemeyer: Standardisierung zwischen Kooperation und Wettbewerb. Eine spieltheoretische Betrachtung. 1998.

Band 11 Stefan M. Golder: Migration und Arbeitsmarkt. Eine empirische Analyse der Performance von Ausländem in der Schweiz. 1999.

Band 12 Stefan Kramer: Die Wirkung einer Internationalisierung des Yen auf die japanischen Finanzmärkte, die japanische Geldpolitik und die Usancen der Fakturierung. 1999.

Band 13 Antje Marielle Gerhold: Wirtschaftliche Integration und Kooperation im asiatisch-pazifischen Raum. Die APEC. 1999.

Band 14 Tamim Achim Dawar: Deutsche Direktinvestitionen in Australien. Eine Evaluation der theoretischen Erklärungsansätze und der Standortattraktivität des Produktions- und Investitionsstandortes Australien. 1999.

Band 15 Hans-Markus Johannsen: Die ordnungspolitische Haltung Frankreichs im Prozeß der europäischen Einigung. 1999.

Band 16 Annette Schönherr: Vereinigungsbedingte Dimensionen regionaler Arbeitsmobilität. Wirkungen unter analytisch einfachen Bedingungen und potentielle individuelle Migrationsgewinne in Deutschland nach der Vereinigung. 1999.

Band 17 Henrik Müller: Wechselkurspolitik des Eurolandes. Konfliktstoff für die neue währungspolitische Ära. 1999.

Band 18 Lars H. Wengorz: Die Bedeutung von Unternehmertum und Eigentum für die Existenz von Unternehmen. Eine methodenkritische Analyse der Transformation des Wirtschaftssystems in Russland. 2000.

Band 19 Eckart Bauer: Konzeptionelle Grundfragen eines Kinderleistungsausgleichs im Rahmen einer umlagefinanzierten zwangsweisen Rentenversicherung. 2000. 
Band 20 Hubertus Hille: Enlarging the European Union. A Computable General Equilibrium Assessment of Different Integration Scenarios of Central and Eastern Europe. 2001.

Band 21 Tobias Just: Globalisierung und Ideologie. Eine Analyse der Existenz und Persistenz von Partisaneffekten bei zunehmender Internationalisierung der Märkte. 2001.

Band 22 Simone Claber: Großbritannien und die Europäische Integration unter besonderer Berücksichtigung ordnungspolitischer Aspekte. 2002.

Band 23 Silvia Rottenbiller: Essential Facilities als ordnungspolitisches Problem. 2002.

Band 24 Peggy Dreyhaupt von Speicher: Die Regionen Polens, Ungarns und der Tschechischen Republik vor dem EU-Beitritt. Interregionale Disparitäten, Bestimmungsfaktoren und Lösungsansätze. 2002.

Band 25 Gerhard Rösl: Seigniorage in der EWU. Eine Analyse der Notenbankgewinnentstehung und -verwendung des Eurosystems. 2002. 
Gerhard Rösl - 978-3-631-75006-3

Downloaded from PubFactory at 01/11/2019 09:21:25AM

via free access 


\section{Das Glaubwürdigkeitsproblem in der Geldpolitik: Ein Vergleich möglicher Lösungen}

\section{Eine theoretische Analyse von Zentralbank- unabhängigkeit und -reputation unter Berücksichtigung alternativer Informationsstrukturen}

Frankfurt/M., Berlin, Bern, Bruxelles, New York, Oxford, Wien, 2002.

236 S., zahlr. Tab.

Europäische Hochschulschriften: Reihe 5, Volks- und Betriebswirtschaft.

Bd. 2909

ISBN 3-631-39699-6 • br. € 37.80* / US-\$33.95 / £ 23.-

Die anhaltende Debatte um den Konflikt zwischen Glaubwürdigkeit und Flexibilität von Zentralbanken wird von den Erkenntnissen der spieltheoretisch fundierten Literatur zur Theorie der Geldpolitik geprägt. Hier knüpft die Arbeit an und präsentiert Lösungen für das Dilemma zeitinkonsistenter Geldpolitik. Ein systematischer Vergleich wird für alternative Informationsstrukturen durchgeführt. Der Übergang von der Betrachtung einer Periode auf den dynamischen Kontext ermöglicht zudem die Integration von Reputationseffekten und die Analyse von Outputpersistenz. Neben der Alternative eines optimalen Vertrages erweist sich die mittlerweile von vielen Zentralbanken praktizierte Inflation Targeting-Strategie als überlegen.

Aus dem Inhalt: Das Zeitinkonsistenzproblem der Geldpolitik - Commitment und Diskretion - Delegation an eine unabhängige Zentralbank: starre Regel, konservativer Zentralbanker, Vertrag, Inflation Targeting - Geldpolitik bei Unsicherheit und Informationsasymmetrie - Dynamischer Kontext: Reputation und Einfluß von Outputpersistenz

Frankfurt/M - Berlin - Bern Bruxelles - New York Oxford Wien

Auslieferung: Verlag Peter Lang AG

Moosstr. 1, CH-2542 Pieterlen

Telefax 0041 (0) $32 / 3761727$

*ınklusıve der ın Deutschland gültıgen Mehrwertsteuer

Pressànderungen vorbehalten

Homepage http://www.peterlang.de 
Gerhard Rösl - 978-3-631-75006-3

Downloaded from PubFactory at 01/11/2019 09:21:25AM

via free access 